Cochrane Database of Systematic Reviews

\title{
Antidepressants for smoking cessation (Review)
}

Howes S, Hartmann-Boyce J, Livingstone-Banks J, Hong B, Lindson N

Howes S, Hartmann-Boyce J, Livingstone-Banks J, Hong B, Lindson N.

Antidepressants for smoking cessation.

Cochrane Database of Systematic Reviews 2020, Issue 4. Art. No.: CD000031.

DOI: 10.1002/14651858.CD000031.pub5.

www.cochranelibrary.com 
TABLE OF CONTENTS

HEADER

ABSTRACT

PLAIN LANGUAGE SUMMARY

SUMMARY OF FINDINGS

BACKGROUND

OBJECTIVES

METHODS

RESULTS

Figure 1.

Figure 2.

DISCUSSION

Figure 3.

Figure 4.

Figure 5.

Figure 6.

AUTHORS' CONCLUSIONS

ACKNOWLEDGEMENTS

REFERENCES

CHARACTERISTICS OF STUDIES

DATA AND ANALYSES

Analysis 1.1. Comparison 1 Bupropion versus placebo/no pharmacotherapy control, Outcome 1 Smoking cessation. .............

Analysis 1.2. Comparison 1 Bupropion versus placebo/no pharmacotherapy control, Outcome 2 Smoking cessation - subgroup by level of behavioural support.

Analysis 1.3. Comparison 1 Bupropion versus placebo/no pharmacotherapy control, Outcome 3 Smoking cessation - subgroup by mental health disorders.

Analysis 1.4. Comparison 1 Bupropion versus placebo/no pharmacotherapy control, Outcome 4 Adverse events. ..................

Analysis 1.5. Comparison 1 Bupropion versus placebo/no pharmacotherapy control, Outcome 5 Serious adverse events. .......

Analysis 1.6. Comparison 1 Bupropion versus placebo/no pharmacotherapy control, Outcome 6 Psychiatric adverse events. ..

Analysis 1.7. Comparison 1 Bupropion versus placebo/no pharmacotherapy control, Outcome 7 Seizures.

Analysis 1.8. Comparison 1 Bupropion versus placebo/no pharmacotherapy control, Outcome 8 Overdoses.

Analysis 1.9. Comparison 1 Bupropion versus placebo/no pharmacotherapy control, Outcome 9 Suicide attempts. ................

Analysis 1.10. Comparison 1 Bupropion versus placebo/no pharmacotherapy control, Outcome 10 Death by suicide. .............

Analysis 1.11. Comparison 1 Bupropion versus placebo/no pharmacotherapy control, Outcome 11 All-cause mortality. .........

Analysis 1.12. Comparison 1 Bupropion versus placebo/no pharmacotherapy control, Outcome 12 Anxiety. ...........................

Analysis 1.13. Comparison 1 Bupropion versus placebo/no pharmacotherapy control, Outcome 13 Insomnia. ........................

Analysis 1.14. Comparison 1 Bupropion versus placebo/no pharmacotherapy control, Outcome 14 Dropouts due to drug. .....

Analysis 2.1. Comparison 2 Bupropion plus nicotine replacement therapy (NRT) versus NRT alone, Outcome 1 Smoking cessation.

Analysis 2.2. Comparison 2 Bupropion plus nicotine replacement therapy (NRT) versus NRT alone, Outcome 2 Adverse events.

Analysis 2.3. Comparison 2 Bupropion plus nicotine replacement therapy (NRT) versus NRT alone, Outcome 3 Serious adverse events.

Analysis 2.4. Comparison 2 Bupropion plus nicotine replacement therapy (NRT) versus NRT alone, Outcome 4 Seizures. ........ Analysis 2.5. Comparison 2 Bupropion plus nicotine replacement therapy (NRT) versus NRT alone, Outcome 5 Suicide attempts.

Analysis 2.6. Comparison 2 Bupropion plus nicotine replacement therapy (NRT) versus NRT alone, Outcome 6 Death by suicide.

Analysis 2.7. Comparison 2 Bupropion plus nicotine replacement therapy (NRT) versus NRT alone, Outcome 7 All-cause mortality.

Analysis 2.8. Comparison 2 Bupropion plus nicotine replacement therapy (NRT) versus NRT alone, Outcome 8 Insomnia. ....... Analysis 2.9. Comparison 2 Bupropion plus nicotine replacement therapy (NRT) versus NRT alone, Outcome 9 Anxiety. .......... Analysis 2.10. Comparison 2 Bupropion plus nicotine replacement therapy (NRT) versus NRT alone, Outcome 10 Dropouts due to drug. 
Analysis 3.1. Comparison 3 Bupropion plus varenicline versus varenicline alone, Outcome 1 Smoking cessation.

Analysis 3.2. Comparison 3 Bupropion plus varenicline versus varenicline alone, Outcome 2 Adverse events.

Analysis 3.3. Comparison 3 Bupropion plus varenicline versus varenicline alone, Outcome 3 Serious adverse events. .............

Analysis 3.4. Comparison 3 Bupropion plus varenicline versus varenicline alone, Outcome 4 Psychiatric adverse events. .......

Analysis 3.5. Comparison 3 Bupropion plus varenicline versus varenicline alone, Outcome 5 Seizures. ....................................

Analysis 3.6. Comparison 3 Bupropion plus varenicline versus varenicline alone, Outcome 6 Overdoses.

Analysis 3.7. Comparison 3 Bupropion plus varenicline versus varenicline alone, Outcome 7 Suicide attempts.

Analysis 3.8. Comparison 3 Bupropion plus varenicline versus varenicline alone, Outcome 8 Death by suicide.

Analysis 3.9. Comparison 3 Bupropion plus varenicline versus varenicline alone, Outcome 9 All-cause mortality.

Analysis 3.10. Comparison 3 Bupropion plus varenicline versus varenicline alone, Outcome 10 Anxiety.

Analysis 3.11. Comparison 3 Bupropion plus varenicline versus varenicline alone, Outcome 11 Insomnia.

Analysis 3.12. Comparison 3 Bupropion plus varenicline versus varenicline alone, Outcome 12 Dropouts due to drug. ............

Analysis 4.1. Comparison 4 Exploratory safety analysis: effects of bupropion only across comparisons, Outcome 1 Adverse events.

Analysis 4.2. Comparison 4 Exploratory safety analysis: effects of bupropion only across comparisons, Outcome 2 Psychiatric adverse events.

Analysis 4.3. Comparison 4 Exploratory safety analysis: effects of bupropion only across comparisons, Outcome 3 Serious adverse events.

Analysis 4.4. Comparison 4 Exploratory safety analysis: effects of bupropion only across comparisons, Outcome 4 Dropouts due to drug.

Analysis 5.1. Comparison 5 Bupropion versus varenicline, Outcome 1 Smoking cessation.

Analysis 5.2. Comparison 5 Bupropion versus varenicline, Outcome 2 Adverse events.

Analysis 5.3. Comparison 5 Bupropion versus varenicline, Outcome 3 Serious adverse events.

Analysis 5.4. Comparison 5 Bupropion versus varenicline, Outcome 4 Psychiatric adverse events.

Analysis 5.5. Comparison 5 Bupropion versus varenicline, Outcome 5 Seizures.

Analysis 5.6. Comparison 5 Bupropion versus varenicline, Outcome 6 Overdoses.

\section{0}

Analysis 5.7. Comparison 5 Bupropion versus varenicline, Outcome 7 Suicide attempts.

Analysis 5.8. Comparison 5 Bupropion versus varenicline, Outcome 8 Death by suicide.

Analysis 5.9. Comparison 5 Bupropion versus varenicline, Outcome 9 All-cause mortality.

Analysis 5.10. Comparison 5 Bupropion versus varenicline, Outcome 10 Insomnia.

Analysis 5.11. Comparison 5 Bupropion versus varenicline, Outcome 11 Anxiety.

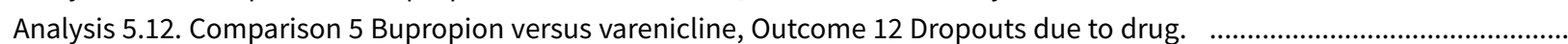
Analysis 6.1. Comparison 6 Bupropion versus nicotine replacement therapy (NRT), Outcome 1 Smoking cessation. ................ Analysis 6.2. Comparison 6 Bupropion versus nicotine replacement therapy (NRT), Outcome 2 Adverse events. ..................... Analysis 6.3. Comparison 6 Bupropion versus nicotine replacement therapy (NRT), Outcome 3 Serious adverse events. ......... Analysis 6.4. Comparison 6 Bupropion versus nicotine replacement therapy (NRT), Outcome 4 Psychiatric adverse events. ....

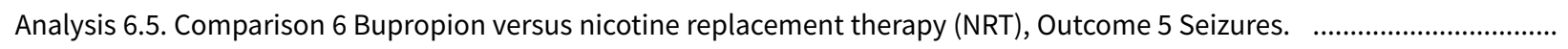

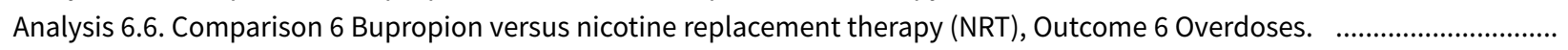
Analysis 6.7. Comparison 6 Bupropion versus nicotine replacement therapy (NRT), Outcome 7 Suicide attempts. .................. Analysis 6.8. Comparison 6 Bupropion versus nicotine replacement therapy (NRT), Outcome 8 Death by suicide. ................... Analysis 6.9. Comparison 6 Bupropion versus nicotine replacement therapy (NRT), Outcome 9 All-cause mortality. ................

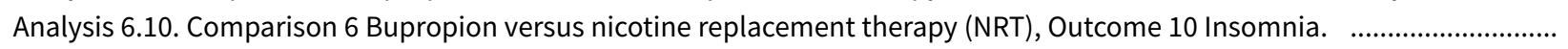
Analysis 6.11. Comparison 6 Bupropion versus nicotine replacement therapy (NRT), Outcome 11 Anxiety. ............................ Analysis 6.12. Comparison 6 Bupropion versus nicotine replacement therapy (NRT), Outcome 12 Dropouts due to drug. ........ Analysis 7.1. Comparison 7 Bupropion versus nortriptyline, Outcome 1 Smoking cessation.

Analysis 7.4. Comparison 7 Bupropion versus nortriptyline, Outcome 4 Dropouts due to drug. ............................................

Analysis 8.1. Comparison 8 Bupropion versus gabapentin, Outcome 1 Serious adverse events. .............................................

Analysis 8.2. Comparison 8 Bupropion versus gabapentin, Outcome 2 Dropouts due to drug. ..............................................

Analysis 9.1. Comparison 9 Bupropion (different doses), Outcome 1 Smoking cessation. .......................................................

Analysis 9.2. Comparison 9 Bupropion (different doses), Outcome 2 Serious adverse events. ............................................... 205

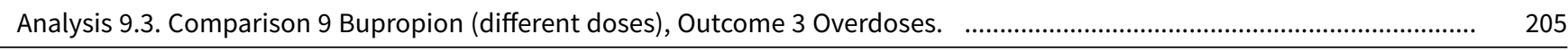


Analysis 9.4. Comparison 9 Bupropion (different doses), Outcome 4 Suicide attempts

Analysis 9.5. Comparison 9 Bupropion (different doses), Outcome 5 Death by suicide.

Analysis 9.6. Comparison 9 Bupropion (different doses), Outcome 6 All-cause mortality.

Analysis 9.7. Comparison 9 Bupropion (different doses), Outcome 7 Insomnia.

Analysis 9.8. Comparison 9 Bupropion (different doses), Outcome 8 Anxiety.

Analysis 9.9. Comparison 9 Bupropion (different doses), Outcome 9 Dropouts due to drug.

Analysis 10.1. Comparison 10 Nortriptyline versus placebo, Outcome 1 Smoking cessation.

Analysis 10.2. Comparison 10 Nortriptyline versus placebo, Outcome 2 Serious adverse events.

Analysis 10.3. Comparison 10 Nortriptyline versus placebo, Outcome 3 Insomnia.

Analysis 10.4. Comparison 10 Nortriptyline versus placebo, Outcome 4 Anxiety.

Analysis 10.5. Comparison 10 Nortriptyline versus placebo, Outcome 5 Dropouts due to drug.

Analysis 11.1. Comparison 11 Selective serotonin reuptake inhibitors (SSRIs) versus placebo, Outcome 1 Smoking cessation. ..

Analysis 11.2. Comparison 11 Selective serotonin reuptake inhibitors (SSRIs) versus placebo, Outcome 2 Adverse events. ......

Analysis 11.3. Comparison 11 Selective serotonin reuptake inhibitors (SSRIs) versus placebo, Outcome 3 Dropouts due to drug.

Analysis 12.1. Comparison 12 Monoamine oxidase inhibitor (MAOI) versus placebo, Outcome 1 Smoking cessation.

Analysis 12.2. Comparison 12 Monoamine oxidase inhibitor (MAOI) versus placebo, Outcome 2 Adverse events.

Analysis 12.3. Comparison 12 Monoamine oxidase inhibitor (MAOI) versus placebo, Outcome 3 Psychiatric adverse events. .... Analysis 12.4. Comparison 12 Monoamine oxidase inhibitor (MAOI) versus placebo, Outcome 4 Serious adverse events. ..........

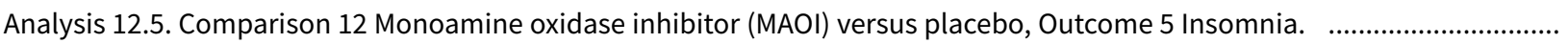
Analysis 12.6. Comparison 12 Monoamine oxidase inhibitor (MAOI) versus placebo, Outcome 6 Anxiety.

Analysis 12.7. Comparison 12 Monoamine oxidase inhibitor (MAOI) versus placebo, Outcome 7 Dropouts due to drug. ...........

Analysis 13.1. Comparison 13 Venlafaxine versus placebo, Outcome 1 Smoking cessation. .....................................................

Analysis 13.2. Comparison 13 Venlafaxine versus placebo, Outcome 2 Dropouts due to drug.

Analysis 14.1. Comparison 14 Hypericum (St John's wort) versus placebo, Outcome 1 Smoking cessation. ............................

Analysis 14.2. Comparison 14 Hypericum (St John's wort) versus placebo, Outcome 2 Serious adverse events. ......................

Analysis 14.3. Comparison 14 Hypericum (St John's wort) versus placebo, Outcome 3 All-cause mortality. ............................

Analysis 14.4. Comparison 14 Hypericum (St John's wort) versus placebo, Outcome 4 Dropouts due to drug. ........................

Analysis 15.1. Comparison 15 S-Adenosyl-L-Methionine (SAMe) versus placebo, Outcome 1 Smoking cessation. .....................

Analysis 15.2. Comparison 15 S-Adenosyl-L-Methionine (SAMe) versus placebo, Outcome 2 Adverse events. ..........................

Analysis 15.3. Comparison 15 S-Adenosyl-L-Methionine (SAMe) versus placebo, Outcome 3 Insomnia.

Analysis 15.4. Comparison 15 S-Adenosyl-L-Methionine (SAMe) versus placebo, Outcome 4 Dropouts due to drug. .................

Analysis 16.1. Comparison 16 Nortriptyline plus nicotine replacement therapy (NRT) versus NRT alone, Outcome 1 Smoking cessation.

Analysis 16.2. Comparison 16 Nortriptyline plus nicotine replacement therapy (NRT) versus NRT alone, Outcome 2 Insomnia. .

Analysis 16.3. Comparison 16 Nortriptyline plus nicotine replacement therapy (NRT) versus NRT alone, Outcome 3 Dropouts due to drug.

Analysis 17.1. Comparison 17 Selective serotonin reuptake inhibitor (SSRI) plus NRT versus NRT alone, Outcome 1 Smoking cessation.

Analysis 18.1. Comparison 18 Selegeline plus nicotine replacement therapy (NRT) versus NRT alone, Outcome 1 Serious adverse events.

Analysis 18.2. Comparison 18 Selegeline plus nicotine replacement therapy (NRT) versus NRT alone, Outcome 2 Dropouts due to drug.

Analysis 19.1. Comparison 19 EVT302 plus nicotine replacement therapy (NRT) versus NRT alone, Outcome 1 Adverse events. .

Analysis 19.2. Comparison 19 EVT302 plus nicotine replacement therapy (NRT) versus NRT alone, Outcome 2 Serious adverse events.

Analysis 19.3. Comparison 19 EVT302 plus nicotine replacement therapy (NRT) versus NRT alone, Outcome 3 Dropouts due to drug.

Analysis 20.1. Comparison 20 Fluoxetine (30 mg versus $60 \mathrm{mg}$ ), Outcome 1 Smoking cessation.

Analysis 20.2. Comparison 20 Fluoxetine (30 mg versus $60 \mathrm{mg}$ ), Outcome 2 Dropouts due to drug.

Analysis 21.1. Comparison 21 Lazabemide (100 mg versus $200 \mathrm{mg}$ ), Outcome 1 Serious adverse events.

Analysis 21.2. Comparison 21 Lazabemide (100 mg versus $200 \mathrm{mg}$ ), Outcome 2 Insomnia.

Analysis 21.3. Comparison 21 Lazabemide (100 mg versus $200 \mathrm{mg}$ ), Outcome 3 Anxiety.

Analysis 21.4. Comparison 21 Lazabemide (100 mg versus $200 \mathrm{mg}$ ), Outcome 4 Dropouts due to drug. 
Analysis 22.1. Comparison 22 Hypericum (St John's wort) (300 mg versus $600 \mathrm{mg}$ ), Outcome 1 Smoking cessation.

Analysis 22.2. Comparison 22 Hypericum (St John's wort) (300 mg versus $600 \mathrm{mg}$ ), Outcome 2 Adverse events.

Analysis 23.1. Comparison $23 \mathrm{~S}$-Adenosyl-L-Methionine (SAMe) ( $800 \mathrm{mg}$ versus $1600 \mathrm{mg}$ ), Outcome 1 Adverse events.

Analysis 23.2. Comparison 23 S-Adenosyl-L-Methionine (SAMe) (800 mg versus $1600 \mathrm{mg}$ ), Outcome 2 Dropouts due to drug. ... 227 ADDITIONAL TABLES

APPENDICES

WHAT'S NEW

HISTORY

DECLARATIONS OF INTEREST

SOURCES OF SUPPORT 
[Intervention Review]

\section{Antidepressants for smoking cessation}

Seth Howes ${ }^{1}$, Jamie Hartmann-Boyce ${ }^{1}$, Jonathan Livingstone-Banks ${ }^{1}$, Bosun Hong ${ }^{2}$, Nicola Lindson ${ }^{1}$

${ }^{1}$ Nuffield Department of Primary Care Health Sciences, University of Oxford, Oxford, UK. ${ }^{2}$ Oral Surgery Department, Birmingham Dental Hospital, Birmingham, UK

Contact address: Nicola Lindson, Nuffield Department of Primary Care Health Sciences, University of Oxford, Oxford, UK. nicola.lindson@phc.ox.ac.uk.

Editorial group: Cochrane Tobacco Addiction Group.

Publication status and date: New search for studies and content updated (no change to conclusions), published in Issue 4, 2020.

Citation: Howes S, Hartmann-Boyce J, Livingstone-Banks J, Hong B, Lindson N. Antidepressants for smoking cessation. Cochrane Database of Systematic Reviews 2020, Issue 4. Art. No.: CD000031. DOI: 10.1002/14651858.CD000031.pub5.

Copyright @ 2020 The Cochrane Collaboration. Published by John Wiley \& Sons, Ltd.

\section{A B S T R A C T}

\section{Background}

Whilst the pharmacological profiles and mechanisms of antidepressants are varied, there are common reasons why they might help people to stop smoking tobacco. Firstly, nicotine withdrawal may produce depressive symptoms and antidepressants may relieve these. Additionally, some antidepressants may have a specific effect on neural pathways or receptors that underlie nicotine addiction.

\section{Objectives}

To assess the evidence for the efficacy, safety and tolerability of medications with antidepressant properties in assisting long-term tobacco smoking cessation in people who smoke cigarettes.

\section{Search methods}

We searched the Cochrane Tobacco Addiction Specialized Register, which includes reports of trials indexed in the Cochrane Central Register of Controlled Trials (CENTRAL), MEDLINE, Embase, and PsycINFO, clinicaltrials.gov, the ICTRP, and other reviews and meeting abstracts, in May 2019.

\section{Selection criteria}

We included randomized controlled trials (RCTs) that recruited smokers, and compared antidepressant medications with placebo or no treatment, an alternative pharmacotherapy, or the same medication used in a different way. We excluded trials with less than six months follow-up from efficacy analyses. We included trials with any follow-up length in safety analyses.

\section{Data collection and analysis}

We extracted data and assessed risk of bias using standard Cochrane methods. We also used GRADE to assess the certainty of the evidence.

The primary outcome measure was smoking cessation after at least six months follow-up, expressed as a risk ratio (RR) and $95 \%$ confidence intervals (Cls). We used the most rigorous definition of abstinence available in each trial, and biochemically validated rates if available. Where appropriate, we performed meta-analysis using a fixed-effect model.

Similarly, we presented incidence of safety and tolerance outcomes, including adverse events (AEs), serious adverse events (SAEs), psychiatric AEs, seizures, overdoses, suicide attempts, death by suicide, all-cause mortality, and trial dropout due to drug, as RRs (95\% Cls).

\section{Main results}

We included 115 studies (33 new to this update) in this review; most recruited adult participants from the community or from smoking cessation clinics. We judged 28 of the studies to be at high risk of bias; however, restricting analyses only to studies at low or unclear 
risk did not change clinical interpretation of the results. There was high-certainty evidence that bupropion increased long-term smoking cessation rates (RR 1.64, 95\% $\mathrm{Cl} 1.52$ to $1.77 ; \mathrm{I}^{2}=15 \%$; 45 studies, 17,866 participants). There was insufficient evidence to establish whether participants taking bupropion were more likely to report SAEs compared to those taking placebo. Results were imprecise and Cls encompassed no difference (RR 1.16, 95\% Cl 0.90 to $1.48 ; \mathrm{I}^{2}=0 \% ; 21$ studies, 10,625 participants; moderate-certainty evidence, downgraded one level due to imprecision). We found high-certainty evidence that use of bupropion resulted in more trial dropouts due to adverse events of the drug than placebo (RR 1.37, 95\% CI 1.21 to 1.56; $\left.\right|^{2}=19 \% ; 25$ studies, 12,340 participants). Participants randomized to bupropion were also more likely to report psychiatric AEs compared with those randomized to placebo (RR $1.25,95 \% \mathrm{Cl} 1.15$ to $1.37 ; \mathrm{I}^{2}=15 \% ; 6$ studies, 4439 participants).

We also looked at the safety and efficacy of bupropion when combined with other non-antidepressant smoking cessation therapies. There was insufficient evidence to establish whether combination bupropion and nicotine replacement therapy (NRT) resulted in superior quit rates to NRT alone (RR 1.19, 95\% Cl 0.94 to $1.51 ;\left.\right|^{2}=52 \% ; 12$ studies, 3487 participants), or whether combination bupropion and varenicline resulted in superior quit rates to varenicline alone (RR $1.21,95 \% \mathrm{Cl} 0.95$ to $1.55 ; \mathrm{I}^{2}=15 \%$; 3 studies, 1057 participants). We judged the certainty of evidence to be low and moderate, respectively; in both cases due to imprecision, and also due to inconsistency in the former. Safety data were sparse for these comparisons, making it difficult to draw clear conclusions.

A meta-analysis of six studies provided evidence that bupropion resulted in inferior smoking cessation rates to varenicline (RR $0.71,95 \%$ $\mathrm{Cl} 0.64$ to $0.79 ; \mathrm{I}^{2}=0 \% ; 6$ studies, 6286 participants), whilst there was no evidence of a difference in efficacy between bupropion and NRT (RR $0.99,95 \% \mathrm{Cl} 0.91$ to $1.09 ;\left.\right|^{2}=18 \% ; 10$ studies, 8230 participants).

We also found some evidence that nortriptyline aided smoking cessation when compared with placebo (RR $2.03,95 \% \mathrm{Cl} 1.48$ to 2.78 ; 12 = 16\%; 6 studies, 975 participants), whilst there was insufficient evidence to determine whether bupropion or nortriptyline were more effective when compared with one another (RR 1.30 (favouring bupropion), $95 \% \mathrm{Cl} 0.93$ to 1.82; $\left.\right|^{2}=0 \% ; 3$ studies, 417 participants). There was no evidence that any of the other antidepressants tested (including St John's Wort, selective serotonin reuptake inhibitors (SSRIs), monoamine oxidase inhibitors (MAOIs)) had a beneficial effect on smoking cessation. Findings were sparse and inconsistent as to whether antidepressants, primarily bupropion and nortriptyline, had a particular benefit for people with current or previous depression.

\section{Authors' conclusions}

There is high-certainty evidence that bupropion can aid long-term smoking cessation. However, bupropion also increases the number of adverse events, including psychiatric AEs, and there is high-certainty evidence that people taking bupropion are more likely to discontinue treatment compared with placebo. However, there is no clear evidence to suggest whether people taking bupropion experience more or fewer SAEs than those taking placebo (moderate certainty). Nortriptyline also appears to have a beneficial effect on smoking quit rates relative to placebo. Evidence suggests that bupropion may be as successful as NRT and nortriptyline in helping people to quit smoking, but that it is less effective than varenicline. There is insufficient evidence to determine whether the other antidepressants tested, such as SSRIs, aid smoking cessation, and when looking at safety and tolerance outcomes, in most cases, paucity of data made it difficult to draw conclusions. Due to the high-certainty evidence, further studies investigating the efficacy of bupropion versus placebo are unlikely to change our interpretation of the effect, providing no clear justification for pursuing bupropion for smoking cessation over front-line smoking cessation aids already available. However, it is important that where studies of antidepressants for smoking cessation are carried out they measure and report safety and tolerability clearly.

\section{PLAIN LANGUAGE SUMMARY}

\section{Do medicines used to treat depression help people to quit smoking?}

\section{Background and review questions}

Some medicines and supplements that have been used to treat depression (antidepressants) have also been tested to see whether they can help people to stop smoking. Two of these treatments - bupropion (sometimes called Zyban) and nortriptyline - are sometimes given to help people quit smoking. This review looks at whether using antidepressants actually helps people to stop smoking (for six months or longer), and also looks at the safety of using these medicines.

\section{Study characteristics}

This review includes 115 studies looking at how helpful and safe different antidepressants are when used to quit smoking. Most of the studies were conducted in adults. We included studies of any length when looking at safety, but studies needed to be at least six months long when assessing whether people had managed to quit smoking. The evidence is up to date to May 2019.

\section{Key results}

Using the antidepressant, bupropion, makes it 52\% to $77 \%$ more likely that a person will successfully stop smoking, which is equal to five to seven more people successfully quitting for six months or more for every one hundred people who try to quit. There is evidence that people who use the antidepressant, nortriptyline, to quit smoking also improve their chances of success. There is not enough evidence to determine whether other antidepressants help people to quit smoking. 
There is evidence that bupropion increases unwanted effects, particularly those relating to mental health, and that unwanted effects may increase the chance that people stop using the medicine. However, the evidence does not suggest that bupropion is more likely to result in death, hospitalization, or life-threatening events, like seizures. There is not enough information to draw clear conclusions about the safety of nortriptyline for stopping smoking.

The evidence does not suggest that taking bupropion at the same time as other stop-smoking medicines, like varenicline (sometimes known as Champix or Chantix) or nicotine replacement therapy makes people more likely to quit smoking. People are as likely to quit smoking when using bupropion as when using nortriptyline or nicotine replacement therapy, however people using varenicline are more likely to quit than those using bupropion.

\section{Certainty of evidence}

There is high-certainty evidence that bupropion helps people to quit smoking, meaning further research is very unlikely to change this conclusion. However, there is also high-certainty evidence to suggest that people using bupropion are more likely to stop taking the medicine because of unpleasant effects than those taking a pill without medication (a placebo). The certainty of the evidence was moderate, low or very low for the other key questions we looked at. This means that the findings of those questions may change when more research is carried out. In most cases this was because there were not enough studies or studies were too small. 
SUMMARY OF FINDINGS

Summary of findings for the main comparison. Bupropion compared to placebo/no pharmacotherapy control for smoking cessation

Bupropion compared to placebo/control for smoking cessation

Population: people who smoke

Setting: any; studies conducted in Asia, Australasia, Europe, USA

Intervention: bupropion

Comparison: placebo/control

\begin{tabular}{|c|c|c|c|c|c|c|}
\hline \multirow[t]{2}{*}{ Outcomes } & \multicolumn{2}{|c|}{ Anticipated absolute effects ${ }^{*}(95 \% \mathrm{Cl})$} & \multirow{2}{*}{$\begin{array}{l}\text { Relative effect } \\
(95 \% \mathrm{Cl})\end{array}$} & \multirow{2}{*}{$\begin{array}{l}\text { № of participants } \\
\text { (studies) }\end{array}$} & \multirow{2}{*}{$\begin{array}{l}\text { Certainty of the } \\
\text { evidence } \\
\text { (GRADE) }\end{array}$} & \multirow[t]{2}{*}{ Comments } \\
\hline & $\begin{array}{l}\text { Risk with placebo/con- } \\
\text { trol }\end{array}$ & Risk with bupropion & & & & \\
\hline \multirow{2}{*}{$\begin{array}{l}\text { Smoking cessation (at } \\
\text { least six months fol- } \\
\text { low-up) }\end{array}$} & \multicolumn{2}{|l|}{ Study population } & \multirow{2}{*}{$\begin{array}{l}\text { RR } 1.64 \\
\text { (1.52 to } 1.77)\end{array}$} & \multirow{2}{*}{$\begin{array}{l}17,866 \\
\text { (46 RCTs) }\end{array}$} & \multirow{2}{*}{$\begin{array}{l}\oplus \oplus \oplus \oplus \\
\text { High }\end{array}$} & \\
\hline & 11 per 100 & $\begin{array}{l}18 \text { per } 100 \\
\text { (17 to } 20)\end{array}$ & & & & \\
\hline \multirow[t]{2}{*}{ Serious adverse events } & \multicolumn{2}{|l|}{ Study population } & \multirow{2}{*}{$\begin{array}{l}\text { RR } 1.16 \\
\text { (0.90 to } 1.48)\end{array}$} & \multirow{2}{*}{$\begin{array}{l}10,625 \\
\text { (21 RCTs) }\end{array}$} & \multirow{2}{*}{$\begin{array}{l}\oplus \oplus \oplus \ominus \\
\text { Moderate }\end{array}$} & \\
\hline & 2 per 100 & $\begin{array}{l}3 \text { per } 100 \\
(2 \text { to } 3)\end{array}$ & & & & \\
\hline \multirow{2}{*}{$\begin{array}{l}\text { Dropouts due to adverse } \\
\text { events of the drug }\end{array}$} & Study population & & \multirow{2}{*}{$\begin{array}{l}\text { RR } 1.37 \\
\text { (1.21 to } 1.56)\end{array}$} & \multirow{2}{*}{$\begin{array}{l}12,340 \\
\text { (25 RCTs) }\end{array}$} & \multirow{2}{*}{$\begin{array}{l}\oplus \oplus \oplus \oplus \\
\text { High }\end{array}$} & \\
\hline & 7 per 100 & $\begin{array}{l}9 \text { per } 100 \\
(8 \text { to } 10)\end{array}$ & & & & \\
\hline
\end{tabular}

${ }^{*}$ The risk in the intervention group (and its $95 \%$ confidence interval) is based on the assumed risk in the comparison group and the relative effect of the intervention (and its $95 \% \mathrm{Cl})$.

Cl: confidence interval; $\mathbf{R C T}$ : randomized controlled trial; RR: risk ratio

\section{GRADE Working Group grades of evidence}

High certainty: we are very confident that the true effect lies close to that of the estimate of the effect.

Moderate certainty: we are moderately confident in the effect estimate; the true effect is likely to be close to the estimate of the effect, but there is a possibility that it is substantially different.

Low certainty: our confidence in the effect estimate is limited; the true effect may be substantially different from the estimate of the effect.

Very low certainty: we have very little confidence in the effect estimate; the true effect is likely to be substantially different from the estimate of effect. 


\section{Summary of findings 2. Bupropion plus NRT compared to NRT alone for smoking cessation}

\section{Bupropion plus NRT compared to NRT alone for smoking cessation}

Population: people who smoke

Setting: any; studies conducted in UK, USA

Intervention: bupropion and NRT

Comparison: NRT alone

\begin{tabular}{|c|c|c|c|c|c|c|}
\hline \multirow[t]{2}{*}{ Outcomes } & \multicolumn{2}{|c|}{ Anticipated absolute effects ${ }^{\star}(95 \% \mathrm{Cl})$} & \multirow{2}{*}{$\begin{array}{l}\text { Relative effect } \\
(95 \% \mathrm{Cl})\end{array}$} & \multirow{2}{*}{$\begin{array}{l}\text { № of partici- } \\
\text { pants } \\
\text { (studies) }\end{array}$} & \multirow{2}{*}{$\begin{array}{l}\text { Certainty of the } \\
\text { evidence } \\
\text { (GRADE) }\end{array}$} & \multirow[t]{2}{*}{ Comments } \\
\hline & Risk with NRT alone & $\begin{array}{l}\text { Risk with bupropi- } \\
\text { on and NRT }\end{array}$ & & & & \\
\hline \multirow{2}{*}{$\begin{array}{l}\text { Smoking cessation (at least six } \\
\text { months follow-up) }\end{array}$} & Study population & & \multirow{2}{*}{$\begin{array}{l}\text { RR } 1.19 \\
\text { (0.94 to } 1.51)\end{array}$} & \multirow{2}{*}{$\begin{array}{l}3487 \\
(12 \text { RCTs })\end{array}$} & \multirow{2}{*}{$\begin{array}{l}\oplus \oplus \ominus \ominus \\
\text { Lowa,b }^{a}\end{array}$} & \\
\hline & 19 per 100 & $\begin{array}{l}22 \text { per } 100 \\
\text { (17 to } 28)\end{array}$ & & & & \\
\hline \multirow[t]{2}{*}{ Serious adverse events } & Study population & & \multirow{2}{*}{$\begin{array}{l}\text { RR } 1.53 \\
(0.25 \text { to } 8.91)\end{array}$} & \multirow{2}{*}{$\begin{array}{l}607 \\
\text { (3 RCTs) }\end{array}$} & \multirow{2}{*}{$\begin{array}{l}\oplus \ominus \odot \ominus \\
\text { Very lowc,d }\end{array}$} & \\
\hline & 1 per 100 & $\begin{array}{l}1 \text { per } 100 \\
(0 \text { to } 6)\end{array}$ & & & & \\
\hline \multirow{2}{*}{$\begin{array}{l}\text { Dropouts due to adverse events } \\
\text { of the drug }\end{array}$} & Study population & & \multirow{2}{*}{$\begin{array}{l}\text { RR } 1.67 \\
\text { (0.95 to } 2.80)\end{array}$} & \multirow{2}{*}{$\begin{array}{l}538 \\
(2 \mathrm{RCTs})\end{array}$} & \multirow{2}{*}{$\begin{array}{l}\oplus \oplus \Theta \Theta \\
\text { Lowd }\end{array}$} & \\
\hline & 7 per 100 & $\begin{array}{l}11 \text { per } 100 \\
(6 \text { to } 19)\end{array}$ & & & & \\
\hline
\end{tabular}

${ }^{*}$ The risk in the intervention group (and its $95 \%$ confidence interval) is based on the assumed risk in the comparison group and the relative effect of the intervention (and its $95 \% \mathrm{Cl})$.

Cl: confidence interval; NRT: nicotine replacement therapy; RCT: randomized controlled trial; RR: risk ratio.

\section{GRADE Working Group grades of evidence}

High certainty: we are very confident that the true effect lies close to that of the estimate of the effect.

Moderate certainty: we are moderately confident in the effect estimate; the true effect is likely to be close to the estimate of the effect, but there is a possibility that it is substantially different.

Low certainty: our confidence in the effect estimate is limited; the true effect may be substantially different from the estimate of the effect.

Very low certainty: we have very little confidence in the effect estimate; the true effect is likely to be substantially different from the estimate of effect. 
${ }^{a}$ Downgraded one level due to inconsistency. Unexplained statistical heterogeneity $(12=52 \%)$.

bDowngraded one level due to imprecision. Confidence interval encompasses no difference as well as clinically significant benefit.

cDowngraded one level due to risk of bias. One of the three included studies judged to be at high risk of bias. Removing this study reduced the point estimate to 1.00 .

dDowngraded two levels due to imprecision. Fewer than 100 events.

\section{Summary of findings 3. Bupropion plus varenicline compared to varenicline alone for smoking cessation}

\section{Bupropion plus varenicline compared to varenicline alone for smoking cessation}

Population: people who smoke

Setting: any; studies conducted in USA

Intervention: bupropion and varenicline

Comparison: varenicline alone

\begin{tabular}{|c|c|c|c|c|c|c|}
\hline \multirow[t]{2}{*}{ Outcomes } & \multicolumn{2}{|c|}{ Anticipated absolute effects* $(95 \% \mathrm{Cl})$} & \multirow{2}{*}{$\begin{array}{l}\text { Relative effect } \\
(95 \% \mathrm{Cl})\end{array}$} & \multirow{2}{*}{$\begin{array}{l}\text { № of partici- } \\
\text { pants } \\
\text { (studies) }\end{array}$} & \multirow{2}{*}{$\begin{array}{l}\text { Certainty of the } \\
\text { evidence } \\
\text { (GRADE) }\end{array}$} & \multirow[t]{2}{*}{ Comments } \\
\hline & $\begin{array}{l}\text { Risk with varenicline } \\
\text { alone }\end{array}$ & $\begin{array}{l}\text { Risk with bupropi- } \\
\text { on and varenicline }\end{array}$ & & & & \\
\hline \multirow{2}{*}{$\begin{array}{l}\text { Smoking cessation (at least six } \\
\text { months follow-up) }\end{array}$} & Study population & & \multirow{2}{*}{$\begin{array}{l}\text { RR } 1.21 \\
\text { (0.95 to } 1.55)\end{array}$} & \multirow{2}{*}{$\begin{array}{l}1057 \\
\text { (3 RCTs) }\end{array}$} & \multirow{2}{*}{$\begin{array}{l}\oplus \oplus \oplus \ominus \\
\text { Moderate } a\end{array}$} & \\
\hline & 21 per 100 & $\begin{array}{l}26 \text { per } 100 \\
\text { (20 to } 33 \text { ) }\end{array}$ & & & & \\
\hline \multirow[t]{2}{*}{ Serious adverse events } & Study population & & \multirow{2}{*}{$\begin{array}{l}\text { RR } 1.36 \\
\text { (0.65 to } 2.84)\end{array}$} & \multirow{2}{*}{$\begin{array}{l}1094 \\
\text { (5 RCTs) }\end{array}$} & \multirow{2}{*}{$\begin{array}{l}\oplus \oplus \Theta \ominus \\
\text { Low }^{b}\end{array}$} & \\
\hline & 2 per 100 & $\begin{array}{l}3 \text { per } 100 \\
(1 \text { to } 6)\end{array}$ & & & & \\
\hline \multirow{2}{*}{$\begin{array}{l}\text { Dropouts due to adverse events } \\
\text { of the drug }\end{array}$} & Study population & & \multirow{2}{*}{$\begin{array}{l}\text { RR } 0.80 \\
\text { (0.45 to } 1.45)\end{array}$} & \multirow{2}{*}{$\begin{array}{l}1230 \\
(4 \mathrm{RCTs})\end{array}$} & \multirow{2}{*}{$\begin{array}{l}\oplus \oplus \Theta \Theta \\
\text { Low }^{b}\end{array}$} & \\
\hline & 4 per 100 & $\begin{array}{l}3 \text { per } 100 \\
(2 \text { to } 6)\end{array}$ & & & & \\
\hline
\end{tabular}

${ }^{*}$ The risk in the intervention group (and its $95 \%$ confidence interval) is based on the assumed risk in the comparison group and the relative effect of the intervention (and its $95 \% \mathrm{Cl})$.

Cl: confidence interval; $\mathbf{R C T}$ : randomized controlled trial; RR: risk ratio.

\section{GRADE Working Group grades of evidence}

High certainty: we are very confident that the true effect lies close to that of the estimate of the effect.

Moderate certainty: we are moderately confident in the effect estimate; the true effect is likely to be close to the estimate of the effect, but there is a possibility that it is substantially different.

Low certainty: our confidence in the effect estimate is limited; the true effect may be substantially different from the estimate of the effect. 
Very low certainty: we have very little confidence in the effect estimate; the true effect is likely to be substantially different from the estimate of effect.

aDowngraded one level due to imprecision. Fewer than 300 events overall. Confidence intervals encompass clinically significant benefit as well as no difference.

Downgraded two levels due to imprecision. Fewer than 100 events overall. Confidence intervals encompass clinically significant harm as well as clinically significant benefit. 


\section{B A C K G R O U N D}

\section{Description of the condition}

Tobacco use is one of the leading causes of preventable illness and death worldwide, accounting for over eight million deaths annually (GBD RFC 2017). Extrapolation based on current smoking trends, suggests that without widespread quitting, approximately 400 million tobacco-related deaths will occur between 2010 and 2050 , mostly among current smokers (Jha 2011). Most smokers would like to stop (CDC 2017); however, quitting tobacco use is difficult. This is because users develop both a psychological and physiological dependence on smoking. The physiological dependence is caused by a component of tobacco, called nicotine (McNeill 2017).

\section{Description of the intervention}

Whilst antidepressant medications are primarily used for the treatment of depression and disorders of negative affect, they have also been used to help individuals stop smoking. They offer an alternative to other frontline smoking cessation therapies, such as nicotine replacement therapy (NRT), and nicotine agonists, such as varenicline.

The following medications and substances, regarded as having antidepressant properties, have been investigated for their effect on smoking cessation in at least one study.

- Tricyclic antidepressants (TCAs): doxepin, imipramine and nortriptyline

- Monoamine oxidase inhibitors (MAOIs): moclobemide, selegiline, lazabemide, and EVT302

- Selective serotonin reuptake inhibitors (SSRIs): fluoxetine, paroxetine, sertraline, citalopram, and zimeledine

- Atypical antidepressants: bupropion, tryptophan, venlafaxine

- Extracts of St. John's wort (Hypericum perforatum L)

- Dietary supplement: S-Adenosyl-L-Methionine (SAMe)

Of the antidepressant medications indicated for smoking cessation, the most commonly used is bupropion. It has both dopaminergic and adrenergic actions, and appears to be an antagonist at the nicotinic acetylcholinergic receptor (Fryer 1999). It has been licensed as a prescription aid to smoking cessation in many countries. The usual dose for smoking cessation is 150 $\mathrm{mg}$ once a day for three days, increasing to $150 \mathrm{mg}$ twice a day continued for 7 to 12 weeks, and quit attempts are generally initiated one week after starting pharmacotherapy.

Following bupropion, the second most commonly tested medication for smoking cessation is the TCA, nortriptyline. It enhances noradrenergic and serotonergic activity by blocking reuptake of these neurotransmitters (Benowitz 2000). It is licensed for smoking cessation in New Zealand. The recommended regimen is 10 to 28 days of titration before the quit attempt, followed by a 12-week dose of $75 \mathrm{mg}$ to $100 \mathrm{mg}$ daily (Cahill 2013).

No other antidepressants are currently licensed for use as smoking cessation aids, although others have been tested for possible use.

\section{How the intervention might work}

Multiple observations have provided a rationale for studying the effects of antidepressant medications for smoking cessation: a history of depression is found more frequently amongst smokers than nonsmokers, nicotine may have antidepressant effects, and antidepressants influence the neurotransmitters and receptors involved in nicotine addiction (Benowitz 2000; Kotlyar 2001). It has also been hypothesized that cessation may precipitate depression, however evidence suggests that this is unlikely to be the case, and that cessation may actually reduce the likelihood of depression (Taylor 2014).

The diverse pharmacological targets of antidepressants means their mechanisms of action are varied. Evidence suggests bupropion may aid smoking cessation by blocking nicotine effects, relieving withdrawal (Cryan 2003; West 2008), and reducing depressed mood (Lerman 2002a). Monoamine oxidase-A (MOA-A) inhibitors may aid smoking cessation by substituting the ability of smoking to act as a MOA inhibitor (Lewis 2007). It has been hypothesized that SSRIs might be helpful because they increase serotonin, which is also associated with improving negative affect (Benowitz 2000). The mechanisms of other antidepressants for smoking cessation remain unstudied.

Although there is an evident relationship between alleviating negative affect and antidepressant pharmacology, it is unclear whether antidepressants work mostly due to reducing negative affect, reducing urges to smoke or withdrawal symptoms, or by acting as nicotine blockers.

\section{Why it is important to do this review}

The ongoing impact of smoking on global morbidity and mortality necessitates effective and safe treatments to aid smoking cessation. Since the last update of this review was published in 2014 (Hughes 2014), a substantial amount of new evidence has emerged to assess antidepressants as smoking cessation aids. This has the potential to change or strengthen our conclusions regarding the efficacy of some of these antidepressants when compared with no treatment, whilst also strengthening the evidence regarding the safety of those antidepressant currently being used to help people quit smoking (bupropion and nortriptyline). Further evidence on safety outcomes may help to clarify the potential interaction between bupropion and seizures, as well as psychiatric adverse events. Multiple trials and observational studies have previously associated bupropion with increasing the risk of medically important adverse events, including seizures, anxiety, depression, and insomnia (Aubin 2012). New evidence may also help us to directly compare the safety and efficacy of antidepressants with other front-line smoking cessation medications, providing a further aid to decision making when helping people to quit tobacco smoking.

\section{O B J E C T IVES}

To assess the evidence for the efficacy, safety and tolerability of medications with antidepressant properties in assisting long-term tobacco smoking cessation in people who smoke cigarettes.

\section{METHODS}

\section{Criteria for considering studies for this review Types of studies}

We included randomized controlled trials (RCTs) and cluster-RCTs. 


\section{Types of participants}

We included tobacco smokers of any age, with or without a history of mental illness. We did not include pregnant women, as these smokers are covered in a separate Cochrane Review (Coleman 2015).

\section{Types of interventions}

We included trials studying pharmacotherapies with antidepressant properties for smoking cessation. We included trials assessing different doses, durations and schedules of antidepressants.

We excluded trials where an additional, uncontrolled nonantidepressant intervention component was used in only one of the trial arms. This is because the confounding effects of this intervention would have made it difficult to determine whether any change in outcome was related to the antidepressant or the confounding intervention component. Additionally, we excluded trials investigating antidepressant use for smoking harm reduction or relapse prevention, as they are covered elsewhere (LindsonHawley 2016 and Livingstone-Banks 2019, respectively).

\section{Comparators}

The following comparators were eligible for assessing safety, efficacy and tolerability: placebo, no pharmacotherapy, alternative therapeutic control, or different dosages/treatment regimes of the same antidepressant.

\section{Types of outcome measures}

\section{Primary outcomes}

- Efficacy, measured as smoking cessation

For this outcome we only included studies that set out to report smoking cessation rates at least six months after baseline, in line with the standard methods of Cochrane Tobacco Addiction. Where cessation was assessed at multiple intervals, we report only the longest follow-up data. Additionally, where multiple definitions of abstinence are assessed, we report the strictest of these definitions (e.g. continuous/prolonged abstinence over point prevalence abstinence). We also report biochemical validation of abstinence over self-reported abstinence (but it was not necessary for abstinence to have been biochemically validated for a study to be included).

\section{Secondary outcomes}

- Safety, measured as:

* number of people experiencing adverse events (AEs) of any severity (e.g. abnormal test findings, clinically significant symptoms and signs, changes in physical examination findings, hypersensitivity, and progression or worsening of underlying disease)

* number of people experiencing psychiatric AEs (e.g. adverse events relating to mental health)

* number of people experiencing serious adverse events (SAEs), i.e. events that result in death, are life-threatening (immediate risk of death), require inpatient hospitalization or prolongation of existing hospitalization, result in persistent or significant disability or incapacity, and/or result in congenital anomaly or birth defect (e.g. seizures, overdoses, suicide attempts, death by suicide, all-cause mortality).

We also recorded the following SAEs specifically, as these have previously been associated with the use of antidepressants for smoking cessation.

- Number of people experiencing seizures

- Number of people experiencing overdoses

- Number of people experiencing suicide attempts

- Number of people experiencing death by suicide

- Number of people experiencing all-cause mortality

- Tolerability, measured as the number of participants who dropped out of the trial due to adverse events

For all safety and tolerability outcomes, we considered studies with follow-up of any length.

\section{Search methods for identification of studies}

\section{Electronic searches}

We identified studies from the Cochrane Tobacco Addiction Specialized Register. At the time of the updated search in May 2019, the Register included the results of searches of the Cochrane Central Register of Controlled trials (CENTRAL; 2019, Issue 4); MEDLINE (via OVID) to update April 2019; Embase (via OVID) to April 2019; PsycINFO (via OVID) to update April 2019; US National Library of Medicine ClinicalTrials.gov (ClinicalTrials.gov); and the World Health Organization International Clinical Trials Registry Platform (ICTRP) to April 2019. See the Cochrane Tobacco Addiction website for full search strategies and a list of other resources searched to populate the Register. We searched the Register for reports of studies evaluating bupropion, nortriptyline or any other pharmacotherapy classified as having an antidepressant effect. Search terms included relevant individual drug names or antidepressant ${ }^{\star}$ or antidepressive ${ }^{\star}$. See Appendix 1 for the Register search strategy.

\section{Data collection and analysis}

\section{Selection of studies}

Two review authors (of JHB, JLB, NL, SH) independently screened titles and abstracts resulting from our searches for relevance, and obtained full-text records of reports of eligible or possibly eligible studies. Two review authors (of JHB, JLB, NL, SH) then independently screened each full-text record for eligibility. Any disagreements were resolved through discussion with a third review author. For conference abstracts or trial registry entries where the record contained insufficient evidence for us to determine the eligibility of the study, we attempted to contact study investigators to obtain any additional data needed to make a final decision. We recorded all screening decisions made and presented the flow of studies and references through the reviewing process using a PRISMA flow diagram (Moher 2009).

\section{Data extraction and management}

Two review authors (of $\mathrm{BH}, \mathrm{JHB}, \mathrm{JLB}, \mathrm{NL}, \mathrm{SH}$ ) independently extracted the following study data and compared the findings. Any discrepancies were resolved by mutual consent.

- Type of antidepressant 
- Country and setting

- Recruitment method

- Definition of smoker used

- Participant demographics (i.e. average age, gender, average cigarettes per day)

- Intervention and control description (including dose, schedule, and behavioural support common to all arms)

- Efficacy outcome(s) used in meta-analysis, including length of follow-up, definition of abstinence, and biochemical validation of smoking cessation

- Any analysis investigating the interaction between efficacy and participants' depression status

- Safety and tolerability outcomes, including AEs, psychiatric AEs, SAEs, types of SAEs, withdrawals due to treatment

- Sources of funding and declarations of interest

\section{Assessment of risk of bias in included studies}

We assessed included studies for risks of selection bias (method of random sequence generation and allocation concealment), bias due to an absence of blinding (taking into account both performance and detection bias in a single domain), attrition bias (levels and reporting of loss to follow-up), and any other threats to study validity, using the Cochrane 'Risk of bias' tool (Higgins 2011). For each new study in this update, two review authors (of JHB, JLB, NL, SH) independently assessed each study for each domain, in accordance with 'Risk of bias' guidance developed by Cochrane Tobacco Addiction to assess smoking cessation studies. Where there was any disagreement on the assessment, it was resolved through discussion with a third review author.

We considered studies at high risk of performance and detection bias where there was no blinding of participants or personnel or where there was evidence of unblinding; at unclear risk if insufficient information was available with which to judge; and at low risk if the study reported blinding of participants and personnel in detail and there was no evidence of unblinding. We considered studies to be at low risk of attrition bias where over half of the participants were followed up at the longest follow-up and where numbers followed up were similar across arms (difference $<20 \%$ ).

\section{Measures of treatment effect}

\section{Smoking cessation}

We calculated cessation rates for all studies that reported cessation at least six months following baseline. For each study, we used the strictest available criteria to define cessation as described above.

Where data were available, we expressed cessation as a risk ratio (RR) for each study. We calculated this as follows: (quitters in treatment group/total randomized to treatment group)/(quitters in control group/total randomized to control group), alongside $95 \%$ confidence intervals (Cls). A RR $>1$ indicates increased likelihood of quitting in the intervention group than in the control condition.

\section{Adverse events (AEs) and serious adverse events (SAEs)}

We calculated $A E$ rates for all studies that reported adequate data, regardless of study length. Where numerical data were available, we expressed safety and tolerability data as RRs $(95 \% \mathrm{Cl})$. We calculated this as follows: (number of participants reporting (S)AEs in treatment group/total randomized to treatment group)/(number of participants reporting (S)AEs in control group/total randomized to control group). A RR > 1 indicates an increased likelihood of experiencing an $A E$ or $S A E$ in the intervention group than in the control condition.

In addition to overall AEs and overall SAEs, we calculated RRs (95\% $\mathrm{Cl}$ ) for the following safety and tolerability outcomes, where data were available.

- Psychiatric AEs

- Seizures

- Overdoses

- Suicide attempts

- Death by suicide

- All-cause mortality

- Dropout due to adverse events

- Insomnia

- Anxiety

\section{Unit of analysis issues}

We only judged one cluster-RCT to be eligible for inclusion (Siddiqi 2013). This study was not pooled in any meta-analysis due to substantial heterogeneity of programme effects across clusters.

\section{Dealing with missing data}

As far as possible, we used an intention-to-treat (ITT) analysis with people who dropped out or were lost to follow-up treated as continuing smokers. Where participants appeared to have been randomized, but were not included in the data presented by the authors (and we were unable to obtain these), we noted this in the study description (see Characteristics of included studies). We extracted numbers lost to follow-up from study reports and used these to assess the risk of attrition bias.

\section{Assessment of heterogeneity}

Before pooling studies, we considered both methodological and clinical variance between studies. Where pooling was deemed appropriate we investigated statistical heterogeneity using the 12 statistic (Higgins 2003). This describes the percentage variability in effect estimates that is due to heterogeneity rather than sampling error (chance).

\section{Assessment of reporting biases}

Where a comparison included a sufficient number of studies ( $\geq 10$ ), we generated funnel plots to analyse and report on potential publication bias as advised by the Cochrane Handbook for Systematic Reviews of Interventions (Higgins 2019).

We therefore generated funnel plots for the following comparisons.

- Bupropion versus placebo/control - smoking cessation

- Bupropion versus placebo/control - AEs

- Bupropion versus placebo/control - SAEs

- Bupropion versus placebo/control - seizures

- Bupropion versus placebo/control - suicide attempts

- Bupropion versus placebo/control - death by suicide

- Bupropion versus placebo/control - all-cause mortality

- Bupropion versus placebo/control - dropout due to drug 
- Bupropion versus placebo/control - anxiety

- Bupropion versus placebo/control - insomnia

- Bupropion and nicotine replacement therapy (NRT) versus NRT alone - smoking cessation

- Bupropion versus NRT - smoking cessation

\section{Data synthesis}

For each type of medication and comparison where more than one eligible trial was identified, we performed separate metaanalyses of cessation and safety outcomes using Mantel-Haenszel fixed-effect methods. We pooled RRs and $95 \% \mathrm{Cls}$ from individual study estimates to estimate pooled RRs $(95 \% \mathrm{Cls})$. Where studies contributed more than one intervention arm to a pooled analysis, we split the control arm to avoid double-counting.

We also carried out post hoc, exploratory analyses to inform our approach to safety and tolerance for the next update of this review. We combined the following comparisons when evaluating AEs, psychiatric AEs, SAEs, and dropouts due to adverse effects.

- Bupropion compared to placebo/control

- Bupropion plus NRT compared to NRT alone

- Bupropion plus varenicline compared to varenicline alone

The rationale for this was that these studies all tested the additional effect of bupropion, and there was no evidence of an interaction for safety and tolerability outcomes (whereas there may be for effectiveness). We subgrouped studies by their comparison type, though acknowledge that these subgroups may currently be underpowered to detect differences between groups.

\section{Subgroup analysis and investigation of heterogeneity}

For comparisons where we had sufficient data, we separated participant data into the following subgroups to determine whether antidepressants had differential effects on the relevant population or intervention groups.

- Split by mental health diagnoses: mental health diagnoses versus no mental health diagnoses

- Split by level of behavioural support: multisession group support versus multisession individual counselling versus low intensity support versus not specified. To be identified as low intensity, support had to be regarded as part of the provision of routine care, i.e. time spent with smoker (including assessment for the trial) less than 30 minutes at the initial consultation, with no more than two further assessment and reinforcement visits.

Where reported, we also extracted data from analyses evaluating a potential interaction between current depression or past history of depression and quit rates. We relied upon the definition of depression used by study authors, which included both formal diagnoses and scores on validated depression scales. This interaction is investigated in more detail in van der Meer 2013.

\section{Sensitivity analysis}

We carried out the following sensitivity analyses.

- We excluded studies from meta-analyses that were judged to be at high risk of bias for any of the assessed bias domains. We judged whether this exclusion notably altered the pooled RRs $(95 \% \mathrm{Cl})$.

- We excluded studies from meta-analyses with industry support. We did this in two stages: 1) we excluded studies that were funded by the pharmaceutical industry; 2) we excluded studies that were funded by the pharmaceutical industry or where the study medication was provided by the pharmaceutical industry. We judged whether this exclusion notably altered the pooled RRs $(95 \% \mathrm{Cl})$.

\section{'Summary of findings' tables}

We created 'Summary of findings' tables using standard Cochrane methodology (Higgins 2019), for the following comparisons, which we judged to be most clinically relevant.

- Bupropion compared to placebo/control

- Bupropion plus NRT compared to NRT alone

- Bupropion plus varenicline compared to varenicline alone

We judged these comparisons to be of most relevance because bupropion is currently the only antidepressant used as a front-line therapy for smoking cessation worldwide.

Following standard Cochrane methodology (Higgins 2019), we used GRADEpro GDT software and the five GRADE considerations (risk of bias, consistency of effect, imprecision, indirectness, and publication bias) to assess the certainty of the body of evidence for smoking cessation, SAEs, and dropout due to adverse events of the drug, and to draw conclusions about the certainty of the evidence within the text of the review (Schünemann 2013). We chose these outcomes as they are important factors to consider regarding pharmaceutical efficacy, safety and tolerability, and are therefore useful to both clinicians and patients when deciding whether to provide or use a smoking cessation pharmacotherapy.

\section{RESULTS}

\section{Description of studies}

See Characteristics of included studies; Characteristics of excluded studies; Characteristics of ongoing studies

\section{Results of the search}

The most recent literature search for this update generated 397 records. After duplicates were removed, 362 records remained for title and abstract screening. We ruled out 213 records at this stage, leaving 149 records for full-text screening. At this stage we identified 33 new, included studies (reported across 85 records in total) and three ongoing studies. See Figure 1 for full details of record/study flow information for the most recent updated search. 


\section{Figure 1. Flow diagram for 2019 search update only}

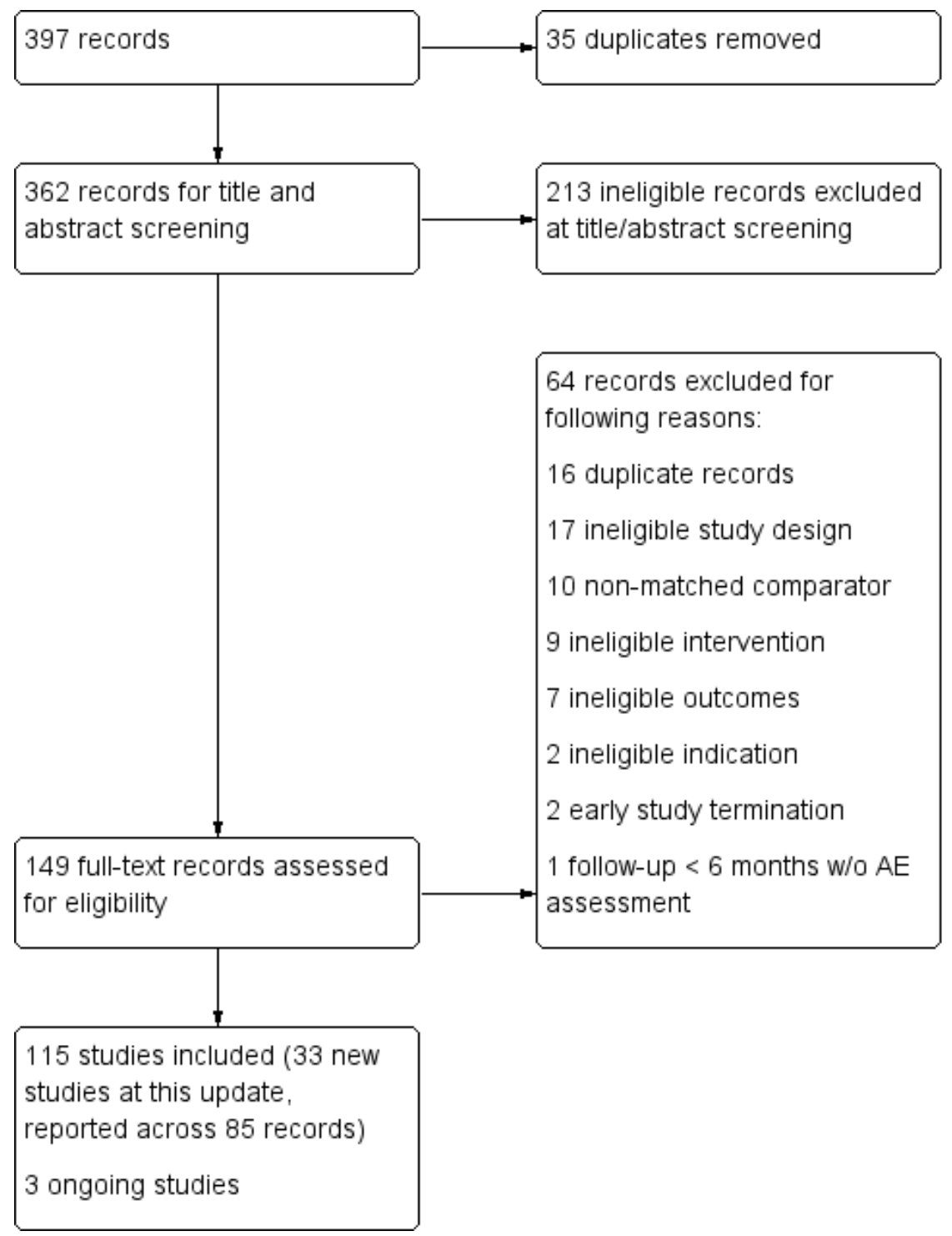

\section{Included studies}

We identified 33 additional eligible trials at this update, yielding a total of 115 included trials. The new trials studied:

- bupropion: Anthenelli 2016; Benli 2017; Cinciripini 2018; CTRI/2013/07/003830; Ebbert 2014; Elsasser 2002; Fatemi 2013; Gilbert 2019; Gray 2011; Gray 2012; Johns 2017; KaramHage 2011; Moreno-Coutino 2015; NCT00132821; NCT00308763; NCT00495352; NCT00593099; NCT01406223; Perkins 2013; Rose 2014; Rose 2017; Sheng 2013; Singh 2010; Tidey 2011; Urdapilleta-Herrera 2013; Weiner 2012; White 2005; Zincir 2013

- EVT302: Berlin 2012

- fluoxetine: Minami 2014; NCT00578669

- lazabemide: Berlin 2002

- St John's wort: Barnes 2006

Further details of these newly included, as well as previously included studies, including dosing schedules, are recorded in the Characteristics of included studies tables.

\section{Bupropion}

Overall, we included 87 studies of bupropion. Outcomes for four of these studies are based only on conference abstracts or pharmaceutical company data (Ferry 1992; Ferry 1994; Selby 2003; SMK20001).

The majority of trials were conducted in North America, but we also included studies from Australia (Myles 2004); Brazil (Haggsträm 2006); China (Sheng 2013); Europe (Aubin 2004; Dalsgarð 2004; Fossati 2007; Górecka 2003; Rovina 2009; Stapleton 2013; Wagena 2005; Wittchen 2011; Zellweger 2005); India (CTRI/2013/07/003830; Johns 2017; Singh 2010); Israel (Planer 2011); New Zealand (Holt 2005); Pakistan (Siddiqi 2013); Taiwan (NCT00495352); and Turkey (Benli 2017; Uyar 2007; Zincir 2013). Three studies were carried out across multiple continents (Anthenelli 2016; Tonnesen 2003; Tonstad 2003).

A number of trials specifically recruited cohorts of participants with health conditions, including: 
- alcoholism (Grant 2007; Hays 2009; Karam-Hage 2011)

- bipolar disorder (NCT00593099)

- cancer (Schnoll 2010)

- cardiovascular disease (Eisenberg 2013; Planer 2011; Rigotti 2006; Tonstad 2003)

- chronic obstructive pulmonary disease (Górecka 2003; Tashkin 2001; Wagena 2005)

- mild depression (Moreno-Coutino 2015)

- psychiatric conditions (Anthenelli 2016)

- schizophrenia (Evins 2001; Evins 2005; Evins 2007; Fatemi 2013; George 2002; George 2008; NCT00495352; Weiner 2012)

- post-traumatic stress disorder (Hertzberg 2001)

- tuberculosis or suspected tuberculosis (Siddiqi 2013; CTRI/2013/07/003830)

Three of the studies in people with cardiovascular disease, and one other, enrolled hospital inpatients (Eisenberg 2013; Planer 2011; Rigotti 2006; Simon 2009).

Trials also studied specific populations of:

- adolescents (Gray 2011; Gray 2012; Killen 2004; Muramoto 2007)

- African-Americans (Ahluwalia 2002; Cox 2012)

- healthcare workers (Zellweger 2005)

- hospital staff (Dalsgarð 2004)

- low-income and minority (NCT00308763)

- Maori (Holt 2005)

- males (Rose 2017)

- smokers awaiting surgery (Myles 2004)

- smokers who had previously failed to quit smoking using bupropion (Gonzales 2001; Selby 2003)

- smokers who had just failed to quit using nicotine replacement therapy (NRT) (Hurt 2003; Rose 2013; Rose 2014).

More than half the bupropion studies followed participants for at least 12 months from the start of treatment or the target quit day. Twenty-nine studies followed up participants for six months. The duration of follow-up was below six months for 12 of the included studies, was of unknown duration for six studies, and one study measured number of days abstinent rather than numbers abstinent at a particular time point (Perkins 2013). However, these studies did measure safety outcomes; therefore they contributed data to our meta-analyses of adverse events data, but not smoking cessation data.

In those studies which met or exceeded the six-month followup threshold, the majority reported an outcome of sustained (prolonged) abstinence. However, in 25 (33\%) studies, only point prevalence rates were given, or the definition of abstinence was unclear.

Forty-six trials evaluated bupropion for smoking cessation as a single pharmacotherapy versus placebo/nonpharmacotherapeutic control, and three studies compared different doses of bupropion (Hurt 1997; Muramoto 2007; Swan 2003). Both Muramoto 2007 and Swan 2003 compared a $150 \mathrm{mg}$ dose per day with a $300 \mathrm{mg}$ dose per day, whereas Hurt 1997 looked at $100 \mathrm{mg}$ per day versus $150 \mathrm{mg}$ per day versus $300 \mathrm{mg}$ per day. We pooled studies in which bupropion was used in combination with another pharmacotherapy or versus another pharmacotherapy in separate comparisons, as listed below.

- Bupropion as an adjunct to NRT versus NRT alone (16 trials)

- Bupropion as an adjunct to varenicline versus varenicline alone (6 trials)

- Bupropion versus NRT (10 trials)

- Bupropion versus varenicline (10 trials)

- Bupropion versus nortriptyline (3 trials)

- Bupropion versus gabapentin (1 trial)

\section{Nortriptyline}

We included 10 studies of the tricyclic antidepressant, nortriptyline in this review. Hall and colleagues conducted three trials (Hall 1998; Hall 2002; Hall 2004), and Prochazka and colleagues two (Prochazka 1998; Prochazka 2004), with all these trials conducted in the USA. One study was conducted in Australia (Richmond 2013), two in Brazil (Da Costa 2002; Haggsträm 2006), one in the Netherlands (Wagena 2005), and one in the UK (Aveyard 2008).

Richmond 2013 was the only study to be conducted in a specialist population, recruiting male prisoners who had been incarcerated for at least one month and had at least six months remaining of their sentences.

All studies were placebo controlled. They used nortriptyline doses of $75 \mathrm{mg} /$ day to $100 \mathrm{mg} /$ day or titrated doses to serum levels recommended for depression during the week prior to the quit date.

Treatment duration ranged from 12 to 14 weeks. Nearly all studies used a definition of cessation based on a sustained period of abstinence. Aveyard 2008, Hall 1998, Hall 2002, Hall 2004, and Richmond 2013 reported outcomes at $\geq 12$ months of follow-up and the other six studies had a maximum follow-up of six months.

The three studies by Hall and colleagues used factorial designs to test nortriptyline versus placebo crossed with different intensities of behavioural support (Hall 1998; Hall 2002; Hall 2004). Conversely, the remaining studies provided a set amount of behavioural support to all participants, ranging from brief behavioural counselling to repeated group and individual sessions.

Six studies tested nortriptyline as a monotherapy, and four studies tested nortriptyline as an adjunct to NRT.

\section{Selective serotonin reuptake inhibitors (SSRIs)}

\section{Fluoxetine}

Seven studies of fluoxetine have been included in this review, with two of these studies identified for inclusion in the current update (Minami 2014; NCT00578669).

The majority of these trials took place in the USA (Brown 2014; Minami 2014; NCT00578669; Niaura 2002; Saules 2004; Spring 2007), and one in Iceland (Blondal 1999). Participants were recruited from clinics (Blondal 1999; Brown 2014; Niaura 2002; Saules 2004; Spring 2007), the community (Minami 2014), or through an unknown recruitment method (NCT00578669). 
Brown 2014 was the only study to be conducted in a specialist population, recruiting smokers with elevated depressive symptoms.

Six of these studies conducted follow-up to at least six months for cessation outcomes. Minami 2014 had a follow-up duration of fewer than six months, so we only evaluated adverse events data for this study.

Four studies used varying doses of fluoxetine as a single pharmacotherapy: Niaura 2002 compared a $30 \mathrm{mg}$ daily dose, a $60 \mathrm{mg}$ daily dose, or placebo for 10 weeks; Spring 2007 used 60 mg or placebo for 12 weeks; NCT00578669 compared 20 mg daily for eight weeks preceding and following the target quit date to placebo. Minami 2014 also compared fluoxetine as a monotherapy (20 mg daily for 8 weeks prior to and following the target quit date) to placebo only.

The remaining three trials investigated fluoxetine as an adjunct to NRT, and used similar doses of fluoxetine: Blondal 1999 used $20 \mathrm{mg}$ / day or placebo for three months as an adjunct to nicotine inhaler; Saules 2004 used $20 \mathrm{mg} /$ day or $40 \mathrm{mg} /$ day or placebo for 10 weeks as an adjunct to nicotine patch; and Brown 2014 compared 10 weeks of $20 \mathrm{mg}$ daily fluoxetine, 16 weeks of $20 \mathrm{mg}$ daily fluoxetine, or no additional treatment in participants using nicotine patch for eight weeks.

\section{Paroxetine}

One trial assessed paroxetine (20 mg, $40 \mathrm{mg}$ or placebo) for nine weeks as an adjunct to nicotine patch (Killen 2000). It was conducted in the USA, with participants recruited from the community. It measured smoking cessation (defined as 7-day point prevalence) at six months follow-up.

\section{Sertraline}

One trial with six-month follow-up assessed sertraline $(200 \mathrm{mg} /$ day) for 11 weeks versus placebo in conjunction with six individual counselling sessions. All participants had a past history of major depression (Covey 2002).

\section{Monoamine oxidase inhibitors}

\section{Moclobemide}

Moclobemide was tested for smoking cessation in one placebocontrolled trial, carried out in France (Berlin 1995). Participants were recruited using advertisements in community healthcare settings. Treatment with $400 \mathrm{mg} /$ day began one week before quit day and continued for two months, reducing to $200 \mathrm{mg} /$ day for a further month. No behavioural counselling was provided. Final follow-up for smoking cessation (defined as prolonged abstinence) was at 12 months.

\section{Selegiline}

Five long-term trials testing selegiline are included in this review, carried out in the USA (George 2003; Kahn 2012; Killen 2010; Weinberger 2010), and Israel (Biberman 2003). All studies recruited participants from the community.

Almost all studies delivered selegiline as a monotherapy compared to placebo, excluding Biberman 2003, which used a combination therapy of selegiline and nicotine patch compared to placebo.
Three studies used $10 \mathrm{mg} /$ day of oral treatment (Biberman 2003; George 2003; Weinberger 2010), and two used $6 \mathrm{mg} /$ day of patch treatment (Kahn 2012; Killen 2010). The nicotine patches also used in Biberman 2003 delivered $21 \mathrm{mg} /$ day of nicotine for eight weeks. Three studies had treatment durations of nine weeks (George 2003; Kahn 2012; Weinberger 2010), one had a treatment duration of eight weeks (Killen 2010), and one continued therapy for 26 weeks (Biberman 2003). Three of the studies completed follow-up at six months (George 2003; Kahn 2012; Killen 2010), and two continued follow-up to 12 months (Biberman 2003; Weinberger 2010).

\section{Lazabemide}

Berlin 2002 is the only study of lazabemide included in this review. Due to its nature as a dose-finding, exploratory study, its follow-up period for smoking cessation was only eight weeks. Therefore, we only consider its safety data within this review.

The study was conducted in both France and Belgium; however, the method of participant recruitment is not reported. Participants were given either $50 \mathrm{mg}$ lazabemide, $100 \mathrm{mg}$ lazabemide or placebo. It was halted early due to liver toxicity observed in trials of the medication for other indications.

\section{EVT302}

Berlin 2012 is the only study of EVT302 included in this review. Its follow-up for smoking cessation is only eight weeks, therefore we only consider its safety data within this review.

The study was conducted in Germany, with participants recruited through media advertisements. It compared EVT302 monotherapy ( $5 \mathrm{mg} /$ day for 1 week preceding and 7 weeks following the target quit date) with placebo. It additionally compared EVT302 combination therapy with nicotine patch $(21 \mathrm{mg} /$ day for 7 weeks post-target quit date) versus placebo EVT302 and nicotine patch.

\section{Venlafaxine}

Cinciripini 2005 is the only study of venflaxine included in this review. It recruited from the community and compared venlafaxine at a dose of up to $225 \mathrm{mg} /$ day with placebo. All participants also received nicotine patches and nine brief individual counselling sessions; follow-up was for 12 months.

\section{Hypericum (St John's wort)}

Three studies of hypericum are included (Barnes 2006; Parsons 2009; Sood 2010), with Barnes 2006 newly included at this update. These studies took place in the USA (Sood 2010) and the UK (Barnes 2006; Parsons 2009). Participants were recruited from the community (Barnes 2006; Sood 2010) and stop-smoking clinics (Parsons 2009).

All three studies reported prolonged abstinence at six months. Barnes 2006 compared $300 \mathrm{mg} /$ day to $600 \mathrm{mg} /$ day, starting one week prior to the target quit date and continuing for 12 weeks thereafter; Parsons 2009 compared 14 weeks of $900 \mathrm{mg} /$ day St John's wort to placebo, starting two weeks prior to target quit date and continuing for 12 weeks thereafter; Sood 2010 compared 900 $\mathrm{mg} /$ day, $1800 \mathrm{mg} /$ day, and placebo for 12 weeks. 


\section{S-Adenosyl-L-Methionine (SAMe)}

Sood 2012 is the only study of SAMe included in this review. It compared $1600 \mathrm{mg} /$ day or $800 \mathrm{mg} /$ day SAMe to placebo for eight weeks, with smoking cessation follow-up at six months.

\section{Excluded studies}

For studies that were potentially relevant, but that we excluded, we have provided our reasons for exclusion in Characteristics of excluded studies. Reasons that records were excluded at full-text stage for this update specifically, are also summarized in Figure 1.

As part of this update to the review, we have excluded studies investigating the use of antidepressants for smoking relapse prevention and harm reduction, as these studies are included in other reviews (Lindson-Hawley 2016; Livingstone-Banks 2019). Therefore, we have now excluded seven studies of relapse prevention (Covey 2007; Croghan 2007; Hall 2011; Hays 2001; Hays 2009; Hurt 2003; Killen 2006), and one of harm reduction (Hatsukami 2004), which were included in the previous update (Hughes 2014).

We identified the following three ongoing studies as part of our search which are likely to be relevant for inclusion when complete.
- NCT03326128: compares two high doses of bupropion (300 mg/ day to $450 \mathrm{mg} /$ day, starting 4 weeks prior to and following target quit date).

- NCT03342027: a factorial trial comparing bupropion to placebo, as well as an eight-session tailored behavioural intervention.

- Zawertailo 2018: compares bupropion $(150 \mathrm{mg} /$ day for the first 3 days, then twice daily for the remainder of the 12 weeks, starting 7 days prior to target quit day) and varenicline ( $0.5 \mathrm{mg}$ once daily for first 3 days, then $0.5 \mathrm{mg}$ twice daily for next 4 days, then 1 $\mathrm{mg}$ twice daily for the remainder of the 12 weeks, starting 7 days prior to target quit day).

Further details of these ongoing studies are summarized in the Characteristics of ongoing studies table.

\section{Risk of bias in included studies}

Overall, we judged 12 studies to be at low risk of bias (low risk of bias across all domains), 28 at high risk of bias (high risk of bias in at least 1 domain), and the remaining 75 at unclear risk of bias. Reasons for the judgements made below are detailed in the Characteristics of included studies table, and a summary illustration of the 'Risk of bias' profile across studies is shown in Figure 2. 
Figure 2. Risk of bias summary: review authors' judgements about each risk of bias item for each included study.

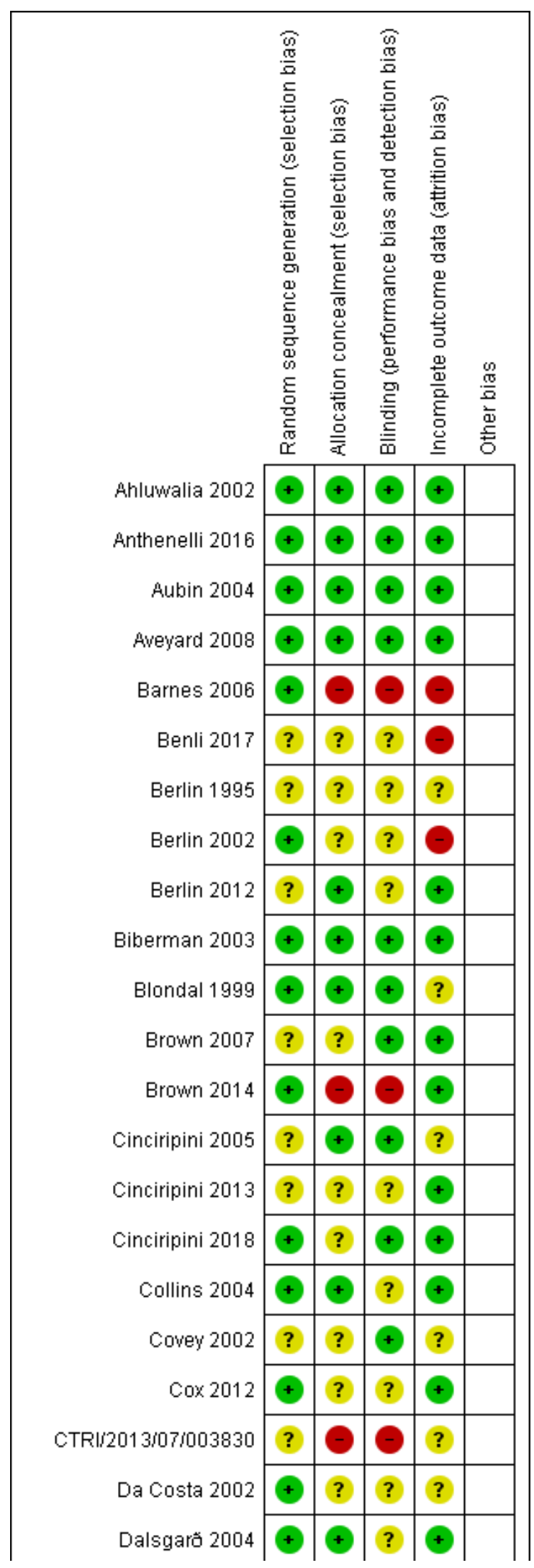


Figure 2. (Continued)

\begin{tabular}{|c|c|c|c|c|c|}
\hline \multirow{2}{*}{\multicolumn{6}{|c|}{\begin{tabular}{|l|l|l|l|} 
& & 0 & 0 \\
\end{tabular}}} \\
\hline Dalsgaró 2004 & & & & & \\
\hline Ebbert 2014 & 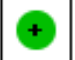 & $\oplus$ & + & $\odot$ & \\
\hline Eisenberg 2013 & $\odot$ & + & $?$ & 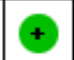 & \\
\hline Elsasser 2002 & $?$ & $?$ & $?$ & - & \\
\hline Evins 2001 & $?$ & $?$ & $?$ & 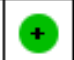 & \\
\hline Evins 2005 & $?$ & $?$ & $?$ & + & \\
\hline Evins 2007 & $?$ & $?$ & $\odot$ & 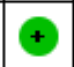 & \\
\hline Fatemi 2013 & $?$ & $?$ & $?$ & $?$ & \\
\hline Ferry 1992 & $?$ & $?$ & $?$ & $?$ & \\
\hline Ferry 1994 & $?$ & $?$ & $?$ & $?$ & \\
\hline Fossati 2007 & $?$ & $?$ & $?$ & + & \\
\hline Gariti 2009 & $\odot$ & $?$ & + & + & \\
\hline George 2002 & $?$ & $?$ & $?$ & $?$ & \\
\hline George 2003 & $?$ & $?$ & + & - & \\
\hline George 2008 & $?$ & $?$ & $?$ & + & \\
\hline Gilbert 2019 & $\odot$ & $?$ & $\odot$ & + & \\
\hline Gonzales 2001 & + & $?$ & + & $?$ & \\
\hline Gonzales 2006 & $\odot$ & + & $\odot$ & + & \\
\hline Górecka 2003 & $?$ & $?$ & 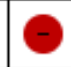 & $?$ & \\
\hline Grant 2007 & $?$ & $?$ & $?$ & + & \\
\hline Gray 2011 & $?$ & $?$ & $?$ & + & \\
\hline Gray 2012 & $?$ & $?$ & + & $?$ & \\
\hline Haggsträm 2006 & $?$ & $?$ & + & $?$ & \\
\hline Hall 1998 & + & $\odot$ & $?$ & + & \\
\hline Hall 2002 & $?$ & $\odot$ & $\Theta$ & + & \\
\hline Hall 2004 & $?$ & $?$ & $\odot$ & + & \\
\hline Hertberg 2001 & $?$ & $?$ & $?$ & - & \\
\hline Holt 2005 & + & $?$ & $\odot$ & $\Theta$ & \\
\hline Hurt 1997 & $?$ & $?$ & $?$ & $?$ & \\
\hline Johns 2017 & $?$ & $?$ & $?$ & $?$ & \\
\hline Jorenby 1999 & $\odot$ & $?$ & $?$ & + & \\
\hline
\end{tabular}


Figure 2. (Continued)

\begin{tabular}{|c|c|c|c|c|}
\hline Jorenby 1999 & $\odot$ & $?$ & $?$ & $\odot$ \\
\hline Jorenby 2006 & $\odot$ & + & $?$ & $\odot$ \\
\hline Kahn 2012 & $?$ & ? & $?$ & $\odot$ \\
\hline Kalman 2011 & $?$ & $?$ & $?$ & + \\
\hline Karam-Hage 2011 & $?$ & $?$ & $?$ & + \\
\hline Killen 2000 & $?$ & $?$ & $?$ & $?$ \\
\hline Killen 2004 & $?$ & $?$ & + & + \\
\hline Killen 2010 & + & + & + & + \\
\hline Levine 2010 & $?$ & $?$ & $?$ & $\odot$ \\
\hline McCarthy 2008 & $\odot$ & + & 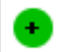 & + \\
\hline Minami 2014 & $\odot$ & $?$ & $\oplus$ & $?$ \\
\hline Moreno-Coutino 2015 & $\Theta$ & $\Theta$ & $\odot$ & $\Theta$ \\
\hline Muramoto 2007 & + & + & + & + \\
\hline Myles 2004 & + & $?$ & $?$ & + \\
\hline NCT00132821 & $?$ & $?$ & $?$ & ? \\
\hline NCT00308763 & $?$ & $?$ & $?$ & $?$ \\
\hline NCT00495352 & ? & ? & ? & $?$ \\
\hline NCT00578669 & ? & ? & ? & $?$ \\
\hline NCT00593099 & ? & ? & ? & + \\
\hline NCT01406223 & $?$ & $?$ & $?$ & $\odot$ \\
\hline Niaura 2002 & $?$ & $?$ & $?$ & $\odot$ \\
\hline Nides 2006 & + & + & ? & + \\
\hline Parsons 2009 & + & + & + & + \\
\hline Perkins 2013 & $?$ & $?$ & + & $?$ \\
\hline Piper 2007 & $?$ & ? & ? & + \\
\hline Piper 2009 & $?$ & + & $?$ & + \\
\hline Planer 2011 & $?$ & $?$ & + & + \\
\hline Prochazka 1998 & $?$ & ? & - & - \\
\hline Prochazka 2004 & + & + & $\Theta$ & + \\
\hline Richmond 2013 & $?$ & $?$ & $?$ & + \\
\hline Rigotti 2006 & + & + & $\oplus$ & + \\
\hline
\end{tabular}


Figure 2. (Continued)

\begin{tabular}{|c|c|c|c|c|c|}
\hline Rigotti 2006 & + & + & + & + & \\
\hline Rose 2013 & $?$ & $?$ & $?$ & - & \\
\hline Rose 2014 & $?$ & $?$ & $?$ & + & \\
\hline Rose 2017 & $?$ & $?$ & $?$ & + & \\
\hline Rovina 2009 & $?$ & $?$ & - & $?$ & \\
\hline Saules 2004 & $?$ & $?$ & $?$ & $?$ & \\
\hline Schmit 2007 & + & + & $?$ & + & \\
\hline Schnoll 2010 & $?$ & $?$ & ? & + & \\
\hline Selby 2003 & $?$ & $?$ & $?$ & $?$ & \\
\hline Sheng 2013 & + & $?$ & + & + & \\
\hline Siddiqi 2013 & + & + & - & + & \\
\hline Simon 2004 & $\odot$ & $?$ & $?$ & + & \\
\hline Simon 2009 & $\odot$ & $?$ & $\odot$ & + & \\
\hline Singh 2010 & $?$ & $?$ & & $?$ & \\
\hline Smith 2009 & $?$ & $?$ & & + & \\
\hline SMK20001 & $?$ & $?$ & $?$ & + & \\
\hline Sood 2010 & + & $?$ & $?$ & $?$ & \\
\hline Sood 2012 & ? & $?$ & $?$ & + & \\
\hline Spring 2007 & + & $?$ & $?$ & + & \\
\hline Stapleton 2013 & + & + & - & + & \\
\hline Swan 2003 & $\odot$ & + & - & + & \\
\hline Tashkin 2001 & + & + & $?$ & + & \\
\hline Tidey 2011 & + & $?$ & $?$ & + & \\
\hline Tonnesen 2003 & $\odot$ & + & $?$ & + & \\
\hline Tonstad 2003 & $?$ & $?$ & $?$ & $?$ & \\
\hline Urdapilleta-Herrera 2013 & $?$ & $?$ & $?$ & $?$ & \\
\hline Uyar 2007 & $?$ & $?$ & ค & $?$ & \\
\hline Wagena 2005 & $\odot$ & 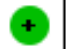 & $?$ & $\oplus$ & \\
\hline Weinberger 2010 & $?$ & $?$ & $\odot$ & $?$ & \\
\hline Weiner 2012 & $?$ & $?$ & $?$ & + & $?$ \\
\hline White 2005 & $?$ & $?$ & & + & \\
\hline
\end{tabular}


Figure 2. (Continued)

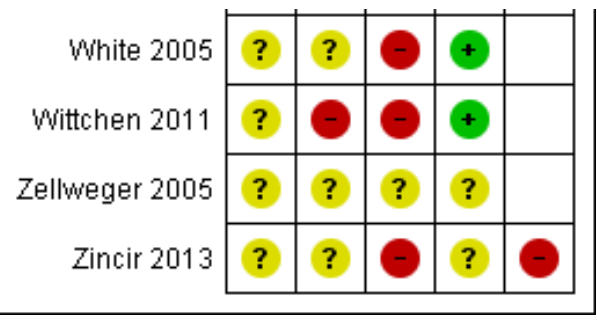

\section{Allocation}

We assessed selection bias through investigating methods of random sequence generation and allocation concealment for each study. We rated 46 studies at low risk for random sequence generation, 68 at unclear risk and one at high risk (MorenoCoutino 2015). We judged 31 studies to be at low risk for allocation concealment, 79 at unclear risk and five at high risk. When assessing both random sequence generation and allocation concealment, we assessed studies to be at unclear risk where there was insufficient methodological information available to be sure whether adequate measures had been taken to avoid selection bias.

\section{Blinding}

We assessed any risk of bias linked to blinding as one domain. However, we took into account both performance and detection bias when making this judgement. We judged 32 studies to be at low risk of bias for this domain, 64 at unclear risk and 19 at high risk. Where studies stated that they were "double-blind" only, with no explicit clarification of who was blinded, we judged this to be unclear risk.

\section{Incomplete outcome data}

We judged studies to be at a low risk of attrition bias where the numbers of participants lost to follow-up were clearly reported and the overall number lost to follow-up was not more than $50 \%$, and the difference in loss to follow-up between groups was no greater than $20 \%$. This is in accordance with 'Risk of bias' guidance produced by Cochrane Tobacco Addiction for assessing smoking cessation studies. We judged 69 of the studies to be at low risk of bias, 34 at unclear risk and 12 at high risk.

\section{Other potential sources of bias}

We found three studies with other sources of potential bias beyond those domains detailed previously. Siddiqi 2013 demonstrated substantial heterogeneity of programme effects across the different clusters of their cluster-RCT. Twenty per cent of participants in the control arm smoked only hookah (no cigarettes) compared with $4 \%$ in the intervention arm. We judged that this put the study at high risk of bias. Weiner 2012 details that there was insufficient study drug available to meet demand. It is unclear how this was dealt with and whether it is accounted for in the dropouts reported. We judged this to be an unclear risk of bias. Finally, Zincir 2013 details that there were no adverse events recorded during their study. This seems highly unlikely according to the common definition of adverse events, and there is no detail given of how adverse events were measured in the study. We have therefore judged this to put the study at high risk of bias.

\section{Effects of interventions}

See: Summary of findings for the main comparison Bupropion compared to placebo/no pharmacotherapy control for smoking cessation; Summary of findings 2 Bupropion plus NRT compared to NRT alone for smoking cessation; Summary of findings 3 Bupropion plus varenicline compared to varenicline alone for smoking cessation

\section{Bupropion versus placebo/no pharmacotherapy control \\ Smoking cessation}

There was evidence to suggest that bupropion was effective when compared to placebo or a non-pharmacotherapeutic control to assist smoking cessation. Our meta-analysis included 46 trials in which bupropion was the sole pharmacotherapy, with 17,866 participants: pooled risk ratio (RR) 1.64, 95\% confidence interval (CI) 1.52 to $1.77 ;\left.\right|^{2}=15 \%$; high-certainty evidence; Analysis 1.1 ; Summary of findings for the main comparison). The results were not sensitive to the exclusion of studies judged to be at high or unclear risk of bias overall. We excluded one cluster-RCT of bupropion versus no pharmacotherapy from our meta-analysis due to substantial heterogeneity of programme effects across clusters. This trial detected no evidence of a difference between bupropion and no pharmacotherapy (both groups received behavioural support) for smoking cessation at any follow-up point (adjusted RR at 6-month follow-up: 1.1, 95\% Cl 0.5 to 2.3; 1299 participants) (Siddiqi 2013). Sensitivity analyses excluding studies with industry support did not indicate that our findings were sensitive to the inclusion of these studies (see Table 1).

We found no evidence suggesting that the effect of bupropion on smoking cessation depended upon the level of behavioural support offered to people stopping smoking. Three trials directly compared bupropion and placebo in factorial designs varying the behavioural support. There was no evidence from any of the three trials that the efficacy of bupropion differed between the lower and higher levels of behavioural support (Hall 2002; McCarthy 2008), or by the type of counselling approach used (Schmitz 2007). We also carried out a between-study subgroup analysis of the possible interaction with behavioural support. We did this by classifying studies into low and high intensities of behavioural support (further split into delivery to a group or to individuals), using the criteria set in the Cochrane Review of NRT versus control (Hartmann-Boyce 2018). Low-intensity support consisted of less than 30 minutes at the initial consultation, with no more than two further assessment and reinforcement visits. Only one small trial met this criteria (Myles 2004). We found no evidence of a difference between subgroups ( 12 $=0 \%$; Analysis 1.2). 
One trial directly compared bupropion and placebo in a cohort of participants with mental health disorders to a cohort without (Anthenelli 2016). There was no evidence indicating that the effect of bupropion depended upon whether people had or did not have a psychiatric disorder. We also carried out a between studies subgroup analysis to assess the potential interaction between cessation rates and mental health disorders. We did this by pooling studies (or subgroups of studies) into groups depending upon whether the participants were recruited specifically because they had a mental health disorder or they represented the general population (including some studies that excluded people with current mental health disorders). Some of these groups included people with serious mental health disorders, such as people with schizophrenia (Evins 2001; Evins 2005; George 2002), or other disorders including post-traumatic stress disorder (PTSD; Hertzberg 2001), and a mix of mental health disorders (Anthenelli 2016). We found no evidence of a differential effect of bupropion on cessation between subgroups (Analysis $1.3 ;\left.\right|^{2}=15 \%$ ).

\section{Depression}

Four studies comparing bupropion to placebo/control analysed whether there was any interaction between depression and smoking quit rates (Anthenelli 2016 (analysis reported in West 2018); Aubin 2004; Cinciripini 2018; Kalman 2011). We did not find any evidence of this (Table 2).

\section{Safety}

There was evidence to suggest that taking bupropion increased the incidence of adverse events (AEs) relative to placebo or nonpharmacotherapeutic control (RR $1.14,95 \% \mathrm{Cl} 1.11$ to $1.18 ; 19$ studies, 10,893 participants; Analysis 1.4). However, a moderate degree of heterogeneity was detected between studies $(12=63 \%)$. Meta-analysis of 21 studies did not provide clear evidence that the use of bupropion increased the likelihood of serious adverse events (SAEs) (RR 1.16, 95\% Cl 0.90 to $1.48 ; 1^{2}=0 \%$; 21 studies, 10,625 participants; moderate-certainty evidence; Analysis 1.5; Summary of findings for the main comparison), however the Cls encompassed both no difference as well as a clinically significant increase.

There was also evidence to suggest bupropion increased the likelihood of developing psychiatric AEs. We meta-analysed six studies (RR 1.25, 95\% Cl 1.15 to 1.36; 6 studies, 4439 participants; Analysis 1.6). This effect is largely driven by Anthenelli 2016 (with an overall weighting of $96.9 \%$ ), however as we judged this study to be at low risk of bias, and the effects are consistent with those detected by the other studies included in the analysis $(12=15 \%)$, this is not deemed to be problematic.

There was insufficient evidence to determine whether bupropion use was associated with the likelihood of seizures (RR 2.93, 95\% Cl 0.64 to $13.37 ;\left.\right|^{2}=0 \% ; 13$ studies, 7344 participants; Analysis 1.7), risk of overdose (RR $2.15,95 \% \mathrm{Cl} 0.23$ to $19.86 ; \mathrm{I}^{2}=0 \% ; 5$ studies, 5585 participants; Analysis 1.8), suicide attempts (RR 1.62, 95\% Cl 0.29 to $8.92 ; 1^{2}=0 \% ; 10$ studies, 6484 participants; Analysis 1.9), risk of death by suicide (RR $0.34,95 \% \mathrm{Cl} 0.01$ to $8.26 ; \mathrm{I}^{2}=\mathrm{n} / \mathrm{a}$; 14 studies, 8822 participants; Analysis 1.10), or all-cause mortality risk (RR 0.89 , $95 \% \mathrm{Cl} 0.42$ to $1.87 ; \mathrm{I}^{2}=0 \% ; 21$ studies, 11,403 participants; Analysis 1.11). In all cases the number of events reported were very low, which resulted in substantial imprecision and $\mathrm{Cls}$ encompassing both clinically significant benefit and harm.
However, there was evidence that those randomized to receive bupropion were more likely to report symptoms of anxiety (RR 1.42, $95 \% \mathrm{Cl} 1.21$ to $1.67 ;\left.\right|^{2}=40 \% ; 11$ studies, 7406 participants; Analysis 1.12) and insomnia (RR $1.78,95 \% \mathrm{Cl} 1.62$ to $1.96 ; \mathrm{I}^{2}=12 \% ; 22$ studies, 11,077 participants; Analysis 1.13) at follow-up.

\section{Tolerability}

There was evidence that the risk of dropout due to AEs of the drug was higher in groups receiving bupropion relative to placebo or no pharmaceutical treatment (RR $1.37,95 \% \mathrm{Cl} 1.21$ to 1.56 ; $\left.\right|^{2}=19 \%$; 25 studies, 12,340 participants; high certainty evidence; Analysis 1.14; Summary of findings for the main comparison). Our point estimate suggests that participants taking bupropion had a $21 \%$ to $56 \%$ increased risk of dropping out relative to control.

We carried out sensitivity analyses (not shown) for all of the above safety and tolerability analyses, removing studies at overall high risk of bias, where this was relevant. In no cases did this change the interpretation of the effect. Additional sensitivity analyses, excluding studies with industry support, did not indicate that our findings were sensitive to the inclusion of these studies (see Table 1).

\section{Bupropion plus nicotine replacement therapy (NRT) versus NRT alone}

\section{Smoking cessation}

There was moderate statistical heterogeneity in the results of 12 studies comparing bupropion plus nicotine replacement therapy (NRT) to NRT alone for smoking cessation (RR 1.19, 95\% Cl 0.94 to $1.51 ;\left.\right|^{2}=52 \% ; 12$ studies, 3487 participants; low certainty evidence; Analysis 2.1; Summary of findings 2). The analysis thus found no clear evidence of a benefit of using bupropion plus NRT over using NRT alone. Nine of the 12 studies used nicotine patch, but two studies provided participants with nicotine lozenge (Piper 2009; Smith 2009), and one offered a choice of NRT (Stapleton 2013). However, splitting the analysis into these subgroups did not explain the heterogeneity detected ( $12=0 \%$ for subgroup differences), nor did the exclusion of studies that did not use a bupropion placebo in the control arm (Smith 2009; Stapleton 2013). Removing the three studies deemed to be at an overall high risk of bias did not change the interpretation of the pooled effect estimate (Rose 2013; Smith 2009; Stapleton 2013). Sensitivity analyses excluding studies with industry support did not indicate that our findings were sensitive to the inclusion of these studies (see Table 1). Although the direction of the effect estimate changed when studies funded by the pharmaceutical industry, or where the medication was supplied by the pharmaceutical industry, were excluded; 95\% $\mathrm{Cls}$ still encompassed evidence of benefit as well as harm.

\section{Depression}

None of the relevant included studies investigated depression as a moderator of smoking quit rates.

\section{Safety}

There was evidence to indicate an increased risk of AEs when using combination bupropion and NRT relative to taking NRT alone (RR $1.21,95 \% \mathrm{Cl} 1.02$ to $1.43 ; \mathrm{I}^{2}=0 \% ; 2$ studies, 313 participants; Analysis 2.2); however the number of events was low $(n=192)$, and when one study at high risk of bias was removed the outcome become more imprecise and the $\mathrm{Cl}$ spanned one (RR 1.24, 95\% Cl 
0.98 to 1.56). There was insufficient evidence for the other safety outcomes we analysed for this comparison (SAEs, seizures, suicide attempts, death by suicide, all-cause mortality). Very few studies had relevant data, and those that did recorded few events. In the case of the SAEs outcome, the removal of one study deemed to be at high risk of bias changed the effect estimate from $R R=1.52$ (95\% Cl 0.26 to $8.89 ; 1^{2}=0 \% ; 3$ studies, 607 participants; very low certainty evidence; Analysis 2.3; Summary of findings 2) to RR $=1.00$ ( $95 \% \mathrm{Cl} 0.06$ to $15.83 ; \mathrm{I}^{2}=\mathrm{n} / \mathrm{a} ; 2$ studies, 538 participants). Although this did not change the clinical interpretation of the result it does demonstrate that the effect estimate was highly dependent on this potentially biased study.

There was some evidence that bupropion plus NRT led to increased reporting of insomnia in comparison to NRT alone (RR 1.55, 95\% Cl 1.24 to $1.93 ; 12=0 \%$; 2 studies, 556 participants; Analysis 2.8); however there was no clear evidence of an increase in anxiety in the bupropion plus NRT groups (RR $1.58,95 \% \mathrm{Cl} 0.97$ to 2.56 ; $\mathrm{I}^{2}=47 \%$; 3 studies, 1218 participants; Analysis 2.9). In both cases the results were based on a small number of studies and event rates were low $(<300)$.

\section{Tolerability}

Only two studies measured dropout due to AEs of the drug, providing insufficient information to draw conclusions and an imprecise pooled effect estimate (RR 1.67, 95\% Cl 0.95 to $2.92 ; \mathrm{I}^{2}$ $=0 \% ; 2$ studies, 538 participants; low certainty evidence; Analysis 2.10; Summary of findings 2).

Removing studies judged to be at high risk of bias from safety and tolerability analyses did not affect the interpretation of these effects, and sensitivity analyses, excluding studies with industry support, did not indicate that our findings were sensitive to the inclusion of these studies (see Table 1).

\section{Bupropion plus varenicline versus varenicline alone}

\section{Smoking cessation}

Our analysis did not find evidence that combination bupropion and varenicline resulted in higher smoking cessation rates than varenicline alone $\left(\mathrm{RR} 1.21,95 \% \mathrm{Cl} 0.95\right.$ to $1.55 ; \mathrm{I}^{2}=15 \% ; 3$ studies, 1057 participants; moderate certainty evidence; Analysis 3.1; Summary of findings 3). Confidence intervals encompassed the possibility of no clinically significant difference in quit rates as well as a clinically significant benefit of bupropion combined with varenicline. We did not carry out a sensitivity analysis to account for risk of bias as we did not judge any of the studies in the analysis to be at high risk. A sensitivity analysis excluding studies with industry support did not indicate that our findings were sensitive to the inclusion of these studies (see Table 1).

\section{Depression}

None of the relevant included studies investigated a potential link between depression and quit rates.

\section{Safety}

There was evidence to indicate an increased risk of AEs, as well as psychiatric AEs, when taking combination bupropion and varenicline compared to varenicline alone (AEs: RR 1.09, 95\% Cl 1.02 to $1.17 ;\left.\right|^{2}=78 \%$; 4 studies, 1043 participants; Analysis 3.2) (psychiatric AEs: RR 1.15, 95\% Cl 1.03 to $1.30 ;\left.\right|^{2}=75 \%$; 2 studies,
835 participants; Analysis 3.4). However, in both cases we observed substantial heterogeneity, meaning these pooled estimates should be treated with caution.

We did not find evidence to suggest an increased likelihood of SAEs (low certainty evidence; Summary of findings 3), overdoses, seizures, suicide attempts, death by suicide, or all-cause mortality in the combination bupropion and varenicline trial arms in comparison to varenicline alone. However, there were few studies and events for these outcomes. In all cases (apart from those outcomes with no events; Analysis 3.5; Analysis 3.8) Cls encompassed one (Analysis 3.3; Analysis 3.6; Analysis 3.7; Analysis 3.9).

There was some evidence that randomization to combination bupropion and varenicline resulted in greater reporting of anxiety (RR 1.55, 95\% Cl 1.01 to $2.38 ; \mathrm{I}^{2}=0 \%$; 2 studies, 499 participants; Analysis 3.10) and insomnia (RR $1.45,95 \% \mathrm{Cl} 1.14$ to 1.84 ; $\mathrm{I}^{2}=0 \%$; 2 studies, 499 participants; Analysis 3.11) than varenicline alone at follow-up. However, these results should be treated with caution as there were a low number of events in both analyses $(<200)$.

\section{Tolerability}

We did not find evidence to suggest an increased likelihood of dropout due to drug in the combination bupropion and varenicline trial arms in comparison to varenicline alone. However, results were imprecise and $\mathrm{Cls}$ encompassed one (low certainty evidence; Analysis 3.12; Summary of findings 3).

Where it was relevant to carry out sensitivity analyses removing studies judged to be at high risk of bias for the above safety and tolerability analyses, we found no evidence of a change in the clinical interpretation of results. Further sensitivity analyses excluding studies with industry support did not indicate that our findings were sensitive to the inclusion of these studies (see Table 1).

\section{Exploratary safety and tolerability analyses combining comparisons}

We carried out exploratory post hoc analyses combining the AEs (Analysis 4.1), psychiatric AEs (Analysis 4.2), SAEs (Analysis 4.3), and dropout due to adverse events (Analysis 4.4) outcomes across the above three comparisons (i.e. bupropion versus control; bupropion plus NRT versus NRT; bupropion plus varenicline versus varenicline). We subgrouped by the original comparison to test for any potential interactions. Significant subgroup differences were not detected for any of the outcomes; however these results should be treated with caution as some of the subgroups were underpowered. Overall pooled effects indicated that AEs (RR 1.14, $95 \% \mathrm{Cl} 1.11$ to $1.17 ; \mathrm{I}^{2}=70 \%$; subgroup differences $\mathrm{I}^{2}=3 \% ; 25$ studies, 12,249 participants; Analysis 4.1), psychiatric AEs (RR 1.24, $95 \% \mathrm{Cl} 1.15$ to $1.33 ; \mathrm{I}^{2}=45 \%$; subgroup differences $\mathrm{I}^{2}=23 \%$; 8 studies, 5274 participants; Analysis 4.2) and dropouts due to AEs of the drug (RR $1.35,95 \% \mathrm{Cl} 1.20$ to $1.52 ; \mathrm{I}^{2}=12 \%$; subgroup differences $\left.\right|^{2}=44 \%$; 30 studies, 14,108 participants; Analysis 4.4 ) were all increased by bupropion. However, there was substantial overall heterogeneity for the adverse event outcome, and some moderate heterogeneity between subgroups for the dropout due to AEs outcome - although the latter did not reach statistical significance $(P=0.17)$. There was still no clear evidence of an increased risk of SAEs when using bupropion. However, despite 
combining more studies there was still some imprecision in this result, meaning that $95 \% \mathrm{Cls}$ still incorporated a potential increase in SAEs when using bupropion, as well as no increase (RR 1.17, 95\% $\mathrm{Cl} 0.93$ to $1.47 ; \mathrm{I}^{2}=0 \%$; subgroup differences $\mathrm{I}^{2}=0 \%$; 28 studies, 12,500 participants; Analysis 4.3).

\section{Bupropion versus front-line smoking cessation monotherapies}

\section{Smoking cessation}

We found evidence to suggest bupropion was less effective than varenicline for smoking cessation (RR $0.71,95 \% \mathrm{Cl} 0.64$ to $0.79 ; \mathrm{I}^{2}$ $=0 \% ; 6$ studies, 6286 participants; Analysis 5.1), whereas there was no clear evidence that bupropion resulted in better cessation rates than NRT (RR 0.99, 95\% Cl 0.91 to $1.09 ; \mathrm{I}^{2}=18 \%$; 10 studies, 8230 participants; Analysis 6.1). This was based upon our meta-analyses of 10 relevant studies, in which we pooled studies investigating all forms of NRT (patch, lozenge, or a choice). When comparing the results of our analyses across separate subgroups of NRT (including combination patch and lozenge) we found that there was no strong evidence of significant subgroup differences $\left(I^{2}=47.8 \% ; P=0.12\right)$. In neither case did removing studies deemed to be at an overall high risk of bias change the interpretation of the effect estimates.

\section{Depression}

One post hoc analysis found that bupropion was more effective than NRT in those with a history of depression (Stapleton 2013). See Table 2.

\section{Safety}

There was evidence that randomization to bupropion resulted in minimal difference in reporting of AEs when compared to both varenicline and NRT (Analysis 5.2; Analysis 6.2). The same was true of SAEs, however there were much fewer events in these analyses, meaning they were underpowered and we can have less certainty in their results (Analysis 5.3; Analysis 6.3). When focusing on psychiatric AEs only there was no evidence of a difference when comparing bupropion to varenicline (Analysis 5.4); and heterogeneity was so high when comparing bupropion to NRT that it was deemed inappropriate to present a pooled estimate $\left(1^{2}\right.$ = 92\%; Analysis 6.4). There was insufficient evidence to indicate whether bupropion increased the risk of many of the other safety outcomes assessed (seizures, overdoses, suicide attempts, death by suicide and all-cause mortality) when compared to varenicline and NRT due to a paucity of relevant data, meaning that when estimates could be calculated these were extremely imprecise with $\mathrm{Cls}$ encompassing both potential benefit and harm of the intervention.

We also found evidence that participants in the bupropion groups experienced more insomnia and anxiety than people in the varenicline groups (insomnia: RR $1.40,95 \% \mathrm{Cl} 1.22$ to 1.60 ; $\mathrm{I}^{2}=$ 9\%; 3 studies, 5208 participants; Analysis 5.10; anxiety: RR 1.28, $95 \% \mathrm{Cl} 1.07$ to $1.53 ; \mathrm{I}^{2}=0 \%$; 2 studies, 4705 participants; Analysis 5.11) and NRT groups (insomnia: RR $1.31,95 \% \mathrm{Cl} 1.10$ to 1.55 ; $\left.\right|^{2}=$ 47\%; 2 studies, 4128 participants; Analysis 6.10; anxiety: RR 1.31, $95 \% \mathrm{Cl} 1.06$ to $1.62 ; \mathrm{I}^{2}=67 \% ; 2$ studies, 4855 participants; Analysis 6.11) at follow-up. However, we detected moderate heterogeneity for both the insomnia and anxiety outcomes for the comparison to NRT, and when we carried out a sensitivity analysis, removing the study judged to be at high risk of bias, for the anxiety outcome (Analysis 6.11) the $95 \%$ Cls shifted to incorporate no between-group difference in anxiety (RR $1.23,95 \% \mathrm{Cl} 0.99$ to $1.53 ; \mathrm{I}^{2}=13 \% ; 1$ study, 4028 participants).

\section{Tolerability}

Compared to both varenicline (RR $1.12,95 \% \mathrm{Cl} 0.96$ to $1.31 ; \mathrm{I}^{2}$ = 23\%; 6 studies, 6103 participants; Analysis 5.12) and NRT (RR $1.14,95 \% \mathrm{Cl} 0.95$ to $1.38 ; 12=33 \%$; 4 studies, 4825 participants; Analysis 6.12) there was no clear evidence that bupropion led to an increase in trial dropouts due to AEs; however in both cases the $\mathrm{Cls}$ encompassed fewer dropouts in the comparator as well as no difference.

We carried out sensitivity analyses for all of the safety and tolerability analyses, removing studies judged to be at high risk of bias, where appropriate. None of these analyses resulted in a difference in the clinical interpretation of effects.

\section{Bupropion versus other pharmacotherapies}

\section{Smoking cessation}

There was no clear evidence that bupropion was more effective than nortriptyline in aiding smoking cessation (RR 1.30, 95\% Cl 0.93 to $1.82 ; I^{2}=0 \%$; 3 studies, 417 participants; Analysis 7.1 ), although event rates were low (101 participants), and the result imprecise. This result was similar when one study judged to be at high risk of bias (Hall 2002), was removed from the analysis.

\section{Depression}

Only two trials examined the interaction between depression and quit rates for bupropion and nortriptyline (Hall 2002; Wagena 2005). Both of the within-study analyses found that participants classified as depressed were more likely to quit using bupropion than nortriptyline (Table 2).

\section{Safety}

There was insufficient evidence to determine whether bupropion increased the risk of any of the safety outcomes included in this review when compared to nortriptyline (Analysis 7.2; Analysis 7.3), or gabapentin (Analysis 8.1). Where data were available, it was sparse and resulted in imprecise pooled estimates encompassing one. In one instance (bupropion versus nortriptyline; insomnia outcome) heterogeneity was so high that it was not appropriate to present a pooled estimate $(12=90 \%$; Analysis 7.3).

\section{Tolerability}

There was also insufficient evidence to determine whether bupropion increased the risk of trial dropouts due to adverse events when compared to both nortriptyline (Analysis 7.4) and gabapentin (Analysis 8.2), with imprecise estimates in both cases.

Where possible, for the above safety and tolerability outcomes, we carried out sensitivity analyses removing studies judged to be at high risk of bias; however in the rare cases where this was appropriate there was no appreciable change in the interpretation of the effect estimates.

\section{Bupropion at different doses \\ Smoking cessation}

There was no clear evidence to indicate a differential effect between a $150 \mathrm{mg}$ or $300 \mathrm{mg}$ dose of bupropion on the likelihood of smoking 
cessation. Whilst the pooled estimate was 1.08 in favour of a $300 \mathrm{mg}$ dose, the $95 \% \mathrm{Cl}$ encompassed a potential benefit of either dose (RR 1.08, 95\% Cl 0.93 to 1.26 ; $1^{2}=49 \%$; 3 studies, 2042 participants; Analysis 9.1).

\section{Depression}

None of the relevant included studies investigated a potential link between depression and quit rates.

\section{Safety}

We were unable to draw conclusions about any of the safety outcomes for this comparison. Analyses that could be carried out (SAEs Analysis 9.2; overdoses Analysis 9.3; suicide attempts Analysis 9.4; death by suicide Analysis 9.5; all-cause mortality Analysis 9.6; insomnia Analysis 9.7; anxiety Analysis 9.8), suffered from substantial imprecision due to a low number of events (ranging from 0 to 99), and in all cases 95\% Cls encompassed one.

\section{Tolerability}

Our analysis of dropouts due to adverse event data also suffered from imprecision (Analysis 9.9), and we were unable to draw conclusions.

A sensitivity analysis removing studies judged to be at high risk of bias was only appropriate for the cessation outcome; removing the one study deemed to be at high risk of bias did not alter the clinical interpretation of the result.

\section{Other antidepressant monotherapies versus control}

\section{Smoking cessation}

Pooling six trials comparing nortriptyline to placebo showed evidence of benefit of nortriptyline over placebo (RR $2.03,95 \% \mathrm{Cl}$ 1.48 to $2.78 ;\left.\right|^{2}=16 \%$; 6 studies, 975 participants; Analysis 10.1) for smoking cessation. Removing two studies judged to be at high risk of bias did not influence the result (Hall 2002; Prochazka 1998).

We did not find clear evidence to indicate that selective serotonin reuptake inhibitors (SSRIs) increased the likelihood of smoking cessation relative to control ( $\mathrm{RR} 0.93,95 \% \mathrm{Cl} 0.71$ to $1.22 ; \mathrm{I}^{2}=0 \%$; 4 studies, 1594 participants; Analysis 11.1); however there was a low number of events across studies (193 participants) and this should be taken into account. We subgrouped our meta-analysis by the type of SSRI used in the trial (2 fluoxetine: Niaura 2002; Spring 2007; 1 paroxetine: Killen 2000; 1 sertraline: Covey 2002), and found no evidence of a subgroup difference $\left(I^{2}=0 \%\right)$.

We also found no clear evidence that monoamine oxidase inhibitors (MAOIs) increased the likelihood of smoking cessation relative to control (RR 1.29, $95 \% \mathrm{Cl} 0.93$ to $1.79 ; 1^{2}=0 \% ; 6$ studies, 827 participants; Analysis 12.1); however, again event rates were low, resulting in imprecision (193 participants). There was no effect of removing the one study deemed to be at high risk of bias (George 2003). Our meta-analysis included one trial of moclobemide (Berlin 1995) and five of selegiline (Biberman 2003; George 2003; Kahn 2012; Killen 2010; Weinberger 2010), and we subgrouped these accordingly. We did not identify any evidence of a subgroup difference $\left(1^{2}=0 \%\right)$.

One trial of venlafaxine (Cinciripini 2005) showed no evidence of increased smoking cessation compared to placebo (RR 1.22, 95\%
$\mathrm{Cl} 0.64$ to 2.32; $\mathrm{I}^{2}$ = n/a; 1 study, 147 participants; Analysis 13.1). However, the effect estimate was imprecise and $\mathrm{Cls}$ encompassed both potential benefit and harm.

Two small trials comparing St John's wort to placebo (Parsons 2009; Sood 2010), provided no clear evidence to suggest it was a better smoking cessation aid than placebo when pooled (RR $0.81,95 \% \mathrm{Cl}$ 0.26 to $2.53 ; 1^{2}=29 \%$; 2 studies, 261 participants; Analysis 14.1); however there was substantial imprecision.

The one trial assessing S-Adenosyl-L-Methionine (SAMe) compared to placebo provided no evidence of benefit for smoking cessation (RR $0.70 ; \mathrm{Cl} 0.24$ to $2.07 ; \mathrm{I}^{2}=\mathrm{n} / \mathrm{a} ; 1$ study; 120 participants; Analysis 15.1); however, the number of included participants and the number of events were small.

\section{Depression}

One within-study comparison found that a past history of depression did not appear to moderate the efficacy of nortriptyline, but subgroup numbers were small (Hall 1998). However, another within-study analysis found that the most effective factor for ensuring the efficacy of nortriptyline was a negative history of depression (Da Costa 2002).

Of the three studies conducting post hoc analyses of fluoxetine (Saules 2004; Spring 2007) and paroxetine (Killen 2000) to assess the interaction between depression and antidepressant quit rates, none provided evidence to support this interaction (George 2003; Kahn 2012).

The two studies conducting post hoc analyses of selegiline to assess the interaction between depression and antidepressant quit rates also did not provide evidence to support this interaction (George 2003; Kahn 2012).

\section{Safety}

One trial investigated the likelihood of SAEs when randomized to receive nortriptyline in comparison to placebo (Haggsträm 2006). No SAEs were reported in either trial arm (Analysis 10.2). The insomnia and anxiety outcomes provided insufficient evidence of any effect for this comparison (Analysis 10.3; Analysis 10.4).

There was insufficient evidence to indicate whether SSRIs increased the risk of AEs relative to placebo. Only one small trial of fluoxetine investigated this (NCT00578669; Analysis 11.2).

For the comparison of MAOIs relative to placebo, there was no evidence of increased risk of experiencing either AEs (Analysis 12.2), psychiatric AEs (Analysis 12.3), or SAEs (Analysis 12.4); however the latter two analyses suffered from substantial imprecision and should be treated with caution. Substantial imprecision and heterogeneity also meant that we were unable to draw conclusions regarding insomnia and anxiety (Analysis 12.5; Analysis 12.6).

The one study assessing safety outcomes for St John's wort versus placebo (Parsons 2009), did not provide sufficient evidence to assess whether it increased the likelihood of SAEs or all-cause mortality specifically (Analysis 14.2; Analysis 14.3), and a study of SAMe versus placebo (Sood 2012), did not provide sufficient evidence on AEs or insomnia (Analysis 15.2; Analysis 15.3). 


\section{Tolerability}

Our meta-analysis including four studies comparing nortriptyline to placebo found evidence that dropout due to treatment was approximately twice as likely when randomized to nortriptyline (RR $1.99,95 \% \mathrm{Cl} 1.18$ to $3.36 ; \mathrm{I}^{2}=23 \%$; 4 studies, 537 participants; Analysis 10.5). This result should be treated with caution due to imprecision; however the removal of two studies judged to be at high risk of bias did not change the interpretation of the result (Hall 2004; Prochazka 1998).

There was also evidence to suggest SSRIs may increase the likelihood of dropout due to drug (RR $2.59,95 \% \mathrm{Cl} 1.70$ to $3.94 ; \mathrm{I}^{2}$ $=0 \%$; 3 studies, 1270 participants; Analysis 11.3). When the four included studies were subgrouped into two of fluoxetine (Niaura 2002; Spring 2007), and one of sertraline (Covey 2002), there was no evidence of a subgroup difference $\left(I^{2}=0 \%\right)$.

There was some evidence that there may be an increased risk of drug discontinuation in the MAOI groups, and this persisted when we removed one study judged to be at high risk of bias. However, there was substantial imprecision in this analysis (Analysis 12.7).

One study each assessed dropout due to drug for St John's wort versus placebo (Parsons 2009; Analysis 14.4), venflaxine versus placebo (Cinciripini 2005; Analysis 13.2), and SAMe versus placebo (Sood 2012; Analysis 15.4). These studies did not provide sufficient evidence to draw clear conclusions.

\section{Other antidepressant combination therapies versus control}

\section{Smoking cessation}

Pooling four trials using nortriptyline as an adjunct to nicotine patch therapy (Aveyard 2008; Hall 2004; Prochazka 2004; Richmond 2013), did not provide evidence of a benefit of combination nortriptyline and NRT for smoking cessation relative to NRT alone (RR $1.21,95 \% \mathrm{Cl} 0.94$ to $1.55 ; \mathrm{I}^{2}=26 \%$; 4 studies, 1644 participants; Analysis 16.1); however there was imprecision around the effect estimate, with the Cls encompassing both no difference and a clinically significant benefit. The interpretation of the result remained the same when we removed studies judged to be at an overall high risk of bias.

Three trials evaluated fluoxetine as an adjunct to NRT (Blondal 1999; Brown 2014; Saules 2004), but also did not provide evidence of an increased likelihood of smoking cessation relative to NRT alone when pooled (RR $0.70,95 \% \mathrm{Cl} 0.48$ to $1.03 ; \mathrm{I}^{2}=0 \% ; 3$ studies, 466 participants; Analysis 17.1). Again, interpretation did not change when we removed studies judged to be at risk of bias, and there was evidence of imprecision. However, in this instance $\mathrm{Cls}$ encompassed the possibility of no difference and a clinically significant harm.

\section{Depression}

One study comparing nortriptyline plus NRT to NRT alone found no evidence supporting depression as a moderator of abstinence in either the combination nortriptyline and NRT or the placebo arms of the trial (Aveyard 2008).

\section{Safety}

One trial investigated the effect of combination nortriptyline and NRT on the likelihood of insomnia when compared to NRT alone (Prochazka 2004). However the study only reported a very small number of events across trial arms, resulting in substantial imprecision, and making it impossible to draw any conclusions (Analysis 16.2).

There was also insufficient evidence from one study investigating the effect of selegiline plus NRT versus NRT alone on SAEs (Biberman 2003; Analysis 18.1). Similarly Berlin 2012 alone provides insufficient data to assess the effects of EVT302 plus NRT versus NRT alone on AEs (Analysis 19.1) and SAEs (Analysis 19.2).

\section{Tolerability}

One trial investigated the effect of combination nortriptyline and NRT on the likelihood of trial discontinuation (Prochazka 2004); however events were low, making it impossible to draw conclusions (Analysis 16.3). There was insufficient information available from the one study comparing dropout due to AEs between selegiline plus NRT versus NRT alone (Biberman 2003; Analysis 18.2), and the one study comparing EVT302 plus NRT versus NRT alone (Berlin 2012; Analysis 19.3) to draw conclusions.

\section{Other antidepressants at different doses}

\section{Smoking cessation}

We are unable to evaluate the efficacy of $300 \mathrm{mg}$ versus 600 mg St John's wort, as the one trial comparing these differences (Barnes 2006) had too small a sample size (28 participants), with no individuals abstinent from smoking at 12 months follow-up. One study compared the efficacy of $30 \mathrm{mg}$ versus $60 \mathrm{mg}$ of fluoxetine, and found the same quit rates in both groups (RR 1.00, 95\% Cl 0.63 to $1.59 ; 1^{2}=$ n/a; 656 participants; Analysis 20.1); however this result should be treated with caution due to imprecision.

\section{Depression}

These studies did not investigate depression as a moderator of smoking quit rates.

\section{Safety}

Berlin 2002 only followed up participants to eight weeks and therefore we did not use efficacy data from this study; however they reported safety data. The study compared $100 \mathrm{mg}$ with 200 $\mathrm{mg}$ daily doses of lazabemide. No SAEs were recorded during the trial (Analysis 21.1). There was insufficient evidence to conclude whether participants randomized to the higher dose were more likely to suffer from symptoms of insomnia (Analysis 21.2) or anxiety (Analysis 21.3).

Due to the very small sample size of Barnes 2006, there was insufficient evidence to assess the likelihood of AEs in participants receiving a $300 \mathrm{mg}$ daily dose of St. John's wort versus a 600 mg dose (28 participants; Analysis 22.2). Similarly, there was insufficient evidence investigating the effect of a $800 \mathrm{mg}$ daily dose of SAMe versus a $1600 \mathrm{mg}$ daily dose on the risk of AEs (Sood 2012; Analysis 23.1).

\section{Tolerabiliy}

Niaura 2002 found some evidence that a $60 \mathrm{mg}$ daily dose of fluoxetine compared to a $30 \mathrm{mg}$ dose daily increased the likelihood of trial discontinuation due to drug treatment (RR $0.64,95 \% \mathrm{Cl} 0.46$ to $0.87 ; 1^{2}=n / a ; 1$ study, 656 participants; Analysis 20.2). 
However, there was insufficient evidence to conclude whether participants randomized to the higher $200 \mathrm{mg}$ dose of lazabemide were more likely to drop out of the trial due to the medication than participants randomized to the lower $100 \mathrm{mg}$ dose (Berlin 2002; Analysis 21.4), or whether participants randomized to a $1600 \mathrm{mg}$ dose of SAMe were more likely to drop out than those randomized to a $800 \mathrm{mg}$ dose (Sood 2012; Analysis 23.2).

\section{DISCUSSION}

\section{Summary of main results}

This review summarizes and evaluates the evidence investigating the efficacy, safety and tolerability of different types of antidepressant for smoking cessation. This review includes 115 studies in total. Forty-six trials of 17,866 participants provide a large, high-certainty evidence base confirming the benefit of bupropion used as a single pharmacotherapy for smoking cessation (Summary of findings for the main comparison). The pooled estimate suggests that bupropion increased long-term quitting success by $52 \%$ to $77 \%$ when compared with placebo. Treatment effects appeared to be comparable across the range of populations, settings and types of behavioural support studied, including those with and without a past history of depression. There is evidence to suggest that bupropion increases the risk of adverse events (AEs), including psychiatric AEs, and the likelihood that users will discontinue treatment; however evidence does not currently suggest that bupropion increases the risk of serious adverse events (SAEs).

Our review finds no evidence of an additional benefit of adding bupropion to nicotine replacement therapy (NRT) (low-certainty evidence; Summary of findings 2) or varenicline treatment (moderate-certainty evidence; Summary of findings 3) when compared to NRT or varenicline alone, respectively. There was insufficient evidence to draw conclusions on safety outcomes when using bupropion as an adjunct to NRT or varenicline. This is due to a lack of studies assessing these outcomes, and few events recorded for those studies that did (very low-certainty and low-certainty evidence, respectively).

The evidence does not suggest a difference in the efficacy of bupropion plus NRT, or nortriptyline, for smoking cessation. However, participants taking bupropion may be between $21 \%$ and $36 \%$ less likely to quit than those treated with varenicline, based on evidence from 6286 participants. The evidence relating to the safety of treatment is inconclusive when comparing bupropion to NRT, varenicline and nortriptyline due to a paucity of studies, overall participants, and events.

We found evidence that nortriptyline is also an effective agent to aid smoking cessation when compared with placebo, based on a meta-analysis of six studies, including 975 participants. However, there is no clear evidence that other antidepressants, including selective serotonin reuptake inhibitors (SSRIs), monoamine oxidase inhibitors (MAOIs), venflaxine, St John's wort, and SAdenosyl-L-Methionine (SAMe), are effective as cessation aids. Therefore, despite SSRIs being commonly used to treat depression there does not seem to be any justification for continuing to pursue their use for smoking cessation, where other more clearly effective options exist.
Few studies examined whether current or previous depression moderated the effectiveness of antidepressants to aid smoking cessation. Those comparing bupropion to placebo found no evidence of an interaction between depression and use of bupropion. Studies contributing to other comparisons found varied but uncertain results.

\section{Overall completeness and applicability of evidence}

The searches conducted for this study were broad and identified any studies where a drug was described as being an 'antidepressant' or 'antidepressive'. In cases where we were unsure of whether a medication was classed as an antidepressant, we conducted a brief literature search to clarify whether they had been used in other research as antidepressants, so as to ensure we included all relevant medications. We also searched trial registers to identify any ongoing or completed but unpublished, registered studies assessing the efficacy and safety of antidepressants for smoking cessation.

Studies included in this review recruited adult smokers who were typically motivated to quit. Of the study populations included in our review, the lowest mean cigarettes smoked per day was 10 , and the highest was 44 , meaning that most studies included participants with significant tobacco addiction. These results may not apply to populations with few symptoms of tobacco addiction. In addition, the minority of studies specifically recruited participants with mental health disorders. Of these five studies, one was weighted particularly heavily in the meta-analysis (Anthenelli 2016). Anthenelli 2016 recruited a subset of participants with mental health disorders, who were described as 'clinically stable', suggesting that they may not be entirely representative of the wider population diagnosed with a mental health disorder. Further studies are needed among those with depression to provide greater confidence in our findings, which suggest that bupropion is as effective for smoking cessation in people with a mental health diagnosis as those without.

\section{Certainty of the evidence}

Of the 115 studies included in this review, we judged 12 to be at low risk of bias for all domains, and 28 to be at high risk in one or more domains. We judged the remaining 75 studies to be at an unclear risk due to a lack of reporting of key information. In these cases it is impossible to know whether these studies were at any risk of bias or whether the information was simply not reported. To investigate the potential impact of studies that we judged to be at high risk of bias on results, we carried out sensitivity analyses, removing studies judged to be at high risk from analyses and observing the effects on results (where this was possible). In most cases this had no effect on the clinical interpretation of the analyses.

We assessed the certainty of the evidence by creating 'Summary of findings' tables and carrying out GRADE ratings (Schünemann 2013) for three of the comparisons (bupropion versus placebo/ no pharmacotherapy control (Summary of findings for the main comparison); bupropion plus NRT versus NRT alone (Summary of findings 2); bupropion plus varenicline versus varenicline alone (Summary of findings 3). The efficacy of bupropion versus placebo/ pharmacotherapy control for smoking cessation generated highcertainty evidence. We judged combination bupropion and varenicline to be of moderate certainty, whilst we judged the combination bupropion and NRT to be of low-certainty evidence. 
We judged the safety outcomes for bupropion versus placebo/ pharmacotherapy control of SAEs and dropout due to drug to have moderate- and high-certainty evidence, respectively. However, for the bupropion combination therapy with NRT or varenicline comparisons, we judged the evidence for these safety outcomes to be of very low- and low-certainty, respectively. The main reason for downgrading the evidence was imprecision (low overall numbers of participants and events), as well as risk of bias in one case (judgements of high risk that may affect the result), and inconsistency (moderate heterogeneity in analysis detected) in another case.

\section{Potential biases in the review process}

We consider the review process used to be robust, and do not believe we have introduced any biases. For outcome assessment, we followed the standard methods used for Cochrane Tobacco Addiction cessation reviews. Our search of the Cochrane Tobacco Addiction Specialized Register, allowed us to capture three ongoing studies. However, there may be unpublished data that our searches did not uncover.

We generated and interpreted funnel plots for all analyses that included 10 or more studies. Four of these were for outcomes summarized in our 'Summary of findings' tables (smoking cessation, SAEs and dropout due to adverse events of the drug) and contributed to our GRADE ratings for the following comparisons: bupropion versus placebo/pharmacotherapy control (Figure 3, Figure 4, Figure 5, respectively), and smoking cessation for bupropion plus NRT versus NRT alone (Figure 6). None of these plots appeared to demonstrate evidence of publication bias. However, only 12 studies contributed to the funnel plot for bupropion plus NRT versus NRT alone (a relatively small number), so this should be interpreted with caution. We also tested whether the inclusion of studies funded by the pharmaceutical industry, or where a pharmaceutical company had supplied the medication for the study, was impacting on the pooled results of our analyses. In no case did there appear to be any clear evidence of this (Table 1).

\section{Figure 3. Funnel plot of comparison: 1 Bupropion versus placebo/control, outcome: 1.1 Smoking cessation.}

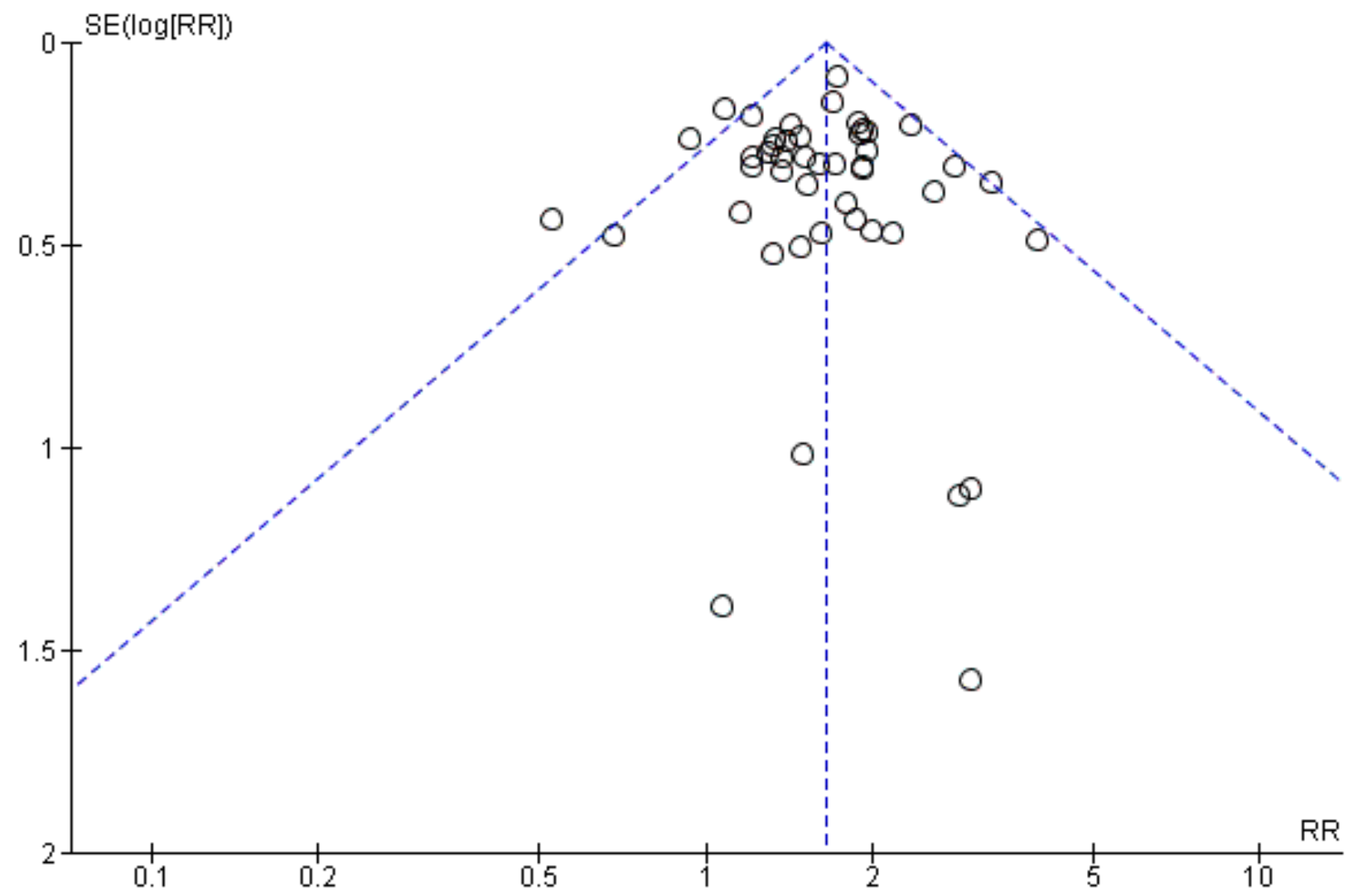


Figure 4. Funnel plot of comparison: 1 Bupropion versus placebo/control, outcome: 1.5 Serious adverse events.

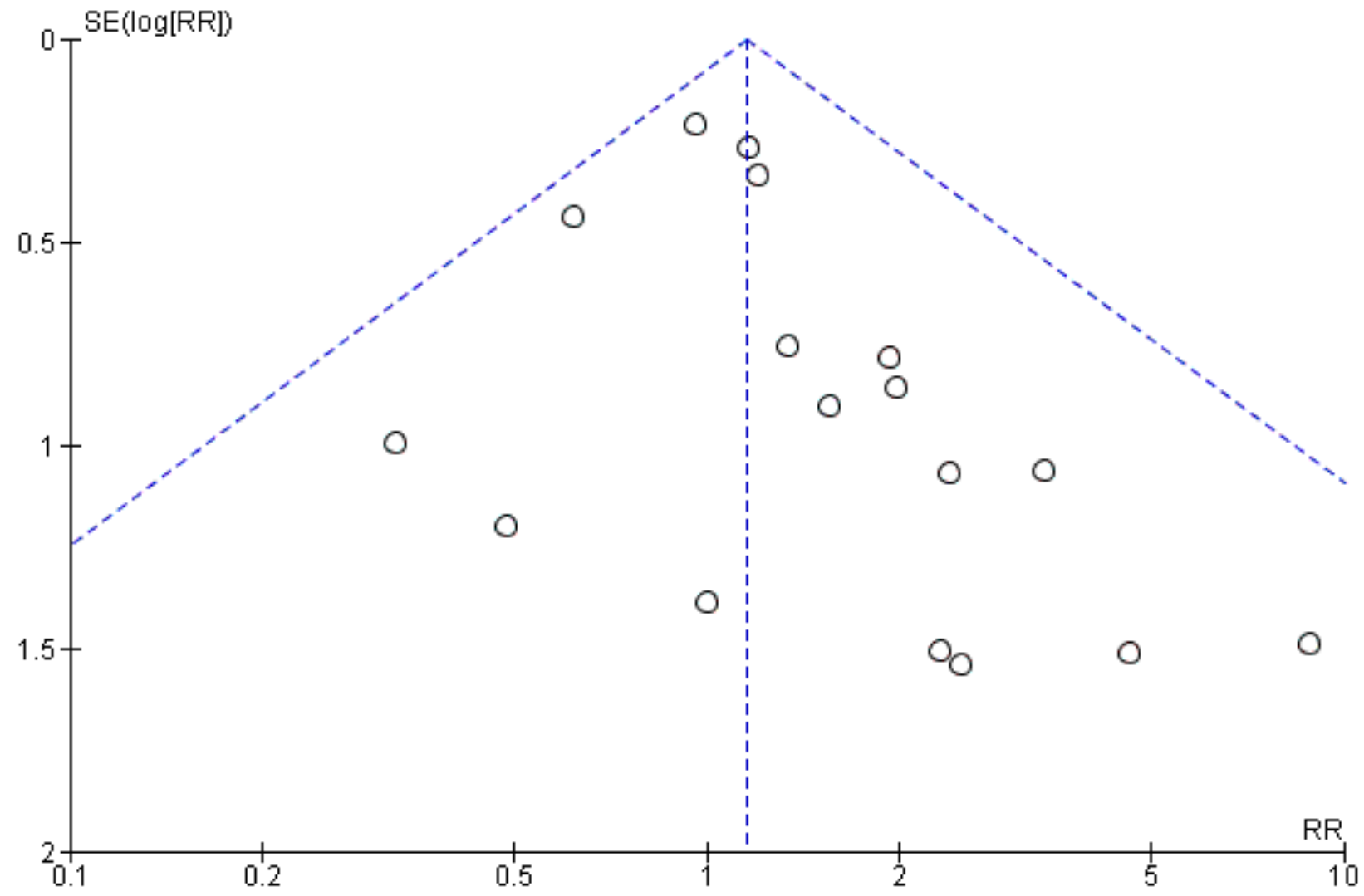


Figure 5. Funnel plot of comparison: 1 Bupropion versus placebo/control, outcome: 1.14 Dropouts due to drug.

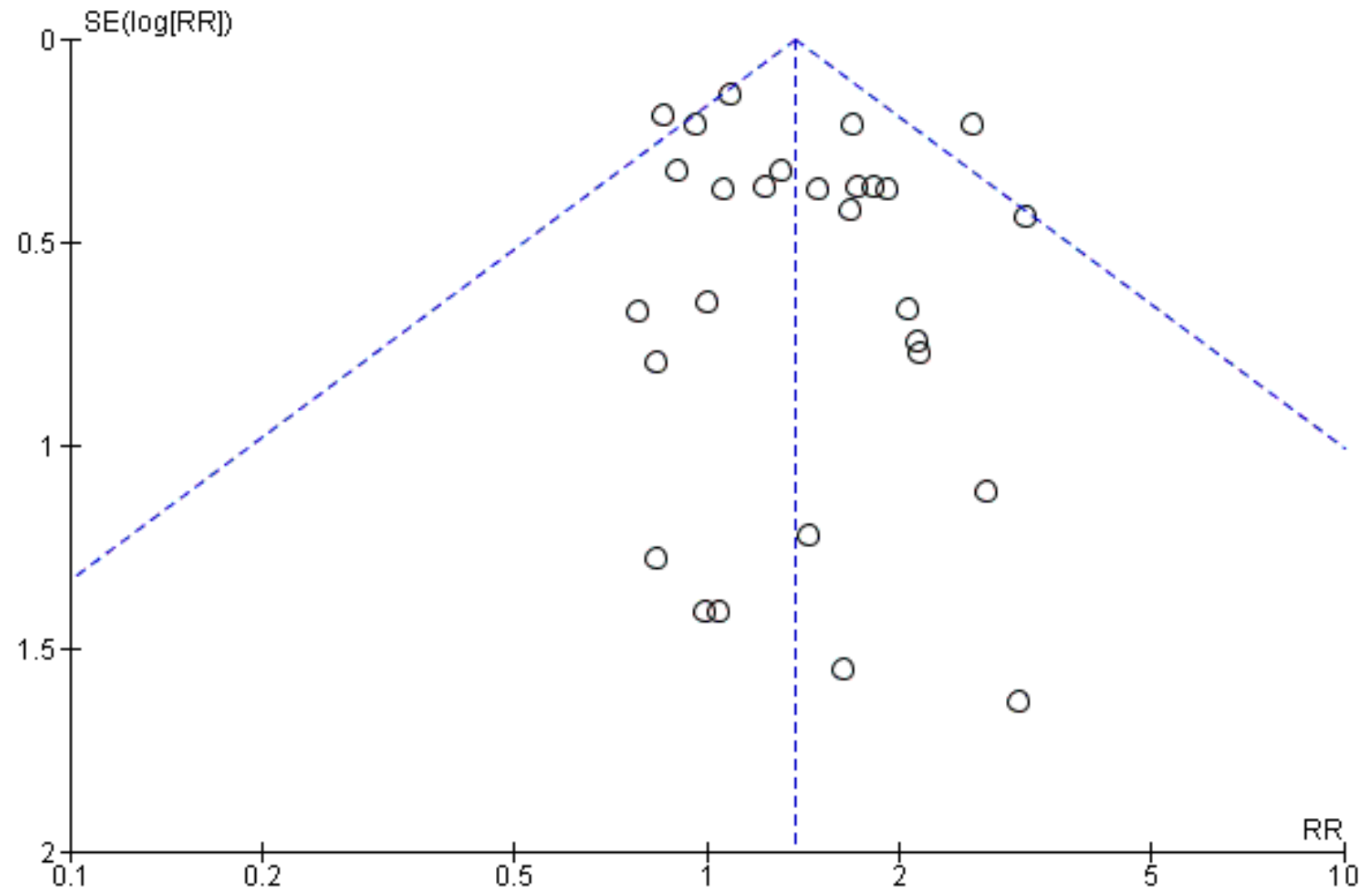


Figure 6. Funnel plot of comparison: 2 Bupropion and NRT versus NRT alone, outcome: 2.1 Smoking cessation.

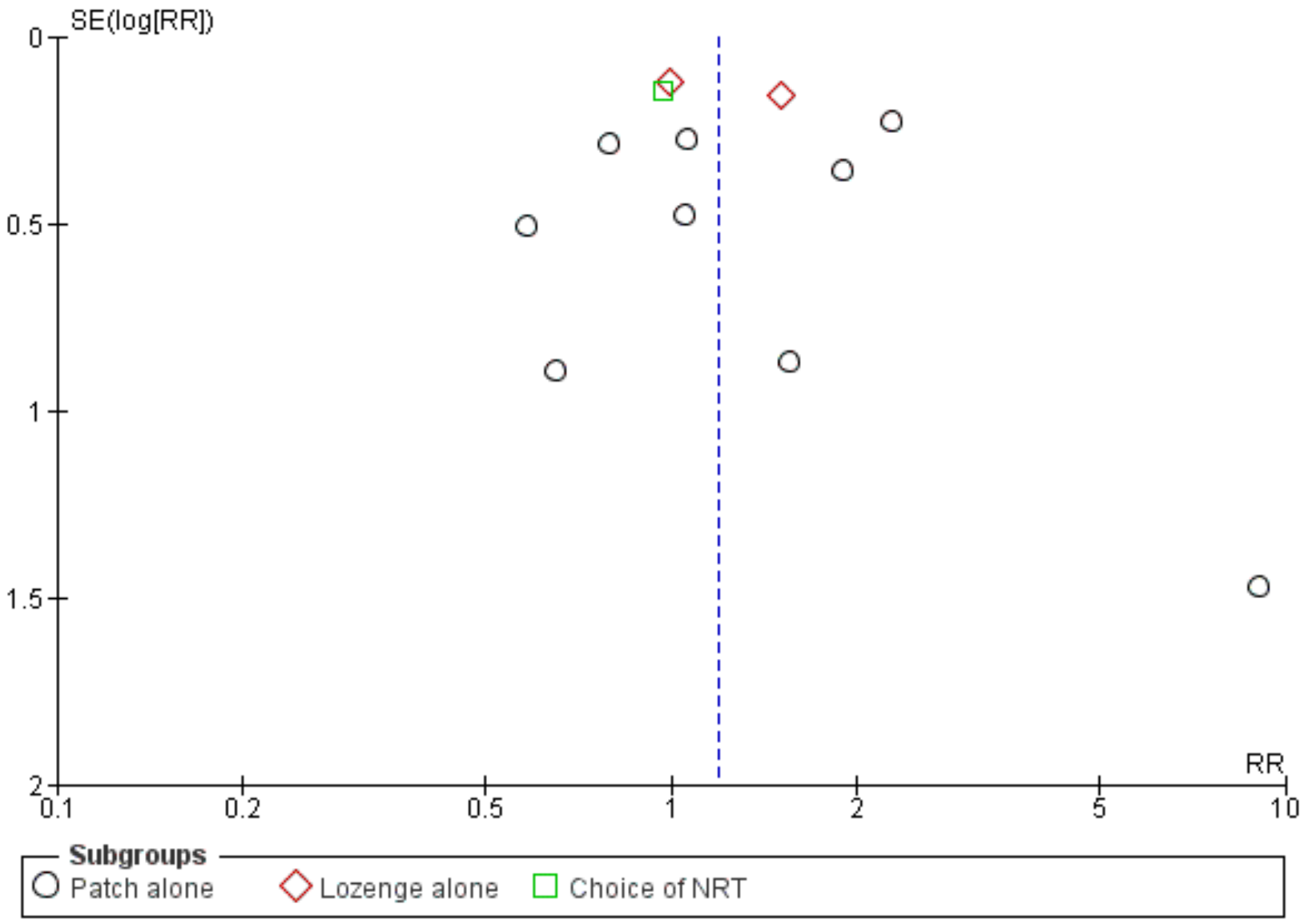

We considered participants lost to follow-up as smokers, which is current best practice in this field (West 2005). The Cochrane Tobacco Addiction policy is to present effect estimates as risk ratios (RRs), as these are easier to interpret than odds ratios (ORs), but this means that where there are no events measured in both comparison groups RRs cannot be calculated, and therefore do not contribute to the meta-analysis. We considered alternative statistical approaches to deal with this, but concluded that other approaches would be more difficult to interpret and that overall conclusions would not change as a result.

\section{Agreements and disagreements with other studies or reviews}

The findings of this review are in agreement with the conclusions of other reviews and guidelines in a variety of populations (Cahill 2013; Hughes 2005; McRobbie 2005; Mills 2006, Tsoi 2010). USA smoking cessation guidelines continue to recommend bupropion as a first-line therapy (Fiore 2008), and recommend nortriptyline as a second-line therapy due to possible AEs. Open uncontrolled trials and observational studies of bupropion have shown real-life quit rates comparable to those found in the clinical trials included in this review (Paluck 2006; Wilkes 2005). In addition, our findings regarding the beneficial effect of bupropion for smoking cessation, specifically in smokers with mental illness, are consistent with a subset from a separate Cochrane Review evaluating smoking cessation treatments exclusively in populations with current or past depression (van der Meer 2013).

However, our findings on the effectiveness of bupropion as an adjunct to NRT differ from the results of the United States Public Health Service (USPHS) clinical practice guideline (Fiore 2008). Whereas we did not detect a significant difference in efficacy when bupropion and NRT were used together compared to NRT alone, the USA guideline reported an OR of 1.30 (95\% confidence interval (CI) 1.0 to 1.80) favouring combination therapy (Fiore 2008, Table 6.28). The difference in meta-analytic outcomes may be because our analysis included several studies of hard-to-treat populations not included in the USPHS analysis. Also, it could be because our analysis was a collation of 12 direct, within-study randomized comparisons, whereas the USPHS carried out an indirect acrossstudy comparison of the results from the combination arms of three trials and the patch-alone arms of 32 studies.

Cahill 2013 used both direct and indirect statistical comparisons to compare the efficacy of bupropion to NRT and varenicline, using network meta-analysis. The effect estimates generated resulted in similar conclusions to the ones drawn here, i.e. bupropion and single-form NRT resulted in similar quit rates and varenicline resulted in higher quit rates than bupropion. However, indirect comparisons made by Cahill 2013 also suggested that combination NRT was more effective than bupropion, whereas our subgroup analysis did not provide clear evidence of this. 
Similar to our findings, other studies and systematic reviews looking at the SAE profile of bupropion remain inconclusive (Cahill 2013; Grandi 2011; Wightman 2010). Whilst our review did not find that bupropion significantly increased the incidence of seizures (RR $1.64,95 \% \mathrm{Cl} 0.08$ to 33.95 ), with substantial imprecision detected, the point estimate does indicate a rate of approximately 1.5 events per 1000 people taking bupropion, compared to a rate of 1 per 1000 cases presented elsewhere (Cahill 2013).

In contrast to the findings of the very large-scale EAGLES trial, we have concluded that bupropion significantly increases psychiatric AEs (Anthenelli 2016). Whilst Anthenelli 2016 contributes over $95 \%$ of psychiatric AE data to our meta-analysis, it concluded that bupropion does not significantly increase the incidence of psychiatric AEs. This discrepancy may be the result of including psychiatric AEs of any severity in our relevant meta-analysis, whereas Anthenelli 2016 used a composite measure of only moderate and severe intensity psychiatric events for their primary analysis. It is not possible for us to corroborate whether we would find the same if we were only to include moderate and severe psychiatric events, as study reporting does not allow us to discriminate between these events according to severity.

Taking into account the combined evidence from this review and Cahill 2013, suggesting that varenicline is more efficacious than bupropion, and evidence from Cahill 2016, suggesting that psychiatric AEs are not increased by varenicline; varenicline may be a more suitable option for people who wish to take a prescription medication to quit smoking, especially those with mental health disorders.

\section{AUTHORS' CONCLUSIONS}

\section{Implications for practice}

- Bupropion and nortriptyline are effective pharmacological aids for smoking cessation. There is no good evidence that one is superior to the other. Bupropion increases the rate of long-term quitting by approximately $52 \%$ to $77 \%$, and this effect appears to be stable regardless of the amount of behavioural support provided, and whether participants have current or a history of mental health disorders.

- Bupropion may cause an increase in adverse events (AEs), and specifically psychiatric AEs, leading to discontinuation of drug use in some users (approximately 9\%). However, estimates of serious adverse events (SAEs, i.e. events that result in hospitalization, disability or death) include the possibility of no difference as well as a potential $1 \%$ increase when compared to placebo.

- There is no evidence of higher quit rates when combining bupropion with either nicotine replacement therapy (NRT) or varenicline relative to each drug taken alone.

- Bupropion appears to be as effective as NRT for smoking cessation; however varenicline may result in somewhere between $27 \%$ to $56 \%$ higher quit rates than bupropion.

- There is a paucity of data investigating the efficacy and safety of antidepressants other than bupropion for smoking cessation, but there is sufficient data to show that, in the light of the effectiveness of other medications, selective serotonin reuptake inhibitors (SSRIs) offer no worthwhile increase in smoking cessation rates.

- The evidence is insufficient to draw conclusions about whether existing depression modifies the efficacy of antidepressants for smoking cessation.

\section{Implications for research}

- There is high-certainty evidence that bupropion increases quit rates at six months or longer in adults motivated to quit. We consider that further research is highly unlikely to change our confidence in the efficacy of bupropion in this population. However, further studies could increase our confidence in the likelihood of SAEs and any future studies comparing bupropion to placebo should ensure these are recorded and reported in detail.

- More studies assessing the efficacy and safety of different doses of bupropion, as well as doses higher than $300 \mathrm{mg}$ would clarify the most effective bupropion dosing strategy.

- More high-certainty studies are needed to assess the efficacy of bupropion when combined with varenicline treatment or NRT treatment.

- More high-certainty studies are needed to assess whether bupropion is particularly efficacious for supporting smoking cessation in people with depression.

- New studies of any antidepressant used as a treatment for smoking cessation should ensure that they measure and report on the number of participants experiencing SAEs and AEs, as well as reporting on the number of dropouts due to treatment. These numbers should be reported separately by study arm, as well as overall. Specifically, studies of bupropion should report on numbers of psychiatric AEs and provide more detail on the severity of these events.

\section{ACKNOWLEDGEMENTS}

Our thanks to all of the previous authors of this review (John Hughes, Lindsay Stead, Tim Lancaster, Kate Cahill). We also thank Drs Niaura, Borrelli, Spring, Fiore, Hurt, Mizes, Ferry, Schuh, Cinciripini, Hays, Prochazka, Ahluwalia, Mayo, Collins, Novotny, Brown, David, Evins, Le Foll, Glover, McClernon, Le Foll and Piper for assistance with additional information or data on studies.

We thank Ryan J Courtney (University of New South Wales, National Drug and Alcohol Research Centre) and Dr Emily Peckham (University of York) for their peer review comments, Sandra Wilcox for consumer review comments and Professor Jamie Brown for editorial review, on this update.

This review was authored by employees of Cochrane Tobacco Addiction, which receives infrastructure funding from the National Institute for Health Research (NIHR). The views and opinions expressed therein are those of the authors and do not necessarily reflect those of the Systematic Reviews Programme, NIHR, National Health Service (NHS) or the Department of Health. This particular publication arises from research funded by Research England's Strategic Priorities Fund (SPF) QR allocation. JHB was funded in part by the NIHR Oxford Biomedical Research Centre (BRC). 


\section{RE F E R E N C E S}

\section{References to studies included in this review}

Ahluwalia 2002 \{published data only\}

* Ahluwalia JS, Harris KJ, Catley D, Okuyemi KS, Mayo MS. Sustained-release bupropion for smoking cessation in African Americans: a randomized controlled trial. JAMA 2002;288:468-74.

Boardman T, Catley D, Mayo MS, Ahluwalia JS. Self-efficacy and motivation to quit during participation in a smoking cessation program. International Journal of Behavioral Medicine 2005;12:266-72.

Catley D, Harris KJ, Okuyemi KS, Mayo MS, Pankey E, Ahluwalia JS. The influence of depressive symptoms on smoking cessation among African Americans in a randomized trial of bupropion. Nicotine \& Tobacco Research 2005;7(6):859-70.

Harris KJ, Ahluwalia JS, Catley D, Okuyemi KS, Mayo MS, Resnicow K. Successful recruitment of minorities into clinical trials: the Kick It at Swope project. Nicotine \& Tobacco Research 2003;5:575-84.

Harris KJ, Okuyemi KS, Catley D, Mayo MS, Ge B, Ahluwalia JS. Predictors of smoking cessation among African-Americans enrolled in a randomized controlled trial of bupropion. Preventive Medicine 2004;38:498-502.

Okuyemi KS, Ahluwalia JS, Ebersole Robinson M, Catley D, Mayo MS, Resnicow K. Does menthol attenuate the effect of bupropion among African American smokers?. Addiction 2003;98:1387-93.

Thomas JL, Guo H, Lynam IM, Powell JN, Okuyemi KS, Bronars CA, et al. The impact of perceived treatment assignment on smoking cessation outcomes among AfricanAmerican smokers. Journal of General Internal Medicine 2008;23(9):1361-6.

Zhu AZ, Zhou Q, Cox LS, David SP, Ahluwalia JS, Benowitz NL, et al. Association of CHRNA5-A3-B4 SNP rs2036527 with smoking cessation therapy response in African-American smokers. Clinical Pharmacology and Therapeutics 2014;96(2):256-65.

\section{Anthenelli 2016 \{published data only\}}

* Anthenelli RM, Benowitz NL, West R, St Aubin L, McRae T, Lawrence D, et al. Neuropsychiatric safety and efficacy of varenicline, bupropion, and nicotine patch in smokers with and without psychiatric disorders (EAGLES): a doubleblind, randomised, placebo-controlled clinical trial. Lancet 2016;387(10037):2507-20.

Anthenelli RM, Gaffney M, Benowitz NL, West R, McRae T, Russ $C$, et al. Predictors of neuropsychiatric adverse events with smoking cessation medications in the randomized controlled EAGLES Trial. Journal of General Internal Medicine 2019;34(6):862-70.

Baker CL, Pietri G. A cost-effectiveness analysis of varenicline for smoking cessation using data from the EAGLES trial. ClinicoEconomics and Outcomes Research 2018;10:67-74.
Benowitz NL, Pipe A, West R, Hays JT, Tonstad S, McRae T, et al. Cardiovascular safety of varenicline, bupropion, and nicotine patch in smokers: a randomized clinical trial. JAMA Internal Medicine 2018;178(5):622-31.

EudraCT 2010-022914-15. A phase 4, randomized, double-blind, active and placebo -controlled, multicenter study evaluating the neuropsychiatric safety and efficacy of 12 weeks varenicline tartrate $1 \mathrm{mg}$ bid and bupropion hydrochloride $150 \mathrm{mg}$ bid for smoking cessation in subjects with and without a history of psychiatric disorders. clinicaltrialsregister.eu/ctr-search/search? query=2010-022914-15 (first received 14 October 2011).

Evins AE, Benowitz NL, West R, Russ C, McRae T, Lawrence D, et al. Neuropsychiatric safety and efficacy of varenicline, bupropion, and nicotine patch in smokers with psychotic, anxiety, and mood disorders in the EAGLES Trial. Journal of Clinical Psychopharmacology 2019;39(2):108-16.

NCT01456936. Study evaluating the safety and efficacy of varenicline and bupropion for smoking cessation in subjects with and without a history of psychiatric disorders. clinicaltrials.gov/ct2/show/NCT01330030 (first received 21 October 2011).

NCT01574703. Study to evaluate cardiac assessments following different treatments of smoking cessation medications in subjects with and without psychiatric disorders. clinicaltrials.gov/ct2/show/NCT01574703 (first received 10 April 2012).

West R, Evins AE, Benowitz NL, Russ C, McRae T, Lawrence D, et al. Factors associated with the efficacy of smoking cessation treatments and predictors of smoking abstinence in EAGLES. Addiction 2018;113(8):1507-16.

Wilcox C, Oskooilar N, Guevarra K, Linh Tong M, Grosz D, Morrissey J, et al. A double-blind, active-and placebo-controlled evaluation of the neuropsychiatric safety and efficacy of varenicline and bupropion for smoking cessation in subjects with (pre-existing) psychiatric disorders: an objective blinded analysis. Neuropsychopharmacology 2015;40:S106-271.

Aubin 2004 \{published data only\}

* Aubin HJ, Lebargy F, Berlin I, Bidaut-Mazel C, ChemaliHudry J, Lagrue G. Efficacy of bupropion and predictors of successful outcome in a sample of French smokers: a randomized placebo-controlled trial. Addiction 2004;99:1206-18.

Lebargy F, Aubin HJ, Lagrue G, Bidaut-Mazel C, ChemaliHudry J, Poulain L. A placebo-controlled, double-blind study of Zyban LP: An effective and well-tolerated aid to smoking cessation - preliminary results (POS4-69). Society for Research on Nicotine and Tobacco 9th Annual Meeting; 2003 February 19-22; New Orleans (LA). 2003.

\section{Aveyard 2008 \{published data only\}}

* Aveyard P, Johnson C, Fillingham S, Parsons A, Murphy M. Nortriptyline plus nicotine replacement versus placebo plus 
nicotine replacement for smoking cessation: pragmatic randomised controlled trial. BMJ 2008;336(7655):1223-7.

Aveyard P, Johnson C, Murphy M, Johnstone E, Walton R, Fillingham $S$, et al. A pragmatic randomised controlled trial to test the efficacy of nortriptyline plus nicotine replacement therapy (NRT) versus a placebo plus NRT in helping smokers to stop and testing the role of noradrenergic and dopaminergic genetic variants in smoking cessation [PI-TS-02]. Society for Research on Nicotine and Tobacco 8th European Meeting; 2006 September 23-26; Kusadasi, Turkey. 2006.

\section{Barnes 2006 \{published data only\}}

Barnes J, Barber N, Wheatley D, Williamson EM. A pilot randomised, open, uncontrolled, clinical study of two dosages of St John's wort (Hypericum perforatum) herb extract (LI-160) as an aid to motivational/behavioural support in smoking cessation. Planta Medica 2006;72(4):378-82.

\section{Benli 2017 \{published data only\}}

* Benli AR, Erturhan S, Oruc MA, Kalpakci P, Sunay D, Demirel Y. A comparison of the efficacy of varenicline and bupropion and an evaluation of the effect of the medications in the context of the smoking cessation programme. Tobacco Induced Diseases 2017;15:10

\section{Berlin 1995 \{published data only\}}

* Berlin I, Said S, Spreux Varoquaux O, Launay JM, Olivares R, Millet $\mathrm{V}$, et al. A reversible monoamine oxidase A inhibitor (moclobemide) facilitates smoking cessation and abstinence in heavy, dependent smokers. Clinical Pharmacology and Therapeutics 1995;58:444-52.

Berlin I, Spreux Varoquaux O, Said S, Launay JM. Effects of past history of major depression on smoking characteristics, monoamine oxidase-A and -B activities and withdrawal symptoms in dependent smokers. Drug and Alcohol Dependence 1997;45:31-7.

\section{Berlin 2002 \{published data only\}}

Berlin I, Aubin HJ, Pedarriosse AM, Rames A, Lancrenon S, Lagrue $G$. Lazabemide, a selective, reversible monoamine oxidase $\mathrm{B}$ inhibitor, as an aid to smoking cessation. Addiction 2002;97:1347-54

\section{Berlin 2012 \{published data only\}}

Berlin I, Hunneyball IM, Greiling D, Jones SP, Fuder H, Stahl HD. A selective reversible monoamine oxidase $B$ inhibitor in smoking cessation: effects on its own and in association with transdermal nicotine patch. Psychopharmacology 2012;223(1):89-98. []

\section{Biberman 2003 \{published data only\}}

Biberman R, Neumann R, Katzir I, Gerber Y. A randomized controlled trial of oral selegiline plus nicotine skin patch compared with placebo plus nicotine skin patch for smoking cessation. Addiction 2003;98:1403-7.

\section{Blondal 1999 \{published data only\}}

Blondal T, Gudmundsson LJ, Tomasson K, Jonsdottir D, Hilmarsdottir $\mathrm{H}$, Kristjansson $\mathrm{F}$, et al. The effects of fluoxetine combined with nicotine inhalers in smoking cessation - a randomized trial. Addiction 1999;94:1007-15.

Brown 2007 \{published data only\}

Abrantes AM, Strong DR, Lloyd-Richardson EE, Niaura R, Kahler CW, Brown RA. Regular exercise as a protective factor in relapse following smoking cessation treatment. American Journal on Addictions 2009;18(1):100-1.

* Brown RA, Niaura R, Lloyd-Richardson EE, Strong DR, Kahler CW, Abrantes AM, et al. Bupropion and cognitivebehavioral treatment for depression in smoking cessation. Nicotine \& Tobacco Research 2007;9:721-30.

David SP, Brown RA, Papandonatos GD, Kahler CW, LloydRichardson EE, Munafo MR, et al. Pharmacogenetic clinical trial of sustained-release bupropion for smoking cessation. Nicotine \& Tobacco Research 2007;9:821-33.

David SP, Niaura R, Papandonatos GD, Shadel WG, Burkholder GJ, Britt DM, et al. Does the DRD2-Taq1 A polymorphism influence treatment response to bupropion hydrochloride for reduction of the nicotine withdrawal syndrome?. Nicotine \& Tobacco Research 2003;5:935-42.

David SP, Strong DR, Leventhal AM, Lancaster MA, McGeary JE, Munafo MR, et al. Influence of a dopamine pathway additive genetic efficacy score on smoking cessation: results from two randomized clinical trials of bupropion. Addiction 2013;108(12):2202-11.

David SP, Strong DR, Munafo MR, Brown RA, LloydRichardson EE, Wileyto PE, et al. Bupropion efficacy for smoking cessation is influenced by the DRD2 Taq1A polymorphism: Analysis of pooled data from two clinical trials. Nicotine \& Tobacco Research 2007;9(12):1251-7.

Leventhal AM, David SP, Brightman M, Strong D, McGeary JE, Brown RA, et al. Dopamine D4 receptor gene variation moderates the efficacy of bupropion for smoking cessation. Pharmacogenomics Journal 2012;12(1):86-92. []

Li Y, Wileyto EP, Heitjan DF. Modeling smoking cessation data with alternating states and a cure fraction using frailty models. Statistics in Medicine 2010; Vol. 29, issue 6:627-38. []

Okun ML, Levine MD, Houck P, Perkins KA, Marcus MD. Subjective sleep disturbance during a smoking cessation program: associations with relapse. Addictive Behaviors 2011; Vol. 36, issue 8:861-4. [; 9400123000011571]

Strong DR, Kahler CW, Leventhal AM, Abrantes AM, LloydRichardson E, Niaura R, et al. Impact of bupropion and cognitive-behavioral treatment for depression on positive affect, negative affect, and urges to smoke during cessation treatment. Nicotine \& Tobacco Research 2009; Vol. 11, issue 10:1142-53. []

Uhl GR, Liu QR, Drgon T, Johnson C, Walther D, Rose JE, et al. Molecular genetics of successful smoking cessation: convergent genome-wide association study results. Archives of General Psychiatry 2008;65(6):683-93. 
Brown 2014 \{published data only\}

* Brown RA, Abrantes AM, Strong DR, Niaura R, Kahler CW, Miller IW, et al. Efficacy of sequential use of fluoxetine for smoking cessation in elevated depressive symptom smokers. Nicotine \& Tobacco Research 2014;16(2):197-207.

Brown RA, Strong DR, Abrantes AM, Miller IW, Kahler CW, Niaura R, et al. Efficacy of sequential use of fluoxetine for smoking cessation in elevated depressive symptom smokers. Society for Research on Nicotine \& Tobacco 17th Annual Meeting; 2011 February 16-19; Toronto 2011:28S. []

Brown RA, Strong DR, Miller IW, Kahler CW, Niaura R, Price LH. Efficacy of sequential vs. concurrent use of fluoxetine in smoking cessation for elevated depressive symptom smokers (SYM8D). Society for Research on Nicotine and Tobacco 13th Annual Meeting; 2007 February 21-24, Austin (TX). 2007.

Minami H, Kahler CW, Bloom EL, Strong DR, Abrantes AM, Zywiak WH, et al. Effects of depression history and sex on the efficacy of sequential versus standard fluoxetine for smoking cessation in elevated depressive symptom smokers. Addictive Disorders \& Their Treatment 2015;14(1):29-39.

\section{Cinciripini 2005 \{published data only\}}

Cinciripini PM, Tsoh JY, Friedman K, Wetter D, Cinciripini LG, Skaar KL. A placebo controlled evaluation of venlafaxine for smoking cessation: preliminary findings [Abstract A18]. Society for Research on Nicotine and Tobacco Annual Meeting; 1998 Mar 27-29; New Orleans (LA). 1998.

* Cinciripini PM, Tsoh JY, Wetter DW, Lam C, de Moor C, Cinciripini $L$, et al. Combined effects of venlafaxine, nicotine replacement, and brief counseling on smoking cessation. Experimental and Clinical Psychopharmacology 2005;13:282-92.

Cinciripini PM, Wetter D, Minna J, Tsoh JY, Gritz ER, Baile WF. The effects of brief counseling, transdermal nicotine replacement and antidepressant therapy on smoking cessation among smokers carrying the DRD2 A1 allele (PA3A). Society for Research on Nicotine and Tobacco Fifth Annual Meeting; Mar 5-7 1999; San Diego, California. 1999.

Cinciripini PM, Wetter DW, Tomlinson GE, Tsoh JY, de Moor CA, Cinciripini LG, et al. The effects of the DRD2 polymorphism on smoking cessation and negative affect: Evidence for a pharmacogenetic effect on mood. Nicotine \& Tobacco Research 2004;6:229-39.

\section{Cinciripini 2013 \{published data only\}}

Cinciripini PM, Green CE, Robinson JD, Karam-Hage M, Engelmann JM, Minnix JA, et al. Benefits of varenicline vs. bupropion for smoking cessation: a Bayesian analysis of the interaction of reward sensitivity and treatment. Psychopharmacology 2017;234(11):1769-79.

* Cinciripini PM, Robinson JD, Karam-Hage M, Minnix JA, Lam C, Versace $F$, et al. Effects of varenicline and bupropion sustainedrelease use plus intensive smoking cessation counseling on prolonged abstinence from smoking and on depression, negative affect, and other symptoms of nicotine withdrawal. JAMA Psychiatry 2013;70(5):522-33. []
Cui Y, Engelmann JM, Xian J, Minnix JA, Lam CY, Karam-Hage M, et al. Pharmacological intervention and abstinence in smokers undergoing cessation treatment: a psychophysiological study. International Journal of Psychophysiology 2018;123:25-34.

Versace F, Stevens EM, Robinson JD, Cui Y, Deweese MM, Engelmann JM, et al. Brain responses to cigarette-related and emotional images in smokers during smoking cessation: no effect of varenicline or bupropion on the late positive potential. Nicotine \& Tobacco Research 2017;21(2):234-40.

\section{Cinciripini 2018 \{published data only\}}

* Cinciripini PM, Minnix JA, Green CE, Robinson JD, Engelmann JM, Versace F, et al. An RCT with the combination of varenicline and bupropion for smoking cessation: clinical implications for front line use. Addiction 2018;113:1673-82.

\section{Collins 2004 \{published data only\}}

Bergen AW, Javitz HS, Su L, He Y, Conti DV, Benowitz NL, et al. The DRD4 Exon III VNTR, Bupropion, and Associations With Prospective Abstinence. Nicotine \& Tobacco Research 2013;15(7):1190-1200.

Berrettini WH, Wileyto EP, Epstein L, Restine S, Hawk L, Shields P, et al. Catechol-O-methyltransferase (COMT) gene variants predict response to bupropion therapy for tobacco dependence. Biological Psychiatry 2007;61(1):111-8.

* Collins B, Wileyto P, Patterson F, Rukstalis M, AudrainMcGovern J, Kaufmann V, et al. Gender differences in smoking cessation in a placebo-controlled trial of bupropion with behavioral counseling. Nicotine \& Tobacco Research 2004;6:27-37.

Conti DV, Lee W, Li D, Liu J, Van Den BD, Thomas PD, et al. Nicotinic acetylcholine receptor beta2 subunit gene implicated in a systems-based candidate gene study of smoking cessation. Human Molecular Genetics 2008;17(18):2834-48.

David SP, Strong DR, Leventhal AM, Lancaster MA, McGeary JE, Munafo MR, et al. Influence of a dopamine pathway additive genetic efficacy score on smoking cessation: results from two randomized clinical trials of bupropion. Addiction 2013;108(12):2202-11.

David SP, Strong DR, Munafo MR, Brown RA, LloydRichardson EE, Wileyto PE, et al. Bupropion efficacy for smoking cessation is influenced by the DRD2 Taq1A polymorphism: Analysis of pooled data from two clinical trials. Nicotine \& Tobacco Research 2007;9(12):1251-7.

Gold AB, Wileyto EP, Jepson C, Lori A, Cubells JF, Lerman C. Galanin receptor 1 (GALR1) SNP is associated with craving and smoking relapse. Neuropsychopharmacology 2011; Vol. 36:S378. [; 9400123000012457$]$

Gold AB, Wileyto EP, Lori A, Conti D, Cubells JF, Lerman C. Pharmacogenetic association of the galanin receptor (GALR1) SNP rs2717162 with smoking cessation. Neuropsychopharmacology 2012;37(7):1683-8. [] 
Hu J, Redden DT, Berrettini WH, Shields PG, Restine SL, Pinto A, et al. No evidence for a major role of polymorphisms during bupropion treatment. Obesity 2006;14(11):1863-7.

Javitz HS, Swan GE, Lerman C. The dynamics of the urge-tosmoke following smoking cessation via pharmacotherapy. Addiction 2011; Vol. 106, issue 10:1835-45. []

Lee AM, Jepson C, Hoffmann E, Epstein L, Hawk LW, Lerman C, et al. CYP2B6 genotype alters abstinence rates in a bupropion smoking cessation trial. Biological Psychiatry 2007;62(6):635-41.

Lee W, Bergen AW, Swan GE, Li D, Liu J, Thomas P, et al. Genderstratified gene and gene-treatment interactions in smoking cessation. Pharmacogenomics Journal 2012;12(6):521-32.

Lerman C, Jepson C, Wileyto EP, Epstein LH, Rukstalis M, Patterson $\mathrm{F}$, et al. Role of functional genetic variation in the dopamine $D 2$ receptor (DRD2) in response to bupropion and nicotine replacement therapy for tobacco dependence: results of two randomized clinical trials. Neuropsychopharmacology 2006;31:231-42.

Lerman C, Niaura R, Collins BN, Wileyto P, Audrain MJ, Pinto A, et al. Effect of bupropion on depression symptoms in a smoking cessation clinical trial. Psychology of Addictive Behaviors 2004;18:362-6.

Lerman C, Roth D, Kaufmann V, Audrain J, Hawk L, Liu AY, et al. Mediating mechanisms for the impact of bupropion in smoking cessation treatment. Drug and Alcohol Dependence 2002;67:219-23.

Lerman C, Shields PG, Wileyto EP, Audrain J, Hawk LH Jr, Pinto A, et al. Effects of dopamine transporter and receptor polymorphisms on smoking cessation in a bupropion clinical trial. Health Psychology 2003;22:541-8.

Lerman C, Shields PG, Wileyto EP, Audrain J, Pinto A, Hawk L, et al. Pharmacogenetic investigation of smoking cessation treatment. Pharmacogenetics 2002;12:627-34.

Patterson F, Schnoll RA, Wileyto EP, Pinto A, Epstein LH, Shields PG, et al. Toward personalized therapy for smoking cessation: a randomized placebo-controlled trial of bupropion. Clinical Pharmacology \& Therapeutics 2008;84:320-5.

Schnoll RA, Epstein L, Audrain J, Niaura R, Hawk L, Shields PG, et al. Can the blind see? Participant guess about treatment arm assignment may influence outcome in a clinical trial of bupropion for smoking cessation. Journal of Substance Abuse Treatment 2008;34(2):234-41.

Uhl GR, Liu QR, Drgon T, Johnson C, Walther D, Rose JE, et al. Molecular genetics of successful smoking cessation: convergent genome-wide association study results. Archives of General Psychiatry 2008;65(6):683-93.

Wileyto EP, Patterson F, Niaura R, Epstein LH, Brown RA, Audrain-McGovern J, et al. Recurrent event analysis of lapse and recovery in a smoking cessation clinical trial using bupropion. Nicotine \& Tobacco Research 2005;7:257-68.
Wileyto P, Patterson F, Niaura R, Epstein L, Brown R, AudrainMcGovern J, et al. Do small lapses predict relapse to smoking behavior under bupropion treatment?. Nicotine \& Tobacco Research 2004;6:357-66.

\section{Covey 2002 \{published data only\}}

Berlin I, Chen H, Covey LS. Depressive mood, suicide ideation and anxiety in smokers who do and smokers who do not manage to stop smoking after a target quit date. Addiction 2010; Vol. 105, issue 12:2209-16. []

Covey LS, Glassman AH, Stetner F, Rivelli S. A trial of sertraline for smokers with past major depression. Society for Research on Nicotine and Tobacco Meeting. Arlington, VA (www.srnt.org/ events/abstracts99/index.htm) 2000.

* Covey LS, Glassman AH, Stetner F, Rivelli S, Stage K. A randomized trial of sertraline as a cessation aid for smokers with a history of major depression. American Journal of Psychiatry 2002;159:1731-7.

NCT00063323. Maintenance treatment for abstinent smokers. clinicaltrials.gov/ct2/show/NCT00063323 (first received 1 July 2003).

\section{Cox 2012 \{published data only\}}

Berg CJ, Cox LS, Choi WS, Mayo MS, Krebill R, Bronars CA, et al. Assessment of depression among African American light smokers. Journal of Health Psychology 2012;17(2):197-206.

Buchanan TS, Cox LS, Nollen NL, Thomas JL, Berg CJ, Mayo MS, et al. Perceived treatment assignment and smoking cessation in a clinical trial of bupropion. Cancer Epidemiology, Biomarkers \& Prevention 2011;20(4):721. []

Buchanan TS, Sanderson Cox L, Thomas JL, Nollen NL, Berg CJ, Mayo MS, et al. Perceived treatment assignment and smoking cessation in a clinical trial of bupropion versus placebo. Nicotine \& Tobacco Research 2013;15(2):567-71.

Cox LS, Faseru B, Mayo MS, Krebill R, Snow TS, Bronars CA, et al. Design, baseline characteristics, and retention of African American light smokers into a randomized trial involving biological data. Trials 2011; Vol. 12:22. []

* Cox LS, Nollen NL, Mayo MS, Choi WS, Faseru B, Benowitz NL, et al. Bupropion for smoking cessation in African American light smokers: a randomized controlled trial. Journal of the National Cancer Institute 2012;104(4):290-8.

Faseru B, Choi WS, Krebill R, Mayo MS, Nollen NL, Okuyemi KS, et al. Factors associated with smoking menthol cigarettes among treatment-seeking African American light smokers. Addictive Behaviors. England, 2011; Vol. 36, issue 12:1321-4. []

Faseru B, Nollen NL, Mayo MS, Krebill R, Choi WS, Benowitz NL, et al. Predictors of cessation in African American light smokers enrolled in a bupropion clinical trial. Addictive Behaviors 2013;38(3):1796-803. [CRS: 9400107000000930 ]

Nollen NL, Mayo MS, Ahluwalia JS, Tyndale RF, Benowitz NL, Faseru B, et al. Factors associated with discontinuation of bupropion and counseling among African American light 
smokers in a randomized clinical trial. Annals of Behavioral Medicine 2013;46(3):336-48.

Zhu AZ, Cox LS, Nollen N, Faseru B, Okuyemi KS, Ahluwalia JS, et al. CYP2B6 and bupropion's smoking-cessation pharmacology: the role of hydroxybupropion. Clinical Pharmacology and Therapeutics 2012;92(6):771-7. []

Zhu AZ, Zhou Q, Cox LS, David SP, Ahluwalia JS, Benowitz NL, et al. Association of CHRNA5-A3-B4 SNP rs2036527 with smoking cessation therapy response in African-American smokers. Clinical Pharmacology and Therapeutics 2014;96(2):256-65.

\section{CTRI/2013/07/003830 \{published data only\}}

CTRI/2013/07/003830. A study to evaluate different strategies-(medicine, enhanced counselling, standard counselling) for stopping smoking in TB patients in TB program in India. apps.who.int/trialsearch/Trial2.aspx? TrialID=CTRI/2013/07/003830 (first received 23 July 2013).

\section{Da Costa 2002 \{published data only\}}

da Costa C, Younes R, Lourenco M. Smoking cessation: A randomized double-blind study comparing nortriptyline to placebo [abstract]. American Journal of Respiratory and Critical Care Medicine 2001;163(5 Suppl):A354.

* da Costa CL, Younes RN, Lourenco MT-C. Stopping smoking: a prospective, randomized, double-blind study comparing nortriptyline to placebo. Chest 2002;122:403-8.

\section{Dalsgarð 2004 \{published data only\}}

* Dalsgarð OJ, Hansen NC, Søes-Petersen U, Evald T, Høegholm A, Barber J, et al. A multicenter, randomized, double-blind, placebo-controlled, 6-month trial of bupropion hydrochloride sustained-release tablets as an aid to smoking cessation in hospital employees. Nicotine \& Tobacco Research 2004;6:55-61.

Dalsgarð OJ, Vestbo J. A multicenter, randomised, doubleblind, placebo-controlled 6 month trial to evaluate efficacy and tolerability of bupropion hydrochloride sustained release (SR) tablets as treatment for nicotine dependency in healthcare workers and as an aid to smoking cessation (ZYB30009). Poster and oral presentation. European Congress on Tobacco or Health; 2002 June 20-22; Warsaw, Poland. 2002.

\section{Ebbert 2014 \{published data only\}}

* Ebbert JO, Hatsukami DK, Croghan IT, Schroeder DR, Allen SS, Hays JT, et al. Combination varenicline and bupropion SR for tobacco-dependence treatment in cigarette smokers: a randomized trial. JAMA 2014;311(2):155-63.

Hong AS, Elrashidi MY, Schroeder DR, Ebbert JO. Depressive symptoms among patients receiving varenicline and bupropion for smoking cessation. Journal of Substance Abuse Treatment 2015;52:78-81.

\section{Eisenberg 2013 \{published data only\}}

Benowitz NL, Prochaska JJ. Smoking cessation after acute myocardial infarction. Journal of the American College of Cardiology 2013;61(5):533-5. []
Eisenberg MJ, Grandi SM, Gervais A, Joseph L, O'Loughlin J, Paradis $\mathrm{G}$, et al. Bupropion for smoking cessation in patients hospitalized with acute myocardial infarction: A randomized, placebo-controlled trial. Canadian Journal of Cardiology 2011;27(5 Suppl 1):S344. []

* Eisenberg MJ, Grandi SM, Gervais A, O'Loughlin J, Paradis G, Rinfret $S$, et al. Bupropion for smoking cessation in patients hospitalized with acute myocardial infarction: A randomized, placebo-controlled trial. Journal of the American College of Cardiology 2013;61(5):524-32. []

Filion KB, Grandi SM, Joseph L, O'Loughlin J, Paradis G, Pilote L, et al. The effect of bupropion on symptoms of depression among patients attempting to quit smoking post-myocardial infarction: the zesca trial. Circulation 2012;125 Suppl 10:P090.

Grandi S, Filion K, Gervais A, Joseph L, O'Loughlin J, Paradis G, et al. The effect of adherence to treatment on smoking abstinence in patients post-acute myocardial infarction. 61th Annual Scientific Session of the American College of Cardiology and i2 Summit: Innovation in Intervention, ACC.12; 2012 March 24-27; Chicago (IL). 2012:E1749.

Grandi SM, Eisenberg MJ, Joseph L, O'Loughlin J, Paradis G, Filion KB. Cessation treatment adherence and smoking abstinence in patients after acute myocardial infarction. American Heart Journal 2016;173:35-40.

Grandi SM, Filion KB, Gervais A, Joseph L, O'Loughlin J, Paradis $\mathrm{G}$, et al. The effect of smoking cessation on weight at 12 months in patients post-myocardial infarction [abstract]. Circulation. 2012; Vol. 10 Suppl:P090. []

Grandi SM, Filion KB, Gervais A, Joseph L, O'Loughlin J, Paradis $G$, et al. The effect of treatment adherence on smoking abstinence in patients post-acute myocardial infarction. Journal of Population Therapeutics and Clinical Pharmacology 2012;19(2):123-4.

Grandi SM, Filion KB, Gervais A, Joseph L, O'Loughlin J, Paradis $\mathrm{G}$, et al. Weight change in patients attempting to quit smoking post-myocardial infarction. American Journal of Medicine 2014;127(7):641-9.

Grandi SM, Filion KB, Joseph L, O'Loughlin J, Pilote L, Eisenberg MJ. Baseline predictors of relapse to smoking at 12 months in patients post-myocardial infarction. Canadian Journal of Cardiology 2013;29(10 Suppl 1):S257.

Shimony A, Grandi SM, Pilote L, Joseph L, O'Loughlin J, Paradis $\mathrm{G}$, et al. Utilization of evidence-based therapy for acute coronary syndrome in high-income and low/middle-income countries. American Journal of Cardiology 2014;113(5):793-7.

Windle SB, Grandi S, Shimony A, Gervais A, Joseph L, O'Loughlin J, et al. Use of medical therapy in patients 12 months post-acute myocardial infarction. Journal of the American College of Cardiology 2012;59(13 Suppl 1):E364.

Zhang DD, Eisenberg M, Grandi SM, Joseph L, Pilote L, Filion K. Bupropion, smoking cessation, and health-related quality of life following an acute myocardial infarction. Canadian Journal of Cardiology 2013;29(10 Suppl 1):S290-1. 
Zhang DD, Eisenberg MJ, Grandi SM, Joseph L, O'Loughlin J, Paradis $\mathrm{G}$, et al. Bupropion, smoking cessation, and healthrelated quality of life following an acute myocardial infarction. Journal of Population Therapeutics and Clinical Pharmacology 2014;21(3):e346-56.

\section{Elsasser 2002 \{published data only\}}

Elsasser GN, Guck TP, Destache CJ, Daher PM, Frey DR, Jones J, et al. Sustained release bupropion in the treatment of nicotine addiction among teenage smokers (RP-32). Rapid Communication Poster Abstracts. Society for Research on Nicotine and Tobacco 8th Annual Meeting; 2002 February 20-23; Savannah, Georgia. 2002.

\section{Evins 2001 \{published data only\}}

Evins AE, Cather C, Rigotti NA, Freudenreich O, Henderson DC, Olm Shipman CM, et al. Two-year follow-up of a smoking cessation trial in patients with schizophrenia: increased rates of smoking cessation and reduction. Journal of Clinical Psychiatry 2004;65:307-11.

* Evins AE, Mays VK, Rigotti NA, Tisdale T, Cather C, Goff DC. A pilot trial of bupropion added to cognitive behavioral therapy for smoking cessation in schizophrenia. Nicotine \& Tobacco Research 2001;3:397-403.

\section{Evins 2005 \{published data only\}}

Evins AE, Cather C, Culhane M, Freudenreich O, Rigotti NA, Goff DC. Smoking cessation in schizophrenia: A double blind placebo controlled trial of bupropion SR added to cognitive behavioral therapy. Biological Psychiatry 2004;55:806.

* Evins AE, Cather C, Deckersbach T, Freudenreich O, Culhane MA, Olm-Shipman CM, et al. A double-blind placebo-controlled trial of bupropion sustained-release for smoking cessation in schizophrenia. Journal of Clinical Psychopharmacology 2005;25:218-25.

Evins AE, Deckersbach T, Cather C, Freudenreich O, Culhane MA, Henderson DC, et al. Independent effects of tobacco abstinence and bupropion on cognitive function in schizophrenia. Journal of Clinical Psychiatry 2005;66:1184-90.

\section{Evins 2007 \{published data only\}}

Evins AE, Cather C, Culhane M, Birnbaum AS, Horowitz J, Hsieh E, et al. A placebo-controlled study of bupropion SR added to high dose nicotine replacement therapy for smoking cessation or reduction in schizophrenia (POS2-104). Society for Research on Nicotine and Tobacco 12th Annual Meeting; 2006 February 15-18; Orlando (FL). 2006.

* Evins AE, Cather C, Culhane MA, Birnbaum A, Horowitz J, Hsieh E, et al. A 12-week double-blind, placebo-controlled study of bupropion SR added to high-dose dual nicotine replacement therapy for smoking cessation or reduction in schizophrenia. Journal of Clinical Psychopharmacology 2007;27:380-6.

NCT00307203. Safety and effectiveness of sustained release bupropion in treating individuals with schizophrenia who smoke. clinicaltrials.gov/ct2/show/NCT00307203 (first received 27 March 2006).

\section{Fatemi 2013 \{published data only\}}

Fatemi SH, Yousefi MK, Kneeland RE, Liesch SB, Folsom TD, Thuras PD. Antismoking and potential antipsychotic effects of varenicline in subjects with schizophrenia or schizoaffective disorder: a double-blind placebo and bupropion-controlled study. Schizophrenia Research 2013;146(1-3):376-8.

Ferry 1992 \{published and unpublished data\}

Ferry LH, Robbins AS, Scariati PD, Masterson A, Abbey DE, Burchette RJ. Enhancement of smoking cessation using the antidepressant bupropion hydrochloride. Circulation 1992;86(4 Suppl 1):I-671.

\section{Ferry 1994 \{published and unpublished data\}}

Ferry LH, Burchette RJ. Efficacy of bupropion for smoking cessation in non depressed smokers [Abstract]. Journal of Addictive Diseases 1994;13(4):249.

\section{Fossati 2007 \{published data only\}}

Ferketich AK, Fossati R, Apolone G. An evaluation of the Italian version of the Fagerstrom Test for Nicotine Dependence. Psychological Reports 2008;102:687-94.

* Fossati R, Apolone G, Negri E, Compagnoni A, La Vecchia C, Mangano S, et al. A double-blind, placebo-controlled, randomized trial of bupropion for smoking cessation in primary care. Archives of Internal Medicine 2007;167:1791-7.

\section{Gariti 2009 \{published data only\}}

Gariti P, Lynch K, Alterman A, Kampman K, Xie H, Varillo K. Comparing smoking treatment programs for lighter smokers with and without a history of heavier smoking. Journal of Substance Abuse Treatment 2009; Vol. 37, issue 3:247-55. []

\section{George 2002 \{published data only\}}

George TP, Vessicchio JC, Termine A, Bregartner TA, Feingold A Rounsaville BJ, et al. A placebo controlled trial of bupropion for smoking cessation in schizophrenia. Biological Psychiatry 2002;52:53-61. [9400123000002832]

\section{George 2003 \{published data only\}}

* George TP, Vessicchio JC, Termine A, Jatlow PI, Kosten TR, O'Malley SS. A preliminary placebo-controlled trial of selegiline hydrochloride for smoking cessation. Biological Psychiatry 2003;53(2):136-43.

Lara XD, Vessicchio JC, Termine A, Kosten TR, O'Malley SS, George TP. Selegiline versus placebo for smoking cessation in nicotine dependent refractory smokers (PO2 02). Society for Research on Nicotine and Tobacco 7th Annual Meeting; 2001 March 23-23; Seattle (WA). 2001:53. []

\section{George 2008 \{published data only\}}

* George TP, Vessicchio JC, Sacco KA, Weinberger AH, Dudas MM, Allen TM, et al. A placebo-controlled trial of bupropion combined with nicotine patch for smoking cessation in schizophrenia. Biological Psychiatry 2008;63(11):1092-6.

George TP, Vessicchio JC, Weinberger AH, Sacco KA. Sustainedrelease bupropion combined with transdermal nicotine patch for smoking cessation in schizophrenia (SYM11C). Society for 
Research on Nicotine and Tobacco 13th Annual Meeting; 2007 February 21-24; Austin (TX). 2007.

Moss TG, Sacco KA, Allen TM, Weinberger AH, Vessicchio JC, George TP. Prefrontal cognitive dysfunction is associated with tobacco dependence treatment failure in smokers with schizophrenia. Drug and Alcohol Dependence 2009; Vol. 104, issue 1-2:94-9. []

\section{Gilbert 2019 \{published data only\}}

Gilbert DG, Rabinovich NE, Gilbert-Matuskowitz EA, Klein KP, Pergadia ML. Smoking cessation symptoms across 67 days compared with randomized controls-moderation by nicotine replacement therapy, bupropion, and negativeaffect traits. Experimental and Clinical Psychopharmacology 2019;27(6):536-51.

\section{Gonzales 2001 \{published data only\}}

* Gonzales D, Nides M, Ferry LH, Segall N, Herrero L, Modell J, et al. Retreatment with bupropion SR: results from 12-month follow-up (RP-83). Rapid Communication Poster Abstracts. Society for Research on Nicotine and Tobacco 8th Annual Meeting; 2002 February 20-23; Savannah (GA). 2002.

Gonzales DH, Nides MA, Ferry LH, Kustra RP, Jamerson BD, Segall N, et al. Bupropion SR as an aid to smoking cessation in smokers treated previously with bupropion: A randomized placebo-controlled study. Clinical Pharmacology and Therapeutics 2001;69:438-44.

\section{Gonzales 2006 \{published data only\}}

Gonzales D, Rennard SI, Nides M. Varenicline effective for smoking cessation. Journal of Family Practice 2006;55(10):848-9.

* Gonzales D, Rennard SI, Nides M, Oncken C, Azoulay S, Billing CB, et al. Varenicline, an alpha4beta2 nicotinic acetylcholine receptor partial agonist, vs sustained-release bupropion and placebo for smoking cessation: a randomized controlled trial. JAMA 2006;296:47-55.

Hays JT, Croghan IT, Baker CL, Cappelleri JC, Bushmakin AG. Changes in health-related quality of life with smoking cessation treatment. European Journal of Public Health 2012;22(2):224-9.

Hays JT, Leischow SJ, Lawrence D, Lee TC. Adherence to treatment for tobacco dependence: association with smoking abstinence and predictors of adherence. Nicotine \& Tobacco Research 2010; Vol. 12, issue 6:574-81. []

Jackson KC, Nahoopii R, Said Q, Dirani R, Brixner D. An employer-based cost-benefit analysis of a novel pharmacotherapy agent for smoking cessation. Journal of Occupational \& Environmental Medicine 2007;49(4):453-60.

King DP, Paciga S, Pickering E, Benowitz NL, Bierut LJ, Conti DV, et al. Smoking cessation pharmacogenetics: analysis of varenicline and bupropion in placebo-controlled clinical trials. Neuropsychopharmacology 2012;37(3):641-50. []

Prignot J. Care for adherence to treatment for tobacco dependence. Breathe 2011; Vol. 7, issue 3:291. []
West R, Baker CL, Cappelleri JC, Bushmakin AG. Effect of varenicline and bupropion SR on craving, nicotine withdrawal symptoms, and rewarding effects of smoking during a quit attempt. Psychopharmacology 2008;197(3):371-7.

Górecka 2003 \{published data only\}

* Górecka D, Bednarek M, Nowinski A, Puscinska E, Goljan-Geremek A, Zielinski J. Effect of treatment for nicotine dependence in patients with COPD [Wyniki leczenia uzaleznienia od nikotyny chorych na przewlekla obturacyjna chorobe pluc]. Pneumonologia i Alergologia Polska 2003;71:411-7.

\section{Grant 2007 \{published data only\}}

* Grant KM, Kelley SS, Smith LM, Agrawal S, Meyer JR, Romberger DJ. Bupropion and nicotine patch as smoking cessation aids in alcoholics. Alcohol 2007;41(5):381-91.

NCT00044434. Bupropion as a smoking cessation aid in alcoholics. clinicaltrials.gov/ct2/show/NCT00044434 (first received 30 August 2002).

\section{Gray 2011 \{published data only\}}

Carpenter MJ, Baker NL, Gray KM, Upadhyaya HP. Assessment of nicotine dependence among adolescent and young adult smokers: A comparison of measures. Addictive Behaviors 2010; Vol. 35, issue 11:977-82. []

* Gray KM, Carpenter MJ, Baker NL, Hartwell KJ, Lewis AL, Hiott DW, et al. Bupropion SR and contingency management for adolescent smoking cessation. Journal of Substance Abuse Treatment 2011; Vol. 40, issue 1:77-86. []

Gray KM, Carpenter MJ, Baker NL, Klintworth EM, Leinbach AS, Upadhyaya HP, et al. Bupropion SR and contingency management in adolescent smokers: main findings. College on Problems of Drug Dependence 71st Annual Meeting; 2009 June 20-25; Reno/Sparks (NV). Reno/Sparks, Nevada, 2009:74.

\section{Gray 2012 \{published data only\}}

Gray KM, Carpenter MJ, Lewis AL, Klintworth EM, Upadhyaya HP. Varenicline versus bupropion $\mathrm{XL}$ for smoking cessation in older adolescents: a randomized, double-blind pilot trial. Nicotine \& Tobacco Research 2012;14(2):235-9.

\section{Haggsträm 2006 \{published data only\}}

Haggsträm FM, Chatkin JM, Sussenbach-Vaz E, Cesari DH, Fam CF, Fritscher CC. A controlled trial of nortriptyline, sustained-release bupropion and placebo for smoking cessation: preliminary results. Pulmonary Pharmacology \& Therapeutics 2006;19:205-9.

Hall 1998 \{published data only\}

Haas AL, Munoz RF, Humfleet GL, Reus VI, Hall SM. Influences of mood, depression history, and treatment modality on outcomes in smoking cessation. Journal of Consulting \& Clinical Psychology 2004;72:563-70.

Hall SM, Gorecki JA, Reus VI, Humfleet GL, Munoz RF. Belief about drug assignment and abstinence in treatment of cigarette smoking using nortriptyline. Nicotine \& Tobacco Research 2007;9(4):467-71. 
* Hall SM, Reus VI, Munoz RF, Sees KL, Humfleet G, Hartz DT, et al. Nortriptyline and cognitive-behavioral therapy in the treatment of cigarette smoking. Archives of General Psychiatry 1998;55:683-90.

Mooney ME, Reus VI, Gorecki J, Hall SM, Humfleet GL, Munoz RF, et al. Therapeutic drug monitoring of nortriptyline in smoking cessation: a multistudy analysis. Clinical Pharmacology \& Therapeutics 2008;83:436-42.

\section{Hall 2002 \{published data only\}}

Hall SM, Gorecki JA, Reus VI, Humfleet GL, Munoz RF. Belief about drug assignment and abstinence in treatment of cigarette smoking using nortriptyline. Nicotine \& Tobacco Research 2007;9(4):467-71.

Hall SM, Humfleet G, Maude-Griffin R, Reus VI, Munoz R, Hartz DT. Nortriptyline versus bupropion and medical management versus psychological intervention in smoking treatment (PA 5A). Society for Research on Nicotine and Tobacco 7th Annual Meeting; 2001 March 23-23; Seattle (WA). 2001:31.

* Hall SM, Humfleet GL, Reus VI, Munoz RF, Hartz DT, MaudeGriffin R. Psychological intervention and antidepressant treatment in smoking cessation. Archives of General Psychiatry 2002;59:930-6.

Hall SM, Lightwood JM, Humfleet GL, Bostrom A, Reus VI, Munoz R. Cost-effectiveness of bupropion, nortriptyline, and psychological intervention in smoking cessation. Journal of Behavioral Health Services \& Research 2005;32:381-92.

Mooney ME, Reus VI, Gorecki J, Hall SM, Humfleet GL, Munoz RF, et al. Therapeutic drug monitoring of nortriptyline in smoking cessation: a multistudy analysis. Clinical Pharmacology \& Therapeutics 2008;83:436-42.

\section{Hall 2004 \{published data only\}}

* Hall SM, Humfleet GL, Reus VI, Munoz RF, Cullen J. Extended nortriptyline and psychological treatment for cigarette smoking. American Journal of Psychiatry 2004;161:2100-7.

Mooney ME, Reus VI, Gorecki J, Hall SM, Humfleet GL, Munoz RF, et al. Therapeutic drug monitoring of nortriptyline in smoking cessation: a multistudy analysis. Clinical Pharmacology \& Therapeutics 2008;83:436-42.

\section{Hertzberg 2001 \{published data only\}}

Hertzberg MA, Moore SD, Feldman ME, Beckham JC. A preliminary study of bupropion sustained-release for smoking cessation in patients with chronic posttraumatic stress disorder. Journal of Clinical Psychopharmacology 2001;21:94-8.

\section{Holt 2005 \{published data only\}}

Holt S, Timu-Parata C, Ryder-Lewis S, Weatherall M, Beasley R. Efficacy of bupropion in the indigenous Maori population in New Zealand. Thorax 2005;60:120-3.

\section{Hurt 1997 \{published and unpublished data\}}

Dale LC, Glover ED, Sachs DP, Schroeder DR, Offord KP, Croghan IT, et al. Bupropion for smoking cessation: predictors of successful outcome. Chest 2001;119:1357-64.
Glaxo Wellcome. Presentation for FDA approval of Bupropion sustained release for smoking cessation (10 December 1996). Dr J Andrew Johnston.

Hayford KE, Patten CA, Rummans TA, Schroeder DR, Offord KP, Croghan IT, et al. Efficacy of bupropion for smoking cessation in smokers with a former history of major depression or alcoholism. British Journal of Psychiatry 1999;174:173-8.

Hurt RD, Glover ED, Sachs DPL, Dale LC, Schroeder DR. Bupropion for smoking cessation: A double-blind, placebocontrolled dose response trial. Journal of Addictive Diseases 1996;15:137.

* Hurt RD, Sachs DPL, Glover ED, Offord KP, Johnston JA, Dale LC, et al. A comparison of sustained-release bupropion and placebo for smoking cessation. New England Journal of Medicine 1997;337:1195-202.

Johnston JA, Fiedler-Kelly J, Glover ED, Sachs DP, Grasela TH, DeVeaugh-Geiss J. Relationship between drug exposure and the efficacy and safety of bupropion sustained release for smoking cessation. Nicotine \& Tobacco Research 2001;3:131-40.

\section{Johns 2017 \{published data only\}}

Johns DA. The efficacy of combination therapy with varenicline and bupropion for smoking cessation. Annals of Oncology 2017;28 Suppl 2:6-8.

\section{Jorenby 1999 \{published data only\}}

Durcan MJ, White J, Jorenby DE, Fiore MC, Rennard SI, Leischow SJ, et al. Impact of prior nicotine replacement therapy on smoking cessation efficacy. American Journal of Health Behavior 2002;26:213-20.

Jamerson BD, Nides M, Jorenby DE, Donahue R, Garrett P, Johnston JA, et al. Late-term smoking cessation despite initial failure: an evaluation of bupropion sustained release, nicotine patch, combination therapy, and placebo. Clinical Therapeutics 2001;23:744-52.

* Jorenby DE, Leischow SJ, Nides MA, Rennard SI, Johnston JA, Hughes AR, et al. A controlled trial of sustained-release bupropion, a nicotine patch, or both for smoking cessation. New England Journal of Medicine 1999;340:685-91.

Nielsen K, Fiore MC. Cost-benefit analysis of sustained-release bupropion, nicotine patch, or both for smoking cessation. Preventive Medicine 2000;30:209-16.

Smith SS, Jorenby DE, Leischow SJ, Nides MA, Rennard SI, Johnston AJ, et al. Targeting smokers at increased risk for relapse: treating women and those with a history of depression. Nicotine \& Tobacco Research 2003;5:99-109.

\section{Jorenby 2006 \{published data only\}}

Hays JT, Croghan IT, Baker CL, Cappelleri JC, Bushmakin AG. Changes in health-related quality of life with smoking cessation treatment. European Journal of Public Health 2012;22(2):224-9.

Hays JT, Leischow SJ, Lawrence D, Lee TC. Adherence to treatment for tobacco dependence: association with smoking 
abstinence and predictors of adherence. Nicotine \& Tobacco Research 2010; Vol. 12, issue 6:574-81. []

* Jorenby DE, Hays JT, Rigotti NA, Azoulay S, Watsky EJ, Williams KE, et al. Efficacy of varenicline, an alpha4beta2 nicotinic acetylcholine receptor partial agonist, vs placebo or sustained-release bupropion for smoking cessation: a randomized controlled trial. JAMA 2006;296:56-63.

King DP, Paciga S, Pickering E, Benowitz NL, Bierut LJ, Conti DV, et al. Smoking cessation pharmacogenetics: analysis of varenicline and bupropion in placebo-controlled clinical trials. Neuropsychopharmacology 2012;37(3):641-50. []

West R, Baker CL, Cappelleri JC, Bushmakin AG. Effect of varenicline and bupropion SR on craving, nicotine withdrawal symptoms, and rewarding effects of smoking during a quit attempt. Psychopharmacology 2008;197(3):371-7.

\section{Kahn 2012 \{published data only\}}

Kahn R, Gorgon L, Jones K, McSherry F, Glover ED, Anthenelli RM, et al. Selegiline transdermal system (STS) as an aid for smoking cessation. Nicotine \& Tobacco Research. United Kingdom: Oxford University Press (Great Clarendon Street, Oxford OX2 6DP, United Kingdom), 2012; Vol. 14, issue 3:377-82. []

NCT00439413. Selegiline for smoking cessation - 1 . clinicaltrials.gov/ct2/show/NCT00439413 (first received 23 February 2007).

\section{Kalman 2011 \{published data only\}}

* Kalman D, Herz L, Monti P, Kahler CW, Mooney M, Rodrigues S, et al. Incremental efficacy of adding bupropion to the nicotine patch for smoking cessation in smokers with a recent history of alcohol dependence: results from a randomized, doubleblind, placebo-controlled study. Drug and Alcohol Dependence 2011;118(2-3):111-8. []

Madden GJ, Kalman D. Effects of bupropion on simulated demand for cigarettes and the subjective effects of smoking. Nicotine \& Tobacco Research 2010; Vol. 12, issue 4:416-22. []

McGeary J. Predictors of relapse in a bupropion trial for smoking cessation in recently-abstinent alcoholics: Preliminary results using an aggregate genetic risk score. Behavior Genetics 2011;41(6):923.

McGeary JE, Knopik VS, Hayes JE, Palmer RH, Monti PM, Kalman D. Predictors of relapse in a bupropion trial for smoking cessation in recently-abstinent alcoholics: Preliminary results using an aggregate genetic risk score. Substance Abuse: Research and Treatment 2012;6(1):107-14.

NCT00304707. Effectiveness of bupropion for smokers recovering from alcohol dependence. clinicaltrials.gov/ct2/ show/NCT00304707 (first received 20 March 2017).

\section{Karam-Hage 2011 \{published data only\}}

Karam-Hage M, Strobbe S, Robinson JD, Brower KJ. BupropionSR for smoking cessation in early recovery from alcohol dependence: a placebo-controlled, double-blind pilot study.
American Journal of Drug and Alcohol Abuse 2011;37(6):487-90. []

\section{Killen 2000 \{published data only\}}

Killen JD, Fortmann SP, Schatzberg A, Hayward C, Varady A. Onset of major depression during treatment for nicotine dependence. Addictive Behaviors 2003;28:461-70.

* Killen JD, Fortmann SP, Schatzberg AF, Hayward C, Sussman L, Rothman M, et al. Nicotine patch and paroxetine for smoking cessation. Journal of Consulting and Clinical Psychology 2000;68:883-9.

\section{Killen 2004 \{published data only\}}

Killen JD, Robinson TN, Ammerman S, Hayward C, Rogers J, Samuels D. Major depression among adolescent smokers undergoing treatment for nicotine dependence. Addictive Behaviors 2004;29:1517-26.

* Killen JD, Robinson TN, Ammerman S, Hayward C, Rogers J, Stone C, et al. Randomized clinical trial of the efficacy of bupropion combined with nicotine patch in the treatment of adolescent smokers. Journal of Consulting and Clinical Psychology 2004;72:729-35.

\section{Killen 2010 \{published data only\}}

* Killen JD, Fortmann SP, Murphy GMJ, Hayward C, Fong D, Lowenthal $\mathrm{K}$, et al. Failure to improve cigarette smoking abstinence with transdermal selegiline + cognitive behavior therapy. Addiction 2010; Vol. 105, issue 9:1660-8. []

NCT01330030. Selegiline patch for treatment of nicotine dependence. clinicaltrials.gov/ct2/show/NCT01330030 (first received 6 April 2011).

Sarginson JE, Killen JD, Lazzeroni LC, Fortmann SP, Ryan HS, Ameli N, et al. Response to transdermal selegiline smoking cessation therapy and markers in the $15 \mathrm{q} 24$ chromosomal region. Nicotine \& Tobacco Research 2015;17(9):1126-33.

\section{Levine 2010 \{published data only\}}

Creswell KG, Cheng Y, Levine MD. A test of the stressbuffering model of social support in smoking cessation: is the relationship between social support and time to relapse mediated by reduced withdrawal symptoms?. Nicotine \& Tobacco Research 2015;17(5):566-71.

Levine MD, Cheng Y, Kalarchian MA, Perkins KA, Marcus MD. Dietary intake after smoking cessation among weightconcerned women smokers. Psychology of Addictive Behaviors 2012;26(4):969-73.

* Levine MD, Perkins KA, Kalarchian MA, Cheng Y, Houck PR, Slane JD, et al. Bupropion and cognitive behavioural therapy for weight-concerned women smokers. Archives of Internal Medicine 2010; Vol. 170, issue 6:543-50. []

Okun ML, Levine MD, Houck P, Perkins KA, Marcus MD. Subjective sleep disturbance during a smoking cessation program: associations with relapse. Addictive Behaviors 2011; Vol. 36, issue 8:861-4. [] 
McCarthy 2008 \{published data only\}

McCarthy DE. Mechanisms of tobacco cessation treatment: Self-report mediators of counseling and bupropion sustained release treatment. Dissertation Abstracts International: Section B: The Sciences and Engineering 2007;67(9-B):5414.

McCarthy DE, Piasecki TM, Jorenby DE, Lawrence DL, Shiffman S, Baker TB. A multi-level analysis of non-significant counseling effects in a randomized smoking cessation trial. Addiction 2010; Vol. 105, issue 12:2195-208. []

McCarthy DE, Piasecki TM, Lawrence DL, Fiore MC, Baker TB. Efficacy of bupropion SR and individual counseling among adults attempting to quit smoking (POS1-041). Society for Research on Nicotine and Tobacco 10th Annual Meeting; 2004 February 18-21; Phoenix (AZ). 2004.

McCarthy DE, Piasecki TM, Lawrence DL, Jorenby DE, Shiffman S, Baker TB. Psychological mediators of bupropion sustained-release treatment for smoking cessation. Addiction 2008;103(9):1521-33.

* McCarthy DE, Piasecki TM, Lawrence DL, Jorenby DE, Shiffman S, Fiore MC, et al. A randomized controlled clinical trial of bupropion SR and individual smoking cessation counseling. Nicotine \& Tobacco Research 2008;10:717-29.

Minami H, Tran LT, McCarthy DE. Using ecological measures of smoking trigger exposure to predict smoking cessation milestones. Psychology of Addictive Behaviors 2015;29(1):122-8.

NCT01621009. Bupropion SR plus counseling for smoking cessation. clinicaltrials.gov/ct2/show/NCT01621009 (first received 15 June 2012).

\section{Minami 2014 \{published data only\}}

Minami H, Kahler CW, Bloom EL, Prince MA, Abrantes AM, Strong DR, et al. Effects of sequential fluoxetine and gender on prequit depressive symptoms, affect, craving, and quit day abstinence in smokers with elevated depressive symptoms: a growth curve modeling approach. Experimental and Clinical Psychopharmacology 2014;22(5):392-406.

\section{Moreno-Coutino 2015 \{published data only\}}

Moreno-Coutino A, Perez-Lopez A, Gallegos LV. Predictors of retention in a multicomponent treatment for smokers. Revista de Psiquiatria Clinica 2016;43(6):134-8.

* Moreno-Coutiño A, García-Anguiano F, Ruiz-Velasco S, Medina-Mora ME. Assessment of depressive symptoms in severe smokers with minimal-mild depressive symptomatology receiving pre-smoking abstinence for integrated treatment: a randomized clinical trial. Salud Mental 2015;38(6):433-9.

\section{Muramoto 2007 \{published data only\}}

Best D. Bupropion assists with tobacco cessation in adolescents but relapse is high. Journal of Pediatrics 2008; Vol. 152, issue 5:738-9. []

Floden L, Taren DL, Muramoto ML, Leischow SJ. BMI changes in adolescents treated with bupropion SR for smoking cessation. Obesity 2016;24(1):26-9.
Leischow SJ, Muramoto ML, Matthews E, Floden LL, Grana RA. Adolescent smoking cessation with bupropion: the role of adherence. Nicotine \& Tobacco Research 2016;18(5):1202-5.

* Muramoto ML, Leischow SJ, Sherrill D, Matthews E, Strayer LJ. Randomized, double-blind, placebo-controlled trial of 2 dosages of sustained-release bupropion for adolescent smoking cessation. Archives of Pediatrics \& Adolescent Medicine 2007;161:1068-74.

Taren D, Fankem S, Muramoto M. Weight loss in adolescents who quit smoking with bupropion [RP-071]. Society for Research on Nicotine and Tobacco 11th Annual Meeting; 2005 March 20-23; Prague, Czech Republic. Rapid Communications posters. 2005.

\section{Myles 2004 \{published data only\}}

Myles PS, Leslie K, Angliss M, Mezzavia P, Lee L. Effectiveness of bupropion as an aid to stopping smoking before elective surgery: a randomised controlled trial. Anaesthesia 2004;59:1053-8.

\section{NCT00132821 \{published data only\}}

* NCT00132821. Impact of smoking cessation on sleep - 5 . clinicaltrials.gov/ct2/show/NCT00132821 (first received 22 August 2005).

\section{NCT00308763 \{published data only\}}

NCT00308763. Nicotine patch and bupropion to reduce smoking rates in younger, low-income, and minority individuals. clinicaltrials.gov/ct2/show/NCT00308763 (first received 30 March 2006).

\section{NCT00495352 \{published data only\}}

NCT00495352. The pharmacogenetic study, readiness to change, and pharmacological intervention for smoking cessation in schizophrenia. clinicaltrials.gov/ct2/show/ NCT00495352 (first received 3 July 2007).

\section{NCT00578669 \{published data only\}}

NCT00578669. Sequential use of fluoxetine for smokers With elevated depressive symptoms. clinicaltrials.gov/ct2/show/ NCT00578669 (first received 21 December 2007).

\section{NCT00593099 \{published data only\}}

NCT00593099. A preliminary study of sustained-release bupropion for smoking cessation in bipolar affective disorder. www.clinicaltrials.gov/ct2/show/NCT00593099 (first received 14 January 2008).

\section{NCT01406223 \{published data only\}}

NCT01406223. Mechanistic evaluations of pre-cessation therapies for smoking cessation. clinicaltrials.gov/ct2/show/ NCT01406223 (first recieved 1 August 2011).

\section{Niaura 2002 \{published data only\}}

Borrelli B, Niaura R, Keuthen NJ, Goldstein MG, Depue JD, Murphy $C$, et al. Development of major depressive disorder during smoking-cessation treatment. Journal of Clinical Psychiatry 1996;57:534-8. 
Borrelli B, Papandonatos G, Spring B, Hitsman B, Niaura R. Experimenter-defined quit dates for smoking cessation: adherence improves outcomes for women but not for men. Addiction 2004;99:378-85.

Borrelli B, Spring B, Niaura R, Hitsman B, Papandonatos G. Influences of gender and weight gain on short-term relapse to smoking in a cessation trial. Journal of Consulting and Clinical Psychology 2001;69:511-15.

Borrelli B, Spring B, Niaura R, Kristeller J, Ockene JK, Keuthen NJ. Weight suppression and weight rebound in exsmokers treated with fluoxetine. Journal of Consulting and Clinical Psychiatry 1999;67:124-31.

Cook JW, Spring B, McChargue DE, Borrelli B, Hitsman B, Niaura R, et al. Influence of fluoxetine on positive and negative affect in a clinic-based smoking cessation trial. Psychopharmacology 2004;173:153-9.

Doran N, Spring B, Borrelli B, McChargue D, Hitsman B, Niaura R, et al. Elevated positive mood: a mixed blessing for abstinence. Psychology of Addictive Behaviors 2006;20:36-43.

Hitsman B, Spring B, Borrelli B, Niaura R, Papandonatos GD. Influence of antidepressant pharmacotherapy on behavioral treatment adherence and smoking cessation outcome in a combined treatment involving fluoxetine. Experimental \& Clinical Psychopharmacology 2001;9:355-62.

Mizes JS, Sloan DM, Segraves K, Spring B, Pingatore R, Kristeller J. Fluoxetine and weight-gain in smoking cessation - examination of actual weight-gain and fear of weight-gain [abstract]. Psychopharmacology Bulletin 1996;32:491.

Niaura R, Goldstein M, Spring B, Keuthen N, Kristeller J, DePue J, et al. Fluoxetine for smoking cessation: A multicenter randomized double blind dose response study. Society for Behavioral Medicine Annual Meeting; 1997 April 18; San Francisco (CA).

* Niaura R, Spring B, Borrelli B, Hedeker D, Goldstein MG, Keuthen $\mathrm{N}$, et al. Multicenter trial of fluoxetine as an adjunct to behavioral smoking cessation treatment. Journal of Consulting and Clinical Psychology 2002;70:887-96.

Swan GE, Jack LM, Niaura R, Borrelli B, Spring B. Subgroups of smokers with different success rates after treatment with fluoxetine for smoking cessation [abstract]. Nicotine \& Tobacco Research 1999;1:281.

\section{Nides 2006 \{published data only\}}

NCT00150241. A seven-week dose-ranging study of CP-526,555 compared with placebo and zyban for smoking cessation. clinicaltrials.gov/ct2/show/NCT00150241 (first received 8 September 2005).

* Nides M, Oncken C, Gonzales D, Rennard S, Watsky EJ, Anziano R, et al. Smoking cessation with varenicline, a selective alpha4beta2 nicotinic receptor partial agonist: Results from a 7-week, randomized, placebo- and bupropion-controlled trial with 1-year follow-up. Archives of Internal Medicine 2006;166:1561-8.
Oncken C, Watsky E, Reeves K, Anziano R. Varenicline is efficacious and well tolerated in promoting smoking cessation: results from a 7-week, randomized, placebo- and bupropioncontrolled trial. Society for Research on Nicotine and Tobacco 11th Annual Meeting; 2005 March 20-23; Prague, Czech Republic. 2005.

\section{Parsons 2009 \{published data only\}}

EudraCT 2005-000662-39. A 2×2 phase II randomized controlled trial to investigate the efficacy of NRT plus St John's wort versus NRT plus placebo in smoking cessation and to examine the efficacy of chromium nicotinate versus placebo in preventing weight gain while stopping smoking. - SJW and chromium in smoking cessation. clinicaltrialsregister.eu/ctr-search/search? query=2005-000662-39 (first received 4 October 2005).

ISRCTN31302738. A 2 × 2 phase II randomised controlled trial to investigate the efficacy of St John's wort versus placebo in smoking cessation and the efficacy of chromium intake in preventing weight gain. isrctn.com/ISRCTN31302738 (first received 8 February 2006).

* Parsons A, Ingram J, Inglis J, Aveyard P, Johnstone E, Brown K, et al. A proof of concept randomised placebo controlled factorial trial to examine the efficacy of St John's wort for smoking cessation and chromium to prevent weight gain on smoking cessation. Drug and Alcohol Dependence 2009; Vol. 102 , issue 1-3:116-22. []

Perkins 2013 \{published data only\}

* Perkins KA, Lerman C, Karelitz JL, Jao NC, Chengappa KN, Sparks GM. Sensitivity and specificity of a procedure for early human screening of novel smoking cessation medications. Addiction 2013;108(11):1962-8.

Piper 2007 \{published data only\}

Bekiroglu K, Russell MA, Lagoa CM, Lanza ST, Piper ME. Evaluating the effect of smoking cessation treatment on a complex dynamical system. Drug and Alcohol Dependence 2017;180:215-22.

Piper ME. Bupropion alone and in combination with nicotine gum: Efficacy, mediation and moderation. Dissertation Abstracts International: Section B: The Sciences and Engineering 2007;67(9-B):5418.

* Piper ME, Federman EB, McCarthy DE, Bolt DM, Smith SS, Fiore MC, et al. Efficacy of bupropion alone and in combination with nicotine gum. Nicotine \& Tobacco Research 2007;9:947-54.

Piper ME, Federman EB, McCarthy DE, Bolt DM, Smith SS, Fiore MC, et al. Mediators of bupropion treatment effects (SYM 2C). Society for Research on Nicotine and Tobacco 14th Annual Meeting; 2008 February 26 - March 1; Portland (OR) 2008:31. [; 9400123000005187]

Piper ME, Federman EB, Smith SS, Fiore MC, Baker TB. Efficacy of bupropion SR alone and combined with 4-mg gum (PA2-2). Society for Research on Nicotine and Tobacco 10th Annual Meeting; 2004 February 18-21, Phoenix (AZ). 2004:18.

Piper ME, Federmen EB, McCarthy DE, Bolt DM, Smith SS, Fiore MC, et al. Using mediational models to explore the nature 
of tobacco motivation and tobacco treatment effects. Journal of Abnormal Psychology 2008;117:94-105.

Piper 2009 \{published and unpublished data\}

Asthana A, Johnson HM, Piper ME, Fiore MC, Baker TB, Stein JH. Effects of smoking intensity and cessation on inflammatory markers in a large cohort of active smokers. American Heart Journal 2010; Vol. 160, issue 3:458-63. []

Berg KM, Piper M, Fiore M, Baker T, Jorenby DE. Alcohol use after tobacco cessation: immediate consequences. Journal of General Internal Medicine 2012;27(Suppl 2):99-574.

Bolt DM, Piper ME, Theobald WE, Baker TB. Why two smoking cessation agents work better than one: role of craving suppression. Journal of Consulting and Clinical Psychology 2012;80(1):54-65.

Chen LS, Bloom AJ, Baker TB, Smith SS, Piper ME, Martinez M, et al. Pharmacotherapy effects on smoking cessation vary with nicotine metabolism gene (CYP2A6). Addiction 2014;109(1):128-37.

Cook JW, Lanza ST, Chu W, Baker TB, Piper ME. Anhedonia: its dynamic relations with craving, negative affect, and treatment during a quit smoking attempt. Nicotine \& Tobacco Research 2017;19(6):703-9.

Culverhouse RC, Chen LS, Saccone NL, Ma Y, Piper ME, Baker TB, et al. Variants in the CHRNA5-CHRNA3-CHRNB4 region of chromosome 15 predict gastrointestinal adverse events in the TTURC smoking cessation trial. Nicotine \& Tobacco Research 2019;22(2):248-55.

Gepner AD, Piper ME, Johnson HM, Fiore MC, Baker TB, Stein JH. Effects of smoking and smoking cessation on lipids and lipoproteins: outcomes from a randomized clinical trial. American Heart Journal 2011; Vol. 161, issue 1:145-51. []

Japuntich SJ, Leventhal AM, Piper ME, Bolt DM, Roberts LJ, Fiore MC, et al. Smoker characteristics and smoking-cessation milestones. American Journal of Preventive Medicine 2011; Vol. 40 , issue $3: 286-94$. []

Japuntich SJ, Piper ME, Leventhal AM, Bolt DM, Baker TB. The effect of five smoking cessation pharmacotherapies on smoking cessation milestones. Journal of Consulting and Clinical Psychology 2011; Vol. 79, issue 1:34-42. []

Loh WY, Piper ME, Schlam TR, Fiore MC, Smith SS, Jorenby DE, et al. Should all smokers use combination smoking cessation pharmacotherapy? Using novel analytic methods to detect differential treatment effects over 8 weeks of pharmacotherapy. Nicotine \& Tobacco Research 2012;14(2):131-41.

McCarthy DE, Ebssa L, Witkiewitz K, Shiffman S. Paths to tobacco abstinence: A repeated-measures latent class analysis. Journal of Consulting and Clinical Psychology 2015;83(4):696-708.

Piper ME, Cook JW, Schlam TR, Jorenby DE, Baker TB. Anxiety diagnoses in smokers seeking cessation treatment: relations with tobacco dependence, withdrawal, outcome and response to treatment. Addiction 2011; Vol. 106, issue 2:418-27. []
Piper ME, Cook JW, Schlam TR, Jorenby DE, Smith SS, Bolt DM, et al. Gender, race, and education differences in abstinence rates among participants in two randomized smoking cessation trials. Nicotine \& Tobacco Research 2010;12(6):647-57. []

Piper ME, Kenford S, Fiore MC, Baker TB. Smoking cessation and quality of life: changes in life satisfaction over 3 years following a quit attempt. Annals of Behavioral Medicine 2012; Vol. 43, issue 2:262-70. []

Piper ME, Schlam TR, Cook JW, Sheffer MA, Smith SS, Loh WY, et al. Tobacco withdrawal components and their relations with cessation success. Psychopharmacology 2011;216(4):569-78. []

* Piper ME, Smith SS, Schlam TR, Fiore MC, Jorenby DE, Fraser D, et al. A randomized placebo-controlled clinical trial of 5 smoking cessation pharmacotherapies. Archives of General Psychiatry 2009; Vol. 66, issue 11:1253-62. []

Smith SS, Fiore MC, Baker TB. Smoking cessation in smokers who smoke menthol and non-menthol cigarettes. Addiction 2014;109(12):2107-17.

\section{Planer 2011 \{published data only\}}

Planer D, Lev I, Elitzur Y, Sharon N, Ouzan E, Pugatsch T, et al. Bupropion for smoking cessation in patients with acute coronary syndrome. Archives of Internal Medicine 2011; Vol. 171, issue 12:1055-60. []

\section{Prochazka 1998 \{published data only\}}

Prochazka AV, Weaver MJ, Keller RT, Fryer GE, Licari PA, Lofaso D. A randomized trial of nortriptyline for smoking cessation. Archives of Internal Medicine 1998;158:2035-9.

Prochazka 2004 \{published data only\}

NCT00018148. Combined nortriptyline and transdermal nicotine for smoking cessation. clinicaltrials.gov/ct2/show/ NCT00018148 (first received 5 July 2001).

* Prochazka AV, Kick S, Steinbrunn C, Miyoshi T, Fryer GE. A randomized trial of nortriptyline combined with transdermal nicotine for smoking cessation. Archives of Internal Medicine 2004;164:2229-33.

Prochazka AV, Reyes R, Steinbrunn C, Miyoshi T. Randomized trial of nortriptyline combined with transdermal nicotine for smoking cessation (PO3 26). Society for Research on Nicotine and Tobacco 7th Annual Meeting; 2001 March 23-23; Seattle (WA). 2001:73.

\section{Richmond 2013 \{published data only\}}

Richmond R, Indig D, Butler T, Wilhelm K, Archer V, Wodak A. A randomized controlled trial of a smoking cessation intervention conducted among prisoners. Addiction 2013;108(5):966-74.

\section{Rigotti 2006 \{published data only\}}

Rigotti N, Thorndike A, Regan S, Pasternak R, Chang Y, McKool K, et al. Safety and efficacy of bupropion for smokers hospitalized with acute cardiovascular disease [abstract]. Nicotine \& Tobacco Research 2005;7:682.

* Rigotti NA, Thorndike AN, Regan S, McKool K, Pasternak RC, Chang Y, et al. Bupropion for smokers hospitalized with 
acute cardiovascular disease. American Journal of Medicine 2006;119:1080-7.

Thorndike AN, Regan S, McKool K, Pasternak RC, Swartz S, Torres-Finnerty N, et al. Depressive symptoms and smoking cessation after hospitalization for cardiovascular disease. Archives of Internal Medicine 2008;168(2):186-91.

\section{Rose 2013 \{published data only\}}

Rose JE, Behm FM. Adapting smoking cessation treatment according to initial response to precessation nicotine patch. American Journal of Psychiatry 2013;170:860-7. []

\section{Rose 2014 \{published data only\}}

* Rose JE, Behm FM. Combination treatment with varenicline and bupropion in an adaptive smoking cessation paradigm. American Journal of Psychiatry 2014;171(11):1199-205.

Rose JE, Behm FM. Combination varenicline/bupropion treatment benefits male NRT-nonresponders. Society for Research on Nicotine and Tobacco 19th Annual Meeting; 2013 March 13-16 Boston (MA). 2013:261.

\section{Rose 2017 \{published data only\}}

NCT01806779. Combination bupropion/varenicline for smoking cessation in male smokers. clinicaltrials.gov/ct2/show/ NCT01806779 (first received 7 March 2013).

* Rose JE, Behm FM. Combination varenicline/bupropion treatment benefits highly dependent smokers in an adaptive smoking cessation paradigm. Nicotine \& Tobacco Research 2017;19(8):999-1002.

\section{Rovina 2009 \{published data only\}}

Rovina N, Nikoloutsou I, Katsani G, Dima E, Fransis K, Roussos C, et al. Effectiveness of pharmacotherapy and behavioral interventions for smoking cessation in actual clinical practice. Therapeutic Advances in Respiratory Disease 2009; Vol. 3, issue 6:279-87. []

\section{Saules 2004 \{published and unpublished data\}}

* Saules KK, Schuh LM, Arfken CL, Reed K, Kilbey MM, Schuster CR. Double-blind placebo-controlled trial of fluoxetine in smoking cessation treatment including nicotine patch and cognitive-behavioral group therapy. American Journal on Addictions 2004;13:438-46.

Schuh LM, Downey KK, Hopper JA, Tancer M, Schuster CR. Fluoxetine in smoking cessation treatment. College on Problems of Drug Dependence 62nd Annual Meeting; 2000 June 17-20; San Juan, Puerto Rico 2000.

\section{Schmitz 2007 \{published data only\}}

Schmitz JM, Stotts AL, Mooney ME, Delaune KA, Moeller GF. Bupropion and cognitive-behavioral therapy for smoking cessation in women. [erratum appears in Nicotine Tob Res. 2007 Jul;9(7):785]. Nicotine \& Tobacco Research 2007;9(6):699-709.

\section{Schnoll 2010 \{published data only\}}

Martinez E, Tatum KL, Weber DM, Kuzla N, Pendley A, Campbell K, et al. Issues related to implementing a smoking cessation clinical trial for cancer patients. Cancer Causes \& Control 2009; Vol. 20, issue 1:97-104. []

Schnoll R, Lazev A, Sobel M, Tatum K, Butler D, Lerman C. Preliminary results from a randomized trial of bupropion for smoking cessation among cancer patients. Society for Research on Nicotine and Tobacco 11th Annual Meeting; 2005 March 20-23; Prague, Czech Republic. 2005.

Schnoll RA, Martinez E, Langer C, Miyamoto C, Leone F. Predictors of smoking cessation among cancer patients enrolled in a smoking cessation program. Acta Oncologica 2011; Vol. 50, issue 5:678-84. []

* Schnoll RA, Martinez E, Tatum KL, Weber DM, Kuzla N, Glass M, et al. A bupropion smoking cessation clinical trial for cancer patients. Cancer Causes \& Control 2010; Vol. 21, issue 6:811-20. []

\section{Selby 2003 \{published and unpublished data\}}

GlaxoSmithKline Clinical Trials Register. Study No: ZYB40001. A randomized, double-blind, placebo-controlled, 12-week smoking cessation trial of Zyban (150 mg bid) in adult smokers previously treated with Zyban. ctr.glaxowellcome.co.ukSummary-bupropion-IV_ZYB40001.pdf (accessed 23 August 2006).

Selby P, Ainslie M, Stepner N, Roberts J. Sustained-release bupropion (Zybanr) is effective in the re-treatment of relapsed adult smokers. American Journal of Respiratory and Critical Care Medicine 2003;167(7):A47.

* Selby P, Brands B, Stepner N. Retreatment with ZYban SR: 52 week follow-up of a Canadian Multicentre trial (POS3-63). Society for Research on Nicotine and Tobacco 9th Annual Meeting; 2003 February 19-22; New Orleans. 2003.

Selby P, Brosky G, Baker R, Lertzman M, Dakin P, Roberts J. Zyban is effective in the retreatment of relapsed adult smokers (PO4 68). Society for Research on Nicotine and Tobacco 7th Annual Meeting; 2001 March 23-23; Seattle (WA). 2001:114.

\section{Sheng 2013 \{published data only\}}

Sheng LX, Tang YL, Jiang ZN, Yao CH, Gao JY, Xu GZ, et al. Sustained-release bupropion for smoking cessation in a Chinese sample: a double-blind, placebo-controlled, randomized trial. Nicotine \& Tobacco Research 2013;15(2):320-5. []

\section{Siddiqi 2013 \{published data only\}}

Dogar O, Jawad M, Shah SK, Newell JN, Kanaan M, Khan MA, et al. Effect of cessation interventions on hookah smoking: posthoc analysis of a cluster-randomized controlled trial. Nicotine \& Tobacco Research 2014;16(6):682-8.

Siddiqi K, Khan A, Ahmad M, Dogar O, Kanaan M, Newell JN, et al. Action to stop smoking in suspected tuberculosis (assist) in Pakistan: A cluster randomized, controlled trial. Annals of Internal Medicine 2013;158(9):667-75. []

Siddiqi K, Khan A, Ahmad M, Shafiq-ur-Rehman. An intervention to stop smoking among patients suspected of TB--evaluation of an integrated approach. BMC Public Health 2010;10:160. [] 
Simon 2004 \{published data only\}

Caplan BJ. The "bupropion for smoking cessation" trial from a family practice perspective. Archives of Internal Medicine 2005;165:470.

* Simon JA, Duncan C, Carmody TP, Hudes ES. Bupropion for smoking cessation: a randomized trial. Archives of Internal Medicine 2004;164:1797-803.

Simon JA, Duncan C, Carmody TP, Hudes ES. Bupropion plus nicotine replacement no better than replacement alone. Journal of Family Practice 2004;53:953-4.

\section{Simon 2009 \{published data only\}}

Simon JA, Duncan C, Huggins J, Solkowitz S, Carmody TP. Sustained-release bupropion for hospital-based smoking cessation: a randomized trial. Nicotine \& Tobacco Research 2009;11(6):663-9.

\section{Singh 2010 \{published data only\}}

Singh P, Kumar R. Assessment of the effectiveness of sustained release Bupropion and intensive physician advice in smoking cessation. Lung India 2010; Vol. 27, issue 1:11-8. []

\section{Smith 2009 \{published data only\}}

Loh WY, Piper ME, Schlam TR, Fiore MC, Smith SS, Jorenby DE, et al. Should all smokers use combination smoking cessation pharmacotherapy? Using novel analytic methods to detect differential treatment effects over 8 weeks of pharmacotherapy. Nicotine \& Tobacco Research 2012;14(2):131-41.

Piper ME, Cook JW, Schlam TR, Jorenby DE, Smith SS, Bolt DM, et al. Gender, race, and education differences in abstinence rates among participants in two randomized smoking cessation trials. Nicotine \& Tobacco Research 2010;12(6):647-57. []

* Smith SS, McCarthy DE, Japuntich SJ, Christiansen B, Piper ME, Jorenby DE, et al. Comparative effectiveness of 5 smoking cessation pharmacotherapies in primary care clinics. Archives of Internal Medicine 2009; Vol. 169, issue 22:2148-55. []

\section{SMK20001 \{unpublished data only\}}

SMK 20001. A multi-center, double-blind, double-dummy, placebo-controlled, randomized, parallel group, dose response evaluation of a new chemical entity (NCE) and Zyban (bupropion hydrochloride) sustained release $(300 \mathrm{mg} /$ day) versus placebo as aids to smoking cessation. gskstudyregister.com/en/trial-details/?id=SMK20001 (accessed 2 March 2020).

\section{Sood 2010 \{published data only\}}

NCT00405912. St. John's wort for tobacco cessation. clinicaltrials.gov/ct2/show/NCT00405912 (first received 30 November 2006).

* Sood A, Ebbert JO, Prasad K, Croghan IT, Bauer B, Schroeder DR. A randomized clinical trial of St. John's wort for smoking cessation. Journal of Alternative and Complementary Medicine 2010; Vol. 16, issue 7:761-7. []

\section{Sood 2012 \{published data only\}}

Sood A, Prasad K, Croghan IT, Schroeder DR, Ehlers SL, Ebbert JO. S-Adenosyl-L-methionine (SAMe) for smoking abstinence: A randomized clinical trial. Journal of Alternative and Complementary Medicine 2012;18(9):854-9. []

\section{Spring 2007 \{published data only\}}

Carrington A, Doran N, Spring B. Fluoxetine moderates the association between trait-anxiety and smoking status following behavioral treatment for smoking cessation (POS4-81). Society for Research on Nicotine and Tobacco 9th Annual Meeting; 2003 February 19-22; New Orleans (LA). 2003.

NCT00113737. Fluoxetine as a quit smoking aid for depression prone. clinicaltrials.gov/ct2/show/NCT00113737 (first received 10 June 2005).

* Spring B, Doran N, Pagoto S, McChargue D, Cook JW, Bailey K, et al. Fluoxetine, smoking, and history of major depression: $\mathrm{A}$ randomized controlled trial. Journal of Consulting \& Clinical Psychology 2007;75:85-94.

Spring B, Doran N, Pagoto S, McChargue DE, Cook JW, Bailey K, et al. Reduced abstinence for smokers previously treated with fluoxetine (PA1-1). Society for Research on Nicotine and Tobacco 10th Annual Meeting; 2004 February 18-21; Phoenix (AZ). 2004.

\section{Stapleton 2013 \{published data only\}}

Stapleton J, West R, Hajek P, Wheeler J, Vangeli E, Abdi Z, et al. Randomized trial of NRT, bupropion, and NRT plus bupropion for smoking cessation: effectiveness in clinical practice. Addiction 2013;108(12):2193-201. [DOI: 10.1111/add.12304]

\section{Swan 2003 \{published data only\}}

Catz S, Jack LM, Swan GE, McClure J. Adherence to bupropion SR in a smoking cessation effectiveness trial (POS2-77). Society for Research on Nicotine and Tobacco 12th Annual Meeting; 2006 February 15-18; Orlando (FL). 2006.

Jack LM, Swan GE, Thompson E, Curry SJ, McAfee T, Dacey S, et al. Bupropion SR and smoking cessation in actual practice: methods for recruitment, screening, and exclusion for a field trial in a managed-care setting. Preventive Medicine 2003;36:585-93.

Javitz HS, Swan GE, Zbikowski SM, Curry SJ, McAfee TA, Decker DL, et al. Cost-effectiveness of different combinations of bupropion SR dose and behavioral treatment for smoking cessation: a societal perspective. American Journal of Managed Care 2004;10:217-26.

McAfee T, Zbikowski SM, Bush T, McClure J, Swan G, Jack LM, et al. The effectiveness of bupropion SR and phone counseling for light and heavy smokers (PA2-1). Society for Research on Nicotine and Tobacco 10th Annual Meeting; 2004 February 18-21; Phoenix (AZ). 2004.

Swan GE, Jack LM, Curry S, Chorost M, Javitz H, McAfee T, et al. Bupropion SR and counseling for smoking cessation in actual practice: Predictors of outcome. Nicotine \& Tobacco Research 2003;5:911-21. 
Swan GE, Jack LM, Javitz HS, McAfee T, McClure JB. Predictors of 12-month outcome in smokers who received bupropion sustained-release for smoking cessation. Central Nervous System Drugs 2008;22(3):239-56.

Swan GE, Jack LM, Valdes AM, Ring HZ, Ton CC, Curry SJ, et al. Joint effect of dopaminergic genes on likelihood of smoking following treatment with bupropion SR. Health Psychology 2007;26:361-8

Swan GE, Javitz HS, Jack LM, Curry SJ, McAfee T. Heterogeneity in 12-month outcome among female and male smokers. Addiction 2004;99:237-50.

* Swan GE, McAfee T, Curry SJ, Jack LM, Javitz H, Dacey S, et al. Effectiveness of bupropion sustained release for smoking cessation in a health care setting: a randomized trial. Archives of Internal Medicine 2003;163:2337-44.

Swan GE, Valdes AM, Ring HZ, Khroyan TV, Jack LM, Ton CC, et al. Dopamine receptor DRD2 genotype and smoking cessation outcome following treatment with bupropion SR. Pharmacogenomics Journal 2005;5:21-9.

\section{Tashkin 2001 \{published data only\}}

Patel MK, Tashkin DP, Kanner RE, Bailey WC, Buist A, Anderson PJ, et al. A multicenter evaluation of the effects of bupropion hydrochloride sustained release tablets (Bup $\mathrm{SR}$ ) versus placebo in a population of smokers with chronic obstructive pulmonary disease (PO130). 11th World Conference on Tobacco or Health; 2000 Aug 6-11; Chicago (IL). 2000; Vol. $1: 118$.

* Tashkin D, Kanner R, Bailey W, Buist S, Anderson P, Nides M, et al. Smoking cessation in patients with chronic obstructive pulmonary disease: a double-blind, placebo-controlled, randomised trial. Lancet 2001;357:1571-5.

\section{Tidey 2011 \{published data only\}}

NCT00136760. Contingent incentives plus bupropion for smoking in people with schizophrenia. clinicaltrials.gov/ct2/ show/NCT00136760 (first received 29 August 2005).

* Tidey JW, Rohsenow DJ, Kaplan GB, Swift RM, Reid N. Effects of contingency management and bupropion on cigarette smoking in smokers with schizophrenia. Psychopharmacology 2011;217(2):279-87.

\section{Tonnesen 2003 \{published data only\}}

Bollinger CT, Gilljam H, Lebargy F, van Spiegel PI, Edwards J, Hider A, et al. Bupropion hydrochloride (Zyban) is effective and well tolerated as an aid to smoking cessation - a multicountry study. Abstract and presentation at 11th Annual meeting of European Respiratory Society, Berlin, September 22-26 2001. European Respiratory Journal 2001;18(Suppl 33):12s.

\footnotetext{
* Tonnesen P, Tonstad S, Hjalmarson A, Lebargy F, van Spiegel PI, Hider A, et al. A multicentre, randomized, double-blind, placebo-controlled, 1-year study of bupropion SR for smoking cessation. Journal of Internal Medicine 2003;254:184-92.
}

Tonstad S, Aaserud E, Hjalmarson A, Peiffer G, van der Molen T, Hider A, et al. Zyban is an effective and well tolerated aid to smoking cessation in a general smoking population - a multicountry study. Society for Research on Nicotine and Tobacco 3rd Europe Conference; 2001 September 19-22; Paris, France 2001:46.

\section{Tonstad 2003 \{published data only\}}

McRobbie H, Brath H, Astbury C, Hider A, Sweet R. Bupropion hydrochloride sustained release (SR) is an effective and well tolerated aid to smoking cessation in smokers with cardiovascular disease 12 month follow-up phase data (ZYB40014). Abstract and Presentation at European Respiratory Society meeting; 2002 September 14-18; Stockholm, Sweden. 2002.

* Tonstad S, Farsang C, Klaene G, Lewis K, Manolis A, Perruchoud AP, et al. Bupropion SR for smoking cessation in smokers with cardiovascular disease: a multicentre, randomised study. European Heart Journal 2003;24:946-55.

van Spiegel PI, Lewis K, Seinost G, Astbury C, Hider A, Sweet R. Bupropion hydrochloride (Zyban) is an effective and well tolerated aid to smoking cessation in smokers with cardiovascular disease - a multicountry study. Abstract and presentation at 11th Annual meeting of European Respiratory Society, Berlin, September 22-26. European Respiratory Journal 2001;18(Suppl 33):13s.

\section{Urdapilleta-Herrera 2013 \{published data only\}}

Urdapilleta-Herrera E, Pina-Rosales MF, Vargas-Rojas MI, Ramirez-Venegas A, Sansores-Martinez R. Bupropion together with cognitive-conductual therapy (CBT) is an alternative for a long-term abstinence of smoking. European Respiratory Journal 2013;42(57):3347.

\section{Uyar 2007 \{published data only\}}

Uyar M, Bayram N, Filiz A, Elbek O, Topçu A, Dikensoy O, et al. Comparison of nicotine patch and bupropion in treating tobacco dependence. European Respiratory Journal 2005;26(Suppl 49):388s.

* Uyar M, Filiz A, Bayram N, Elbek O, Herken H, Topcu A, et al. $A$ randomized trial of smoking cessation. Medication versus motivation. Saudi Medical Journal 2007;28(6):922-6.

\section{Wagena 2005 \{published data only\}}

Quaak M, van Schayck Constant P, Postma Dirkje S, Wagena Edwin J, van Schooten Frederik J. Genetic variants in the serotonin transporter influence the efficacy of bupropion and nortriptyline in smoking cessation. Addiction 2012; Vol. 107, issue 1:178-87. []

* Wagena EJ, Knipschild PG, Huibers MJ, Wouters EF, Schayck CP. Efficacy of bupropion and nortriptyline for smoking cessation among people who are at risk for or have chronic obstructive pulmonary disease: Results from a randomized, placebo-controlled trial. Nicotine \& Tobacco Research 2005;7(4):683-4. []

van Schayck CP, Kaper J, Wagena EJ, Wouters EF, Severens JL. The cost-effectiveness of antidepressants for smoking cessation 
in chronic obstructive pulmonary disease (COPD) patients. Addiction 2009; Vol. 104, issue 12:2110-7. []

Weinberger 2010 \{published and unpublished data\}

Weinberger AH, George TP, Mckee SA. Differences in smoking expectancies in smokers with and without a history of major depression. Addictive Behaviors 2011; Vol. 36, issue 4:434-7. []

Weinberger AH, Mckee SA, George TP. Changes in smoking expectancies in abstinent, reducing, and non-abstinent participants during a pharmacological trial for smoking cessation. Nicotine \& Tobacco Research 2010; Vol. 12, issue 9:937-43. []

* Weinberger AH, Reutenauer EL, Jatlow PI, O'Malley SS, Potenza MN, George TP. A double-blind, placebo-controlled, randomized clinical trial of oral selegiline hydrochloride for smoking cessation in nicotine-dependent cigarette smokers. Drug and Alcohol Dependence 2010; Vol. 107, issue 2-3:188-95. []

Weinberger AH, Reutenauer EL, O'Malley SS, Potenza MN, George TP. A randomized placebo-controlled clinical trial of selegiline for smoking cessation: Preliminary results (POS5-29). Society for Research on Nicotine and Tobacco 15th Annual Meeting; 2009 April 27-30; Dublin, Ireland.

Weinberger AH, Reutenauer EL, Solorzano M, O'Malley SS, Potenza MN, George TP. A randomized placebo controlled clinical trial of selegiline for smoking cessation (abstract 653). CPDD 71st Annual Meeting; 2009 June 20-25; Reno (NV).

\section{Weiner 2012 \{published data only\}}

Mann-Wrobel MC, Bennett ME, Weiner EE, Buchanan RW, Ball MP. Smoking history and motivation to quit in smokers with schizophrenia in a smoking cessation program. Schizophrenia Research 2011; Vol. 126, issue 1-3:277-83. []

* Weiner E, Ball MP, Buchholz AS, Gold JM, Evins AE, McMahon RP, et al. Bupropion sustained release added to group support for smoking cessation in schizophrenia: a new randomized trial and a meta-analysis. Journal of Clinical Psychiatry. United States, 2012; Vol. 73, issue 1:95-102. []

\section{White 2005 \{published data only\}}

White WD, Crockford D, Patten S, el Guebaly N. A randomized, open-label pilot comparison of gabapentin and bupropion SR for smoking cessation. Nicotine \& Tobacco Research 2005;7(5):809-13.

\section{Wittchen 2011 \{published data only\}}

Wittchen HU, Hoch E, Klotsche J, Muehlig S. Smoking cessation in primary care - a randomized controlled trial of bupropion, nicotine replacements, CBT and a minimal intervention. International Journal of Methods in Psychiatric Research 2011;20(1):28-39. []

\section{Zellweger 2005 \{published data only\}}

Puska P, Brath H, Astbury C, Hider AE. Zyban is an effective and well tolerated aid to smoking cessation in a healthcare professionals population - a multi-country study. Society for
Research on Nicotine and Tobacco 3rd European Conference; 2001 September 19-22; Paris, France. 2001:45.

Zellweger JP, Blaziene A, Astbury C, Hider A, Hogue S. Bupropion hydrochloride sustained release is an effective and well tolerated aid to smoking cessation in a healthcare professionals population - a multicountry study. Abstract and presentation at 11th Annual meeting of European Respiratory Society, Berlin, September 22-26 2001. European Respiratory Journal 2001;18(Suppl 33):166s.

* Zellweger JP, Boelcskei PL, Carrozzi L, Sepper R, Sweet R, Hider AZ. Bupropion SR vs placebo for smoking cessation in health care professionals. American Journal of Health Behavior 2005;29:240-9.

\section{Zincir 2013 \{published data only\}}

Zincir SB, Kaymak E, Sunbul EA, Zincir N. Comparison of the effects of varenicline, bupropion and nicotine replacement therapy on smoking cessation program [Vareniklin, bupropion ve nikotin yerine koyma tedavilerinin sigara birakma programini surdurme uzerine etkilerinin karsilastirilmasi]. Bulletin of Clinical Psychopharmacology 2012;22 Suppl 1:S35.

* Zincir SB, Zincir S, Kaymak E, Sunbul EA. Comparison of the effectiveness of varenicline, extended-release bupropion and nicotine replacement therapy on the success and the maintenance of a smoking cessation program. Klinik Psikofarmakoloji Bulteni 2013;23(3):224-30.

\section{References to studies excluded from this review}

\section{Akbarpour 2010 \{published data only\}}

Akbarpour F, Rezaei O, Khodaie-Ardakani MR, Sheikhvatan M, Goodarzi H, Dolatshahi B. A double-blind placebo-controlled trial of bupropion for smoking abstinence and cognition improvement in schizophrenia. Minerva Psichiatrica 2010; Vol. 51, issue 4:263-9. []

\section{Aryanpur 2016 \{published data only\}}

Aryanpur M, Hosseini M, Masjedi MR, Mortaz E, Tabarsi P, Soori $\mathrm{H}$, et al. A randomized controlled trial of smoking cessation methods in patients newly-diagnosed with pulmonary tuberculosis. BMC Infectious Diseases 2016;16:369.

\section{Banham 2010 \{published data only\}}

Banham L, Gilbody S. Smoking cessation in severe mental illness: What works?. Addiction 2010; Vol. 105, issue 7:1176-89.

\section{Becker 2003 \{unpublished data only\}}

Becker B, Bock B, Carmona-Barros R. St. John's Wort oral spray reduces withdrawal symptoms during quitting smoking (POS4-82). Society for Research on Nicotine and Tobacco 9th Annual Meeting; 2003 February 19-22; New Orleans (LA). 2003.

\section{Berlin 2005 \{published data only\}}

Berlin I, Covey LS, Jiang HP, Hamer D. Lack of effect of D2 dopamine receptor Taql A polymorphism on smoking cessation. Nicotine \& Tobacco Research 2005;7:725-8. 
Bloch 2010 \{published data only\}

Bloch B, Reshef A, Cohen T, Tafla A, Gathas S, Israel S, et al. Preliminary effects of bupropion and the promoter region (HTTLPR) serotonin transporter (SLC6A4) polymorphism on smoking behavior in schizophrenia. Psychiatry Research 2010; Vol. 175, issue 1-2:38-42. []

\section{Bowen 1991 \{published data only\}}

Bowen DJ, Spring B, Fox E. Tryptophan and high-carbohydrate diets as adjuncts to smoking cessation therapy. Journal of Behavioral Medicine 1991;14(2):97-110.

\section{Brauer 2000 \{unpublished data only\}}

Brauer LH, Paxton DA, Stock CT, Rose JE. Selegiline and transdermal nicotine for smoking cessation. Society for Research on Nicotine and Tobacco Annual Conference; 2000 Feb 18-20; Arlington (VA) 2000.

\section{Breitling 2008 \{published data only\}}

Breitling LP, Twardella D, Brenner H. High effectiveness of short treatment with bupropion for smoking cessation in general care. Thorax 2008;63:476-7.

\section{Brody 2013 \{published data only\}}

Brody AL, Mukhin AG, Stephanie Shulenberger, Mamoun MS, Kozman M, Phuong J, et al. Treatment for tobacco dependence: effect on brain nicotinic acetylcholine receptor density. Neuropsychopharmacology 2013;38(8):1548-56.

\section{Carrão 2007 \{published data only\}}

Carrao JL, Moreira LB, Fuchs FD. The efficacy of the combination of sertraline with buspirone for smoking cessation. A randomized clinical trial in nondepressed smokers. European Archives of Psychiatry \& Clinical Neuroscience 2007;257:383-8.

\section{Chan 2005 \{published data only\}}

Chan B, Einarson A, Koren G. Effectiveness of bupropion for smoking cessation during pregnancy. Journal of Addictive Diseases 2005;24(2):19-23.

\section{Chandrashekar 2015 \{published data only\}}

Chandrashekar M, Sattar FA, Bondade S, Kumar KK. A comparative study of different modalities of treatment in nicotine dependence syndrome. Asian Journal of Psychiatry 2015;17:29-35

\section{Christenhusz 2012 \{published data only\}}

Christenhusz LC, Prenger R, Pieterse ME, Seydel ER, van der Palen J. Cost-effectiveness of an intensive smoking cessation intervention for COPD outpatients. Nicotine \& Tobacco Research 2012;14(6):657-63.

\section{Cornelius 1997 \{published data only\}}

Cornelius JR, Salloum IM, Ehler JG, Jarrett PJ, Cornelius MD, Black A, et al. Double-blind fluoxetine in depressed alcoholic smokers. Psychopharmacology Bulletin 1997;33:165-70.

\section{Cornelius 1999 \{published data only\}}

Cornelius JR, Perkins KA, Salloum IM, Thase ME, Moss HB. Fluoxetine versus placebo to decrease the smoking of depressed alcoholic patients [letter]. Journal of Clinical Psychopharmacology 1999;19:183-4.

\section{Covey 2007 \{published data only\}}

Covey LS, Botello-Harbaum M, Glassman AH, Masmela J, LoDuca C, Salzman V, et al. Smokers' response to combination bupropion, nicotine patch, and counseling treatment by race/ ethnicity. Ethnicity \& Disease 2008;18:59-64.

* Covey LS, Glassman AH, Jiang H, Fried J, Masmela J, LoDuca C, et al. A randomized trial of bupropion and/or nicotine gum as maintenance treatment for preventing smoking relapse. Addiction 2007;102:1292-302.

\section{Croghan 2007 \{published data only\}}

Clark MM, Hurt RD, Croghan IT, Patten CA, Novotny P, Sloan JA, et al. The prevalence of weight concerns in a smoking abstinence clinical trial. Addictive Behaviors 2006;31:1144-52.

Croghan IT, Hurt RD, Croghan GA, Sloan JA. Comparing nicotine inhaler, bupropion and nicotine inhaler plus bupropion in treating tobacco dependence [abstract]. Nicotine \& Tobacco Research 2005;7:680-1.

* Croghan IT, Hurt RD, Dakhil SR, Croghan GA, Sloan JA, Novotny PJ, et al. Randomized comparison of a nicotine inhaler and bupropion for smoking cessation and relapse prevention. Mayo Clinic Proceedings 2007;82:186-95.

Croghan IT, Hurt RD, Ebbert JO, Croghan GA, Polk Jr OD, Stella PJ, et al. Racial differences in smoking abstinence rates in a multicenter, randomized, open-label trial in the United States. Journal of Public Health 2010; Vol. 18, issue 1:59-68. []

\section{Cropsey 2015 \{published data only\}}

Cropsey KL, Jardin BF, Burkholder GA, Clark CB, Raper JL, Saag MS. An algorithm approach to determining smoking cessation treatment for persons living with HIV/AIDS: results of a pilot trial. Journal of Acquired Immune Deficiency Syndromes 2015;69(3):291-8.

Dalack 1995 \{published data only\}

Dalack GW, Glassman AH, Rivelli S, Covey LS, Stetner F. Mood, major depression, and fluoxetine response in cigarette smokers. American Journal of Psychiatry 1995;152:398-403.

\section{Dale 2002 \{published data only\}}

Dale LC, Ebbert JO, Schroeder DR, Croghan IT, Rasmussen DF, Trautman JA, et al. Bupropion for the treatment of nicotine dependence in spit tobacco users: a pilot study. Nicotine Tobacco Research 2002;4(3):267-74.

Dale 2007 \{published data only\}

* Dale LC, Ebbert JO, Glover ED, Croghan IT, Schroeder DR, Severson HH, et al. Bupropion SR for the treatment of smokeless tobacco use. Drug \& Alcohol Dependence 2007;90(1):56-63.

Thomas JL, Ebbert JO, Patten CA, Dale LC, Bronars CA, Schroeder DR. Measuring nicotine dependence among smokeless tobacco users. Addictive Behaviors 2006;31(9):1511-21. 
Daniela 2008 \{published data only\}

Daniela I, Carmen C. The combination of sertraline with buspirone for smoking cessation process - The effectiveness and adverse events. Toxicology Letters 2008;180(Suppl 1):S130.

\section{Edwards 1989 \{published data only\}}

* Edwards NB, Murphy JK, Downs AD, Ackerman BJ, Rosenthal TL. Doxepin as an adjunct to smoking cessation: a double-blind pilot study. American Journal of Psychiatry 1989;146(3):373-6.

Murphy JK, Edwards NB, Downs AD, Ackerman BJ, Rosenthal TL. Effects of doxepin on withdrawal symptoms in smoking cessation. American Journal of Psychiatry 1990;147(10):1353-7.

\section{EUCTR2005-006189-32-AT \{published data only\}}

EU Clinical Trials Register. Clinical evaluation study: "Bupropion versus Psychodynamic mental training according to Dr. Grohs for smoke withdrawal" [Klinische Evaluierungsstudie: "Bupropion versus Psychodynamisches Mentaltraining nach Dr. Grohs zur Raucherentwohnung]. who.int/trialsearch/ Trial2.aspx?TrialID=EUCTR2005-006189-32-AT (first received 1 February 2006).

\section{Evins 2008 \{published data only\}}

Evins AE, Alpert JE, Pava J, Petersen TJ, Farabaugh AH, Fava M. A double blind placebo controlled trial of bupropion added to nicotine patch and cognitive behavioral therapy in smokers with current or past unipolar depressive disorder. Neuropsychopharmacology 2005;30 Suppl 1:S91.

* Evins AE, Culhane MA, Alpert JE, Pava J, Liese BS, Farabaugh $A$, et al. A controlled trial of bupropion added to nicotine patch and behavioral therapy for smoking cessation in adults with unipolar depressive disorders. Journal of Clinical Psychopharmacology 2008;28:660-6.

\section{Fatemi 2005 \{published data only\}}

Fatemi SH, Stary JM, Hatsukami DK, Murphy SE. A doubleblind placebo-controlled cross over trial of bupropion in smoking reduction in schizophrenia. Schizophrenia Research 2005;76(2-3):353-6.

\section{Frederick 1997 \{published data only\}}

Frederick SL, Hall SM, Sees KL. The effect of venlafaxine on smoking cessation in subjects with and without a history of depression. NIDA Research Monograph 1997;174:208.

\section{Gawin 1989 \{published data only\}}

Gawin F, Compton M, Byck R. Buspirone reduces smoking [letter]. Archives of General Psychiatry 1989;46(3):288-9.

\section{Gifford 2011 \{published data only\}}

Gifford EV, Kohlenberg BS, Hayes SC, Pierson HM, Piasecki MP, Antonuccio DO, et al. Does acceptance and relationship focused behavior therapy contribute to bupropion outcomes? A randomized controlled trial of functional analytic psychotherapy and acceptance and commitment therapy for smoking cessation. Behavior Therapy 2011; Vol. 42, issue 4:700-15. []
Glover 2002 \{published data only\}

Glover ED, Glover PN, Sullivan CR, Cerullo CL, Hobbs G. A comparison of sustained-release bupropion and placebo for smokeless tobacco cessation. American Journal of Health Behavior 2002;26(5):386-93.

Gold 2002 \{published data only\}

Gold PB, Rubey RN, Harvey RT. Naturalistic, self-assignment comparative trial of bupropion SR, a nicotine patch, or both for smoking cessation treatment in primary care. American Journal of Addiction 2002;11(4):315-31.

\section{Grandi 2011 \{published data only\}}

Grandi S, Shimony A, Eisenberg MJ. The efficacy and safety of bupropion started in-hospital for smoking cessation in patients with cardiovascular disease: A systematic review and meta-analysis. Circulation 2011; Vol. 124, issue 21 Suppl 1. [; 9400123000012459]

\section{Grassi 2009 \{published data only\}}

Grassi MC, Enea D, Ferketich AK, Lu B, Nencini P. A smoking ban in public places increases the efficacy of bupropion and counseling on cessation outcomes at 1 year. Nicotine \& Tobacco Research 2009; Vol. 11, issue 9:1114-21. []

Hall 2009 \{published data only\}

Hall SM, Humfleet GL, Muñoz RF, Reus VI, Robbins JA, Prochaska JJ. Extended treatment of older cigarette smokers. Addiction 2009; Vol. 104, issue 6:1043-52. []

\section{Hall 2011 \{published data only\}}

* Hall SM, Humfleet GL, Munoz RF, Reus VI, Prochaska JJ, Robbins JA. Using extended cognitive behavioral treatment and medication to treat dependent smokers. American Journal of Public Health 2011; Vol. 101, issue 12:2349-56. []

Prochaska JJ, Hall SM, Humfleet G, Munoz RF, Reus V, Gorecki J, et al. Physical activity as a strategy for maintaining tobacco abstinence: a randomized trial. Preventive Medicine 2008; Vol. 47 , issue 2:215-20. []

\section{Hatsukami 2004 \{published data only\}}

* Hatsukami DK, Rennard S, Patel MK, Kotlyar M, Malcolm R, Nides MA, et al. Effects of sustained-release bupropion among persons interested in reducing but not quitting smoking. American Journal of Medicine 2004;116:151-7.

Rennard S, Hatsukami D, Malcolm RE, Patel MK, Jamerson BD, Dozier G. Zyban (bupropion HCL SR) vs placebo as an aid to smoking reduction among smokers unwilling and unable to quit smoking (PO4 77). Society for Research on Nicotine and Tobacco 7th Annual Meeting; 2001 March 23-23; Seattle (WA). 2001:117.

\section{Hawk 2008 \{unpublished data only\}}

Hawk LW, Mahoney MC, Ashare RL, Rhodes JD, Oliver JA, Cummings KM, et al. Preliminary evidence of extinction of smoking behavior with bupropion (PA9-4). Society for Research on Nicotine and Tobacco 14th Annual Meeting; 2008 February 26-March 1; Portland (OR). 2008. 
Hawk 2015 \{published data only\}

Hawk LW Jr, Ashare RL, Rhodes JD, Oliver JA, Cummings KM, Mahoney M. Does extended pre quit bupropion aid in extinguishing smoking behavior?. Nicotine \& Tobacco Research 2015;17(11):1377-84.

\section{Hays 2001 \{published data only\}}

Abel GA, Hays JT, Decker PA, Croghan GA, Kuter DJ, Rigotti NA. Effects of biochemically confirmed smoking cessation on white blood cell count. Mayo Clinical Proceedings 2005;80:1022-8.

Cox LS, Patten CA, Niaura RS, Decker PA, Rigotti N, Sachs DP, et al. Efficacy of bupropion for relapse prevention in smokers with and without a past history of major depression. Journal of General Internal Medicine 2004;19:828-34.

Durcan MJ, Deener G, White J, Johnston JA, Gonzales D, Niaura R, et al. The effect of bupropion sustained-release on cigarette craving after smoking cessation. Clinical Therapeutics 2002;24:540-51.

Durcan MJ, Johnston JA, White J, Gonzales D, Sachs DP, Rigotti N, et al. Bupropion SR for relapse prevention: a "slipsallowed" analysis. American Journal of Health Behavior 2004;28(5):456-63.

Gonzales D, Bjornson W, Durcan MJ, White JD, Johnston JA, Buist AS, et al. Effects of gender on relapse prevention in smokers treated with bupropion SR. American Journal of Preventive Medicine 2002;22:234-39.

* Hays JT, Hurt RD, Rigotti NA, Niaura R, Gonzales D, Durcan MJ, et al. Sustained-release bupropion for pharmacologic relapse prevention after smoking cessation. A randomized, controlled trial. Annals of Internal Medicine 2001;135:423-33.

Hurt RD, Wolter TD, Rigotti N, Hays JT, Niaura R, Durcan MJ, et al. Bupropion for pharmacologic relapse prevention to smoking - Predictors of outcome. Addictive Behaviors 2002;27(4):493-507.

Rigotti N, Thorndike AN, Durcan MJ, White JD, Johnston AJ, Niaura R, et al. Attenuation of post-cessation weight gain in smokers taking bupropion: The effect of gender. Abstract Book. Society for Research on Nicotine and Tobacco 6th Annual Meeting; 2000 Feb 18-20; Arlington (VA). 2000.

\section{Hays 2009 \{published data only\}}

Hays JT, Hurt RD, Decker PA, Croghan IT, Offord KP, Patten CA. A randomized, controlled trial of bupropion sustained-release for preventing tobacco relapse in recovering alcoholics. Nicotine \& Tobacco Research 2009; Vol. 11, issue 7:859-67. []

\section{Hilberink 2005 \{published data only\}}

Hilberink SR, Jacobs JE, Breteler MH, de Vries H, Grol RP. General practice counseling for patients with chronic obstructive pulmonary disease to quit smoking: Impact after 1 year of two complex interventions. Patient Education and Counseling 2011; Vol. 83, issue 1:120-4. []

Hitsman 1999 \{published data only\}

* Hitsman B, Pingitore R, Spring B, Mahableshwarkar A, Mizes JS, Segraves KA, et al. Antidepressant pharmacotherapy helps some cigarette smokers more than others. Journal of Consulting and Clinical Psychiatry 1999;67:547-54.

Hitsman B, Spring B, Borrelli B, Niaura R, Papandonatos G. Adherence to medication versus behavioral therapy as predictors of smoking cessation in combined treatment involving fluoxetine [abstract]. Society for Research on Nicotine and Tobacco Annual Conference; 2000 Feb 18-20; Arlington (VA) 2000.

\section{Houtsmuller 2002 \{published data only\}}

Houtsmuller EJ, Stitzer ML. Selegiline effects on smoking and abstinence [abstract]. CPDD Annual Meeting; 1998 June 12-17; Scottsdale (AZ) 1998.

* Houtsmuller EJ, Thornton JA, Stitzer ML. Effects of selegiline (l-deprenyl) during smoking and short-term abstinence. Psychopharmacology (Berl) 2002;163:213-20.

\section{Hurt 2003 \{published and unpublished data\}}

Hurt RD, Croghan GA, Sloan JA, Krook JE, Silberstein PT. Bupropion for relapse prevention after nicotine patch therapy [PA 5B abstract ]. Society for Research on Nicotine and Tobacco 7th Annual Meeting; 2001 March 23-23; Seattle (WA). 2001:32.

* Hurt RD, Krook JE, Croghan IT, Loprinzi CL, Sloan JA, Novotny PJ, et al. Nicotine patch therapy based on smoking rate followed by bupropion for prevention of relapse to smoking. Journal of Clinical Oncology 2003;21:914-20.

\section{Hussain 2010 \{published data only\}}

Hussain S, Zawertailo L, Busto U, Zack M, Farvolden P, Selby P. The impact of chronic bupropion on plasma cotinine and on the subjective effects of ad lib smoking: a randomized controlled trial in unmotivated smokers. Addictive Behaviors 2010; Vol. 35, issue $2: 164-7$. []

Isgro 2015 \{published data only\}

Isgro M, Doran N, Heffner JL, Bekman N, Wong E, Tibbs J. Type a/type $b$ alcoholism predicts differential response to topiramate in a smoking cessation trial in dually-diagnosed men. Alcoholism: Clinical and Experimental Research 2015;39(Suppl 1):76A

\section{Jacobs 1971 \{published data only\}}

Jacobs MA, Spilken AZ, Norman MM, Wohlberg GW, Knapp PH. Interaction of personality and treatment conditions associated with success in a smoking control program. Psychosomatic Medicine 1971;33(6):545-56

Kalman 2004 \{unpublished data only\}

Kalman D, Engler P, Monti P. Preliminary findings from a pilot treatment study of smokers in early alcohol recovery (POS1-072). Society for Research on Nicotine and Tobacco 10th Annual Meeting; 2004 February 18-21, Phoenix (AZ). 2004.

Khunrong 2016 \{published data only\}

Khunrong P, Sittipunt C. Comparison of efficacy of varenicline and nortriptyline - short-term smoking cessation in outpatient setting. European Respiratory Journal 2016;48(60):4601. 
Killen 2006 \{published data only\}

* Killen JD, Fortmann SP, Murphy GM Jr, Hayward C, Arredondo C, Cromp D, et al. Extended treatment with Bupropion SR for cigarette smoking cessation. Journal of Consulting and Clinical Psychology 2006;74(2):286-94.

Sarginson JE, Killen JD, Lazzeroni LC, Fortmann SP, Ryan HS, Schatzberg AF, et al. Markers in the 15q24 nicotinic receptor subunit gene cluster (CHRNA5-A3-B4) predict severity of nicotine addiction and response to smoking cessation therapy. American Journal of Medical Genetics. Part B, Neuropsychiatric Genetics 2011; Vol. 156, issue 3:275-84. []

\section{Kotz 2009 \{published data only\}}

Kotz D, Wesseling G, Huibers MJ, van Schayck OC. Efficacy of confrontational counselling for smoking cessation in smokers with previously undiagnosed mild to moderate airflow limitation: study protocol of a randomized controlled trial. BMC Public Health 2007;7:332.

* Kotz D, Wesseling G, Huibers MJ, van Schayck OC. Efficacy of confronting smokers with airflow limitation for smoking cessation. European Respiratory Journal 2009;33:754-62.

\section{Kras 2010 \{published data only\}}

Kras M, Stough C, Scholey A, Kure C, Camfield D. Hypericum perforatum, nicotine patches and combination hypericum perforatum/nicotine patches for smoking cessation. European Neuropsychopharmacology 2010; Vol. 20:S608-9. []

\section{Lawvere 2006 \{published data only\}}

Lawvere S, Mahoney MC, Cummings KM, Hyland AJ. St John's Wort for smoking cessation: twelve months post cessation. Society for Research on Nicotine and Tobacco 11th Annual Meeting; 2005 March 20-23; Prague, Czech Republic. 2005.

* Lawvere S, Mahoney MC, Cummings KM, Kepner JL, Hyland A, Lawrence DD, et al. A Phase II study of St. John's Wort for smoking cessation. Complementary Therapies in Medicine 2006;14(3):175-84.

\section{Li 2009 \{published data only\}}

Li J, Zhang T, Wang B, Li X. An efficacy analysis of bupropion for smoking cessation in schizophrenia. Zhongguo Xinyao $\mathrm{Yu}$ Linchuang Zazhi [Chinese Journal of New Drugs and Clinical Remedies] 2009; Vol. 28, issue 3:231-4. []

\section{Miller 2003 \{published data only\}}

Miller H, Ranger-Moore J, Hingten M. Bupropion SR for smoking cessation in pregnancy: a pilot study [abstract]. American Journal of Obstetrics and Gynecology 2003;189(6):S133.

\section{Monuteaux 2007 \{published data only\}}

Monuteaux MC, Spencer TJ, Faraone SV, Wilson AM, Biederman J. A randomized, placebo-controlled clinical trial of bupropion for the prevention of smoking in children and adolescents with attention-deficit/hyperactivity disorder. Journal of Clinical Psychiatry 2007;68(7):1094-101.

\footnotetext{
Mooney 2008 \{published data only\}

* Mooney ME, Poling J, Gonzalez G, Gonsai K, Kosten T, Sofuoglu M. Preliminary study of buprenorphine and bupropion
}

for opioid-dependent smokers. American Journal on Addictions 2008;17(4):287-92.

Sofuoglu M, Mooney M, Gonzalez G, Gonsai K, Poling J, Kosten T. Buprenorphine and bupropion combination for opioiddependent smokers. 68th Annual Scientific Meeting of the College on Problems of Drug Dependence; 2006 June 17-22; Scottsdale (AZ). 2006.

\section{Mooney 2016 \{published data only\}}

Mooney ME, Schmitz JM, Allen S, Grabowski J, Pentel P, Oliver A. Bupropion and naltrexone for smoking cessation: a doubleblind randomized placebo-controlled clinical trial. Clinical Pharmacology and Therapeutics 2016;100(4):344-52.

\section{Naranjo 1990 \{published data only\}}

Naranjo CA, Kadlec KE, Sanhueza P, Woodley Remus D, Sellers EM. Fluoxetine differentially alters alcohol intake and other consummatory behaviors in problem drinkers. Clinical Pharmacology and Therapeutics 1990;47:490-8.

\section{NCT00032084 \{published data only\}}

NCT00032084. S0002 - a program to quit smoking with or without bupropion in treating patients with stage I or II non-small cell lung cancer who have undergone surgery. clinicaltrials.gov/show/NCT00032084 (first received 27 January 2003).

NCT00119210 \{published data only\}

NCT00119210. Pilot study of bupropion for smoking cessation in postpartum non-breastfeeding women. clinicaltrials.gov/show/ NCT00119210 (accessed 13 July 2005).

\section{NCT00136747 \{published data only\}}

NCT00136747. The effects of memantine and bupropion on acute, reinforcing, and conditioned effects of cigarettes - 1 . clinicaltrials.gov/show/NCT00136747 (accessed 29 August 2005).

\section{NCT00136786 \{published data only\}}

NCT00136786. Effect of memantine versus bupropion on smoking relapse in nicotine-dependent individuals - 3 . clinicaltrials.gov/show/NCT00136786 (first received 29 August 2005).

\section{NCT00158171 \{published data only\}}

NCT00158171. Effectiveness of various smoking cessation therapies in reducing smoking in adolescents - 1 . clinicaltrials.gov/show/NCT00158171 (first received 29 August 2005).

\section{NCT00248118 \{published data only\}}

NCT00248118. Efficacy and safety of bupropion for treatment of adolescent smoking. clinicaltrials.gov/ct2/show/NCT00248118 (first received 3 November 2005).

\section{NCT00320697 \{published data only\}}

NCT00320697. Smoking relapse prevention in schizophrenia. clinicaltrials.gov/show/NCT00320697 (first received 3 May 2006). 
NCT00390923 \{published data only (unpublished sought but not used)\}

NCT00390923. Testing a full substitution therapy approach as treatment of tobacco dependence. clinicaltrials.gov/ct2/show/ NCT00390923 (first received 23 October 2006).

NCT00484692 \{published data only\}

NCT00484692. Randomized trial of ultrashort psychotherapy vs sustained-release bupropion for smoking cessation. clinicaltrials.gov/show/NCT00484692 (first received 3 May 2006).

\section{NCT00580853 \{published data only\}}

NCT00580853. The effect of varenicline (Chantix) and bupropion (Zyban) on smoking lapse behavior. clinicaltrials.gov/show/ nct00580853 (first received 27 December 2007).

NCT00670904 \{published data only\}

NCT00670904. Randomized trial assessing the effectiveness of a pharmacist-delivered program for smoking cessation. clinicaltrials.gov/show/NCT00670904 (first received 2 May 2008).

NCT00936299 \{published data only\}

* NCT00936299. Bupropion for ADHD in adolescents with substance use disorder. clinicaltrials.gov/ct2/show/ NCT00936299 (first received 10 July 2009).

NCT01850589 \{published data only\}

NCT01850589. Comparison of conservative and aggressive smoking cessation treatment strategies in a vascular surgery office practice. clinicaltrials.gov/show/NCT01850589 (first received 10 July 2009).

NCT01965405 \{published data only\}

NCT01965405. Smoking cessation for people living with HIV/ AIDS. clinicaltrials.gov/show/nct01965405 (first received 18 October 2013).

\section{NCT02736474 \{published data only\}}

NCT02736474. Naltrexone and bupropion combination on obese, smoking patients with schizophrenia. clinicaltrials.gov/ show/NCT02736474 (first received 13 April 2016).

NCT03471767 \{published data only\}

NCT03471767. AXS-05 phase II trial on smoking behavior. clinicaltrials.gov/show/NCT03471767 (first received 21 March 2018)

\section{NCT03920319 \{published data only\}}

NCT03920319. Bupropion and cigarette-related cues in smokers. clinicaltrials.gov/show/nct03920319 (first received 18 April 2019).

\section{Neumann 2000 \{published and unpublished data\}}

Neumann JK, Peeples B, East J, Ellis AR. Nicotine reduction: effectiveness of bupropion. British Journal of Psychiatry 2000;177:87-8

\section{Neumann 2002 \{published data only\}}

Neumann JK, Peeples B, Seneker A. Nicotine reduction and bupropion. Chest 2002;121:1378.

\section{Niederhofer 2004 \{published data only\}}

* Niederhofer H, Huber M. Bupropion may support psychosocial treatment of nicotine-dependent adolescents: preliminary results. Pharmacotherapy 2004;24(11):1524-8.

\section{Olmstead 1999 \{published data only\}}

Olmstead R, Kelly J, Chin C, Iwamoto-Schaap PN, Madsen DC, Huerta L, et al. Combined bupropion and mecamylamine treatment for smoking cessation: a pilot trial. Society for Research on Nicotine and Tobacco Fifth Annual Meeting; 1999 March 5-7; San Diego (CA). 1999.

Paluck 2006 \{published data only\} Paluck EC, McCormack JP, Ensom MH, Levine M, Soon JA, Fielding DW. Outcomes of bupropion therapy for smoking cessation during routine clinical use. Annals of Pharmacotherapy 2996;40(2):185-90.

Pomerleau 1991 \{published data only\}

Pomerleau OF, Pomerleau CS, Morrell EM, Lowenbergh JM. Effects of fluoxetine on weight gain and food intake in smokers who reduce nicotine intake. Psychoneuroendocrinology 1991; 16:433-40.

\section{Raynor 2005 \{published data only\}}

Raynor DA. Adherence to pharmacological smoking cessation treatment among weight-concerned women. Dissertation Abstracts International: Section B: The Sciences and Engineering 2005;65(8-B):4301.

Robinson 1991 \{published data only\}

Robinson MD, Smith WA, Cederstrom EA, Sutherland DE. Buspirone effect on tobacco withdrawal symptoms: a pilot study. Journal of the American Board of Family Practice 1991;4(2):89-94.

Rovina 2003 \{unpublished data only\}

Gratziou C, Rovina N, Athanassa Z, Francis K, Evangelou E, Chiotis D, et al. Evaluation of prolonged bupropion treatment as an aid in smoking cessation [abstract]. European Respiratory Journal 2002;20 Suppl 38:611s.

Rovina N, Gratziou C, Nikoloutsou I, Athanassa Z, Francis K, Roussos C. Ideal duration of therapy with bupropion $\mathrm{HCL}$ : Comparison between short and long treatment. Abstract book: Society for Research on Nicotine and Tobacco 5th European Meeting; 2003 November 20-22; Padua. 2003.

Rovina N, Gratziou C, Nikoloutsou I, Athanassa Z, Francis K, Roussos C. Short or prolonged treatment with bupropion $\mathrm{HCL}$ in smoking cessation therapy. European Respiratory Journal 2003;22 Suppl 45:165s.

\section{Schepis 2006 \{unpublished data only\}}

Schepis TS, Warren KA, Rao U. Evaluation of a cognitivebehavioral smoking cessation treatment for adolescents and young adults (POS2-53). Society for Research on Nicotine and Tobacco 12th Annual Meeting; 2006 February 15-18; Orlando (FL). 2006. 
Sellers 1987 \{published data only\}

Sellers EM, Naranjo CA, Kadlec K. Do serotonin uptake inhibitors decrease smoking? Observations in a group of heavy drinkers. Journal of Clinical Psychopharmacology 1987;7:417-20.

\section{Sherman 2008 \{published data only\}}

Sherman SE, Aldana I, Estrada M, York L. Comparing the tolerability and effectiveness of two treatment regimens in a smoking clinic. Military Medicine 2008;173(6):550-4.

\section{Shiffman 2000 \{published data only\}}

Shiffman S, Johnston JA, Khayrallah M, Elash CA, Gwaltney CJ, Paty JA, et al. The effect of bupropion on nicotine craving and withdrawal. Psychopharmacology 2000;148:33-40.

\section{Shoptaw 2008 \{published data only\}}

Shoptaw S, Heinzerling KG, Rotheram-Fuller E, Steward T, Wang J, Swanson AN, et al. Randomized, placebo-controlled trial of bupropion for the treatment of methamphetamine dependence. Drug and Alcohol Dependence 2008;96(3):222-32.

\section{Sittipunt 2007 \{published data only\}}

Sittipunt C, Kawkitinarong K, Wongtim S, Udompanich V. The effectiveness of nortriptyline plus brief motivation counseling for the treatment of smoking cessation in Thai active smokers [Abstract]. Respirology 2007;12(Suppl 4):A223.

\section{Sonntag 2003 \{published data only\}}

Hoch E, Wittchen HU. Population health perspective on smoking cessation: A randomized controlled trial of different methods in primary health care (RPOS 3-71). Society for Research on Nicotine and Tobacco 12th Annual Meeting; 2006 February 15-18; Orlando (FL). 2006.

Sonntag H, Hoch E, Jahn B, Spiegel B, Pfister H, Wittchen HU. Smoking cessation in primary care: implementation effectiveness and optimized allocation. Suchtmedizin in Forschung und Praxis 2003;5:137-41.

\section{Spring 1995 \{published data only\}}

Spring B, Wurtman J, Wurtman R, el Khoury A, Goldberg H, McDermott J, et al. Efficacies of dexfenfluramine and fluoxetine in preventing weight gain after smoking cessation. American Journal of Clinical Nutrition 1995;62(6):1181-7.

\section{Stein 1993 \{published data only\}}

Stein RA, Jarvik ME, Gorelick DA. Impairment of memory by fluoxetine in smokers. Experimental and Clinical Psychopharmacology 1993;1:188-93.

\section{Steinberg 2009 \{published data only\}}

Steinberg MB, Greenhaus S, Schmelzer AC, Bover MT, Foulds J, Hoover DR, et al. Triple-combination pharmacotherapy for medically ill smokers: a randomized trial. Annals of Internal Medicine 2009;150(7):447-54.

\section{Strayer 2004 \{unpublished data only\}}

Strayer SM, Flusche A, Hodge J, Martindale JR. Effectiveness trial of Zyban for smoking cessation in the outpatient setting (POS1-044). Abstract Book. Society for Research on Nicotine and
Tobacco 10th Annual Meeting; 2004 February 18-21; Phoenix (AZ). 2004:45.

Swanson 2003 \{published data only\}

Swanson NA, Burroughs CC, Long MA, Lee RW. Controlled trial for smoking cessation in a Navy shipboard population using nicotine patch, sustained-release bupropion, or both. Military Medicine 2003;168:830-4.

Tidey 2009 \{published data only\}

Tidey JW, Rohsenow DJ. Intention to quit moderates the effect of bupropion on smoking urge. Nicotine \& Tobacco Research 2009;11(3):308-12.

\section{Toll 2007 \{published data only\}}

Jatlow P, Toll BA, Leary V, Krishnan-Sarin S, O'Malley SS. Comparison of expired carbon monoxide and plasma cotinine as markers of cigarette abstinence. Drug and Alcohol Dependence 2008;98(3):203-9.

Leeman RF, Mckee SA, Toll BA, Krishnan-Sarin S, Cooney JL, Makuch RW, et al. Risk factors for treatment failure in smokers: Relationship to alcohol use and to lifetime history of an alcohol use disorder. Nicotine \& Tobacco Research 2008;10(12):1793-809.

* Toll BA, O'Malley SS, Katulak NA, Wu R, Dubin JA, Latimer A, et al. Comparing gain- and loss-framed messages for smoking cessation with sustained-release bupropion: a randomized controlled trial. Psychology of Addictive Behaviors 2007;21(4):534-44

Toll BA, Salovey P, O'Malley SS, Mazure CM, Latimer A, Mckee SA. Message framing for smoking cessation: the interaction of risk perceptions and gender. Nicotine \& Tobacco Research 2008;10(1):195-200.

\section{Weinberger 2008 \{published data only\}}

Weinberger AH, Vessicchio JC, Sacco KA, Creeden CL, Chengappa KN, George TP. A preliminary study of sustainedrelease bupropion for smoking cessation in bipolar disorder. Journal of Clinical Psychopharmacology 2008;28(5):584-7.

\section{Weiner 2001 \{published data only\}}

Weiner E, Ball MP, Summerfelt A, Gold J, Buchanan RW. Effects of sustained-release bupropion and supportive group therapy on cigarette consumption in patients with schizophrenia. American Journal of Psychiatry 2001;158(4):635-7.

\section{Winhusen 2012 \{published data only\}}

Winhusen T, Stitzer M, Woody G, Brigham G, Kropp F, Ghitza U, et al. Design considerations for a study to evaluate the impact of smoking cessation treatment on stimulant use outcomes in stimulant-dependent individuals. Contemporary Clinical Trials 2012;33(1):197-205.

\section{Zernig 2008 \{published data only\}}

Zernig G, Wallner R, Grohs U, Kriechbaum N, Kemmler G, Saria A. A randomized trial of short psychotherapy versus sustained-release bupropion for smoking cessation. Addiction 2008;103(12):2024-31. 


\section{ZYB30011 \{unpublished data only\}}

ZYB 30011. A multicentre, randomised, double- blind, placebo controlled study to evaluate the efficacy and tolerability of bupropion hydrochloride (SR) sustained release $(2 \times 150 \mathrm{mg}$ per day) versus placebo as an aid to smoking cessation in smokers with at least one cardiovascular (CV) risk factor. gskstudyregister.com/en/trial-details/?id=ZYB\%2030011 (accessed 4 August 2009).

\section{References to ongoing studies}

NCT03326128 \{published data only\}

NCT03326128. High dose bupropion for smoking cessation. clinicaltrials.gov/ct2/show/NCT03326128 (first received 31 October 2017).

\section{NCT03342027 \{published data only\}}

NCT03342027. Smoking cessation interventions for people living with HIV in Nairobi, Kenya. clinicaltrials.gov/ct2/show/ NCT03342027 (first received 14 November 2017).

\section{Zawertailo 2018 \{published data only\}}

NCT02146911. The MATCH (Medication Aids for Tobacco Cessation and Health) Study. clinicaltrials.gov/ct2/show/ NCT02146911 (first received 26 May 2014).

* Zawertailo L, Mansoursadeghi-Gilan T, Zhang H, Hussain S, Le Foll B, Selby P. Varenicline and bupropion for long-term smoking cessation (the MATCH Study): protocol for a real-world, pragmatic, randomized controlled trial. JMIR Research Protocols 2018;7(10):e10826.

\section{Additional references}

\section{Aubin 2012}

HJ Aubin. Tolerability and safety of sustained-release bupropion in the management of smoking cessation. Drugs 2002;62:45-52.

\section{Benowitz 2000}

Benowitz NL, Peng MW. Non-nicotine pharmacotherapy for smoking cessation. CNS Drugs 2000;13:265-85.

\section{Cahill 2013}

Cahill K, Stevens S, Perera R, Lancaster T. Pharmacological interventions for smoking cessation: an overview and network meta-analysis. Cochrane Database of Systematic Reviews 2013, Issue 5. [DOI: 10.1002/14651858.CD009329.pub2]

\section{Cahill 2016}

Cahill K, Lindson-Hawley N, Thomas KH, Fanshawe TR, Lancaster T. Nicotine receptor partial agonists for smoking cessation. Cochrane Database of Systematic Reviews 2016, Issue 5. [DOI: 10.1002/14651858.CD006103.pub7]

\section{CDC 2017}

Centers for Disease Control and Prevention. Quitting Smoking Among Adults-United States, 2000-2015. Morbidity and Mortality Weekly Report 2017;52:1457-64.

\section{Coleman 2015}

Coleman T, Chamberlain C, Davey MA, Cooper SE, Leonardi-Bee J. Pharmacological interventions for promoting smoking cessation during pregnancy. Cochrane Database of Systematic Reviews 2015, Issue 12. [DOI: 10.1002/14651858.CD010078.pub2]

\section{Cryan 2003}

Cryan JF, Bruijnzeel AW, Skjei KL, Markou A. Bupropion enhances brain reward function and reverses the affective and somatic aspects of nicotine withdrawal in the rat. Psychopharmacology 2003;168:347-58.

\section{Ebbert 2011}

Ebbert J, Montori VM, Erwin PJ, Stead LF. Interventions for smokeless tobacco use cessation. Cochrane Database of Systematic Reviews 2011, Issue 2. [DOI: 10.1002/14651858.CD004306.pub4]

\section{Fiore 2008}

Fiore MC, Jaén CR, Baker TB, et al. Treating Tobacco Use and Dependence: 2008 Update. Clinical Practice Guideline. AHRQ publication No. 00-0032. Rockville, MD: US Dept of Health and Human Services. Public Health Services, 2008.

\section{Fryer 1999}

Fryer JD, Lukas RJ. Noncompetitive functional inhibition at diverse, human nicotinic acetylcholine receptor subtypes by bupropion, phencyclidine, and ibogaine. Journal of Pharmacology and Experimental Therapeutics 1999;288:88-92.

\section{GBD RFC 2017}

GBD 2017 Risk Factors Collaborators. Global, regional, and national comparative risk assessment of 84 behavioural, environmental and occupational, and metabolic risks or clusters of risks for 195 countries and territories, 19902017: a systematic analysis for the Global Burden of Disease Study 2017. Lancet 2018;392(10159):1923-94. [DOI: 10.1016/ S0140-6736(18)32225-6]

\section{GRADEpro GDT [Computer program]}

McMaster University (developed by Evidence Prime). GRADEpro GDT. Version accessed 13 January 2020. Hamilton (ON): McMaster University (developed by Evidence Prime).

\section{Hartmann-Boyce 2018}

Hartmann-Boyce J, Chepkin SC, Ye W, Bullen C, Lancaster T. Nicotine replacement therapy versus control for smoking cessation. Cochrane Database of Systematic Reviews 2018, Issue 5. [DOI: 10.1002/14651858.CD000146.pub5]

\section{Higgins 2003}

Higgins JP, Thompson SG, Deeks JJ, Altman DG. Measuring inconsistency in meta-analysis. BMJ 2003;327:557-60.

\section{Higgins 2011}

Higgins JP, Green S, editor(s). Cochrane Handbook for Systematic Reviews of Interventions Version 5.1.0 (updated March 2011). The Cochrane Collaboration, 2011. Available from handbook.cochrane.org. 


\section{Higgins 2019}

Higgins JP, Thomas J, Chandler J, Cumpston M, Li T, Page MJ, et al. editor(s). Cochrane Handbook for Systematic Reviews of Interventions Version 6.0 (updated July 2019). The Cochrane Collaboration, 2019. Available from www.training.cochrane.org/ handbook. Cochrane, 2019.

\section{Hughes 2005}

Hughes JR, Stead LF, Lancaster T. Nortriptyline for smoking cessation: A review. Nicotine \& Tobacco Research 2005; 7:491-9.

\section{Jha 2011}

Jha P. Avoidable deaths from smoking: a global perspective. Public Health Reviews 2011;33(2):569-600.

\section{Kotlyar 2001}

Kotlyar M, Golding M, Hatsukami DK, Jamerson BD. Effect of nonnicotine pharmacotherapy on smoking behavior. Pharmacotherapy 2001;21:1530-48.

\section{Lerman 2002a}

Lerman C, Roth D, Kaufmann V, Audrain J, Hawk L, Liu AY, et al. Mediating mechanisms for the impact of bupropion in smoking cessation treatment. Drug and Alcohol Dependence 2002;67:219-23.

\section{Lewis 2007}

A Lewis, JH Miller, RA Lea. Monoamine oxidase and tobacco dependence. NeuroToxicology 2007;28(1):182-95.

\section{Lindson-Hawley 2016}

Lindson-Hawley N, Hartmann-Boyce J, Fanshawe TR, Begh R, Farley A, Lancaster T. Interventions to reduce harm from continued tobacco use. Cochrane Database of Systematic Reviews 2016, Issue 10. [DOI: 10.1002/14651858.CD005231.pub3]

\section{Livingstone-Banks 2019}

Livingstone-Banks J, Norris E, Hartmann-Boyce J, West R, Jarvis M, Chubb E, et al. Relapse prevention interventions for smoking cessation. Cochrane Database of Systematic Reviews 2019, Issue 10. [DOI: 10.1002/14651858.CD003999.pub6]

\section{McNeill 2017}

McNeill A, Robson D. A man before his time: Russell's insights into nicotine, smoking, treatment and curbing the smoking problem. Addiction 2017;113(4):759-63. [DOI: 10.1111/ add.14043]

\section{McRobbie 2005}

McRobbie H, Lee M, Juniper Z. Non-nicotine pharmacotherapies for smoking cessation. Respiratory Medicine 2005;99:1202-12.

\section{Mills 2006}

Mills EJ, Wu P, Lockhart I, Thorlund K, Puhan M, Ebbert JO. Comparisons of high-dose and combination nicotine replacement therapy, varenicline, and bupropion for smoking cessation: a systematic review and multiple treatment meta-analysis. Annals of Medicine 2012;44(6):588-97. [DOI: 10.3109/07853890.2012.705016]

\section{Moher 2009}

Moher D, Liberati A, Tetzlaff J, Altman DG. Preferred reporting items for systematic reviews and meta-analyses: the PRISMA statement. Annals of Internal Medicine 2009;151(4):264-9. [DOI: 10.7326/0003-4819-151-4-200908180-00135]

\section{Schünemann 2013}

Schünemann H, Brożek J, Guyatt G, Oxman A, editor(s). Handbook for grading the quality of evidence and the strength of recommendations using the GRADE approach (updated October 2013). GRADE Working Group, 2013. Available from gdt.guidelinedevelopment.org/app/handbook/handbook.html.

\section{Taylor 2014}

Taylor G, McNeill A, Girling A, Farley A, Lindson-Hawley N, Aveyard $P$. Change in mental health after smoking cessation: systematic review and meta-analysis. BMJ 2014;348:g1151. [DOI: 10.1136/bmj.g1151]

\section{Tsoi 2010}

Tsoi DT, Porwal M, Webster AC. Efficacy and safety of bupropion for smoking cessation and reduction in schizophrenia: systematic review and meta-analysis. British Journal of Psychiatry 2010;196(5):346-53. [DOI: 10.1192/ bjp.bp.109.066019]

\section{van der Meer 2013}

van der Meer RM, Willemsen MC, Smit F, Cuijpers P. Smoking cessation interventions for smokers with current or past depression. Cochrane Database of Systematic Reviews 2013, Issue 8. [DOI: 10.1002/14651858.CD006102.pub2]

\section{West 2005}

West R, Hajek P, Stead L, Stapleton J. Outcome criteria in smoking cessation trials: proposal for a common standard. Addiction 2005;100(3):299-303. [DOI: 10.1111/ j.1360-0443.2004.00995.x]

\section{West 2008}

West R, Baker CL, Cappelleri JC, Bushmakin AG. Effect of varenicline and bupropion SR on craving, nicotine withdrawal symptoms, and rewarding effects of smoking during a quit attempt. Psychopharmacology 2008;197(3):371-7.

\section{West 2018}

West R, Evins AE, Benowitz NL, Russ C, McRae T, Lawrence D, et al. Factors associated with the efficacy of smoking cessation treatments and predictors of smoking abstinence in EAGLES. Addiction 2018;113(8):1507-16.

\section{Wightman 2010}

Wightman DS, Foster VJ, Krishen A, Richard NE, Modell JG. Meta-analysis of suicidality in placebo-controlled clinical trials of adults taking bupropion. Primary Care Companion to the Journal of Clinical Psychiatry 2010;12(5):e1-8. []

\section{Wilkes 2005}

Wilkes S, Evans A, Henderson M, Gibson J. Pragmatic, observational study of bupropion treatment for smoking cessation in general practice. Postgraduate Medical Journal 2005;81:719-22. 


\section{References to other published versions of this review}

Hughes 1994

Hughes JR. Non-nicotine pharmacotherapies for smoking cessation. Journal of Drug Development 1994;6:197-203.

\section{Hughes 2000}

Hughes JR, Stead LF, Lancaster T. Anxiolytics and antidepressants for smoking cessation. Cochrane Database of Systematic Reviews 2000, Issue 4.

\section{Hughes 2002}

Hughes JR, Stead LF, Lancaster T. Antidepressants for smoking cessation. Cochrane Database of Systematic Reviews 2002, Issue 1.

\section{Hughes 2003}

Hughes JR, Stead LF, Lancaster T. Antidepressants for smoking cessation. Cochrane Database of Systematic Reviews 2003, Issue 2. [DOI: 10.1002/14651858.CD000031]

\section{CHARACTERISTICS OF STUDIES}

Characteristics of included studies [ordered by study ID]

\section{Hughes 2004}

Hughes J, Stead L, Lancaster T. Antidepressants for smoking cessation. Cochrane Database of Systematic Reviews 2004, Issue 4. [DOI: 10.1002/14651858.CD000031.pub2]

\section{Hughes 2007a}

Hughes JR, Stead LF, Lancaster T. Antidepressants for smoking cessation. Cochrane Database of Systematic Reviews 2007, Issue 1. [DOI: 10.1002/14651858.CD000031.pub3]

\section{Hughes 2014}

Hughes JR, Stead LF, Hartmann-Boyce J, Cahill K, Lancaster T. Antidepressants for smoking cessation. Cochrane Database of Systematic Reviews 2014, Issue 1. [DOI: 10.1002/14651858.CD000031.pub4]

* Indicates the major publication for the study

Ahluwalia 2002

\begin{tabular}{|c|c|}
\hline Methods & $\begin{array}{l}\text { Study design: RCT } \\
\text { Country: USA } \\
\text { Setting: community-based healthcare centre } \\
\text { Recruitment method: community volunteers }\end{array}$ \\
\hline Participants & $\begin{array}{l}600 \text { African American smokers randomized; } 70 \% \text { female, average age } 44 \text {; average cigarettes per day } 17 \text {; } \\
27 \% \text { had possible clinical depression CES-D }>16\end{array}$ \\
\hline Interventions & $\begin{array}{l}\text { - Bupropion, } 300 \mathrm{mg} / \text { day for } 7 \text { weeks } \\
\text { - Placebo } \\
\text { Common components: } 8 \text { sessions of in-person or telephone counselling and self-help guide }\end{array}$ \\
\hline Outcomes & $\begin{array}{l}\text { - Smoking cessation: prolonged absinence at } 26 \text { weeks. Validated by } \mathrm{CO} \leq 10 \mathrm{ppm} \text {, discrepancies re- } \\
\text { solved with cotinine } \leq 20 \mathrm{mg} \\
\text { - Adverse events: measured for } 26 \text { weeks }\end{array}$ \\
\hline Funding Source & National Cancer Institute. GlaxoSmithKline provided study medication. \\
\hline Author conflicts of interest & $\begin{array}{l}\text { Dr Ahluwalia has served as a consultant for GlaxoSmith2Kline and Pharmacia Consumer. Glax- } \\
\text { onSmithKline provided study medication but played no role in the design, conduct of the study, or in- } \\
\text { terpretation and analysis of the data. }\end{array}$ \\
\hline Notes & Continuous abstinence rates shown in Figure 3 of paper. Figures obtained from authors \\
\hline \multicolumn{2}{|l|}{ Risk of bias } \\
\hline Bias & Support for judgement \\
\hline
\end{tabular}


Ahluwalia 2002 (Continued)

Random sequence genera- Low risk Quote: "Randomization codes were generated in blocks of 50 and sent to the tion (selection bias) pharmaceutical company..."

\begin{tabular}{lll}
\hline $\begin{array}{l}\text { Allocation concealment } \\
\text { (selection bias) }\end{array}$ & Low risk & $\begin{array}{l}\text { Quote: "... [the pharmaceutical company]... packaged the treatment and then } \\
\text { shipped the blinded drug to the investigator." Shows blinded drugs were pro- } \\
\text { vided to investigator }\end{array}$ \\
\hline $\begin{array}{l}\text { Blinding (performance } \\
\text { bias and detection bias) } \\
\text { All outcomes }\end{array}$ & Low risk & $\begin{array}{l}\text { Quote: "Blinding was successful. At the end of treatment, 58\% (150/259) of } \\
\text { participants correctly guessed that they received bupropion SR [sustained re- } \\
\text { lease], and 41\% (104/253) correctly guessed they received placebo." }\end{array}$ \\
\hline
\end{tabular}

Incomplete outcome data Low risk Approximately $32 \%$ lost to follow-up in each group; included as smokers (attrition bias)

All outcomes

Anthenelli 2016

Methods
Study design: RCT
Countries: USA, Australia, Canada, Denmark, Finland, Germany, New Zealand, South Africa, Spain, Bul-
garia, Russian Federation, Slovakia, Argentina, Brazil, Chile, and Mexico
Setting: clinical trial centres, academic centres, and outpatient clinics treating patients with and with-
out psychiatric disorders
Recruitment method: from the investigators' own clinics; through newspaper, radio, and television ad-
vertising; fliers and posters
8144 participants; 56\% female; average age 46.5; average cigarettes per day 21, mean FTND 5.8
Specialist population: participants were made up of two cohorts (a psychiatric cohort (N = 4074) and
a non-psychiatric cohort (N = 3984)). Participants were included in the psychiatric cohort if they met
Diagnostic and Statistical Manual of Mental Disorders, Fourth Edition, Text Revision (DSM-IV-TR) diag-
nostic criteria for mood disorders including major depressive disorder or bipolar disorder; anxiety dis-
orders including panic disorder, with or without agoraphobia, post-traumatic stress disorder, obses-
sive-compulsive disorder, social phobia, and generalized anxiety disorder; psychotic disorders includ-
ing schizophrenia and schizoaffective disorders; or borderline personality disorder. Participants in the
non-psychiatric cohort had no confirmed history of DSM-IV-TR Axis I or II disorders.

\begin{tabular}{ll}
\hline Interventions & Bupropion sustained release and placebo varenicline and placebo nicotine patch. $150 \mathrm{mg}$ twice a day \\
for 12 weeks \\
- Varenicline and placebo bupropion sustained release and placebo nicotine patch. $1 \mathrm{mg}$ twice a day \\
for 12 weeks \\
- Transdermal nicotine patch and placebo varenicline and placebo bupropion sustained release. $21 \mathrm{mg}$ \\
per day with taper for 12 weeks \\
- Placebo bupropion sustained release and placebo varenicline and placebo nicotine patch. For 12 \\
weeks. \\
Common components: smoking cessation counselling consisting of 10 minute sessions at each of the \\
15 clinic visits, totalling 2 hours and 30 minutes
\end{tabular}


Anthenelli 2016 (Continued)

Author conflicts of interest
RMA reports receiving grants from Pfizer and Alkermes, and providing consulting and advisory board services to Pfizer, Arena Pharmaceuticals, and Cerecor. RMA's writing of this manuscript was supported, in part, by National Institute on Alcohol Abuse and Alcoholism grant numbers U01 AA013641 and R01 AA019720; National Institute on Drug Abuse/Veterans Affairs Co-operative Studies numbers 1031 and 1032; and Veterans Affairs Merit Award number NEUA-003-08S. NLB reports providing consulting and advisory board services to Pfizer and GlaxoSmithKline, and having been a paid expert witness in litigation against tobacco companies. RW reports receiving grants from Pfizer, Johnson \& Johnson, and GlaxoSmithKline, and receiving personal fees for advisory board services from Pfizer and GlaxoSmithKline. RW's salary is funded by Cancer Research UK. AEE reports receiving grants from Pfizer and Forum Pharmaceuticals, and receiving personal fees for advisory board services from Pfizer and Reckitt Benckiser. AEE's writing of the manuscript was supported by a National Institute on Drug Abuse Career Award in Patient-Oriented Research, number K24 DA030443. LSA, TM, DL, and CR are employees and stockholders of Pfizer. JA is an employee of GlaxoSmithKline and stockholder of that company. AK is a PAREXEL employee working on behalf of GlaxoSmithKline.

Notes

\section{Risk of bias}

\begin{tabular}{lll}
\hline Bias & Authors' judgement & Support for judgement \\
\hline $\begin{array}{l}\text { Random sequence genera- } \\
\text { tion (selection bias) }\end{array}$ & Low risk & $\begin{array}{l}\text { Quote: "A randomisation administrator, independent from the clinical study } \\
\text { team, prepared the computer-generated randomisation schedule used to as- } \\
\end{array}$ \\
& & $\begin{array}{l}\text { sign participants to treatment using a block size of } 8(1: 1: 1: 1 \text { ratio) for each of } \\
\text { the 20 diagnosis by region combinations." }\end{array}$ \\
&
\end{tabular}

Allocation concealment Low risk Quote: "Investigators obtained participant identification numbers via a web(selection bias) based or telephone call-in drug management system. Study product kit codes did not allow deciphering of randomised treatment or block size. As such, participants, investigators, and research personnel were masked to treatment assignments."

$\begin{array}{ll}\text { Blinding (performance } & \text { Quote: "The triple dummy design feature required participants to take study } \\ \text { bias and detection bias) } & \text { medications as masked tablets dispensed in separate varenicline and bupropi- } \\ \text { All outcomes } & \text { on pill bottles each with matching placebo along with either applying active or } \\ & \text { placebo patches on a daily basis." } \\ & \text { Quote: "Investigators obtained participant identification numbers via a web- } \\ \text { based or telephone call-in drug management system. Study product kit codes } \\ \text { did not allow deciphering of randomised treatment or block size. As such, par- } \\ \text { ticipants, investigators, and research personnel were masked to treatment as- } \\ \text { signments." }\end{array}$

Incomplete outcome data Low risk
(attrition bias)

$439 / 2037$ (21.6\%) of the varenicline group, $448 / 2034$ (22.0\%) of the bupropion All outcomes group, $481 / 2038(23.6 \%)$ of the patch group and $483 / 2035(23.7 \%)$ of the placebo group were lost to follow-up. Therefore, loss to follow-up was less than $50 \%$ and similar across study arms.

Aubin 2004

\begin{tabular}{ll}
\hline Methods & $\begin{array}{l}\text { Study design: RCT } \\
\text { Country: France } \\
\text { Setting: } 74 \text { cessation outpatient clinics } \\
\text { Recruitment: volunteers }\end{array}$ \\
\hline Participants & 504 participants randomized: $56 \%$ female, average age 41 , average cigarettes per day: not stated \\
\hline
\end{tabular}


Aubin 2004 (Continued)
Interventions
- Bupropion $300 \mathrm{mg}$ for 7 weeks
- Placebo
Common components: motivational support at clinic visits at baseline, w3, w7, w12 and 3 phone calls TQD, 2 to 3 days later, w5, w18

\begin{tabular}{ll}
\hline Outcomes & $\begin{array}{l}\text { Abstinence at w26 (continuous from w4) } \\
\text { Validation: } \mathrm{CO}<10 \mathrm{ppm}\end{array}$ \\
\hline Funding Source & GlaxoSmithKline \\
\hline Author conflicts of interest & The lead author (H J Aubin) is a paid consultant of GSK \\
\hline Notes & First included as Lebargy 2003 based on abstract \\
\hline
\end{tabular}

\section{Risk of bias}

\begin{tabular}{|c|c|c|}
\hline Bias & Authors' judgement & Support for judgement \\
\hline $\begin{array}{l}\text { Random sequence genera- } \\
\text { tion (selection bias) }\end{array}$ & Low risk & $\begin{array}{l}\text { Quote: "The computerized randomization schedule, prepared by the sponsor, } \\
\text { was inaccessible to the investigator who was provided with a specific set of se- } \\
\text { quential treatment numbers." }\end{array}$ \\
\hline $\begin{array}{l}\text { Allocation concealment } \\
\text { (selection bias) }\end{array}$ & Low risk & $\begin{array}{l}\text { Quote: "The computerized randomization schedule, prepared by the sponsor, } \\
\text { was inaccessible to the investigator who was provided with a specific set of se- } \\
\text { quential treatment numbers." }\end{array}$ \\
\hline $\begin{array}{l}\text { Blinding (performance } \\
\text { bias and detection bias) } \\
\text { All outcomes }\end{array}$ & Low risk & $\begin{array}{l}\text { Quote: "Double-blind" "Blinding was assured by matching the placebo to the } \\
\text { bupropion tablets..." }\end{array}$ \\
\hline $\begin{array}{l}\text { Incomplete outcome data } \\
\text { (attrition bias) } \\
\text { All outcomes }\end{array}$ & Low risk & $\begin{array}{l}26 \% \text { of the placebo and } 27 \% \text { of the bupropion groups lost; included as smok- } \\
\text { ers }\end{array}$ \\
\hline
\end{tabular}

\section{Aveyard 2008}

\begin{tabular}{ll}
\hline Methods & Study design: RCT \\
& $\begin{array}{l}\text { Country: UK } \\
\text { Setting: National Health Service stop smoking clinics } \\
\text { Recruitment: people attending clinics }\end{array}$ \\
\hline Participants & \begin{tabular}{l}
901 smokers, $\geq 10 /$ day; $46 \%$ female, average age 43, average cigarettes per day 21 \\
\hline Interventions
\end{tabular} \\
& $\begin{array}{l}\text { - Nortriptyline. } 75 \mathrm{mg} / \text { day, for } 8 \mathrm{w} \text { including tapering (max dose for } 6 \mathrm{w}) \\
\text { All participants received free NRT and had behavioural support, the majority attending group sessions }\end{array}$ \\
\hline Outcomes & $\begin{array}{l}\text { Smoking cessation: prolonged abstinence at } 12 \text { months from day } 15 \text { post-quit (validated by CO at 4w, } \\
\text { saliva cotinine (collected by post) at } 6 \text { months and } 12 \text { months) }\end{array}$ \\
\hline Funding Source & $\begin{array}{l}\text { Cancer Research UK and National Institute for Health Research. Medication provided by King Pharma- } \\
\text { ceuticals }\end{array}$ \\
\hline \hline
\end{tabular}


Aveyard 2008 (Continued)

Author conflicts of interest

PA has done consultancy work for the pharmaceutical and biotechnology industry that has led to payments to him and his institution. This includes work for companies providing smoking cessation treatment, including NRT. MM has received consultancy income from the European Network for Smoking Prevention and has provided scientific consultancy services through the University of Oxford ISIS Innovation to the National Audit Office and G-Nostics.

Notes

\section{Risk of bias}

\section{Bias Authors' judgement Support for judgement}

Random sequence genera- Low risk Quote: "An independent statistician generated the randomisation schedule tion (selection bias) in Stata. We used block randomisation, with randomly ordered block sizes of two, four, and six, stratified by stop smoking adviser."

\begin{tabular}{lll}
\hline $\begin{array}{l}\text { Allocation concealment } \\
\text { (selection bias) }\end{array}$ & Low risk & $\begin{array}{l}\text { Study nurses recruited participants, and the study administrator (who had not } \\
\text { met the participants) allocated participants in sequence against the list for } \\
\text { each adviser. Only the administrator and the pharmacist knew the allocation. }\end{array}$ \\
\hline $\begin{array}{l}\text { Blinding (performance } \\
\text { bias and detection bias) } \\
\text { All outcomes }\end{array}$ & Low risk & $\begin{array}{l}\text { Quote: "Advisers, participants, and study staff...were blind to allocation... } \\
\text { tablets were encapsulated, and identical powder filled capsules provided the } \\
\text { placebos." }\end{array}$
\end{tabular}

$\begin{array}{ll}\begin{array}{l}\text { Incomplete outcome data } \\ \text { (attrition bias) }\end{array} & \text { Low risk }\end{array} \quad \begin{aligned} & 12 \% \text { intervention, } 17 \% \text { control lost at } 12 \text { months, included as smokers. Au- } \\ & \text { thors note that majority of losses were already smoking. }\end{aligned}$

All outcomes thors note that majority of losses were already smoking.

Barnes 2006

Study design: RCT
Country: UK
Setting: private consulting room in a community pharmacy
Recruitment method: advertisements were placed in newspapers regional to the pharmacy; informa-
tion leaflets were placed in the pharmacy, along with a window display on smoking cessation which
mentioned the study; local radio interviews were given

$\begin{array}{ll}\text { Participants } & \begin{array}{l}28 \text { participants randomized; } 17 \% \text { female; average age 42.8; average cigarettes per day 15.5; FTND: } 26 \\ \text { ppts }<8 \text { and } 2 \text { ppts } \geq 8\end{array}\end{array}$

Interventions - St John's Wort, $300 \mathrm{mg}$ per day

- St John's Wort, $300 \mathrm{mg}$ twice per day

Common components: one hour of general smoking cessation advice and motivational support

\begin{tabular}{ll}
\hline Outcomes & $\bullet$ Smoking cessation: 12 months continuous abstinence following quit date (validated by CO) \\
\hline Funding Source & Lichtwer Pharma (UK) Ltd \\
\hline Author conflicts of interest & Lead author received funding by fellowship from Lichtwer Pharma UK Ltd \\
\hline Notes &
\end{tabular}

\section{Risk of bias}


Barnes 2006 (Continued)

Bias Authors' judgement Support for judgement

Random sequence genera- Low risk tion (selection bias)

Quote: "A computer-generated randomisation list of random treatment assignments ('A' or 'B', corresponding to lower and higher dosages of SJW, respectively) in blocks of 4 without stratification was prepared in advance."

\begin{tabular}{ll}
\hline $\begin{array}{l}\text { Allocation concealment } \\
\text { (selection bias) }\end{array}$ & $\begin{array}{l}\text { Quote: "Participants enrolled into the study were assigned to the next consec- } \\
\text { utive treatment." As the pharmacist was unblinded, they would therefore have } \\
\text { been aware of the allocation of the participants. }\end{array}$
\end{tabular}

\begin{tabular}{|c|c|c|}
\hline $\begin{array}{l}\text { Blinding (performance } \\
\text { bias and detection bias) }\end{array}$ & High risk & $\begin{array}{l}\text { Quote: "This was a prospective, open, uncontrolled, pharmacy-based, pilot } \\
\text { study." }\end{array}$ \\
\hline
\end{tabular}

All outcomes

$\begin{array}{ll}\text { Incomplete outcome data } \quad \text { High risk } & 11 / 15 \text { in once daily arm }+10 / 13 \text { in twice daily arm were lost to follow-up . } \\ \text { (attrition bias) } & \text { Therefore, loss to follow-up is greater than } 50 \% \text { in each trial arm. }\end{array}$

All outcomes

Therefore, loss to follow-up is greater than $50 \%$ in each trial arm.

Benli 2017

Study design: RCT
Country: Turkey
Setting: a smoking cessation clinic
Recruitment method: participants applied to the smoking cessation clinic directly by calling the Turk-
ish Ministry of Health's 'stop smoking' helpline and making an appointment.

\begin{tabular}{ll}
\hline Participants & $\begin{array}{l}\text { An unspecified number of participants were randomised. } 405 \text { participants were analysed. 17.5\% fe- } \\
\text { male; average age 35.2; average age 35.2; average cigarettes per day 23; mean FTND 6.3 }\end{array}$ \\
\hline Interventions & Bupropion. Provided for 3 months \\
& Common components: behavioural therapy support with a biopsychosocial approach \\
\hline Outcomes & Smoking cessation: 7-day PPA at 12 months. Validated by a CO level $\leq 5$ ppm \\
\hline Funding Source & No funding \\
\hline Author conflicts of interest & The authors declare that they have no competing interests \\
\hline Notes &
\end{tabular}

\section{Risk of bias}

\begin{tabular}{lll}
\hline Bias & Authors' judgement & Support for judgement \\
\hline $\begin{array}{l}\text { Random sequence genera- } \\
\text { tion (selection bias) }\end{array}$ & Unclear risk & $\begin{array}{l}\text { Quote: "Patients who were to receive the medication were randomly deter- } \\
\text { mined by the medication support center in order to provide a constant distri- } \\
\text { bution rate of varenicline and bupropion and so that physicians would not be } \\
\text { aware of the medication distribution." } \\
\text { Comment: no further detail is provided. }\end{array}$ \\
\hline $\begin{array}{l}\text { Allocation concealment } \\
\text { (selection bias) }\end{array}$ & Unclear risk & $\begin{array}{l}\text { Quote: "Patients who were to receive the medication were randomly deter- } \\
\text { mined by the medication support center in order to provide a constant distri- }\end{array}$ \\
\hline
\end{tabular}


Benli 2017 (Continued)

bution rate of varenicline and bupropion and so that physicians would not be aware of the medication distribution." Comment: no further detail is provided.

Blinding (performance
bias and detection bias)

All outcomes
Unclear risk

Quote: "Patients who were to receive the medication were randomly determined by the medication support center in order to provide a constant distribution rate of varenicline and bupropion and so that physicians would not be aware of the medication distribution"

Comment: some attempt appears to have been made to blind physicians to group assignment, however no further detail is given, so it is unclear whether participants and outcome assessors were blinded.

Only those followed up at 12 months are included in analysis

Incomplete outcome data High risk

(attrition bias)

All outcomes

\section{Berlin 1995}

\begin{tabular}{|c|c|}
\hline Methods & $\begin{array}{l}\text { Study design: RCT } \\
\text { Country: France } \\
\text { Setting: clinic } \\
\text { Recruitment: by adverts in general practices or from occupational medicine departments }\end{array}$ \\
\hline Participants & 88 smokers randomized; no current major depression or anxiety disorders; $57 \%$ had history of MDD \\
\hline Interventions & $\begin{array}{l}\text { - Moclobemide, } 400 \mathrm{mg} / \mathrm{day} \text { for } 1 \mathrm{w} \text { pre- and } 2 \text { months post-TQD, } 200 \mathrm{mg} \text { for } 3 \text { rd month } \\
\text { - Placebo } \\
\text { No behavioural intervention or counselling }\end{array}$ \\
\hline Outcomes & $\begin{array}{l}\text { - Smoking cessation: prolonged abstinence at } 1 \text { year (validated at all visits up to } 6 \text { months by plasma } \\
\text { cotinine } \leq 20 \mathrm{ng} / \mathrm{mL} \text {. 1-year abstinence based on telephone self-report by } 6 \text { month quitters) } \\
\text { - Adverse events: measured until } 91 \text { days post-quit }\end{array}$ \\
\hline Funding Source & Roche \\
\hline Author conflicts of interest & None specified \\
\hline Notes & $\begin{array}{l}\text { There were no serious adverse reactions. Insomnia was more common in drug (36\%) than placebo ( } 7 \%) \\
\text { groups. There were } 4 \text { dropouts for adverse effects/relapse in drug and } 2 \text { in placebo }\end{array}$ \\
\hline
\end{tabular}

\section{Risk of bias}

\begin{tabular}{lll}
\hline Bias & Authors' judgement & Support for judgement \\
\hline $\begin{array}{l}\text { Random sequence genera- } \\
\text { tion (selection bias) }\end{array}$ & Unclear risk & Randomization method not described \\
\hline $\begin{array}{l}\text { Allocation concealment } \\
\text { (selection bias) }\end{array}$ & Unclear risk & Double-blind, but blinding at allocation not explicit \\
\hline $\begin{array}{l}\text { Blinding (performance } \\
\text { bias and detection bias) } \\
\text { All outcomes }\end{array}$ & Unclear risk & Quote: "Double-blind" but further detail not provided \\
\hline
\end{tabular}


Berlin 1995 (Continued)

Incomplete outcome data Unclear risk Quote: "Relapses and subjects lost from follow-up were considered treatment (attrition bias)

failures." Number lost to follow-up not reported

All outcomes

Berlin 2002

\begin{tabular}{ll}
\hline Methods & Study design: RCT \\
Countries: France and Belgium \\
Setting: General practices and anti-smoking clinics
\end{tabular}

Participants

330 participants randomized; $43.9 \%$ female; average age 39.9; average cigarettes per day 24.7; mean FTND 6.2

Interventions

- Lazabemide, $50 \mathrm{mg}$ twice daily for 8 weeks

- Lazabemide, $100 \mathrm{mg}$ twice daily for 8 weeks

- Placebo, twice daily for 8 weeks

Common components: brief cognitive behavioral intervention at each visit, totalling 2 hours

\begin{tabular}{ll}
\hline Outcomes & Smoking cessation: follow-up is 8 weeks, too short to be included in this review \\
- Adverse events: measured over a period of 8 weeks
\end{tabular}

Funding Source F Hoffmann-La Roche

Author conflicts of interest None detailed

Notes

\section{Risk of bias}

Bias Authors' judgement Support for judgement

Random sequence genera- Low risk Quote: "subjects were assigned a treatment number according to the computtion (selection bias) er-generated randomization table"

Allocation concealment Unclear risk Quote: "Eligible subjects were assigned a treatment number according to the (selection bias) computer-generated randomization table."

Comment: no further information is provided, therefore who was blinded and how is unclear

\begin{tabular}{|c|c|c|}
\hline \multirow{2}{*}{$\begin{array}{l}\text { Blinding (performance } \\
\text { bias and detection bias) } \\
\text { All outcomes }\end{array}$} & Unclear risk & $\begin{array}{l}\text { "This was a randomized, placebo-controlled, double-blind, parallel-group, } \\
\text { multicenter proof-of-concept study" }\end{array}$ \\
\hline & & Comment: no further information is provided \\
\hline $\begin{array}{l}\text { Incomplete outcome data } \\
\text { (attrition bias) } \\
\text { All outcomes }\end{array}$ & High risk & $\begin{array}{l}60 \% \text { in placebo }(68 / 114) ; 62 \% 100 \mathrm{mg} / \text { day lazabemide }(67 / 108) \text {; and } 54 \% 200 \\
\mathrm{mg} / \text { day lazabemide }(58 / 108) \text { were lost to follow-up. Therefore, loss to fol- } \\
\text { low-up is above } 50 \% \text { in all groups. }\end{array}$ \\
\hline
\end{tabular}


Berlin 2012

\begin{tabular}{|c|c|}
\hline Methods & $\begin{array}{l}\text { Study design: RCT } \\
\text { Country: Germany } \\
\text { Setting: investigation centres } \\
\text { Recruitment method: media advertisements }\end{array}$ \\
\hline Participants & $\begin{array}{l}412 \text { participants randomized; } 37.4 \% \text { female; average age } 35 \text {; average cigarettes per day } 19 \text {; mean FTND } \\
5.4\end{array}$ \\
\hline Interventions & $\begin{array}{l}\text { - EVT302, } 1 \text { × } 5 \text { mg tablet per day for } 8 \text { weeks ( } 1 \text { week pre-quit and } 7 \text { weeks post-quit) } \\
\text { - Placebo EVT302, } 1 \text { × } 5 \text { mg per day for } 8 \text { weeks ( } 1 \text { week pre-quit and } 7 \text { weeks post-quit) } \\
\text { - Placebo EVT302 and nicotine patch. Placebo EVT302 dosing was } 1 \times 5 \text { mg per day for } 8 \text { weeks ( } 1 \text { week } \\
\text { pre-quit and } 7 \text { weeks post-quit). Nicotine patch ( } 21 \mathrm{mg} / 24 \text { hours) was given for } 7 \text { weeks post-quit. } \\
\text { Common components: educational booklet on smoking cessation and a 10-minute counselling session } \\
\text { at each visit, totalling } 1 \text { hour and } 50 \text { minutes }\end{array}$ \\
\hline Outcomes & $\begin{array}{l}\text { - Smoking cessation: follow-up is } 12 \text { weeks, too short to be included in this review } \\
\text { - Adverse events: recorded over } 8 \text { weeks }\end{array}$ \\
\hline Funding Source & Evotec NeuroSciences GmbH \\
\hline Author conflicts of interest & $\begin{array}{l}\text { Ivan Berlin has received consultancy payments and travel funding from Pfizer Ltd and Sanofi Aventis in } \\
\text { the last } 5 \text { years. He received a consultancy payment from Evotec Ltd for preparing the current study's } \\
\text { research protocol. Ian M Hunneyball, Doris Greiling, Stephen Jones and Hermann Fuder were employ- } \\
\text { ees of Evotec. Hans-Detlev Stahl is an employee of ClinPharm International GmbH Prufzentrum Leipzig. }\end{array}$ \\
\hline
\end{tabular}

Notes

\section{Risk of bias}

\section{Bias Authors' judgement Support for judgement}

Random sequence genera- Unclear risk tion (selection bias)

Quote: "Randomisation was performed by an independent statistician. A block size of 20 was used with each block containing medication assignments in a 7:7:3:3 ratio for EVT302 $5 \mathrm{mg} /$ day or placebo and EVT302 $5 \mathrm{mg}$ /day or placebo on top of NP [nicotine pill]. No stratification was used. Medication numbers were generated for a total of 25 blocks. The randomisation list was uploaded into the [interactive voice recognition system (IVRS)] allowing the centralised use of randomisation." No detail of how sequences were generated

$\begin{array}{ll}\begin{array}{l}\text { Allocation concealment } \\ \text { (selection bias) }\end{array} & \text { Low risk } \\ & \begin{array}{l}\text { Quote: "A central randomisation with an interactive voice recognition system } \\ \text { (IVRS) was used which indicated the treatment to deliver upon the investiga- } \\ \text { tors' call." }\end{array}\end{array}$

\begin{tabular}{|c|c|c|}
\hline $\begin{array}{l}\text { Blinding (performance } \\
\text { bias and detection bias) }\end{array}$ & Unclear risk & $\begin{array}{l}\text { Study stated as being double-blinded, although no further information is given } \\
\text { beyond this. Nicotine pill is unblinded, however }\end{array}$ \\
\hline
\end{tabular}

All outcomes

$\begin{array}{ll}\begin{array}{l}\text { Incomplete outcome data } \\ \text { (attrition bias) }\end{array} & \begin{array}{l}\text { Dropout rates are all below } 50 \% \text { - EVT302: } 16 \text { (10\%); placebo: } 14 \text { (11\%); EVT302 } \\ \text { + nicotine pill: } 5(8 \%) ; \text { placebo + nicotine pill: } 2 \text { (3\%) }\end{array}\end{array}$

All outcomes 
Biberman 2003

\begin{tabular}{ll}
\hline Methods & Study design: RCT \\
& $\begin{array}{l}\text { Country: Israel } \\
\text { Setting: } 3 \text { community-based clinics } \\
\text { Recruitment: mailing to members of public health service provider }\end{array}$ \\
\hline Participants & 109 smokers randomised; 38\% females, average age 42, average cigarettes per day 27 to 30 \\
\hline Interventions & - Selegiline, 10 mg/day for 26 weeks, nicotine patch 21 mg for 8 weeks including tapering \\
& $\begin{array}{l}\text { Common components: behavioural support from trained family physician; weekly then fortnightly vis- } \\
\text { its for } 12 \text { weeks }\end{array}$ \\
\hline Outcomes & Abstinence at 52 weeks, continuous with validation at each visit \\
\hline Funding Source & Validation: negative for urine nicotine, cotinine, 3-hydroxycotinine (Niccheck) \\
\hline Author conflicts of interest & None specified \\
\hline Notes & No serious AEs, no significant differences in AEs, 2 selegiline discontinuations
\end{tabular}

\section{Risk of bias}

\begin{tabular}{lll}
\hline Bias & Authors' judgement & Support for judgement \\
\hline $\begin{array}{l}\text { Random sequence genera- } \\
\text { tion (selection bias) }\end{array}$ & Low risk & $\begin{array}{l}\text { Quote: "Four hundred dice-throwing generated a randomized sequence code; } \\
199 \text { containers prepacked with selegiline and 201 containers prepacked with } \\
\text { placebo were numbered accordingly." Comment: judged adequate }\end{array}$ \\
\hline $\begin{array}{l}\text { Allocation concealment } \\
\text { (selection bias) }\end{array}$ & Low risk & $\begin{array}{l}\text { Quote: "The code was sealed, kept secretly and was revealed for the first time } \\
\text { when the last participant finished the } 12 \text { months of follow-up. The first partic- } \\
\text { ipant who joined the trial after the initial visit run-in phase received the first } \\
\text { bottle from the container set number } 001 \text {, the second } \\
\text { participant from set number } 002 \text { and so on. The trial coordinator arranged } \\
\text { participant's allocation." } \\
\text { Comment: judged adequate }\end{array}$ \\
& &
\end{tabular}

\begin{tabular}{|c|c|c|}
\hline $\begin{array}{l}\text { Blinding (performance } \\
\text { bias and detection bias) } \\
\text { All outcomes }\end{array}$ & Low risk & $\begin{array}{l}\text { Quote: "Double-blind" (see above) "No discontinuation difference for selegi- } \\
\text { line or placebo was observed among the groups, which implies masking suc- } \\
\text { cess." }\end{array}$ \\
\hline
\end{tabular}

Alloutcomes risk

Incomplete outcome data Low risk

19 lost to follow-up, included as smokers in meta-analysis

(attrition bias)

All outcomes

Blondal 1999

\begin{tabular}{ll}
\hline Methods & Study design: RCT \\
& Country: Iceland \\
& Setting: cessation clinic \\
& Recruitment: community volunteers
\end{tabular}


Blondal 1999 (Continued)

Participants $\quad 100$ smokers randomized; $62 \%$ female; average age 41; average cigarettes per day 28

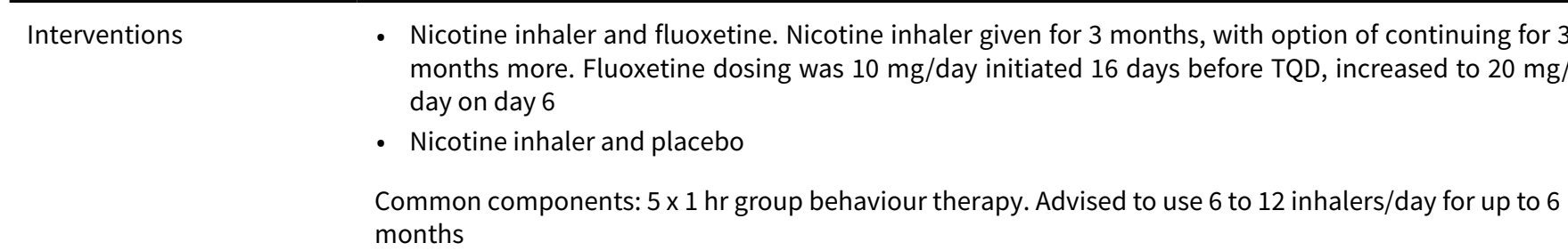

- Smoking cessation: abstinence at 1 year (sustained from quit day). Validated by CO < 10 ppm at all
assessments ( 6 weeks, 3 months, 6 months, 12 months)
- Adverse events: measured for 16 days

Funding Source

Oddur Olafsson Fund, Pharmacia and Upjohn Consumer Health Care. Delta Pharmaceutical Company provided fluoxetine and placebo and fluoxetine analyses. Helsingborg, Sweden provided a grant, nicotine inhalers and nicotine analyses.

Author conflicts of interest None specified

Notes

\section{Risk of bias}

\begin{tabular}{|c|c|c|}
\hline Bias & Authors' judgement & Support for judgement \\
\hline $\begin{array}{l}\text { Random sequence genera- } \\
\text { tion (selection bias) }\end{array}$ & Low risk & $\begin{array}{l}\text { Computer-generated randomization; part of the randomization procedure was } \\
\text { performed by the manufacturer at another location where the code was also } \\
\text { kept until it was broken in May } 1997 \text {. }\end{array}$ \\
\hline $\begin{array}{l}\text { Allocation concealment } \\
\text { (selection bias) }\end{array}$ & Low risk & $\begin{array}{l}\text { Randomization codes applied to pill boxes which were then allocated sequen- } \\
\text { tially. "This part of the randomization procedure was performed by the manu- } \\
\text { facturer at another location where the code was also kept." }\end{array}$ \\
\hline $\begin{array}{l}\text { Blinding (performance } \\
\text { bias and detection bias) } \\
\text { All outcomes }\end{array}$ & Low risk & $\begin{array}{l}\text { Quote: "Double-blind." "...pill boxes, with either fluoxetine or an identical ap- } \\
\text { pearing placebo containing the same ingredients except fluoxetine, were la- } \\
\text { belled with numbers ranging from } 100 \text { to } 210 . "\end{array}$ \\
\hline $\begin{array}{l}\text { Incomplete outcome data } \\
\text { (attrition bias) } \\
\text { All outcomes }\end{array}$ & Unclear risk & $\begin{array}{l}\text { Low numbers lost to follow-up but reported results exclude } 5 \text { withdrawals; } 3 \\
\text { from fluoxetine group due to adverse effects - nervousness and anxiety, } 1 \text { from } \\
\text { fluoxetine due to pregnancy, } 1 \text { from placebo who had purchased fluoxetine }\end{array}$ \\
\hline
\end{tabular}

\section{Brown 2007}

\begin{tabular}{ll}
\hline Methods & Study design: $2 \times 2$ factorial RCT \\
Country: USA & $\begin{array}{l}\text { Setting: } 2 \text { clinical sites (Butler Hospital, Miriam Hospital) } \\
\text { Recruitment: community volunteers }\end{array}$ \\
\hline Participants & 524 participants randomised; $48 \%$ female; average age 44; average cigarettes per day 25 \\
\hline Interventions & Bupropion $300 \mathrm{mg} /$ day for 12 weeks \\
& Placebo
\end{tabular}


Brown 2007 (Continued)

$2 \times 2$ factorial design. Alternative psychosocial treatments were standard cessation therapy or plus CBT for depression. Both had $12 \times 90$ min groups twice weekly/weekly/monthly for 12 weeks. TQD 5th session. Collapsed in this analysis

\begin{tabular}{ll}
\hline Outcomes & $\begin{array}{l}\text { Smoking cessation: abstinence at } 12 \text { months (sustained at } 4 \text { visits). Validated by CO } \leq 10 \mathrm{ppm} \text {, saliva } \\
\text { cotinine } \leq 15 \mathrm{ng} / \mathrm{mL}\end{array}$ \\
\hline Funding Source & Adverse events: measured for 12 weeks \\
\hline Author conflicts of interest & National Institutes of Health \\
\hline Notes & $\begin{array}{l}\text { First included as Brown 2006, part unpublished data. Some genotyping studies combine these partici- } \\
\text { pants with those reported in Collins } 2004\end{array}$ \\
\hline
\end{tabular}

\section{Risk of bias}

\begin{tabular}{lll}
\hline Bias & Authors' judgement & Support for judgement \\
\hline $\begin{array}{l}\text { Random sequence genera- } \\
\text { tion (selection bias) }\end{array}$ & Unclear risk & $\begin{array}{l}\text { Quote: "Participants were randomly assigned to one of two treatment sites, } \\
\text { where they were to receive one of two manualized group treatments ... Partici- } \\
\text { pants } \\
\text { were then randomly assigned to receive one of two medication conditions, } \\
\text { bupropion or placebo, using the urn randomization technique." }\end{array}$
\end{tabular}

Allocation concealment Unclear risk
(selection bias)

Quote: "Whereas we were able to balance the drug and placebo conditions on an individual basis, behavioral treatments were randomized by group and thus were more susceptible to fluctuations in recruitment and to the availability at both sites of pairings of a senior and a junior therapist trained in CBTD". Knowledge of behavioural assignment was probably not concealed but seems unlikely to have led to individual selection bias.

\begin{tabular}{|c|c|c|}
\hline $\begin{array}{l}\text { Blinding (performance } \\
\text { bias and detection bias) } \\
\text { All outcomes }\end{array}$ & Low risk & $\begin{array}{l}\text { Quote: "Double-blind." Psychological condition unlikely to be blinded but un- } \\
\text { likely to affect comparisons included in this review. "All participants and study } \\
\text { staff were blind to medication condition." }\end{array}$ \\
\hline
\end{tabular}

$\begin{array}{ll}\begin{array}{l}\text { Incomplete outcome data } \\ \text { (attrition bias) }\end{array} & \text { Low risk }\end{array} \begin{aligned} & 81 \% \text { provided complete outcome data at all follow-ups, not related to treat- } \\ & \text { ment condition. All participants included in ITT analyses }\end{aligned}$
All outcomes $81 \%$ provided complete outcome data at all follow-ups, not related to treat-
ment condition. All participants included in ITT analyses

$\longrightarrow$

Brown 2014

\begin{tabular}{ll}
\hline Methods & Study design: RCT \\
& Country: USA \\
& Setting: clinic \\
& Recruitment: via newspaper, radio, and television advertisements \\
\hline Participants & 216 smokers with elevated depressive symptoms (CES-D score $\geq 6$ ) randomized; 38.4\% female, average \\
& age 45.9; average cigarettes per day 21 ; mean FTND 5.6 \\
\hline Interventions & Fluoxetine and nicotine patch, 10 weeks of $20 \mathrm{mg}$ (beginning 2 weeks prior to TQD) \\
- & Nicotine patch
\end{tabular}


Brown 2014 (Continued)

Common components: nicotine patch for 8 weeks starting on TQD $(21 \mathrm{mg} /$ day for 4 weeks, $14 \mathrm{mg} /$ day for 2 weeks, $7 \mathrm{mg} /$ day for last 2 weeks), 5 sessions of brief behavioural smoking cessation treatment (in person and phone over 4 weeks, 20 to 30 mins each), totalling 140 minutes

\begin{tabular}{ll}
\hline Outcomes & $\begin{array}{l}\text { - Smoking cessation: continuous abstinence at } 12 \text { months. Validated by salivary cotinine }<10 \mathrm{ng} / \mathrm{mL} \\
\text { - }\end{array}$ \\
\hline Funding Source & American Cancer Society \\
\hline Author conflicts of interest & $\begin{array}{l}\text { LHP reports receiving grant/research support from Medtronic, Neuronetics, HRSA, and NeoSync; serv- } \\
\text { ing on an advisory panel for Abbott; and serving as a consultant for Wiley, Springer, Qatar National Re- } \\
\text { search Fund, and Abbott }\end{array}$ \\
\hline Notes & $\begin{array}{l}\text { New for } 2013 \\
\text { Significantly higher abstinence in } 16 \text { week arm than in } 10-\text { week arm, results presented separately in } \\
\text { meta-analysis with control divided. } \mathrm{N} \text { abstinent not reported, extrapolated from percentages provided }\end{array}$ \\
\hline
\end{tabular}

\section{Risk of bias}

\begin{tabular}{lll}
\hline Bias & Authors' judgement & Support for judgement \\
\hline $\begin{array}{l}\text { Random sequence genera- } \\
\text { tion (selection bias) }\end{array}$ & Low risk & $\begin{array}{l}\text { Quote: "randomly assigned to one of the three treatment conditions using urn } \\
\text { randomization" }\end{array}$ \\
\hline $\begin{array}{l}\text { Allocation concealment } \\
\text { (selection bias) }\end{array}$ & High risk & Quote: "Open-label" \\
\hline $\begin{array}{l}\text { Blinding (performance } \\
\text { bias and detection bias) } \\
\text { All outcomes }\end{array}$ & High risk & Quote: "Open-label" \\
\hline $\begin{array}{l}\text { Incomplete outcome data } \\
\text { (attrition bias) } \\
\begin{array}{l}\text { All outcomes } \\
\hline\end{array}\end{array}$ & Low risk & Over $90 \%$ followed up at 12 months. Similar rates across arms \\
\hline
\end{tabular}

Cinciripini 2005

\begin{tabular}{ll}
\hline Methods & $\begin{array}{l}\text { Study design: RCT } \\
\text { Country: USA } \\
\text { Setting: clinic } \\
\text { Recruitment: community volunteers }\end{array}$ \\
\hline Participants & 135 smokers randomized; $50 \%$ female, average age 46 , average cigarettes per day 27 \\
\hline Interventions & $\begin{array}{l}\text { Venlafaxine, titrated to max. of } 225 \mathrm{mg} / \text { day from } 3 \text { weels before quit day for } 21 \text { weeks, including } 2 \\
\text { weeks tapering }\end{array}$ \\
& Common components: 6 weeks, 22 mg nicotine patch, and $9 \times 15$-min behavioural counselling \\
\hline Outcomes & Smoking cessation: ppa at 12 months. Validated by $\mathrm{CO} \leq 10 \mathrm{ppm}$ and/or saliva cotinine $<15 \mathrm{ng} / \mathrm{uL}$ \\
\hline
\end{tabular}


Cinciripini 2005 (Continued)

Funding Source National Institutes for Health and National Institute for Drug Abuse. Medication provided free of charge by Wyeth Ayerst Laboratories.

\begin{tabular}{ll}
\hline Author conflicts of interest & None specified \\
\hline Notes & First included as Cinciripini 1999 based on abstract \\
\hline
\end{tabular}

\section{Risk of bias}

\begin{tabular}{lll}
\hline Bias & Authors' judgement & Support for judgement \\
\hline $\begin{array}{l}\text { Random sequence genera- } \\
\text { tion (selection bias) }\end{array}$ & Unclear risk & Randomization method not described. Stratification by depression history \\
\hline $\begin{array}{l}\text { Allocation concealment } \\
\text { (selection bias) }\end{array}$ & Low risk & $\begin{array}{l}\text { Randomization by pharmacy, all study personnel with direct patient contact } \\
\text { blind }\end{array}$ \\
\hline $\begin{array}{l}\text { Blinding (performance } \\
\text { bias and detection bias) } \\
\text { All outcomes }\end{array}$ & Low risk & $\begin{array}{l}\text { Quote: "Double-blind... Blinding of the study staff to the medication was main- } \\
\text { tained using prenumbered pill containers, assigned to each participant at ran- } \\
\text { domization by the pharmacy. All study personnel with direct patient contact } \\
\text { were blind to group assignment." }\end{array}$ \\
\hline $\begin{array}{l}\text { Incomplete outcome data } \\
\text { (attrition bias) } \\
\text { All outcomes }\end{array}$ & Unclear risk & $\begin{array}{l}\text { Majority of participants followed up (65 intervention; 63 control), participants } \\
\text { lost to follow-up counted as smokers }\end{array}$ \\
\hline
\end{tabular}

Cinciripini 2013

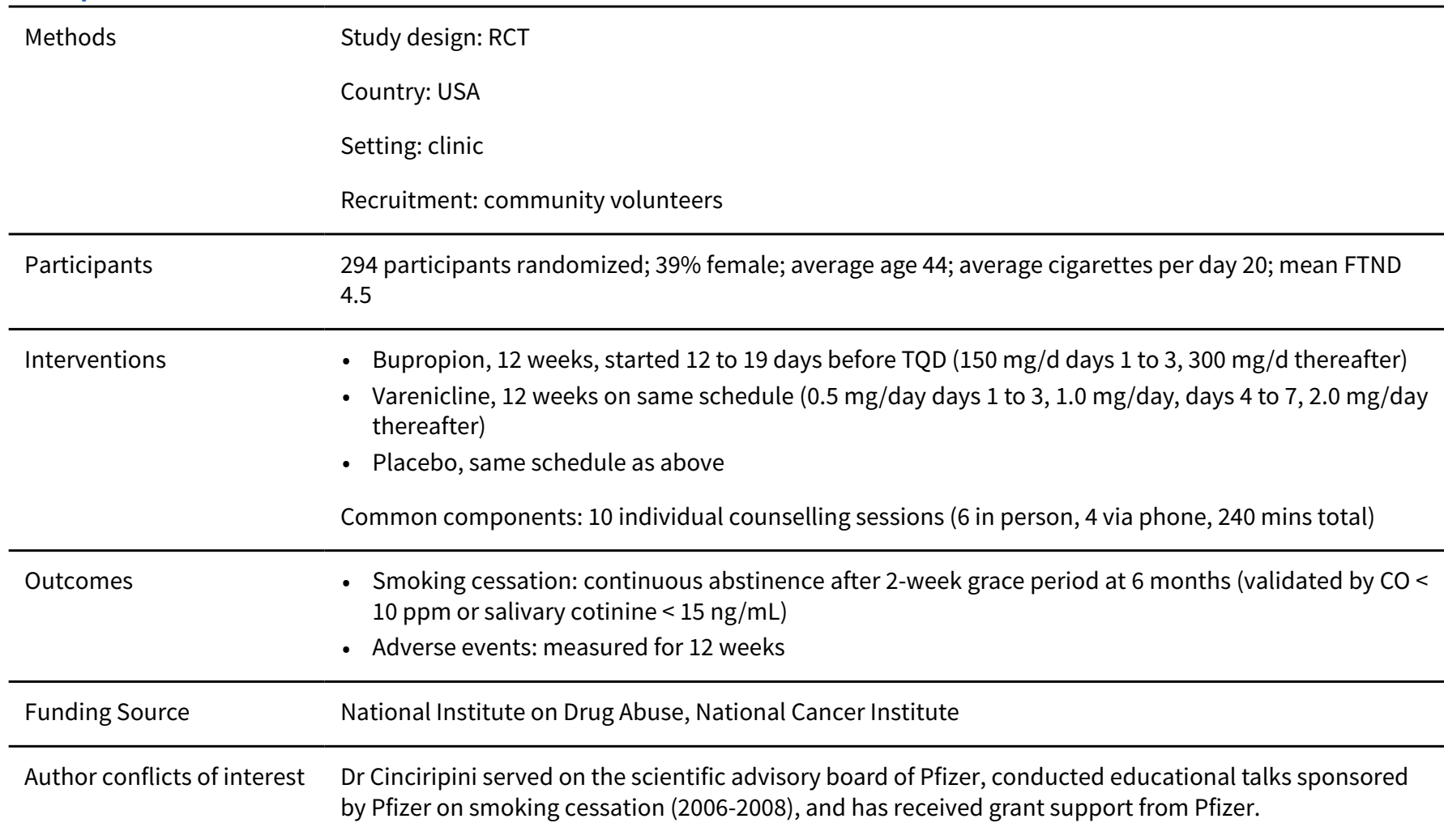


Cinciripini 2013 (Continued)

Notes
New for 2013. In less than $1 \%$ of the total cases, participants who did not attend a follow-up were coded as abstinent because they were abstinent at the following data point. All other losses to follow-up counted as smokers. Author provided further detail on AE measurements via email.

\section{Risk of bias}

\begin{tabular}{lll}
\hline Bias & Authors' judgement & Support for judgement \\
\hline $\begin{array}{l}\text { Random sequence genera- } \\
\text { tion (selection bias) }\end{array}$ & Unclear risk & Quote: “Adaptive randomization," no further detail provided \\
\hline $\begin{array}{l}\text { Allocation concealment } \\
\text { (selection bias) }\end{array}$ & Unclear risk & Not reported \\
\hline $\begin{array}{l}\text { Blinding (performance } \\
\text { bias and detection bias) } \\
\text { All outcomes }\end{array}$ & Unclear risk & Quote: "Blinded” but no further information provided \\
\hline $\begin{array}{l}\text { Incomplete outcome data } \\
\text { (attrition bias) }\end{array}$ & Low risk & \\
\begin{tabular}{l} 
All outcomes \\
\hline
\end{tabular} & & $\begin{array}{l}73 \% \text { followed up at } 6 \text { months, similar rates across arms, all lost to follow-up } \\
\text { known to be smokers }\end{array}$ \\
\hline
\end{tabular}

Cinciripini 2018

\begin{tabular}{|c|c|}
\hline Methods & $\begin{array}{l}\text { Study design: RCT } \\
\text { Country: USA } \\
\text { Setting: hospital-based out-patient clinic specializing in cancer prevention } \\
\text { Recruitment method: paid and unpaid media advertising }\end{array}$ \\
\hline Participants & $\begin{array}{l}385 \text { participants randomised; } 41.5 \% \text { female; average age } 49.0 \text {; average cigarettes per day } 19.7 \text {; mean } \\
\text { FTND } 2.1\end{array}$ \\
\hline Interventions & $\begin{array}{l}\text { - Bupropion and varenicline, } 150 \mathrm{mg} \text { of bupropion per day for days } 1-3 \text {, then } 150 \mathrm{mg} \text { twice daily there- } \\
\text { after. } 0.5 \mathrm{mg} \text { of varenicline per day for days } 1-3 \text {, then } 0.5 \mathrm{mg} \text { twice daily for days } 4-7 \text {, then } 1 \mathrm{mg} \text { twice } \\
\text { daily thereafter } \\
\text { - Varenicline, dose and schedule given as in bupropion and varenicline intervention. Matching placebo } \\
\text { for bupropion } \\
\text { - Matching placebo. }\end{array}$ \\
\hline
\end{tabular}

Common components: in-person and phone counselling, totalling 215 minutes

\section{Outcomes}

- Smoking cessation: prolonged abstinence at 12 months, with relapse defined as smoking on 7 or more consecutive days or smoking at least one cigarette over 2 consecutive weeks within that same time interval (validated by $\mathrm{CO}<4 \mathrm{ppm}$ )

- Adverse events: measured for 12 months
The project was supported by the United States National Institutes of Health (NIH) grant R01DA024709 (Principle Investigator PMC) and by The University of Texas MD Anderson's Cancer Center Support Grant CA016672, funded by the National Cancer Institute (NCI). Pfizer (New York, NY) provided the active and matching placebo varenicline capsules 
Cinciripini 2018 (Continued)

support from Pfizer. MKH participated in two multisite Pfizer-funded trials and received varenicline from Pfizer to conduct four NIH-funded trials.

\section{Notes}

\section{Risk of bias}

\begin{tabular}{|c|c|c|}
\hline Bias & Authors' judgement & Support for judgement \\
\hline $\begin{array}{l}\text { Random sequence genera- } \\
\text { tion (selection bias) }\end{array}$ & Low risk & $\begin{array}{l}\text { Quote: "an algorithm developed and managed by study data managers, whose } \\
\text { role was limited to data quality and integrity management". }\end{array}$ \\
\hline $\begin{array}{l}\text { Allocation concealment } \\
\text { (selection bias) }\end{array}$ & Unclear risk & $\begin{array}{l}\text { No details as to how randomly-generated sequence was transferred and im- } \\
\text { plemented to staff delivering medication to participants. }\end{array}$ \\
\hline $\begin{array}{l}\text { Blinding (performance } \\
\text { bias and detection bias) } \\
\text { All outcomes }\end{array}$ & Low risk & $\begin{array}{l}\text { Quote: "Participants, medical and research staff who interacted with partici- } \\
\text { pants and the study investigators were blinded to group assignment." }\end{array}$ \\
\hline $\begin{array}{l}\text { Incomplete outcome data } \\
\text { (attrition bias) } \\
\text { All outcomes }\end{array}$ & Low risk & $\begin{array}{l}\text { Dropout rates are as follows: } \\
\text { 20/56 placebo; } \\
48 / 166 \text { varenicline; } \\
\text { 38/163 combination. } \\
\text { Dropout rates are below } 50 \% \text { in each arm }\end{array}$ \\
\hline
\end{tabular}

Collins 2004

\begin{tabular}{|c|c|}
\hline Methods & $\begin{array}{l}\text { Study design: RCT } \\
\text { Country: USA } \\
\text { Setting: } 2 \text { clinical research sites } \\
\text { Recruitment: community volunteers }\end{array}$ \\
\hline Participants & $\begin{array}{l}555 \text { participants randomized; excluding history of psychiatric disorder including MDD; } 57 \% \text { female, av- } \\
\text { erage age } 46 \text {, average cigarettes per day } 21\end{array}$ \\
\hline Interventions & $\begin{array}{l}\text { - Bupropion. } 300 \mathrm{mg} / \text { day for } 10 \text { weeks beginning } 2 \text { weeks before TQD } \\
\text { - Placebo } \\
\text { Common components: } 7 \text { sessions group behavioural counselling }\end{array}$ \\
\hline Outcomes & $\begin{array}{l}\text { - Smoking cessation: prolonged abstinence at } 6 \text { months (from week } 2,7 \text { consecutive days of smoking } \\
\text { defined as relapse). Validated by saliva cotinine } \leq 15 \mathrm{ng} / \mathrm{mL} \text {. } \\
\text { - Adverse events: measured for unspecified period }\end{array}$ \\
\hline Funding Source & $\begin{array}{l}\text { National Cancer Institute, National Institute on Drug Abuse, National Center for Research Resources. } \\
\text { Treatment provided free of charge by GlaxoSmithKline. }\end{array}$ \\
\hline Author conflicts of interest & None specified \\
\hline Notes & $\begin{array}{l}\text { Replaces Lerman } 2002 \text { which reported subset of data. Denominators supplied by 1st author, excludes } \\
114 \text { who withdrew before intervention. Some study details from Lerman 2006. Some genotyping stud- } \\
\text { ies combine these participants with those reported in Brown } 2007 \text {. }\end{array}$ \\
\hline
\end{tabular}


Collins 2004 (Continued)

\section{Risk of bias}

\begin{tabular}{lll}
\hline Bias & Authors' judgement & Support for judgement \\
\hline $\begin{array}{l}\text { Random sequence genera- } \\
\text { tion (selection bias) }\end{array}$ & Low risk & $\begin{array}{l}\text { Quote: "Randomization was determined by a computer-generated randomiza- } \\
\text { tion scheme operated by a senior data manager; stratification was carried out } \\
\text { by study site" (Lerman 2006) }\end{array}$ \\
\hline $\begin{array}{l}\text { Allocation concealment } \\
\text { (selection bias) }\end{array}$ & Low risk & Centrally generated and allocation concealed from counsellors and assessors \\
\hline $\begin{array}{l}\text { Blinding (performance } \\
\text { bias and detection bias) } \\
\text { All outcomes }\end{array}$ & Unclear risk & Placebo used but blinding procedure not described in detail \\
\hline
\end{tabular}

Incomplete outcome data Low risk (attrition bias)

All outcomes

$6 \%$ lost to follow-up at 6-month follow-up; included as smokers

\begin{tabular}{ll}
\hline Covey 2002 & \\
\hline Methods & $\begin{array}{l}\text { Study design: RCT } \\
\text { Country: USA } \\
\text { Setting: clinic } \\
\text { Recruitment: volunteers }\end{array}$ \\
\hline Participants & $\begin{array}{l}\text { 134 smokers with a history of past MDD were randomized; } 65 \% \text { female; average age } 44.5 \\
\text { weeks }+9 \text { day taper, including 1-week placebo washout prior to randomization }\end{array}$ \\
\hline Interventions & Placebo \\
Common components: 9 x 45 min individual counselling sessions at clinic visits
\end{tabular}

\begin{tabular}{ll}
\hline Outcomes & $\begin{array}{l}\text { Smoking cessation: 7-day ppa } 6 \text { months after end of treatment. Validated by serum cotinine }<25 \text { ng/ } \\
\mathrm{mL}\end{array}$ \\
\hline Funding Source & Adverse events: measured for 35 weeks \\
\hline Author conflicts of interest & Pfizer, Inc and National Institute on Drug Abuse \\
\hline Notes & "Pfizer, Inc., provided support for conducting the study." \\
\hline
\end{tabular}

\section{Risk of bias}

\begin{tabular}{lll}
\hline Bias & Authors' judgement & Support for judgement \\
\hline $\begin{array}{l}\text { Random sequence genera- } \\
\text { tion (selection bias) }\end{array}$ & Unclear risk & Randomization method not described \\
\hline $\begin{array}{l}\text { Allocation concealment } \\
\text { (selection bias) }\end{array}$ & Unclear risk & Not specified \\
\hline
\end{tabular}


Covey 2002 (Continued)

Blinding (performance Low risk Quote: "double-blind" "Medications were provided in prepared bottles that bias and detection bias) were numbered according to the randomization schedule and dispensed at All outcomes each visit. All study staff at the clinic site were blinded to treatment assignment."

\begin{tabular}{|c|c|c|}
\hline $\begin{array}{l}\text { Incomplete outcome data } \\
\text { (attrition bias) } \\
\text { All outcomes }\end{array}$ & Unclear risk & $\begin{array}{l}\text { Quote: "The subjects lost to follow-up after random assignment were consid- } \\
\text { ered treatment failures." Total participants lost to follw-up at } 6 \text { months not re- } \\
\text { ported }\end{array}$ \\
\hline
\end{tabular}

Cox 2012

\begin{tabular}{ll}
\hline Methods & Study design: RCT \\
& Country: USA \\
& Setting: urban community-based clinic \\
& Recruitment: volunteers, via healthcare settings and via community \\
\hline Participants & 540 African American light smokers ( $\leq 10$ cigarettes per day for $\geq 2$ years, smoked on $\geq 25$ days in past \\
& month); $66 \%$ female; average age 47 ; average cigarettes per day 8 ; average FTND 3.2 \\
\hline Interventions & Bupropion, 300 mg for 7 weeks (150 mg $1 x d$ for $3 d$, then 150 mg $2 x d$ for remainder) \\
C Placebo, same schedule as bupropion \\
at start
\end{tabular}

\begin{tabular}{ll}
\hline Outcomes & Smoking cessation: 7-day ppa at 6 months. Validated by salivary cotinine $<15 \mathrm{ng} / \mathrm{mL}$ \\
- Adverse events: measured for 16 weeks
\end{tabular}

Funding Source

National Cancer Institute, National Institutes of Health, National Institute for Minority Health and Disparities
Author conflicts of interest Dr JS Ahluwalia serves as a consultant to Pfizer Pharmaceuticals, Inc; Dr NL Benowitz serves as a con- sultant to Pfizer Pharmaceuticals, Inc, and has been a paid expert witness in litigation against tobacco companies; Dr RF Tyndale holds shares in Nicogen Research, Inc, a company that is focused on novel smoking cessation treatment approaches

Notes New for 2013 update. SAEs only reported at week 3 (none reported), not included in SAE analysis

\section{Risk of bias}

\begin{tabular}{lll}
\hline Bias & Authors' judgement & Support for judgement \\
\hline $\begin{array}{l}\text { Random sequence genera- } \\
\text { tion (selection bias) }\end{array}$ & Low risk & Computer-generated random numbers table \\
\hline $\begin{array}{l}\text { Allocation concealment } \\
\text { (selection bias) }\end{array}$ & Unclear risk & Not reported \\
\hline $\begin{array}{l}\text { Blinding (performance } \\
\text { bias and detection bias) } \\
\text { All outcomes }\end{array}$ & Unclear risk & $\begin{array}{l}\text { Quote: "Both participants and investigators were blinded to the pharma- } \\
\text { cotherapy condition." No further information provided, unclear if counsellors } \\
\text { blinded to treatment condition }\end{array}$ \\
\hline
\end{tabular}


Cox 2012 (Continued)

Incomplete outcome data Low risk $\quad 30 \%$ lost to follow-up at 6 months, no difference between groups (attrition bias)

All outcomes

\section{CTRI/2013/07/003830}

\begin{tabular}{|c|c|c|}
\hline \multirow[t]{3}{*}{ Methods } & \multicolumn{2}{|l|}{ Study design: RCT } \\
\hline & \multicolumn{2}{|l|}{ Country: India } \\
\hline & \multicolumn{2}{|c|}{ Setting: 2 primary health centres } \\
\hline Participants & \multicolumn{2}{|c|}{ Current smokers currently undergoing treatment for tuberculosis } \\
\hline \multirow[t]{3}{*}{ Interventions } & \multicolumn{2}{|c|}{ - Bupropion SR. 150 mg given once daily for three days, followed by twice daily for seven weeks } \\
\hline & \multicolumn{2}{|c|}{ No information given as to whether the trial was placebo-controlled } \\
\hline & \multicolumn{2}{|c|}{ All participants given standard counselling, totalling 30 minutes } \\
\hline Outcomes & \multicolumn{2}{|c|}{ - Smoking cessation: not specified. Validated by self-report and carbon monoxide monitors } \\
\hline Funding Source & \multicolumn{2}{|c|}{ United States Agency for International Developement through World Health Organization } \\
\hline Author conflicts of interest & \multicolumn{2}{|l|}{ None specified } \\
\hline \multicolumn{3}{|l|}{ Notes } \\
\hline \multicolumn{3}{|l|}{ Risk of bias } \\
\hline Bias & Authors' judgement & Support for judgement \\
\hline $\begin{array}{l}\text { Random sequence genera- } \\
\text { tion (selection bias) }\end{array}$ & Unclear risk & $\begin{array}{l}\text { Quote: "Permuted block randomization, fixed". This however may not be com- } \\
\text { puter generated, and therefore not truly random }\end{array}$ \\
\hline $\begin{array}{l}\text { Allocation concealment } \\
\text { (selection bias) }\end{array}$ & High risk & $\begin{array}{l}\text { Study is open-label, so both participants and researchers are aware of drug al- } \\
\text { location. }\end{array}$ \\
\hline $\begin{array}{l}\text { Blinding (performance } \\
\text { bias and detection bias) } \\
\text { All outcomes }\end{array}$ & High risk & $\begin{array}{l}\text { Study is open-label, so both participants and researchers are aware of drug al- } \\
\text { location. }\end{array}$ \\
\hline $\begin{array}{l}\text { Incomplete outcome data } \\
\text { (attrition bias) } \\
\text { All outcomes }\end{array}$ & Unclear risk & Dropouts not specified \\
\hline
\end{tabular}

\section{Da Costa 2002}

$\begin{array}{ll}\text { Methods } & \text { Study design: RCT } \\ & \text { Country: Brazil } \\ & \text { Setting: cessation clinic } \\ & \text { Recruitment: volunteers to a smokers' support group }\end{array}$


Da Costa 2002 (Continued)

Participants 144 smokers randomized; "predominantly female"; age, cigarettes per day not described

- Nortriptyline, max. 75 mg/day for 6 weeks including titration period, begun 1 week before start of behaviour therapy

- Placebo

Common components: 6-weekly group CBT

Outcomes

- Smoking cessation: prolonged abstinence at 6 months after end of treatment (validation method not specified)

- Adverse events: measured for unspecified period

\begin{tabular}{ll}
\hline Funding Source & None specified \\
\hline Author conflicts of interest & None specified \\
\hline Notes & \\
\hline
\end{tabular}

\section{Risk of bias}

\begin{tabular}{|c|c|c|}
\hline Bias & Authors' judgement & Support for judgement \\
\hline $\begin{array}{l}\text { Random sequence genera- } \\
\text { tion (selection bias) }\end{array}$ & Low risk & $\begin{array}{l}\text { Quote: "Each patient chose a blind number from a box ...' } \\
\text { Comment: probably adequate }\end{array}$ \\
\hline $\begin{array}{l}\text { Allocation concealment } \\
\text { (selection bias) }\end{array}$ & Unclear risk & $\begin{array}{l}\text { Quote: "... with each number corresponding to a "medication kit" that was ex- } \\
\text { ternally undistinguishable. Patients and professionals participating in this } \\
\text { study were blindfolded for this distribution." Comment: potentially adequate } \\
\text { but difference in numbers in each group not accounted for }\end{array}$ \\
\hline $\begin{array}{l}\text { Blinding (performance } \\
\text { bias and detection bias) } \\
\text { All outcomes }\end{array}$ & Unclear risk & Quote: "Double-blind" but insufficient detail provided \\
\hline $\begin{array}{l}\text { Incomplete outcome data } \\
\text { (attrition bias) } \\
\text { All outcomes }\end{array}$ & Unclear risk & Number lost in each group not clear \\
\hline
\end{tabular}

\section{Dalsgarð 2004}

\begin{tabular}{ll}
\hline Methods & Study design: RCT \\
& $\begin{array}{l}\text { Country: Denmark } \\
\text { Setting: } 5 \text { hospitals } \\
\text { Recruitment: hospital staff }\end{array}$ \\
\hline Participants & $\begin{array}{l}\text { 335 smokers including physicians, nurses, other hospital service and admin staff; } 75 \% \text { female; average } \\
\text { age 43; average cigarettes per day } 19\end{array}$ \\
\hline Interventions & Bupropion, 300 mg/day for 7 weeks \\
& Common components: motivational support around TQD, at weeks 3 and 7, and at 12-week follow-up \\
\hline
\end{tabular}


Dalsgarð 2004 (Continued)

Outcomes

Funding Source

- Smoking cessation: prolonged abstinence at 6 months (starting from week 4) Validated by $\mathrm{CO}<10$ ppm

Author conflicts of interest None specified

Notes

\section{Risk of bias}

\begin{tabular}{lll}
\hline Bias & Authors' judgement & Support for judgement \\
\hline $\begin{array}{l}\text { Random sequence genera- } \\
\text { tion (selection bias) }\end{array}$ & Low risk & Randomization was computer generated and blinded \\
\hline $\begin{array}{l}\text { Allocation concealment } \\
\text { (selection bias) }\end{array}$ & Low risk & $\begin{array}{l}\text { Allocation was double-blinded and bupropion and placebo tablets were iden- } \\
\text { tical in form and number. }\end{array}$ \\
\hline $\begin{array}{l}\text { Blinding (performance } \\
\text { bias and detection bias) } \\
\text { All outcomes }\end{array}$ & Unclear risk & $\begin{array}{l}\text { Quote: "Double-blind" } \\
\text { Comment: clear that participants were blinded but unclear if all staff were } \\
\text { blinded }\end{array}$ \\
$\begin{array}{l}\text { Incomplete outcome data } \\
\text { (attrition bias) } \\
\text { All outcomes }\end{array}$ & Low risk & $\begin{array}{l}32 \% \text { of the bupropion group and 43\% the placebo group discontinued treat- } \\
\text { ment, included in analysis }\end{array}$ \\
\hline
\end{tabular}

\section{Ebbert 2014}

Study design: RCT
Country: USA
Setting: Mayo Clinic in Rochester, Minnesota and University of Minnesota

\begin{tabular}{ll}
\hline Participants & 506 participants randomized; $47 \%$ female; average age 42.0; average cigarettes per day 19.6; mean FT- \\
ND 5.3
\end{tabular}
ND 5.3

Interventions

- Bupropion SR and varenicline. Bupropion SR was taken once daily $(150 \mathrm{mg})$ for days 1 to 3 , then twice daily (total of $300 \mathrm{mg} / \mathrm{d}$ ) for 12 weeks. Varenicline was taken once daily $(0.5 \mathrm{mg})$ for 3 days, then 0.5 $\mathrm{mg}$ twice daily (total of $1 \mathrm{mg} / \mathrm{d}$ ) for days 4 to 7 , and finally to the maintenance dose of $1 \mathrm{mg}$ twice daily (total, $2 \mathrm{mg} / \mathrm{d}$ ) for 11 weeks.

- Varenicline and placebo. Varenicline was taken according to the above dosing and schedule with matching placebo in place of bupropion.

Common components: brief behavioral counselling at each clinic visit, totalling 110 minutes

\begin{tabular}{ll}
\hline Outcomes & Smoking cessation: prolonged abstinence (no smoking from 2 weeks after the target quit date) at 52 \\
& weeks. Validated by CO \\
- Adverse events: measured for 52 weeks
\end{tabular}

Funding Source

The clinical trial was supported by National Institutes of Health (NIH) grant CA 138417 (primary investigator, Dr Ebbert). Medication (varenicline) was provided by Pfizer 
Ebbert 2014 (Continued)

Author conflicts of interest All authors have completed and submitted the ICMJE Form for Disclosure of Potential Conflicts of Interest. Dr Ebbert reports serving as an investigator for clinical trials funded by Pfizer, receipt of consultancy fees from GlaxoSmithKline, research support from Pfizer, and research support from Orexigen and JHP Pharmaceuticals outside of the current study. Dr Hatsukami reports receipt of research support from Nabi Biopharmaceuticals outside of the current study. Dr Hays reports serving as an investigator for clinical trials funded by Pfizer. Dr Hurt reports receipt of consulting fees from Pfizer, an unrestricted grant from Pfizer Medical Education Group, and provision of expert testimony in Florida tobacco litigation cases.

Notes

\section{Risk of bias}

\begin{tabular}{|c|c|c|}
\hline Bias & Authors' judgement & Support for judgement \\
\hline $\begin{array}{l}\text { Random sequence genera- } \\
\text { tion (selection bias) }\end{array}$ & Low risk & $\begin{array}{l}\text { Quote: "computer-generated randomization sequence with variable-sized } \\
\text { blocks ranging from } 2 \text { to } 8 \text { stratified by study site". }\end{array}$ \\
\hline $\begin{array}{l}\text { Allocation concealment } \\
\text { (selection bias) }\end{array}$ & Low risk & Central pharmacy was used to allocate interventions \\
\hline $\begin{array}{l}\text { Blinding (performance } \\
\text { bias and detection bias) } \\
\text { All outcomes }\end{array}$ & Low risk & $\begin{array}{l}\text { Quote: "Study medication was labeled and dispensed according to participant } \\
\text { identification, ensuring that treatment assignment remained concealed from } \\
\text { the participant, investigators, and all study personnel having participant con- } \\
\text { tact." }\end{array}$ \\
\hline $\begin{array}{l}\text { Incomplete outcome data } \\
\text { (attrition bias) } \\
\text { All outcomes }\end{array}$ & Low risk & $\begin{array}{l}\text { Dropout rates are as follows: } 40 / 249 \text { varenicline + bupropion; } 42 / 257 \text { vareni- } \\
\text { cline + placebo } \\
\text { Dropout rate is below } 50 \% \text { in all trial arms }\end{array}$ \\
\hline
\end{tabular}

Eisenberg 2013

\begin{tabular}{|c|c|}
\hline \multirow[t]{4}{*}{ Methods } & Study design: RCT \\
\hline & Country: Canada \\
\hline & Setting: 38 hospitals \\
\hline & Recruitment: hospital patients with acute myocardial infarction \\
\hline Participants & $\begin{array}{l}392 \text { smokers of at least } 10 \text { cigarettes per day, hospitalized with enzyme positive acute myocardial in- } \\
\text { farction. } 16 \% \text { female; average age 54; average cigarettes per day 23; average FTND not specified }\end{array}$ \\
\hline \multirow[t]{2}{*}{ Interventions } & $\begin{array}{l}\text { - Bupropion, } 300 \mathrm{mg} / \text { day for } 9 \text { weeks ( } 150 \mathrm{mg} \text { for } 3 \text { days, then } 150 \mathrm{mg} 2 \text { x day for remainder) } \\
\text { - Placebo, same schedule as bupropion }\end{array}$ \\
\hline & $\begin{array}{l}\text { Common components: } 7 \text { one-to-one counselling sessions by research nurses at baseline and all fol- } \\
\text { low-ups of }<20 \text { mins (average 5) - mix of phone and in-person }\end{array}$ \\
\hline \multirow[t]{2}{*}{ Outcomes } & $\begin{array}{l}\text { - Smoking cessation: } 12 \text { months continuous abstinence ( } 7 \text { days ppa also reported). Validated by } \mathrm{CO} \leq \\
10 \mathrm{ppm}\end{array}$ \\
\hline & - Adverse events: non-SAEs measured for 9 weeks. SAEs measured for 12 months \\
\hline Funding Source & Canadian Institutes of Health Research and Heart and Stroke Foundation of Quebec \\
\hline
\end{tabular}


Eisenberg 2013 (Continued)

Author conflicts of interest Drs Eisenberg and Gervais reported that they served as paid consultants for Pfizer Canada Inc.'s Varenicline Advisory Board. Dr Gervais reported that he received funds from Pfizer Canada Inc., for lectures including service on speaker bureaus, development of educational presentations, and travel/accommodations/meeting ex- penses. Dr Eisenberg received funding from Pfizer Canada Inc., to perform the Evaluation of Varenicline (Champix) in Smoking Cessation for Patients Post-Acute Coronary Syndrome [EVITA] Trial; NCT00794573).

Notes New for 2013 update

Patients not allowed to smoke whilst hospitalized. SAEs reported over 12 months, so not included in analysis. No quit extracted from percentages provided; denominators do not include 9 deaths in bupropion and 6 deaths in placebo group, all deemed not to be related to study medication.

Adherence to treatment: $72.3 \%$ bupropion, $82 \%$ placebo took at least 1 pill per day

\section{Risk of bias}

\begin{tabular}{lll}
\hline Bias & Authors' judgement & Support for judgement \\
\hline $\begin{array}{l}\text { Random sequence genera- } \\
\text { tion (selection bias) }\end{array}$ & Low risk & $\begin{array}{l}\text { Quote: "Randomization was done via an internet website using random blocks } \\
\text { of } 2 \text { and } 4 \text { and was stratified by center to ensure that similar numbers of pa- } \\
\text { tients were randomized to the } 2 \text { arms of the study at each study center" }\end{array}$ \\
\hline $\begin{array}{l}\text { Allocation concealment } \\
\text { (selection bias) }\end{array}$ & Low risk & Allocation performed centrally, see above \\
\hline $\begin{array}{l}\text { Blinding (performance } \\
\text { bias and detection bias) } \\
\text { All outcomes }\end{array}$ & Unclear risk & $\begin{array}{l}\text { Quote: "Double-blind." "All clinical end points were adjudicated by members } \\
\text { of the Endpoints Evaluation Committee who were blinded to treatment assign- } \\
\text { ment." } \\
\text { Comment: no further information provided }\end{array}$ \\
\hline
\end{tabular}

Incomplete outcome data Low risk $\quad 77 \%$ followed up at 12 months, similar across arms

(attrition bias)

All outcomes

Elsasser 2002

\begin{tabular}{ll} 
Methods & Study design: RCT \\
Country: USA & $\begin{array}{l}\text { Setting: community-based } \\
\text { Recruitment method: recruited from the community }\end{array}$ \\
\hline Participants & $\begin{array}{l}17 \text { participants randomized; } 41.2 \% \text { female; average age 16.5; average cigarettes per day not specified; } \\
\text { mean FTND not specified }\end{array}$ \\
& All participants were between 14-19 years old \\
\hline Interventions & Bupropion SR, 150 mg twice daily for an unspecified duration \\
& All participants recieved an unkown number and duration of behavioural modification sessions. \\
\hline Outcomes & $\begin{array}{l}\text { Smoking cessation: prolonged abstinence between weeks 8-12 - too short a follow-up for considera- } \\
\text { tion for this outcome as part of our review }\end{array}$ \\
\hline Adverse events: measured for 12 weeks
\end{tabular}


Elsasser 2002 (Continued)

Funding Source Funding receieved from GlaxoWellcome

Author conflicts of interest None specified

Notes

\section{Risk of bias}

\begin{tabular}{|c|c|c|}
\hline Bias & Authors' judgement & Support for judgement \\
\hline $\begin{array}{l}\text { Random sequence genera- } \\
\text { tion (selection bias) }\end{array}$ & Unclear risk & $\begin{array}{l}\text { Quote: "randomized, double-blind, placebo-controlled trial" } \\
\text { Comment: no further information given }\end{array}$ \\
\hline $\begin{array}{l}\text { Allocation concealment } \\
\text { (selection bias) }\end{array}$ & Unclear risk & $\begin{array}{l}\text { Quote: "randomized, double-blind, placebo-controlled trial" } \\
\text { Comment: no further information given }\end{array}$ \\
\hline $\begin{array}{l}\text { Blinding (performance } \\
\text { bias and detection bias) } \\
\text { All outcomes }\end{array}$ & Unclear risk & $\begin{array}{l}\text { Quote: "randomized, double-blind, placebo-controlled trial" } \\
\text { Comment: no further information given }\end{array}$ \\
\hline $\begin{array}{l}\text { Incomplete outcome data } \\
\text { (attrition bias) } \\
\text { All outcomes }\end{array}$ & High risk & $\begin{array}{l}\text { Dropout rates are as follows: } 2 / 9(22.2 \%) \text { in the placebo; } 4 / 8(50 \%) \text { of the } \\
\text { bupropion group. } \\
\text { Therefore dropout was higher than } 20 \% \text { between the two groups. }\end{array}$ \\
\hline
\end{tabular}

\section{Evins 2001}

\begin{tabular}{|c|c|}
\hline Methods & $\begin{array}{l}\text { Study design: RCT } \\
\text { Country: USA } \\
\text { Setting: outpatient clinic } \\
\text { Recruitment: volunteers }\end{array}$ \\
\hline Participants & $\begin{array}{l}18 \text { smokers with stable schizophrenia (excluding } 1 \text { dropout prior to medication); 39\% female; average } \\
\text { age 45.5/42.7; average cigarettes per day } 34\end{array}$ \\
\hline Interventions & $\begin{array}{l}\text { - Bupropion. } 300 \mathrm{mg} / \text { day for } 3 \text { months. TQD after week } 3 \\
\text { - Placebo } \\
\text { Common components: } 9 \times 1 \text { hour weekly group CBT }\end{array}$ \\
\hline Outcomes & $\begin{array}{l}\text { - Smoking cessation: prolonged abstinence at } 6 \text { months. Validated by } \mathrm{CO}<9 \mathrm{ppm} \text { or serum cotinine }< \\
14 \mathrm{ng} / \mathrm{mL} \\
\text { - Adverse events: measured for } 24 \text { weeks }\end{array}$ \\
\hline Funding Source & $\begin{array}{l}\text { National Association for Research on Schizophrenia and Affective Disorders. Medication provided by } \\
\text { Glaxo Wellcome Inc }\end{array}$ \\
\hline Author conflicts of interest & None specified \\
\hline Notes & $\begin{array}{l}\text { 2-year follow-up also reported. } 3 \text { additional quitters, not used in meta-analysis since additional therapy } \\
\text { used }\end{array}$ \\
\hline
\end{tabular}

\section{Risk of bias}


Evins 2001 (Continued)

\begin{tabular}{lll} 
Bias & Authors' judgement & Support for judgement \\
\hline $\begin{array}{l}\text { Random sequence genera- } \\
\text { tion (selection bias) }\end{array}$ & Unclear risk & Randomization method not described \\
\hline $\begin{array}{l}\text { Allocation concealment } \\
\text { (selection bias) }\end{array}$ & Unclear risk & Not specified \\
\hline $\begin{array}{l}\text { Blinding (performance } \\
\text { bias and detection bias) } \\
\text { All outcomes }\end{array}$ & Unclear risk & $\begin{array}{l}\text { Quote: "Subjects were randomly assigned to 12 weeks of double-blind bupro- } \\
\text { pion SR, 150 mg/day, or an identical appearing placebo tablet added to their } \\
\text { usual medication regimen." } \\
\text { Comment: unclear if all staff members were blinded }\end{array}$ \\
\hline
\end{tabular}

Incomplete outcome data Low risk (attrition bias)

All outcomes
Quote: "Nineteen subjects were enrolled and 18 subjects completed the 6month smoking cessation trial."

\section{Evins 2005}

\begin{tabular}{|c|c|c|}
\hline Methods & \multicolumn{2}{|c|}{$\begin{array}{l}\text { Study design: RCT } \\
\text { Country: USA } \\
\text { Setting: clinic } \\
\text { Recruitment: volunteers }\end{array}$} \\
\hline Participants & \multicolumn{2}{|c|}{$\begin{array}{l}56 \text { smokers with schizophrenia (excluding } 6 \text { dropouts prior to medication); } 27 \% \text { female; average age } 45 \text {, } \\
\text { average cigarettes per day } 37 / 26\end{array}$} \\
\hline Interventions & \multicolumn{2}{|c|}{$\begin{array}{l}\text { - Bupropion, } 300 \mathrm{mg} / \text { day for } 3 \text { months } \\
\text { - Placebo } \\
\text { Common components: } 12 \text { session group CBT }\end{array}$} \\
\hline Outcomes & \multicolumn{2}{|c|}{$\begin{array}{l}\text { - Smoking cessation: } 7 \text { day ppa at } 6 \text { months. Validated by } \mathrm{CO}<9 \mathrm{ppm} \\
\text { - Adverse events: measured for unspecified period }\end{array}$} \\
\hline Funding Source & \multicolumn{2}{|c|}{$\begin{array}{l}\text { National Association for Research on Schizophrenia and Affective Disorders. Medication provided by } \\
\text { GlaxoSmithKline }\end{array}$} \\
\hline Author conflicts of interest & \multicolumn{2}{|l|}{ None specified } \\
\hline Notes & \multicolumn{2}{|c|}{ There was a significant treatment effect at EOT. } \\
\hline \multicolumn{3}{|l|}{ Risk of bias } \\
\hline Bias & Authors' judgement & Support for judgement \\
\hline $\begin{array}{l}\text { Random sequence genera- } \\
\text { tion (selection bias) }\end{array}$ & Unclear risk & Randomization method not stated \\
\hline $\begin{array}{l}\text { Allocation concealment } \\
\text { (selection bias) }\end{array}$ & Unclear risk & Allocation concealment not described \\
\hline $\begin{array}{l}\text { Blinding (performance } \\
\text { bias and detection bias) }\end{array}$ & Unclear risk & $\begin{array}{l}\text { Quote: "Double-blind" with "identical placebo tablets." No further information } \\
\text { provided }\end{array}$ \\
\hline
\end{tabular}


Evins 2005 (Continued)

All outcomes

Incomplete outcome data Low risk (attrition bias)

All outcomes
Only people taking at least one dose of study medication included in analyses in paper. 5 in each group lost to follow-up and included as smokers

\section{Evins 2007}

\begin{tabular}{|c|c|}
\hline Methods & $\begin{array}{l}\text { Study design: RCT } \\
\text { Country: USA } \\
\text { Setting: community mental health centre } \\
\text { Recruitment: outpatients }\end{array}$ \\
\hline Participants & $\begin{array}{l}51 \text { smokers ( } \geq 10 \text { cigarettes per day) with schizophrenia; average age } 44 \text {; average cigarettes per day } \\
28 / 25\end{array}$ \\
\hline Interventions & $\begin{array}{l}\text { - Bupropion, } 300 \mathrm{mg} / \text { day for } 3 \text { months, nicotine patch, } 21 \mathrm{mg} \text { for } 8 \text { weeks including tapering, } 2 \mathrm{mg} \text { nico- } \\
\text { tine gum } \\
\text { - Placebo and NRT, same schedule as bupropion } 1 \\
\text { Common components: } 12 \text { session group CBT, TQD week } 4\end{array}$ \\
\hline Outcomes & $\begin{array}{l}\text { - Smoking cessation: abstinence at } 12 \text { months from TQD. Validated by } \mathrm{CO} \leq 8 \mathrm{ppm} \\
\text { - Adverse events: measured for unspecified period }\end{array}$ \\
\hline Funding Source & Massachusetts Department of Mental Health. Medication provided by GlaxoSmithKline \\
\hline Author conflicts of interest & None specified \\
\hline Notes & Used in bupropion + NR \\
\hline
\end{tabular}

\section{Risk of bias}

\begin{tabular}{|c|c|c|}
\hline Bias & Authors' judgement & Support for judgement \\
\hline $\begin{array}{l}\text { Random sequence genera- } \\
\text { tion (selection bias) }\end{array}$ & Unclear risk & Randomization method not described \\
\hline $\begin{array}{l}\text { Allocation concealment } \\
\text { (selection bias) }\end{array}$ & Unclear risk & Allocation concealment not described \\
\hline $\begin{array}{l}\text { Blinding (performance } \\
\text { bias and detection bias) } \\
\text { All outcomes }\end{array}$ & Low risk & $\begin{array}{l}\text { Quote: "Participants and investigators remained blind to the treatment condi- } \\
\text { tion (bupropion or placebo) } \\
\text { throughout the follow-up period." "Assessment of treatment assignment was } \\
\text { at the level of chance for both participants and staff at Weeks } 4 \text { and } 12 \text { for both } \\
\text { treatment assignments." }\end{array}$ \\
\hline $\begin{array}{l}\text { Incomplete outcome data } \\
\text { (attrition bias) } \\
\text { All outcomes }\end{array}$ & Low risk & $\begin{array}{l}20 \% \text { of the bupropion group and } 18 \% \text { of the placebo group were lost to fol- } \\
\text { low-up at week 12; included as smokers. All other participants followed up at } \\
12 \text { months }\end{array}$ \\
\hline
\end{tabular}


Fatemi 2013

\begin{tabular}{ll}
\hline Methods & Study design: RCT \\
Country: USA \\
Setting: not specified \\
Recruitment method: not specified
\end{tabular}

Participants

24 participants randomized; percentage female unspecified; average age not specified; average cigarettes per day not specified, mean FTND not specified

All participants had been diagnosed with schizophrenia or schizoaffective disorder.

\begin{tabular}{ll}
\hline Interventions & Varenicline, $1 \mathrm{mg}$ twice daily for 12 weeks \\
- & Buproprion SR, $150 \mathrm{mg}$ twice daily for 12 weeks \\
- Matched placebo & Common components: 20 minutes of antismoking counselling at each visit, totalling 80 minutes \\
\hline Outcomes & - Smoking cessation: definition not specified \\
\hline Funding Source & Adverse events: measured for 12 weeks \\
\hline Grant support recieved from the National Institute on Drug Abuse (grant \# R01DA024674-01A1) to SHF. \\
Pfizer provided free samples of varenicline and placebo and had no role in design or conduct of this \\
study. Watson Laboratories provided free samples of Bupropion SR.
\end{tabular}

Author conflicts of interest None specified

\section{Notes}

\section{Risk of bias}

\begin{tabular}{lll}
\hline Bias & Authors' judgement & Support for judgement \\
\hline $\begin{array}{l}\text { Random sequence genera- } \\
\text { tion (selection bias) }\end{array}$ & Unclear risk & No relevant information provided \\
\hline $\begin{array}{l}\text { Allocation concealment } \\
\text { (selection bias) }\end{array}$ & Unclear risk & No relevant information provided \\
\hline $\begin{array}{l}\text { Blinding (performance } \\
\text { bias and detection bias) } \\
\text { All outcomes }\end{array}$ & Unclear risk & No relevant information provided \\
\hline $\begin{array}{l}\text { Incomplete outcome data } \\
\text { (attrition bias) } \\
\text { All outcomes }\end{array}$ & Unclear risk & Dropout rate is 41\%, but difference between groups not detailed \\
\hline
\end{tabular}

Ferry 1992

$\begin{array}{ll}\text { Methods } & \text { Study design: RCT } \\ \text { Country: USA } \\ \text { Setting: clinic } \\ \text { Recruitment: not specified }\end{array}$


Ferry 1992 (Continued)

\begin{tabular}{ll} 
Participants & 42 male smokers \\
\hline Interventions & Bupropion, $300 \mathrm{mg} /$ day for 3 months \\
- Placebo & Common components: group smoking cessation and relapse prevention counselling
\end{tabular}

\begin{tabular}{ll}
\hline Outcomes & - Smoking cessation: sustained abstinence at $6 \mathrm{~m}$ from end of treatment. Validated by saliva cotinine \\
- Adverse events: measured for unspecified period
\end{tabular}

\begin{tabular}{ll}
\hline Funding Source & None specified \\
\hline Author conflicts of interest & None specified \\
\hline Notes & Abstract with no further details
\end{tabular}

\section{Risk of bias}

\begin{tabular}{lll}
\hline Bias & Authors' judgement & Support for judgement \\
\hline $\begin{array}{l}\text { Random sequence genera- } \\
\text { tion (selection bias) }\end{array}$ & Unclear risk & Randomization method not described \\
\hline $\begin{array}{l}\text { Allocation concealment } \\
\text { (selection bias) }\end{array}$ & Unclear risk & Allocation concealment not described \\
\hline $\begin{array}{l}\text { Blinding (performance } \\
\text { bias and detection bias) } \\
\text { All outcomes }\end{array}$ & Unclear risk & Quote: "Double-blind," no further detail provided \\
\hline $\begin{array}{l}\text { Incomplete outcome data } \\
\text { (attrition bias) } \\
\begin{array}{l}\text { All outcomes } \\
\end{array}\end{array}$ & Unclear risk & No details given \\
\hline
\end{tabular}

Ferry 1994

\begin{tabular}{ll}
\hline Methods & Study design: RCT \\
& $\begin{array}{l}\text { Country: USA } \\
\text { Setting: Veterans Medical Centre } \\
\text { Recruitment: not specified }\end{array}$ \\
\hline Participants & 190 smokers \\
\hline Interventions & Bupropion, $100 \mathrm{mg} \times 3 /$ day for 12 weeks \\
& Placebo \\
Common components: group smoking cessation and relapse prevention counselling; TQD within first 4
\end{tabular}


Ferry 1994 (Continued)

\begin{tabular}{ll} 
Funding Source & None specified \\
\hline Author conflicts of interest & None specified \\
\hline Notes & Abstract with long-term abstinence data supplied by author
\end{tabular}

\section{Risk of bias}

\begin{tabular}{lll}
\hline Bias & Authors' judgement & Support for judgement \\
\hline $\begin{array}{l}\text { Random sequence genera- } \\
\text { tion (selection bias) }\end{array}$ & Unclear risk & Randomization method not described \\
\hline $\begin{array}{l}\text { Allocation concealment } \\
\text { (selection bias) }\end{array}$ & Unclear risk & Allocation concealment not described \\
\hline $\begin{array}{l}\text { Blinding (performance } \\
\text { bias and detection bias) } \\
\text { All outcomes }\end{array}$ & Unclear risk & Quote: "Double-blind," no further detail provided \\
\hline $\begin{array}{l}\text { Incomplete outcome data } \\
\text { (attrition bias) } \\
\text { All outcomes }\end{array}$ & Unclear risk & $\begin{array}{l}72 \% \text { followed-up intervention, } 61 \% \text { followed-up control. "The most conserva- } \\
\text { tive approach to analysis would reclassify all of these individuals as smokers } \\
\text { due to protocol violation." }\end{array}$ \\
\hline
\end{tabular}

Fossati 2007

\begin{tabular}{|c|c|}
\hline Methods & $\begin{array}{l}\text { Study design: RCT } \\
\text { Country: Italy } \\
\text { Setting: primary care clinics } \\
\text { Recruitment: patients of } 71 \text { general practitioners }\end{array}$ \\
\hline Participants & 593 smokers randomised; $40 \%$ female; average age 49; average cigarettes per day 22 \\
\hline Interventions & $\begin{array}{l}\text { - Bupropion, } 300 \mathrm{mg} / \text { day for } 7 \text { weeks } \\
\text { - Placebo } \\
\text { Common components: GP visits at enrolment and 4, 7,26 \& } 52 \text { weeks, phone calls } 1 \text { day pre-TQD, } 3 \\
\text { days post-TQD, } 10 \text { weeks post-enrolment. Classified as low intensity }\end{array}$ \\
\hline Outcomes & $\begin{array}{l}\text { - Smoking cessation: abstinence at } 12 \text { months (continuous from week } 4 \text { ). Validated by } \mathrm{CO} \leq 10 \mathrm{ppm} \text { at } \\
\text { each visit } \\
\text { - Adverse events: measured for } 52 \text { weeks }\end{array}$ \\
\hline Funding Source & Mario Negri Institute and GlaxoSmithKline \\
\hline Author conflicts of interest & Dr Apolone has received consulting and lecture fees from GlaxoSmithKline \\
\hline Notes & \\
\hline Risk of bias & \\
\hline Bias & Support for judgement \\
\hline
\end{tabular}


Fossati 2007 (Continued)

Random sequence genera- Unclear risk Method of sequence generation not specified tion (selection bias)

$\begin{array}{ll}\begin{array}{l}\text { Allocation concealment } \\ \text { (selection bias) }\end{array} \quad \text { Unclear risk } & \begin{array}{l}\text { Stated to be double-blind, but not explicit that GPs blind to randomization } \\ \text { code. }\end{array}\end{array}$

\begin{tabular}{|c|c|c|}
\hline $\begin{array}{l}\text { Blinding (performance } \\
\text { bias and detection bias) } \\
\text { All outcomes }\end{array}$ & Unclear risk & Quote: "Double-blind", further detail not provided \\
\hline $\begin{array}{l}\text { Incomplete outcome data } \\
\text { (attrition bias) } \\
\text { All outcomes }\end{array}$ & Low risk & $\begin{array}{l}\text { 15\% Bupropion and } 17 \% \text { placebo did not attend } 12-\text { month follow-up, included } \\
\text { as smokers }\end{array}$ \\
\hline
\end{tabular}

\section{Gariti 2009}

\begin{tabular}{ll}
\hline Methods & Study design: $2 \times 2$ factorial RCT \\
Country: USA \\
Setting: university \\
Recruitment: self-referral from community
\end{tabular}

\begin{tabular}{ll}
\hline Participants & $\begin{array}{l}260 \text { light smokers (6-15 cigarettes per day) motivated to quit; } 57 \% \text { female, average age 54; average cig- } \\
\text { arettes per day 11; average FTND } 4\end{array}$
\end{tabular}

\begin{tabular}{ll}
\hline Interventions & Bupropion SR and placebo patch. Bupropion for 9 weeks. Patch for 8 weeks. 10 weeks individualized \\
counselling sessions \\
-
\end{tabular}

\begin{tabular}{ll}
\hline Funding Source & National Institute on Drug Abuse \\
\hline Author conflicts of interest & None specified \\
\hline
\end{tabular}

\begin{tabular}{ll}
\hline Notes & New for 2013 update \\
& Used in direct comparison of bupropion and NRT only, pooling 1+2 versus $3+4$ \\
\hline
\end{tabular}

\section{Risk of bias}

\begin{tabular}{lll}
\hline Bias & Authors' judgement & Support for judgement \\
\hline $\begin{array}{l}\text { Random sequence genera- } \\
\text { tion (selection bias) }\end{array}$ & Low risk & Computerized 'urn randomization' \\
\hline
\end{tabular}


Gariti 2009 (Continued)

\begin{tabular}{|c|c|c|}
\hline $\begin{array}{l}\text { Allocation concealment } \\
\text { (selection bias) }\end{array}$ & Unclear risk & Not specified \\
\hline $\begin{array}{l}\text { Blinding (performance } \\
\text { bias and detection bias) } \\
\text { All outcomes }\end{array}$ & Low risk & $\begin{array}{l}\text { Quote: "double-blind, double-dummy" for medication component. "Neither } \\
\text { the nurses nor the participants knew which of the two formulations contained } \\
\text { the active formulation." }\end{array}$ \\
\hline $\begin{array}{l}\text { Incomplete outcome data } \\
\text { (attrition bias) } \\
\text { All outcomes }\end{array}$ & Low risk & $\begin{array}{l}\text { Missing data included as smokers. Similar losses to follow-up across both } \\
\text { groups }\end{array}$ \\
\hline
\end{tabular}

George 2002

\begin{tabular}{ll}
\hline Methods & Study design: RCT \\
& $\begin{array}{l}\text { Country: USA } \\
\text { Setting: mental health clinic } \\
\text { Recruitment: outpatients }\end{array}$ \\
\hline Participants & $\begin{array}{l}32 \text { smokers with schizophrenia motivated to quit; } 44 \% \text { female; average age 41/45; average cigarettes } \\
\text { per day } 24\end{array}$ \\
\hline Interventions & Bupropion, $300 \mathrm{mg} /$ day for 9 weeks. TQD 3 weeks \\
& Common components: 10 x 60 -minute weekly group therapy \\
\hline Outcomes & Smoking cessation: 7 day ppa at 6 months. Validated by expired CO < 10 ppm \\
\hline Funding Source & Adverse events: measured for unspecified period \\
\hline Author conflicts of interest & Schizophrenia and Depression. Medication provided by GlaxoSmithKline \\
\hline Notes & Nonecified
\end{tabular}

\section{Risk of bias}

\begin{tabular}{lll}
\hline Bias & Authors' judgement & Support for judgement \\
\hline $\begin{array}{l}\text { Random sequence genera- } \\
\text { tion (selection bias) }\end{array}$ & Unclear risk & Randomization method not described \\
\hline $\begin{array}{l}\text { Allocation concealment } \\
\text { (selection bias) }\end{array}$ & Unclear risk & Not described \\
\hline $\begin{array}{l}\text { Blinding (performance } \\
\text { bias and detection bias) } \\
\text { All outcomes }\end{array}$ & Unclear risk & $\begin{array}{l}\text { Quote: "Both subjects and research staff were blinded to study medication } \\
\text { assignment. Study medications were prepared by research pharmacists at } \\
\text { CMHC, using encapsulation of SR bupropion tablets with blue 00 opaque cap- } \\
\text { sules; placebo capsules contained only a dextrose matrix." }\end{array}$ \\
\hline
\end{tabular}

\begin{tabular}{|c|c|c|}
\hline $\begin{array}{l}\text { Incomplete outcome data } \\
\text { (attrition bias) }\end{array}$ & Unclear risk & $\begin{array}{l}\text { Quote: "Subjects who were lost during the trial or at } 6 \text {-month follow-up were } \\
\text { counted as smokers." Number followed-up at } 6 \text { months not reported }\end{array}$ \\
\hline
\end{tabular}




\begin{tabular}{ll}
\hline Methods & Study design: RCT \\
& $\begin{array}{l}\text { Country: USA } \\
\text { Setting: outpatient smoking research clinic } \\
\text { Recruitment: community volunteers }\end{array}$ \\
\hline Participants & 40 smokers; $63 \%$ female; average age 49; average cigarettes per day 23 \\
\hline Interventions & - Selegiline. $10 \mathrm{mg} /$ day for 9 weeks (5 mg/day in week 1 and week 9) \\
\hline Outcomes & Placebo \\
\hline Funding Source & Adverse events: measured for unspecified period \\
\hline Author conflicts of interest & $\begin{array}{l}\text { None specified } \\
\text { None specified }\end{array}$ \\
\hline Notes & $\begin{array}{l}\text { "The main side effects of SEL were anorexia, gastrointestinal symptoms, and insomnia. None of the } \\
\text { differences in adverse event ratings were significant in the SEL compared with the PLA group, and the } \\
\text { drug was well tolerated compared with the placebo group. Reports of anxiety/agitation in both the SEL } \\
\text { and PLA groups during the trial were high." } \\
\text { Funding: National Institute on Drug Abuse, US Department of Veteran Affairs, National Alliance for Re- } \\
\text { search on Schizophrenia and Depression }\end{array}$ \\
\hline
\end{tabular}

\section{Risk of bias}

\begin{tabular}{lll}
\hline Bias & Authors' judgement & Support for judgement \\
\hline $\begin{array}{l}\text { Random sequence genera- } \\
\text { tion (selection bias) }\end{array}$ & Unclear risk & Randomization method not described \\
\hline $\begin{array}{l}\text { Allocation concealment } \\
\text { (selection bias) }\end{array}$ & Unclear risk & Method not described \\
\hline $\begin{array}{l}\text { Blinding (performance } \\
\text { bias and detection bias) } \\
\text { All outcomes }\end{array}$ & Low risk & $\begin{array}{l}\text { Double-blind, adequacy of blinding tested in research staff; results suggested } \\
\text { blinding was adequate }\end{array}$ \\
\hline $\begin{array}{l}\text { Incomplete outcome data } \\
\text { (attrition bias) }\end{array}$ & High risk & \\
$\begin{array}{l}\text { All outcomes } \\
\text { 29/40 not assessed at } 6 \text { months. Greater loss to follow-up in placebo, exact da- } \\
\text { ta not reported }\end{array}$ \\
\hline
\end{tabular}

\begin{tabular}{ll} 
George 2008 & \\
\hline Methods & Study design: RCT \\
& Country: USA \\
& Setting: mental health centre \\
& Recruitment: outpatients
\end{tabular}

Participants

58 smokers with schizophrenia or schizoaffective disorder (excludes 1 receiving no study medication); $40 \%$ female; average age 40; average cigarettes per day $\sim 23$ 
George 2008 (Continued)

Interventions
- Bupropion, $300 \mathrm{mg} /$ day for 9 weeks, begun 7 days pre-TQD

- Placebo

Common components: nicotine patch $(21 \mathrm{mg} / 24 \mathrm{hrs})$ for 8 weeks from TQD and group behaviour therapy 10 -weekly sessions

\begin{tabular}{ll}
\hline Outcomes & - Smoking cessation: ppa at 6 months. Validated by CO $<10 \mathrm{ppm}$ \\
& - Adverse events: measured for unspecified period \\
\hline Funding Source & National Institute on Drug Abuse, National Alliance for Research on Schizophrenia and Depression \\
\hline Author conflicts of interest & None specified \\
\hline Notes & Bupropion as adjunct to NRT \\
\hline
\end{tabular}

\section{Risk of bias}

\begin{tabular}{|c|c|c|}
\hline Bias & Authors' judgement & Support for judgement \\
\hline $\begin{array}{l}\text { Random sequence genera- } \\
\text { tion (selection bias) }\end{array}$ & Unclear risk & Randomization method not described \\
\hline $\begin{array}{l}\text { Allocation concealment } \\
\text { (selection bias) }\end{array}$ & Unclear risk & Not described \\
\hline $\begin{array}{l}\text { Blinding (performance } \\
\text { bias and detection bias) } \\
\text { All outcomes }\end{array}$ & Unclear risk & Quote: "Double blind" but no additional details given \\
\hline $\begin{array}{l}\text { Incomplete outcome data } \\
\text { (attrition bias) } \\
\text { All outcomes }\end{array}$ & Low risk & $\begin{array}{l}6 / 29 \text { intervention and } 10 / 29 \text { control did not complete trial, included as smok- } \\
\text { ers }\end{array}$ \\
\hline
\end{tabular}

\section{Gilbert 2019}

\begin{tabular}{ll}
\hline Methods & Study design: RCT \\
Country: USA & Setting: from the community \\
Recruitment method: newspaper ads and community and university postings
\end{tabular}

\section{Outcomes}

- Smoking cessation: prolonged abstinence at 12 months. Validation method not specified 
Gilbert 2019 (Continued)

- Adverse events: measured for 62 days

Funding Source Supported by the National Institute on Drug Abuse (NIDA) Grant R01 DA012289 awarded to David G Gilbert

Author conflicts of interest None specified

Notes

\section{Risk of bias}

\begin{tabular}{lll}
\hline Bias & Authors' judgement & Support for judgement \\
\hline $\begin{array}{l}\text { Random sequence genera- } \\
\text { tion (selection bias) }\end{array}$ & Low risk & $\begin{array}{l}\text { Quote: randomized by “urn technique without replacement approach via a } \\
28: 28: 28: 16 \text { ratio to one of four groups." }\end{array}$ \\
\hline $\begin{array}{l}\text { Allocation concealment } \\
\text { (selection bias) }\end{array}$ & Unclear risk & No relevant information given \\
\hline $\begin{array}{l}\text { Blinding (performance } \\
\text { bias and detection bias) } \\
\text { All outcomes }\end{array}$ & Low risk & $\begin{array}{l}\text { Quote: "Researchers and participants in the quit groups were blind to pill and } \\
\text { patch type." }\end{array}$ \\
\hline $\begin{array}{l}\text { Incomplete outcome data } \\
\text { (attrition bias) } \\
\text { All outcomes }\end{array}$ & Low risk & Dropout rates: 0/34 - bupropion; 0/38 - nicotine patch; 0/35 - placebo \\
\hline
\end{tabular}

Gonzales 2001

\begin{tabular}{ll}
\hline Methods & Study design: RCT \\
& $\begin{array}{l}\text { Country: USA } \\
\text { Setting: } 16 \text { clinical trial centres } \\
\text { Recruitment: volunteers who had previously failed to quit using bupropion }\end{array}$ \\
\hline Participants & $\begin{array}{l}450 \text { smokers who had previously used bupropion for at least } 2 \text { weeks without adverse effects and failed } \\
\text { to quit; 55\% female in placebo arm, 48\% female in bupropion arm; average age 45; average cigarettes } \\
\text { per day not specified }\end{array}$ \\
\hline Interventions & Bupropion, 300 mg/day for 12 weeks, begun 7 days pre-TQD \\
& $\begin{array}{l}\text { Common components: brief individual counselling at visits weeks 1-7, 9, 12, + telephone counselling at } \\
4 \text { months and 5 months }\end{array}$ \\
\hline Outcomes & $\begin{array}{l}\text { Smoking cessation: prolonged abstinence } 12 \text { months, starting from week 4. Validated by CO } \\
\text { at each visit }\end{array}$ \\
& Adverse events: measured for unspecified duration \\
\hline Funding Source & GlaxoWellcome Inc \\
\hline Author conflicts of interest & None specified \\
\hline 6-month data published. 12-month data presented in a poster used since 2003 update
\end{tabular}


Gonzales 2001 (Continued)

Risk of bias

\begin{tabular}{|c|c|c|}
\hline Bias & Authors' judgement & Support for judgement \\
\hline $\begin{array}{l}\text { Random sequence genera- } \\
\text { tion (selection bias) }\end{array}$ & Low risk & $\begin{array}{l}\text { Quote: "Participants who satisfied the inclusion criteria were randomized to } \\
\text { the treatment phase and received either bupropion SR ... or matching placebo. } \\
\text { Eligible participants were assigned a protocol-specific treatment number on } \\
\text { the basis of a randomization code provided by GlaxoWellcome." }\end{array}$ \\
\hline $\begin{array}{l}\text { Allocation concealment } \\
\text { (selection bias) }\end{array}$ & Unclear risk & Allocation concealment method not described \\
\hline $\begin{array}{l}\text { Blinding (performance } \\
\text { bias and detection bias) } \\
\text { All outcomes }\end{array}$ & Low risk & $\begin{array}{l}\text { Quote: "Even though participants and the site staff were blinded to the drug } \\
\text { assignments and the site staff did not encourage participants to speculate on } \\
\text { their assignments, the lower placebo abstinence rates in the current study } \\
\text { may be attributable to the previous experiences of participants with bupropi- } \\
\text { on in their previous cessation attempts." However, little difference in comple- } \\
\text { tion between two arms, suggesting blinding may have been successful. }\end{array}$ \\
\hline $\begin{array}{l}\text { Incomplete outcome data } \\
\text { (attrition bias) } \\
\text { All outcomes }\end{array}$ & Unclear risk & $\begin{array}{l}\text { Quote: "...all participants who stopped participating in the study during the } \\
\text { treatment phase were considered to be smokers." Number of participants fol- } \\
\text { lowed-up at } 12 \text { months unclear }\end{array}$ \\
\hline
\end{tabular}

\section{Gonzales 2006}

\begin{tabular}{|c|c|}
\hline Methods & $\begin{array}{l}\text { Study design: RCT } \\
\text { Country: USA } \\
\text { Setting: } 19 \text { clinical trial centres } \\
\text { Recruitment: community volunteers }\end{array}$ \\
\hline Participants & $\begin{array}{l}673 \text { participants, with prior exposure to bupropion excluded; } 46 \% \text { female; average age } 42 \text {; average cig- } \\
\text { arettes per day } 21\end{array}$ \\
\hline Interventions & $\begin{array}{l}\text { - Bupropion, } 300 \mathrm{mg} / \mathrm{day} \text { for } 12 \text { weeks, begun } 7 \text { days pre-TQD } \\
\text { - Varenicline, } 2 \mathrm{mg} / \mathrm{day} \\
\text { - Placebo } \\
\text { Common components: brief (<10-minute) standardized individual counselling at } 12 \text { weekly visits dur- } \\
\text { ing drug phase and } 11 \text { clinic/phone visits during follow-up, problem solving and relapse prevention }\end{array}$ \\
\hline Outcomes & $\begin{array}{l}\text { - Smoking cessation: sustained abstinence at } 1 \text { year (starting from week } 4 \text { ). Validated by } \mathrm{CO} \leq 10 \mathrm{ppm} \\
\text { at each visit } \\
\text { - Adverse events: measured for } 13 \text { weeks }\end{array}$ \\
\hline Funding Source & Pfizer, Inc \\
\hline Author conflicts of interest & $\begin{array}{l}\text { Dr Gonzales reports having received research contracts from Pfizer, Sanofi-Aventis, GlaxoSmithKline, } \\
\text { and Nabi Biopharmaceuticals; consulting fees and honoraria from Pfizer, Sanofi-Aventis, and Glax- } \\
\text { oSmithKline; and owning } 5 \text { shares of Pfizer stock. Dr Rennard reports having had or currently having } \\
\text { a number of relationships with companies who provide product and/or services relevant to outpa- } \\
\text { tient management of COPD. These relationships include serving as a consultant for Adams, Almirall, } \\
\text { Altana, Array Bio- pharma, AstraZeneca, Aventis, Biolipox, Centocor, Dey, Critical Therapeutics, Glax- } \\
\text { oSmithKline, Johnson \& Johnson, Merck, Novartis, Ono Pharma, Otsuka, RJ Reynolds, Roche, Sankyo, } \\
\text { Schering-Plough, Scios, and Wyeth; advising regarding clinical trials for Altana, Astra- Zeneca, Aven- } \\
\text { tis, Centocor, GlaxoSmithKline, Novartis, Pfizer, and Philip Morris; and speaking at continuing med- }\end{array}$ \\
\hline
\end{tabular}


ical education programs and performing funded research both at basic and clinical levels for Altana, Astra-Zeneca, Boehringer Ingelheim, GlaxoSmithKline, and Novartis. Dr Nides reports having received research grants, consulting fees, and honoraria from Pfizer, Sanofi-Aventis, and GlaxoSmithKline. Dr Oncken reports having received research grants, consulting fees, and honoraria from Pfizer; receiving, at no cost, nicotine replacement and placebo products from GlaxoSmith- Kline for smoking cessation studies; and receiving honoraria from Pri-Med. Drs Azoulay, Watsky, Gong, Williams, and Reeves and Mr Billing report owning Pfizer stock or having stock options in Pfizer.

$\begin{array}{ll}\text { Notes } & \text { Bupropion was an active control for varenicline. } \\ \text { Bupropion versus placebo and bupropion versus varenicline comparisons contribute to review }\end{array}$

\section{Risk of bias}

\begin{tabular}{lll}
\hline Bias & Authors' judgement & Support for judgement \\
\hline $\begin{array}{l}\text { Random sequence genera- } \\
\text { tion (selection bias) }\end{array}$ & Low risk & $\begin{array}{l}\text { Quote: "predefined ... computer-generated randomization sequence", 1:1:1, } \\
\text { using block size of 6, stratified by centre }\end{array}$ \\
\hline $\begin{array}{l}\text { Allocation concealment } \\
\text { (selection bias) }\end{array}$ & Low risk & Central allocation \\
\hline $\begin{array}{l}\text { Blinding (performance } \\
\text { bias and detection bias) }\end{array}$ & Low risk & $\begin{array}{l}\text { Quote: "Participants and investigators were blinded to drug treatment assign- } \\
\text { ments[, and] ... were not encouraged to guess their treatment assignment". }\end{array}$ \\
\hline $\begin{array}{l}\text { Incomplete outcome data } \\
\text { (attrition bias) } \\
\text { All outcomes }\end{array}$ & Low risk & \\
\hline
\end{tabular}

All outcomes

Grant 2007

$\begin{array}{ll}\text { Methods } & \text { Study design: RCT } \\ & \text { Country: USA } \\ \text { Setting: } 2 \text { substance use disorder clinics } \\ \text { Recruitment: alcoholics in residential or outpatient treatment programmes }\end{array}$

\begin{tabular}{ll}
\hline Participants & 58 alcoholic smokers; $16 \%$ female; average age 40; average cigarettes per day 25 \\
\hline Interventions & - Bupropion, $300 \mathrm{mg}$ for 60 days + nicotine patch $21 \mathrm{mg}$ for 8 weeks including tapering \\
- Placebo and nicotine patch \\
Common components: 1-hour cessation group (and 4-weekly assessment visits) \\
\hline Outcomes & - Smoking cessation: 7 day ppa at 6 months. No biochemical validation, collaterals contacted, incon- \\
& sistent, adjusted rates not reported
\end{tabular}

Funding Source National Institute on Alcohol Abuse and Alocholism

Author conflicts of interest None specified

\section{Notes}

\section{Risk of bias}


Grant 2007 (Continued)

\begin{tabular}{lll} 
Bias & Authors' judgement & Support for judgement \\
\hline $\begin{array}{l}\text { Random sequence genera- } \\
\text { tion (selection bias) }\end{array}$ & Unclear risk & Randomization method not described \\
\hline $\begin{array}{l}\text { Allocation concealment } \\
\text { (selection bias) }\end{array}$ & Unclear risk & Not described \\
\hline $\begin{array}{l}\text { Blinding (performance } \\
\text { bias and detection bias) } \\
\text { All outcomes }\end{array}$ & Unclear risk & $\begin{array}{l}\text { Quote: "Double-blind" but unclear who was blinded, no further information } \\
\text { provided }\end{array}$ \\
\hline $\begin{array}{l}\text { Incomplete outcome data } \\
\text { (attrition bias) } \\
\text { All outcomes }\end{array}$ & Low risk & $\begin{array}{l}\text { Higher loss in bupropion (40\%) than placebo (21\%) but still within 20\% range } \\
\text { of each other. ITT analysis }\end{array}$ \\
\hline
\end{tabular}

Gray 2011

Study design: RCT
Country: USA
Setting: university research clinic or high school health clinic
Recruitment method: through local secondary schools, colleges, universities, and community media
advertisements

\begin{tabular}{ll}
\hline Participants & All participants were between 12 and 21 years \\
& 134 participants randomized; $41.8 \%$ female; average age 18.5; average cigarettes per day 10.8 ; mean \\
FTND 4.2
\end{tabular}

Interventions

- Bupropion and contingency management. $150 \mathrm{mg}$ once daily for three days, then $150 \mathrm{mg}$ twice daily for remainder of 6-week treatment period. Contingency management consisted of monetary compensation for biologically verified abstinence at visits. Abstinence at the first visit was $\$ 10$, with subsequent consecutive abstinent visits escalating by USD 3 (USD 13, USD 16, USD 19, and so on). If a participant relapsed, he or she was not eligible for contingent compensation at that visit, and the contingent reward for the next abstinent visit was reset to USD 10 (with eligibility to escalate by USD 3 at subsequent abstinent visits). Thus, the maximum amount of compensation throughout the 6-week treatment period was USD 275.

- Bupropion and non-contingnecy management. Bupropion given according to schedule above. Noncontingency mangement consisted of fixed compensation (USD 10 per visit) for attending the twiceweekly treatment visits.

- Matched placebo and contingency management

- Matched placebo and non-contingnecy management

All participants received smoking cessation booklets and were eligible for a weekly bonus payment of USD 5 throughout active treatment for completion of study materials, including daily smoking diaries. In addition, all participants received USD 30 for completing the initial assessment visit, USD 20 for completing the initial medication management visit, and USD 20 for completing the final post-treatment follow-up visit.

\begin{tabular}{ll}
\hline Outcomes & Smoking cessation: 12 weeks - too short a follow-up for this outcome to be considered in this review \\
- Adverse events: measured for 6 weeks
\end{tabular}


Gray 2011 (Continued)

Public Health Service, Grant M01 RR01070 (Medical University of South Carolina Clinical and Translational Research Center)

Author conflicts of interest $\quad$ Dr Gray has received research support from Pfizer, Inc. (medication and placebo supply for research funded by the National Institute on Drug Abuse). Dr Hartwell has received grant support through Global Research Awards for Nicotine Dependence, an independent competitive grants program supported by Pfizer Inc. Dr Hiott is a past speakers' bureau member of Bristol-Myers Squibb and Abbott Labs. Dr Deas has been an advisory board and speakers' bureau member of Eli Lilly and Company. Dr Upadhyaya is a past consultant and/or advisory board member of Eli Lilly and Company and Shire Pharmaceuticals. Dr Upadhyaya is an ex-stockholder of New River Pharmaceutical Company, is a past speakers' bureau member of Shire Pharmaceuticals and Pfizer, Inc., and has received research support from Cephalon, Inc., Eli Lilly and Company, and Pfizer Inc. Dr Upadhyaya recently became an employee of, and is a holder of stock in, EliLilly and Company. The other investigators deny any potential conflicts of interest.

Notes

\section{Risk of bias}

\begin{tabular}{|c|c|c|}
\hline Bias & Authors' judgement & Support for judgement \\
\hline $\begin{array}{l}\text { Random sequence genera- } \\
\text { tion (selection bias) }\end{array}$ & Unclear risk & No relevant information given \\
\hline $\begin{array}{l}\text { Allocation concealment } \\
\text { (selection bias) }\end{array}$ & Unclear risk & No relevant information given \\
\hline $\begin{array}{l}\text { Blinding (performance } \\
\text { bias and detection bias) } \\
\text { All outcomes }\end{array}$ & Unclear risk & $\begin{array}{l}\text { Quote: "double blinded; encapsulated by the university Investigational Drug } \\
\text { Service so that the active and placebo medication appeared identical". No fur- } \\
\text { ther information given }\end{array}$ \\
\hline $\begin{array}{l}\text { Incomplete outcome data } \\
\text { (attrition bias) } \\
\text { All outcomes }\end{array}$ & Low risk & $\begin{array}{l}\text { Dropout rates: } 12 / 37 \text { ( } 32.4 \%) \text { in bupropion and contingnecy management; } \\
13 / 36(36.1 \%) \text { in bupropion and non-contingnecy management; } 14 / 29(48.3 \%) \\
\text { in placebo \% contingnecy management; } 10 / 32(31.3 \%) \text { in placebo and non- } \\
\text { contingnecy management }\end{array}$ \\
\hline
\end{tabular}

\section{Gray 2012}

\begin{tabular}{|c|c|}
\hline \multirow[t]{4}{*}{ Methods } & Study design: RCT \\
\hline & Country: USA \\
\hline & Setting: community \\
\hline & Recruitment method: community media advertisement (e.g. flyers, newspapers, advertisements) \\
\hline \multirow[t]{2}{*}{ Participants } & $\begin{array}{l}29 \text { participants randomized; } 51.8 \% \text { female; average age 18.9; average cigarettes per day 15.6; mean FT- } \\
\text { ND } 6.7\end{array}$ \\
\hline & Adolescent smokers, aged 15-20 \\
\hline \multirow[t]{2}{*}{ Interventions } & $\begin{array}{l}\text { - Bupropion XL + placebo. } 150 \mathrm{mg} \text { once daily for } 7 \text { days, then } 300 \mathrm{mg} \text { daily thereafter. Placebo capsules } \\
\text { were used at times when no active medication was scheduled. }\end{array}$ \\
\hline & $\begin{array}{l}\text { - Varenicline + placebo. Participants } \geq 55 \mathrm{~kg} \text { received } 0.5 \mathrm{mg} \text { daily for } 3 \text { days, } 0.5 \mathrm{mg} \text { twice daily for } 4 \\
\text { days, and then } 1 \mathrm{mg} \text { twice daily thereafter. Those }<55 \mathrm{~kg} \text { received } 0.5 \mathrm{mg} \text { daily for } 7 \text { days and then } \\
0.5 \mathrm{mg} \text { twice daily thereafter }\end{array}$ \\
\hline
\end{tabular}


Gray 2012 (Continued)

All participants recieved quit smoking brochures and brief individual cessation counselling, totalling 90 minutes.

\begin{tabular}{ll}
\hline Outcomes & Smoking cessation: 12 weeks - too short a follow-up for this outcome to be considered in this review \\
- Adverse events: measured for 12 weeks
\end{tabular}
Funding Source Medical University of South Carolina Hollings Cancer Center Pilot Research Program and the National Institutes of Health (K12DA000357, K23DA020482, R25DA020537, and UL1RR029882)
Author conflicts of interest Dr Upadhyaya is an employee and stockholder of Eli Lilly and Company. The other authors do not have potential conflicts to declare.

\section{Notes}

\section{Risk of bias}

\begin{tabular}{lll}
\hline Bias & Authors' judgement & Support for judgement \\
\hline $\begin{array}{l}\text { Random sequence genera- } \\
\text { tion (selection bias) }\end{array}$ & Unclear risk & No relevant information given \\
\hline $\begin{array}{l}\text { Allocation concealment } \\
\text { (selection bias) }\end{array}$ & Unclear risk & No relevant information given \\
\hline $\begin{array}{l}\text { Blinding (performance } \\
\text { bias and detection bias) } \\
\text { All outcomes }\end{array}$ & Low risk & $\begin{array}{l}\text { Quote: “The university investigational drug service encased medications in } \\
\text { identical-appearing capsules and dispensed them in weekly blister packs with } \\
\text { specific instructions on day/ time for each dose." }\end{array}$ \\
\hline $\begin{array}{l}\text { Incomplete outcome data } \\
\text { (attrition bias) } \\
\text { All outcomes }\end{array}$ & Unclear risk & $\begin{array}{l}\text { The paper gives study retention figures, but does not specify whether they are } \\
\text { lost to followup. }\end{array}$ \\
\hline
\end{tabular}

\section{Górecka 2003}

\begin{tabular}{|c|c|}
\hline Methods & $\begin{array}{l}\text { Study design: RCT } \\
\text { Country: Poland } \\
\text { Setting: Smokers' clinic } \\
\text { Recruitment: smokers with a diagnosis of COPD and failure to stop smoking with advice alone }\end{array}$ \\
\hline Participants & $\begin{array}{l}70 \text { smokers with COPD } \\
43 \% \text { female; average age } 56 \text {; average cigarettes per day } 24\end{array}$ \\
\hline Interventions & $\begin{array}{l}\text { - Bupropion, } 300 \mathrm{mg} / \text { day for } 7 \text { weeks } \\
\text { - Nicotine patch, } 15 \mathrm{mg} / \text { day for } 8 \text { weeks } \\
\text { Common components: support at clinic visits at baseline, } 2 \text { weeks, EOT }\end{array}$ \\
\hline Outcomes & $\begin{array}{l}\text { - Smoking cessation: sustained abstinence at } 1 \text { year. Validated by } \mathrm{CO}<10 \mathrm{ppm} \\
\text { - Adverse events: period of measurement unspecified }\end{array}$ \\
\hline Funding Source & None specified \\
\hline Author conflicts of interest & None specified \\
\hline
\end{tabular}


Górecka 2003 (Continued)

Notes

\section{Risk of bias}

\begin{tabular}{lll}
\hline Bias & Authors' judgement & Support for judgement \\
\hline $\begin{array}{l}\text { Random sequence genera- } \\
\text { tion (selection bias) }\end{array}$ & Unclear risk & Randomization method not described \\
\hline $\begin{array}{l}\text { Allocation concealment } \\
\text { (selection bias) }\end{array}$ & Unclear risk & Allocation concealment not described \\
\hline $\begin{array}{l}\text { Blinding (performance } \\
\text { bias and detection bias) } \\
\text { All outcomes }\end{array}$ & High risk & $\begin{array}{l}\text { Not described but presumably no blinding, as participants will have known as- } \\
\text { signment based on patch versus pill }\end{array}$ \\
\hline $\begin{array}{l}\text { Incomplete outcome data } \\
\text { (attrition bias) }\end{array}$ & Unclear risk & Not described \\
All outcomes & & \\
\hline
\end{tabular}

\section{Haggsträm 2006}

$\begin{array}{ll}\text { Methods } & \text { Study design: RCT } \\ & \text { Country: Brazil } \\ \text { Setting: smoking cessation clinic } \\ \text { Recruitment: community volunteers }\end{array}$

\begin{tabular}{ll}
\hline Participants & $\begin{array}{l}156 \text { smokers; FTND > 4; 70\% female in placebo and nortriptyline arms, 59\% in bupro } \\
\text { age 44; average cigarettes per day not specified }\end{array}$ \\
\hline Interventions & Bupropion, $300 \mathrm{mg} /$ day for 60 days, placebo nortriptyline, TQD during week 2 \\
- Nortripytyline, $75 \mathrm{mg} /$ day for 60 days, placebo bupropion \\
- Double placebo \\
Common components: 6 × 15-min individual CBT, weekly then bi-weekly
\end{tabular}

\begin{tabular}{ll}
\hline Outcomes & $\begin{array}{l}\text { Smoking cessation: conintuous abstinence at } 6 \text { metres (starting from TQD). Validated by CO } \leq 10 \text { ppm } \\
\text { at } 3 \text { months and } 6 \text { months } \\
\text { - Adverse events: measured for } 26 \text { weeks }\end{array}$ \\
\hline Funding Source & None specified \\
\hline Author conflicts of interest & None specified \\
\hline
\end{tabular}

\section{Notes}

\section{Risk of bias}

\begin{tabular}{lll}
\hline Bias & Authors' judgement & Support for judgement \\
\hline $\begin{array}{l}\text { Random sequence genera- } \\
\text { tion (selection bias) }\end{array}$ & Unclear risk & Randomization method not described \\
\hline
\end{tabular}


Haggsträm 2006 (Continued)

\begin{tabular}{l}
$\begin{array}{l}\text { Allocation concealment } \\
\text { (selection bias) }\end{array} \quad$ Unclear risk $\quad$ Allocation concealment not described \\
\hline
\end{tabular}

\begin{tabular}{|c|c|c|}
\hline $\begin{array}{l}\text { Blinding (performance } \\
\text { bias and detection bias) } \\
\text { All outcomes }\end{array}$ & Low risk & $\begin{array}{l}\text { Double-blind, double-dummy. "Both investigators and patients were blind to } \\
\text { the treatment" }\end{array}$ \\
\hline
\end{tabular}

Incomplete outcome data Unclear risk Numbers lost to follow-up not reported, all included as smokers
(attrition bias)
All outcomes

\section{Hall 1998}

\begin{tabular}{|c|c|}
\hline Methods & $\begin{array}{l}\text { Study design: } 2 \times 2 \text { factorial RCT } \\
\text { Country: USA } \\
\text { Setting: clinic } \\
\text { Recruitment: community volunteers }\end{array}$ \\
\hline Participants & 199 smokers, 33\% had history of MDD; 55\% female; average age 40 ; average cigarettes per day $21-25$ \\
\hline Interventions & $\begin{array}{l}\text { - Nortriptyline, titrated to therapeutic levels - usually } 75 \mathrm{mg} / \text { day to } 100 \mathrm{mg} / \text { day, } 12 \text { weeks } \\
\text { Placebo } \\
2 \times 2 \text { factorial design. Alternative psychological Rxs were } 10 \text { sessions of CBT or } 5 \text { sessions of health edu- } \\
\text { cation control. Collapsed in this analysis }\end{array}$ \\
\hline Outcomes & $\begin{array}{l}\text { - Smoking cessation: prolonged abstinence at } 1 \text { year post-EOT. Validated by } \mathrm{CO} \text { at weeks } 12,24,39 \text { and } \\
64 \\
\text { - Adverse events: measured for } 6 \text { weeks }\end{array}$ \\
\hline
\end{tabular}

Funding Source National Instutute on Drug Abuse and Veterans Administration

\section{Author conflicts of interest None specified}

Notes There were no significant main or intervention effects for MDD category, so these are pooled

\section{Risk of bias}

\begin{tabular}{lll}
\hline Bias & Authors' judgement & Support for judgement \\
\hline $\begin{array}{l}\text { Random sequence genera- } \\
\text { tion (selection bias) }\end{array}$ & Low risk & $\begin{array}{l}\text { Computer randomization, after stratification on history of MDD and number of } \\
\text { cigarettes smoked }\end{array}$ \\
\hline $\begin{array}{l}\text { Allocation concealment } \\
\text { (selection bias) }\end{array}$ & Low risk & Allocation generated at enrolment \\
\hline $\begin{array}{l}\text { Blinding (performance } \\
\text { bias and detection bias) } \\
\text { All outcomes }\end{array}$ & Unclear risk & $\begin{array}{l}\text { Quote: "Medication was placebo controlled and double blind. Placebo and ac- } \\
\text { tive drug were identical in appearance." However, no detail on who was blind- } \\
\text { ed. }\end{array}$ \\
\hline $\begin{array}{l}\text { Incomplete outcome data } \\
\text { (attrition bias) }\end{array}$ & Low risk & $\begin{array}{l}30 \% \text { did not complete treatment in placebo and 17\% in active groups. Analy- } \\
\text { All outcomes }\end{array}$ \\
\hline
\end{tabular}


Hall 2002

\begin{tabular}{|c|c|}
\hline Methods & $\begin{array}{l}\text { Study design: } 3 \text { × } 2 \text { factorial RCT } \\
\text { Country: USA } \\
\text { Setting: cessation research centre } \\
\text { Recruitment: community volunteers }\end{array}$ \\
\hline Participants & 220 smokers; $40 \%$ to $47 \%$ female; average age $37-43$; average cigarettes per day $20-23$ \\
\hline Interventions & $\begin{array}{l}\text { - Bupropion, } 300 \mathrm{mg} / \mathrm{day}, 12 \text { weeks } \\
\text { - Nortriptyline, titrated to therapeutic levels, } 12 \text { weeks } \\
\text { - Placebo } \\
3 \times 2 \text { factorial design. Alternative psychological interventions were Medical Management (MM, physi- } \\
\text { cian advice, S-H, } 10 \text { mins to } 20 \text { mins } 1 \text { st visit, } 5 \text { minds at } 2,6,11 \text { weeks) or Psychosocial Intervention (PI, } \\
\text { as MM plus } 5 \times 90 \text {-min group sessions at 4, 5, 7, } 11 \text { weeks) }\end{array}$ \\
\hline
\end{tabular}

\begin{tabular}{ll}
\hline Outcomes & $\begin{array}{l}\text { Smoking cessation: prolonged abstinence at } 1 \text { year (47 weeks post-quit date). Validated by CO } \leq 10 \\
\text { ppm, urine cotinine } \leq 60 \mathrm{ng} / \mathrm{mL}\end{array}$ \\
& Adverse events: measured for unspecified period \\
\hline Funding Source & National Institute on Drug Abuse, National Cancer Institute \\
\hline Author conflicts of interest & None specified \\
\hline Notes & $\begin{array}{l}\text { No significant interaction between pharmacotherapy and behaviour therapy, so behavioural therapy } \\
\text { arms collapsed in main analysis. Bupropion and nortriptyline compared to placebo and head-to-head. } \\
\text { Levels of support compared for bupropion only, ppa rates used. Not included in behavioural support } \\
\text { subgroup. }\end{array}$ \\
\hline
\end{tabular}

\section{Risk of bias}

\begin{tabular}{|c|c|c|}
\hline Bias & Authors' judgement & Support for judgement \\
\hline $\begin{array}{l}\text { Random sequence genera- } \\
\text { tion (selection bias) }\end{array}$ & Unclear risk & $\begin{array}{l}\text { Quote: "Participants were stratified by number of cigarettes smoked, sex and } \\
\text { history of depression vs no history, and randomly assigned to } 1 \text { of the } 6 \text { experi- } \\
\text { mental cells." }\end{array}$ \\
\hline $\begin{array}{l}\text { Allocation concealment } \\
\text { (selection bias) }\end{array}$ & Low risk & $\begin{array}{l}\text { Quote: "We encapsulated both drugs to maintain the patency of the bupropion } \\
\text { formulation and to provide a blinded drug. All participants received capsules } \\
\text { that were identical in number and appearance" but blinding of allocation not } \\
\text { explicit. }\end{array}$ \\
\hline $\begin{array}{l}\text { Blinding (performance } \\
\text { bias and detection bias) } \\
\text { All outcomes }\end{array}$ & High risk & $\begin{array}{l}\text { Double-blind but participants informed about adverse effects of each drug and } \\
87 \% \text { of participants taking active drug guessed that they were (compared to } \\
67 \% \text { placebo group). Bupropion participants no more likely than nortriptyline } \\
\text { participants to correctly identify which drug they had received. }\end{array}$ \\
\hline $\begin{array}{l}\text { Incomplete outcome data } \\
\text { (attrition bias) } \\
\text { All outcomes }\end{array}$ & Low risk & $\begin{array}{l}19 \% \text { lost to follow-up at } 52 \text { weeks. No significant difference across conditions. } \\
\text { Included as smokers in analyses }\end{array}$ \\
\hline
\end{tabular}


Hall 2004

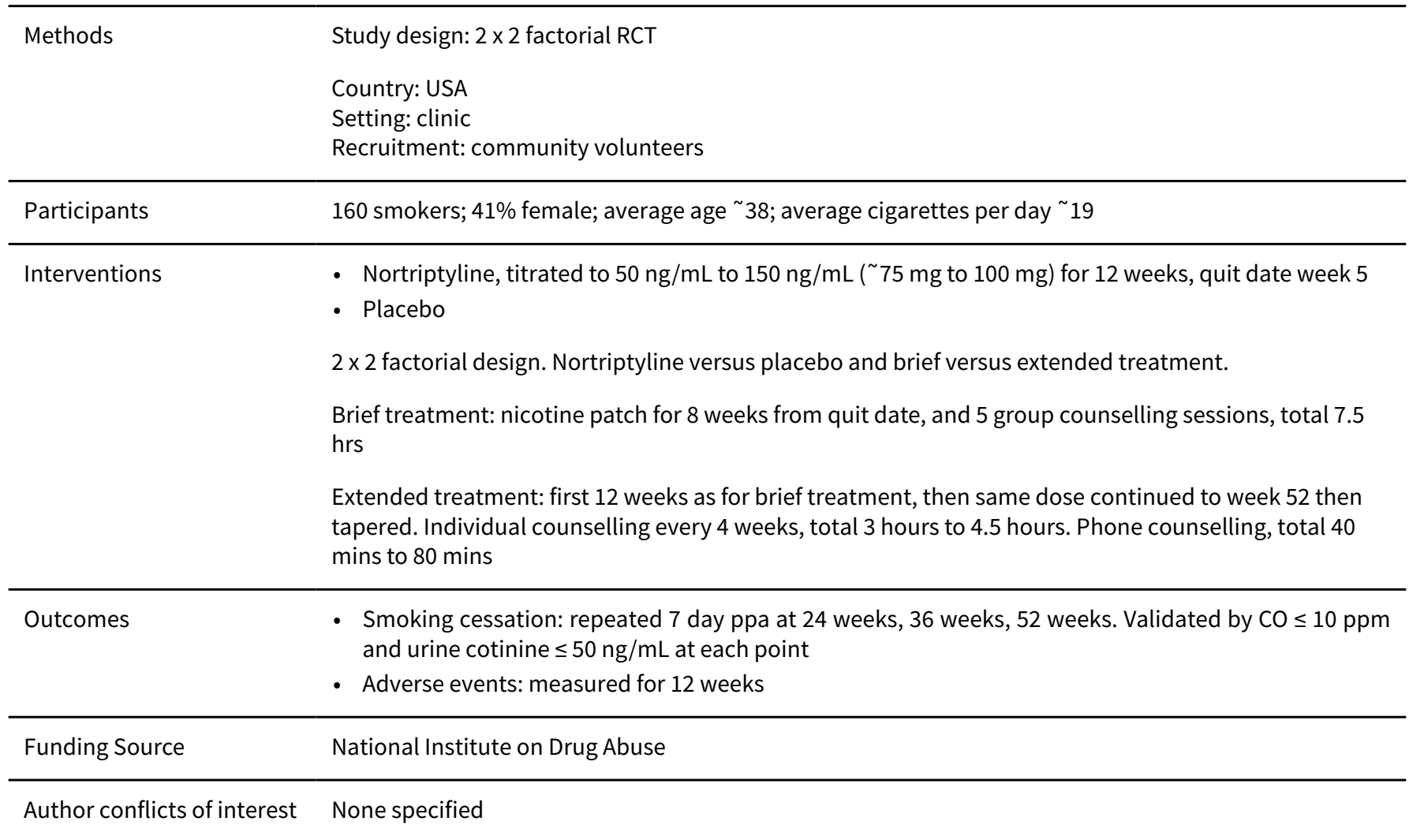

Notes Factorial design, brief and extended treatment entered in meta-analysis separately. In the active extended treatment arm, participants were still receiving nortriptyline at the time of final follow-up.

\section{Risk of bias}

\begin{tabular}{lll}
\hline Bias & Authors' judgement & Support for judgement \\
\hline $\begin{array}{l}\text { Random sequence genera- } \\
\text { tion (selection bias) }\end{array}$ & Unclear risk & $\begin{array}{l}\text { Randomization stratified on cigarettes per day, prior NRT use, MDD history; } \\
\text { method not specified }\end{array}$ \\
\hline $\begin{array}{l}\text { Allocation concealment } \\
\text { (selection bias) }\end{array}$ & Unclear risk & Allocation concealment not described \\
\hline $\begin{array}{l}\text { Blinding (performance } \\
\text { bias and detection bias) } \\
\text { All outcomes }\end{array}$ & High risk & $\begin{array}{l}\text { Quote: "participants given active drug were more likely to guess that they had } \\
\text { received active drug (63\%) than the placebo participants were to believe they } \\
\text { were taking active drug (37\%)" }\end{array}$ \\
\hline $\begin{array}{l}\text { Incomplete outcome data } \\
\text { (attrition bias) } \\
\text { All outcomes }\end{array}$ & Low risk & $9 \%$ lost at week 52, included as smokers \\
\hline
\end{tabular}

Hertzberg 2001

$\begin{array}{ll}\text { Methods } & \text { Study design: RCT } \\ & \text { Country: USA } \\ \text { Setting: Veterans Affairs Medical Centre (VAMC) } \\ \text { Recruitment: VAMC outpatient volunteers }\end{array}$


Hertzberg 2001 (Continued)

Participants 15 male veterans with post-traumatic stress disorder; average age 50; average cigarettes per day 33

\begin{tabular}{|c|c|c|}
\hline Interventions & \multicolumn{2}{|c|}{$\begin{array}{l}\text { - Bupropion, } 300 \mathrm{mg} / \mathrm{day}, 12 \text { weeks begun at least } 1 \text { week before TQD } \\
\text { - Placebo } \\
\text { Common components: individual counselling pre-quit, weeks } 1,2,4,8,12\end{array}$} \\
\hline Outcomes & \multicolumn{2}{|c|}{$\begin{array}{l}\text { - Smoking cessation: prolonged abstinence at } 6 \text { months. Validated at weeks } 2,8 \text { by } C O \leq 10 \mathrm{ppm} \\
\text { - Adverse events: measured for } 12 \text { weeks }\end{array}$} \\
\hline Funding Source & \multicolumn{2}{|c|}{ Glaxo Wellcome Inc, National Cancer Institute } \\
\hline Author conflicts of interest & \multicolumn{2}{|l|}{ None specified } \\
\hline Notes & \multicolumn{2}{|c|}{2 of the successful quitters were taking bupropion at 6 months, prescribed after end of study } \\
\hline \multicolumn{3}{|l|}{ Risk of bias } \\
\hline Bias & Authors' judgement & Support for judgement \\
\hline $\begin{array}{l}\text { Random sequence genera- } \\
\text { tion (selection bias) }\end{array}$ & Unclear risk & Randomization method not described \\
\hline $\begin{array}{l}\text { Allocation concealment } \\
\text { (selection bias) }\end{array}$ & Unclear risk & Allocation concealment not described \\
\hline $\begin{array}{l}\text { Blinding (performance } \\
\text { bias and detection bias) } \\
\text { All outcomes }\end{array}$ & Unclear risk & Double-blind, no further information provided \\
\hline $\begin{array}{l}\text { Incomplete outcome data } \\
\text { (attrition bias) } \\
\text { All outcomes }\end{array}$ & High risk & $\begin{array}{l}\text { Uneven attrition between arms; very high percentage lost to follow-up in } \\
\text { placebo group. } 30 \% \text { of the participants receiving bupropion SR did not com- } \\
\text { plete the full } 12 \text {-week trial; } 80 \% \text { of the placebo group failed to complete the } \\
\text { trial and were considered to have resumed smoking. }\end{array}$ \\
\hline
\end{tabular}

Holt 2005

\begin{tabular}{ll}
\hline Methods & $\begin{array}{l}\text { Study design: RCT } \\
\text { Country: New Zealand } \\
\text { Setting: cessation clinic } \\
\text { Recruitment: Maori community volunteers aged } 16-70\end{array}$ \\
\hline Participants & 134 smokers; $72 \%$ female; average age $42 / 38$ \\
\hline Interventions & Bupropion, $300 \mathrm{mg} /$ day for 7 weeks \\
& Placebo \\
& Common components: counselling at 3 clinic visits during medication and 3 monthly follow-ups, moti- \\
vational phone call 1 day before and 2 days after TQD
\end{tabular}

$\begin{array}{ll}\text { Outcomes } & \text { Smoking cessation: continuous abstinence at } 12 \text { months. Validated by } \mathrm{CO} \text { at each visit } \\ \text { - Adverse events: measured for } 12 \text { months }\end{array}$

Funding Source GlaxoSmithKline


Holt 2005 (Continued)

Author conflicts of interest P3 Research, the Wellington School of Medicine and Health Sciences, and the Medical Research Institute of New Zealand have all received research grants from GlaxoSmithKline and Novartis. SH and RB have received fees for consulting and reimbursement for attending symposia from GlaxoSmithKline and Novartis.

\section{Notes}

\section{Risk of bias}

\begin{tabular}{lll}
\hline Bias & Authors' judgement & Support for judgement \\
\hline $\begin{array}{l}\text { Random sequence genera- } \\
\text { tion (selection bias) }\end{array}$ & Low risk & Randomization using a computer generated code \\
\hline $\begin{array}{l}\text { Allocation concealment } \\
\text { (selection bias) }\end{array}$ & Unclear risk & Not described \\
\hline $\begin{array}{l}\text { Blinding (performance } \\
\text { bias and detection bias) } \\
\text { All outcomes }\end{array}$ & Low risk & $\begin{array}{l}\text { Quote: "Neither the study team nor the participant was aware of which treat- } \\
\text { ment had been allocated until the end of the 12 month study period." }\end{array}$ \\
\hline $\begin{array}{l}\text { Incomplete outcome data } \\
\text { (attrition bias) } \\
\text { All outcomes }\end{array}$ & High risk & $\begin{array}{l}\text { High and uneven loss to follow-up, with less than half of placebo group fol- } \\
\text { lowed up at } 12 \text { months. 36\% lost in bupropion group and 52\% in placebo at } 12 \\
\text { months. "Participants who were lost to follow up were categorised as smok- } \\
\text { ers ... often this was confirmed by family members or friends." }\end{array}$ \\
\hline
\end{tabular}

Hurt 1997

$\begin{array}{ll}\text { Methods } & \text { Study design: RCT } \\ & \text { Country: USA } \\ \text { Setting: multicentre } & \text { Recruitment: community volunteers }\end{array}$

\section{Participants}

615 smokers; 55\% female; average age 44; average cigarettes per day 27

- Bupropion, $100 \mathrm{mg} /$ day for 7 weeks
- Bupropion, $150 \mathrm{mg} /$ day
- Bupropion, $300 \mathrm{mg} /$ day
- Placebo
Common components: physician advice, S-H materials, and brief individual counselling by study assis-
tant at each visit

\begin{tabular}{ll}
\hline Outcomes & $\begin{array}{l}\text { Smoking cessation: prolonged abstinence at } 12 \text { months (starting from day 22). Validated by CO } \leq 10 \\
\text { ppm }\end{array}$ \\
& Adverse events: measured for 52 weeks \\
\hline Funding Source & Glaxo Wellcome \\
\hline Author conflicts of interest & None specified \\
\hline Notes & 300 mg compared with placebo in main analysis
\end{tabular}


Hurt 1997 (Continued)

There was no evidence that history of major depression or alcoholism interacted with treatment condition or was associated with poorer outcomes. Prolonged abstinence rates at 12 months as supplied by Glaxo Wellcome: $300 \mathrm{mg}$ 21; $150 \mathrm{mg}$ 23; Placebo 15

\begin{tabular}{lll}
\hline Risk of bias & & \\
\hline Bias & Authors' judgement & Support for judgement \\
\hline $\begin{array}{l}\text { Random sequence genera- } \\
\text { tion (selection bias) }\end{array}$ & Unclear risk & Randomized, stratified by site, method not described \\
\hline $\begin{array}{l}\text { Allocation concealment } \\
\text { (selection bias) }\end{array}$ & Unclear risk & Allocation concealment not described \\
\hline $\begin{array}{l}\text { Blinding (performance } \\
\text { bias and detection bias) } \\
\text { All outcomes }\end{array}$ & Unclear risk & Quote: "Double-blind" but no detail given on who was blinded \\
\hline $\begin{array}{l}\text { Incomplete outcome data } \\
\text { (attrition bias) } \\
\text { All outcomes }\end{array}$ & Unclear risk & $\begin{array}{l}\text { Quote: "Subjects who missed a follow-up visit were considered to be smok- } \\
\text { ing.... The rate of completion of the study increased with the dose and was } 57 \\
\text { percent, } 65 \text { percent, } 64 \text { percent, and } 71 \text { percent for the placebo, 100-mg, 150- } \\
\text { mg, and 300-mg groups, respectively..." }\end{array}$ \\
\hline
\end{tabular}

Johns 2017

\begin{tabular}{ll}
\hline Methods & Study design: RCT \\
& Country: India \\
& Setting and recruitment method not specified \\
\hline Participants & 300 participants randomized \\
\hline Interventions & - Bupropion, 150 mg twice daily for 12 weeks \\
& - Barenicline, 1 mg twice daily for 12 weeks \\
\hline Outcomes & - Smoking cessation: continuous abstinence at 6 months. Validated by CO \\
\hline Funding Source & None specified \\
\hline Author conflicts of interest & None specified \\
\hline Notes &
\end{tabular}

Notes

\section{Risk of bias}

\begin{tabular}{lll}
\hline Bias & Authors' judgement & Support for judgement \\
\hline $\begin{array}{l}\text { Random sequence genera- } \\
\text { tion (selection bias) }\end{array}$ & Unclear risk & States trial was randomized, no further detail given \\
\hline $\begin{array}{l}\text { Allocation concealment } \\
\text { (selection bias) }\end{array}$ & Unclear risk & No relevant information given \\
\hline
\end{tabular}


Johns 2017 (Continued)

Blinding (performance Unclear risk States only that the study was 'double-blind', no further detail given bias and detection bias)

All outcomes

Incomplete outcome data Unclear risk No relevant information given
(attrition bias)

(attrition bias)

All outcomes

Jorenby 1999

\begin{tabular}{|c|c|}
\hline Methods & $\begin{array}{l}\text { Study design: } 2 \times 2 \text { factorial RCT } \\
\text { Country: USA } \\
\text { Setting: multicentre clinical trial units } \\
\text { Recruitment: community volunteers }\end{array}$ \\
\hline Participants & 893 smokers; 52\% female; average age 43; average cigarettes per day 25 \\
\hline Interventions & $\begin{array}{l}\text { - Nicotine patch and bupropion SR. Nicotine patch dosing and schedule } 24 \mathrm{hr}, 21 \mathrm{mg} \text { for } 6 \text { weeks, ta- } \\
\text { pered for } 2 \text { weeks. Bupropion dosing and schedule was } 300 \mathrm{mg} \text { for } 9 \text { weeks from } 1 \text { week before quit day } \\
\text { - Bupropion and placebo patch } \\
\text { - Nicotine patch and placebo tablets } \\
\text { - Placebo patch and placebo tablets } \\
\text { Common components: brief (<15 min) individual counselling session at each weekly assessment. One } \\
\text { telephone call } 3 \text { days after quit day }\end{array}$ \\
\hline Outcomes & $\begin{array}{l}\text { - Smoking cessation: continuous ppa at } 12 \text { months. Validated by } \mathrm{CO}<10 \mathrm{ppm} \text { at each clinic visit } \\
\text { - Adverse events: measured for unspecified period }\end{array}$ \\
\hline Funding Source & Glaxo Wellcome \\
\hline Author conflicts of interest & $\begin{array}{l}\text { Dr Jorenby has organized medical education presentations sponsored by Glaxo Wellcome and SmithK- } \\
\text { line Beecham. Dr Leischow has served as a consultant for McNeil Consumer Products, Pharmacia and } \\
\text { Upjohn, and Glaxo Wellcome and has organized medical education presentations sponsored by Glaxo } \\
\text { Wellcome. Dr Nides has served as a consultant for Glaxo Wellcome, Novartis, and SmithKline Beecham } \\
\text { and has organized medical education presentations sponsored by Glaxo Wellcome. Dr Rennard has } \\
\text { served as a consultant for Glaxo Wellcome, Novartis, and SmithKline Beecham and has organized } \\
\text { medical education presentations sponsored by Glaxo Wellcome. Dr Muramoto has organized medical } \\
\text { education presentations sponsored by Glaxo Wellcome. Mr Daughton has served as a consultant for } \\
\text { SmithKline Beecham and Hoechst Marion Roussel and has organized medical education presentations } \\
\text { sponsored by Glaxo Wellcome and Hoechst Marion Roussel. Dr Fiore has served as a consultant for No- } \\
\text { vartis, Glaxo Wellcome, SmithKline Beecham, and McNeil Consumer Products and has organized med- } \\
\text { ical education presentations sponsored by Novartis, Elan Pharma, Lederle Laboratories, Glaxo Well- } \\
\text { come, McNeil Consumer Products, and SmithKline Beecham. Dr Baker has served as a consultant for } \\
\text { SmithKline Beecham and has organized medical education presentations sponsored by Elan Pharma } \\
\text { and Glaxo Wellcome. }\end{array}$ \\
\hline
\end{tabular}

\section{Risk of bias}


Jorenby 1999 (Continued)

Random sequence genera- Low risk Quote: "The subjects were randomly assigned to one of four treatments with tion (selection bias) use of an unequal-cell design...[but] Randomization was not balanced within sites."

\begin{tabular}{lll}
\hline $\begin{array}{l}\text { Allocation concealment } \\
\text { (selection bias) }\end{array}$ & Unclear risk & Allocation concealment method unclear \\
\hline $\begin{array}{l}\text { Blinding (performance } \\
\text { bias and detection bias) } \\
\text { All outcomes }\end{array}$ & Unclear risk & Quote: "Double-blind" but no further detail provided \\
\hline $\begin{array}{l}\text { Incomplete outcome data } \\
\text { (attrition bias) } \\
\text { All outcomes }\end{array}$ & Low risk & $\begin{array}{l}\text { Quote: "All subjects who discontinued treatment early or who were lost to fol- } \\
\text { low-up were classified as smokers." Approximately 20\% left the study and pro- } \\
\text { vided no additional information. 15\% stopped taking medication but partici- } \\
\text { pated in follow-up assessments. }\end{array}$ \\
\hline
\end{tabular}

Jorenby 2006

\begin{tabular}{ll}
\hline Methods & Study design: RCT \\
& $\begin{array}{l}\text { Country: USA } \\
\text { Setting: multicentre clinical trial units } \\
\text { Recruitment: community volunteers }\end{array}$ \\
\hline Participants & $\begin{array}{l}683 \text { smokers (in relevant arms), with prior exposure to bupropion excluded; } 41 \% \text { female; average age } \\
\text { 42; average cigarettes per day } 22\end{array}$ \\
\hline Interventions & Bupropion 300 mg for 12 weeks + placebo varenicline \\
& - Varenicline 2 mg for 12 weeks + placebo bupropion \\
& Common components: brief (< 10 min) individual counselling at each weekly assessment for 12 weeks \\
and 5 follow-up visits. One telephone call 3 days after quit day
\end{tabular}

\begin{tabular}{ll}
\hline Outcomes & Smoking cessation: sustained abstinence at 12 momth, from week 9 . Validated by $\mathrm{CO}<10 \mathrm{ppm}$ at each \\
clinic visit
\end{tabular}

\begin{tabular}{|c|c|}
\hline Funding Source & Pfizer Inc \\
\hline Author conflicts of interest & $\begin{array}{l}\text { Dr Jorenby reported receiving research support from Pfizer, Nabi Biopharmaceutical, Sanofi-Aventis } \\
\text { and consulting fees from Nabi Biopharmaceutical. Dr Hays reported receiving a research grant from } \\
\text { Pfizer. Dr Rigotti reported receiving research grant funding and consulting fees from GlaxoSmithKline, } \\
\text { which markets smoking cessation medications, and Pfizer and Sanofi-Aventis, which are developing } \\
\text { smoking cessation medications. Dr Rigotti also reported receiving consulting fees from Merck, which is } \\
\text { developing smoking cessation medications. }\end{array}$ \\
\hline
\end{tabular}

$\begin{array}{ll}\text { Notes } & \text { Bupropion was an active control for varenicline. } \\ \text { Bupropion versus placebo and bupropion versus varenicline comparisons contribute to the review. }\end{array}$

\section{Risk of bias}

\begin{tabular}{lll}
\hline Bias & Authors' judgement & Support for judgement \\
\hline $\begin{array}{l}\text { Random sequence genera- } \\
\text { tion (selection bias) }\end{array}$ & Low risk & $\begin{array}{l}\text { Quote: "Randomization was completed centrally by using a computer-gen- } \\
\text { erated list and sites used an electronic system to assign participants to treat- } \\
\text { ment." }\end{array}$ \\
\hline
\end{tabular}


Jorenby 2006 (Continued)

Allocation concealment Low risk $\quad$ Quote: "Folders [containing medication or placebo] for all participants (re(selection bias) gardless of treatment assignment) were identical throughout the treatment phase including a period of dose titration (week 1 ) and treatment at the target dose (weeks 2-12)."

\section{Blinding (performance Unclear risk}

bias and detection bias)

Quote: "in a double-blind manner," no further information provided

All outcomes

Incomplete outcome data Low risk

(attrition bias)

All outcomes
Over the period of treatment and follow-up 14\% of those receiving varenicline were lost to follow-up; $14 \%$ randomized to bupropion lost to follow-up; $16 \%$ of the placebo group were lost to follow-up. "Participants whose smoking status was unknown or whose carbon monoxide level was higher than $10 \mathrm{ppm}$ were classified as smoking during both the treatment phase and follow-up."

\section{Kahn 2012}

\begin{tabular}{|c|c|}
\hline \multirow[t]{4}{*}{ Methods } & Study design: RCT \\
\hline & Country: USA \\
\hline & Setting: clinics \\
\hline & Recruitment: community \\
\hline Participants & 246 smokers; 49\% female; average age 46; average cigarettes per day 22 \\
\hline \multirow[t]{2}{*}{ Interventions } & $\begin{array}{l}\text { - Selegiline patch ( } 6 \mathrm{mg} / 24 \mathrm{hr}) \text { for } 9 \text { weeks, starting } 7 \text { days before TQD } \\
\text { - Placebo patch, same schedule as selegeline }\end{array}$ \\
\hline & Common components: 9 weekly individual counselling sessions of approximately 10 mins each \\
\hline \multirow[t]{2}{*}{ Outcomes } & $\begin{array}{l}\text { - Smoking cessation: prolonged abstinence at } 6 \text { months (continuous from week } 6 \text { onwards) Validated } \\
\text { by } C O<9 \mathrm{ppm}\end{array}$ \\
\hline & - Adverse events: measured for 26 weeks \\
\hline Funding Source & National Institutes of Health, National Institute on Drug Abuse \\
\hline Author conflicts of interest & None specified \\
\hline \multirow[t]{3}{*}{ Notes } & New for 2013 update \\
\hline & Some additional information on study characteristics provided by author. \\
\hline & Mean compliance rates $91.6 \%$ and $91.3 \%$ for the selegiline and placebo groups \\
\hline
\end{tabular}

\section{Risk of bias}

\section{Bias}

Random sequence genera- Unclear risk tion (selection bias)

Unclear risk

\section{Authors' judgement Support for judgement}


Kahn 2012 (Continued)

Blinding (performance Unclear risk Quote: "Double-blind," no further details provided bias and detection bias)

All outcomes

Incomplete outcome data Low risk
(attrition bias)

All outcomes

Kalman 2011

\begin{tabular}{|c|c|}
\hline \multirow[t]{4}{*}{ Methods } & Study design: RCT \\
\hline & Country: USA \\
\hline & Setting: not specified \\
\hline & Recruitment: Veterans Administration Medical Center \\
\hline Participants & $\begin{array}{l}143 \text { smokers with } 2 \text { to } 12 \text { months alcohol abstinence, with history of alcohol abuse or dependence; } \\
\text { mean age 49; } 17 \% \text { female; average cigarettes per day 20.8; mean FTND } 5.9\end{array}$ \\
\hline \multirow[t]{2}{*}{ Interventions } & $\begin{array}{l}\text { - Bupropion, } 8 \text { weeks (started } 1 \text { week before TQD, first } 3 \text { days } 150 \mathrm{mg} / \text { day, rest of period } 2 \text { x } 150 \mathrm{mg} / \mathrm{day} \text { ) } \\
\text { - Placebo, same schedule as above }\end{array}$ \\
\hline & $\begin{array}{l}\text { Common components: nicotine patch ( } 7 \text { weeks starting on TQD; } 21 \text { mg weeks 1-4, } 14 \text { mg weeks 5-6, } 7 \\
\text { mg week 7) and } 8 \text { weekly counselling sessions starting } 1 \text { week before TQD (one-to-one sessions based } \\
\text { on CBT and MI) }\end{array}$ \\
\hline
\end{tabular}

\begin{tabular}{ll}
\hline Outcomes & $\begin{array}{l}\text { Smoking cessation: prolonged abstinence at 24 weeks (no smoking after first } 2 \text { weeks after TQD). Val- } \\
\text { idated by salivary cotinine } \leq 15 \mathrm{ng} / \mathrm{mL} \\
\text { - Adverse events: measured for unspecified period }\end{array}$ \\
\hline Funding Source & National Institute of Drug Abuse, National Institute on Alcohol Abuse and Alocholism \\
\hline Author conflicts of interest & None specified \\
\hline Notes & New for 2013 update \\
& N quit calculated from percentages provided \\
\hline
\end{tabular}

\section{Risk of bias}

\begin{tabular}{lll}
\hline Bias & Authors' judgement & Support for judgement \\
\hline $\begin{array}{l}\text { Random sequence genera- } \\
\text { tion (selection bias) }\end{array}$ & Unclear risk & Quote: "Urn randomization," no further details provided \\
\hline $\begin{array}{l}\text { Allocation concealment } \\
\text { (selection bias) }\end{array}$ & Unclear risk & Not described \\
\hline $\begin{array}{l}\text { Blinding (performance } \\
\text { bias and detection bias) } \\
\text { All outcomes }\end{array}$ & Unclear risk & $\begin{array}{l}\text { Quote: "Double-blind" but no detail on who was blinded in terms of study staff, } \\
\text { including counsellors. "Both medication groups performed at the chance level } \\
\text { in judging medication assignment." }\end{array}$ \\
\hline
\end{tabular}


Kalman 2011 (Continued)

$\begin{array}{ll}\begin{array}{l}\text { Incomplete outcome data } \\ \text { (attrition bias) }\end{array} & \begin{array}{l}13 \text { participants who dropped out prior to receiving medication, not included } \\ \text { in denominators. Further } 18 \% \text { intervention and } 14 \% \text { control lost at } 24 \text { weeks, } \\ \text { All outcomes }\end{array} \\ \text { counted as smoking in analyses. }\end{array}$

Karam-Hage 2011

\begin{tabular}{|c|c|}
\hline Methods & $\begin{array}{l}\text { Study design: RCT } \\
\text { Country: USA } \\
\text { Setting: University of Michigan outpatient addictions clinic } \\
\text { Recruitment method: patients admitted to the outpatient intensive treatment programme }\end{array}$ \\
\hline Participants & $\begin{array}{l}\text { Alcohol- and nicotine-dependent patients } \\
11 \text { participants randomized; } 55 \% \text { female; average age 19.7; average cigarettes per day } 1 \text { pack; mean FT- } \\
\text { ND } 4.8\end{array}$ \\
\hline Interventions & $\begin{array}{l}\text { - Bupropion, } 150 \text { mg once daily for } 7 \text { days, then twice daily for } 7 \text { weeks } \\
\text { - Placebo, same scheduling as bupropion } \\
\text { Common components: minimal smoking cessation counselling and booklet "You Can Quit Smoking" }\end{array}$ \\
\hline Outcomes & $\begin{array}{l}\text { - Smoking cessation: } 8 \text { weeks - too short a follow-up to be considered for this outcome as part of our } \\
\text { review } \\
\text { - Adverse events: measured for } 8 \text { weeks }\end{array}$ \\
\hline Funding Source & University of Michigan's General Clinical Research Center (GCRC) Grant \# MO1 RR00042 \\
\hline Author conflicts of interest & None specified \\
\hline
\end{tabular}

\section{Risk of bias}

\begin{tabular}{lll}
\hline Bias & Authors' judgement & Support for judgement \\
\hline $\begin{array}{l}\text { Random sequence genera- } \\
\text { tion (selection bias) }\end{array}$ & Unclear risk & No relevant information given \\
\hline $\begin{array}{l}\text { Allocation concealment } \\
\text { (selection bias) }\end{array}$ & Unclear risk & No relevant information given \\
\hline $\begin{array}{l}\text { Blinding (performance } \\
\text { bias and detection bias) } \\
\text { All outcomes }\end{array}$ & Unclear risk & No relevant information given \\
\hline $\begin{array}{l}\text { Incomplete outcome data } \\
\text { (attrition bias) } \\
\begin{array}{l}\text { All outcomes } \\
\hline\end{array}\end{array}$ & Low risk & Dropout rates are as follows: $1 / 5$ placebo; $1 / 6$ bupropion \\
\hline
\end{tabular}

\section{Killen 2000}

Methods Study design: RCT


Killen 2000 (Continued)

Country: USA

Setting: clinic

Recruitment: advertisements

\begin{tabular}{ll}
\hline Participants & 224 smokers; 46\% female; average age 46; average cigarettes per day 26 \\
\hline Interventions & Nicotine patch and paroxetine. Nicotine patch for $24 \mathrm{hr}, 21 \mathrm{mg}, 8$ weeks. Paroxetine at $20 \mathrm{mg}$ for 9 \\
weeks including tapering) \\
- Nicotine patch and paroxetine. $40 \mathrm{mg}$ paroxetine. Patch as above \\
Common components: self-help manual and 15 min behavioural counselling at weeks 1 and 4 \\
\hline Outcomes & Smoking cessation: 7 -day ppa at 10 weeks, 26 weeks, and 6 months. Validated by CO $<9$ ppm and \\
& saliva cotinine $<20 \mathrm{ng} / \mathrm{mL}$ at each visit \\
- Adverse events: $\mathrm{measured}$ for 26 weeks
\end{tabular}

\begin{tabular}{ll}
\hline Funding Source & University of California Tobacco-Related Disease Research Program, SmithKline Beecham \\
\hline Author conflicts of interest & None specified
\end{tabular}

Notes $40 \mathrm{mg}$ and $20 \mathrm{mg}$ dose pooled in meta-analysis from 2009. 20/75 quit on $40 \mathrm{mg}, 15 / 75 \mathrm{on} 20 \mathrm{mg}$

\section{Risk of bias}

\begin{tabular}{lll}
\hline Bias & Authors' judgement & Support for judgement \\
\hline $\begin{array}{l}\text { Random sequence genera- } \\
\text { tion (selection bias) }\end{array}$ & Unclear risk & Randomization method not described \\
\hline $\begin{array}{l}\text { Allocation concealment } \\
\text { (selection bias) }\end{array}$ & Unclear risk & Not described \\
\hline $\begin{array}{l}\text { Blinding (performance } \\
\text { bias and detection bias) }\end{array}$ & Unclear risk & Quote: "Double-blind" but unclear who exactly was blinded \\
$\begin{array}{l}\text { All outcomes } \\
\begin{array}{l}\text { Incomplete outcome data } \\
\text { (attrition bias) } \\
\text { All outcomes }\end{array}\end{array}$ & Unclear risk & $\begin{array}{l}\text { Quote: "Those failing to provide confirmation [of smoking status] were reclas- } \\
\text { sified as smokers." Number lost to follow-up not reported }\end{array}$ \\
\hline
\end{tabular}

\section{Killen 2004}

\begin{tabular}{ll}
\hline Methods & Study design: RCT \\
Country: USA & $\begin{array}{l}\text { Setting: continuation high schools } \\
\text { Recruitment: adolescents at schools }\end{array}$ \\
\hline Participants & $\begin{array}{l}211 \text { adolescent smokers, at least } 1 \text { failed quit attempt; } 31 \% \text { female; average age } 17 \text {; average cigarettes } \\
\text { per day } 15\end{array}$ \\
\hline Interventions & Bupropion and nicotine patch. Bupropion at $150 \mathrm{mg}$ for 9 weeks from 1 week before TQD. Nicotine \\
patch for 8 weeks \\
- Placebo and nicotine patch
\end{tabular}


Killen 2004 (Continued)

Common components: weekly 45-min group sessions, skills training

\begin{tabular}{ll} 
Outcomes & $\begin{array}{l}\text { - Smoking abstinence: } 7 \text { day ppa at } 6 \text { months. Validated by saliva cotinine }<20 \mathrm{ng} / \mathrm{mL} \text { at } 6 \mathrm{months} \text { (CO } \\
\text { at EOT) }\end{array}$ \\
\hline Funding Source & Adverse events: measured for unspecified period \\
\hline Author conflicts of interest & None specified \\
\hline Notes & Low compliance with both bupropion and patch therapy \\
\hline
\end{tabular}

\section{Risk of bias}

\begin{tabular}{lll}
\hline Bias & Authors' judgement & Support for judgement \\
\hline $\begin{array}{l}\text { Random sequence genera- } \\
\text { tion (selection bias) }\end{array}$ & Unclear risk & Randomization method not described \\
\hline $\begin{array}{l}\text { Allocation concealment } \\
\text { (selection bias) }\end{array}$ & Unclear risk & Allocation concealment not described \\
\hline $\begin{array}{l}\text { Blinding (performance } \\
\text { bias and detection bias) }\end{array}$ & Low risk & $\begin{array}{l}\text { Quote: "Double-blind." Though further details not provided, assessment of } \\
\text { blind suggests it was successful (30\% placebo and 31\% bupropion correctly } \\
\text { guessed assignment) }\end{array}$ \\
\hline $\begin{array}{l}\text { Incomplete outcome data } \\
\text { (attrition bias) } \\
\text { All outcomes }\end{array}$ & Low risk & 38\% bupropion and 35\% placebo lost at 6 months, included in analysis \\
\hline
\end{tabular}

Killen 2010

\begin{tabular}{ll}
\hline Methods & Study design: RCT \\
& Country: USA \\
& Setting: community \\
& Recruitment: radio, newspapers, community website and notices distributed via local organizations \\
\hline Participants & 243 smokers, 18-65 years old. $30 \%$ female; average age 45; average cigarettes per day 19 \\
\hline Interventions & - Selegiline patch. 8 weeks, $6 \mathrm{mg} / 24$ hr, starting on TQD \\
& $\begin{array}{l}\text { Common components: } 9 \text { sessions of individual counselling to develop cognitive and behavioural skills } \\
\text { to resist urges to smoke }\end{array}$ \\
\hline Outcomes & Smoking cessation: 7-day ppa at 12 months. Validated by CO < 10 ppm \\
\hline Funding Source & $\begin{array}{l}\text { National Institute on Drug Abuse. Medication and matching placebo provided by Somerset Pharmaceu- } \\
\text { ticals, Inc. }\end{array}$ \\
\hline Author conflicts of interest & \begin{tabular}{l} 
None specified \\
\hline
\end{tabular}
\end{tabular}


Killen 2010 (Continued)
Notes
New for 2013 update

\section{Risk of bias}

\begin{tabular}{lll}
\hline Bias & Authors' judgement & Support for judgement \\
\hline $\begin{array}{l}\text { Random sequence genera- } \\
\text { tion (selection bias) }\end{array}$ & Low risk & Random number generator \\
\hline $\begin{array}{l}\text { Allocation concealment } \\
\text { (selection bias) }\end{array}$ & Low risk & $\begin{array}{l}\text { Participant assigned sequential ID numbers corresponding with drug "pre- } \\
\text { packaged and labelled by ID only at an off-site location by an individual who } \\
\text { had no association with the participants." }\end{array}$ \\
\hline $\begin{array}{l}\text { Blinding (performance } \\
\text { bias and detection bias) }\end{array}$ & Low risk & $\begin{array}{l}\text { Quote: "Treatment assignment was concealed from staff and both research } \\
\text { staff and participants were blind to week 52." Assessment of blinding in partici- } \\
\text { pants and study staff suggests it was successful }\end{array}$ \\
\hline $\begin{array}{l}\text { Incomplete outcome data } \\
\text { (attrition bias) } \\
\text { All outcomes }\end{array}$ & Low risk & $\begin{array}{l}87 \% \text { followed up at 12 months, same in both arms. Missing counted as smok- } \\
\text { ers }\end{array}$ \\
\hline
\end{tabular}

\section{Levine 2010}

\begin{tabular}{|c|c|}
\hline \multirow[t]{4}{*}{ Methods } & Study design: $2 \times 2$ factorial RCT \\
\hline & Country: USA \\
\hline & Setting: not specified \\
\hline & Recruitment: community volunteers \\
\hline Participants & 349 weight-concerned women smokers; average age 42; average cigarettes per day 21 ; mean FTND 5.2 \\
\hline \multirow[t]{5}{*}{ Interventions } & $\begin{array}{l}\text { - Bupropion SR. } 26 \text { weeks. } 150 \mathrm{mg} / \text { day for first } 2 \text { days and } 300 \mathrm{mg} / \text { day for remainder of treatment } \\
\text { - Placebo, same schedule }\end{array}$ \\
\hline & Counselling conditions \\
\hline & - Standard cessation counselling \\
\hline & - Standard cessation counselling + material on weight concerns \\
\hline & Common components: $12 \times 90$-minute group counselling sessions delivered over 3 months \\
\hline Outcomes & $\begin{array}{l}\text { - Smoking cessation: prolonged abstinence at } 12 \text { months. Validated by } \mathrm{CO} \leq 8 \mathrm{ppm} \text { and salivary cotinine } \\
\leq 15 \text { ug } \\
\text { - Adverse events: measured for } 26 \text { weeks }\end{array}$ \\
\hline Funding Source & National Institute on Drug Abuse. Medication supplied by GlaxoSmithKline \\
\hline Author conflicts of interest & $\begin{array}{l}\text { Dr Marcus has served as a consultant to GlaxoSmithKline and Sanofi-Aventis. Dr Perkins has served as a } \\
\text { consultant for GlaxoSmithKline }\end{array}$ \\
\hline \multirow[t]{2}{*}{ Notes } & New for 2013 update \\
\hline & $\begin{array}{l}\text { Counselling arms collapsed in analyses (same intensity, just differed in content). } \mathrm{N} \text { abstinent calculated } \\
\text { from percentages given }\end{array}$ \\
\hline
\end{tabular}


Levine 2010 (Continued)

Risk of bias

\begin{tabular}{lll}
\hline Bias & Authors' judgement & Support for judgement \\
\hline $\begin{array}{l}\text { Random sequence genera- } \\
\text { tion (selection bias) }\end{array}$ & Unclear risk & Blocked randomization, method of sequence generation not reported \\
\hline $\begin{array}{l}\text { Allocation concealment } \\
\text { (selection bias) }\end{array}$ & Unclear risk & Not reported \\
\hline $\begin{array}{l}\text { Blinding (performance } \\
\text { bias and detection bias) } \\
\text { All outcomes }\end{array}$ & Unclear risk & Quote: "Double-blind," no further information provided \\
\hline $\begin{array}{l}\text { Incomplete outcome data } \\
\text { (attrition bias) }\end{array}$ & High risk & $\begin{array}{l}\text { Over half lost to follow-up at } 12 \text { months. 48\% followed up overall, similar rates } \\
\text { All outcomes }\end{array}$ \\
\hline
\end{tabular}

\section{McCarthy 2008}

\begin{tabular}{ll}
\hline Methods & Study design: $2 \times 2$ factorial RCT \\
& $\begin{array}{l}\text { Country: USA } \\
\text { Setting: cessation clinic } \\
\text { Recruitment: community volunteers }\end{array}$ \\
\hline Participants & 463 smokers; $50 \%$ female; average age $36-41$; average cigarettes per day 22 \\
\hline Interventions & Bupropion SR 300 mg for 8 weeks \\
- Placebo & Counselling conditions \\
- & $8 \times 10$-min session, 2 prequit, TQD, 5 over 4 weeks \\
- Psychoeducation about medication, support and encouragement. Same number of sessions, 80 mins & less contact time \\
\hline Outcomes & Smoking cessation: 7 day ppa at 12 months. Validated by CO $\leq 10$ ppm. Prolonged self-reported ab- \\
& stinence also assessed \\
- Adverse events: measured for 9 weeks
\end{tabular}

Funding Source

National Cancer Institute, National Instutute on Drug Abuse. GlaxoSmithKline provided placebo medication

Author conflicts of interest Douglas E Jorenby has received research support from Nabi Biopharmaceutical and Pfizer, Inc. and consulting fees from Nabi Biopharmaceutical. Saul Shiffman serves as consultant to GlaxoSmithKline Consumer Healthcare on an exclusive basis regarding over-the-counter smoking cessation products and also is a partner in a company that is developing a new nicotine medication. He is a cofounder of invivodata, inc., which provides electronic diary services for clinical research. In 1998 the University of Wisconsin appointed Dr Fiore to a named Chair, made possible by an unrestricted gift to the university from GlaxoWellcome. GlaxoSmithKline provided complimentary active and placebo medication used in this study

\section{Notes}

Counselling conditions collapsed in main analysis, entered separately in subgroup analysis by intensity. Psychoeducation arms placed in multisession individual counselling subgroup due to high level of contact received, though not classified as counselling in paper. 
McCarthy 2008 (Continued)

Risk of bias

\begin{tabular}{|c|c|c|}
\hline Bias & Authors' judgement & Support for judgement \\
\hline $\begin{array}{l}\text { Random sequence genera- } \\
\text { tion (selection bias) }\end{array}$ & Low risk & Random number table \\
\hline $\begin{array}{l}\text { Allocation concealment } \\
\text { (selection bias) }\end{array}$ & Low risk & $\begin{array}{l}\text { Staff who screened and enrolled participants were unaware of the experimen- } \\
\text { tal condition to be assigned }\end{array}$ \\
\hline $\begin{array}{l}\text { Blinding (performance } \\
\text { bias and detection bias) } \\
\text { All outcomes }\end{array}$ & Low risk & $\begin{array}{l}\text { Double-blind (for medication). "Research staff who interacted with partici- } \\
\text { pants were blind to participants' medication condition assignment." }\end{array}$ \\
\hline $\begin{array}{l}\text { Incomplete outcome data } \\
\text { (attrition bias) } \\
\text { All outcomes }\end{array}$ & Low risk & $\begin{array}{l}171(37 \%) \text { failed to attend quit date visit or lost to follow-up, similar across } \\
\text { groups, included in ITT analysis }\end{array}$ \\
\hline
\end{tabular}

Minami 2014

\begin{tabular}{|c|c|}
\hline Methods & $\begin{array}{l}\text { Study design: RCT } \\
\text { Country: USA } \\
\text { Setting: community. } \\
\text { Recruitment method: "recruited from local community" }\end{array}$ \\
\hline Participants & $\begin{array}{l}\text { Patient with elevated depressive symptoms, as indicated by a Center for Epidemiologic Studies Depres- } \\
\text { sion Scale (CES-D) score > } 6 \\
206 \text { participants randomized; } 48 \% \text { female; average age } 43 \text {; average cigarettes per day } 21 \text {; mean FTND } \\
5.5\end{array}$ \\
\hline Interventions & $\begin{array}{l}\text { - Fluoxetine. } 20 \text { mg each morning, } 8 \text { weeks prior to target quit date and } 8 \text { weeks following } \\
\text { Placebo. According to the schedule detailed above } \\
\text { Common components: } 8 \text {-week supply of nicotine patches and brief counselling, totalling a maximum } \\
\text { of } 150 \text { minutes }\end{array}$ \\
\hline Outcomes & $\begin{array}{l}\text { - Smoking cessation: } 8 \text { weeks - too short a follow-up for this outcome to be considered as part of this } \\
\text { review } \\
\text { - Adverse events: measured for } 8 \text { weeks pre-quit, although whether they recorded post-quit is not clear- } \\
\text { ly specified }\end{array}$ \\
\hline Funding Source & NIDA \\
\hline Author conflicts of interest & $\begin{array}{l}\text { Dr Price reports receiving grant/research support from Medtronic, Neuronetics, NIH, HRSA, and } \\
\text { NeoSync; serving on an advisory panel for Abbott; and serving as a consultant for Wiley, Springer, Qatar } \\
\text { National Research Fund, and Abbott. }\end{array}$ \\
\hline
\end{tabular}

Notes

\section{Risk of bias}


Minami 2014 (Continued)

Random sequence genera- Low risk Quote: "urn randomization to balance the groups on gender, depressive symption (selection bias) toms (CES-D $\geq 16)$, and nicotine dependence (FTND $\geq 7$ )."

Allocation concealment $\quad$ Unclear risk
(selection bias)

(selection bias)

Blinding (performance Low risk

bias and detection bias)

All outcomes

Incomplete outcome data Unclear risk

(attrition bias)

All outcomes
Quote: "assignment was double-blind, such that neither participants nor study staff (including physicians, research assistants, and counselors) were aware of whether the participant was taking fluoxetine or placebo."

\section{Moreno-Coutino 2015}

\begin{tabular}{|c|c|c|}
\hline Methods & \multicolumn{2}{|c|}{$\begin{array}{l}\text { Study design: RCT } \\
\text { Country: Mexico } \\
\text { Setting: smoking cessation clinic } \\
\text { Recruitment method: people seeking smoking cessation treatment at clinic }\end{array}$} \\
\hline Participants & \multicolumn{2}{|c|}{$\begin{array}{l}\text { Heavy smokers with minimal/mild depressive symptomatology. } \\
60 \text { participants randomized; } 38 \% \text { female; average age } 45 \text {; average cigarettes per day } 18.2 \text {; mean FTND } \\
4.7\end{array}$} \\
\hline Interventions & \multicolumn{2}{|c|}{$\begin{array}{l}\text { - Bupropion. } 150 \mathrm{mg} \text { once daily for } 2 \text { weeks prior to target quit date, then } 150 \mathrm{mg} \text { twice daily from } 1 \\
\text { week prior to target quit date until } 4 \text { months of treatment } \\
\text { - Nicotine patch. } 21 \mathrm{mg} \text { starting } 2 \text { weeks before target quit date. } 4 \text { weeks at } 21 \mathrm{mg} \text { following target quit } \\
\text { date, } 14 \mathrm{mg} \text { for } 2 \text { weeks, then } 7 \mathrm{mg} \text { for two weeks } \\
\text { - Bupropion and nicotine patch. Given according to schedules above } \\
\text { Common components: } 4 \text { individual in-person CBT sessions (over } 4 \text { weeks, } 2 \text { pre-quit and } 2 \text { post-quit), } \\
\text { plus } 0.1 \mathrm{mg} \text { low nicotine cigarettes }\end{array}$} \\
\hline Outcomes & \multicolumn{2}{|c|}{$\begin{array}{l}\text { - Smoking cessation: at } 12.5 \text { months } \\
\text { - Adverse events: period of measurement not specified }\end{array}$} \\
\hline Funding Source & \multicolumn{2}{|c|}{ Mexican National University Macro-project in Addictions } \\
\hline Author conflicts of interest & \multicolumn{2}{|l|}{ None specified } \\
\hline \multicolumn{3}{|l|}{ Notes } \\
\hline \multicolumn{3}{|l|}{ Risk of bias } \\
\hline Bias & Authors' judgement & Support for judgement \\
\hline $\begin{array}{l}\text { Random sequence genera- } \\
\text { tion (selection bias) }\end{array}$ & High risk & $\begin{array}{l}\text { Quote: "Those who agreed to continue in the study, entered the raffle (three } \\
\text { different color balls in a dark box) to assign a treatment setting, and were eval- } \\
\text { uated." }\end{array}$ \\
\hline
\end{tabular}


Moreno-Coutino 2015 (Continued)
Allocation concealment High risk
Quote: "Those who agreed to continue in the study, entered the raffle (three (selection bias) different color balls in a dark box) to assign a treatment setting, and were eval- uated."

\begin{tabular}{lll}
$\begin{array}{l}\text { Blinding (performance } \\
\text { bias and detection bias) } \\
\text { All outcomes }\end{array}$ & High risk & $\begin{array}{l}\text { Quote: "evaluations and treatments were conducted by clinical psychologists } \\
\text { who were not blind to the study." }\end{array}$ \\
\hline $\begin{array}{l}\text { Incomplete outcome data } \\
\begin{array}{l}\text { (attrition bias) } \\
\text { All outcomes }\end{array}\end{array}$ & High risk & $\begin{array}{l}\text { High dropout rate from each group }(>50 \%) \text {. Significantly more dropouts from } \\
\text { NRT only arm }\end{array}$ \\
\hline
\end{tabular}

Muramoto 2007

$\begin{array}{ll}\text { Methods } & \text { Study design: RCT } \\ & \text { Country: USA } \\ & \text { Setting: research clinic } \\ & \text { Recruitment: adolescent community volunteers }\end{array}$

\begin{tabular}{ll}
\hline Participants & 312 adolescents (14 to 17); $46 \%$ females; median age 16; median cigarettes per day 11 \\
\hline Interventions & - Bupropion, $300 \mathrm{mg}$ for 7 weeks \\
- Bupropion, $150 \mathrm{mg}$ for 7 weeks \\
- Placebo \\
Common components: brief (10-20 mins) individual counselling session pre-quit and at each weekly as- \\
sessment
\end{tabular}

\begin{tabular}{ll}
\hline Outcomes & Smoking cessation: 7-day ppa at 6 months. Validated by CO < 10 ppm (cotinine at weeks 2 and 6 only) \\
- Adverse events: measured for 26 weeks
\end{tabular}

\begin{tabular}{ll}
\hline Funding Source & National Cancer Institute, The Robert Wood Johnson Foundation, GlaxoSmithKline \\
\hline Author conflicts of interest & $\begin{array}{l}\text { Dr Muramoto has received research contracts from GlaxoSmithKline, Pfizer, and Sanofi-Aventis and is } \\
\text { a speaker for Pfizer. Dr Leischow is a speaker and consultant for Pfizer, and at the time this study was } \\
\text { conducted he was receiving research support from GlaxoSmithKline. }\end{array}$
\end{tabular}

Notes $300 \mathrm{mg}$ arm contributes to main analysis. 2/105 quit in $150 \mathrm{mg}$ group

\section{Risk of bias}

\begin{tabular}{lll}
\hline Bias & Authors' judgement & Support for judgement \\
\hline $\begin{array}{l}\text { Random sequence genera- } \\
\text { tion (selection bias) }\end{array}$ & Low risk & $\begin{array}{l}\text { Quote: "Active study medication and identical-appearing placebo were } \\
\text { prepackaged into 3 sets of identical-appearing blister cards in accordance with } \\
\text { a computer-generated randomization list." }\end{array}$ \\
\hline $\begin{array}{l}\text { Allocation concealment } \\
\text { (selection bias) }\end{array}$ & Low risk & $\begin{array}{l}\text { Quote: "... a research assistant assigned the subject the next treatment number } \\
\text { (and associated blister cards) in sequence." }\end{array}$ \\
\hline $\begin{array}{l}\text { Blinding (performance } \\
\text { bias and detection bias) } \\
\text { All outcomes }\end{array}$ & Low risk & $\begin{array}{l}\text { Quote: "Study subjects and researchers remained blind to treatment group } \\
\text { assignment throughout the study." "9.6\% in the } 300 \text { mg group accurately } \\
\text { guessed their treatment assignment. Across all treatment groups, there were }\end{array}$
\end{tabular}


Muramoto 2007 (Continued)

no significant differences in the proportion of subjects who accurately guessed their treatment group."

\begin{tabular}{|c|c|c|}
\hline $\begin{array}{l}\text { Incomplete outcome data } \\
\text { (attrition bias) } \\
\text { All outcomes }\end{array}$ & Low risk & $\begin{array}{l}\text { Slightly higher lost to follow-up/declined further participation in placebo } \\
\text { group }(30 \%) \text { than active arms (18\%). ITT analysis }\end{array}$ \\
\hline
\end{tabular}

\section{Myles 2004}

\begin{tabular}{ll}
\hline Methods & Study design: RCT \\
& $\begin{array}{l}\text { Country: Australia } \\
\text { Setting: preoperative clinic } \\
\text { Recruitment: smokers awaiting surgery }\end{array}$ \\
\hline Participants & $\begin{array}{l}47 \text { smokers expected to undergo surgery within 8-14 weeks; 34\% female; average age 45/40; 49\% } \\
\text { smoked 21-30 cigarettes per day }\end{array}$ \\
\hline Interventions & Bupropion. 300 mg for 7 weeks \\
& Common components: advice at baseline, 1 phone call 2-4 days after TQD. Low intensity \\
\hline Outcomes & - Smoking cessation: 28 day ppa at 6 months. Validated by CO $\leq 10$ ppm \\
\hline Funding Source & Alfred Hospital Research Trust, Glaxo Wellcome \\
\hline Author conflicts of interest & None specified \\
\hline Notes & More dropouts in placebo group. Only 20 had surgery
\end{tabular}

\section{Risk of bias}

\begin{tabular}{lll}
\hline Bias & Authors' judgement & Support for judgement \\
\hline $\begin{array}{l}\text { Random sequence genera- } \\
\text { tion (selection bias) }\end{array}$ & Low risk & $\begin{array}{l}\text { Patients were randomly allocated from a table of random numbers into one of } \\
\text { two groups: active (bupropion) or placebo (identical appearance) }\end{array}$ \\
\hline $\begin{array}{l}\text { Allocation concealment } \\
\text { (selection bias) }\end{array}$ & Unclear risk & Not described \\
\hline
\end{tabular}

\begin{tabular}{lll}
\hline $\begin{array}{l}\text { Blinding (performance } \\
\text { bias and detection bias) } \\
\text { All outcomes }\end{array}$ & Unclear risk & \\
\hline $\begin{array}{l}\text { Incomplete outcome data } \\
\text { (attrition bias) }\end{array}$ & Low risk & $\begin{array}{l}17 \% \text { lost to follow-up in the bupropion group; } 9 \% \text { lost to follow-up in the } \\
\text { pll outcomes }\end{array}$ \\
\hline
\end{tabular}

Methods Study design: $2 \times 2$ factorial RCT


NCT00132821 (Continued)

Country: USA

Setting: sleep clinic

Recruitment: not specified

\begin{tabular}{ll}
\hline Participants & 59 participants enrolled; smoking at least 20 cigarettes per day. No further patient characteristics given \\
\hline Interventions & Starting 1 week prior to quit day \\
- & Bupropion. $150 \mathrm{mg}$ for 3 days and $300 \mathrm{mg}$ for 60 days \\
- Placebo bupropion & Added on quit day \\
- Nicotine patch ( $21 \mathrm{mg}$ for 6 weeks, $14 \mathrm{mg}$ for 1 week, and $7 \mathrm{mg}$ for 1 week) & - Placebo nicotine patch \\
\hline Outcomes & - Smoking cessation: at 12 months (no definition of abstinence given). Validated by CO \\
\hline Funding Source & National Institute on Drug Abuse \\
\hline Author conflicts of interest & None specified \\
\hline Notes & $\begin{array}{l}\text { Study detailed in trials registry only and results not reported. Attempt to contact the investigator for } \\
\text { further information was unsuccessful }\end{array}$
\end{tabular}

\section{Risk of bias}

\begin{tabular}{lll}
\hline Bias & Authors' judgement & Support for judgement \\
\hline $\begin{array}{l}\text { Random sequence genera- } \\
\text { tion (selection bias) }\end{array}$ & Unclear risk & No relevant information given \\
\hline $\begin{array}{l}\text { Allocation concealment } \\
\text { (selection bias) }\end{array}$ & Unclear risk & No relevant information given \\
\hline $\begin{array}{l}\text { Blinding (performance } \\
\text { bias and detection bias) } \\
\begin{array}{l}\text { All outcomes } \\
\text { Incomplete outcome data }\end{array}\end{array}$ & Unclear risk & No relevant information given \\
$\begin{array}{l}\text { (attrition bias) } \\
\text { All outcomes }\end{array}$ & \\
\hline
\end{tabular}

\section{NCT00308763}

\begin{tabular}{ll}
\hline Methods & Study design: RCT \\
& $\begin{array}{l}\text { Country: USA } \\
\text { Setting: not specified } \\
\text { Recruitment: not specified }\end{array}$ \\
\hline Participants & $\begin{array}{l}594 \text { younger, low-income, and minority smokers enrolled. No further patient characteristics given } \\
\text { Interventions }\end{array}$ \\
$\begin{array}{l}\text { Nicotine patch and placebo bupropion SR. If smoking > } 20 \text { cigarettes per day will be initially given } 21 \\
\text { mg patch; } 10-19 \text { cigarettes per day } 14 \text { mg patch; } 5 \text { - } 9 \text { cigarettes per day } 7 \text { mg patch. If initially placed on } \\
\text { the } 21 \text { mg patch: } 21 \text { mg patch for } 4 \text { weeks, } 14 \text { mg patch for } 4 \text { weeks, } 7 \text { mg patch for } 2 \text { weeks; if initially }\end{array}$ \\
\hline
\end{tabular}


NCT00308763 (Continued)

placed on $14 \mathrm{mg}$ patch: $14 \mathrm{mg}$ patch for 6 weeks, $7 \mathrm{mg}$ patch for 4 weeks; if initially placed on $7 \mathrm{mg}$ patch: $7 \mathrm{mg}$ patch for 10 weeks. Bupropion scheduling as below.

- Placebo nicotine patch and bupropion SR. Bupropion titrated to $150 \mathrm{mg}$, then $150 \mathrm{mg}$ daily for approximately 11 weeks. Placebo patch scheduled as above.

- Nicotine patch and bupropion SR. Same scheduling as above.

\begin{tabular}{ll}
\hline Outcomes & $\begin{array}{l}\text { Smoking cessation: at } 12 \text { months (no definition of abstinence given). Validated by CO and saliva co- } \\
\text { tinine } \\
\text { - Adverse events: not specified whether adverse events were recorded }\end{array}$ \\
\hline Funding Source & NIH (R01HL066025) \\
\hline Author conflicts of interest & None specified \\
\hline Notes & $\begin{array}{l}\text { Study detailed in trials registry only and results not reported. Attempt to contact the investigator for } \\
\text { further information was unsuccessful }\end{array}$ \\
\hline
\end{tabular}

\section{Risk of bias}

\begin{tabular}{lll}
\hline Bias & Authors' judgement & Support for judgement \\
\hline $\begin{array}{l}\text { Random sequence genera- } \\
\text { tion (selection bias) }\end{array}$ & Unclear risk & No relevant information given \\
\hline $\begin{array}{l}\text { Allocation concealment } \\
\text { (selection bias) }\end{array}$ & Unclear risk & No relevant information given \\
\hline $\begin{array}{l}\text { Blinding (performance } \\
\text { bias and detection bias) } \\
\text { All outcomes }\end{array}$ & Unclear risk & No relevant information given \\
\hline $\begin{array}{l}\text { Incomplete outcome data } \\
\text { (attrition bias) } \\
\begin{array}{l}\text { All outcomes } \\
\hline\end{array}\end{array}$ & Unclear risk & No relevant information given \\
\hline
\end{tabular}

\section{NCT00495352}

\begin{tabular}{ll}
\hline Methods & Study design: RCT \\
& $\begin{array}{l}\text { Country: Taiwan } \\
\text { Setting: not specified } \\
\text { Recruitment: not specified }\end{array}$ \\
\hline Participants & $\begin{array}{l}360 \text { motivated psychiatric outpatients with schizophrenia enrolled. No further patient characteristics } \\
\text { detailed }\end{array}$ \\
\hline Interventions & High-dose NRT \\
& - Bupropion \\
\hline Outcomes & Smoking cessation: at 8 weeks, too short a follow-up for consideration in this review \\
\hline Funding Source & Adverse events: not specified whether adverse events were recorded \\
\hline \hline
\end{tabular}


NCT00495352 (Continued)

Author conflicts of interest None specified

Notes Study detailed in trials registry only and results not reported. Attempt to contact the investigator for further information was unsuccessful

\section{Risk of bias}

\begin{tabular}{lll}
\hline Bias & Authors' judgement & Support for judgement \\
\hline $\begin{array}{l}\text { Random sequence genera- } \\
\text { tion (selection bias) }\end{array}$ & Unclear risk & No relevant information given \\
\hline $\begin{array}{l}\text { Allocation concealment } \\
\text { (selection bias) }\end{array}$ & Unclear risk & No relevant information given \\
\hline $\begin{array}{l}\text { Blinding (performance } \\
\text { bias and detection bias) } \\
\text { All outcomes }\end{array}$ & Unclear risk & No relevant information given \\
\hline
\end{tabular}

Incomplete outcome data Unclear risk No relevant information given

(attrition bias)

All outcomes

NCT00578669

\begin{tabular}{ll}
\hline Methods & Study design: RCT \\
& Country: USA \\
& Setting and recuirment method not specified \\
\hline Participants & Participants had elevated depression symptoms. \\
& 206 participants randomized; 48\% female; average age 44; average cigarettes per day 21; mean FTND \\
& 5.7 \\
\hline Interventions & - Fluoxetine. 20 mg once daily, 8 weeks prior to target quit date and weeks thereafter \\
& Common components: nicotine patch as well as "standard smoking cessation treatment" \\
\hline Outcomes & - Smoking cessation: 7-day ppa at 12 months. Validated by CO and saliva cotinine \\
\hline Funding Source & None specified \\
\hline Author conflicts of interest & None specified \\
\hline Notes &
\end{tabular}

Notes

\section{Risk of bias}

Bias Authors' judgement Support for judgement




\section{NCT00578669 (Continued)}

Random sequence genera- Unclear risk No relevant information given tion (selection bias)

Allocation concealment $\quad$ Unclear risk
(selection bias)

(selection bias)

Blinding (performance
bias and detection bias) Unclear risk Placebo controlled, but no further information on blinding provided

All outcomes

Incomplete outcome data Unclear risk

(attrition bias)

All outcomes
Clinical trial registry implies $100 \%$, but not explicitly, so we concluded there was not sufficient information given

\section{NCT00593099}

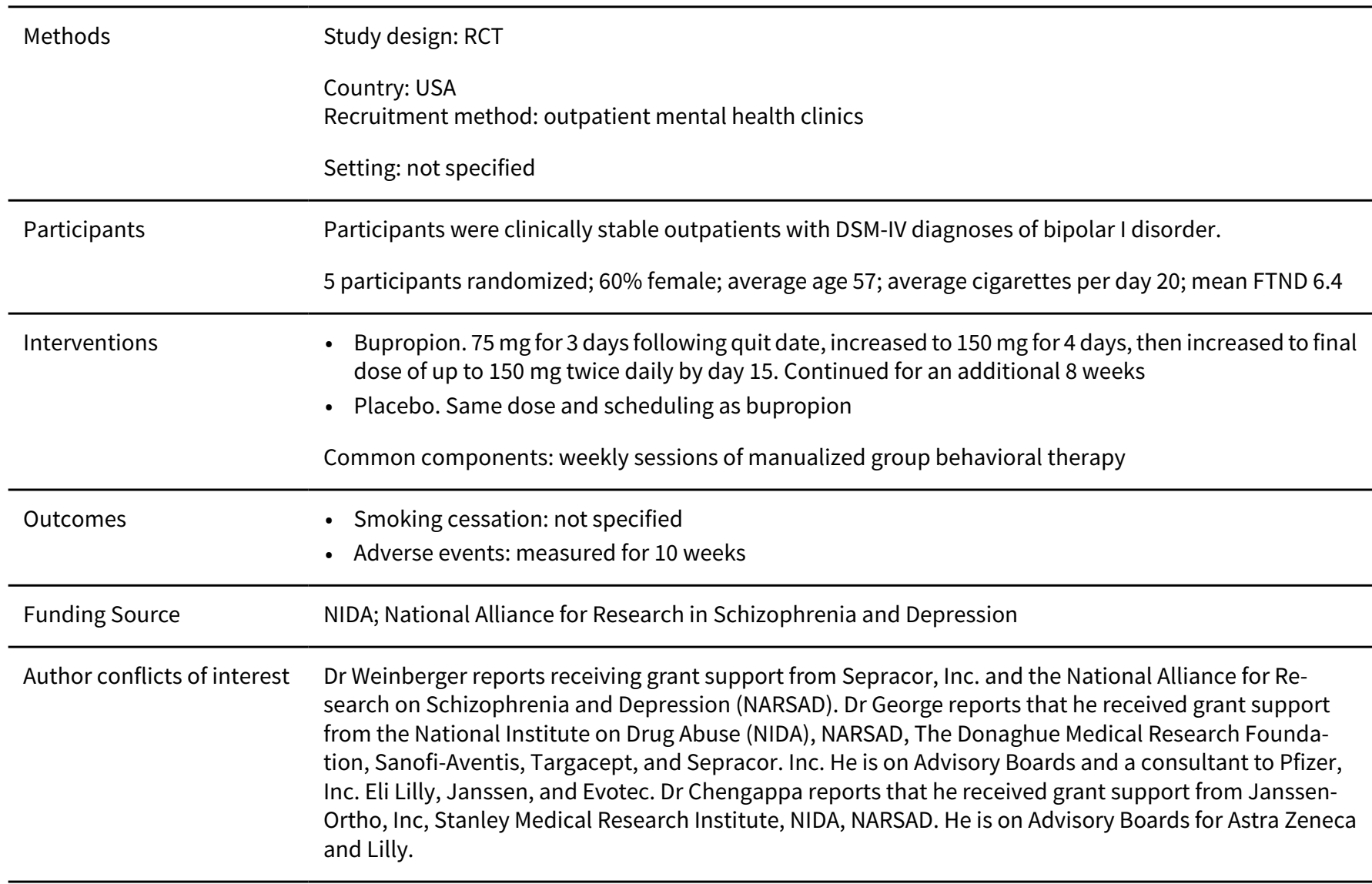

Notes

\section{Risk of bias}

\section{Bias Authors' judgement Support for judgement}

Random sequence genera- Unclear risk No relevant information given
tion (selection bias)




\section{NCT00593099 (Continued)}

Allocation concealment (selection bias)

Blinding (performance bias and detection bias) All outcomes

Incomplete outcome data Low risk (attrition bias)

Unclear risk

No relevant information given

Unclear risk

Paper states that the trial was placebo controlled, but no further information is given
Dropout rates are as follows: $1 / 3$ in placebo; $1 / 2$ in bupropion. Therefore loss to follow-up was less than $50 \%$ and similar between groups.

All outcomes

\section{NCT01406223}

\begin{tabular}{|c|c|}
\hline \multirow[t]{3}{*}{ Methods } & Study design: RCT \\
\hline & Country: USA \\
\hline & Setting and recruitment method not specified \\
\hline Participants & 76 participants randomized; $53 \%$ female; average age 38.8 \\
\hline Interventions & $\begin{array}{l}\text { - Bupropion and varenicline. Bupropion was given } 150 \mathrm{mg} \text { once daily for the first week, then twice daily } \\
\text { for remainder of the } 12 \text {-week treatment period. Varenicline was adminstered } 0.5 \mathrm{mg} \text { once daily start- } \\
\text { ing one week preceding the target quit date, } 0.5 \mathrm{mg} \text { twice daily for the remaining } 4 \text { days of that week, } \\
\text { then } 1 \mathrm{mg} \text { twice daily of the remainder of the } 12 \text {-week treatment period. }\end{array}$ \\
\hline & - Placebo and varenicline. Given according to the relevant schedules detailed above. \\
\hline Outcomes & - Smoking cessation: not specified \\
\hline & - Adverse events: measured for 13 -week treatment period \\
\hline Funding Source & Not specified \\
\hline Author conflicts of interest & Not specified \\
\hline
\end{tabular}

\section{Risk of bias}

\begin{tabular}{lll}
\hline Bias & Authors' judgement & Support for judgement \\
\hline $\begin{array}{l}\text { Random sequence genera- } \\
\text { tion (selection bias) }\end{array}$ & Unclear risk & No relevant information given \\
\hline $\begin{array}{l}\text { Allocation concealment } \\
\text { (selection bias) }\end{array}$ & Unclear risk & No relevant information given \\
\hline $\begin{array}{l}\text { Blinding (performance } \\
\text { bias and detection bias) }\end{array}$ & Unclear risk & $\begin{array}{l}\text { Stated that the study is placebo controlled and there is “double masking”, but } \\
\text { no further detail is given }\end{array}$ \\
\hline $\begin{array}{l}\text { Incomplete outcome data } \\
\text { (attrition bias) }\end{array}$ & High risk & Dropout rates are as follows: $12 / 18$ varenicline; $18 / 20$ varenicline \\
\begin{tabular}{l} 
All outcomes \\
\hline
\end{tabular}
\end{tabular}


Niaura 2002

\begin{tabular}{|c|c|}
\hline Methods & $\begin{array}{l}\text { Study design: RCT } \\
\text { Country: USA } \\
\text { Setting: } 16 \text { clinical trial centres } \\
\text { Recruitment: community volunteers }\end{array}$ \\
\hline Participants & 989 non-depressed smokers; $61 \%$ female; average age 42 ; average cigarettes per day 28 \\
\hline Interventions & $\begin{array}{l}\text { - Fluoxetine. } 30 \mathrm{mg} \text { for } 10 \text { weeks, starting } 2 \text { weeks before TQD } \\
\text { - Fluoxetine. } 60 \mathrm{mg} \text { for } 10 \text { weeks, starting } 2 \text { weeks before TQD } \\
\text { - Placebo } \\
\text { Common components: } 9 \text { sessions ( } 60-90 \text { mins) individual CBT. Included coping skills, stimulus control } \\
\text { techniques and relapse prevention }\end{array}$ \\
\hline Outcomes & $\begin{array}{l}\text { - Smoking cessation: multiple ppa at } 32 \text { weeks from TQD. Validated by saliva cotinine }<20 \mathrm{ng} / \mathrm{mL} \text { at } \\
\text { each visit } \\
\text { - Adverse events: measured for } 6 \text { months }\end{array}$ \\
\hline Funding Source & Eli Lilly and Company \\
\hline Author conflicts of interest & None specified \\
\hline Notes & $\begin{array}{l}\text { Originally based on abstract and data from authors. From } 2002 \text { based on full report. Numbers quit de- } \\
\text { rived from rounded quit rates ( } 10 \% \text { quit in each group) }\end{array}$ \\
\hline
\end{tabular}

\section{Risk of bias}

\begin{tabular}{|c|c|c|}
\hline Bias & Authors' judgement & Support for judgement \\
\hline $\begin{array}{l}\text { Random sequence genera- } \\
\text { tion (selection bias) }\end{array}$ & Unclear risk & Randomization method not described \\
\hline $\begin{array}{l}\text { Allocation concealment } \\
\text { (selection bias) }\end{array}$ & Unclear risk & Not described \\
\hline $\begin{array}{l}\text { Blinding (performance } \\
\text { bias and detection bias) } \\
\text { All outcomes }\end{array}$ & Unclear risk & Double-blind but further detail not provided \\
\hline $\begin{array}{l}\text { Incomplete outcome data } \\
\text { (attrition bias) } \\
\text { All outcomes }\end{array}$ & Low risk & $\begin{array}{l}\text { Missing data in treatment phase addressed, but unclear whether missing data } \\
\text { in follow-up phase addressed. At } 12 \text { months, } 42 \% \text { missing data, similar across } \\
\text { all arms; missing data counted as smokers in our analyses. }\end{array}$ \\
\hline
\end{tabular}

Nides 2006

\begin{tabular}{ll}
\hline Methods & Study design: RCT \\
& Country: USA \\
& Setting: 5 clinical sites \\
& Recruitment: volunteers (phase II study) \\
\hline Participants & 638 smokers (255 in relevant arms, including 2 bupropion and 4 placebo who did not start medication); \\
& $51 \%$ female; average age 41; average cigarettes per day 20 \\
\hline
\end{tabular}


Nides 2006 (Continued)

Interventions

- Bupropion, $300 \mathrm{mg}$ for 7 weeks

- Varenicline, $2 \mathrm{mg}$ for 7 weeks (other dose regimens not used in review)

- Placebo

Common components: up to 10 mins counselling at 7 weekly clinic visits, 12 weeks and 24 weeks

\begin{tabular}{ll}
\hline Outcomes & - Smoking cessation: continuous abstinence at 12 months (starting from week 4). Validated by CO \\
- Adverse events: measured for 11 weeks
\end{tabular}

Funding Source Pfizer

Author conflicts of interest Dr Nides has received research grants, consulting fees, and honoraria from Pfizer, Sanofi-Aventis, and GlaxoSmithKline. Dr Oncken has received research grants, consulting fees, and honoraria from Pfizer; received, at no cost, nicotine replacement and placebo products from GlaxoSmithKline for smoking cessation studies; and received honoraria from Pri-Med. Dr Gonzales reports having received research contracts from Pfizer, Sanofi-Aventis, GlaxoSmithKline and Nabi Biopharmaceuticals; consulting fees and honoraria from Pfizer, Sanofi-Aventis, and GlaxoSmithKline; and owning 5 shares of Pfizer stock. Dr Rennard has had or currently has a number of relationships with companies that provide product and/or services relevant to outpatient management of chronic obstructive pulmonary disease. These relationships include serving as a consultant (Adams, Almirall, Altana, Array Biopharma, AstraZeneca, Aventis, Biolipox, Centocor, Dey, Critical Therapeutics, GlaxoSmithKline, Johnson \& Johnson, Merck, Novartis, Ono Pharma, Otsuka, RJ Reynolds, Roche, Sankyo, Schering-Plough, Scios, and Wyeth); advising regarding clinical trials (Altana, AstraZeneca, Aventis, Centocor, GlaxoSmithKline, Novartis, Pfizer, and Philip Morris); speaking at continuing medical education programmes; and performing funded research at both basic and clinical levels (Altana, AstraZeneca, Boehringer Ingelheim, GlaxoSmithKline, and Novartis). He owns no stock in any pharmaceutical companies. Drs Watsky and Reeves and Mr Anziano are employees of Pfizer and own Pfizer stock or have stock options.

\begin{tabular}{ll}
\hline Notes & Bupropion was an active control for varenicline. \\
& Bupropion versus placebo and bupropion versus $2 \mathrm{mg}$ varenicline comparisons contribute to review. \\
Inclusion of 6 pretreatment dropouts has minimal effect on risk ratio
\end{tabular}

\section{Risk of bias}

\begin{tabular}{lll}
\hline Bias & Authors' judgement & Support for judgement \\
\hline $\begin{array}{l}\text { Random sequence genera- } \\
\text { tion (selection bias) }\end{array}$ & Low risk & $\begin{array}{l}\text { Quote: "...a randomization list was computer generated using a method of ran- } \\
\text { domly permuted blocks and a pseudorandom number generator." }\end{array}$ \\
\hline $\begin{array}{l}\text { Allocation concealment } \\
\text { (selection bias) }\end{array}$ & Low risk & $\begin{array}{l}\text { Quote: "Investigators assigned medication to subjects in numerical order of } \\
\text { acceptance into the study." }\end{array}$ \\
\hline $\begin{array}{l}\text { Blinding (performance } \\
\text { bias and detection bias) }\end{array}$ & Unclear risk & $\begin{array}{l}\text { Quote: "double-blind", "to preserve treatment blinding," no further informa- } \\
\text { tion provided }\end{array}$ \\
\hline $\begin{array}{l}\text { Incomplete outcome data } \\
\text { (attrition bias) } \\
\text { All outcomes }\end{array}$ & Low risk & $\begin{array}{l}\text { Quote: "Subjects who dropped out for any reason were considered to be } \\
\text { smokers at all subsequent time points." 9.5\% of varenicline tartrate } 0.3 \text { mg, } \\
\text { once daily; } 7 \% \text { of varenicline tartrate } 1.0 \text { mg, once daily; } 11 \% \text { of varenicline } \\
\text { tartrate } 1.0 \text { mg, twice daily; } 6 \% \text { of bupropion hydrochloride } 150 \text { mg, twice dai- } \\
\text { ly and } 13 \% \text { of the placebo group were lost to follow-up. }\end{array}$ \\
\hline
\end{tabular}

Parsons 2009

Methods Study design: 2 × 2 factorial RCT


Parsons 2009 (Continued)

\section{Country: UK}

Setting: smoking cessation clinic

Recruitment: direct mail from general practitioner (GP), stop smoking service, newspaper advertisements

\begin{tabular}{ll}
\hline Participants & 143 adult smokers; 62\% female; average age 46; average cigarettes per day 21; mean FTND 5.5 \\
\hline Interventions & - St John's wort, $900 \mathrm{mg} /$ day (300 mg x 3/day) for 14 weeks, started 2 weeks prior to TQD \\
& Common components: 7 weekly individual behavioural support sessions in clinic \\
\hline Outcomes & $\begin{array}{l}\text { - Smoking cessation: prolonged abstinence at } 6 \text { months. Validated by CO } \leq 10 \text { ppm } \\
\text { after quit day ( } 2 \text { weeks prior to quit day to } 4 \text { weeks afterward) }\end{array}$ \\
\hline Funding Source & $\begin{array}{l}\text { Cancer Research UK } \\
\text { Author conflicts of interest }\end{array}$ \\
\hline None specified in the first 4 weeks \\
\hline Notes & $\begin{array}{l}\text { New for } 2013 \\
\text { Factorial trial - also tested the use of chromium versus placebo for weight loss. Arms collapsed for } \\
\text { analysis; no difference detected }\end{array}$
\end{tabular}

\section{Risk of bias}

\begin{tabular}{lll}
\hline Bias & Authors' judgement & Support for judgement \\
\hline $\begin{array}{l}\text { Random sequence genera- } \\
\text { tion (selection bias) }\end{array}$ & Low risk & Via computer program \\
\hline $\begin{array}{l}\text { Allocation concealment } \\
\text { (selection bias) }\end{array}$ & Low risk & $\begin{array}{l}\text { Independent statistician sent randomization codes to medication packing } \\
\text { company, medication allocated in sequence. Researchers blind to allocation }\end{array}$ \\
\hline $\begin{array}{l}\text { Blinding (performance } \\
\text { bias and detection bias) } \\
\text { All outcomes }\end{array}$ & Low risk & $\begin{array}{l}\text { Quote: "Participants, therapists, and outcome assessors were blind to the } \\
\text { treatment allocation." }\end{array}$ \\
\hline $\begin{array}{l}\text { Incomplete outcome data } \\
\text { (attrition bias) } \\
\text { All outcomes }\end{array}$ & Low risk & Over $90 \%$ followed up at 6 months, similar between groups \\
\hline
\end{tabular}

\section{Perkins 2013}

\begin{tabular}{ll}
\hline Methods & Study design: cross-over trial \\
& Country: USA \\
& $\begin{array}{l}\text { Setting: university research centre } \\
\text { Recruitment method: "recruitment notices" were used }\end{array}$ \\
\hline Participants & 45 participants randomized; $60 \%$ female; average age $36 ;$ average cigarettes per day $16 ;$ mean FTND 4.6 \\
\hline Interventions & Bupropion, 150 mg once daily for 3 days, then 150 mg twice daily for 2 weeks
\end{tabular}


Perkins 2013 (Continued)

- Placebo, same schedule as above

Outcomes

- Smoking cessation (strictest definition): measures days abstinent per participant, which is not a relevant outcome to our review

- Adverse events: measured over three-week treatment period
Funding Source
Funded by National Institutes of Health

Author conflicts of interest

Dr Perkins has served as a consultant for Embera Neurotherapeutics, which is unrelated to the current study. Dr Lerman has served as a consultant for GlaxoSmithKline, Pfizer and Astra Zeneca. She has received research funding, unrelated to the current study, from Pfizer and Astra Zeneca. Dr Chengappa has research funding from Pfizer that is unrelated to the current study. Dr Sparks, Mr Karelitz and Ms Jao have no potential conflicts of interest or disclosures to report.

Notes

\section{Risk of bias}

\begin{tabular}{|c|c|c|}
\hline Bias & Authors' judgement & Support for judgement \\
\hline $\begin{array}{l}\text { Random sequence genera- } \\
\text { tion (selection bias) }\end{array}$ & Unclear risk & Quote: “assigned randomly", but no further information provided \\
\hline $\begin{array}{l}\text { Allocation concealment } \\
\text { (selection bias) }\end{array}$ & Unclear risk & No relevant information given \\
\hline $\begin{array}{l}\text { Blinding (performance } \\
\text { bias and detection bias) } \\
\text { All outcomes }\end{array}$ & Low risk & $\begin{array}{l}\text { Analysis of participants knowledge of drug allocation revealed no significant } \\
\text { differences between trial arms: "The respective number (percentage) of sub- } \\
\text { jects identifying the medication as bupropion, modafinil, placebo or do not } \\
\text { know were four, two, five and } 34 \text { ( } 8.9,4.4,11.1 \text { and } 75.6 \%) \text { of } 45 \text { during the } \\
\text { bupropion condition; seven, three, four and } 31 \text { (15.6, } 6.7,8.9 \text { and } 68.9 \%) \text { of } 45 \\
\text { during the modafinil condition; and four, three, eight and } 30(9.1,6.8,18.2 \text { and } \\
67.9 \% \text { ) of } 44 \text { ( } 1 \text { subject with missing data) during the placebo condition. None } \\
\text { of these values differed by medication condition, indicating successful blind- } \\
\text { ing." }\end{array}$ \\
\hline
\end{tabular}

Incomplete outcome data Unclear risk No relevant information given (attrition bias)

All outcomes

Piper 2007

$\begin{array}{ll}\text { Methods } & \text { Study design: RCT } \\ \text { Setting: none specified } \\ \text { Country: USA } \\ \text { Recruitment: volunteers }\end{array}$

\begin{tabular}{ll}
\hline Participants & 608 smokers; $58 \%$ female; average age 42; average cigarettes per day 22 \\
\hline Interventions & - Nicotine gum and bupropion. Gum at $4 \mathrm{mg}$. Bupropion at $300 \mathrm{mg}$ \\
& - Placebo gum and bupropion \\
& Double placebo
\end{tabular}

Common components: three 10-min counselling sessions over 3 weeks 
Piper 2007 (Continued)

Outcomes $\quad$ Smoking cessation: ppa at 12 months. Validated by CO or blood cotinine

- Adverse events: measured for unspecified period

Funding Source National Institutes for Health

Author conflicts of interest In 1998 the University of Wisconsin appointed Dr Fiore to a named chair, made possible by an unrestricted gift to the university from GlaxoWellcome. Dr Baker has received monies to conduct clinical trials from pharmaceutical companies (Nabi, Glaxo, Pfizer, Sanofi)

Notes

\section{Risk of bias}

\begin{tabular}{lll}
\hline Bias & Authors' judgement & Support for judgement \\
\hline $\begin{array}{l}\text { Random sequence genera- } \\
\text { tion (selection bias) }\end{array}$ & Unclear risk & $\begin{array}{l}\text { "Randomization was conducted in double-blind } \\
\text { fashion using blocked randomization within each of } \\
\text { the } 10 \text { [orientation session] cohorts." No further information provided }\end{array}$ \\
\hline $\begin{array}{l}\text { Allocation concealment } \\
\text { (selection bias) }\end{array}$ & Unclear risk & Not stated \\
\hline $\begin{array}{l}\text { Blinding (performance } \\
\text { bias and detection bias) }\end{array}$ & Unclear risk & Described as double-blind, but no further information \\
$\begin{array}{l}\text { All outcomes } \\
\begin{array}{l}\text { Incomplete outcome data } \\
\text { (attrition bias) } \\
\text { All outcomes }\end{array}\end{array}$ & Low risk & $\begin{array}{l}32 \% \text { of bupropion and 36\% of placebo groups lost at } 12 \text { months. "Participants } \\
\text { who could not be reached at follow-up were considered to be smoking for the } \\
\text { purposes of follow-up analyses." }\end{array}$ \\
\hline
\end{tabular}

Piper 2009

\begin{tabular}{|c|c|}
\hline \multirow[t]{4}{*}{ Methods } & Study design: RCT \\
\hline & Country: USA \\
\hline & Setting: community \\
\hline & Recruitment: volunteers \\
\hline Participants & 1504 smokers; $58 \%$ female; average age 45 ; average cigarettes per day 21.4 \\
\hline Interventions & $\begin{array}{l}\text { - Bupropion SR. } 150 \mathrm{mg} \text { twice/day, } 1 \text { week pre-quit, } 8 \text { weeks post-quit } \\
\text { - Bupropion and nicotine lozenge. Duration and dosage as below } \\
\text { - Nicotine lozenge. } 2 \mathrm{mg} \text { or } 4 \mathrm{mg} \text { for } 12 \text { weeks (based on dose-for-dependence level as per instructions) } \\
\text { - Nicotine patch ( } 24 \mathrm{hr}, 21,14 \text {, and } 7 \mathrm{mg} \text { titrated down over } 8 \text { week period post-quit) } \\
\text { - Nicotine lozenge and nicotine patch. Duration and dosage as above } \\
\text { - Placebo bupropion } \\
\text { - Placebo bupropion and placebo lozenge } \\
\text { - Placebo lozenge } \\
\text { - Placebo patch } \\
\text { - Placebo lozenge and placebo patch } \\
\text { Common components: } 7 \text { one-to-one } 10 \text { to } 20 \text {-min counselling sessions }\end{array}$ \\
\hline
\end{tabular}


Piper 2009 (Continued)

Outcomes

- Smoking cessation: 7 day ppa at 6 months. Validated by $\mathrm{CO}<10 \mathrm{ppm}$

- Adverse events: measured for 10 weeks

Funding Source

Majority of funding from National Institute on Drug Abuse and National Center for Research Resources. Medication provided to participants at no extra cost by GlaxoSmithKline.

Author conflicts of interest The authors report the following potential conflicts of interest for the last 5 years: Dr Smith has received research support from Elan Corporation. Dr Baker has served as an investigator on research projects sponsored by pharmaceutical companies, including Sanofi-Synthelabo, Pfizer Inc, and Nabi Biopharmaceuticals. Dr Jorenby has received research support from the National Institute on Drug Abuse, the National Cancer Institute, Pfizer Inc, Sanofi-Synthelabo, and Nabi Biopharmaceuticals. He has received support for educational activities from the National Institute on Drug Abuse and the Veterans Administration and consulting fees from Nabi Biopharmaceuticals. Dr Fiore has received honoraria from Pfizer. He has served as an investigator on research studies at the University of Wisconsin that were funded by Pfizer, Sanofi-Synthelabo, GlaxoSmithKlein, and Nabi Biopharmaceuticals. In 1998, the University of Wisconsin appointed Dr Fiore to a named chair funded by an unrestricted gift to University of Wisconsin from Glaxo Wellcome.

Notes New for 2013 update

Placebo outcomes reported as a whole in published report, author provided data for individual groups. 1 versus 6 in Analyses 1.1, 1.2 and 1.3. 2 versus 3 included in Analysis 1.5. 1 versus 4 in Analysis 1.7.1, 1 versus 3 in Analysis 1.7.2 and 1 versus 5 in Analysis 1.7.3 (intervention arm split in three to avoid triple counting)

\section{Risk of bias}

\begin{tabular}{|c|c|c|}
\hline Bias & Authors' judgement & Support for judgement \\
\hline $\begin{array}{l}\text { Random sequence genera- } \\
\text { tion (selection bias) }\end{array}$ & Unclear risk & $\begin{array}{l}\text { Method of sequence generation not specified. "Randomization was dou- } \\
\text { ble-blind and used a block randomization scheme with sex and self-reported } \\
\text { race as the blocking variables." }\end{array}$ \\
\hline $\begin{array}{l}\text { Allocation concealment } \\
\text { (selection bias) }\end{array}$ & Low risk & $\begin{array}{l}\text { "Staff did not know to which type(s) of medication a participant would be as- } \\
\text { signed until the moment of randomization, and study staff were blinded to } \\
\text { whether the medication was active or placebo." }\end{array}$ \\
\hline $\begin{array}{l}\text { Blinding (performance } \\
\text { bias and detection bias) } \\
\text { All outcomes }\end{array}$ & Unclear risk & $\begin{array}{l}\text { "Double blind" but no further detail provided. } \\
\text { "Study staff were blinded to whether the medication was active or placebo" } \\
\text { Comment: type of medication (i.e. patch, gum, pill) would have been apparent } \\
\text { to both groups }\end{array}$ \\
\hline $\begin{array}{l}\text { Incomplete outcome data } \\
\text { (attrition bias) } \\
\text { All outcomes }\end{array}$ & Low risk & $\begin{array}{l}90 \text { dropouts (out of 1504). Analyses conducted using ITT. Individuals with miss- } \\
\text { ing data considered to be smoking }\end{array}$ \\
\hline
\end{tabular}

Planer 2011

$\begin{array}{ll}\text { Methods } & \text { Study design: RCT } \\ \text { Country: Israel } \\ \text { Setting: hospitals, Jersulem } \\ \text { Recruitment: patients hospitalized for acute coronary syndrome in 2 separate campuses in Jerusalem }\end{array}$


Planer 2011 (Continued)

Participants $\quad 151$ smokers with diagnosis of acute coronary syndrome, motivated to quit; average age $51.9 ; 20.1 \%$ female; average cigarettes per day 31

Interventions

- Bupropion, $150 \mathrm{mg} 1 \mathrm{x}$ day for 3 days, then $2 \mathrm{x}$ day for 2 months

- Placebo, same schedule as above

Common components: counselling (at least 15 min of motivational support) during hospitalization and continued after discharge (at least 2 visits with physician and nurse at 1 month and 2 months and weekly telephone call by nurse during first and second month, then monthly telephone calls during rest of the year)

Outcomes - Smoking cessation: self-reported continuous abstinence at 12 months

- Adverse events: measured for 12 months

\begin{tabular}{ll}
\hline Funding Source & GlaxoSmithKline \\
\hline Author conflicts of interest & None specified \\
\hline
\end{tabular}

Notes New for 2013 update

Study stopped early after interim analysis indicated no benefit

OR adjusted for age, sex, invasive procedure, risk factors, Fagerstrom score, cigarettes per day: 0.90

(95\% confidence interval (Cl) 0.39 to 2.09 )

\section{Risk of bias}

\begin{tabular}{lll}
\hline Bias & Authors' judgement & Support for judgement \\
\hline $\begin{array}{l}\text { Random sequence genera- } \\
\text { tion (selection bias) }\end{array}$ & Unclear risk & Quote: "Randomized," method not specified \\
\hline $\begin{array}{l}\text { Allocation concealment } \\
\text { (selection bias) }\end{array}$ & Unclear risk & Method not specified \\
\hline $\begin{array}{l}\text { Blinding (performance } \\
\text { bias and detection bias) }\end{array}$ & Low risk & $\begin{array}{l}\text { Participants and staff blind to treatment assignment, "Numbered study bot- } \\
\text { tll outcomes were supplied by the study co-ordinator and remained concealed from the } \\
\text { patients and medical staff." } \\
\text { Comment: no biochemical validation but participants blind to condition so } \\
\text { differential misreport unlikely. }\end{array}$ \\
\hline $\begin{array}{l}\text { Incomplete outcome data } \\
\text { (attrition bias) }\end{array}$ & Low risk & $\begin{array}{l}\text { 1 lost to follow-up in each group } \\
\text { All outcomes }\end{array}$ \\
\hline
\end{tabular}

\section{Prochazka 1998}

\begin{tabular}{ll}
\hline Methods & Study design: RCT \\
& $\begin{array}{l}\text { Country: USA } \\
\text { Setting: VAMC and Army Medical Centre } \\
\text { Recruitment: outpatient clinics and campus advertisements }\end{array}$ \\
\hline Participants & 214 smokers (excludes 29 early dropouts); $38 \%$ female; average age 47 \\
\hline Interventions & - Nortriptyline, maximum $75 \mathrm{mg} /$ day from 10 days pre-quit date to 8 weeks after, tapered for 2 weeks
\end{tabular}


Prochazka 1998 (Continued)

\section{- Placebo capsules}

Common components: 2 behavioural group sessions prior to drug therapy. During treatment individual support was provided by the study nurse.

\begin{tabular}{ll}
\hline Outcomes & Smoking cessation: prolonged abstinence at 6 months. Validated by $\mathrm{CO} \leq 9 \mathrm{ppm}$ at each visit and urine \\
cotinine $<50 \mathrm{ng} / \mathrm{mL}$ at 6 months \\
- Adverse events: measured for unspecified period
\end{tabular}

\begin{tabular}{ll}
\hline Funding Source & Department of Veterans Affairs, US Department of Defense \\
\hline Author conflicts of interest & None specified \\
\hline Notes &
\end{tabular}

\section{Risk of bias}

\begin{tabular}{lll}
\hline Bias & Authors' judgement & Support for judgement \\
\hline $\begin{array}{l}\text { Random sequence genera- } \\
\text { tion (selection bias) }\end{array}$ & Unclear risk & Randomization method not described \\
\hline $\begin{array}{l}\text { Allocation concealment } \\
\text { (selection bias) }\end{array}$ & Unclear risk & Not described \\
\hline $\begin{array}{l}\text { Blinding (performance } \\
\text { bias and detection bias) }\end{array}$ & High risk & $\begin{array}{l}\text { Quote: "An unblinded research pharmacist recommended dosage reductions } \\
\text { for those above the therapeutic range and dosage increases for those who } \\
\text { were subtherapeutic. To maintain blinding, dose reductions and increases on } \\
\text { an equal number of randomly selected placebo-treated subjects were also rec- } \\
\text { ommended...our blinding was only partially effective. Because of the high fre- } \\
\text { quency of dry mouth, the nurse and subjects were often able to identify the ac- } \\
\text { tive drug." }\end{array}$
\end{tabular}

\begin{tabular}{|c|c|c|}
\hline $\begin{array}{l}\text { Incomplete outcome data } \\
\text { (attrition bias) } \\
\text { All outcomes }\end{array}$ & High risk & $\begin{array}{l}75 \% \text { dropout rate in placebo, } 61 \% \text { in drug group, majority classified as ineffec- } \\
\text { tive therapy }\end{array}$ \\
\hline
\end{tabular}

All outcomes

\section{Prochazka 2004}

\begin{tabular}{ll}
\hline Methods & Study design: RCT \\
& $\begin{array}{l}\text { Country: USA } \\
\text { Setting: clinic } \\
\text { Recruitment: outpatient clinic and community volunteers }\end{array}$ \\
\hline Participants & $\begin{array}{l}\text { 158 smokers; } 54 \% \text { female; average cigarettes per day } 22 \\
\text { fortriptyline and nicotine patch, maximum } 75 \mathrm{mg} / \text { day for } 14 \text { weeks, from } 2 \text { weeks before TQD tapered } \\
\text { Interventions }\end{array}$ \\
& Placebo capsules and nicotine patch \\
\hline Outcomes & $\begin{array}{l}\text { Smoking cessation: prolonged abstinence at } 6 \text { months. Validated by CO } \leq 9 \text { ppm at each visit, cotinine } \\
<50 \text { ng/mL at } 6 \text { months } \\
\text { Adverse events: measured for unspecified period }\end{array}$ \\
\hline
\end{tabular}


Prochazka 2004 (Continued)

Funding Source Department of Veterans Affairs

Author conflicts of interest None specified

Notes

\section{Risk of bias}

\begin{tabular}{lll}
\hline Bias & Authors' judgement & Support for judgement \\
\hline $\begin{array}{ll}\text { Random sequence genera- } \\
\text { tion (selection bias) }\end{array}$ & Low risk & $\begin{array}{l}\text { Quote: "Subjects were stratified by history of previous major depression and } \\
\text { randomized by means of a computer-generated random number list that was } \\
\text { held by the Research Pharmacy Service of the Denver Veterans Affairs Medical } \\
\text { Center." }\end{array}$
\end{tabular}

\begin{tabular}{|c|c|c|}
\hline $\begin{array}{l}\text { Allocation concealment } \\
\text { (selection bias) }\end{array}$ & Low risk & $\begin{array}{l}\text { Quote: "Once a patient was enrolled, the Research Pharmacy Service random- } \\
\text { ized the subject according to the randomization list." Judged adequate }\end{array}$ \\
\hline
\end{tabular}

\begin{tabular}{|c|c|c|}
\hline $\begin{array}{l}\text { Blinding (performance } \\
\text { bias and detection bias) } \\
\text { All outcomes }\end{array}$ & High risk & $\begin{array}{l}\text { Quote: "...our blinding was only partially effective. Because of the high fre- } \\
\text { quency of dry mouth, the study nurse was often able to identify the active } \\
\text { drug." }\end{array}$ \\
\hline
\end{tabular}

\begin{tabular}{|c|c|c|}
\hline $\begin{array}{l}\text { Incomplete outcome data } \\
\text { (attrition bias) }\end{array}$ & Low risk & $\begin{array}{l}\text { Quote: "Subjects who dropped out were counted as smokers." Number of } \\
\text { dropouts not given }\end{array}$ \\
\hline
\end{tabular}

All outcomes

Quote: "Subjects who dropped out were counted as smokers." Number of dropouts not given

Richmond 2013

\begin{tabular}{|c|c|}
\hline Methods & $\begin{array}{l}\text { Study design: RCT } \\
\text { Country: Australia } \\
\text { Setting: } 18 \text { prisons } \\
\text { Recruitment: referral from clinic staff, flyers and posters in prisons }\end{array}$ \\
\hline Participants & $\begin{array}{l}425 \text { male prisoners aged }>18 \text {, incarcerated for } \geq 1 \text { month with } \geq 6 \text { months of current sentence remain- } \\
\text { ing; FTND } \geq 5 \text {; average age } 34 \text {; average cigarettes per day } 23 ; 83 \% \text { FTND } \geq 6\end{array}$ \\
\hline Interventions & $\begin{array}{l}\text { - Nortriptyline, tablet form for } 13 \text { weeks (TQD week } 3 \text {. Week } 1: 25 \mathrm{mg} / \text { day for } 3 \text { days, } 50 \mathrm{mg} / \text { day for } 4 \\
\text { days. Weeks } 2 \text { to } 1275 \mathrm{mg} / \text { day. Week } 1350 \mathrm{mg} / \text { day for } 4 \text { days, then } 25 \mathrm{mg} / \text { day for } 3 \text { days) } \\
\text { - Placebo, same schedule as above } \\
\text { Common components: two x } 30 \text {-minute counselling sessions with CBT. Self-help materials, access to } \\
\text { quitline. } 10 \text { weeks NRT patch started on TQD; } 21 \mathrm{mg} \text { weeks } 1-6,14 \mathrm{mg} / \text { day weeks } 7-8,7 \mathrm{mg} / \text { day weeks } \\
9-10\end{array}$ \\
\hline Outcomes & $\begin{array}{l}\text { - Smoking cessation: continuous abstinence at } 12 \text { months. Validated by } \mathrm{CO}<10 \mathrm{ppm} \\
\text { - Adverse events: measured for unspecified period }\end{array}$ \\
\hline Funding Source & $\begin{array}{l}\text { National Health and Medical Research Council, NSW Department of Health, Queensland Department of } \\
\text { Health. NRT provided free of charge by GlaxoSmithKline. }\end{array}$ \\
\hline Author conflicts of interest & Tony Butler is supported by an ARC future Fellowship \\
\hline Notes & $\begin{array}{l}\text { New for } 2013 \text { update } \\
\text { N quit extrapolated from percentages provided }\end{array}$ \\
\hline
\end{tabular}


Richmond 2013 (Continued)

\section{Risk of bias}

\begin{tabular}{lll}
\hline Bias & Authors' judgement & Support for judgement \\
\hline $\begin{array}{l}\text { Random sequence genera- } \\
\text { tion (selection bias) }\end{array}$ & Unclear risk & Quote: “Randomization algorithm," no further information provided \\
\hline $\begin{array}{l}\text { Allocation concealment } \\
\text { (selection bias) }\end{array}$ & Unclear risk & Not specified \\
\hline $\begin{array}{l}\text { Blinding (performance } \\
\text { bias and detection bias) } \\
\text { All outcomes }\end{array}$ & Unclear risk & $\begin{array}{l}\text { Quote: "Follow-up assessments were conducted... by a prison nurse research } \\
\text { assistant who was blind to group allocation." Identical placebo. No further in- } \\
\text { formation on blinding provided }\end{array}$ \\
\hline $\begin{array}{l}\text { Incomplete outcome data } \\
\text { (attrition bias) }\end{array}$ & Low risk & $\begin{array}{l}\text { 80\% followed up at 12 months, similar in both groups } \\
\text { All outcomes }\end{array}$ \\
\hline
\end{tabular}

\section{Rigotti 2006}

\begin{tabular}{|c|c|c|}
\hline Methods & \multirow{2}{*}{\multicolumn{2}{|c|}{$\begin{array}{l}\text { Study design: RCT } \\
\text { Country: USA } \\
\text { Setting: hospitals } \\
\text { Recruitment: volunteers }\end{array}$}} \\
\hline & & \\
\hline Participants & \multicolumn{2}{|c|}{$\begin{array}{l}248 \text { smokers hospitalized with cardiovascular disease (excludes } 3 / 3 \text { dropped prior to treatment and } 2 \\
\text { placebo deaths during follow-up); } 31 \% \text { female; average age 56; average cigarettes per day } 23 / 21\end{array}$} \\
\hline Interventions & \multicolumn{2}{|c|}{$\begin{array}{l}\text { Common components: multicomponent CBT cessation and relapse prevention programme, motiva- } \\
\text { tional interviewing approach. Begun in hospital, } 30-45 \text { mins, } 5 \times 10 \text { min post-discharge contacts ( } 2 \text { days, } \\
1 \text { week, } 3 \text { weeks, } 8 \text { weeks, } 12 \text { weeks), self-help, chart prompt for physician. Total time } 80-95 \text { mins }\end{array}$} \\
\hline Outcomes & \multicolumn{2}{|c|}{$\begin{array}{l}\text { - Smoking cessation: sustained abstinence at } 12 \text { months (at multiple follow-ups) Validated by saliva } \\
\text { cotinine at } 12 \text { weeks and } 52 \text { weeks, CO at } 2 \text { weeks and } 4 \text { weeks } \\
\text { - Adverse events: measured for } 52 \text { weeks }\end{array}$} \\
\hline Funding Source & \multicolumn{2}{|c|}{$\begin{array}{l}\text { National Heart, Lung and Blood Institute, National Institutes of Health General Clinical Research Cen- } \\
\text { ters Program, GlaxoSmithKline }\end{array}$} \\
\hline Author conflicts of interest & \multicolumn{2}{|l|}{ None specified } \\
\hline \multicolumn{3}{|l|}{ Notes } \\
\hline \multicolumn{3}{|l|}{ Risk of bias } \\
\hline Bias & Authors' judgement & Support for judgement \\
\hline $\begin{array}{l}\text { Random sequence genera- } \\
\text { tion (selection bias) }\end{array}$ & Low risk & $\begin{array}{l}\text { Quote: "Using a computer program, the study statistician generated a se- } \\
\text { quence of randomly-permuted blocks of } 4 \text { within strata formed by study site } \\
\text { and daily cigarette consumption ( } 10 \text { vs } 10) . "\end{array}$ \\
\hline
\end{tabular}


Rigotti 2006 (Continued)

Allocation concealment Low risk Quote: "The study pharmacist used this sequence, concealed from enrolment (selection bias) staff, to assign participants to study arm. Subjects and study personnel, except the statistician and pharmacist, were blind to treatment assignment."

\begin{tabular}{lll}
$\begin{array}{l}\text { Blinding (performance } \\
\text { bias and detection bias) } \\
\text { All outcomes }\end{array}$ & Low risk & $\begin{array}{l}\text { Quote: "Subjects and study personnel, except the statistician and pharmacist, } \\
\text { were blind to treatment assignment." }\end{array}$ \\
\hline $\begin{array}{l}\text { Incomplete outcome data } \\
\begin{array}{l}\text { (attrition bias) } \\
\text { All outcomes }\end{array}\end{array}$ & Low risk & $\begin{array}{l}\text { Quote: "Subjects were considered smokers if they were lost to follow-up..."; } \\
23 \% \text { lost to follow-up in the bupropion group and } 23 \% \text { in the placebo group }\end{array}$ \\
\hline
\end{tabular}

Rose 2013

\begin{tabular}{|c|c|}
\hline \multirow[t]{4}{*}{ Methods } & Study design: RCT \\
\hline & Country; USA \\
\hline & Setting: clinic \\
\hline & Recruitment: community volunteers \\
\hline Participants & $\begin{array}{l}440 \text { smokers who did not respond successfully to cessation treatment with NRT (phase } 1=335 \text { partici- } \\
\text { pants whose smoking did not decrease by }>50 \% \text { after } 1 \text { week NRT (prior to TQD); phase } 2=105 \text { partici- } \\
\text { pants who lapsed within one week after TQD); } 50 \% \text { female; average age 43; average cigarettes per day } \\
\text { 22; mean FTND 5.8 }\end{array}$ \\
\hline \multirow[t]{2}{*}{ Interventions } & $\begin{array}{l}\text { - Bupropion and nicotine patch. Bupropion for } 12 \text { weeks ( } 150 \mathrm{mg} / \text { day for } 3 \text { days, } 300 \mathrm{mg} / \mathrm{d} \text { for remain- } \\
\text { der). Nicotine patch (patch dose based on } \mathrm{CO}, 21 \mathrm{mg} / \mathrm{day} \text { for CO } \leq 30 \mathrm{ppm}, 42 \mathrm{mg} / \mathrm{day} \text { for CO > } 30 \mathrm{ppm} \text { ) } \\
\text { - Placebo and nicotine patch. Dosing as above }\end{array}$ \\
\hline & $\begin{array}{l}\text { Common components: cessation programme with nicotine patch (discontinued after } 1 \text { week in Phase } 1 \\
\text { varenicline arm) and } 4 \text { to } 6 \text { brief ( }<15 \text { mins) counselling sessions }\end{array}$ \\
\hline \multirow[t]{2}{*}{ Outcomes } & - Smoking cessation: continuous abstinence at 6 months. Validated by $\mathrm{CO} \leq 10 \mathrm{ppm}$ \\
\hline & $\begin{array}{l}\text { - Adverse events: Dr Rose has served as a consultant for Targacept and Philip Morris USA and has a } \\
\text { patent purchase agreement with Philip Morris International. Both authors have received research } \\
\text { funding from Philip Morris USA }\end{array}$ \\
\hline
\end{tabular}

\begin{tabular}{ll}
\hline Funding Source & Supported by grant to Duke University from Philip Morris USA. NRT donated by GlaxoSmithKline \\
\hline Author conflicts of interest & None specified \\
\hline Notes & $\begin{array}{l}\text { New for } 2013 \text { update } \\
\text { Phase } 1 \text { and Phase } 2 \text { combined in meta-analysis. Sensitivity analyses including both separately did not } \\
\text { detect any significant effect on the pooled result. }\end{array}$
\end{tabular}

\section{Risk of bias}

\begin{tabular}{lll}
\hline Bias & Authors' judgement & Support for judgement \\
\hline $\begin{array}{l}\text { Random sequence genera- } \\
\text { tion (selection bias) }\end{array}$ & Unclear risk & Not reported \\
\hline
\end{tabular}


Rose 2013 (Continued)

\begin{tabular}{lll}
$\begin{array}{l}\text { Allocation concealment } \\
\text { (selection bias) }\end{array}$ & Unclear risk & Not reported \\
\hline $\begin{array}{l}\text { Blinding (performance } \\
\text { bias and detection bias) } \\
\text { All outcomes }\end{array}$ & Unclear risk & Quote: "Double-blind," no further information provided \\
\hline $\begin{array}{l}\text { Incomplete outcome data } \\
\text { (attrition bias) } \\
\text { All outcomes }\end{array}$ & High risk & $\begin{array}{l}<50 \% \text { followed up at } 6 \text { months in both phases, similar rates of dropout across } \\
\text { all arms. } 27 \text { participants censored from reported analyses, mainly for protocol } \\
\text { violations, included as smoking here. }\end{array}$ \\
\hline
\end{tabular}

Rose 2014

\begin{tabular}{ll}
\hline Methods & Study design: RCT \\
& Country: USA \\
& Setting: university \\
& Recruitment method: newspaper, radio, and television advertisements \\
\hline Participants & Participants were nicotine patch non-responders (failed to show a reduction of more than $50 \%$ in \\
& smoking after 1 week of nicotine patch treatment) \\
& 222 participants randomized; $54.5 \%$ female; average age 44.1 ; average cigarettes per day 20.7 ; mean \\
& FTND 6.1
\end{tabular}

Interventions

- Bupropion and varenicline. Bupropion given $150 \mathrm{mg}$ once daily for 3 days, then $150 \mathrm{mg}$ twice daily for remainder of 12-week treatment period. Varenicline given $0.5 \mathrm{mg}$ once daily on days 1-3, $0.5 \mathrm{mg}$ twice daily on days 4-7; and $1 \mathrm{mg}$ twice daily for remainder of 12-week treatment period

- Placebo and varenicline. Given according to schedule above

Common components: brief support at each study session, totalling 1 hour and 45 minutes

\begin{tabular}{ll}
\hline Outcomes & Smoking cessation (strictest definition): 7 -day ppa at 6 months. Validated by $\mathrm{CO} \leq 10 \mathrm{ppm}$ \\
- Adverse events: measured for an unspecified period
\end{tabular}

Funding Source National Institute on Drug Abuse grant 1P50 DA027840 and a grant from Philip Morris USA. The sponsors had no role in the planning or execution of the study, data analysis, or publication of results. Active bupropion sustained-release and placebo tablets were supplied by Murty Pharmaceuticals, under contract from the National Institute on Drug Abuse.

Author conflicts of interest The authors have consulting and patent purchase agreements with Philip Morris International for nicotine inhalation technology and consulting agreements with Targacept and Novartis.

\section{Notes}

\section{Risk of bias}

\begin{tabular}{lll}
\hline Bias & Authors' judgement & Support for judgement \\
\hline $\begin{array}{l}\text { Random sequence genera- } \\
\text { tion (selection bias) }\end{array}$ & Unclear risk & No relevant information given \\
\hline $\begin{array}{l}\text { Allocation concealment } \\
\text { (selection bias) }\end{array}$ & Unclear risk & No relevant information given \\
\hline
\end{tabular}


Rose 2014 (Continued)

Blinding (performance Unclear risk Quote: "The study was a double-blind, parallel-arm adaptive treatment trial." bias and detection bias) Placebo tablets were used. No further information provided regarding who All outcomes was blinded

Incomplete outcome data Low risk (attrition bias)

Dropout rates are as follows: $41 / 113(36.3 \%)$ for varenicline and bupropion;

All outcomes

$38 / 109$ (34.9\%) for varenicline and placebo

Rose 2017

Study design: RCT
Country: USA
Setting: research centre (Duke Center for Smoking Cessation)
Recruitment method: not specified

\begin{tabular}{ll}
\hline Participants & All participants were male \\
174 participants randomized; 0\% female; average age 44.0; average cigarettes per day 20.0; mean FTND & 5.5 \\
\hline Interventions & $\begin{array}{l}\text { Bupropion and varenicline. Bupropion scheduling was } 150 \text { mg once daily for } 3 \text { days, followed by } 150 \\
\text { mg twice daily for the remainder of the } 12 \text {-week treatment period. Varenicline scheduling was } 0.5 \text { mg } \\
\text { once daily on days } 1-3,0.5 \text { mg twice daily on days 4-7, followed by } 1 \text { mg twice daily for the remainder } \\
\text { of the } 12 \text {-week treatment period } \\
\text { - Placebo and varenicline. Same schedule as above }\end{array}$
\end{tabular}

Common components: precessation patches for 1 week prior to pharmacological treatments above, and brief support was provided at each session, totalling 1 hour and 30 minutes

- Smoking cessation (strictest definition): 11 weeks - too short a follow-up for this outcome to be con-
sidered in this review
- Adverse events: measured for 12 weeks

Funding Source Grant 1P50 DA027840 from the National Institute on Drug Abuse and a grant from Philip Morris, USA
Author conflicts of interest The authors disclose consulting and patent purchase agreements with Philip Morris International relat- ing to reduced risk tobacco products.

\section{Notes}

\section{Risk of bias}

\begin{tabular}{lll}
\hline Bias & Authors' judgement & Support for judgement \\
\hline $\begin{array}{l}\text { Random sequence genera- } \\
\text { tion (selection bias) }\end{array}$ & Unclear risk & No relevant information given \\
\hline $\begin{array}{l}\text { Allocation concealment } \\
\text { (selection bias) }\end{array}$ & Unclear risk & No relevant information given \\
\hline $\begin{array}{l}\text { Blinding (performance } \\
\text { bias and detection bias) } \\
\text { All outcomes }\end{array}$ & Unclear risk & $\begin{array}{l}\text { Quote: “double-blind, placebo-controlled, parallel-arm trial”. No further infor- } \\
\text { mation provided regarding who was blinded }\end{array}$ \\
\hline
\end{tabular}


Rose 2017 (Continued)

Incomplete outcome data Low risk Dropout rates are as follows: (13.1\%) in the bupropion and varenicline arm; (attrition bias)

$13 / 90(14.4 \%)$ in the placebo and varenicline arm; $11 / 84$. Therefore dropout

All outcomes

was low and similar between groups.

Rovina 2009

\begin{tabular}{|c|c|}
\hline \multirow[t]{4}{*}{ Methods } & Study design: RCT \\
\hline & Country: Greece \\
\hline & Setting: cessation clinic \\
\hline & Recruitment: clinic attenders invited to participate \\
\hline Participants & 205 smokers; 40\% female; average age 45; average cigarettes per day 37 \\
\hline \multirow[t]{4}{*}{ Interventions } & - Bupropion 300 mg/day for 19 weeks + 15 mins physician counselling \\
\hline & $\begin{array}{l}\text { - Bupropion } 300 \mathrm{mg} / \text { day for } 19 \text { weeks + nonspecific group therapy, } 1 \text { hour weekly for } 1 \text { month, then } \\
\text { every } 3 \text { weeks until } 19 \text { weeks }\end{array}$ \\
\hline & - Bupropion 300 mg/day for 19 weeks + CBGT, same schedule \\
\hline & - CBGT without bupropion \\
\hline \multirow[t]{2}{*}{ Outcomes } & $\begin{array}{l}\text { - Smoking cessation: continous abstinence at } 12 \text { months after end of treatment. Validated by } \mathrm{CO} \leq 10 \\
\mathrm{ppm}\end{array}$ \\
\hline & - Adverse events: measured for 31 weeks \\
\hline Funding Source & None specified \\
\hline Author conflicts of interest & $\begin{array}{l}\text { All the authors of this paper declare that they have no financial or other potential conflicts of interest } \\
\text { concerning the subject of this manuscript. }\end{array}$ \\
\hline \multirow[t]{3}{*}{ Notes } & New for 2013 update \\
\hline & $\begin{array}{l}3 \text { versus } 4 \text { used analyses, } 1 \text { and } 2 \text { not included in any analyses (effect of different counselling would } \\
\text { confound effect of bupropion) }\end{array}$ \\
\hline & $\begin{array}{l}\text { Authors do not report } \mathrm{n} \text { abstinent, numbers included in meta-analysis extrapolated from applying per- } \\
\text { centage to overall } \mathrm{n} \text { randomized }\end{array}$ \\
\hline
\end{tabular}

\section{Risk of bias}

\begin{tabular}{lll}
\hline Bias & Authors' judgement & Support for judgement \\
\hline $\begin{array}{l}\text { Random sequence genera- } \\
\text { tion (selection bias) }\end{array}$ & Unclear risk & Randomized, method not stated, 3:1:1:1 ratio \\
\hline $\begin{array}{l}\text { Allocation concealment } \\
\text { (selection bias) }\end{array}$ & Unclear risk & No details reported \\
\hline $\begin{array}{l}\text { Blinding (performance } \\
\text { bias and detection bias) }\end{array}$ & High risk & Open-label, participants and staff aware of allocation \\
$\begin{array}{l}\text { All outcomes } \\
\begin{array}{l}\text { Incomplete outcome data } \\
\text { (attrition bias) } \\
\text { All outcomes }\end{array}\end{array}$ & Unclear risk & $\begin{array}{l}\text { 90\% followed up at 12 months, but authors do not specify percentage per } \\
\text { group and do not specify how participants lost to follow-up were treated. Au- }\end{array}$
\end{tabular}


Rovina 2009 (Continued)

thors only provide percentages abstinent, so $\mathrm{n}$ abstinent in this review may be inflated.

Saules 2004

\begin{tabular}{ll}
\hline Methods & Study design: RCT \\
& $\begin{array}{l}\text { Country: USA } \\
\text { Setting: cessation clinic } \\
\text { Recruitment: volunteers }\end{array}$ \\
\hline Participants & 150 smokers; $55 \%$ female; average age 40 \\
\hline Interventions & - Fluoxetine 40 mg for 14 weeks, nicotine patch for 10 weeks \\
& - Fluoxetine 20 mg for 14 weeks, nicotine patch for 10 weeks \\
& Common components: TQD end of week 4, CBT 6 sessions starting 2 weeks before TQD, 11 clinic visits \\
\hline Outcomes & Smoking cessation: at 12 months (unspecified definition). Validated by CO < 10 ppm \\
\hline Funding Source & Adverse events: measured for 15 weeks \\
\hline Author conflicts of interest & $\begin{array}{l}\text { National Institute on Drug Abuse, State of Michigan. Nicotine patch provided by McNeil Consumer } \\
\text { Healthcare }\end{array}$ \\
\hline Notes & Authors provided quit numbers by treatment group \\
\hline
\end{tabular}

\section{Risk of bias}

\begin{tabular}{lll}
\hline Bias & Authors' judgement & Support for judgement \\
\hline $\begin{array}{l}\text { Random sequence genera- } \\
\text { tion (selection bias) }\end{array}$ & Unclear risk & Randomization method not described \\
\hline $\begin{array}{l}\text { Allocation concealment } \\
\text { (selection bias) }\end{array}$ & Unclear risk & Not described \\
\hline $\begin{array}{l}\text { Blinding (performance } \\
\text { bias and detection bias) }\end{array}$ & Unclear risk & Quote: "Double-blind" but no further information provided \\
$\begin{array}{l}\text { All outcomes } \\
\begin{array}{l}\text { Incomplete outcome data } \\
\text { (attrition bias) } \\
\text { All outcomes }\end{array}\end{array}$ & Unclear risk & $\begin{array}{l}\text { Numbers lost to follow-up not provided by study arm but high: at six months, } \\
\text { only 58 of 150 subjects were followed up. Subjects who dropped out of the } \\
\text { study or lost to follow-up were considered to be smoking again. }\end{array}$ \\
\hline
\end{tabular}

Schmitz 2007

\begin{tabular}{ll} 
Methods & Study design: $2 \times 2$ factorial RCT \\
& Country: USA \\
Setting: research clinic \\
Recruitment: community volunteers \\
\hline \hline
\end{tabular}


Schmitz 2007 (Continued)

\begin{tabular}{ll} 
Participants & 154 women smokers; average age 48; average cigarettes per day 21 \\
\hline Interventions & - Bupropion $300 \mathrm{mg} /$ day for 7 weeks \\
& - Placebo \\
& $\begin{array}{l}\text { Common components: either CBT based on relapse prevention model, or group support therapy, both } \\
7 \text { weekly } 60 \text {-min meetings, TQD morning of } 1 \text { st session, } 10 \text { days after start of medications }\end{array}$ \\
\hline Outcomes & - Smoking cessation: 7 day ppa at 12 months. Validated by CO $\leq 10 \mathrm{ppm}$, saliva cotinine $<15 \mathrm{ng} / \mathrm{mL}$ \\
\hline Funding Source & National Institute on Drug Abuse. Bupropion provided by GlaxoSmithKline. \\
\hline Author conflicts of interest & None specified \\
\hline Notes & Group therapy variants collapsed in main analysis
\end{tabular}

\section{Risk of bias}

\begin{tabular}{lll}
\hline Bias & Authors' judgement & Support for judgement \\
\hline $\begin{array}{l}\text { Random sequence genera- } \\
\text { tion (selection bias) }\end{array}$ & Low risk & Urn procedure, balancing on a range of outcome-related variables \\
\hline $\begin{array}{l}\text { Allocation concealment } \\
\text { (selection bias) }\end{array}$ & Low risk & $\begin{array}{l}\text { Quote: "Investigators and research staff were blind to the randomization } \\
\text { codes, which were kept by a faculty member independent of the } \\
\text { research and treatment team." }\end{array}$ \\
\hline $\begin{array}{l}\text { Blinding (performance } \\
\text { bias and detection bias) }\end{array}$ & Unclear risk & Quote: "Double-blind," further information not provided \\
$\begin{array}{l}\text { All outcomes } \\
\begin{array}{l}\text { Incomplete outcome data } \\
\text { (attrition bias) } \\
\text { All outcomes }\end{array}\end{array}$ & Low risk & $\begin{array}{l}14 \text { 'enrolment failures' who did not receive any treatment are excluded from } \\
\text { analyses. Other non-completers and losses to follow-up included in ITT analy- } \\
\text { sis }\end{array}$ \\
\hline
\end{tabular}

\section{Schnoll 2010}

\begin{tabular}{ll}
\hline Methods & Study design: RCT \\
& Country: USA \\
& Setting: not specified (presumably clinic) \\
& Recruitment: patient lists from physicians treating people with cancer \\
\hline Participants & $\begin{array}{l}246 \text { cancer patients smoking } \geq 2 \text { cigarettes per day; } 48 \% \text { female; average age } 54.8 \text {; average cigarettes } \\
\text { per day } 17.5 ; \text { mean FTND } 3.2 ; 32 \% \text { had tobacco-related tumours }\end{array}$ \\
\hline Interventions & Bupropion 9 weeks, started 2 weeks before TQD (150 $\mathrm{mg} / \mathrm{d}$ first week, 300 mg/d remaining 8 weeks) \\
& Common componenets: 8 weeks nicotine patches and 5 sessions of behavioural counselling (3 in per- \\
son, 2 over phone)
\end{tabular}


Schnoll 2010 (Continued)

- Adverse events: measured for 9-week treatment period

Funding Source National Cancer Institute. NRT provided free of charge from GlaxoSmithKline.

Author conflicts of interest None specified

Notes

\section{Risk of bias}

\begin{tabular}{lll}
\hline Bias & Authors' judgement & Support for judgement \\
\hline $\begin{array}{l}\text { Random sequence genera- } \\
\text { tion (selection bias) }\end{array}$ & Unclear risk & Stratified by depression status. Method of sequence generation not specified \\
\hline $\begin{array}{l}\text { Allocation concealment } \\
\text { (selection bias) }\end{array}$ & Unclear risk & Not specified \\
\hline $\begin{array}{l}\text { Blinding (performance } \\
\text { bias and detection bias) } \\
\text { All outcomes }\end{array}$ & Unclear risk & Quote: "Double-blind," no further information provided \\
\hline $\begin{array}{l}\text { Incomplete outcome data } \\
\text { (attrition bias) } \\
\begin{array}{l}\text { All outcomes } \\
\hline\end{array}\end{array}$ & Low risk & \\
\hline
\end{tabular}

Selby 2003

\begin{tabular}{ll}
\hline Methods & Study design: RCT \\
& $\begin{array}{l}\text { Country: Canada } \\
\text { Setting: } 15 \text { clinical centres } \\
\text { Recruitment: community volunteers }\end{array}$ \\
\hline Participants & $\begin{array}{l}284 \text { smokers previously exposed to bupropion for at least 2weeks, not quit for more than } 24 \text { hours in } \\
\text { previous month }\end{array}$ \\
\hline Interventions & Bupropion 300 mg for 12 weeks \\
& Behavioural support not described \\
\hline Outcomes & Placebo \\
\hline Funding Source & Adverse events: measured for unspecified period \\
\hline Author conflicts of interest & None specified \\
\hline Notes & Based on abstract
\end{tabular}

\section{Risk of bias}

Bias Authors' judgement Support for judgement


Selby 2003 (Continued)

Random sequence genera- Unclear risk $\quad$ Randomization method not described
tion (selection bias)

\begin{tabular}{lll}
\hline $\begin{array}{l}\text { Allocation concealment } \\
\text { (selection bias) }\end{array}$ & Unclear risk & No details given \\
\hline $\begin{array}{l}\text { Blinding (performance } \\
\text { bias and detection bias) }\end{array}$ & Unclear risk & No details given \\
All outcomes & & \\
\hline
\end{tabular}

Incomplete outcome data Unclear risk

(attrition bias)

All outcomes
No details given, unclear how participants lost to follow-up treated in outcome data. $70 \%$ intervention group and $50 \%$ control group completed study

\section{Sheng 2013}

\begin{tabular}{ll}
\hline Methods & Study design: RCT \\
Country: China & Setting: hospital outpatient centres \\
Recruitment method: newspaper advertisements and by word of mouth & \\
\hline Participants & Participants were mainly male \\
& 257 participants randomized; $5.5 \%$ female; average age 39.1; average cigarettes per day 22.5; mean FT- \\
& ND 5.6 \\
\hline Interventions & Bupropion 150 mg daily for days 1 to 3,150 mg twice daily for days 4 to 56, then 150 mg daily for days \\
& 57 to 63 and discontinued on day 64 \\
- Placebo, same tablets and schedule as for bupropion above & All participants were given the same brief education and counselling was administered to both groups \\
by research staff. Counselling topics included motivation, identification of smoking triggers, coping re- \\
sponses, weight management, and use of the medications. The total duration of conselling was 1 hour \\
and 30 minutes.
\end{tabular}

\begin{tabular}{ll}
\hline Outcomes & $\begin{array}{l}\text { - Smoking cessation: } 12 \text { weeks - too short a follow-up for this outcome to be considered in this review } \\
\text { Funding Source }\end{array}$ \\
\hline Zutherse events: not specified
\end{tabular}

\section{Risk of bias}

\begin{tabular}{lll}
\hline Bias & Authors' judgement & Support for judgement \\
\hline $\begin{array}{l}\text { Random sequence genera- } \\
\text { tion (selection bias) }\end{array}$ & Low risk & $\begin{array}{l}\text { Quote: "Participants were assigned to one of two study arms using a computer } \\
\text { algorithm to generate a random list of treatment assignments." }\end{array}$ \\
\hline $\begin{array}{l}\text { Allocation concealment } \\
\text { (selection bias) }\end{array}$ & Unclear risk & No relevant information given \\
\hline
\end{tabular}


Sheng 2013 (Continued)

Blinding (performance Low risk Quote: "Participants in the control arm received placebo pills identical in apbias and detection bias) pearance. All study personnel were blinded to treatment assignment. The All outcomes same brief education and counseling were administered to both groups by a research staff."

Incomplete outcome data Low risk (attrition bias)

All outcomes
Dropout rates are as follows: $14 / 127$ (11.0\%) in the bupropion arm; 18/130 $(13.9 \%)$ in the placebo. Therefore, dropout rates are low and similar between groups.

Siddiqi 2013

Study design: cluster-RCT
Country: Pakistan
Setting: 33 health centres
Recruitment: patients from participating health centres with suspected pulmonary tuberculosis

Participants 1955 adult smokers with suspected tuberculosis (1299 included in arms relevant to this review), smoking $\geq 1$ cigarettes per day or smoking hookah on a daily basis; $5 \%$ female; average age 41 ; average cigarettes per day 19 (where one hookah counts as 2 cigarettes)

Interventions

- Bupropion 7 weeks ( $75 \mathrm{mg} / \mathrm{d}$ first week, $150 \mathrm{mg} / \mathrm{d}$ thereafter)

- No pharmacotherapy

Common components: 2 sessions of brief, in-person behavioural support

(Note, third arm received usual care only, not included in this review)

\begin{tabular}{ll}
\hline Outcomes & Smoking cessation: continuous abstinence at 6 months. Validated by $\mathrm{CO} \leq 9 \mathrm{ppm}$ \\
\hline Funding Source & International Development Research Centre
\end{tabular}

Author conflicts of interest Link provided to list of declarations of interest, but link does not give access to active webpage

\begin{tabular}{ll}
\hline Notes & New for 2013 \\
& $\begin{array}{l}\text { Reported narratively only due to substantial heterogeneity of program effects across clusters. } 275 / 659 \\
\text { quit intervention versus } 254 / 640 \text { control, adjusted risk ratio } 1.1 \text { (0.5 to } 2.3)\end{array}$
\end{tabular}

\section{Risk of bias}

\begin{tabular}{lll}
\hline Bias & Authors' judgement & Support for judgement \\
\hline $\begin{array}{l}\text { Random sequence genera- } \\
\text { tion (selection bias) }\end{array}$ & Low risk & Computer-generated \\
\hline $\begin{array}{l}\text { Allocation concealment } \\
\text { (selection bias) }\end{array}$ & Low risk & Quote: “A researcher who was blinded to center identity" allocated conditions \\
\hline $\begin{array}{l}\text { Blinding (performance } \\
\text { bias and detection bias) }\end{array}$ & High risk & No blinding \\
\hline $\begin{array}{l}\text { Incomplete outcome data } \\
\text { (attrition bias) }\end{array}$ & Low risk & No clinics dropped out post-randomization. Over 90\% of participants followed \\
\hline
\end{tabular}


Siddiqi 2013 (Continued)

All outcomes
Substantial heterogeneity of programme effects across clusters. $20 \%$ of participants in control arm smoked only hookah (no cigarettes) compared to $4 \%$ in intervention arm

Simon 2004

\begin{tabular}{|c|c|}
\hline Methods & $\begin{array}{l}\text { Study design: RCT } \\
\text { Country: USA } \\
\text { Setting: VAMC outpatient units } \\
\text { Recruitment: outpatients }\end{array}$ \\
\hline Participants & 244 smokers, 79\% veterans; 5\% female; average age 50; average cigarettes per day 24 \\
\hline Interventions & $\begin{array}{l}\text { - Bupropion and nicotine patch. Bupropion at } 300 \mathrm{mg} \text { for } 7 \text { weeks. Nicotine patch for } 2 \text { months } \\
\text { - Placebo bupropion and nicotine patch. Schedules as above } \\
\text { Common components: } 3 \text { months CBT counselling, self-help materials and telephone follow-up coun- } \\
\text { selling }\end{array}$ \\
\hline Outcomes & $\begin{array}{l}\text { - Smoking cessation: sustained abstinence at } 12 \text { months (sustained at multiple follow ups). Validated } \\
\text { by saliva cotinine } \\
\text { - Adverse events: measured for } 8 \text { weeks }\end{array}$ \\
\hline Funding Source & California Tobacco-Related Disease Research Program \\
\hline Author conflicts of interest & None specified \\
\hline Notes & $\begin{array}{l}\text { Used in bupropion + NRT versus NRT comparison } \\
2 \text { placebo and } 3 \text { bupropion deaths excluded from denominators } \\
\text { Originally based on abstract, now uses published data and sustained quitting outcome }\end{array}$ \\
\hline
\end{tabular}

\section{Risk of bias}

\begin{tabular}{lll}
\hline Bias & Authors' judgement & Support for judgement \\
\hline $\begin{array}{l}\text { Random sequence genera- } \\
\text { tion (selection bias) }\end{array}$ & Low risk & $\begin{array}{l}\text { Quote: "We assigned participants to the 2 study arms by using a computer al- } \\
\text { gorithm to generate a random list of treatment assignments." }\end{array}$ \\
\hline $\begin{array}{l}\text { Allocation concealment } \\
\text { (selection bias) }\end{array}$ & Unclear risk & Not described \\
\hline $\begin{array}{l}\text { Blinding (performance } \\
\text { bias and detection bias) } \\
\text { All outcomes }\end{array}$ & Unclear risk & $\begin{array}{l}\text { Quote: "All study personnel engaged in providing interventions to participants } \\
\text { were blinded to treatment assignment." "Blinding appeared to be effective in } \\
\text { our study; an approximately equal number of participants were able to guess } \\
\text { what their treatment had been at the end of the study." }\end{array}$ \\
\hline $\begin{array}{l}\text { Incomplete outcome data } \\
\text { (attrition bias) } \\
\text { All outcomes }\end{array}$ & Low risk & $\begin{array}{l}\text { Quote: "Of the 244 participants enrolled, 3 (1\%) were lost to follow-up (all ran- } \\
\text { domized to the placebo arm).... Participants lost to follow-up were considered } \\
\text { smokers." }\end{array}$ \\
\hline
\end{tabular}


Simon 2009

\begin{tabular}{ll}
\hline Methods & Study design: RCT \\
& $\begin{array}{l}\text { Country: USA } \\
\text { Setting: VAMC hospital } \\
\text { Recruitment: hospitalised volunteers }\end{array}$ \\
\hline Participants & $\begin{array}{l}83 \text { inpatients smoking at least } 5 \text { cigarettes per day in previous year, smoking in week before admission, } \\
\text { in contemplation or preparation stage of change }\end{array}$ \\
\hline Interventions & Bupropion 300 mg for 7 weeks \\
& $\begin{array}{l}\text { Placebo } \\
\text { week 5, week } 8, \text { week } 12, \text { recycling encouraged }\end{array}$ \\
\hline Outcomes & $\begin{array}{l}\text { Smoking cessation: continuous abstinence at } 6 \text { months. Validated at each visit by saliva cotinine }<15 \\
\text { ng/mL }\end{array}$ \\
\hline Funding Source & Adverse events: measured for 7 weeks \\
\hline Author conflicts of interest & California Tobacco-Related Disease Research Program 5 phone calls at week 1, week 3, \\
\hline Notes & \begin{tabular}{l}
1 death in bupropion, 1 in placebo excluded from analyses \\
\hline
\end{tabular}
\end{tabular}

\section{Risk of bias}

\begin{tabular}{lll}
\hline Bias & Authors' judgement & Support for judgement \\
\hline $\begin{array}{l}\text { Random sequence genera- } \\
\text { tion (selection bias) }\end{array}$ & Low risk & $\begin{array}{l}\text { Quote: "computer algorithm to generate a random list of treatment assign- } \\
\text { ments." }\end{array}$ \\
\hline $\begin{array}{l}\text { Allocation concealment } \\
\text { (selection bias) }\end{array}$ & Unclear risk & Not described \\
\hline $\begin{array}{l}\text { Blinding (performance } \\
\text { bias and detection bias) } \\
\text { All outcomes }\end{array}$ & Low risk & $\begin{array}{l}\text { Quote: "All study personnel engaged in providing interventions to participants } \\
\text { were blinded to treatment assignment." "A significant percentage of partici- } \\
\text { pants were able to guess correctly whether they were taking active bupropion } \\
\text { or placebo" but as results did not favour intervention group, authors suggest } \\
\text { this unblinding did not bias the results. }\end{array}$ \\
\hline
\end{tabular}

Incomplete outcome data Low risk $\quad 5$ withdrawals, 1 lost to follow-up, 1 death in placebo, 2 withdrawals, 1 lost, 1 (attrition bias) death in bupropion. All except deaths included in meta-analysis

All outcomes

\section{Singh 2010}

\begin{tabular}{ll}
\hline Methods & Study design: RCT \\
& Country: India \\
& Setting: anti-smoking clinic of Vallabhbhai Patel Chest Institute \\
& Recruitment method: not clearly specified \\
\hline Participants & Participants almost solely men
\end{tabular}


Singh 2010 (Continued)

30 participants randomized; 3.3\% female; average age 43.1; average cigarettes per day 18.8; mean FTND 5.6

\begin{tabular}{|c|c|c|}
\hline Interventions & \multicolumn{2}{|c|}{$\begin{array}{l}\text { - Bupropion } 300 \mathrm{mg} \text { daily for seven weeks } \\
\text { Placebo } \\
\text { Common components: physician advice based on National Cancer Institute's } 5 \text { A's i.e. ASK, ADVICE, } \\
\text { ASSESS, ASSIST and ARRANGE. Brief face-to-face personalized anti-smoking advice was given at each of } \\
\text { the } 11 \text { visits. }\end{array}$} \\
\hline Outcomes & \multicolumn{2}{|c|}{$\begin{array}{l}\text { - Smoking cessation: } 16 \text { weeks - too short a follow-up for this outcome to be considered in this review } \\
\text { - Adverse events: measured for six weeks }\end{array}$} \\
\hline Funding Source & \multicolumn{2}{|l|}{ Quote: "nil" } \\
\hline Author conflicts of interest & \multicolumn{2}{|l|}{ None declared } \\
\hline \multicolumn{3}{|l|}{ Notes } \\
\hline \multicolumn{3}{|l|}{ Risk of bias } \\
\hline Bias & Authors' judgement & Support for judgement \\
\hline $\begin{array}{l}\text { Random sequence genera- } \\
\text { tion (selection bias) }\end{array}$ & Unclear risk & $\begin{array}{l}\text { Quote: "At the baseline, subjects were randomly assigned to two groups" } \\
\text { Comment: no further information is given }\end{array}$ \\
\hline $\begin{array}{l}\text { Allocation concealment } \\
\text { (selection bias) }\end{array}$ & Unclear risk & $\begin{array}{l}\text { Quote: "At the baseline, subjects were randomly assigned to two groups" } \\
\text { Comment: no further information is given }\end{array}$ \\
\hline $\begin{array}{l}\text { Blinding (performance } \\
\text { bias and detection bias) } \\
\text { All outcomes }\end{array}$ & High risk & Quote: "It was a single blind placebo control study." \\
\hline $\begin{array}{l}\text { Incomplete outcome data } \\
\text { (attrition bias) } \\
\text { All outcomes }\end{array}$ & Unclear risk & No relevant information given \\
\hline
\end{tabular}

Smith 2009

\begin{tabular}{|c|c|}
\hline \multirow[t]{4}{*}{ Methods } & Study design: RCT \\
\hline & Country: USA \\
\hline & Setting: 12 primary care clinics \\
\hline & Recruitment: volunteers from primary care clinics \\
\hline Participants & 1346 smokers; 56\% female; average age 44; average cigarettes per day 20.3 \\
\hline \multirow[t]{4}{*}{ Interventions } & - Bupropion. Up-titrated during week pre-quitting, $150 \mathrm{mg}$ twice/day for 8 weeks post-quit \\
\hline & $\begin{array}{l}\text { - Nicotine lozenge. } 4 \mathrm{mg} \text { lozenge if first cigarette of day smoked }>30 \text { min after waking, } 2 \text { mg otherwise. } 1 \\
\text { lozenge every } 1-2 \text { hrs post-quit weekk 1-6; } 1 \text { lozenge every } 2-4 \text { hrs week } 7-9 ; 1 \text { lozenge every } 4-8 \text { hours } \\
\text { week } 10-12\end{array}$ \\
\hline & - Nicotine patch. 21 mg post-quit wk 1-4; 14 mg wk 5-6; 7 mg wk 7-8 \\
\hline & - Bupropion and nicotine lozenge. Dosing as above \\
\hline
\end{tabular}


Smith 2009 (Continued)

- Nicotine patch and nicotine lozenge. Dosing as above

Common components: quitline counselling (state provided). All participants received initial session, then could elect to receive up to 4 additional calls + could call for additional support if required.

\begin{tabular}{ll}
\hline Outcomes & Abstinence defintion: 7 day ppa at 6 months. No validation method specified \\
- Adverse events: measured for unspecified period
\end{tabular}

Funding Source Majority of funding from National Institutes of Health, National Institute on Drug Abuse, and National Cancer Institute. Medication provided to participants at no cost by GlaxoSmithKline

Author conflicts of interest $\quad$ Dr Smith has received research support from Elan Corporation plc. Dr Jorenby has received research support from Pfizer Inc, Sanofi-Synthelabo, and Nabi Biopharmaceuticals and has received consulting fees from Nabi Biopharmaceuticals. Dr Fiore has received honoraria from Pfizer Inc and has served as an investigator on research studies at the University of Wisconsin that were funded by Pfizer Inc, Sanofi-Synthelabo, and Nabi Biopharmaceuticals. In 1998, the University of Wisconsin (UW) appointed Dr Fiore to a named Chair funded by an unrestricted gift to UW from Glaxo Wellcome. Dr Baker has served as an investigator on research projects sponsored by pharmaceutical companies including Sanofi-Synthelabo, Pfizer Inc, and Nabi Biopharmaceuticals.

Notes
New for 2013 update
No control so does not contribute to primary analysis. 4 versus 2 used in Analysis 1.5 .1 versus 3 used
in Analysis 1.7.1, 1 versus 2 used in Analysis 1.7.2, and 1 versus 5 used in Analysis 1.7.3 (n in 1 divided
equally between subgroups to avoid triple counting)

\section{Risk of bias}

\begin{tabular}{lll}
\hline Bias & Authors' judgement & Support for judgement \\
\hline $\begin{array}{l}\text { Random sequence genera- } \\
\text { tion (selection bias) }\end{array}$ & Unclear risk & $\begin{array}{l}\text { Quote: "Smokers were randomized to the } 5 \text { treatment conditions within each } \\
\text { clinic with blocking on sex and self-identified race." Insufficient detail with } \\
\text { which to judge. }\end{array}$ \\
\hline $\begin{array}{l}\text { Allocation concealment } \\
\text { (selection bias) }\end{array}$ & Unclear risk & Not specified \\
\hline $\begin{array}{l}\text { Blinding (performance } \\
\text { bias and detection bias) }\end{array}$ & High risk & Open-label \\
\hline $\begin{array}{l}\text { All outcomes } \\
\begin{array}{l}\text { Incomplete outcome data } \\
\text { (attrition bias) } \\
\text { All outcomes }\end{array}\end{array}$ & Low risk & $\begin{array}{l}158 \text { individuals who did not pick up study medication at first point not includ- } \\
\text { ed in analyses; 122 withdrawals and 9 deaths considered to be smoking }\end{array}$ \\
\hline
\end{tabular}

\section{SMK20001}

\begin{tabular}{ll}
\hline Methods & Study design: RCT \\
& $\begin{array}{l}\text { Country: USA } \\
\text { Setting: } 6 \text { clinical trial centres } \\
\text { Recruitment: volunteers for phase II trial }\end{array}$ \\
\hline Participants & 286 smokers; $48 \%$ female; average age 42; average cigarettes per day not soecified \\
\hline Interventions & Bupropion 300 mg for 7 weeks and placebo novel therapy \\
& Double placebo \\
\hline
\end{tabular}


SMK20001 (Continued)

No information about behavioural support

\begin{tabular}{ll}
\hline Outcomes & Smoking cessation: continuous abstinence at 12 months. Validated by CO $\leq 10 \mathrm{ppm}$ \\
\hline Funding Source & GlaxoSmithKline \\
\hline Author conflicts of interest & None specified \\
\hline Notes & Identified from GSK trials website. Also included a novel cessation aid \\
\hline
\end{tabular}

\section{Risk of bias}

\begin{tabular}{lll}
\hline Bias & Authors' judgement & Support for judgement \\
\hline $\begin{array}{l}\text { Random sequence genera- } \\
\text { tion (selection bias) }\end{array}$ & Unclear risk & Randomization method not specified \\
\hline $\begin{array}{l}\text { Allocation concealment } \\
\text { (selection bias) }\end{array}$ & Unclear risk & Allocation concealment not described \\
\hline $\begin{array}{l}\text { Blinding (performance } \\
\text { bias and detection bias) } \\
\text { All outcomes }\end{array}$ & Unclear risk & Double-blind but methods not described \\
\hline
\end{tabular}

Incomplete outcome data Low risk 34\% lost in bupropion, 29\% placebo, included as smokers
(attrition bias)

All outcomes

\section{Sood 2010}

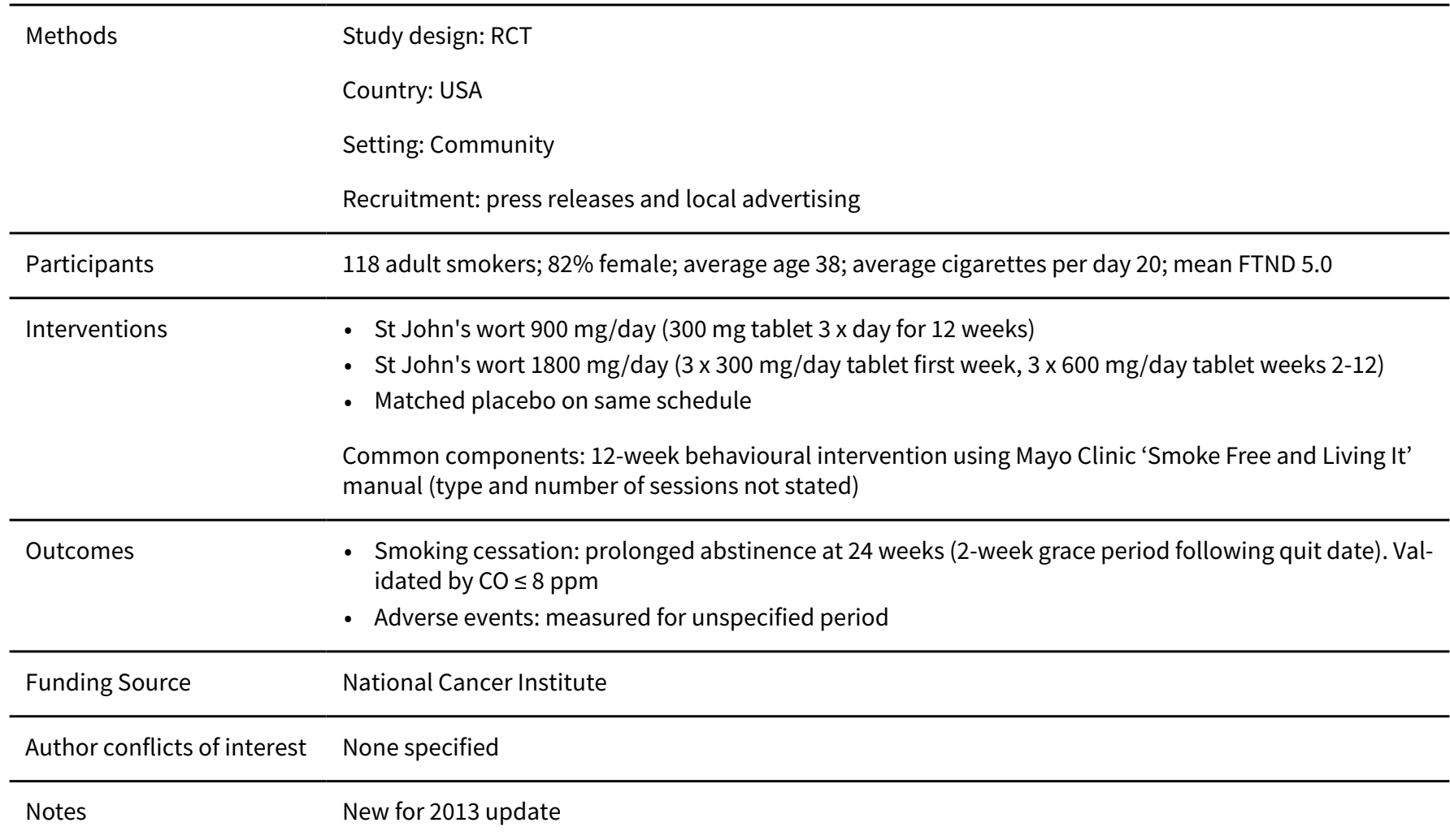


Sood 2010 (Continued)

Groups 1 and 2 combined in meta-analysis; no significant difference between the two (at 24 weeks, 1/39 abstinent intervention 1, 2/40 abstinent intervention 2)

\section{Risk of bias}

\begin{tabular}{|c|c|c|}
\hline Bias & Authors' judgement & Support for judgement \\
\hline $\begin{array}{l}\text { Random sequence genera- } \\
\text { tion (selection bias) }\end{array}$ & Low risk & Generated centrally by Mayo Clinic Division of Biostatistics \\
\hline $\begin{array}{l}\text { Allocation concealment } \\
\text { (selection bias) }\end{array}$ & Unclear risk & Not specified \\
\hline $\begin{array}{l}\text { Blinding (performance } \\
\text { bias and detection bias) } \\
\text { All outcomes }\end{array}$ & Unclear risk & Quote: "Blinded" with matched placebo, no further information provided \\
\hline $\begin{array}{l}\text { Incomplete outcome data } \\
\text { (attrition bias) } \\
\text { All outcomes }\end{array}$ & Unclear risk & $\begin{array}{l}43 \% \text { dropped out within first } 12 \text { weeks, unclear how many dropped out by } 24 \\
\text { weeks. Not given by arm }\end{array}$ \\
\hline
\end{tabular}

Sood 2012

\begin{tabular}{|c|c|}
\hline Methods & $\begin{array}{l}\text { Study design: RCT } \\
\text { Country: USA } \\
\text { Setting: clinic } \\
\text { Recruitment: community volunteers }\end{array}$ \\
\hline Participants & 120 smokers; 47\% female; average age 40; average cigarettes per day 20; mean FTND 5.2 \\
\hline Interventions & $\begin{array}{l}\text { - SAMe } 1600 \mathrm{mg} / \text { day (via mouth) for } 8 \text { weeks } \\
\text { - SAMe } 800 \mathrm{mg} / \text { day. Same schedule as above } \\
\text { - Placebo. Same schedule as above } \\
\text { Common components: behavioural counselling using "Smoke Free and Living It" manual at every clinic } \\
\text { visit (approx. 7) }\end{array}$ \\
\hline Outcomes & $\begin{array}{l}\text { - Smoking cessation: } 7 \text { day ppa at } 6 \text { months (prolonged abstinence measured but not reported). Vali- } \\
\text { dated by } C O \leq 8 \text { ppm } \\
\text { - Adverse events: measured for unspecified period }\end{array}$ \\
\hline Funding Source & National Institutes of Health \\
\hline Author conflicts of interest & None specified \\
\hline Notes & $\begin{array}{l}\text { New for } 2013 \text { update } \\
\text { SAMe is a dietary supplement used to treat depression } \\
\text { No difference between arms } 1 \text { and } 2 \text {, hence combined in meta-analysis }\end{array}$ \\
\hline
\end{tabular}

\section{Risk of bias}

Authors' judgement Support for judgement 
Sood 2012 (Continued)

Random sequence genera- Unclear risk $\quad$ Not reported
tion (selection bias)

\begin{tabular}{lll}
\hline $\begin{array}{l}\text { Allocation concealment } \\
\text { (selection bias) }\end{array}$ & Unclear risk & Not reported \\
\hline $\begin{array}{l}\text { Blinding (performance } \\
\text { bias and detection bias) }\end{array}$ & Unclear risk & Quote: "Blinded," no further detail provided \\
$\begin{array}{l}\text { All outcomes } \\
\text { Incomplete outcome data }\end{array}$ & Low risk & $57 \%$ followed up overall, similar rates between groups \\
$\begin{array}{l}\text { (attrition bias) } \\
\text { All outcomes }\end{array}$ & \\
\hline
\end{tabular}

Spring 2007

\begin{tabular}{|c|c|c|}
\hline Methods & \multicolumn{2}{|c|}{$\begin{array}{l}\text { Study design: RCT } \\
\text { Country: USA } \\
\text { Setting: clinic } \\
\text { Recruitment: community volunteers }\end{array}$} \\
\hline Participants & \multicolumn{2}{|c|}{247 smokers; 54\% female; average age 44; average cigarettes per day 23} \\
\hline Interventions & \multicolumn{2}{|c|}{$\begin{array}{l}\text { - Fluoxetine } 60 \mathrm{mg} \text { (titrated up over } 2 \text { weeks) for } 12 \text { weeks } \\
\text { - Placebo } \\
\text { Common components: group behavioural counselling, } 9 \text { meetings over } 12 \text { weeks }\end{array}$} \\
\hline Outcomes & \multicolumn{2}{|c|}{$\begin{array}{l}\text { - Smoking cessation: prolonged abstinence at } 6 \text { months (starting from } 2 \text { weeks after quit date). Validat- } \\
\text { ed by } \mathrm{CO}<10 \mathrm{ppm} \text {, urine cotinine }<20 \mathrm{ng} / \mathrm{mL} \\
\text { - Adverse events: measured for unspecified period }\end{array}$} \\
\hline Funding Source & \multicolumn{2}{|c|}{ National Institutes of Health, Veterans Affairs. Medication provided by Eli Lilly and Company. } \\
\hline Author conflicts of interest & \multicolumn{2}{|l|}{ None specified } \\
\hline Notes & \multicolumn{2}{|c|}{ First included as Spring 2004 with unpublished data. Full publication reports sustained abstinence } \\
\hline \multicolumn{3}{|l|}{ Risk of bias } \\
\hline Bias & Authors' judgement & Support for judgement \\
\hline $\begin{array}{l}\text { Random sequence genera- } \\
\text { tion (selection bias) }\end{array}$ & Low risk & $\begin{array}{l}\text { Quote: "The study pharmacist stratified participants by depression history and } \\
\text { used computer-generated random numbers to assign them to drug or place- } \\
\text { bo." }\end{array}$ \\
\hline $\begin{array}{l}\text { Allocation concealment } \\
\text { (selection bias) }\end{array}$ & Unclear risk & Allocated by unblinded pharmacist, method not described \\
\hline $\begin{array}{l}\text { Blinding (performance } \\
\text { bias and detection bias) } \\
\text { All outcomes }\end{array}$ & Unclear risk & $\begin{array}{l}\text { Quote: "Research staff and participants were blinded to medication status." } \\
\text { "Drug assignment was guessed correctly by } 59.8 \% \text { of placebo and } 64.6 \% \text { of flu- } \\
\text { oxetine participants. Facilitators guessed correctly for } 65.3 \% \text { of placebo and } \\
55.6 \% \text { of fluoxetine participants." }\end{array}$ \\
\hline
\end{tabular}


Spring 2007 (Continued)

Incomplete outcome data Low risk Withdrawals/lost to follow-up $40 \%$ for fluoxetine, $48 \%$ placebo. Authors re(attrition bias) port similar results from missing assumed smoking and generalized estimating All outcomes

\section{Stapleton 2013}

\begin{tabular}{|c|c|}
\hline \multirow[t]{4}{*}{ Methods } & Study design: RCT \\
\hline & Country: UK \\
\hline & Setting: smoking cessation clinics \\
\hline & Recruitment: people attending smoking cessation clinics \\
\hline Participants & 1071 daily smokers; 53\% female; average age 41; average cigarettes per day 20 \\
\hline \multirow[t]{4}{*}{ Interventions } & $\begin{array}{l}\text { - Bupropion } 8 \text { weeks, started prior to TQD (exact period not specified), } 150 \mathrm{mg} / \mathrm{d} \text { for first } 6 \text { day, then } \\
300 \mathrm{mg} \text { for remainder }\end{array}$ \\
\hline & $\begin{array}{l}\text { - Bupropion and NRT. Bupropion as above. NRT given as choice of single product, } 12 \text { weeks started on } \\
\text { TQD, dosage determined on individual basis }\end{array}$ \\
\hline & - NRT. As above \\
\hline & $\begin{array}{l}\text { Common components: } 7 \text { weekly behavioural support sessions as per standard service protocol. Mainly } \\
\text { group, } 60-90 \text { mins each }\end{array}$ \\
\hline \multirow[t]{2}{*}{ Outcomes } & - Smoking cessation: prolonged abstinence at 6 months. Validated by $\mathrm{CO}<10 \mathrm{ppm}$ \\
\hline & - Adverse events: measured for unspecified period \\
\hline Funding Source & $\begin{array}{l}\text { Department of Health for England. Study medication provided free of charge by Pfizer UK, GSK UK and } \\
\text { Novartis UK. }\end{array}$ \\
\hline Author conflicts of interest & None specified \\
\hline
\end{tabular}

\section{Risk of bias}

\begin{tabular}{lll}
\hline Bias & Authors' judgement & Support for judgement \\
\hline $\begin{array}{l}\text { Random sequence genera- } \\
\text { tion (selection bias) }\end{array}$ & Low risk & $\begin{array}{l}\text { Quote: "Randomization and packaging was organized by an independent sta- } \\
\text { tistician at the host site." }\end{array}$ \\
\hline $\begin{array}{l}\text { Allocation concealment } \\
\text { (selection bias) }\end{array}$ & Low risk & $\begin{array}{l}\text { Quote: "On enrolment, participants selected their envelope from a large batch } \\
\text { and signed it before breaking the seal to reveal their allocation." }\end{array}$ \\
\hline $\begin{array}{l}\text { Blinding (performance } \\
\text { bias and detection bias) } \\
\text { All outcomes }\end{array}$ & High risk & Open label, no blinding \\
\hline
\end{tabular}

$\begin{array}{ll}\begin{array}{l}\text { Incomplete outcome data } \\ \text { (attrition bias) }\end{array} & \text { Low risk } \\ \text { All outcomes } & \begin{array}{l}61.5 \% \text { followed up at both } 1 \text { month and } 6 \text { months, no significant difference be- } \\ \text { tween groups. Prolonged abstinence only imputed for } 16 \% \text { of total }\end{array}\end{array}$




\begin{tabular}{|c|c|}
\hline Methods & $\begin{array}{l}\text { Study design: } 2 \times 2 \text { factorial RCT } \\
\text { Country: USA } \\
\text { Setting: HMO } \\
\text { Recruitment: volunteers from Group Health Co-op membership }\end{array}$ \\
\hline Participants & 1524 smokers; 57\% female; average age 45; average cigarettes per day 23 \\
\hline Interventions & $\begin{array}{l}\text { Factorial design crossing } 2 \text { drug doses with } 2 \text { intensities of behavioural counselling: } \\
\text { - Bupropion } 300 \mathrm{mg} / \text { day versus } 150 \mathrm{mg} / \text { day } \\
\text { - Free and Clear proactive telephone counselling (4 brief calls), access to quitline and S-H materials } \\
\text { vs Zyban Advantage Program (ZAP) tailored S-H materials, single telephone call after TQD, access to } \\
\text { Zyban support line }\end{array}$ \\
\hline Outcomes & $\begin{array}{l}\text { - Smoking cessation: } 7 \text { day ppa at } 12 \text { months. Validation method not specified } \\
\text { - Adverse events: measured for } 13 \text { weeks }\end{array}$ \\
\hline Funding Source & National Cancer Institute \\
\hline Author conflicts of interest & None specified \\
\hline Notes & $\begin{array}{l}\text { Based on published data from } 2004 \\
\text { No dose/behavioural treatment interaction at } 12 \text { months so arms collapsed to compare } 300 \mathrm{mg} \text { vs } 150 \\
\mathrm{mg} \\
\text { Effects differed at } 3 \text { months and } 12 \text { months. Effect of higher dose disappeared and additional support } \\
\text { aided recycling }\end{array}$ \\
\hline
\end{tabular}

\section{Risk of bias}

Bias Authors' judgement Support for judgement

Random sequence genera- Low risk tion (selection bias)

Quote: "Open-label randomized trial...The computer code for the procedure calculated probabilities of group assignment that were dynamically modified based on the number of members in each group so that final group sizes were equal. No restrictions such as stratification or blocking were used as part of the randomization process."

\begin{tabular}{ll}
\hline $\begin{array}{l}\text { Allocation concealment } \\
\text { (selection bias) }\end{array}$ & Low risk \\
\hline
\end{tabular}

\begin{tabular}{lll}
$\begin{array}{l}\text { Blinding (performance } \\
\text { bias and detection bias) } \\
\text { All outcomes }\end{array}$ & High risk & Open-label \\
\hline $\begin{array}{l}\text { Incomplete outcome data } \\
\text { (attrition bias) } \\
\text { All outcomes }\end{array}$ & Low risk & $\begin{array}{l}\text { Similar percentage lost to follow-up across all groups (approx 15\%) Nonre- } \\
\text { sponders treated as smoking }\end{array}$ \\
\hline
\end{tabular}

\section{Tashkin 2001}

\begin{tabular}{ll} 
Methods & Study design: RCT \\
& Country: USA \\
Setting: multicentre \\
Recruitment: advertisements for volunteers \\
\hline \hline
\end{tabular}


Tashkin 2001 (Continued)

Participants $\quad 404$ smokers with mild to moderate COPD (excludes 7 early dropouts who did not take any study medication); $45 \%$ female; average age 53-54; average cigarettes per day 28

\begin{tabular}{ll}
\hline Interventions & Bupropion SR $300 \mathrm{mg} /$ day for 12 weeks from 1 week before TQD \\
- Placebo & Common components: brief face-to-face counselling at each clinic visit (weeks 1-7, 10, 12), telephone \\
counselling 3 days after TQD
\end{tabular}

\begin{tabular}{ll}
\hline Funding Source & Glaxo Wellcome Inc \\
\hline Author conflicts of interest & None specified \\
\hline Notes & ITT population defined as those taking at least one dose of study medication \\
\hline
\end{tabular}

\section{Risk of bias}

\section{Bias Authors' judgement Support for judgement}

Random sequence genera- Low risk Quote: "Randomised as per code provided by Glaxo Wellcome, using block tion (selection bias) sizes of four stratified by centre. Within each block of four, two participants were assigned placebo and two bupropion SR. The randomisation codes were kept at the study sites during the trial and we instructed investigators to break the code only for a medical emergency."

\begin{tabular}{ll}
\hline $\begin{array}{l}\text { Allocation concealment } \\
\text { (selection bias) }\end{array}$ & Low risk
\end{tabular}

Blinding (performance $\quad$ Unclear risk Double-blind study, but further detail not provided
bias and detection bias)
All outcomes

\begin{tabular}{|c|c|c|}
\hline $\begin{array}{l}\text { Incomplete outcome data } \\
\text { (attrition bias) }\end{array}$ & Low risk & $\begin{array}{l}64 \% \text { intervention and } 73 \% \text { control followed up at } 6 \text { months. "All participants } \\
\text { who withdrew from the study were taken to be smokers thereafter." }\end{array}$ \\
\hline
\end{tabular}
(attrition bias)

Tidey 2011

$\begin{array}{ll}\text { Methods } & \text { Study design: factorial trial } \\ & \text { Country: USA } \\ & \text { Setting: Providence Veterans Affairs Medical Center and the Brown University Center for Alcohol and } \\ \text { Addiction Studies } \\ \text { Recruitment method: advertisements posted in the surrounding community and at an outpatient clin- } \\ \text { ic at a local VA medical centre }\end{array}$


Tidey 2011 (Continued) Interventions

- Bupropion $150 \mathrm{mg}$ daily for 3 days, then $150 \mathrm{mg}$ twice daily for 3 weeks, starting 1 week prior to TQD

- Placebo

As this is a factorial trial, all participants were randomized to contingency management or none.

\begin{tabular}{ll}
\hline Outcomes & Smoking cessation: 22 days - too short a follow-up to be considered as part of this review \\
- Adverse events: measured for 22 days
\end{tabular}

Funding Source NIH grant R01-DA17566 to the first author and a Senior Research Career Scientist Award from the Department of Veterans Affairs to the second author

\begin{tabular}{ll}
\hline Author conflicts of interest None detailed \\
\hline Notes
\end{tabular}

\section{Risk of bias}

\begin{tabular}{lll}
\hline Bias & Authors' judgement & Support for judgement \\
\hline $\begin{array}{l}\text { Random sequence genera- } \\
\text { tion (selection bias) }\end{array}$ & Low risk & Quote: "randomized by coin toss." \\
\hline $\begin{array}{l}\text { Allocation concealment } \\
\text { (selection bias) }\end{array}$ & Unclear risk & No relevant information given \\
\hline $\begin{array}{l}\text { Blinding (performance } \\
\text { bias and detection bias) } \\
\text { All outcomes }\end{array}$ & Unclear risk & States "double-blind", but no further information given \\
\hline $\begin{array}{l}\text { Incomplete outcome data } \\
\text { (attrition bias) } \\
\begin{array}{l}\text { All outcomes } \\
\end{array}\end{array}$ & Low risk & $>94 \%$ follow-up in all groups, with no between-group differences \\
\hline
\end{tabular}

\section{Tonnesen 2003}

\begin{tabular}{ll}
\hline Methods & Study design: RCT \\
& $\begin{array}{l}\text { Country: } 8 \text { European countries, Australia, New Zealand } \\
\text { Setting: } 28 \text { clinical trial centres } \\
\text { Recruitment: community volunteers }\end{array}$ \\
\hline Participants & 710 smokers; $51 \%$ female; average age 42; median cigarettes per day 20 \\
\hline Interventions & Bupropion SR $300 \mathrm{mg} /$ day for 7 weeks \\
& Placebo \\
& $\begin{array}{l}\text { Common components: brief motivational support at weekly clinic visits and telephone support during } \\
\text { follow-up. } 11 \text { clinic visits and } 10 \text { phone calls scheduled }\end{array}$ \\
\hline Outcomes & $\begin{array}{l}\text { Smoking cessation: prolonged abstinence at } 52 \text { weeks (starting from week 4). Validated by CO } \leq 10 \\
\text { ppm }\end{array}$ \\
\hline & Adverse events: measured for 52 weeks
\end{tabular}


Tonnesen 2003 (Continued)

Author conflicts of interest S Tonstad has received honoraria from Glaxo-SmithKline for lectures on smoking cessation. R Sweet is a former employee of GlaxoSmithKline. A Hider and J Townsend are currently employees of GlaxoSmithKline. For A Hjalmarsson, PI VanSpiegel, P Tonnesen: no conflict of interest was declared

First included 2003 as Tonstad 2001
ITT population defined as those taking at least one dose of study medication excludes 3 randomized
participants

\section{Risk of bias}

\begin{tabular}{lll}
\hline Bias & Authors' judgement & Support for judgement \\
\hline $\begin{array}{l}\text { Random sequence genera- } \\
\text { tion (selection bias) }\end{array}$ & Low risk & $\begin{array}{l}\text { Quote: "GlaxoSmithKline created a randomization schedule in a 3:1 bupropi- } \\
\text { on: placebo ratio. Each centre received a list with treatment numbers and sub- } \\
\text { jects were consecutively assigned a treatment number at the baseline visit." }\end{array}$ \\
\hline $\begin{array}{l}\text { Allocation concealment } \\
\text { (selection bias) }\end{array}$ & Low risk & $\begin{array}{l}\text { Quote: "GlaxoSmithKline supplied bupropion SR 150 mg and placebo-to- } \\
\text { match tablets for oral administration as white, film-coated tablets." }\end{array}$ \\
\hline $\begin{array}{l}\text { Blinding (performance } \\
\text { bias and detection bias) }\end{array}$ & Unclear risk & Double-blind but methods not described \\
\hline $\begin{array}{l}\text { All outcomes } \\
\begin{array}{l}\text { Incomplete outcome data } \\
\text { (attrition bias) } \\
\text { All outcomes }\end{array}\end{array}$ & Low risk & $9 \%$ of bupropion SR and 12\% placebo were lost to follow-up \\
\hline
\end{tabular}

\section{Tonstad 2003}

\begin{tabular}{ll}
\hline Methods & Study design: RCT \\
& $\begin{array}{l}\text { Country: } 10 \text { countries including European countries, Australia, and NZ } \\
\text { Setting: } 28 \text { clinical trial centres } \\
\text { Recruitment: volunteers with CVD }\end{array}$ \\
\hline Participants & $\begin{array}{l}629 \text { smokers with stable CVD; 23\% female; average age 55; average cigarettes per day 25; 49\% had his- } \\
\text { tory of MI }\end{array}$ \\
\hline Interventions & Bupropion SR 300 mg/day for 7 weeks, begun 1-2 weeks before TQD \\
& $\begin{array}{l}\text { Placebo } \\
\text { follow-up. } 9 \text { clinic visits and } 10 \text { phone calls scheduled }\end{array}$ \\
\hline Outcomes & $\begin{array}{l}\text { Smoking cessation: prolonged abstinence at } 12 \text { months (starting from week 4). Validated by CO } \leq 10 \\
\text { ppm }\end{array}$ \\
\hline Funding Source & Adverse events: measured for 9 weeks \\
\hline Author conflicts of interest & $\begin{array}{l}\text { GlaxoSmithKline } \\
\text { Notes }\end{array}$ \\
\hline $\begin{array}{l}\text { First included } 2003 \text { as McRobbie } 2003 . \text { ITT population = 626 defined as those taking at least one dose of } \\
\text { study medication }\end{array}$ \\
\hline
\end{tabular}


Tonstad 2003 (Continued)

Risk of bias

\begin{tabular}{|c|c|c|}
\hline Bias & Authors' judgement & Support for judgement \\
\hline $\begin{array}{l}\text { Random sequence genera- } \\
\text { tion (selection bias) }\end{array}$ & Unclear risk & Randomization method not described \\
\hline $\begin{array}{l}\text { Allocation concealment } \\
\text { (selection bias) }\end{array}$ & Unclear risk & Not described \\
\hline $\begin{array}{l}\text { Blinding (performance } \\
\text { bias and detection bias) } \\
\text { All outcomes }\end{array}$ & Unclear risk & Double-blind, but no further detail provided \\
\hline $\begin{array}{l}\text { Incomplete outcome data } \\
\text { (attrition bias) } \\
\text { All outcomes }\end{array}$ & Unclear risk & $\begin{array}{l}\text { Number missing follow-up in each group not provided. At } 12 \text { months, } 38 \% \\
\text { bupropion and } 50 \% \text { placebo had prematurely discontinued treatment. "Sub- } \\
\text { jects with missing investigator assessments were assumed to be smokers at } \\
\text { that visit." }\end{array}$ \\
\hline
\end{tabular}

Urdapilleta-Herrera 2013

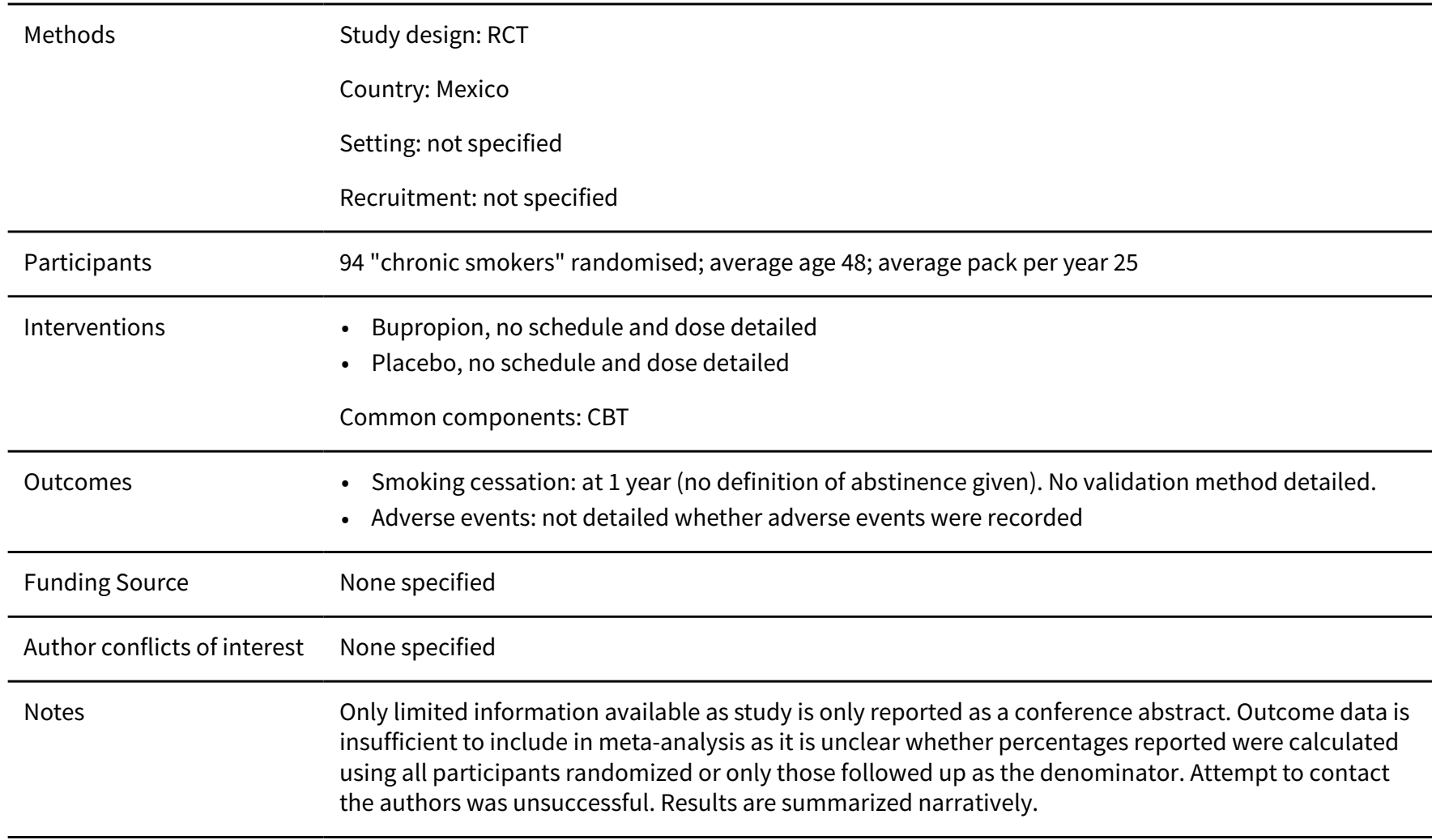

\section{Risk of bias}

\section{Bias}

Random sequence genera-

tion (selection bias)

\section{Authors' judgement Support for judgement}

Unclear risk

No relevant information given 
Urdapilleta-Herrera 2013 (Continued)

\begin{tabular}{lll}
$\begin{array}{l}\text { Allocation concealment } \\
\text { (selection bias) }\end{array}$ & Unclear risk & No relevant information given \\
\hline $\begin{array}{l}\text { Blinding (performance } \\
\text { bias and detection bias) } \\
\text { All outcomes }\end{array}$ & Unclear risk & $\begin{array}{l}\text { Quote: "double-blind" although no information given regarding who was } \\
\text { blinded }\end{array}$ \\
\hline
\end{tabular}

All outcomes

Incomplete outcome data Unclear risk No relevant information given

(attrition bias)

All outcomes

Uyar 2007

\begin{tabular}{ll}
\hline Methods & Study design: RCT \\
& $\begin{array}{l}\text { Country: Turkey } \\
\text { Setting: cessation clinic } \\
\text { Recruitment: cessation clinic patients }\end{array}$ \\
\hline Participants & 131 smokers; $19 \%$ female; average age 36 \\
\hline Interventions & Bupropion 300 mg for 7 weeks \\
& - Advice and follow-up only \\
& $\begin{array}{l}\text { Common components: brief counselling on consequences of smoking with follow-up for } 24 \text { weeks - } \\
\text { more than low intensity }\end{array}$ \\
\hline Outcomes & - Smoking cessation: abstinence at 24 weeks (definition not specified). Validated by CO < 10 ppm \\
\hline Funding Source & Adverse events: measured for unspecified period \\
\hline Author conflicts of interest & \begin{tabular}{l} 
None specified \\
\hline Notes
\end{tabular} \\
\hline $\begin{array}{l}\text { First included based on abstract. Contributes to bupropion versus control and bupropion versus nico- } \\
\text { tine patch }\end{array}$
\end{tabular}

\section{Risk of bias}

\begin{tabular}{lll}
\hline Bias & Authors' judgement & Support for judgement \\
\hline $\begin{array}{l}\text { Random sequence genera- } \\
\text { tion (selection bias) }\end{array}$ & Unclear risk & $\begin{array}{l}\text { Quote: "Randomly allocated", method not described, unclear why fewer in } \\
\text { control condition }\end{array}$ \\
\hline $\begin{array}{l}\text { Allocation concealment } \\
\text { (selection bias) }\end{array}$ & Unclear risk & Allocation concealment not described \\
\hline $\begin{array}{l}\text { Blinding (performance } \\
\text { bias and detection bias) } \\
\text { All outcomes }\end{array}$ & High risk & Open-label \\
\hline
\end{tabular}

Incomplete outcome data Unclear risk $\quad$ No mention of any losses to follow-up
(attrition bias)

All outcomes 
Wagena 2005

\begin{tabular}{ll}
\hline Methods & $\begin{array}{l}\text { Study design: RCT } \\
\text { Country: Netherlands } \\
\text { Setting: university medical centre } \\
\text { Recruitment: community volunteers }\end{array}$ \\
\hline Participants & 255 smokers with or at risk of COPD; $51 \%$ female; average age 51 ; average cigarettes per day 23 \\
\hline Interventions & Bupropion SR $300 \mathrm{mg} /$ day for 12 weeks \\
- Nortriptyline $75 \mathrm{mg} /$ day for 12 weeks \\
- Placebo bupropion or placebo nortriptyline \\
Common components: individual counselling $10-20$ mins at baseline, 1 week and 3 weeks post-TQD \\
(TQD typically day 11 ). Telephone support TQD, 2 weeks, 4 weeks, 6 weeks, 8 weeks, 11 weeks
\end{tabular}

\section{Outcomes}

- Smoking cessation: prolonged abstinence at 26 weeks (puff-free from week 4). Validated by urine cotinine $\leq 60 \mathrm{ng} / \mathrm{mL}$ at 4 weeks, 12 weeks and 26 weeks

- Adverse events: none specified

$\begin{array}{ll}\text { Funding Source } & \text { Netherlands Asthma Foundation, Netherlands Organization for Health Research and Development. } \\ \text { Lundbeck BV provided nortriptyline free of charge }\end{array}$

$$
\text { Author conflicts of interest None specified }
$$

\section{Notes}

\section{Risk of bias}

\begin{tabular}{lll}
\hline Bias & Authors' judgement & Support for judgement \\
\hline $\begin{array}{l}\text { Random sequence genera- } \\
\text { tion (selection bias) }\end{array}$ & Low risk & Computer-generated by pharmacist, stratified by COPD severity, block size 33 \\
\hline $\begin{array}{l}\text { Allocation concealment } \\
\text { (selection bias) }\end{array}$ & Low risk & Research staff blinded throughout study \\
\hline $\begin{array}{l}\text { Blinding (performance } \\
\text { bias and detection bias) }\end{array}$ & Unclear risk & $\begin{array}{l}\text { Double-blind but "at both time points, participants receiving active drug com- } \\
\text { pared with those receiving placebo were more likely to guess that they had re- } \\
\text { ceived bupropion SR and nortriptyline treatment (72\% vs 43\%, P.01; and 62\% } \\
\text { vs 37\%; P=.001; respectively)." }\end{array}$ \\
\hline $\begin{array}{l}\text { Incomplete outcome data } \\
\text { (attrition bias) } \\
\text { All outcomes }\end{array}$ & Low risk & $\begin{array}{l}10 \text { (12\%) bupropion, 13 (16\%) nortriptyline, 12 (13\%) lost or withdrawn. All in- } \\
\text { cluded in ITT analysis }\end{array}$ \\
\hline
\end{tabular}

Weinberger 2010

$\begin{array}{ll}\text { Methods } & \text { Study design: RCT } \\ & \text { Country: USA } \\ & \text { Setting: clinics } \\ & \text { Recruitment: community volunteers }\end{array}$


Weinberger 2010 (Continued)

Participants 101 smokers (excludes 2 taking no medication); 50\% femalel; average age 47; average cigarettes per day 22

Interventions

- Selegiline $10 \mathrm{mg} /$ day for 9 weeks (5 $\mathrm{mg} /$ day in week 1 and week 9 )

- Placebo

Common components: brief weekly counselling

\begin{tabular}{ll}
\hline Outcomes & $\begin{array}{l}\text { - Smoking cessation: } 7 \text { day ppa at } 6 \text { months. Validated by CO and urinary cotinine } \\
\text { - Adverse events: measured for } 10 \text { weeks }\end{array}$ \\
\hline Funding Source & $\begin{array}{l}\text { National Institute of Drug Abuse, Veteran's Administration, Women's Health Research at Yale, NIH, Uni- } \\
\text { versity of Toronto }\end{array}$ \\
\hline Author conflicts of interest & None specified \\
\hline Notes & \\
\hline
\end{tabular}

\section{Risk of bias}

\begin{tabular}{lll}
\hline Bias & Authors' judgement & Support for judgement \\
\hline $\begin{array}{l}\text { Random sequence genera- } \\
\text { tion (selection bias) }\end{array}$ & Unclear risk & Randomization method not described \\
\hline $\begin{array}{l}\text { Allocation concealment } \\
\text { (selection bias) }\end{array}$ & Unclear risk & Not described \\
\hline $\begin{array}{l}\text { Blinding (performance } \\
\text { bias and detection bias) } \\
\text { All outcomes }\end{array}$ & Low risk & $\begin{array}{l}\text { Quote: "Both participants and research staff were blinded to study medication } \\
\text { assignment," } \\
\text { Comment: assessments of staff and participants suggest blinding was ade- } \\
\text { quate }\end{array}$ \\
\hline $\begin{array}{l}\text { Incomplete outcome data } \\
\text { (attrition bias) }\end{array}$ & Unclear risk & $\begin{array}{l}27.5 \% \text { selegiline, 42\% placebo lost at } 6 \text { months. Including all participants is } \\
\text { lll outcomes conservative }\end{array}$ \\
\hline
\end{tabular}

Weiner 2012

\begin{tabular}{ll}
\hline Methods & Study design: RCT \\
Country: USA & \\
Setting: Maryland Psychiatric Research Center \\
Recruitment method: clinically stable outpatients from the Maryland Psychiatric Research Center vol- \\
unteered to participate
\end{tabular}


Weiner 2012 (Continued)

All participants had a 9-week group support programme led by staff trained in the education model of the American Cancer Society Fresh Start Program modified for people with schizophrenia. Each session was structured and incorporated relation exercises with practice "homework". The first group sessions were designed to increase awareness of specific smoking habits and to develop a 'Quit Plan'. A Quit Day Ceremony was held at the fifth group session. Subsequent sessions focused on reworking the Quit Plan. Later groups focused on strategies for participants minimizing weight gain, managing high risk situations, and imagining themselves as non-smokers.

\begin{tabular}{ll}
\hline Outcomes & Smoking cessation: 14 weeks - too short a follow-up for this outcome to be considered as part of this \\
review \\
- Adverse events: measured for 14 weeks
\end{tabular}

Funding Source

Veterans Affairs Capitol Network (VISN 5) Mental Illness Research, Education, and Clinical Center. National Institute of Mental Health Grant (MH068580-01), Advance Center for Intervention Services Research

Author conflicts of interest Ms Ball has served as a consultant to ePharmaSolutions and Pfizer; Dr Gold has served as a consultant to Merck, AstraZeneca, Solvay, Pfizer, and GlaxoSmithKline. Dr Evins has served as a consultant to Pfizer, Boehringer, and Schering Plough and has received grant/research support from GlaxoSmithKline and Pfizer. Dr Buchanan has served as a consultant to Abbott and ClaxoSmithKline; has received grant/ research support from Novartis and Janssen; has served on advisory boards for AstraZeneca, Wyeth, Schering Plough, Solvay and Pfizer, and has received other material or financial support from Bristol-Myers Squibb, Otsuka, Pfizer and Cephalon. Drs Weiner and McMahon and Ms Buchholz report no financial or other relationship relevant to the subject of this article.

Notes

\section{Risk of bias}

\begin{tabular}{|c|c|c|}
\hline Bias & Authors' judgement & Support for judgement \\
\hline $\begin{array}{l}\text { Random sequence genera- } \\
\text { tion (selection bias) }\end{array}$ & Unclear risk & $\begin{array}{l}\text { Quote: "Random assignments made by the statistician." } \\
\text { Comment: no further information given }\end{array}$ \\
\hline $\begin{array}{l}\text { Allocation concealment } \\
\text { (selection bias) }\end{array}$ & Unclear risk & $\begin{array}{l}\text { Quote: "Random assignments made by the statistician." } \\
\text { Comment: no further information given }\end{array}$ \\
\hline $\begin{array}{l}\text { Blinding (performance } \\
\text { bias and detection bias) } \\
\text { All outcomes }\end{array}$ & Unclear risk & $\begin{array}{l}\text { Quote: "double-blind, placebo-controlled clinical trial." } \\
\text { Comment: no further information given }\end{array}$ \\
\hline $\begin{array}{l}\text { Incomplete outcome data } \\
\text { (attrition bias) } \\
\text { All outcomes }\end{array}$ & Low risk & $\begin{array}{l}\text { Dropout rates are as follows: } 8 / 24(33.3 \%) \text { in the bupropion group; } 6 / 22 \\
(27.3 \%) \text { in the placebo group. Therefore overall dropout was less than } 50 \% \\
\text { and similar between groups. }\end{array}$ \\
\hline Other bias & Unclear risk & $\begin{array}{l}\text { "While the target completion number was } 40 \text { there was insufficient study drug } \\
\text { available to meet this goal." It is unclear how this was dealt with and whether it } \\
\text { is accounted for in the dropouts reported in the flow diagram. However loss to } \\
\text { follow-up was similar between arms. }\end{array}$ \\
\hline
\end{tabular}

White 2005

\begin{tabular}{ll}
\hline Methods & Study design: RCT \\
Country: Canada
\end{tabular}


White 2005 (Continued)

Setting: university

Recruitment method: local media

\begin{tabular}{|c|c|}
\hline Participants & $\begin{array}{l}36 \text { participants randomized; } 61.1 \% \text { female; average age } 41.9 \text {; average cigarettes per day } 24.0 \text {; mean FT- } \\
\text { ND } 7.2\end{array}$ \\
\hline Interventions & $\begin{array}{l}\text { - Bupropion } 150 \mathrm{mg} \text { on days } 1-3 \text {, then } 150 \mathrm{mg} \text { twice daily for the remainder of the } 6 \text {-week study } \\
\text { - Gabapentin started at } 300 \mathrm{mg} \text { daily, with titration to } 1800 \mathrm{mg} \text { daily by day } 6 \\
\text { ill participants each week received } 15 \text {-minute one-to-one smoking cessation counselling with a study } \\
\text { investigator, using the Mayo Clinic workbook 'Smoke-Free and Living It" for a total of } 1 \text { hour and } 30 \\
\text { minutes }\end{array}$ \\
\hline Outcomes & $\begin{array}{l}\text { - Smoking cessation: } 6 \text { weeks - too short a follow-up for this outcome to be considered as part of this } \\
\text { review } \\
\text { - Adverse events: measured for } 6 \text { weeks }\end{array}$ \\
\hline
\end{tabular}

Funding Source

Calgary Centre for Advancement of Health. Gabapentin (Neurontin) samples were donated through an informal arrangement with a local representative of Pfizer Canada Inc.

\begin{tabular}{|c|c|c|}
\hline Author conflicts of interest & None detailed & \\
\hline \multicolumn{3}{|l|}{ Notes } \\
\hline \multicolumn{3}{|l|}{ Risk of bias } \\
\hline Bias & Authors' judgement & Support for judgement \\
\hline $\begin{array}{l}\text { Random sequence genera- } \\
\text { tion (selection bias) }\end{array}$ & Unclear risk & $\begin{array}{l}\text { Quote: "we conducted a randomized, open-label pilot trial." } \\
\text { Comment: no further information given }\end{array}$ \\
\hline $\begin{array}{l}\text { Allocation concealment } \\
\text { (selection bias) }\end{array}$ & Unclear risk & $\begin{array}{l}\text { Quote: "we conducted a randomized, open-label pilot trial." } \\
\text { Comment: no further information given }\end{array}$ \\
\hline $\begin{array}{l}\text { Blinding (performance } \\
\text { bias and detection bias) } \\
\text { All outcomes }\end{array}$ & High risk & $\begin{array}{l}\text { Quote: "we conducted a randomized, open-label pilot trial" } \\
\text { Comment: open-label }\end{array}$ \\
\hline $\begin{array}{l}\text { Incomplete outcome data } \\
\text { (attrition bias) } \\
\text { All outcomes }\end{array}$ & Low risk & $\begin{array}{l}\text { Dropout rates are as follows: } 9 / 19(47.4 \%) \text { in the bupropion group; } 6 / 17 \\
(35.3 \%) \text { in the gabapentin group. Therefore overall attrition was less than } 50 \% \\
\text { and similar between arms. }\end{array}$ \\
\hline
\end{tabular}

Wittchen 2011

\begin{tabular}{ll}
\hline Methods & Study design: RCT \\
& Country: Germany \\
& Setting: 167 primary care clinics \\
& Recruitment: patients at participating primary care clinics \\
\hline Participants & 467 "current regular smokers"; $52 \%$ female; average age 43; average cigarettes per day 20 \\
\hline Interventions & - CBT 4-5 one-on-one counselling sessions for $20-30$ mins
\end{tabular}


Wittchen 2011 (Continued)

- CBT and bupropion SR. CBT as above. Bupropion SR (9-12 weeks, $150 \mathrm{mg} ; 1 /$ day for first 6 days; 2/day thereafter)

- CBT and NRT. CBT as above. NRT for 9-12 weeks, patient's choice of patch (7 mg to $52.5 \mathrm{mg}$ ), gum (2 or $4 \mathrm{mg}$ ) or spray $(10 \mathrm{mg} / \mathrm{mL})$

- Minimal intervention (not used in review)
- Smoking cessation: abstinence at 12 months (from EoT). Validation method not specified

- Adverse events: measured for 12 weeks
Funding Source

Patients covered all costs for pharmaceutical treatments. Sponsored by the Federal Ministry of Education and Research; additional support provided by GlaxoSmithKline GmbH \& Co and Pharmacia GmbH

\begin{tabular}{ll}
\hline Author conflicts of interest & None specified \\
\hline Notes & New for 2013 update \\
& $\begin{array}{l}3 \text { versus } 2 \text { included in primary analyses. } 2 \text { versus } 4 \text { included in Analysis } 1.7 \text { comparison of NRT with } \\
\text { bupropion. } 1 \text { not used as results versus bupropion would be confounded with CBT }\end{array}$
\end{tabular}

\section{Risk of bias}

\begin{tabular}{lll}
\hline Bias & Authors' judgement & Support for judgement \\
\hline $\begin{array}{l}\text { Random sequence genera- } \\
\text { tion (selection bias) }\end{array}$ & Unclear risk & $\begin{array}{l}\text { Quote: "Generated by the study center"; used to put } 4 \text { different coloured ques- } \\
\text { tionnaires in random order }\end{array}$ \\
\hline $\begin{array}{l}\text { Allocation concealment } \\
\text { (selection bias) }\end{array}$ & High risk & $\begin{array}{l}\text { Quote: "questionnaires were distributed consecutively to all attending pa- } \\
\text { tients on the target days by nurses. Thus, the assignment of patients was en- } \\
\text { tirely dependent on the consecutive attendance of patients and the random } \\
\text { assignment of a color. Doctors were not allowed to interfere with this study } \\
\text { procedure." But numbers allocated to groups very uneven and discussion } \\
\text { states: "Random checks of this procedure [randomization] and quality assur- } \\
\text { ance tests by study monitors revealed that in some cases in the latter part of } \\
\text { the study treatment was based on patient and physician preferences." }\end{array}$ \\
Comment: therefore no concealment
\end{tabular}

Blinding (performance $\quad$ High risk Neither participants nor providers were blind
bias and detection bias)
All outcomes

\begin{tabular}{|c|c|c|}
\hline $\begin{array}{l}\text { Incomplete outcome data } \\
\text { (attrition bias) }\end{array}$ & Low risk & $\begin{array}{l}\text { Similar number of dropouts between groups; participants lost to follow-up } \\
\text { considered smokers for meta-analysis }\end{array}$ \\
\hline
\end{tabular}

\section{Zellweger 2005}

\begin{tabular}{ll}
\hline Methods & Study design: RCT \\
& $\begin{array}{l}\text { Countries: } 12 \text { European countries } \\
\text { Setting: } 26 \text { clinical trial centres } \\
\text { Recruitment: volunteers, healthcare professionals (qualified practising physician or nurse) }\end{array}$ \\
\hline Participants & $\begin{array}{l}667 \text { smokers (excludes } 1 \text { centre enrolling } 20 \text { people, and } 3 \text { people who took no medication); } 64 \% \text { fe- } \\
\text { male; average age } 40 ; \text { average cigarettes per day } 23 ; 32 \% \text { doctor, } 68 \% \text { nurse }\end{array}$ \\
\hline Interventions & Bupropion SR. $300 \mathrm{mg} /$ day for 7 weeks \\
\hline
\end{tabular}


Zellweger 2005 (Continued)

\section{- Placebo}

Common components: Brief (10-15 min) motivational support at weekly clinic visits and telephone support one day before TQD, 3 days after TQD, monthly during follow-up

\begin{tabular}{ll}
\hline Outcomes & $\begin{array}{l}\text { Smoking cessation. Prolonged abstinence at } 52 \text { weeks (starting from week 4). Validated by CO } \leq 10 \\
\text { ppm }\end{array}$ \\
\hline Funding Source & GlaxoSmithKline \\
\hline Author conflicts of interest & None specified \\
\hline Notes & $\begin{array}{l}\text { Continuous abstinence rates and information on adverse events from GlaxoSmithKline data. One cen- } \\
\text { tre excluded }\end{array}$
\end{tabular}

\section{Risk of bias}

\begin{tabular}{lll}
\hline Bias & Authors' judgement & Support for judgement \\
\hline $\begin{array}{l}\text { Random sequence genera- } \\
\text { tion (selection bias) }\end{array}$ & Unclear risk & Randomization method not described \\
\hline $\begin{array}{l}\text { Allocation concealment } \\
\text { (selection bias) }\end{array}$ & Unclear risk & Not described \\
\hline $\begin{array}{l}\text { Blinding (performance } \\
\text { bias and detection bias) } \\
\text { All outcomes }\end{array}$ & Unclear risk & Double-blind but further detail not provided \\
\hline $\begin{array}{l}\text { Incomplete outcome data } \\
\text { (attrition bias) } \\
\text { All outcomes }\end{array}$ & Unclear risk & $\begin{array}{l}\text { Number lost to follow-up not stated. Participants with missing assessments or } \\
\text { dropouts considered to be smoking }\end{array}$ \\
\hline
\end{tabular}

Zincir 2013

\begin{tabular}{ll}
\hline Methods & Study design: naturalistic clinical follow-up study \\
Country: Turkey & Setting: outpatient smoking cessation clinic in a hospital \\
Recruitment method: patients who presented at the smoking cessation outpatient clinic were includ- \\
ed in the study on a voluntary basis
\end{tabular}


Zincir 2013 (Continued)

patches, 4 weeks of administration in decreasing doses was recommended. The nicotine gum was started between 12 and 24 doses $(2 \mathrm{mg}$ ) a day and gradually decreased.

\begin{tabular}{ll}
\hline Outcomes & Smoking cessation: not specified \\
& - Adverse events: measured for unspecified period
\end{tabular}

\begin{tabular}{ll} 
Funding Source $\quad$ None specified \\
\hline
\end{tabular}

Author conflicts of interest None detailed

\section{Notes}

\section{Risk of bias}

\begin{tabular}{|c|c|c|}
\hline Bias & Authors' judgement & Support for judgement \\
\hline $\begin{array}{l}\text { Random sequence genera- } \\
\text { tion (selection bias) }\end{array}$ & Unclear risk & $\begin{array}{l}\text { Quote: “...they were randomized to the pharmacological therapy groups” } \\
\text { Comment: No further information given }\end{array}$ \\
\hline $\begin{array}{l}\text { Allocation concealment } \\
\text { (selection bias) }\end{array}$ & Unclear risk & $\begin{array}{l}\text { Quote: “...they were randomized to the pharmacological therapy groups" } \\
\text { Comment: no further information given }\end{array}$ \\
\hline $\begin{array}{l}\text { Blinding (performance } \\
\text { bias and detection bias) } \\
\text { All outcomes }\end{array}$ & High risk & $\begin{array}{l}\text { Quote: "This was a naturalistic clinical follow-up study." } \\
\text { Comment: those involved in the study were therefore unblinded }\end{array}$ \\
\hline $\begin{array}{l}\text { Incomplete outcome data } \\
\text { (attrition bias) } \\
\text { All outcomes }\end{array}$ & Unclear risk & $\begin{array}{l}300 \text { participants were randomized and } 251 \text { completed the study. Therefore } \\
49 / 300(16.3 \%) \text { were lost to follow-up overall. However, it is impossible to es- } \\
\text { tablish the number lost to follow-up by group. }\end{array}$ \\
\hline Other bias & High risk & $\begin{array}{l}\text { Quote: "no adverse event was reported during the study". This is highly unlike- } \\
\text { ly to be correct. Additionally, there is no explanation of how adverse events } \\
\text { were assessed. }\end{array}$ \\
\hline
\end{tabular}

AE: adverse event

CBGT: cognitive behavioral group therapy

CBT: cognitive behavioural therapy

CES-D: Center for Epidemiologic Studies Depression Scale

CO: carbon monoxide (in exhaled breath)

COPD: chronic obstructive pulmonary disease

CVD: cardiovascular disease

EOT: end of treatment

FTND: Fagerstrom Test for Nicotine Dependence

FTQ: Fagerstrom Tolerance Questionnaire

ITT: intention-to-treat

MDD: major depressive disorder

MI: myocardial infarction

mins: minutes

NRT: nicotine replacement therapy

ppa: point prevalence abstinence

ppm: parts per million

RCT: randomized controlled trial

RP: relapse prevention

Rx: treatment

SAE: serious adverse event

SAMe: S-Adenosyl-L-Methionine

$\mathrm{S}-\mathrm{H}$ : self-help

SR: sustained release 
TQD: target quit date

VAMC: Veterans Affairs Medical Center

Characteristics of excluded studies [ordered by study ID]

\begin{tabular}{|c|c|}
\hline Study & Reason for exclusion \\
\hline Akbarpour 2010 & Bupropion - short follow-up \\
\hline Aryanpur 2016 & Arms not matched - different behavioural interventions in each \\
\hline Banham 2010 & Not RCT - review of smoking cessation treatment for people with severe mental illness \\
\hline Becker 2003 & St John's wort - short follow-up (1 month) \\
\hline Berlin 2005 & $\begin{array}{l}\text { Befloxatone (reversible monoamine oxidase-B inhibitor) - data not published, treatment reported } \\
\text { to have had no effect on abstinence rates }\end{array}$ \\
\hline Bloch 2010 & Bupropion - trial in people with schizophrenia, short follow-up and cessation not reported \\
\hline Bowen 1991 & $\begin{array}{l}\text { Tryptophan - short follow-up } \\
\text { Tryptophan } 50 \mathrm{mg} / \mathrm{kg} / \text { day, with high carbohydrate low protein diet ( } 7 / 1 \text { ratio), versus placebo and } \\
\text { low carbohydrate high protein diet ( } 1 / 1 \text { ratio) for two weeks }\end{array}$ \\
\hline Brauer 2000 & Selegiline - only preliminary short-term results available. Six month follow-up planned \\
\hline Breitling 2008 & Trial of practitioner education and financial incentives, or cessation drug costs reimbursement \\
\hline Brody 2013 & Ineligible outcomes - less than six months follow-up and no safety data reported \\
\hline Carrão 2007 & Sertraline - combined with buspirone so effect of sertraline could not be isolated \\
\hline Chan 2005 & Bupropion - case control study in pregnant women \\
\hline Chandrashekar 2015 & Short-term follow-up and no safety assessment \\
\hline Christenhusz 2012 & Not randomized to treatments, only treatment strategies \\
\hline Cornelius 1997 & $\begin{array}{l}\text { Fluoxetine - cessation not an outcome. Fluoxetine reduced the amount smoked by depressed alco- } \\
\text { holic smokers }\end{array}$ \\
\hline Cornelius 1999 & $\begin{array}{l}\text { Fluoxetine - short-term outcome in a study of depressed alcoholic participants not attempting to } \\
\text { quit }\end{array}$ \\
\hline Covey 2007 & Previously included. Relapse prevention study. See Livingstone-Banks 2019 \\
\hline Croghan 2007 & Previously included. Relapse prevention study. See Livingstone-Banks 2019 \\
\hline Cropsey 2015 & Randomization to treatment strategy, not actual treatment \\
\hline Dalack 1995 & Fluoxetine - refers to, but does not report on a cessation study \\
\hline Dale 2002 & Bupropion - used for smokeless tobacco cessation, not smoking cessation \\
\hline Dale 2007 & Bupropion - for smokeless tobacco cessation, see Ebbert 2011 \\
\hline Daniela 2008 & Sertraline and buspirone - effect of antidepressant confounded with that of anxiolytic \\
\hline
\end{tabular}




\begin{tabular}{|c|c|}
\hline Study & Reason for exclusion \\
\hline Edwards 1989 & Doxepin - short follow-up (2 months) \\
\hline EUCTR2005-006189-32-AT & Arms not matched \\
\hline Evins 2008 & Bupropion - long-term results not presented due to high loss to follow-up \\
\hline Fatemi 2005 & Bupropion - short-term cross-over trial \\
\hline Frederick 1997 & Venlafaxine - short follow-up (8 weeks) \\
\hline Gawin 1989 & Buspirone - open trial \\
\hline Gifford 2011 & Bupropion - test of behavioural therapy, all participants received bupropion \\
\hline Glover 2002 & Bupropion - used for smokeless tobacco cessation, not smoking cessation \\
\hline Gold 2002 & Bupropion - non-random assignment, participant preference \\
\hline Grandi 2011 & Bupropion - not RCT, review of bupropion use in patients with CVD \\
\hline Grassi 2009 & $\begin{array}{l}\text { Not a RCT, pre-post study of influence of smoking ban on people's selection of smoking cessation } \\
\text { treatment }\end{array}$ \\
\hline Hall 2009 & Bupropion - all participants received bupropion for quitting, test of extended CBT or NRT \\
\hline Hall 2011 & Previously included. Relapse prevention study. See Livingstone-Banks 2019 \\
\hline Hatsukami 2004 & Previously included. Harm reduction study. See Lindson-Hawley 2016 \\
\hline Hawk 2008 & Bupropion - short follow-up (12 weeks). Compares 1 week to 4 week pre-quit use \\
\hline Hawk 2015 & Interventions not matched - same intervention post-quit date \\
\hline Hays 2001 & Previously included. Relapse prevention study. See Livingstone-Banks 2019 \\
\hline Hays 2009 & Previously included. Relapse prevention study. See Livingstone-Banks 2019 \\
\hline Hilberink 2005 & Bupropion - test of NRT + counselling, one cluster received bupropion but is not a test of bupropion \\
\hline Hitsman 1999 & $\begin{array}{l}\text { Fluoxetine - the majority of participants in this study were also part of the multicentre trial report- } \\
\text { ed in Niaura } 2002\end{array}$ \\
\hline Houtsmuller 2002 & Selegiline - short-term laboratory study \\
\hline Hurt 2003 & Previously included. Relapse prevention study. See Livingstone-Banks 2019 \\
\hline Hussain 2010 & Bupropion - short follow-up, trial in unmotivated smokers \\
\hline Isgro 2015 & Topiramate not an antidepressant \\
\hline Jacobs 1971 & Imipramine - short follow-up. Outcome was reduction in smoking to less than $10 \%$ of baseline \\
\hline Kalman 2004 & Bupropion - short follow-up (12 weeks) \\
\hline Khunrong 2016 & Ineligible outcomes \\
\hline
\end{tabular}




\begin{tabular}{|c|c|}
\hline Study & Reason for exclusion \\
\hline Killen 2006 & Previously included. Relapse prevention study. See Livingstone-Banks 2019 \\
\hline Kotz 2009 & $\begin{array}{l}\text { Nortriptyline - pharmacotherapy was confounded with additional counselling from nurse (control } \\
\text { group 1), compared to usual care }\end{array}$ \\
\hline Kras 2010 & St John's wort - short follow-up \\
\hline Lawvere 2006 & St John's wort - uncontrolled study \\
\hline Li 2009 & Bupropion - short follow-up \\
\hline Miller 2003 & Bupropion - short follow-up (8 weeks) \\
\hline Monuteaux 2007 & Bupropion - participants were adolescent non-smokers, not for cessation \\
\hline Mooney 2008 & Bupropion - short follow-up, bupropion for opioid and tobacco dependence \\
\hline Mooney 2016 & Bupropion same in both arms \\
\hline Naranjo 1990 & Fluoxetine - study of short-term smoking behaviour \\
\hline NCT00032084 & Trial terminated before completion \\
\hline NCT00119210 & Trial terminated before completion \\
\hline NCT00136747 & Smoking cessation not measured \\
\hline NCT00136786 & Smoking cessation not measured \\
\hline NCT00158171 & Cessation not measured - harm reduction study \\
\hline NCT00248118 & Bupropion - trial was terminated prior to completion \\
\hline NCT00320697 & Pharmacotherpaies not matched \\
\hline NCT00390923 & Selegiline - study terminated early due to lack of efficacy, results available at 9 weeks only \\
\hline NCT00484692 & $\begin{array}{l}\text { Bupropion - used as an active control to a psychosocial intervention, cannot estimate pharma- } \\
\text { cotherapy effect }\end{array}$ \\
\hline NCT00580853 & Does not measure smoking cessation - ability to resist smoking \\
\hline NCT00670904 & No randomization - participants chose their medication \\
\hline NCT00936299 & Bupropion - no abstinence outcome reported and follow-up only 16 weeks \\
\hline NCT01850589 & Behavioural intervention and pharmacotherapy is different between arms \\
\hline NCT01965405 & All participants in all arms receive the same bupropion treatment \\
\hline NCT02736474 & Both naltrexone and bupropion given together in same arm \\
\hline NCT03471767 & Bupropion given in both arms \\
\hline NCT03920319 & Wrong outcomes \\
\hline
\end{tabular}




\section{Study}

Neumann 2000

\section{Reason for exclusion}

Bupropion - smokers randomized to 1 or 2 months of medication ( $300 \mathrm{mg} /$ day). 91/165 randomized were not included in the analysis, including some 1-month group participants who requested further medication.

\begin{tabular}{|c|c|}
\hline Neumann 2002 & Bupropion - short-term follow-up. Comparison of $300 \mathrm{mg}$ and $150 \mathrm{mg}$ doses \\
\hline Niederhofer 2004 & Participants are required to be abstinent for at least five days prior to enrolment to trial \\
\hline Olmstead 1999 & Bupropion - all participants received bupropion. Short-term follow-up \\
\hline Paluck 2006 & Bupropion - uncontrolled prospective observational study \\
\hline Pomerleau 1991 & Fluoxetine - no cessation data reported \\
\hline Raynor 2005 & $\begin{array}{l}\text { Bupropion - short ( } 90 \text { day) follow-up. Substudy within a larger trial with long-term follow-up, not } \\
\text { yet published }\end{array}$ \\
\hline Robinson 1991 & Buspirone - case series \\
\hline Rovina 2003 & Bupropion - abstract only, trial report not available. Insufficient information to determine inclusion \\
\hline Schepis 2006 & Bupropion - abstract only, trial report not available. Insufficient information to determine inclusion \\
\hline Sellers 1987 & $\begin{array}{l}\text { Zimelidine or citalopram (SSRIs) - placebo-controlled cross-over design study of smoking behav- } \\
\text { iour and alcohol use in non-depressed heavy drinkers }\end{array}$ \\
\hline Sherman 2008 & Bupropion - trial of NRT as adjunct to bupropion \\
\hline Shiffman 2000 & $\begin{array}{l}\text { Bupropion - placebo-controlled short-term study of effects on craving and withdrawal in partici- } \\
\text { pants not wanting to quit smoking permanently }\end{array}$ \\
\hline Shoptaw 2008 & $\begin{array}{l}\text { Bupropion - tested for methamphetamine dependence. Reduction in smoking was a secondary } \\
\text { outcome. Only } 48 / 73 \text { participants smoked, quitting not reported. }\end{array}$ \\
\hline Sittipunt 2007 & Nortriptyline - only 3-month follow-up \\
\hline Sonntag 2003 & Bupropion - abstract only, trial report not available. Insufficient information to determine inclusion \\
\hline Spring 1995 & Fluoxetine - 6-month cessation not reported. Primarily a study of post-cessation weight gain \\
\hline Stein 1993 & Fluoxetine - does not report outcomes from a double-blind study \\
\hline Steinberg 2009 & $\begin{array}{l}\text { Bupropion - confounded with nicotine inhaler and treatment duration in comparison with nicotine } \\
\text { patch alone }\end{array}$ \\
\hline Strayer 2004 & $\begin{array}{l}\text { Bupropion - all participants prescribed bupropion. Test of behavioural interventions, not bupropi- } \\
\text { on. Adverse event data from author used }\end{array}$ \\
\hline Swanson 2003 & Bupropion +/- nicotine patch. Unable to confirm correct denominators \\
\hline Tidey 2009 & Bupropion - laboratory study, outcomes included urge to smoke, not cessation \\
\hline Toll 2007 & Bupropion - all participants had same pharmacotherapy \\
\hline Weinberger 2008 & Bupropion for people with bipolar disorder. Short follow-up ( 8 weeks). Only 5 participants \\
\hline
\end{tabular}




\begin{tabular}{ll}
\hline Study & Reason for exclusion \\
\hline Weiner 2001 & Bupropion - no control group \\
\hline Winhusen 2012 & Bupropion confounded by other agents \\
\hline Zernig 2008 & $\begin{array}{l}\text { Bupropion - used as an active control to a psychosocial intervention, cannot estimate pharma- } \\
\text { cotherapy effect }\end{array}$ \\
\hline ZYB30011 & Bupropion - follow-up only to end of treatment (7 weeks) \\
\hline
\end{tabular}

CBT: cognitive behavioural therapy; NRT: nicotine replacement therapy; CVD: cardiovascular disease; RCT: randomized controlled trial; SSRI: selective serotonin reuptake inhibitor

Characteristics of ongoing studies [ordered by study ID]

NCT03326128

\begin{tabular}{ll}
\hline Trial name or title & High dose bupropion for smoking cessation \\
\hline Methods & Triple-blind randomized trial \\
\hline Participants & 300 heavy smokers who also experience psychiatric symptoms \\
\hline Interventions & Bupropion $300 \mathrm{mg} 4$ weeks before and 4 weeks after TQD \\
& Bupropion $450 \mathrm{mg} 4$ weeks before and 4 weeks after TQD \\
& Common components: standard smoking cessation counselling for 8 weeks \\
\hline Outcomes & $\begin{array}{l}\text { Smoking cessation: point prevalence abstinence at } 26 \text { weeks post-quit date. Validated by self- } \\
\text { report }\end{array}$ \\
& Self report of smoking status \\
\hline
\end{tabular}

\begin{tabular}{ll}
\hline Starting date & May 2019 \\
\hline Contact information & Lauren Whitted, 323-442-1197, Iwhitted@usc.edulwhitted@usc.edu
\end{tabular}

Notes

\section{NCT03342027}

\begin{tabular}{ll}
\hline Trial name or title & Smoking cessation interventions for people living with HIV in Nairobi, Kenya \\
\hline Methods & $2 \times 2$ factorial, double-blind randomized controlled trial \\
\hline Participants & $\begin{array}{l}300 \text { participants people living with HIV, who smoke and who are receiving care in a methadone } \\
\text { maintenance program will be randomized }\end{array}$ \\
\hline Interventions & Bupropion and positively smoke free (an 8-session tailored behavioural intervention for smokers \\
& living with HIV) \\
& Bupropion and standard of care (brief advice to quit) \\
& Placebo and positively smoke free \\
\hline
\end{tabular}


NCT03342027 (Continued)

Outcomes

Smoking cessation: 7-day point prevalence abstinence at 36 weeks. Validated by expired $\mathrm{CO}<7$ ppm

Starting date

20 August 2019

Contact information

Wendy Potts, (410) 706-2490,wpotts@som.umaryland.edu

Notes

Zawertailo 2018

\begin{tabular}{ll}
\hline Trial name or title & The Medication Aids for Tobacco Cessation and Health (MATCH) Study \\
\hline Methods & Randomized, open-label, parallel-arm trial \\
\hline Participants & 968 smokers motivated to quit \\
\hline Interventions & $\begin{array}{l}\text { Bupropion } 150 \mathrm{mg} \text { once daily for first three days, then twice daily for the remainder of } 12 \text { weeks. } \\
\text { Starting } 7 \text { days prior to TQD }\end{array}$ \\
& $\begin{array}{l}\text { Varenicline } 0.5 \mathrm{mg} \text { mg twice daily for the remainder of } 12 \text { weeks. Starting } 7 \text { days prior to TQD } \\
\text { Common components: weekly motivational emails }\end{array}$ \\
\hline Outcomes & Smoking cessation: continuous abstinence at 52 weeks. Validated by saliva cotinine \\
\hline Starting date & 1 May 2014 \\
\hline Contact information & Laurie Zawertailo, 14165358501 ext 77422, laurie.zawertailo@camh.ca \\
\hline Notes &
\end{tabular}

TQD: target quit date

DATA AND ANALYSES

Comparison 1. Bupropion versus placebo/no pharmacotherapy control

\begin{tabular}{lllll}
\hline Outcome or subgroup title & $\begin{array}{l}\text { No. of } \\
\text { studies }\end{array}$ & $\begin{array}{l}\text { No. of } \\
\text { partici- } \\
\text { pants }\end{array}$ & Statistical method & Effect size \\
\hline 1 Smoking cessation & 46 & 17866 & Risk Ratio (M-H, Fixed, 95\% Cl) & $1.64[1.52,1.77]$ \\
\hline $\begin{array}{l}\text { 2 Smoking cessation - subgroup by lev- } \\
\text { el of behavioural support }\end{array}$ & 46 & 17866 & Risk Ratio (M-H, Fixed, 95\% Cl) & $1.64[1.52,1.77]$ \\
\hline $\begin{array}{l}2.1 \text { Multisession group behavioural } \\
\text { support }\end{array}$ & 10 & 2001 & Risk Ratio (M-H, Fixed, 95\% Cl) & $1.76[1.44,2.16]$ \\
\hline \begin{tabular}{l}
2.2 Multisession individual counselling \\
\hline
\end{tabular} & 31 & 15033 & Risk Ratio (M-H, Fixed, 95\% Cl) & $1.63[1.50,1.77]$ \\
\hline
\end{tabular}




\begin{tabular}{|c|c|c|c|c|}
\hline Outcome or subgroup title & $\begin{array}{l}\text { No. of } \\
\text { studies }\end{array}$ & $\begin{array}{l}\text { No. of } \\
\text { partici- } \\
\text { pants }\end{array}$ & Statistical method & Effect size \\
\hline 2.3 Low-intensity support & 1 & 47 & Risk Ratio (M-H, Fixed, 95\% Cl) & $2.88[0.32,25.68]$ \\
\hline 2.4 Not specified & 4 & 785 & Risk Ratio (M-H, Fixed, 95\% Cl) & $1.42[1.00,2.00]$ \\
\hline $\begin{array}{l}3 \text { Smoking cessation - subgroup by } \\
\text { mental health disorders }\end{array}$ & 46 & 17866 & Risk Ratio (M-H, Fixed, 95\% Cl) & $1.64[1.52,1.77]$ \\
\hline 3.1 Psychiatric conditions & 5 & 2180 & Risk Ratio (M-H, Fixed, 95\% Cl) & $1.67[1.30,2.15]$ \\
\hline 3.2 Non-psychiatric & 42 & 15686 & Risk Ratio (M-H, Fixed, 95\% Cl) & $1.63[1.51,1.77]$ \\
\hline 4 Adverse events & 19 & 10893 & Risk Ratio (M-H, Fixed, 95\% Cl) & $1.14[1.11,1.18]$ \\
\hline 5 Serious adverse events & 21 & 10625 & Risk Ratio (M-H, Fixed, 95\% Cl) & $1.16[0.90,1.48]$ \\
\hline 6 Psychiatric adverse events & 6 & 4439 & Risk Ratio (M-H, Fixed, 95\% Cl) & $1.25[1.15,1.37]$ \\
\hline 7 Seizures & 13 & 7344 & Risk Ratio (M-H, Fixed, 95\% Cl) & $2.93[0.64,13.37]$ \\
\hline 8 Overdoses & 5 & 5585 & Risk Ratio (M-H, Fixed, 95\% Cl) & $2.15[0.23,19.86]$ \\
\hline 9 Suicide attempts & 10 & 6484 & Risk Ratio (M-H, Fixed, 95\% Cl) & $1.62[0.29,8.92]$ \\
\hline 10 Death by suicide & 14 & 8822 & Risk Ratio (M-H, Fixed, 95\% Cl) & $0.34[0.01,8.26]$ \\
\hline 11 All-cause mortality & 21 & 11403 & Risk Ratio (M-H, Fixed, 95\% Cl) & $0.89[0.42,1.87]$ \\
\hline 12 Anxiety & 11 & 7406 & Risk Ratio (M-H, Fixed, 95\% Cl) & $1.42[1.21,1.67]$ \\
\hline 13 Insomnia & 22 & 11077 & Risk Ratio (M-H, Fixed, 95\% Cl) & $1.78[1.62,1.96]$ \\
\hline 14 Dropouts due to drug & 25 & 12340 & Risk Ratio (M-H, Fixed, 95\% Cl) & $1.37[1.21,1.56]$ \\
\hline
\end{tabular}

Analysis 1.1. Comparison 1 Bupropion versus placebo/no pharmacotherapy control, Outcome 1 Smoking cessation.

\begin{tabular}{|c|c|c|c|c|c|}
\hline Study or subgroup & $\begin{array}{c}\text { Bupropion } \\
\mathrm{n} / \mathrm{N} \\
\end{array}$ & $\begin{array}{c}\text { Control } \\
n / N\end{array}$ & $\begin{array}{c}\text { Risk Ratio } \\
\text { M-H, Fixed, 95\% Cl }\end{array}$ & Weight & $\begin{array}{c}\text { Risk Ratio } \\
\text { M-H, Fixed, 95\% Cl }\end{array}$ \\
\hline Ahluwalia 2002 & $37 / 300$ & $19 / 300$ & $\longrightarrow$ & $1.98 \%$ & $1.95[1.15,3.31]$ \\
\hline Anthenelli 2016 & $330 / 2034$ & $191 / 2035$ & 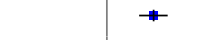 & $19.94 \%$ & $1.73[1.46,2.04]$ \\
\hline Aubin 2004 & $85 / 340$ & $21 / 164$ & 1 & $2.96 \%$ & $1.95[1.26,3.03]$ \\
\hline Brown 2007 & $38 / 255$ & $27 / 269$ & 1 & $2.74 \%$ & $1.48[0.93,2.36]$ \\
\hline Cinciripini 2013 & $23 / 102$ & $15 / 106$ & t & $1.54 \%$ & $1.59[0.88,2.88]$ \\
\hline Cox 2012 & $36 / 270$ & $27 / 270$ & 1 & $2.82 \%$ & $1.33[0.83,2.13]$ \\
\hline Dalsgarð 2004 & $40 / 221$ & $8 / 114$ & 1 & $1.1 \%$ & $2.58[1.25,5.32]$ \\
\hline Eisenberg 2013 & $49 / 183$ & $43 / 194$ & 1 & $4.36 \%$ & $1.21[0.85,1.73]$ \\
\hline Evins 2001 & $1 / 9$ & $0 / 9$ & & $0.05 \%$ & $3[0.14,65.16]$ \\
\hline Evins 2005 & $1 / 27$ & $1 / 29$ & & $0.1 \%$ & $1.07[0.07,16.33]$ \\
\hline Ferry 1992 & $10 / 23$ & $0 / 22$ & & $0.05 \%$ & $20.13[1.25,324]$ \\
\hline
\end{tabular}




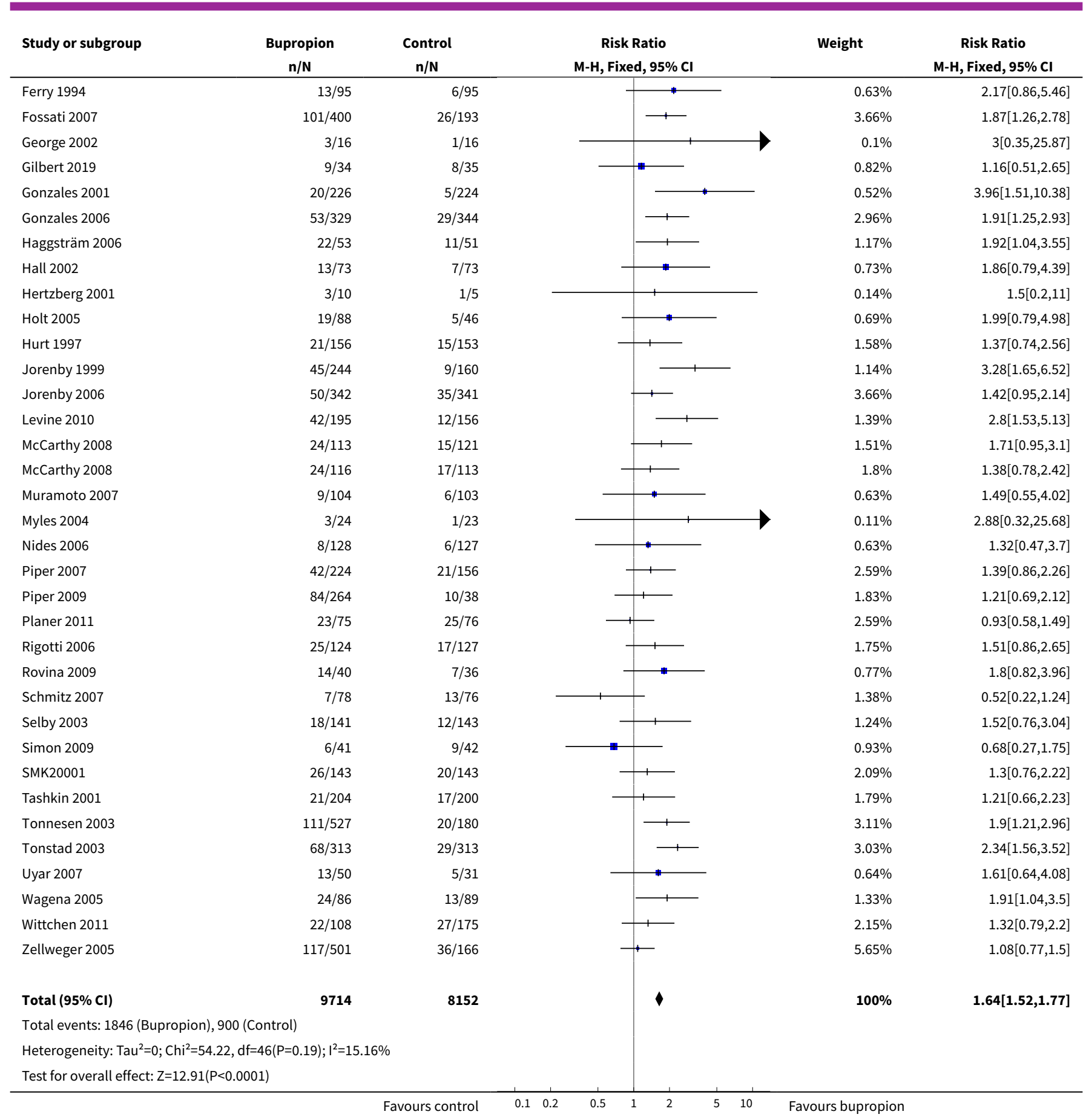

Analysis 1.2. Comparison 1 Bupropion versus placebo/no pharmacotherapy control, Outcome 2 Smoking cessation - subgroup by level of behavioural support.

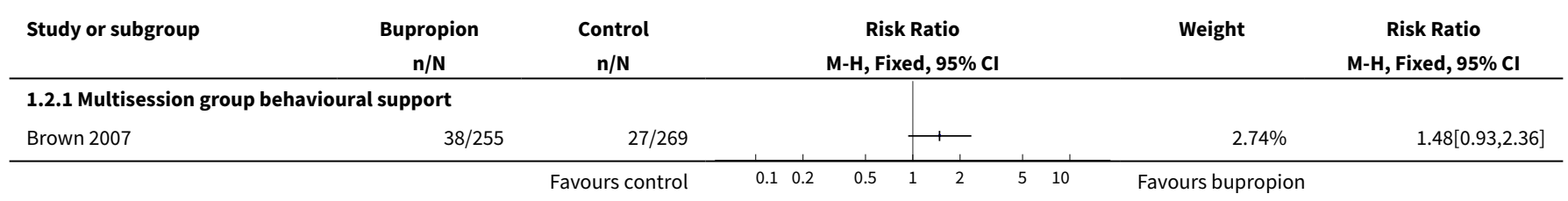




\begin{tabular}{|c|c|c|c|c|c|c|c|c|}
\hline \multirow{2}{*}{$\begin{array}{l}\text { Study or subgroup } \\
\text { Collins } 2004\end{array}$} & \multirow{2}{*}{$\begin{array}{l}\begin{array}{c}\text { Bupropion } \\
\mathbf{n} / \mathbf{N}\end{array} \\
93 / 285\end{array}$} & \multirow{2}{*}{$\begin{array}{l}\text { Control } \\
\text { n/N } \\
52 / 270\end{array}$} & \multicolumn{3}{|c|}{$\begin{array}{c}\text { Risk Ratio } \\
\text { M-H, Fixed, 95\% Cl }\end{array}$} & & \multirow{2}{*}{$\begin{array}{l}\text { Weight } \\
5.58 \%\end{array}$} & \multirow{2}{*}{$\begin{array}{c}\text { Risk Ratio } \\
\text { M-H, Fixed, 95\% Cl } \\
1.69[1.26,2.28]\end{array}$} \\
\hline & & & & & $\rightarrow$ & & & \\
\hline Evins 2001 & $1 / 9$ & $0 / 9$ & & & & & $0.05 \%$ & $3[0.14,65.16]$ \\
\hline Evins 2005 & $1 / 27$ & $1 / 29$ & & & & & $0.1 \%$ & $1.07[0.07,16.33]$ \\
\hline Ferry 1992 & $10 / 23$ & $0 / 22$ & & & & & $0.05 \%$ & $20.13[1.25,324]$ \\
\hline Ferry 1994 & $13 / 95$ & $6 / 95$ & & & $\longrightarrow$ & & $0.63 \%$ & $2.17[0.86,5.46]$ \\
\hline George 2002 & $3 / 16$ & $1 / 16$ & & & & & $0.1 \%$ & $3[0.35,25.87]$ \\
\hline Levine 2010 & $42 / 195$ & $12 / 156$ & & & 1 & - & $1.39 \%$ & $2.8[1.53,5.13]$ \\
\hline Rovina 2009 & $14 / 40$ & $7 / 36$ & & & 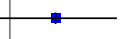 & & $0.77 \%$ & $1.8[0.82,3.96]$ \\
\hline Schmitz 2007 & $7 / 78$ & $13 / 76$ & & & - & & $1.38 \%$ & $0.52[0.22,1.24]$ \\
\hline Subtotal $(95 \% \mathrm{Cl})$ & 1023 & 978 & & & & & $12.8 \%$ & $1.76[1.44,2.16]$ \\
\hline \multicolumn{9}{|c|}{ Total events: 222 (Bupropion), 119 (Control) } \\
\hline \multicolumn{9}{|c|}{ Heterogeneity: $\mathrm{Tau}^{2}=0 ; \mathrm{Chi}^{2}=14.03, \mathrm{df}=9(\mathrm{P}=0.12) ; \mathrm{I}^{2}=35.85 \%$} \\
\hline \multicolumn{9}{|c|}{ Test for overall effect: $Z=5.47(P<0.0001)$} \\
\hline \multicolumn{9}{|c|}{ 1.2.2 Multisession individual counselling } \\
\hline Ahluwalia 2002 & $37 / 300$ & $19 / 300$ & & & 1 & & $1.98 \%$ & $1.95[1.15,3.31]$ \\
\hline Anthenelli 2016 & $330 / 2034$ & $191 / 2035$ & & & $\rightarrow$ & & $19.94 \%$ & $1.73[1.46,2.04]$ \\
\hline Aubin 2004 & $85 / 340$ & $21 / 164$ & & & $\longrightarrow$ & & $2.96 \%$ & $1.95[1.26,3.03]$ \\
\hline Cinciripini 2013 & $23 / 102$ & $15 / 106$ & & & 1 & & $1.54 \%$ & $1.59[0.88,2.88]$ \\
\hline Cox 2012 & $36 / 270$ & $27 / 270$ & & & 1 & & $2.82 \%$ & $1.33[0.83,2.13]$ \\
\hline Dalsgarð 2004 & $40 / 221$ & $8 / 114$ & & & $\longrightarrow$ & - & $1.1 \%$ & $2.58[1.25,5.32]$ \\
\hline Eisenberg 2013 & $49 / 183$ & $43 / 194$ & & & 1 & & $4.36 \%$ & $1.21[0.85,1.73]$ \\
\hline Fossati 2007 & $101 / 400$ & $26 / 193$ & & & $\longrightarrow$ & & $3.66 \%$ & $1.87[1.26,2.78]$ \\
\hline Gonzales 2001 & $20 / 226$ & $5 / 224$ & & & 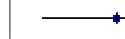 & - & $0.52 \%$ & $3.96[1.51,10.38]$ \\
\hline Gonzales 2006 & $53 / 329$ & $29 / 344$ & & & 1 & & $2.96 \%$ & $1.91[1.25,2.93]$ \\
\hline Haggsträm 2006 & $22 / 53$ & $11 / 51$ & & & 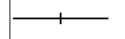 & & $1.17 \%$ & $1.92[1.04,3.55]$ \\
\hline Hertzberg 2001 & $3 / 10$ & $1 / 5$ & & & & & $0.14 \%$ & $1.5[0.2,11]$ \\
\hline Holt 2005 & $19 / 88$ & $5 / 46$ & & & 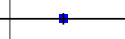 & & $0.69 \%$ & $1.99[0.79,4.98]$ \\
\hline Hurt 1997 & $21 / 156$ & $15 / 153$ & & & + & & $1.58 \%$ & $1.37[0.74,2.56]$ \\
\hline Jorenby 1999 & $45 / 244$ & $9 / 160$ & & & $\longrightarrow$ & - & $1.14 \%$ & $3.28[1.65,6.52]$ \\
\hline Jorenby 2006 & $50 / 342$ & $35 / 341$ & & & 1 & & $3.66 \%$ & $1.42[0.95,2.14]$ \\
\hline McCarthy 2008 & $24 / 116$ & $17 / 113$ & & & 1 & & $1.8 \%$ & $1.38[0.78,2.42]$ \\
\hline McCarthy 2008 & $24 / 113$ & $15 / 121$ & & & & & $1.51 \%$ & $1.71[0.95,3.1]$ \\
\hline Muramoto 2007 & $9 / 104$ & $6 / 103$ & & & $*$ & & $0.63 \%$ & $1.49[0.55,4.02]$ \\
\hline Nides 2006 & $8 / 128$ & $6 / 127$ & & & & & $0.63 \%$ & $1.32[0.47,3.7]$ \\
\hline Piper 2007 & $42 / 224$ & $21 / 156$ & & & 1 & & $2.59 \%$ & $1.39[0.86,2.26]$ \\
\hline Piper 2009 & $84 / 264$ & $10 / 38$ & & & 1 & & $1.83 \%$ & $1.21[0.69,2.12]$ \\
\hline Planer 2011 & $23 / 75$ & $25 / 76$ & & & - & & $2.59 \%$ & $0.93[0.58,1.49]$ \\
\hline Rigotti 2006 & $25 / 124$ & $17 / 127$ & & & 1 & & $1.75 \%$ & $1.51[0.86,2.65]$ \\
\hline Simon 2009 & $6 / 41$ & $9 / 42$ & & 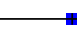 & - & & $0.93 \%$ & $0.68[0.27,1.75]$ \\
\hline Tashkin 2001 & $21 / 204$ & $17 / 200$ & & & + & & $1.79 \%$ & $1.21[0.66,2.23]$ \\
\hline Tonnesen 2003 & $111 / 527$ & $20 / 180$ & & & 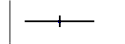 & & $3.11 \%$ & $1.9[1.21,2.96]$ \\
\hline Tonstad 2003 & $68 / 313$ & $29 / 313$ & & & 1 & & $3.03 \%$ & $2.34[1.56,3.52]$ \\
\hline Uyar 2007 & $13 / 50$ & $5 / 31$ & & & $\longrightarrow$ & & $0.64 \%$ & $1.61[0.64,4.08]$ \\
\hline Wagena 2005 & $24 / 86$ & $13 / 89$ & & & 1 & & $1.33 \%$ & $1.91[1.04,3.5]$ \\
\hline Wittchen 2011 & $22 / 108$ & $27 / 175$ & & & + & & $2.15 \%$ & $1.32[0.79,2.2]$ \\
\hline Zellweger 2005 & $117 / 501$ & $36 / 166$ & & & + & & $5.65 \%$ & $1.08[0.77,1.5]$ \\
\hline Subtotal $(95 \% \mathrm{Cl})$ & 8276 & 6757 & & & $\diamond$ & & $82.21 \%$ & $1.63[1.5,1.77]$ \\
\hline \multicolumn{9}{|c|}{ Total events: 1555 (Bupropion), 733 (Control) } \\
\hline \multicolumn{9}{|c|}{ Heterogeneity: $\mathrm{Tau}^{2}=0 ; \mathrm{Chi}^{2}=38.32, \mathrm{df}=31(\mathrm{P}=0.17) ; \mathrm{I}^{2}=19.1 \%$} \\
\hline \multicolumn{9}{|c|}{ Test for overall effect: $Z=11.55(P<0.0001)$} \\
\hline & & Favours control & 0.10 .2 & 0.5 & 2 & $5 \quad 10$ & Favours bupropion & \\
\hline
\end{tabular}




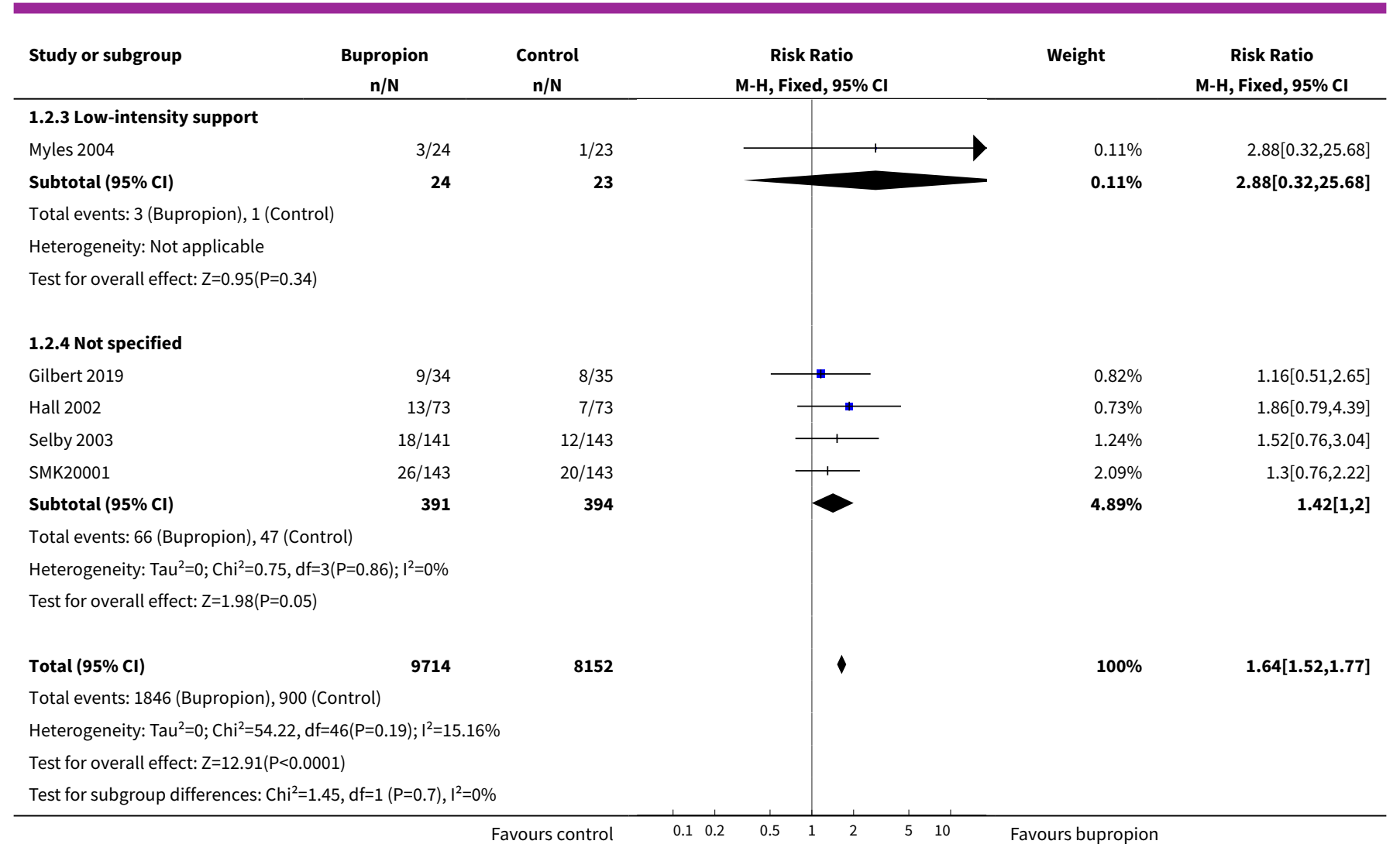

Analysis 1.3. Comparison 1 Bupropion versus placebo/no pharmacotherapy control, Outcome 3 Smoking cessation - subgroup by mental health disorders.

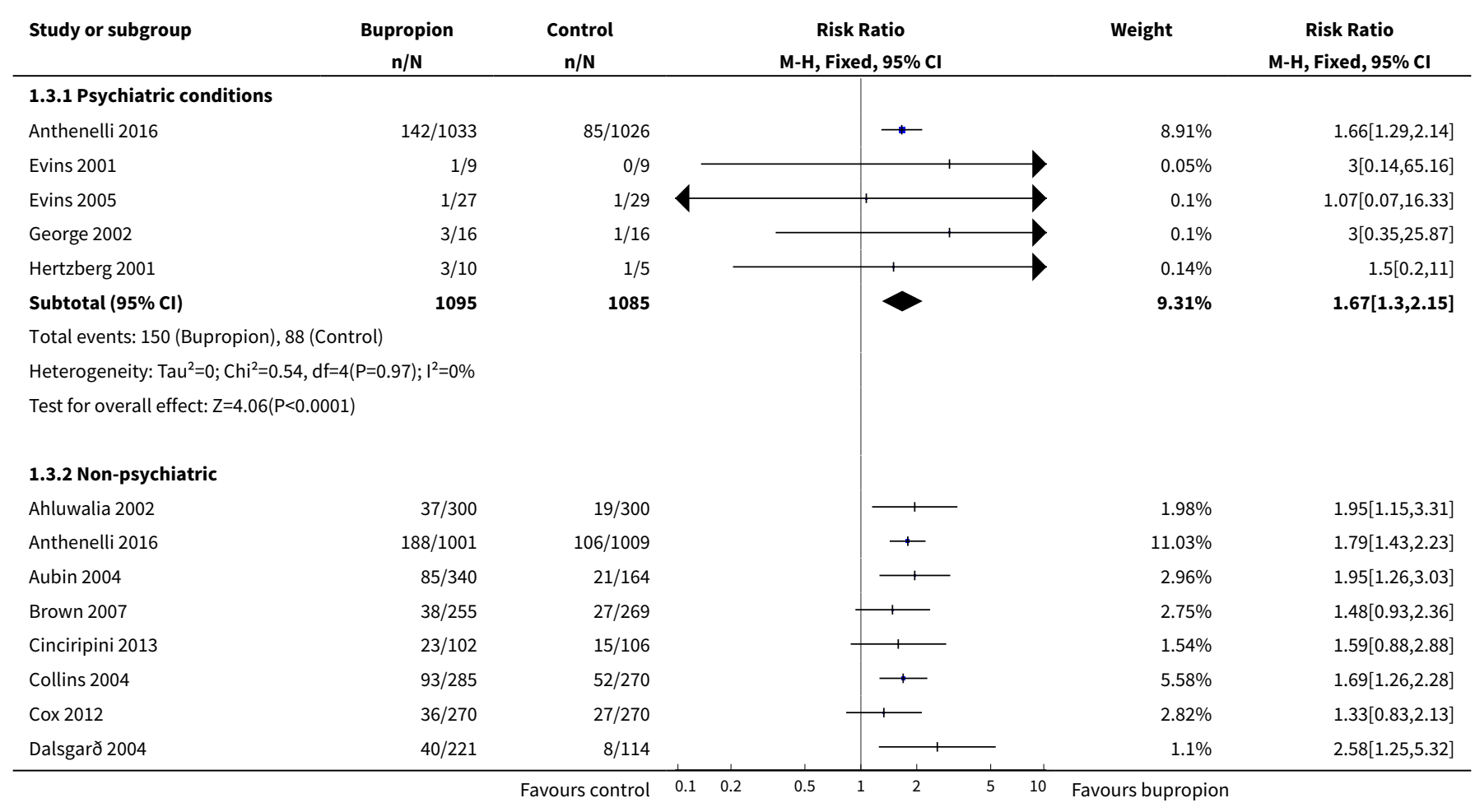




\begin{tabular}{|c|c|c|c|c|c|}
\hline Study or subgroup & $\begin{array}{c}\text { Bupropion } \\
\mathrm{n} / \mathrm{N}\end{array}$ & $\begin{array}{c}\text { Control } \\
n / N\end{array}$ & $\begin{array}{c}\text { Risk Ratio } \\
\text { M-H, Fixed, 95\% CI }\end{array}$ & Weight & $\begin{array}{c}\text { Risk Ratio } \\
\text { M-H, Fixed, } 95 \% \text { CI }\end{array}$ \\
\hline Eisenberg 2013 & $49 / 183$ & $43 / 194$ & 1 & $4.36 \%$ & $1.21[0.85,1.73]$ \\
\hline Ferry 1992 & $10 / 23$ & $0 / 22$ & - & $0.05 \%$ & $20.13[1.25,324]$ \\
\hline Ferry 1994 & $13 / 95$ & $6 / 95$ & & $0.63 \%$ & $2.17[0.86,5.46]$ \\
\hline Fossati 2007 & $101 / 400$ & $26 / 193$ & 1 & $3.66 \%$ & $1.87[1.26,2.78]$ \\
\hline Gilbert 2019 & $9 / 34$ & $8 / 35$ & $\div$ & $0.82 \%$ & $1.16[0.51,2.65]$ \\
\hline Gonzales 2001 & $20 / 226$ & $5 / 224$ & & $0.52 \%$ & $3.96[1.51,10.38]$ \\
\hline Gonzales 2006 & $53 / 329$ & $29 / 344$ & 1 & $2.96 \%$ & $1.91[1.25,2.93]$ \\
\hline Haggsträm 2006 & $22 / 53$ & $11 / 51$ & 1 & $1.17 \%$ & $1.92[1.04,3.55]$ \\
\hline Hall 2002 & $13 / 73$ & $7 / 73$ & & $0.73 \%$ & $1.86[0.79,4.39]$ \\
\hline Holt 2005 & $19 / 88$ & $5 / 46$ & $\longrightarrow$ & $0.69 \%$ & $1.99[0.79,4.98]$ \\
\hline Hurt 1997 & $21 / 156$ & $15 / 153$ & \begin{tabular}{l|l} 
& 1
\end{tabular} & $1.58 \%$ & $1.37[0.74,2.56]$ \\
\hline Jorenby 1999 & $45 / 244$ & $9 / 160$ & & $1.14 \%$ & $3.28[1.65,6.52]$ \\
\hline Jorenby 2006 & $50 / 342$ & $35 / 341$ & 1 & $3.66 \%$ & $1.42[0.95,2.14]$ \\
\hline Levine 2010 & $42 / 195$ & $12 / 156$ & & $1.39 \%$ & $2.8[1.53,5.13]$ \\
\hline McCarthy 2008 & $48 / 229$ & $32 / 234$ & 1 & $3.31 \%$ & $1.53[1.02,2.31]$ \\
\hline Muramoto 2007 & $9 / 104$ & $6 / 103$ & 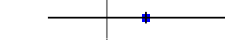 & $0.63 \%$ & $1.49[0.55,4.02]$ \\
\hline Myles 2004 & $3 / 24$ & $1 / 23$ & & $0.11 \%$ & $2.88[0.32,25.68]$ \\
\hline Nides 2006 & $8 / 128$ & $6 / 127$ & $\longrightarrow$ & $0.63 \%$ & $1.32[0.47,3.7]$ \\
\hline Piper 2007 & $42 / 224$ & $21 / 156$ & 1 & $2.59 \%$ & $1.39[0.86,2.26]$ \\
\hline Piper 2009 & $84 / 264$ & $10 / 38$ & & $1.83 \%$ & $1.21[0.69,2.12]$ \\
\hline Planer 2011 & $23 / 75$ & $25 / 76$ & - & $2.59 \%$ & $0.93[0.58,1.49]$ \\
\hline Rigotti 2006 & $25 / 124$ & $17 / 127$ & 1 & $1.75 \%$ & $1.51[0.86,2.65]$ \\
\hline Rovina 2009 & $14 / 40$ & $7 / 36$ & $\longrightarrow$ & $0.77 \%$ & $1.8[0.82,3.96]$ \\
\hline Schmitz 2007 & $7 / 78$ & $13 / 76$ & - & $1.38 \%$ & $0.52[0.22,1.24]$ \\
\hline Selby 2003 & $18 / 141$ & $12 / 143$ & 1 & $1.24 \%$ & $1.52[0.76,3.04]$ \\
\hline Simon 2009 & $6 / 41$ & $9 / 42$ & $\rightarrow-$ & $0.93 \%$ & $0.68[0.27,1.75]$ \\
\hline SMK20001 & $26 / 143$ & $20 / 143$ & & $2.09 \%$ & $1.3[0.76,2.22]$ \\
\hline Tashkin 2001 & $21 / 204$ & $17 / 200$ & + & $1.79 \%$ & $1.21[0.66,2.23]$ \\
\hline Tonnesen 2003 & $111 / 527$ & $20 / 180$ & 1 & $3.11 \%$ & $1.9[1.21,2.96]$ \\
\hline Tonstad 2003 & $68 / 313$ & $29 / 313$ & & $3.03 \%$ & $2.34[1.56,3.52]$ \\
\hline Uyar 2007 & $13 / 50$ & $5 / 31$ & - & $0.64 \%$ & $1.61[0.64,4.08]$ \\
\hline Wagena 2005 & $24 / 86$ & $13 / 89$ & 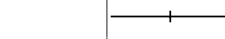 & $1.33 \%$ & $1.91[1.04,3.5]$ \\
\hline Wittchen 2011 & $22 / 108$ & $27 / 175$ & 1 & $2.15 \%$ & $1.32[0.79,2.2]$ \\
\hline Zellweger 2005 & $117 / 501$ & $36 / 166$ & $\rightarrow$ & $5.65 \%$ & $1.08[0.77,1.5]$ \\
\hline Subtotal $(95 \% \mathrm{Cl})$ & 8619 & 7067 & $\diamond$ & $90.69 \%$ & $1.63[1.51,1.77]$ \\
\hline \multicolumn{6}{|c|}{ Total events: 1696 (Bupropion), 812 (Control) } \\
\hline \multicolumn{6}{|c|}{ Heterogeneity: $\mathrm{Tau}^{2}=0 ; \mathrm{Chi}^{2}=53.52, \mathrm{df}=41(\mathrm{P}=0.09) ; \mathrm{I}^{2}=23.39 \%$} \\
\hline \multicolumn{6}{|c|}{ Test for overall effect: $Z=12.27(P<0.0001)$} \\
\hline Total $(95 \% \mathrm{Cl})$ & 9714 & 8152 & $\diamond$ & $100 \%$ & $1.64[1.52,1.77]$ \\
\hline \multicolumn{6}{|c|}{ Total events: 1846 (Bupropion), 900 (Control) } \\
\hline \multicolumn{6}{|c|}{ Heterogeneity: $\mathrm{Tau}^{2}=0 ; \mathrm{Chi}^{2}=54.15, \mathrm{df}=46(\mathrm{P}=0.19) ; \mathrm{I}^{2}=15.05 \%$} \\
\hline \multicolumn{6}{|c|}{ Test for overall effect: $Z=12.92(P<0.0001)$} \\
\hline Test for subgroup dif & $3, d f=1(P=0.86)$, & & & & \\
\hline
\end{tabular}


Analysis 1.4. Comparison 1 Bupropion versus placebo/no pharmacotherapy control, Outcome 4 Adverse events.

\begin{tabular}{|c|c|c|c|c|c|}
\hline Study or subgroup & $\begin{array}{c}\text { Bupropion } \\
\mathrm{n} / \mathrm{N} \\
\end{array}$ & $\begin{array}{c}\text { Control } \\
\mathrm{n} / \mathrm{N}\end{array}$ & $\begin{array}{c}\text { Risk Ratio } \\
\text { M-H, Fixed, 95\% Cl }\end{array}$ & Weight & $\begin{array}{c}\text { Risk Ratio } \\
\text { M-H, Fixed, 95\% Cl }\end{array}$ \\
\hline Anthenelli 2016 & $704 / 989$ & $649 / 999$ & - & $21.7 \%$ & $1.1[1.03,1.16]$ \\
\hline Anthenelli 2016 & $742 / 1017$ & $696 / 1015$ & 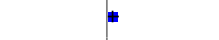 & $23.42 \%$ & $1.06[1.01,1.13]$ \\
\hline Aubin 2004 & $208 / 340$ & $74 / 164$ & + & $3.36 \%$ & $1.36[1.12,1.64]$ \\
\hline Cinciripini 2013 & $82 / 102$ & $84 / 106$ & + & $2.77 \%$ & $1.01[0.88,1.16]$ \\
\hline Cox 2012 & $80 / 270$ & $64 / 270$ & 1 & $2.15 \%$ & $1.25[0.94,1.66]$ \\
\hline Gilbert 2019 & $21 / 34$ & $19 / 35$ & $\longrightarrow$ & $0.63 \%$ & $1.14[0.76,1.7]$ \\
\hline Gonzales 2001 & $162 / 226$ & $131 / 224$ & + & $4.42 \%$ & $1.23[1.07,1.41]$ \\
\hline Gonzales 2006 & $258 / 329$ & $257 / 344$ & * & $8.45 \%$ & $1.05[0.97,1.14]$ \\
\hline Gray 2011 & $47 / 73$ & $29 / 61$ & 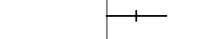 & $1.06 \%$ & $1.35[0.99,1.85]$ \\
\hline Kalman 2011 & $7 / 73$ & $2 / 70$ & 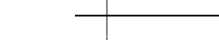 & $0.07 \%$ & $3.36[0.72,15.61]$ \\
\hline McCarthy 2008 & $102 / 229$ & $75 / 234$ & 1 & $2.49 \%$ & $1.39[1.1,1.76]$ \\
\hline Simon 2009 & $11 / 42$ & $4 / 43$ & 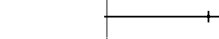 & $0.13 \%$ & $2.82[0.97,8.15]$ \\
\hline SMK20001 & $129 / 143$ & $119 / 143$ & + & $4 \%$ & $1.08[0.99,1.19]$ \\
\hline Tashkin 2001 & $90 / 204$ & $60 / 200$ & 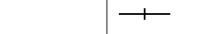 & $2.04 \%$ & $1.47[1.13,1.91]$ \\
\hline Tidey 2011 & $7 / 23$ & $2 / 29$ & & $0.06 \%$ & $4.41[1.01,19.25]$ \\
\hline Tonnesen 2003 & $395 / 527$ & $117 / 180$ & + & $5.86 \%$ & $1.15[1.02,1.3]$ \\
\hline Tonstad 2003 & $201 / 313$ & $181 / 313$ & + & $6.08 \%$ & $1.11[0.98,1.26]$ \\
\hline Zellweger 2005 & $379 / 518$ & $105 / 169$ & + & $5.32 \%$ & $1.18[1.04,1.34]$ \\
\hline Total $(95 \% \mathrm{Cl})$ & 5978 & 4915 & 1 & $100 \%$ & $1.14[1.11,1.18]$ \\
\hline \multicolumn{6}{|c|}{ Total events: 3917 (Bupropion), 2827 (Control) } \\
\hline \multicolumn{6}{|c|}{ Heterogeneity: $\mathrm{Tau}^{2}=0 ; \mathrm{Chi}^{2}=51.53, \mathrm{df}=19(\mathrm{P}<0.0001) ; \mathrm{I}^{2}=63.13 \%$} \\
\hline \multicolumn{6}{|c|}{ Test for overall effect: $Z=8.99(P<0.0001)$} \\
\hline
\end{tabular}

Analysis 1.5. Comparison 1 Bupropion versus placebo/no pharmacotherapy control, Outcome 5 Serious adverse events.

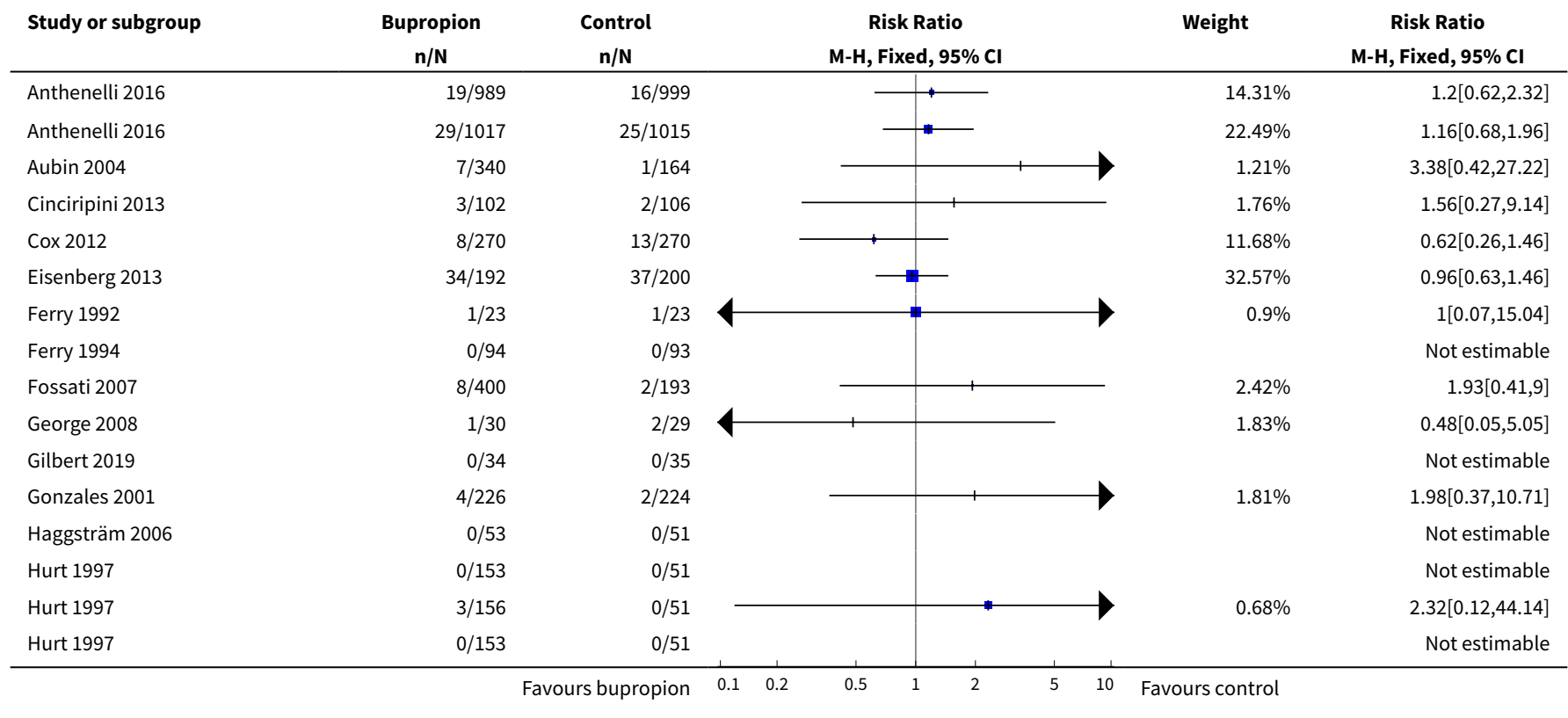




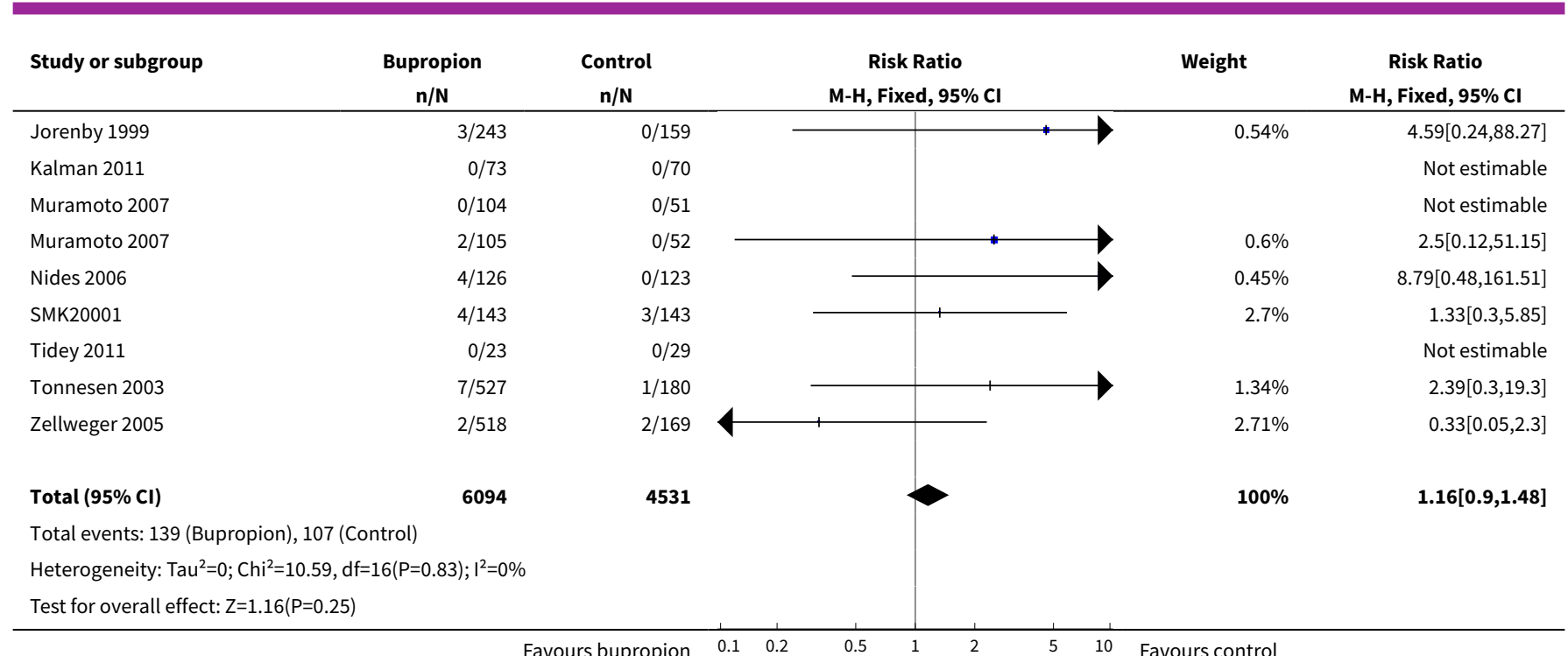

$\begin{array}{lllllllll}\text { Favours bupropion } & 0.1 & 0.2 & 0.5 & 1 & 2 & 5 & 10 & \text { Favours control }\end{array}$

Analysis 1.6. Comparison 1 Bupropion versus placebo/no pharmacotherapy control, Outcome 6 Psychiatric adverse events.

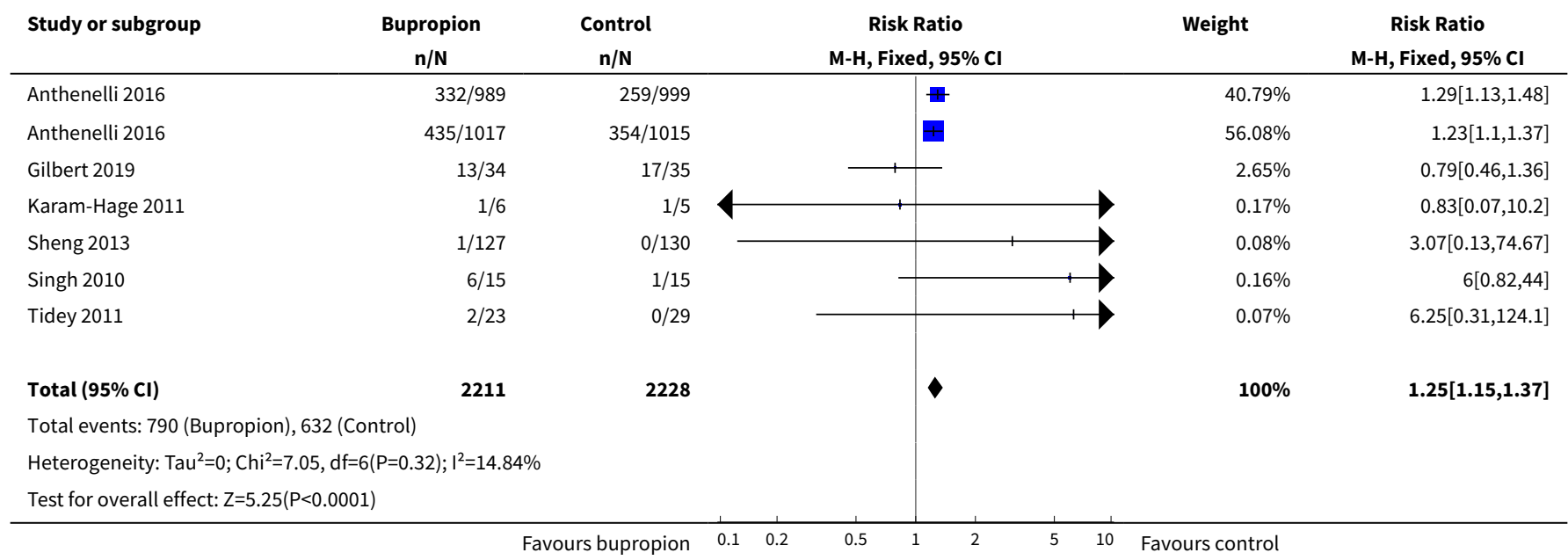

Analysis 1.7. Comparison 1 Bupropion versus placebo/no pharmacotherapy control, Outcome 7 Seizures.

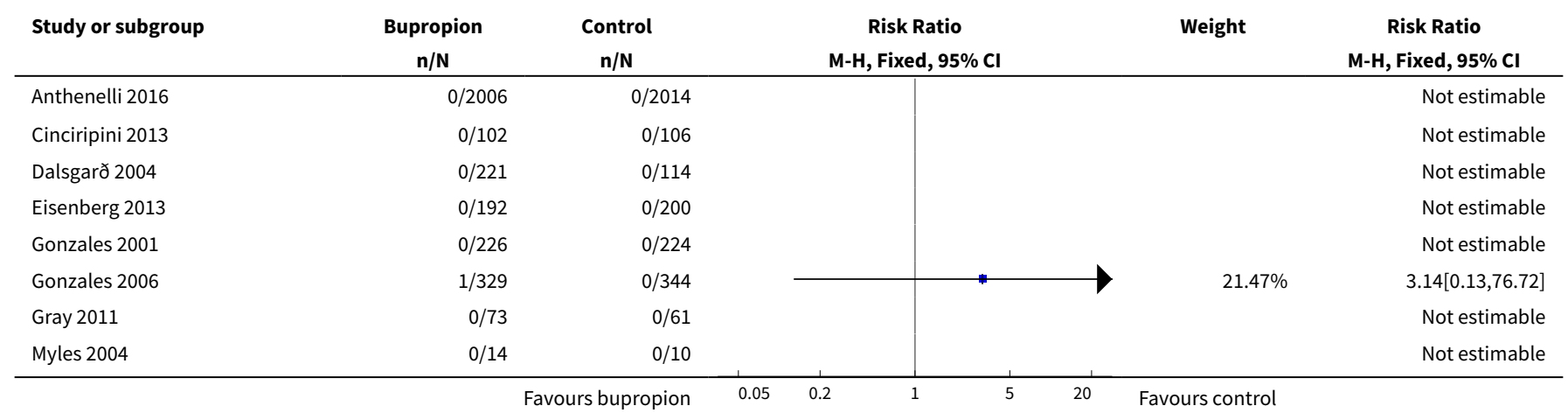




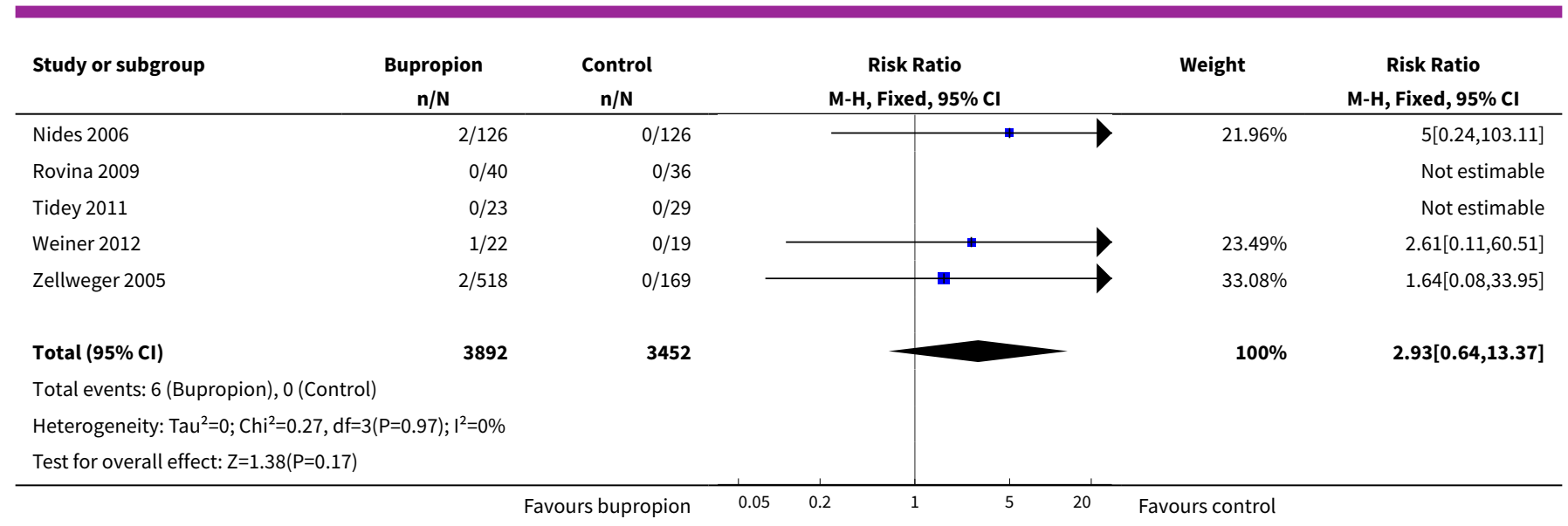

\section{Analysis 1.8. Comparison 1 Bupropion versus placebo/no pharmacotherapy control, Outcome 8 Overdoses.}

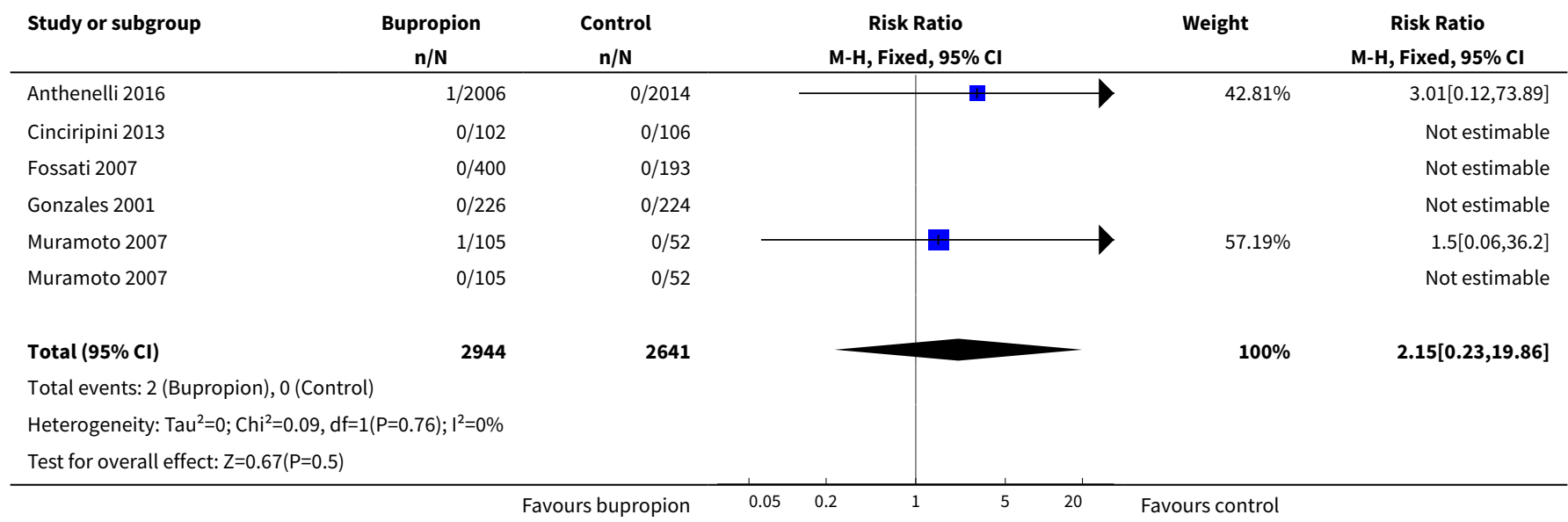

Analysis 1.9. Comparison 1 Bupropion versus placebo/no pharmacotherapy control, Outcome 9 Suicide attempts.

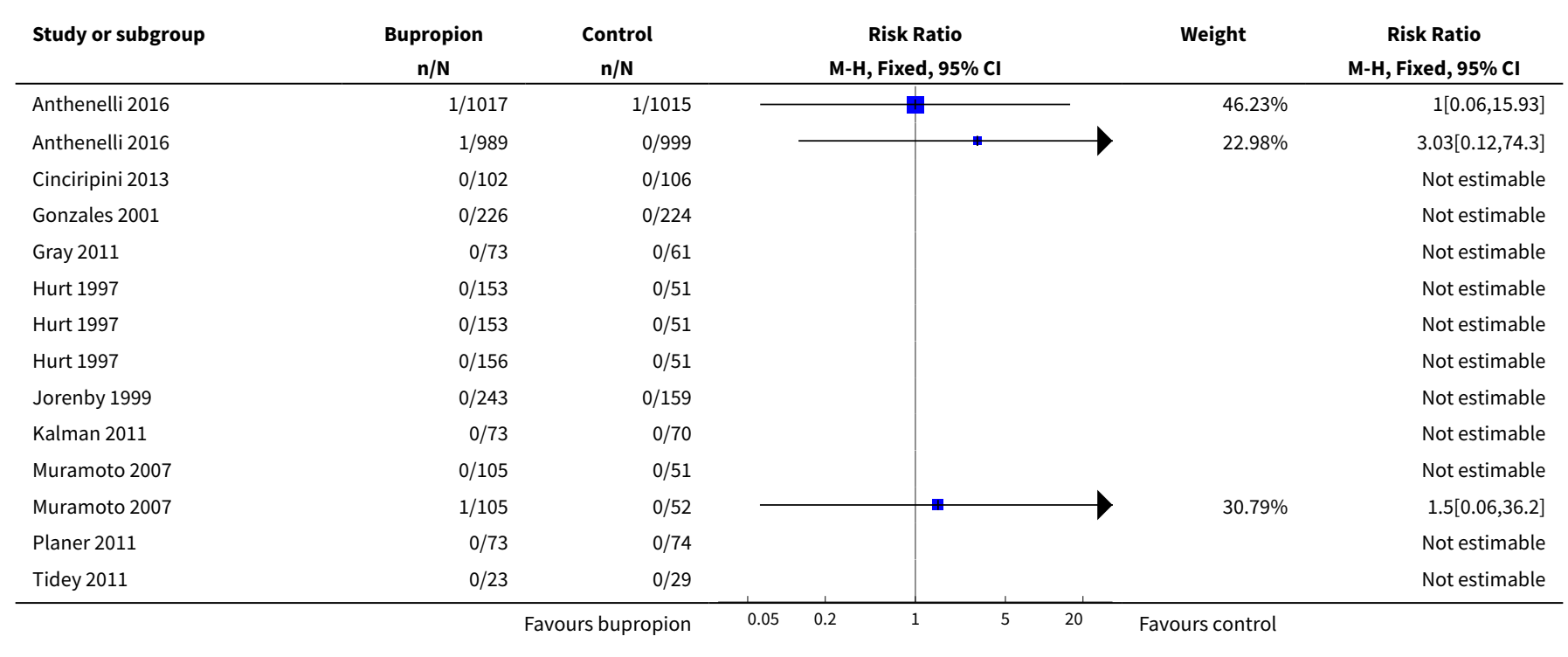




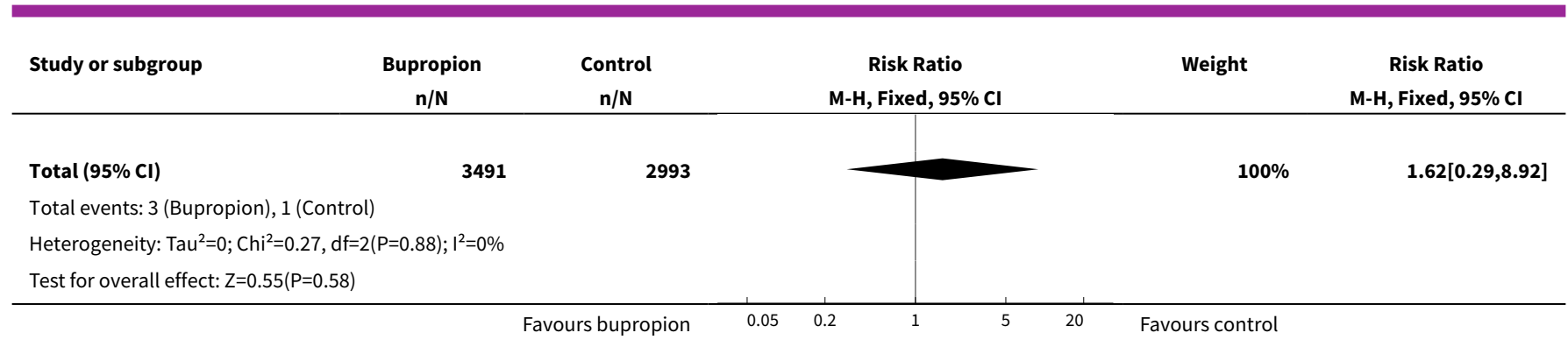

Analysis 1.10. Comparison 1 Bupropion versus placebo/no pharmacotherapy control, Outcome 10 Death by suicide.

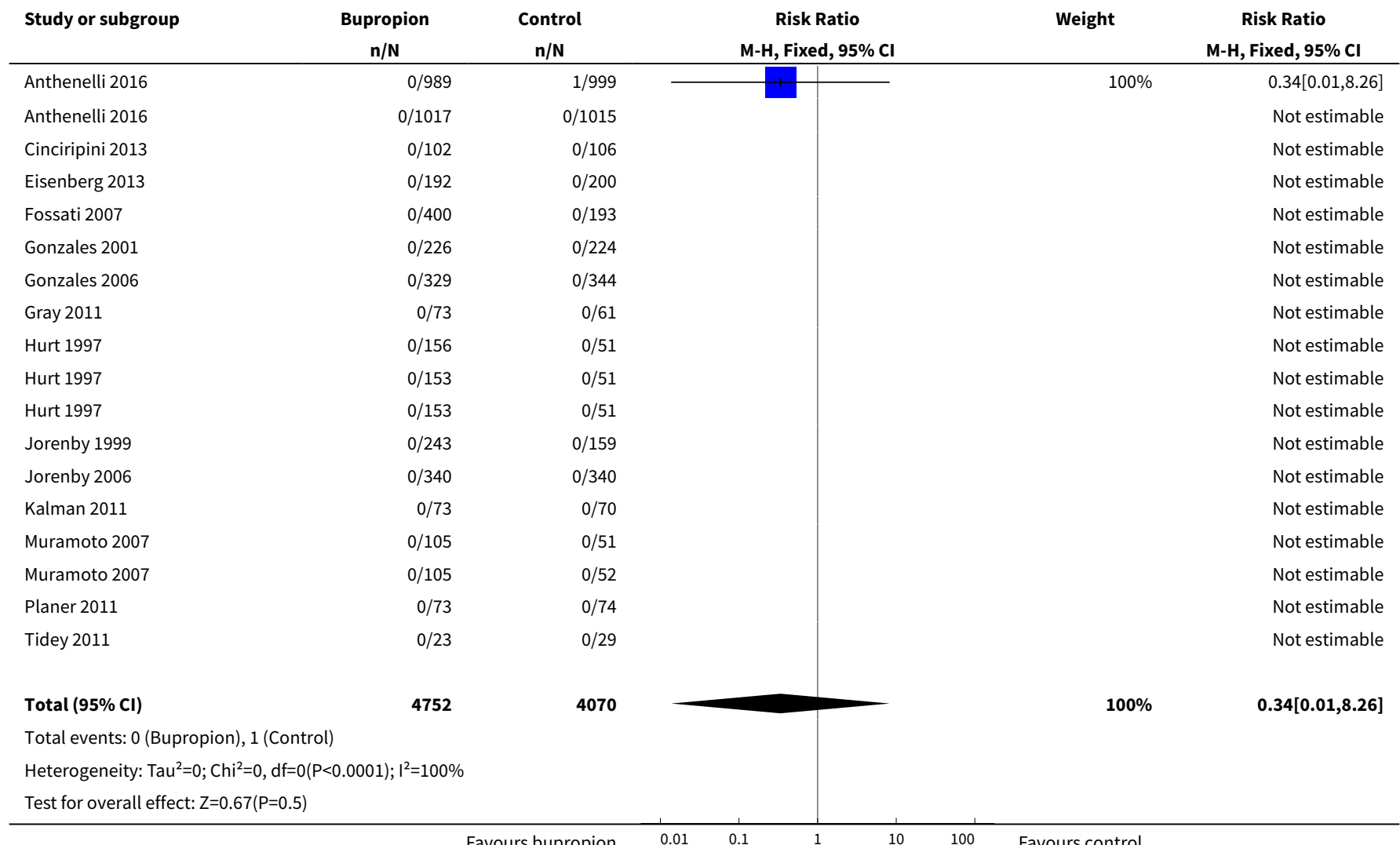

Analysis 1.11. Comparison 1 Bupropion versus placebo/ no pharmacotherapy control, Outcome 11 All-cause mortality.

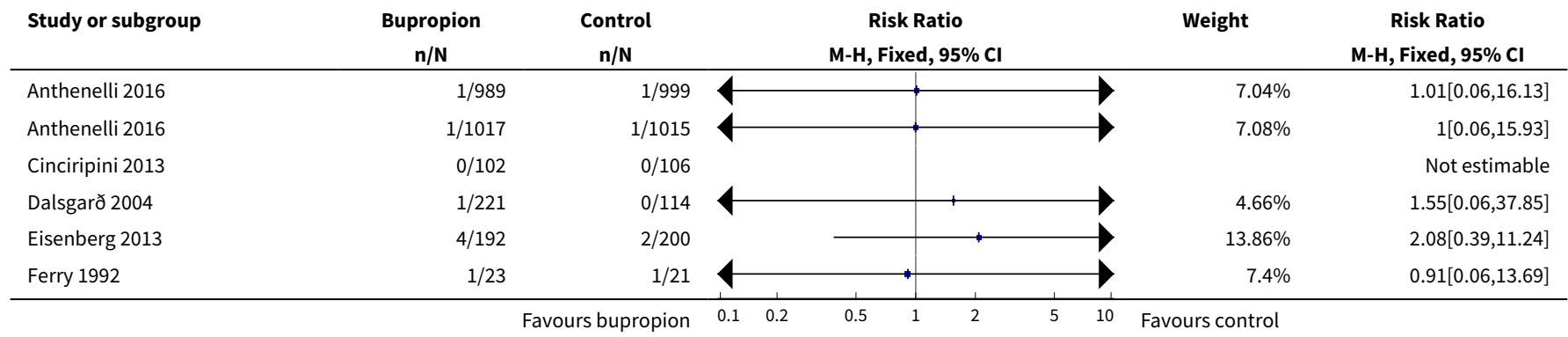




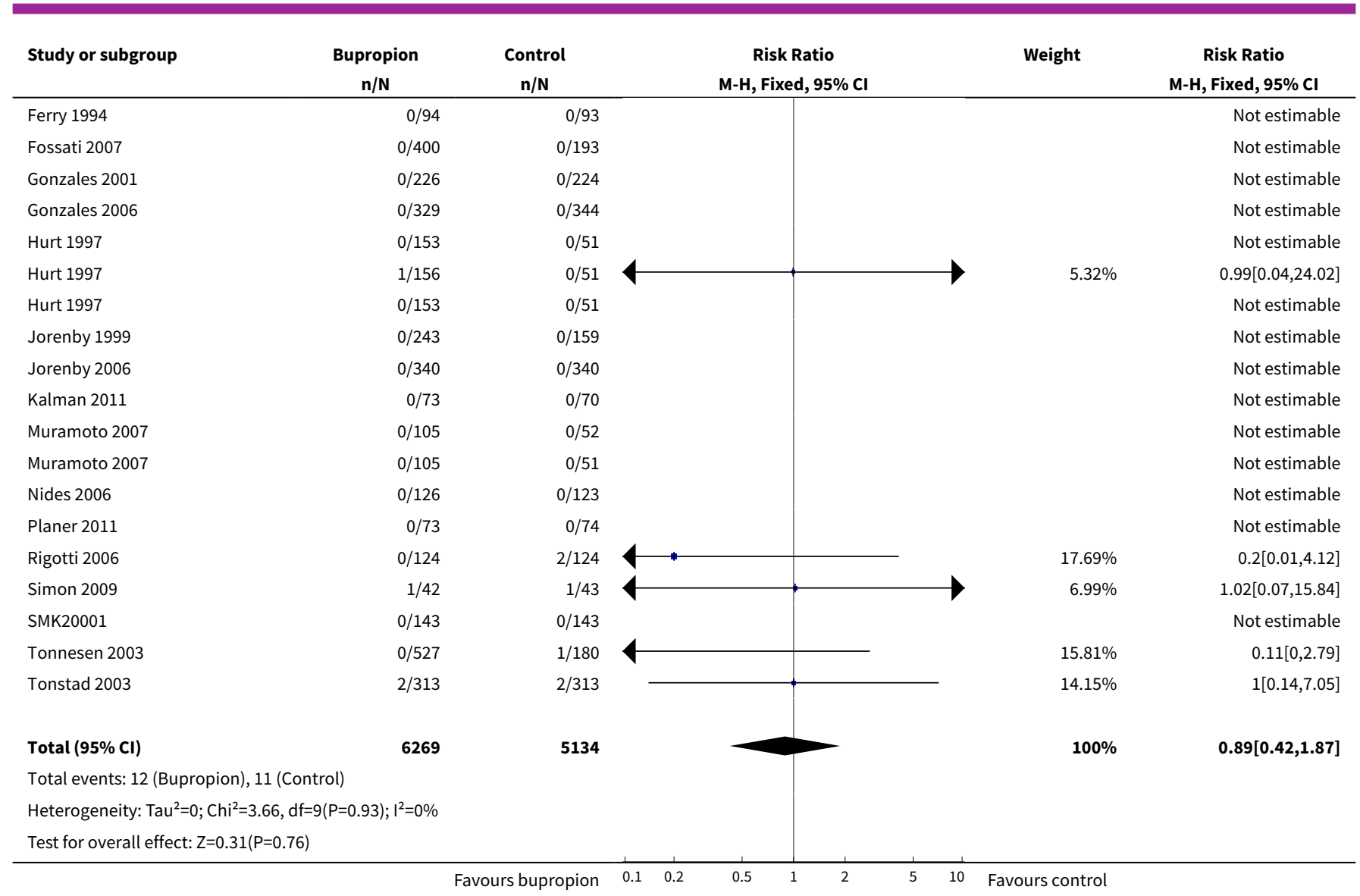

Analysis 1.12. Comparison 1 Bupropion versus placebo/no pharmacotherapy control, Outcome 12 Anxiety.

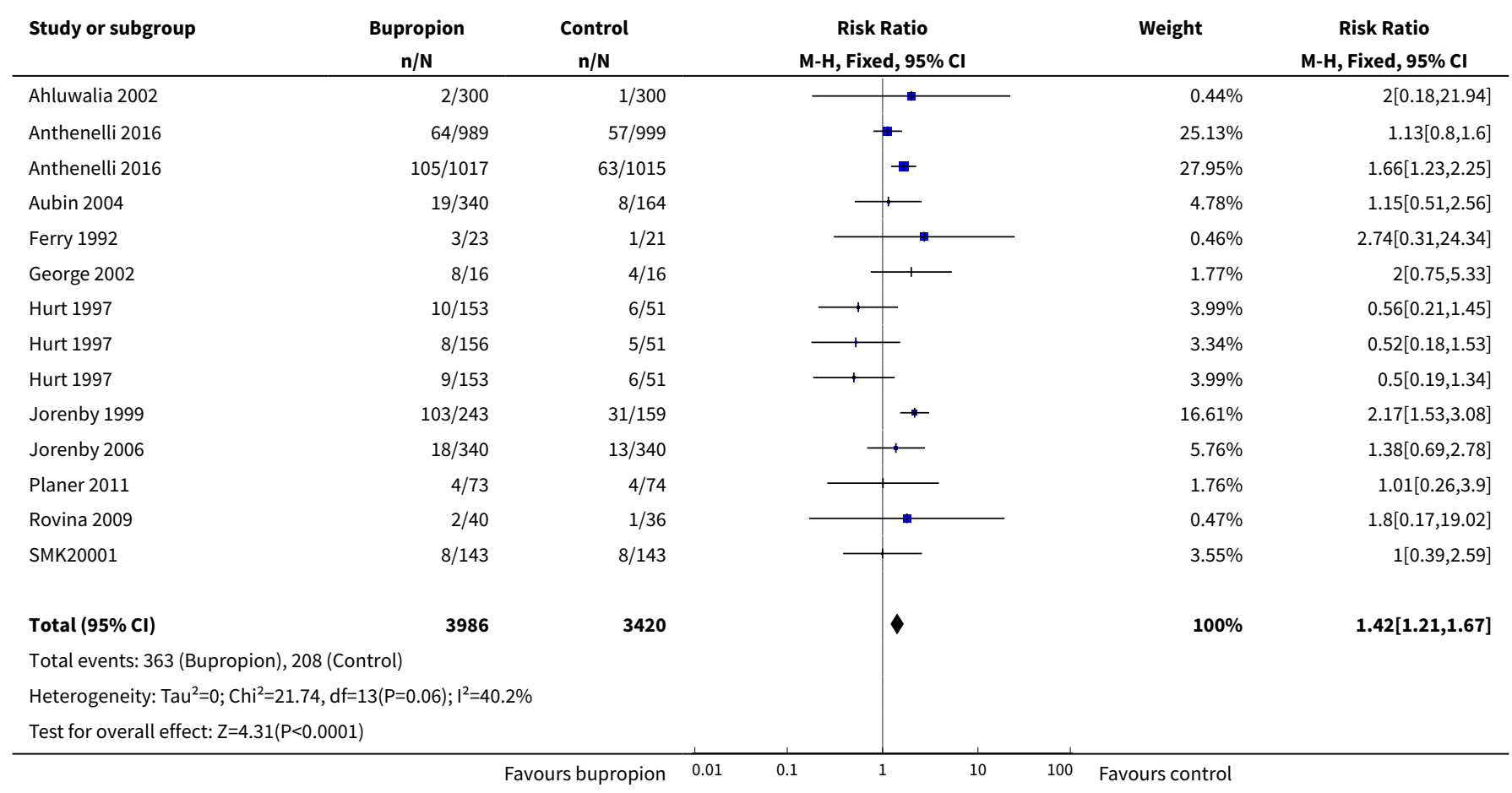


Analysis 1.13. Comparison 1 Bupropion versus placebo/no pharmacotherapy control, Outcome 13 Insomnia.

\begin{tabular}{|c|c|c|c|c|c|}
\hline Study or subgroup & $\begin{array}{c}\text { Bupropion } \\
\mathrm{n} / \mathrm{N}\end{array}$ & $\begin{array}{c}\text { Control } \\
n / N\end{array}$ & $\begin{array}{c}\text { Risk Ratio } \\
\text { M-H, Fixed, } 95 \% \mathrm{Cl}\end{array}$ & Weight & $\begin{array}{c}\text { Risk Ratio } \\
\text { M-H, Fixed, } 95 \% \mathrm{Cl}\end{array}$ \\
\hline Ahluwalia 2002 & $88 / 300$ & $62 / 300$ & + & $10.95 \%$ & $1.42[1.07,1.88]$ \\
\hline Anthenelli 2016 & $126 / 989$ & $73 / 999$ & $\leftarrow$ & $12.83 \%$ & $1.74[1.32,2.29]$ \\
\hline Anthenelli 2016 & $119 / 1017$ & $66 / 1015$ & + & $11.67 \%$ & $1.8[1.35,2.4]$ \\
\hline Dalsgarð 2004 & $61 / 221$ & 20/114 & $\leftarrow$ & $4.66 \%$ & $1.57[1,2.47]$ \\
\hline Eisenberg 2013 & $43 / 192$ & $36 / 200$ & + & $6.23 \%$ & $1.24[0.84,1.85]$ \\
\hline Ferry 1992 & $6 / 23$ & $1 / 21$ & - & $0.18 \%$ & $5.48[0.72,41.82]$ \\
\hline Fossati 2007 & $69 / 400$ & $12 / 193$ & 1 & $2.86 \%$ & $2.77[1.54,5]$ \\
\hline George 2002 & $7 / 16$ & $4 / 16$ & 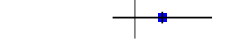 & $0.71 \%$ & $1.75[0.63,4.83]$ \\
\hline Gonzales 2001 & $55 / 226$ & $25 / 224$ & + & $4.44 \%$ & $2.18[1.41,3.37]$ \\
\hline Grant 2007 & $11 / 30$ & $2 / 28$ & $\longrightarrow$ & $0.37 \%$ & $5.13[1.25,21.15]$ \\
\hline Haggsträm 2006 & $27 / 53$ & $9 / 51$ & 1 & $1.62 \%$ & $2.89[1.51,5.52]$ \\
\hline Holt 2005 & $23 / 88$ & $4 / 46$ & $\longrightarrow$ & $0.93 \%$ & $3.01[1.11,8.17]$ \\
\hline Hurt 1997 & $54 / 156$ & $11 / 51$ & 1 & $2.93 \%$ & $1.6[0.91,2.83]$ \\
\hline Hurt 1997 & $46 / 153$ & $10 / 51$ & 1 & $2.65 \%$ & $1.53[0.84,2.81]$ \\
\hline Hurt 1997 & $45 / 153$ & $11 / 51$ & + & $2.92 \%$ & $1.36[0.76,2.43]$ \\
\hline Jorenby 1999 & $21 / 243$ & $10 / 159$ & 1 & $2.14 \%$ & $1.37[0.66,2.84]$ \\
\hline Jorenby 2006 & $72 / 340$ & $43 / 340$ & $\rightarrow$ & $7.6 \%$ & $1.67[1.18,2.37]$ \\
\hline Kalman 2011 & $5 / 73$ & $2 / 70$ & $\longrightarrow$ & $0.36 \%$ & $2.4[0.48,11.95]$ \\
\hline McCarthy 2008 & $35 / 229$ & $10 / 234$ & $\longrightarrow$ & $1.75 \%$ & $3.58[1.81,7.05]$ \\
\hline Myles 2004 & $2 / 14$ & $3 / 10$ & $\longrightarrow$ & $0.62 \%$ & $0.48[0.1,2.35]$ \\
\hline Rovina 2009 & $6 / 40$ & $1 / 36$ & 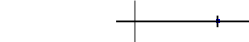 & $0.19 \%$ & $5.4[0.68,42.73]$ \\
\hline Tashkin 2001 & $49 / 204$ & $23 / 200$ & + & $4.1 \%$ & $2.09[1.32,3.29]$ \\
\hline Tonnesen 2003 & $126 / 527$ & $27 / 180$ & $\rightarrow-$ & $7.11 \%$ & $1.59[1.09,2.33]$ \\
\hline Tonstad 2003 & $75 / 313$ & $37 / 313$ & $\rightarrow$ & $6.54 \%$ & $2.03[1.41,2.91]$ \\
\hline Wagena 2005 & $29 / 86$ & $21 / 89$ & + & $3.65 \%$ & $1.43[0.89,2.3]$ \\
\hline Total $(95 \% \mathrm{Cl})$ & 6086 & 4991 & 1 & $100 \%$ & $1.78[1.62,1.96]$ \\
\hline \multicolumn{6}{|c|}{ Total events: 1200 (Bupropion), 523 (Control) } \\
\hline \multicolumn{6}{|c|}{ Heterogeneity: $\mathrm{Tau}^{2}=0 ; \mathrm{Chi}^{2}=27.31, \mathrm{df}=24(\mathrm{P}=0.29) ; \mathrm{I}^{2}=12.11 \%$} \\
\hline \multicolumn{6}{|c|}{ Test for overall effect: $Z=11.84(P<0.0001)$} \\
\hline
\end{tabular}

Analysis 1.14. Comparison 1 Bupropion versus placebo/ no pharmacotherapy control, Outcome 14 Dropouts due to drug.

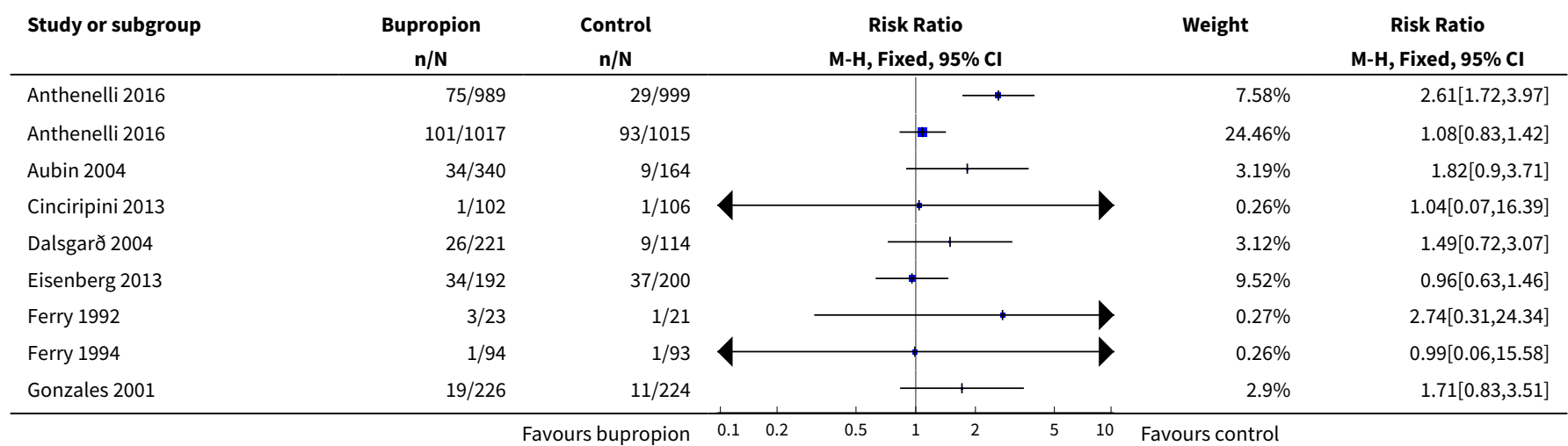




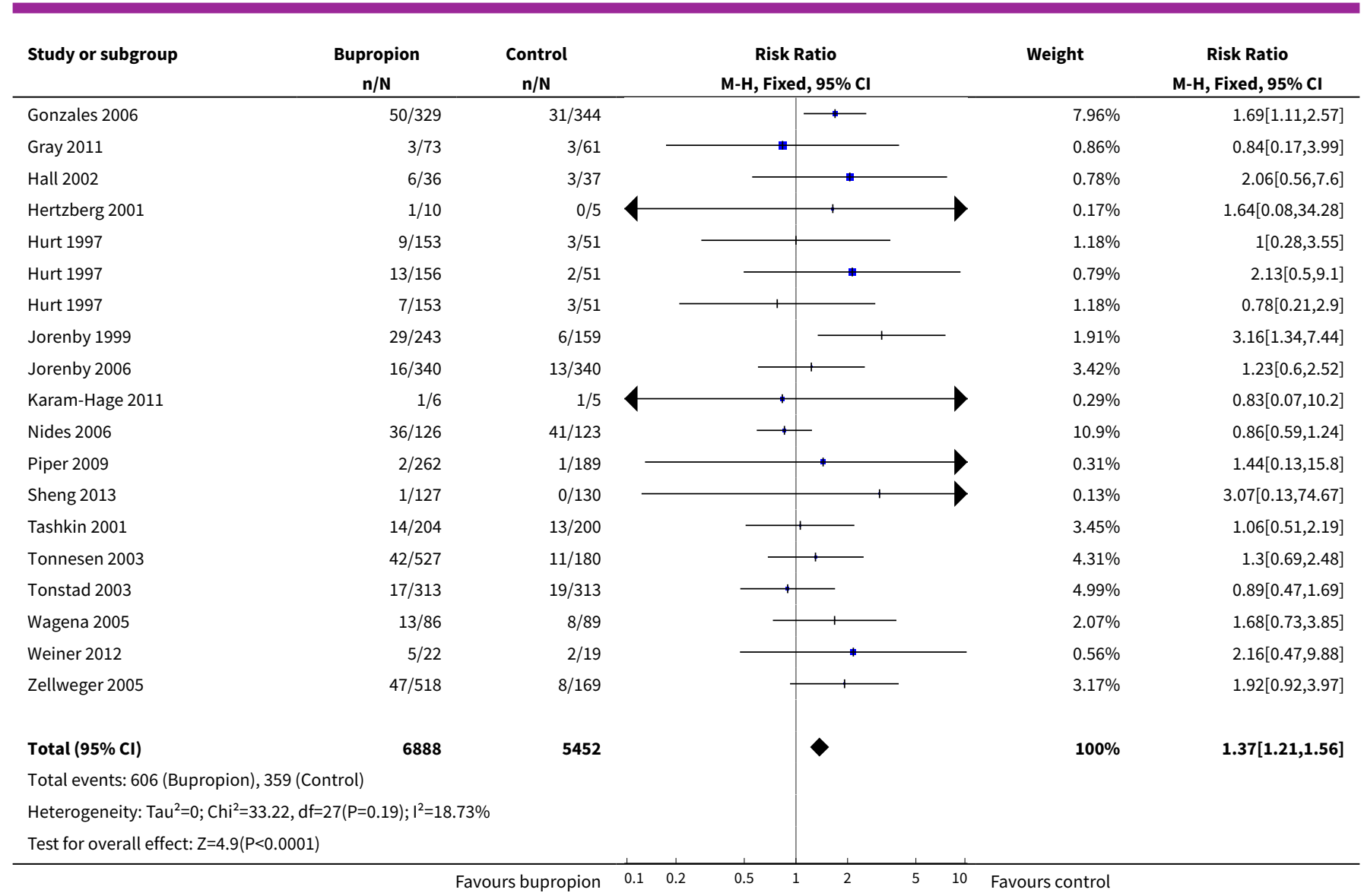

\section{Comparison 2. Bupropion plus nicotine replacement therapy (NRT) versus NRT alone}

\begin{tabular}{lllll}
\hline Outcome or subgroup title & $\begin{array}{l}\text { No. of } \\
\text { studies }\end{array}$ & $\begin{array}{l}\text { No. of } \\
\text { partici- } \\
\text { pants }\end{array}$ & Statistical method & Effect size \\
\hline 1 Smoking cessation & 12 & 3487 & Risk Ratio (M-H, Random, 95\% Cl) & $1.19[0.94,1.51]$ \\
\hline 1.1 Patch alone & 9 & 1774 & Risk Ratio (M-H, Random, 95\% Cl) & $1.24[0.84,1.84]$ \\
\hline 1.2 Lozenge alone & 2 & 1051 & Risk Ratio (M-H, Random, 95\% Cl) & $1.21[0.81,1.81]$ \\
\hline 1.3 Choice of NRT & 1 & 662 & Risk Ratio (M-H, Random, 95\% Cl) & $0.97[0.73,1.28]$ \\
\hline 2 Adverse events & 2 & 313 & Risk Ratio (M-H, Fixed, 95\% Cl) & $1.21[1.02,1.43]$ \\
\hline 3 Serious adverse events & 3 & 607 & Risk Ratio (M-H, Fixed, 95\% Cl) & $1.52[0.26,8.89]$ \\
\hline 4 Seizures & 1 & 527 & Odds Ratio (M-H, Fixed, 95\% Cl) & $2.93[0.12,72.31]$ \\
\hline 5 Suicide attempts & 1 & 487 & Risk Ratio (M-H, Fixed, 95\% Cl) & $0.0[0.0,0.0]$ \\
\hline 6 Death by suicide & 1 & 487 & Risk Ratio (M-H, Fixed, 95\% Cl) & $0.0[0.0,0.0]$ \\
\hline 7 All-cause mortality & 2 & 731 & Risk Ratio (M-H, Fixed, 95\% Cl) & $0.68[0.12,3.98]$ \\
\hline
\end{tabular}




\begin{tabular}{lllll}
\hline Outcome or subgroup title & $\begin{array}{l}\text { No. of } \\
\text { studies }\end{array}$ & $\begin{array}{l}\text { No. of } \\
\text { partici- } \\
\text { pants }\end{array}$ & Statistical method & Effect size \\
\hline 8 Insomnia & 2 & 556 & Risk Ratio (M-H, Fixed, 95\% Cl) & $1.55[1.24,1.93]$ \\
\hline 9 Anxiety & 3 & 1218 & Risk Ratio (M-H, Fixed, 95\% Cl) & $1.58[0.97,2.56]$ \\
\hline 10 Dropouts due to drug & 2 & 538 & Risk Ratio (M-H, Fixed, 95\% Cl) & $1.67[0.95,2.92]$ \\
\hline
\end{tabular}

Analysis 2.1. Comparison 2 Bupropion plus nicotine replacement therapy (NRT) versus NRT alone, Outcome 1 Smoking cessation.

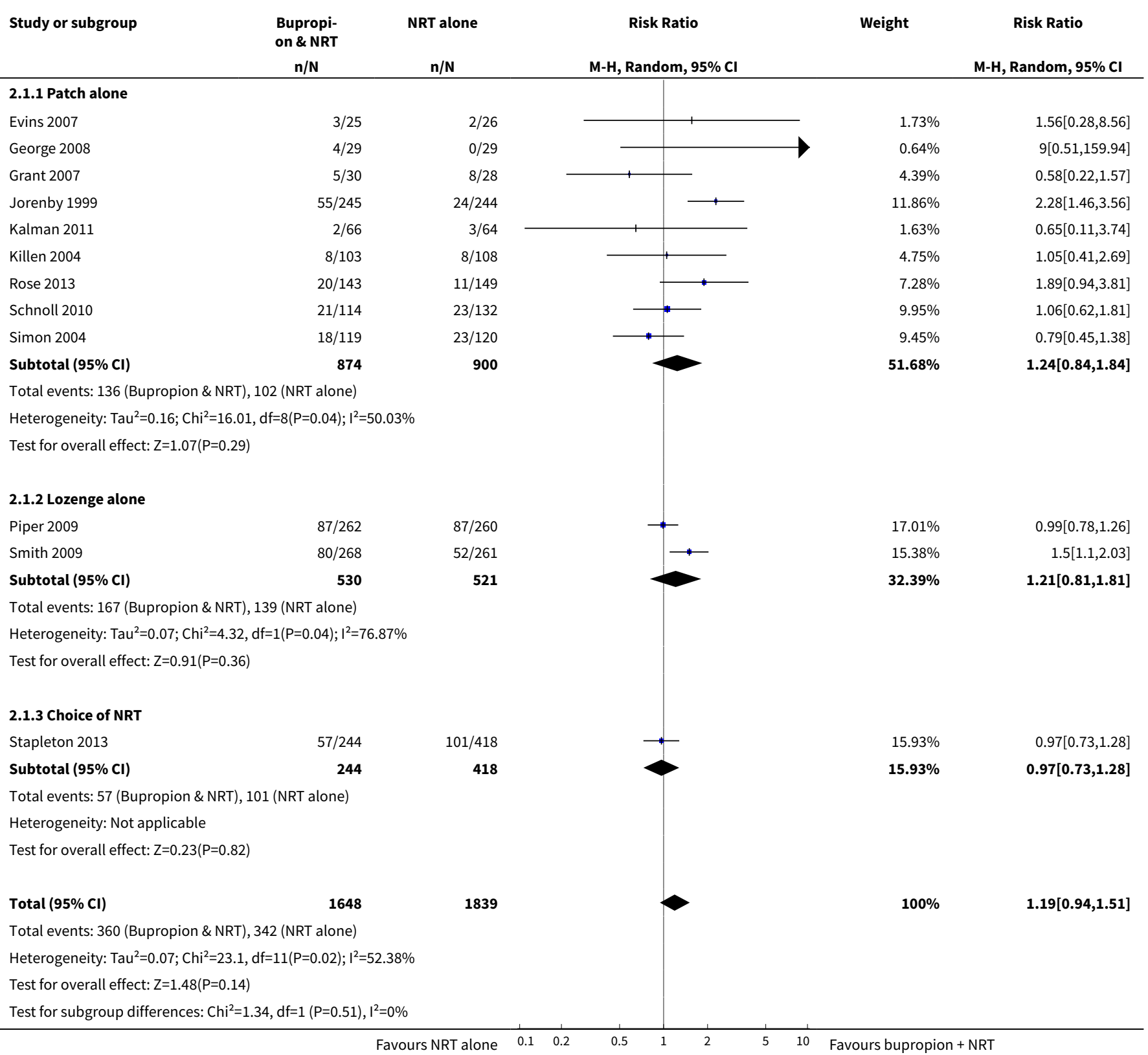


Analysis 2.2. Comparison 2 Bupropion plus nicotine replacement therapy (NRT) versus NRT alone, Outcome 2 Adverse events.

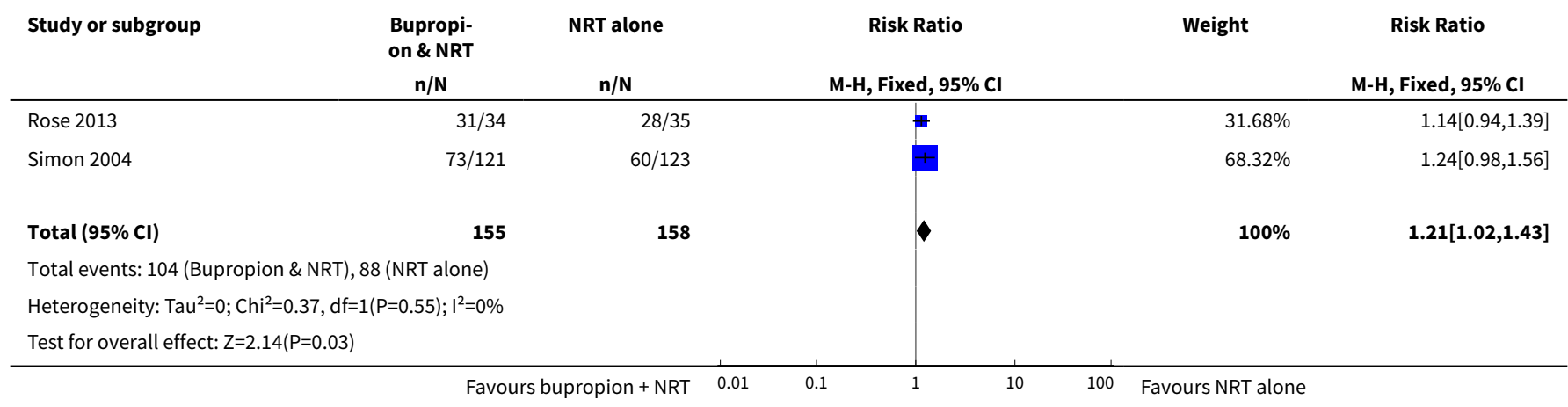

Analysis 2.3. Comparison 2 Bupropion plus nicotine replacement therapy (NRT) versus NRT alone, Outcome 3 Serious adverse events.

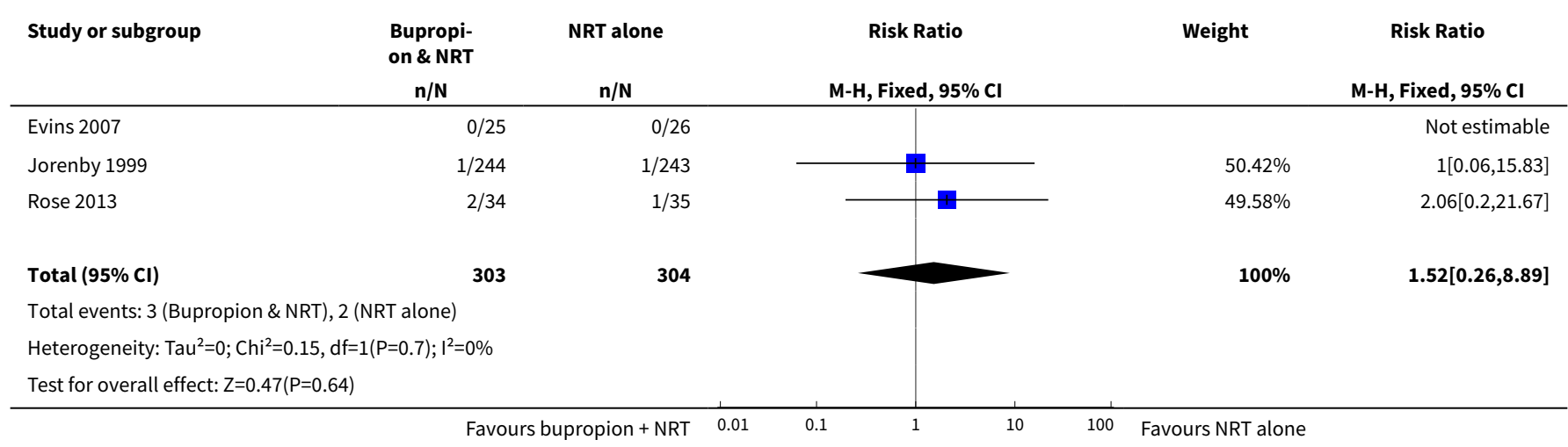

Analysis 2.4. Comparison 2 Bupropion plus nicotine replacement therapy (NRT) versus NRT alone, Outcome 4 Seizures.

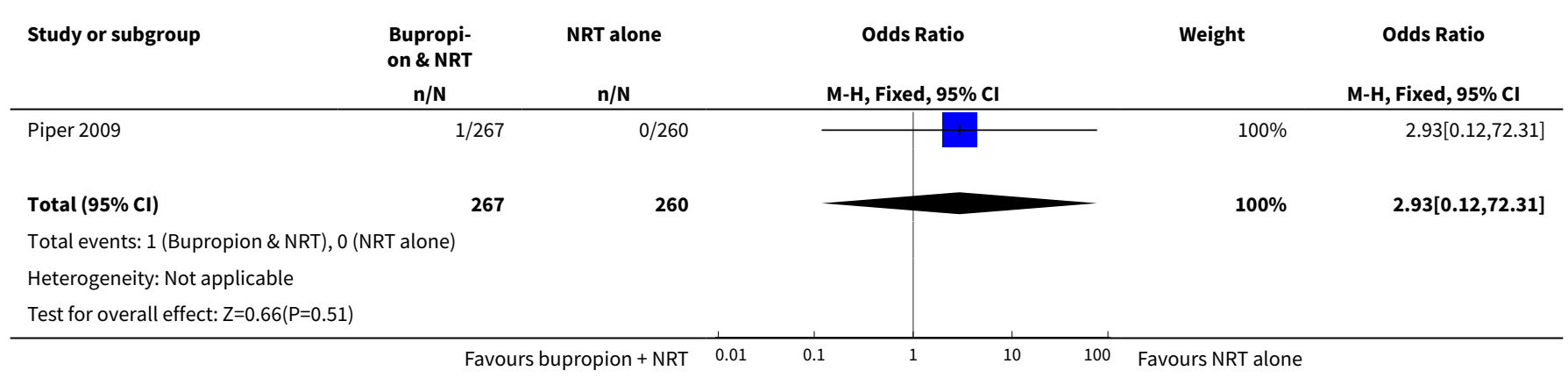


Analysis 2.5. Comparison 2 Bupropion plus nicotine replacement therapy (NRT) versus NRT alone, Outcome 5 Suicide attempts.

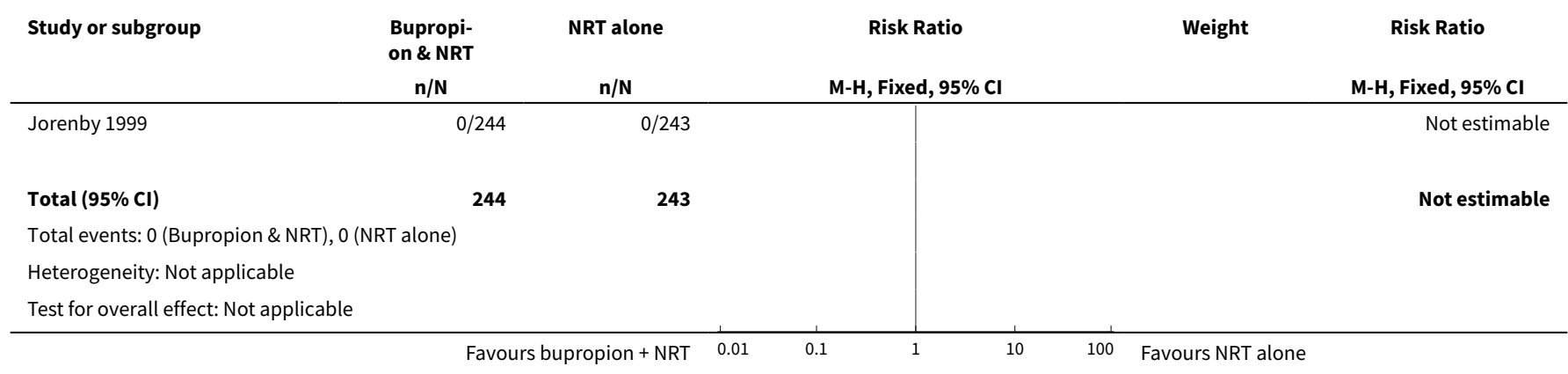

Analysis 2.6. Comparison 2 Bupropion plus nicotine replacement therapy (NRT) versus NRT alone, Outcome 6 Death by suicide.

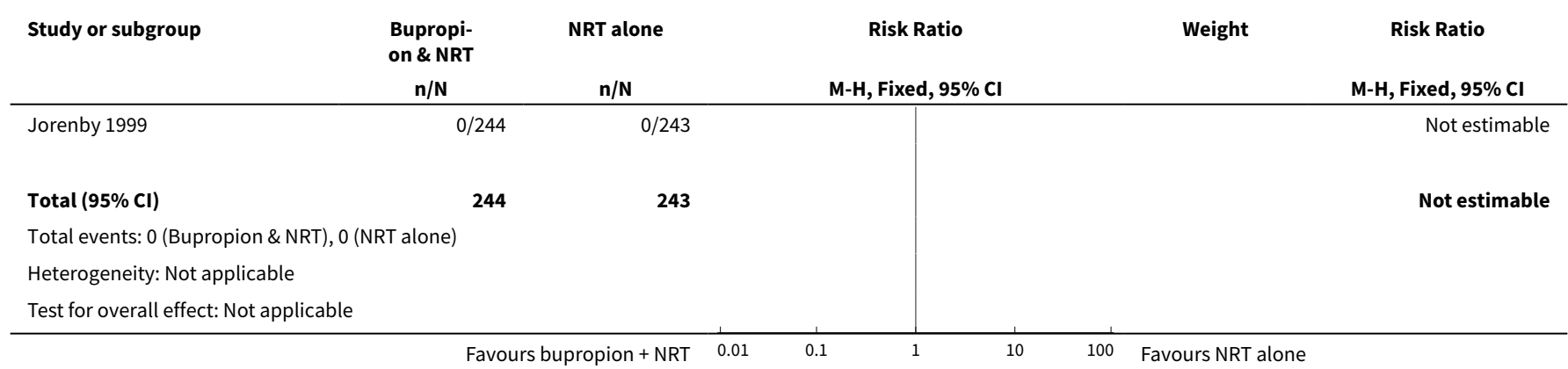

Analysis 2.7. Comparison 2 Bupropion plus nicotine replacement therapy (NRT) versus NRT alone, Outcome 7 All-cause mortality.

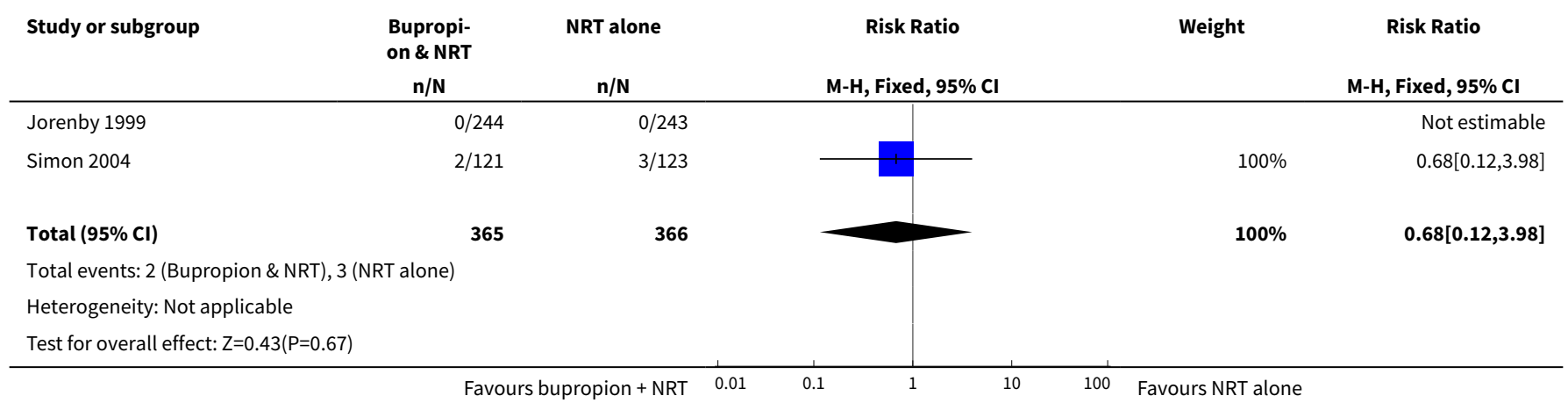


Analysis 2.8. Comparison 2 Bupropion plus nicotine replacement therapy (NRT) versus NRT alone, Outcome 8 Insomnia.

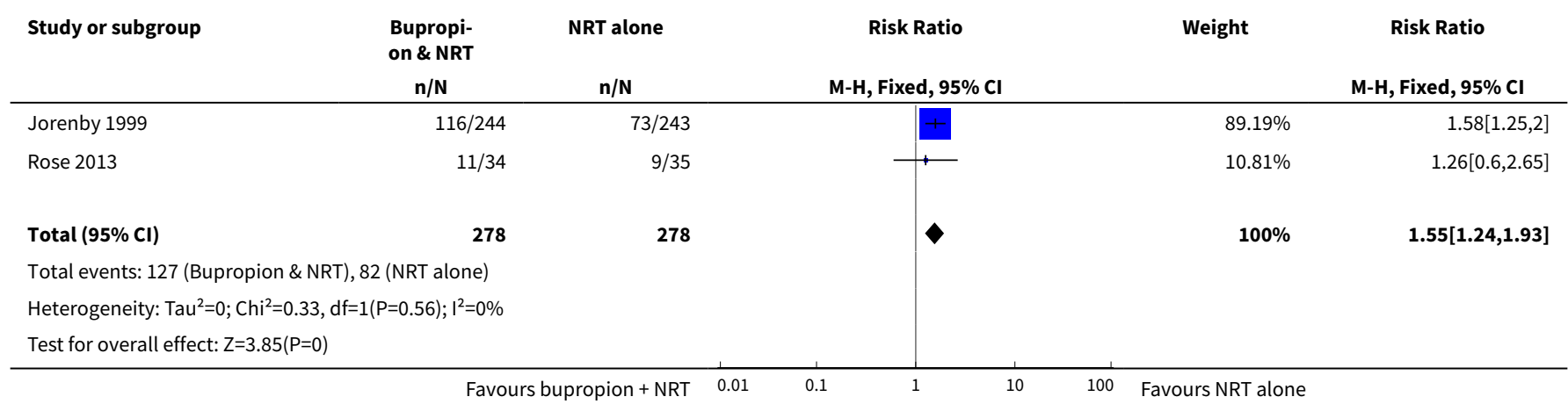

Analysis 2.9. Comparison 2 Bupropion plus nicotine replacement therapy (NRT) versus NRT alone, Outcome 9 Anxiety.

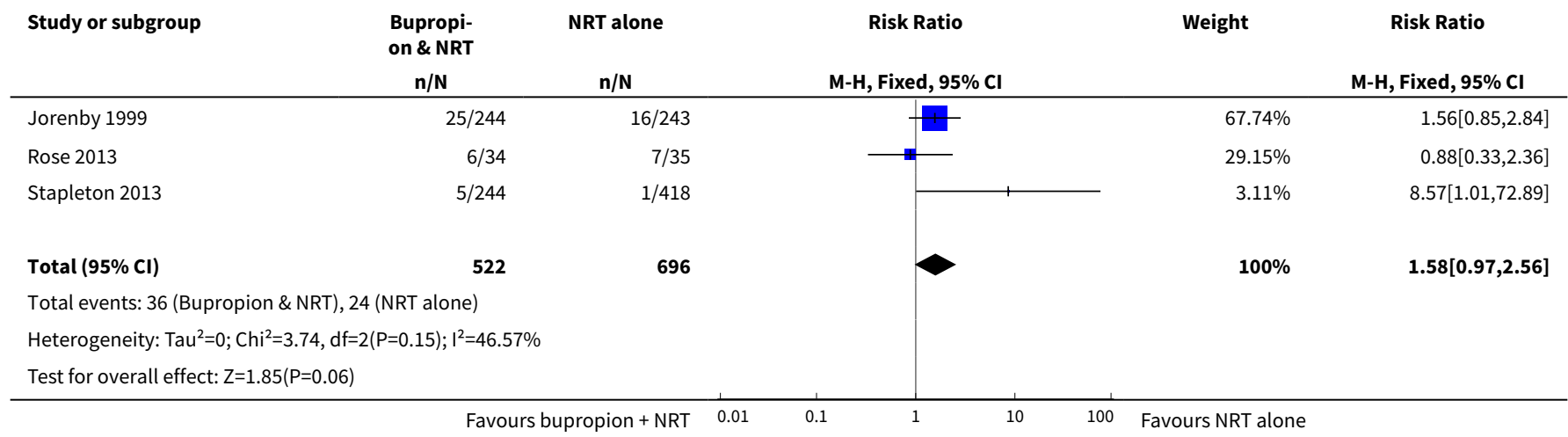

Analysis 2.10. Comparison 2 Bupropion plus nicotine replacement therapy (NRT) versus NRT alone, Outcome 10 Dropouts due to drug.

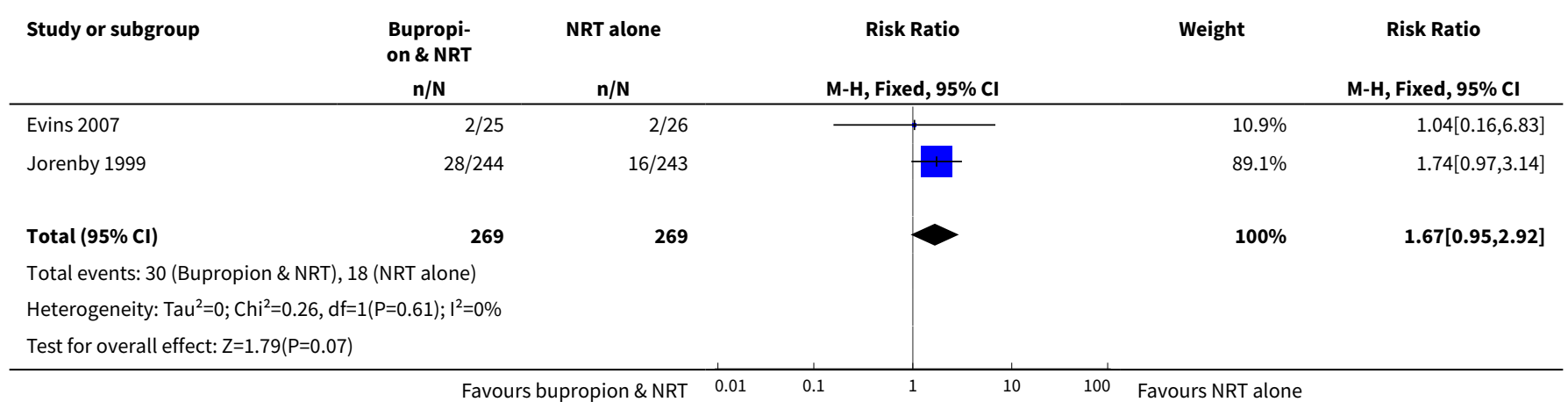


Comparison 3. Bupropion plus varenicline versus varenicline alone

\begin{tabular}{|c|c|c|c|c|}
\hline Outcome or subgroup title & $\begin{array}{l}\text { No. of } \\
\text { studies }\end{array}$ & $\begin{array}{l}\text { No. of } \\
\text { partici- } \\
\text { pants }\end{array}$ & Statistical method & Effect size \\
\hline 1 Smoking cessation & 3 & 1057 & Risk Ratio (M-H, Random, 95\% Cl) & $1.21[0.95,1.55]$ \\
\hline 2 Adverse events & 4 & 1043 & Risk Ratio (M-H, Fixed, 95\% Cl) & $1.09[1.02,1.17]$ \\
\hline 3 Serious adverse events & 5 & 1268 & Risk Ratio (M-H, Fixed, 95\% Cl) & $1.23[0.63,2.42]$ \\
\hline 4 Psychiatric adverse events & 2 & 835 & Risk Ratio (M-H, Fixed, 95\% Cl) & $1.15[1.03,1.30]$ \\
\hline 5 Seizures & 1 & 221 & Risk Ratio (M-H, Fixed, 95\% Cl) & $0.0[0.0,0.0]$ \\
\hline 6 Overdoses & 2 & 550 & Risk Ratio (M-H, Fixed, 95\% Cl) & $0.34[0.01,8.27]$ \\
\hline 7 Suicide attempts & 3 & 1056 & Risk Ratio (M-H, Fixed, 95\% CI) & $0.34[0.04,3.27]$ \\
\hline 8 Death by suicide & 2 & 727 & Risk Ratio (M-H, Fixed, 95\% Cl) & $0.0[0.0,0.0]$ \\
\hline 9 All-cause mortality & 2 & 727 & Risk Ratio (M-H, Fixed, 95\% Cl) & $0.34[0.01,8.40]$ \\
\hline 10 Anxiety & 2 & 499 & Risk Ratio (M-H, Fixed, 95\% Cl) & $1.55[1.01,2.38]$ \\
\hline 11 Insomnia & 2 & 499 & Risk Ratio (M-H, Fixed, 95\% Cl) & $1.45[1.14,1.84]$ \\
\hline 12 Dropouts due to drug & 4 & 1230 & Risk Ratio (M-H, Fixed, 95\% Cl) & $0.80[0.45,1.45]$ \\
\hline
\end{tabular}

Analysis 3.1. Comparison 3 Bupropion plus varenicline versus varenicline alone, Outcome 1 Smoking cessation.

\begin{tabular}{|c|c|c|c|c|c|}
\hline Study or subgroup & $\begin{array}{c}\text { Bupropion \& } \\
\text { varenicline } \\
n / N \\
\end{array}$ & $\begin{array}{c}\text { Vareni- } \\
\text { cline alone } \\
\mathbf{n} / \mathbf{N} \\
\end{array}$ & $\begin{array}{c}\text { Risk Ratio } \\
\text { M-H, Random, 95\% Cl }\end{array}$ & Weight & M-H, Random, $95 \% \mathrm{Cl}$ \\
\hline Cinciripini 2018 & $30 / 163$ & $33 / 166$ & $\longrightarrow$ & $26.21 \%$ & $0.93[0.59,1.44]$ \\
\hline Ebbert 2014 & $77 / 249$ & $63 / 257$ & & $54.34 \%$ & $1.26[0.95,1.68]$ \\
\hline Rose 2014 & $29 / 113$ & $18 / 109$ & 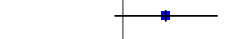 & $19.44 \%$ & $1.55[0.92,2.63]$ \\
\hline \multicolumn{6}{|c|}{ Total events: 136 (Bupropion \& varenicline), 114 (Varenicline alone) } \\
\hline \multicolumn{6}{|c|}{ Heterogeneity: $\mathrm{Tau}^{2}=0.01 ; \mathrm{Chi}^{2}=2.34, \mathrm{df}=2(\mathrm{P}=0.31) ; \mathrm{I}^{2}=14.68 \%$} \\
\hline Test for overall effect & & & & & \\
\hline
\end{tabular}

Analysis 3.2. Comparison 3 Bupropion plus varenicline versus varenicline alone, Outcome 2 Adverse events.

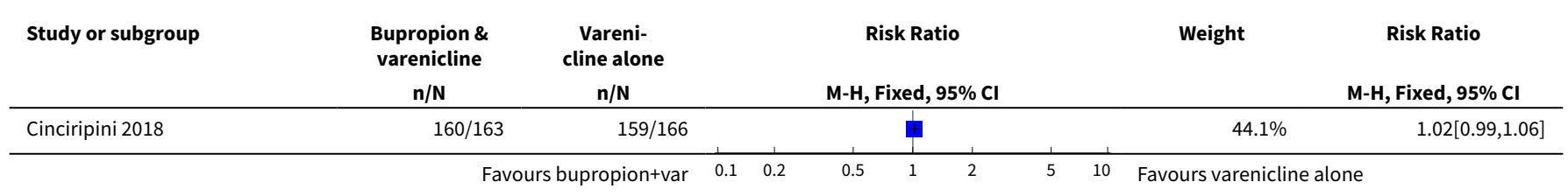




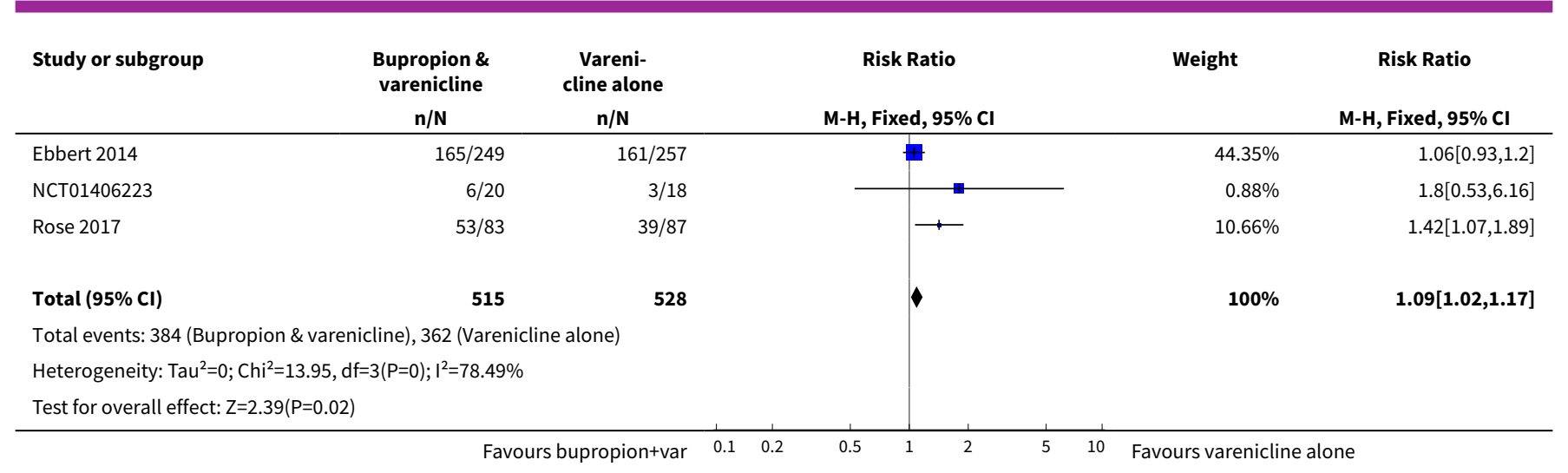

Analysis 3.3. Comparison 3 Bupropion plus varenicline versus varenicline alone, Outcome 3 Serious adverse events.

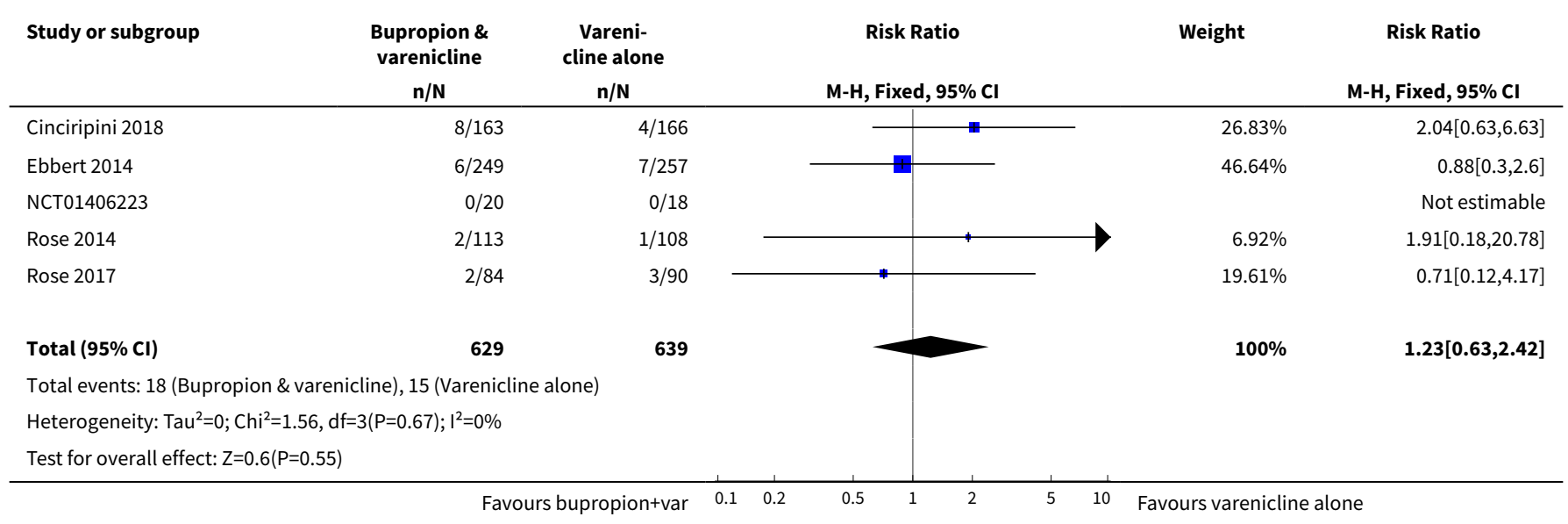

Analysis 3.4. Comparison 3 Bupropion plus varenicline versus varenicline alone, Outcome 4 Psychiatric adverse events.

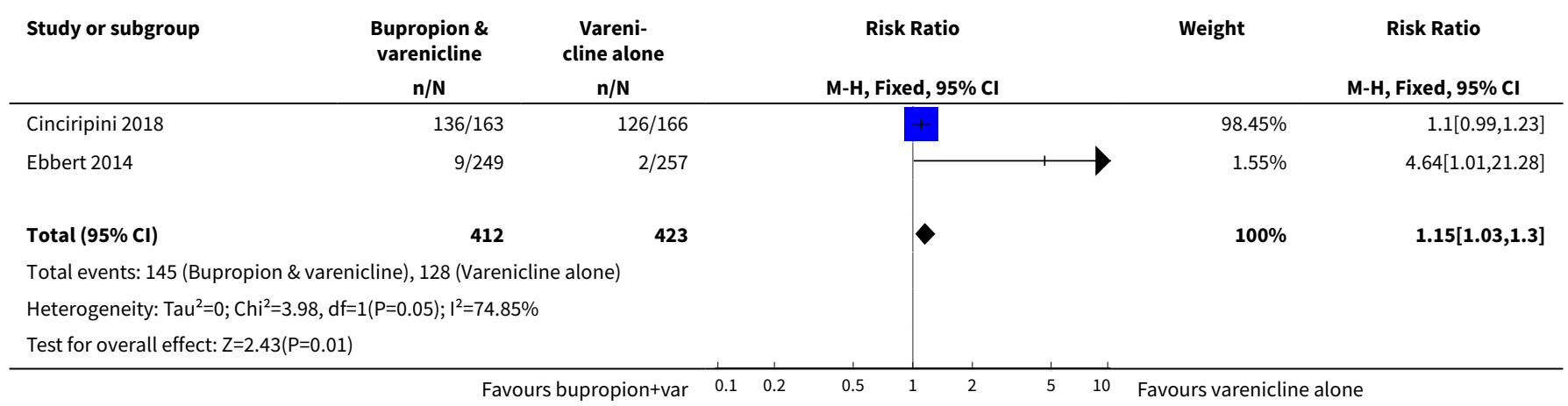


Analysis 3.5. Comparison 3 Bupropion plus varenicline versus varenicline alone, Outcome 5 Seizures.

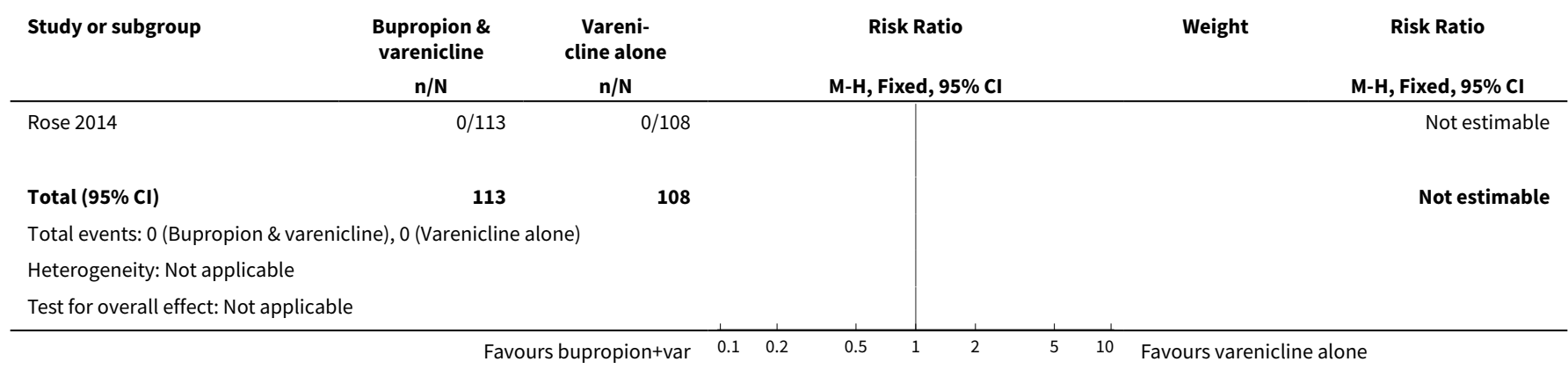

Analysis 3.6. Comparison 3 Bupropion plus varenicline versus varenicline alone, Outcome 6 Overdoses.

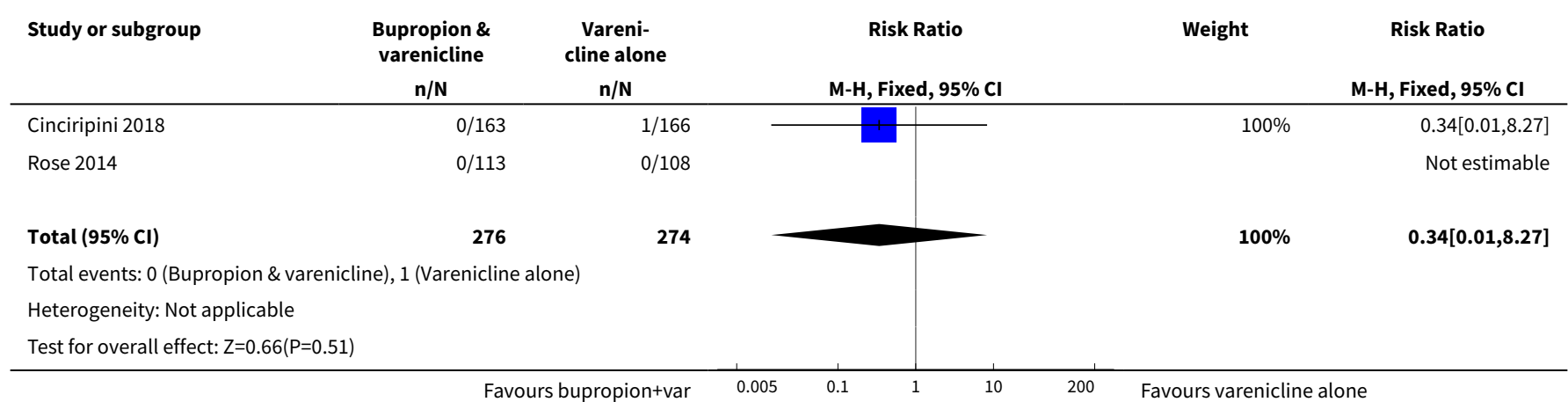

Analysis 3.7. Comparison 3 Bupropion plus varenicline versus varenicline alone, Outcome 7 Suicide attempts.

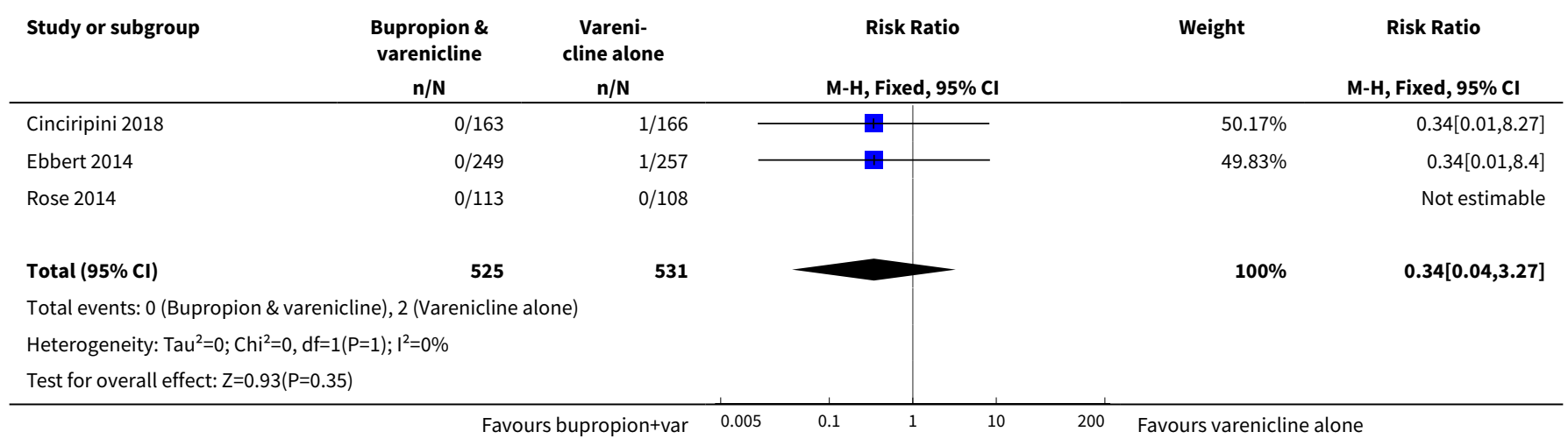

Analysis 3.8. Comparison 3 Bupropion plus varenicline versus varenicline alone, Outcome 8 Death by suicide.

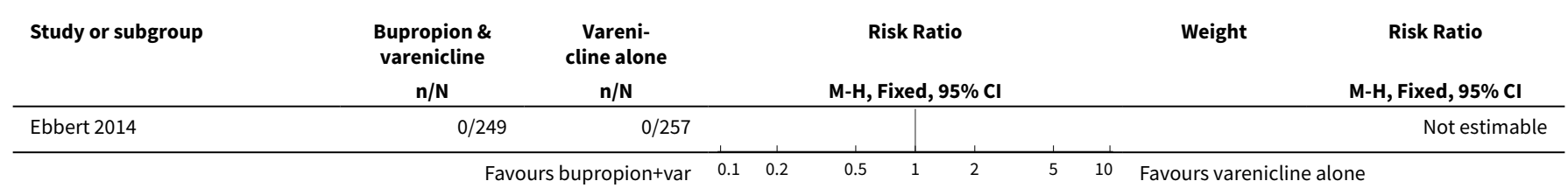




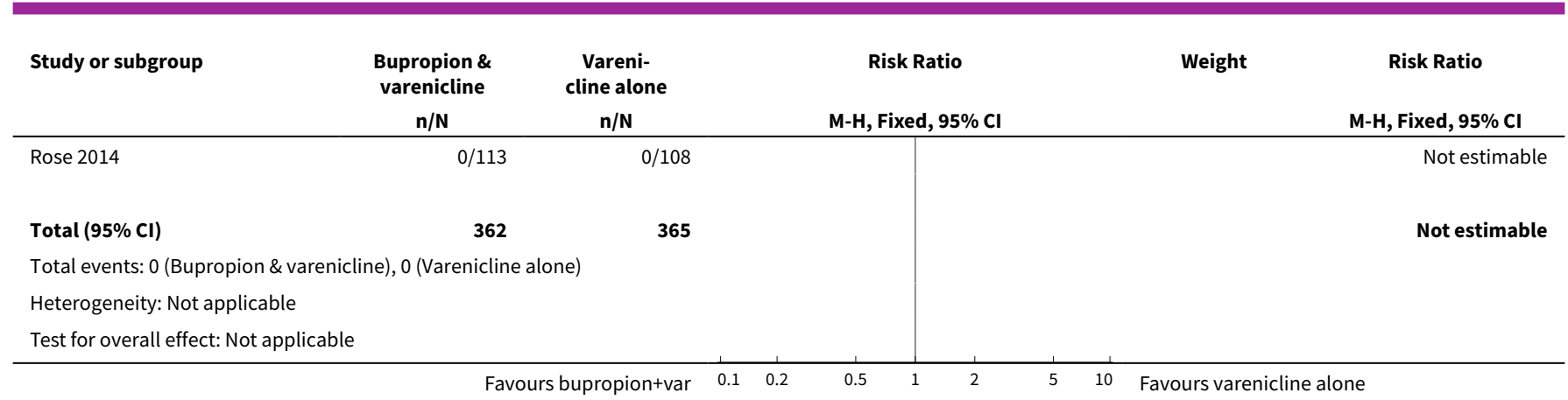

Analysis 3.9. Comparison 3 Bupropion plus varenicline versus varenicline alone, Outcome 9 All-cause mortality.

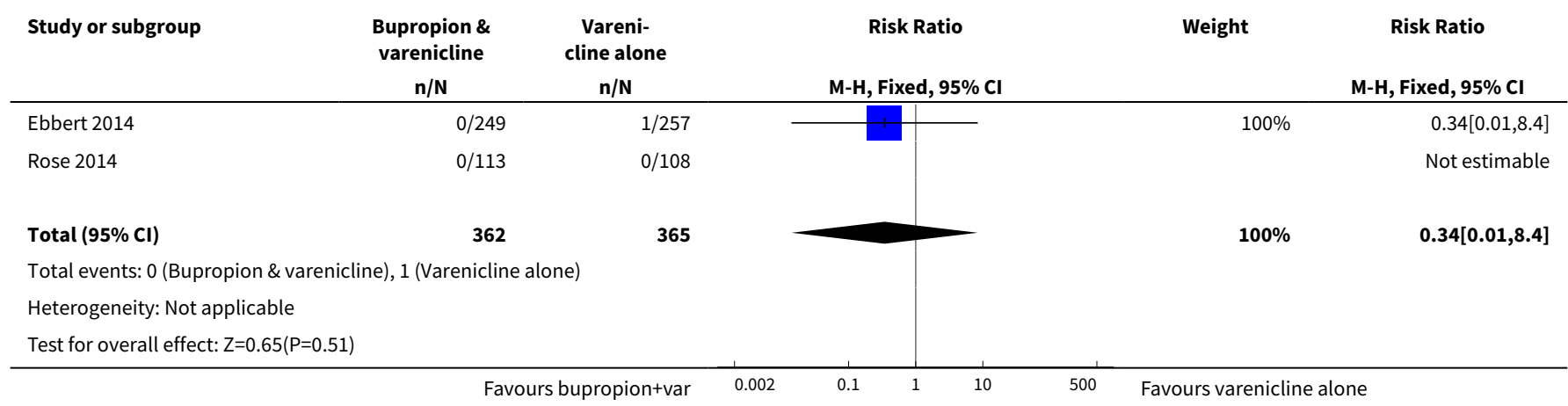

Analysis 3.10. Comparison 3 Bupropion plus varenicline versus varenicline alone, Outcome 10 Anxiety.

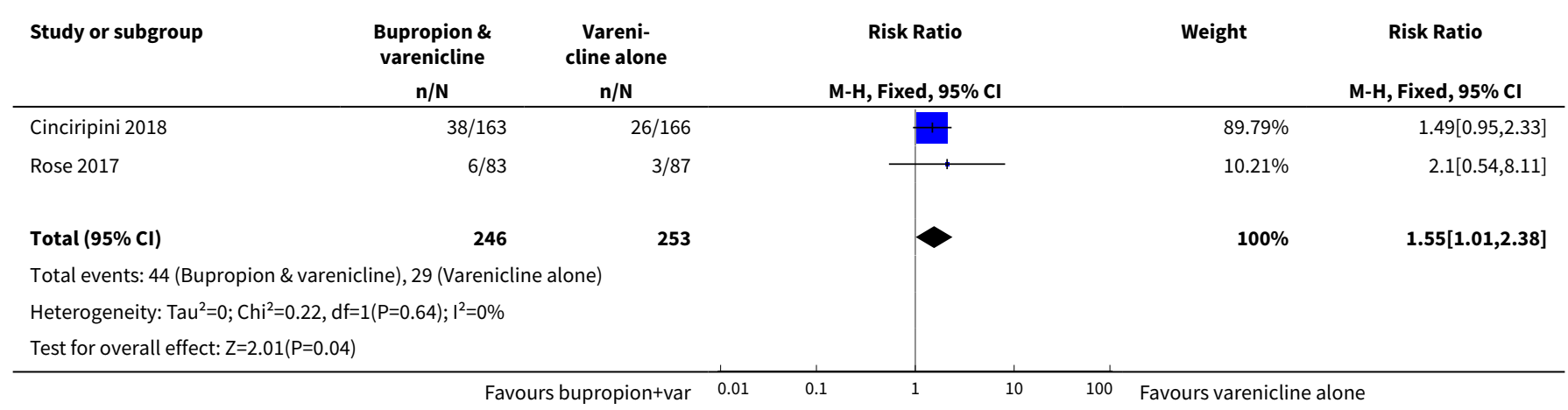

Analysis 3.11. Comparison 3 Bupropion plus varenicline versus varenicline alone, Outcome 11 Insomnia.

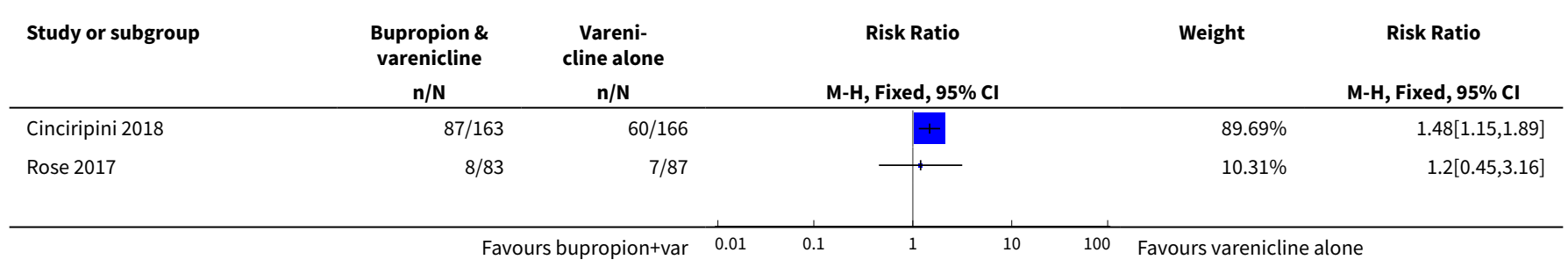




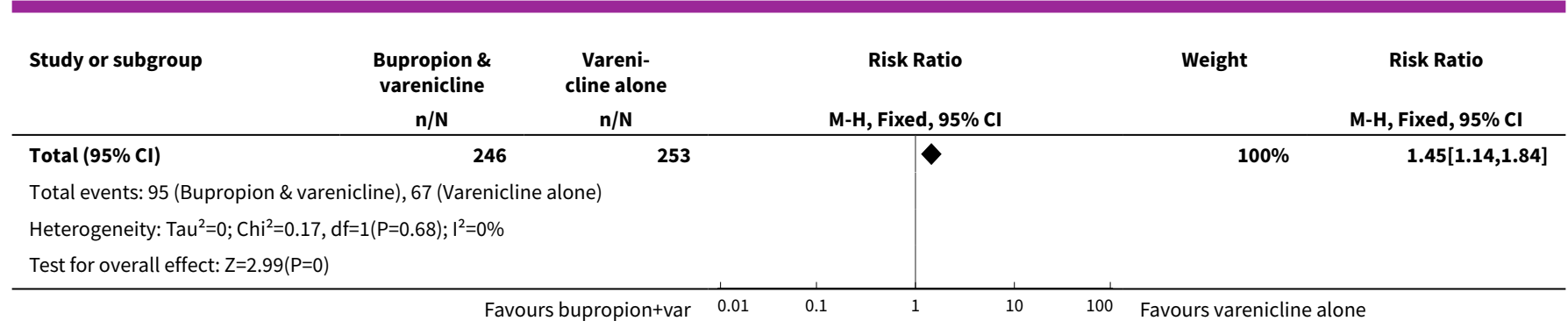

\section{Analysis 3.12. Comparison 3 Bupropion plus varenicline versus varenicline alone, Outcome 12 Dropouts due to drug.}

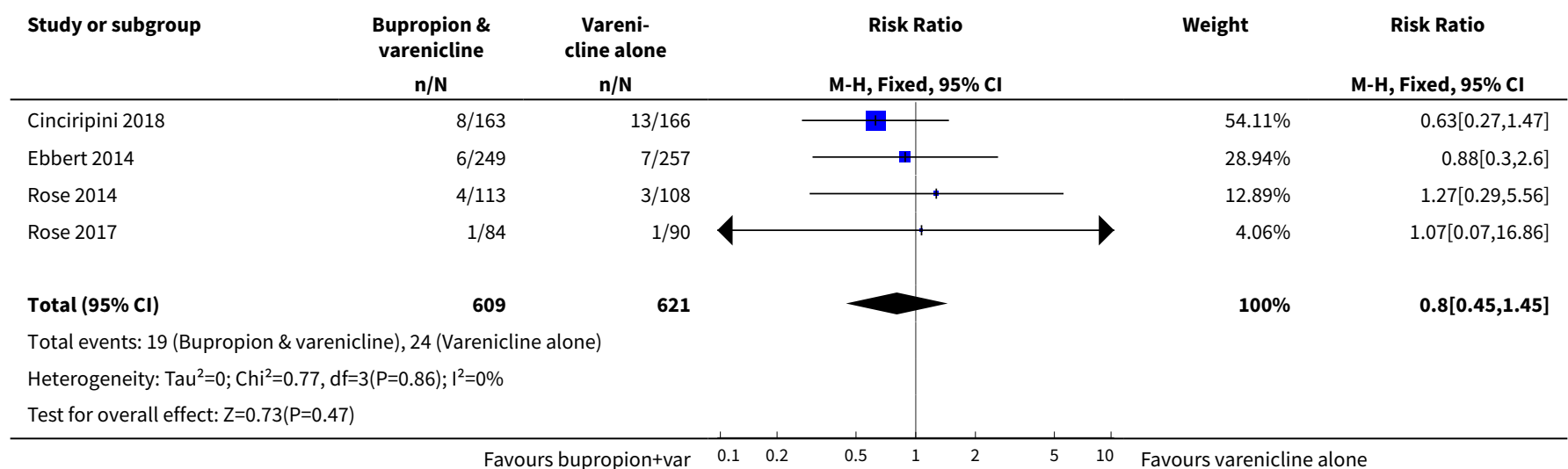

Comparison 4. Exploratory safety analysis: effects of bupropion only across comparisons

\begin{tabular}{|c|c|c|c|c|}
\hline Outcome or subgroup title & $\begin{array}{l}\text { No. of } \\
\text { studies }\end{array}$ & $\begin{array}{l}\text { No. of } \\
\text { partici- } \\
\text { pants }\end{array}$ & Statistical method & Effect size \\
\hline 1 Adverse events & 25 & 12249 & Risk Ratio (M-H, Fixed, 95\% Cl) & $1.14[1.11,1.17]$ \\
\hline 1.1 Bupropion versus control & 19 & 10893 & Risk Ratio (M-H, Fixed, 95\% Cl) & $1.14[1.11,1.18]$ \\
\hline $\begin{array}{l}\text { 1.2 Bupropion + NRT versus } \\
\text { NRT }\end{array}$ & 2 & 313 & Risk Ratio (M-H, Fixed, 95\% Cl) & $1.21[1.02,1.43]$ \\
\hline $\begin{array}{l}1.3 \text { Bupropion + varenicline } \\
\text { versus varenicline }\end{array}$ & 4 & 1043 & Risk Ratio (M-H, Fixed, 95\% Cl) & $1.09[1.02,1.17]$ \\
\hline 2 Psychiatric adverse events & 8 & 5274 & Risk Ratio (M-H, Fixed, 95\% Cl) & $1.24[1.15,1.33]$ \\
\hline 2.1 Bupropion versus control & 6 & 4439 & Risk Ratio (M-H, Fixed, 95\% Cl) & $1.25[1.15,1.37]$ \\
\hline $\begin{array}{l}2.2 \text { Bupropion + varenicline } \\
\text { versus varenicline }\end{array}$ & 2 & 835 & Risk Ratio (M-H, Fixed, 95\% Cl) & $1.15[1.03,1.30]$ \\
\hline 3 Serious adverse events & 28 & 12500 & Risk Ratio (M-H, Fixed, 95\% Cl) & $1.17[0.93,1.47]$ \\
\hline
\end{tabular}




\begin{tabular}{|c|c|c|c|c|}
\hline Outcome or subgroup title & $\begin{array}{l}\text { No. of } \\
\text { studies }\end{array}$ & $\begin{array}{l}\text { No. of } \\
\text { partici- } \\
\text { pants }\end{array}$ & Statistical method & Effect size \\
\hline 3.1 Bupropion versus control & 21 & 10625 & Risk Ratio (M-H, Fixed, 95\% Cl) & $1.16[0.90,1.48]$ \\
\hline $\begin{array}{l}\text { 3.2 Bupropion + NRT versus } \\
\text { NRT }\end{array}$ & 3 & 607 & Risk Ratio (M-H, Fixed, 95\% Cl) & $1.52[0.26,8.89]$ \\
\hline $\begin{array}{l}\text { 3.3 Bupropion + varenicline } \\
\text { versus varenicline }\end{array}$ & 5 & 1268 & Risk Ratio (M-H, Fixed, 95\% Cl) & $1.23[0.63,2.42]$ \\
\hline 4 Dropouts due to drug & 30 & 14108 & Risk Ratio (M-H, Fixed, 95\% Cl) & $1.35[1.20,1.52]$ \\
\hline 4.1 Bupropion versus control & 25 & 12340 & Risk Ratio (M-H, Fixed, 95\% Cl) & $1.37[1.21,1.56]$ \\
\hline $\begin{array}{l}\text { 4.2 Bupropion + NRT versus } \\
\text { NRT }\end{array}$ & 2 & 538 & Risk Ratio (M-H, Fixed, 95\% Cl) & $1.67[0.95,2.92]$ \\
\hline $\begin{array}{l}\text { 4.3 Bupropion + varenicline } \\
\text { versus varenicline }\end{array}$ & 4 & 1230 & Risk Ratio (M-H, Fixed, 95\% Cl) & $0.80[0.45,1.45]$ \\
\hline
\end{tabular}

\section{Analysis 4.1. Comparison 4 Exploratory safety analysis: effects of bupropion only across comparisons, Outcome 1 Adverse events.}

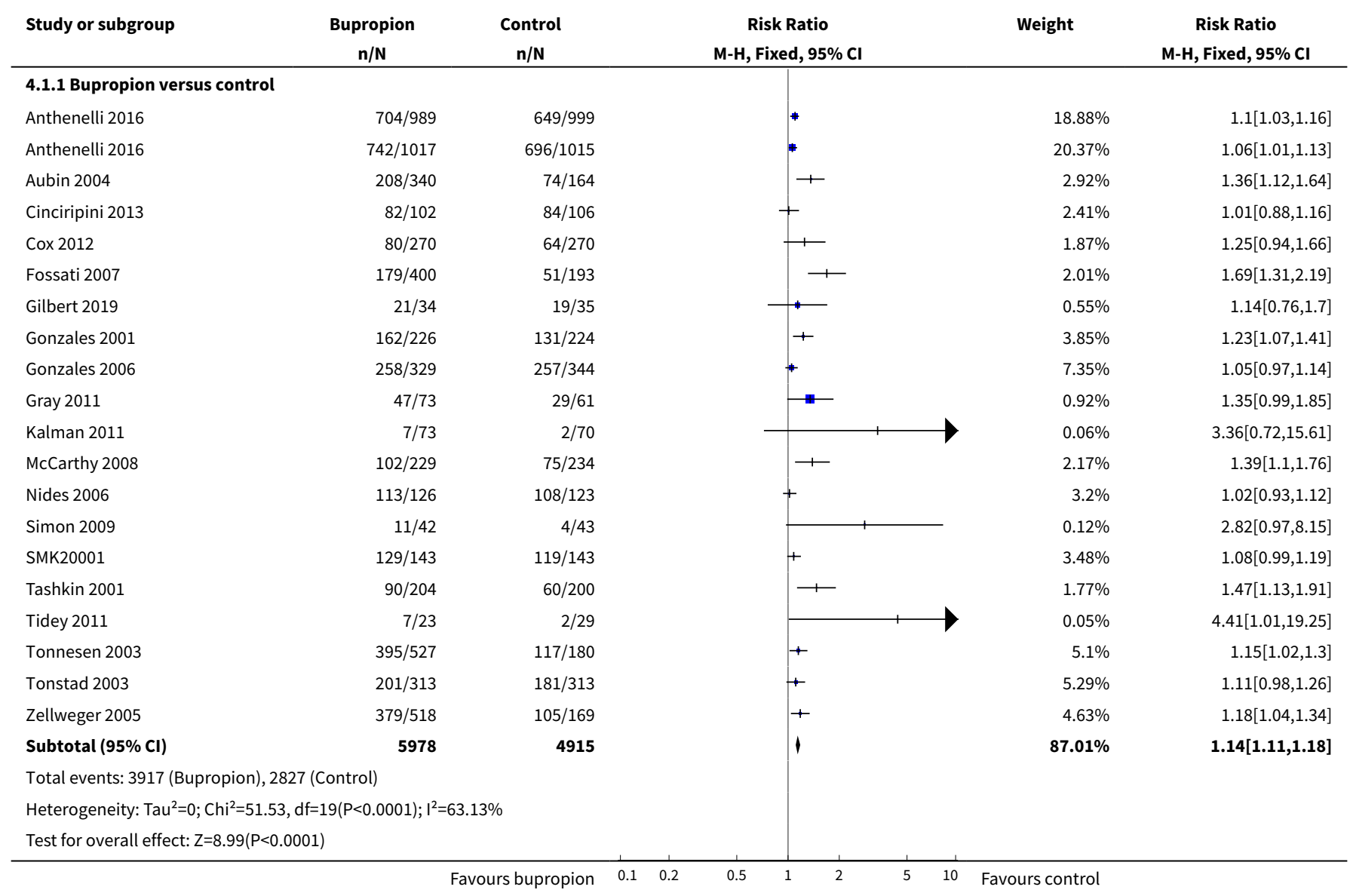




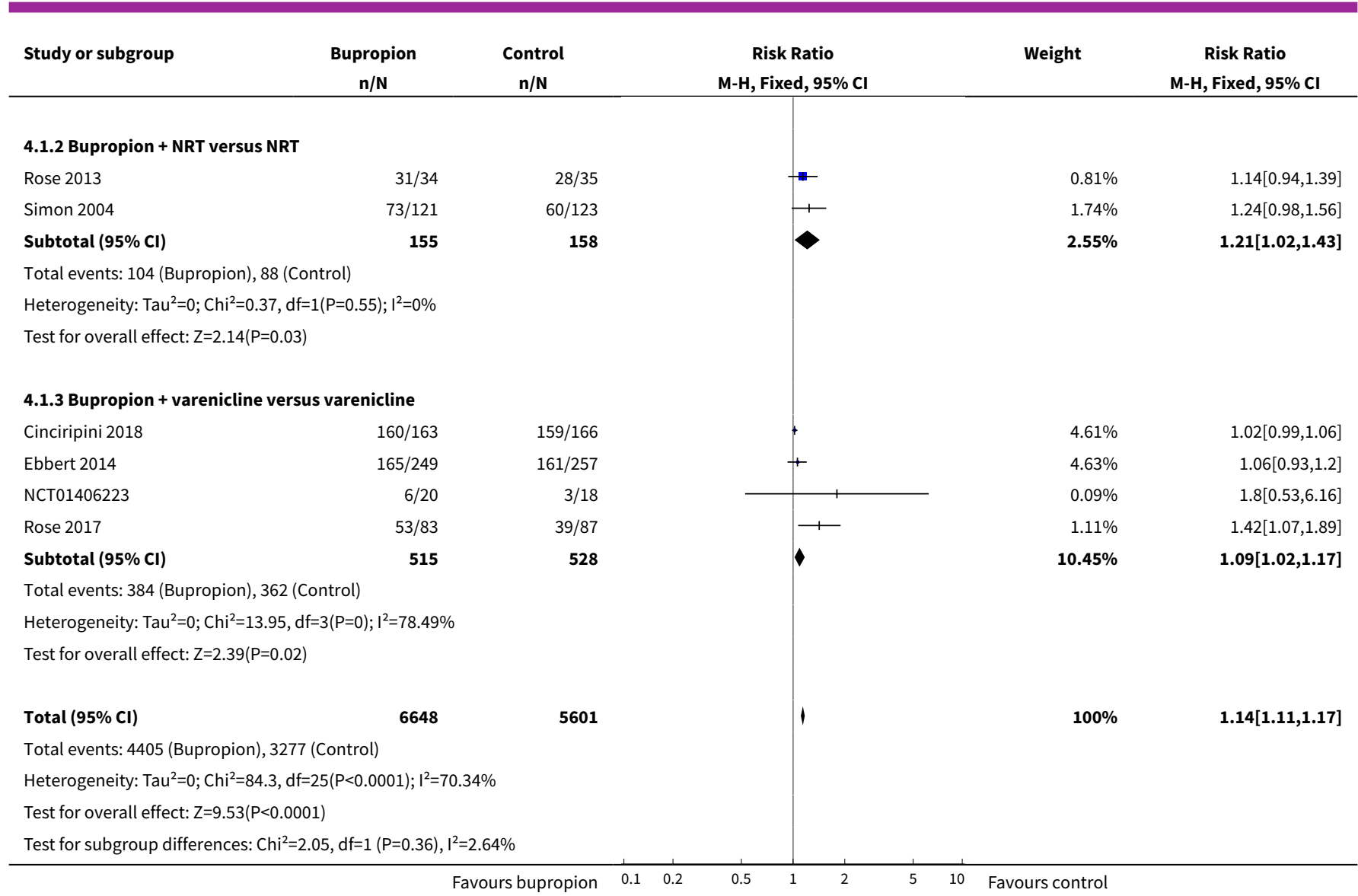

Analysis 4.2. Comparison 4 Exploratory safety analysis: effects of bupropion only across comparisons, Outcome 2 Psychiatric adverse events.

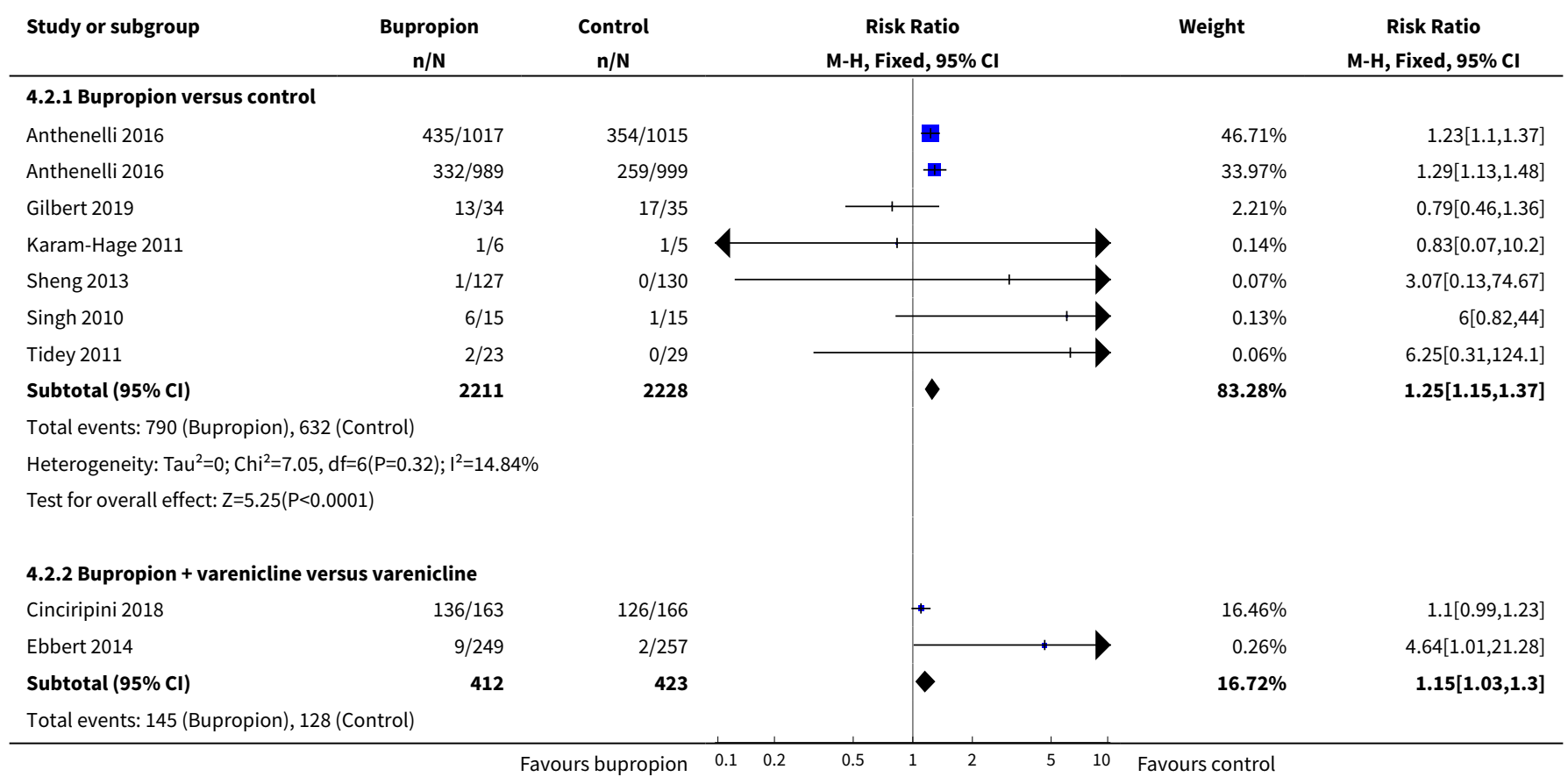




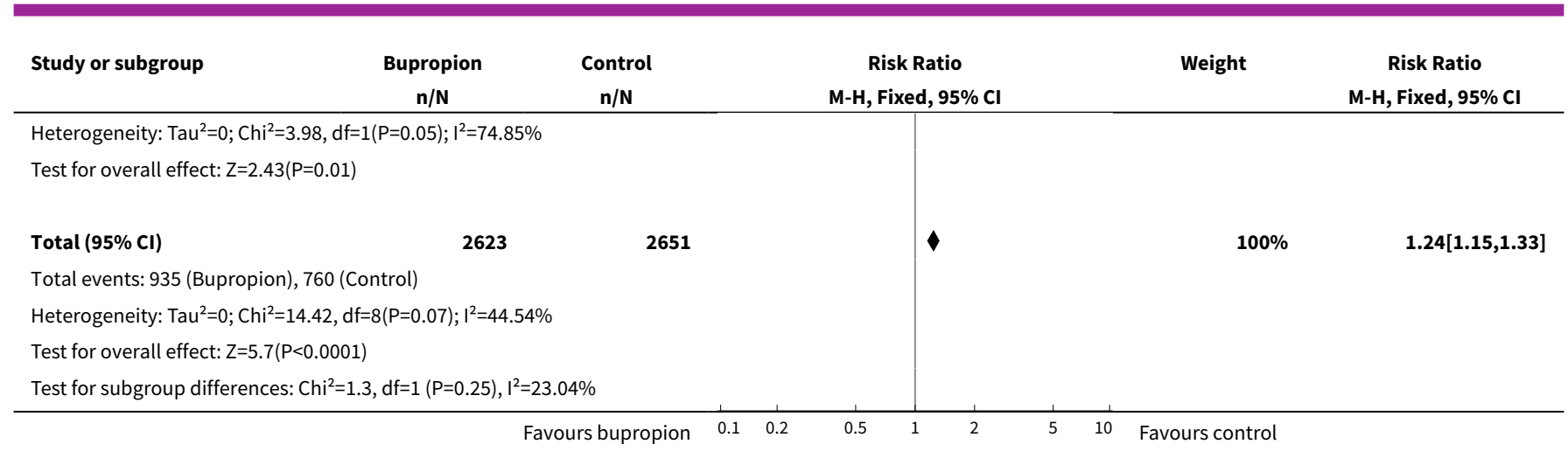

Analysis 4.3. Comparison 4 Exploratory safety analysis: effects of bupropion only across comparisons, Outcome 3 Serious adverse events.

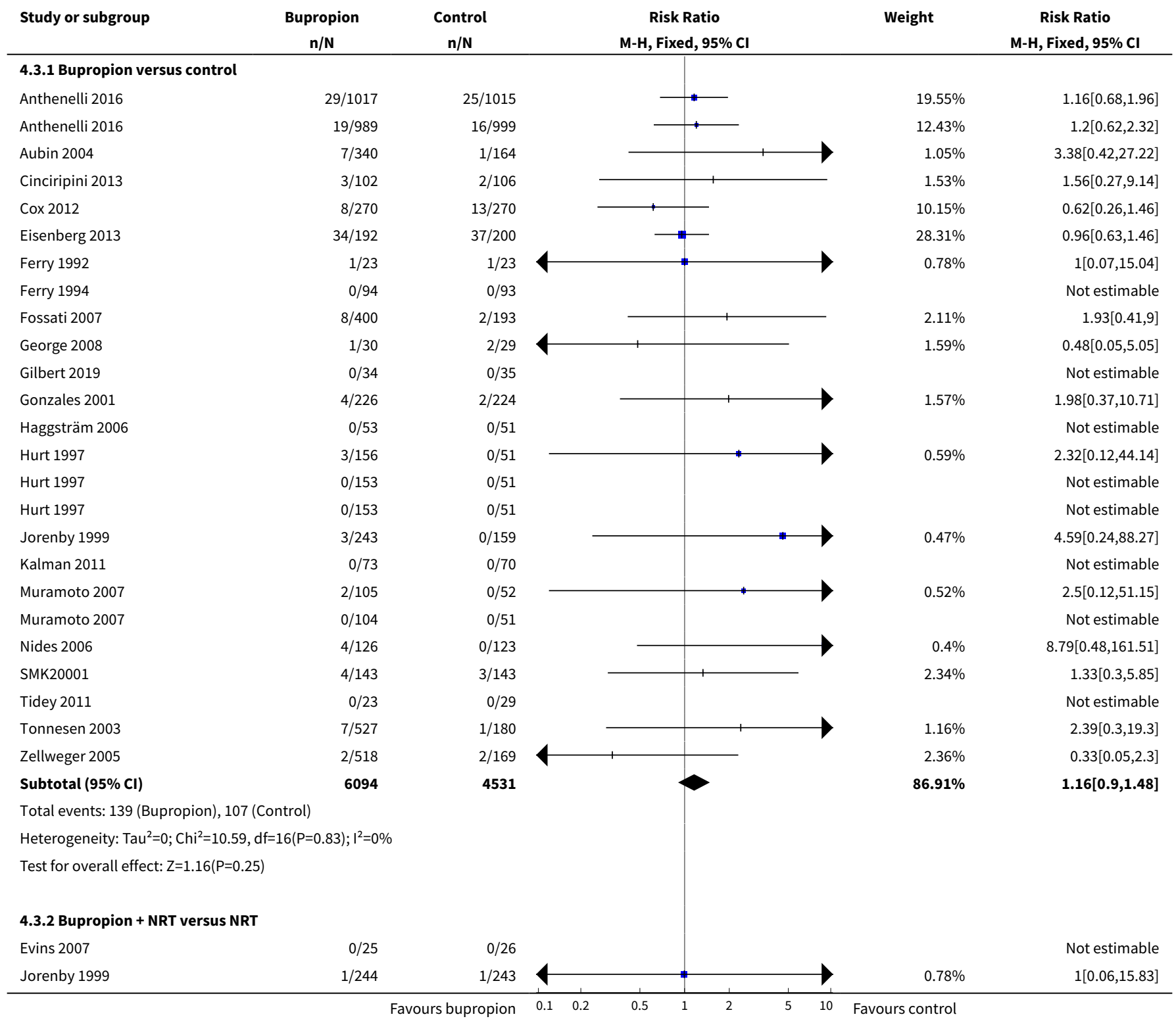




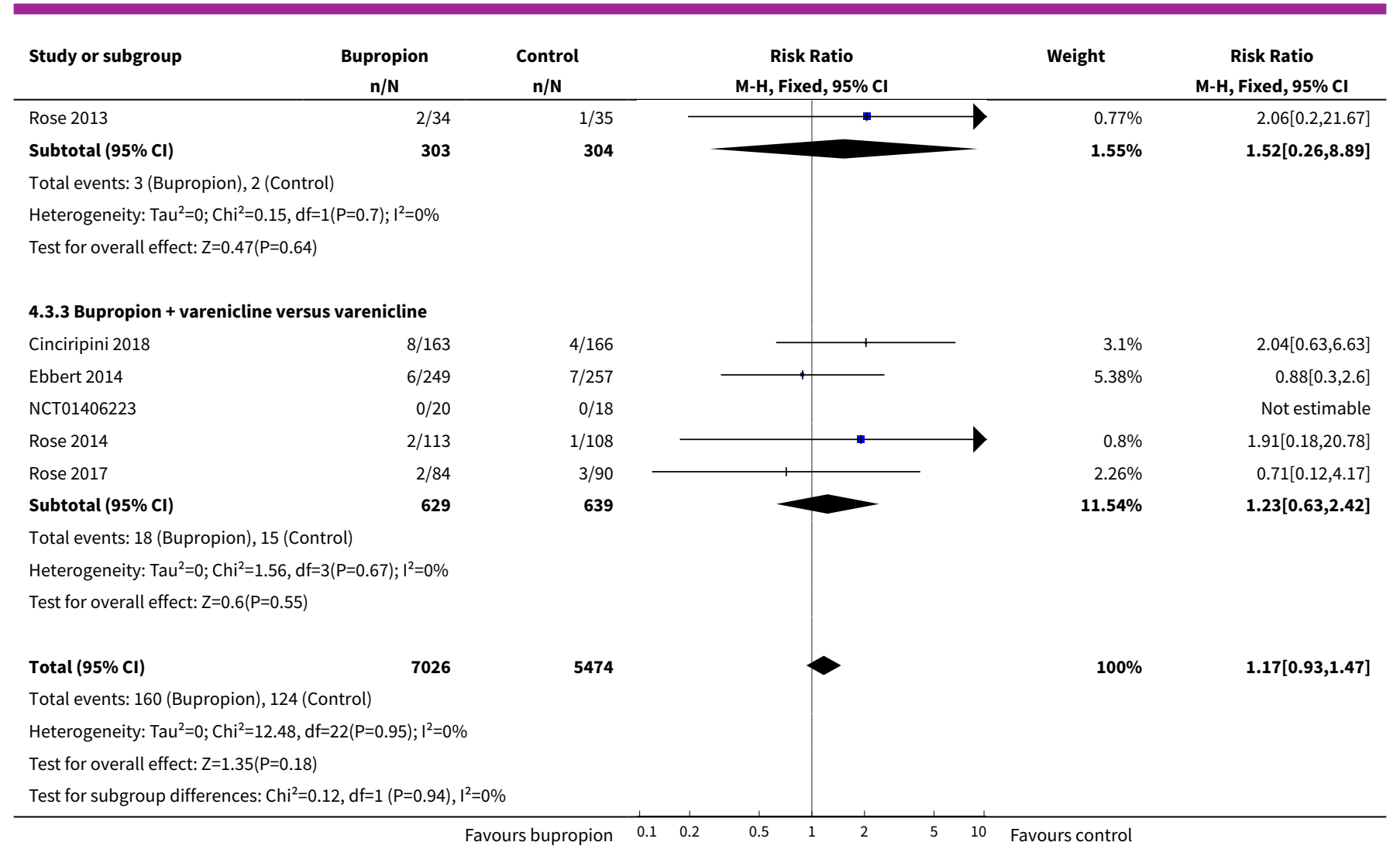

Analysis 4.4. Comparison 4 Exploratory safety analysis: effects of bupropion only across comparisons, Outcome 4 Dropouts due to drug.

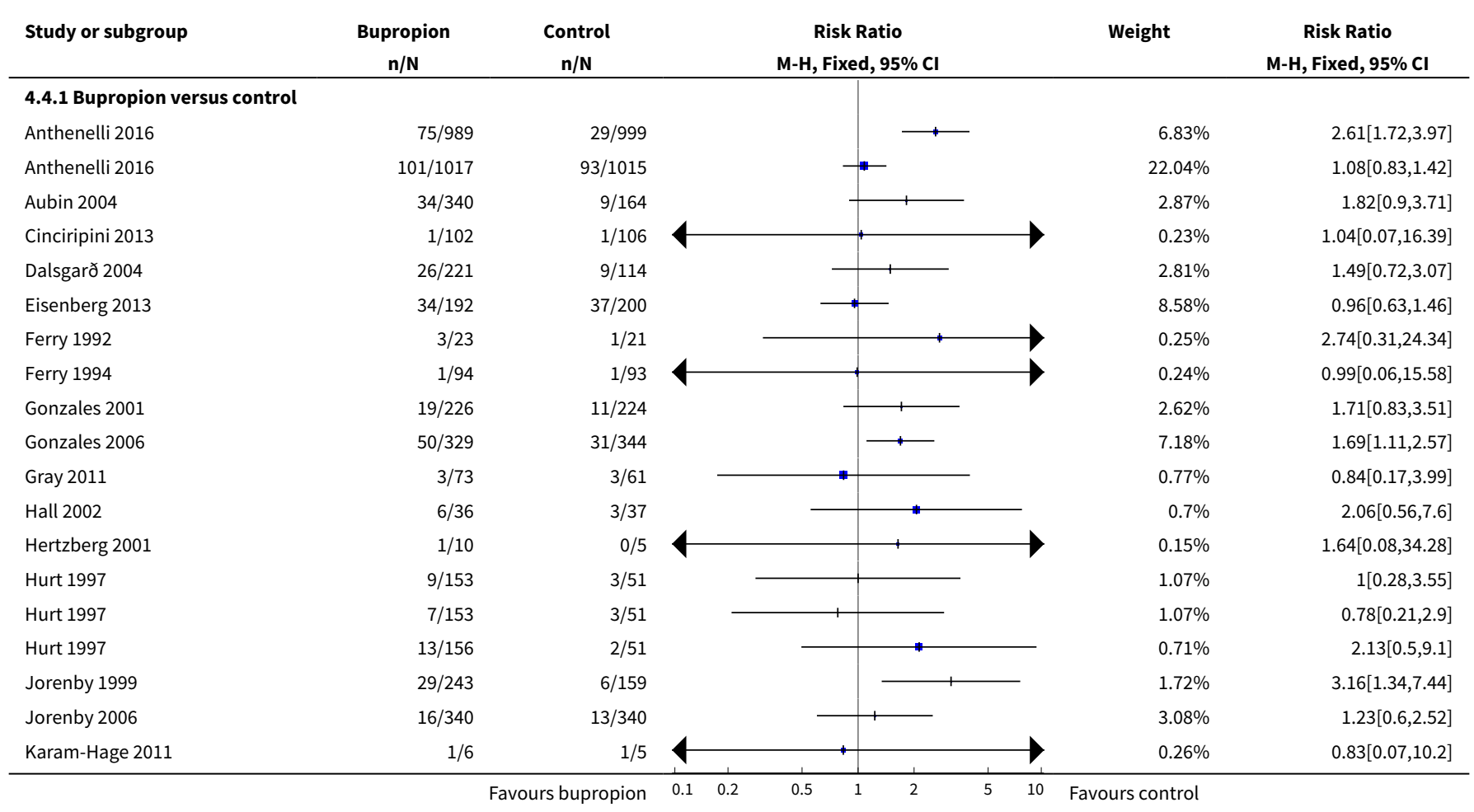




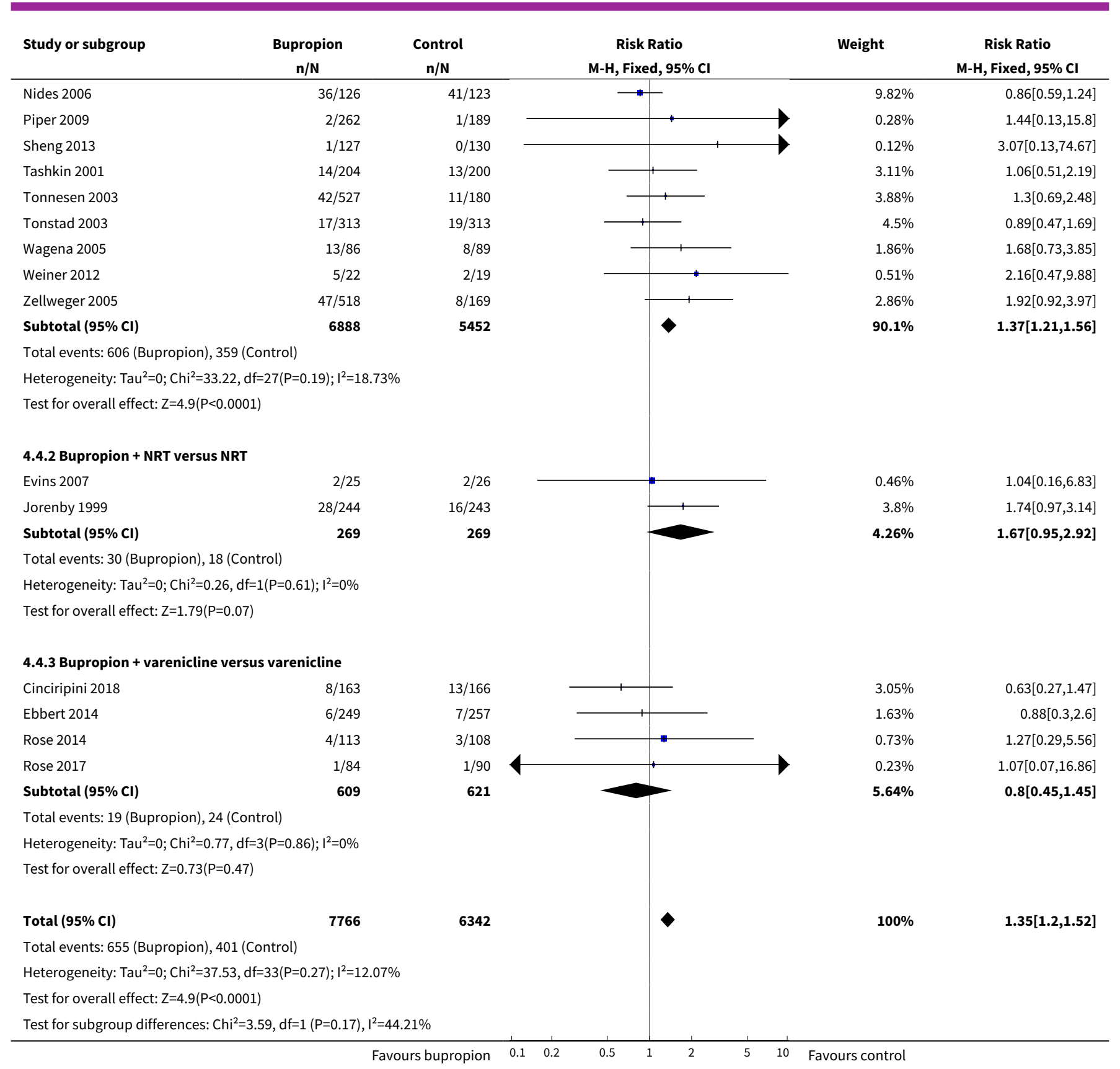

\section{Comparison 5. Bupropion versus varenicline}

\begin{tabular}{lllll}
\hline Outcome or subgroup title & $\begin{array}{l}\text { No. of } \\
\text { studies }\end{array}$ & $\begin{array}{l}\text { No. of } \\
\text { partici- } \\
\text { pants }\end{array}$ & Statistical method & Effect size \\
\hline 1 Smoking cessation & 6 & 6286 & Risk Ratio (M-H, Fixed, 95\% Cl) & $0.71[0.64,0.79]$ \\
\hline 2 Adverse events & 5 & 5780 & Risk Ratio (M-H, Fixed, 95\% Cl) & $0.98[0.95,1.00]$ \\
\hline 3 Serious adverse events & 4 & 4742 & Risk Ratio (M-H, Fixed, 95\% Cl) & $1.39[0.94,2.04]$ \\
\hline
\end{tabular}




\begin{tabular}{lllll}
\hline Outcome or subgroup title & $\begin{array}{l}\text { No. of } \\
\text { studies }\end{array}$ & $\begin{array}{l}\text { No. of } \\
\text { partici- } \\
\text { pants }\end{array}$ & Statistical method & Effect size \\
\hline 4 Psychiatric adverse events & 2 & 4051 & Risk Ratio $(\mathrm{M}-\mathrm{H}$, Fixed, 95\% Cl) & $1.07[0.99,1.16]$ \\
\hline 5 Seizures & 4 & 5389 & Risk Ratio (M-H, Fixed, 95\% Cl) & $7.16[0.92,55.42]$ \\
\hline 6 Overdoses & 2 & 4210 & Risk Ratio (M-H, Fixed, 95\% Cl) & $0.92[0.14,6.25]$ \\
\hline 7 Suicide attempts & 3 & 4239 & Risk Ratio (M-H, Fixed, 95\% Cl) & $3.01[0.31,28.96]$ \\
\hline 8 Death by suicide & 5 & 5600 & Risk Ratio (M-H, Fixed, 95\% Cl) & $0.0[0.0,0.0]$ \\
\hline 9 All-cause mortality & 5 & 6074 & Risk Ratio (M-H, Fixed, 95\% Cl) & $3.01[0.31,28.96]$ \\
\hline 10 Insomnia & 3 & 5208 & Risk Ratio (M-H, Fixed, 95\% Cl) & $1.40[1.22,1.60]$ \\
\hline 11 Anxiety & 2 & 4705 & Risk Ratio (M-H, Fixed, 95\% Cl) & $1.28[1.07,1.53]$ \\
\hline 12 Dropouts due to drug & 6 & 6103 & Risk Ratio (M-H, Fixed, 95\% Cl) & $1.12[0.96,1.31]$
\end{tabular}

Analysis 5.1. Comparison 5 Bupropion versus varenicline, Outcome 1 Smoking cessation.

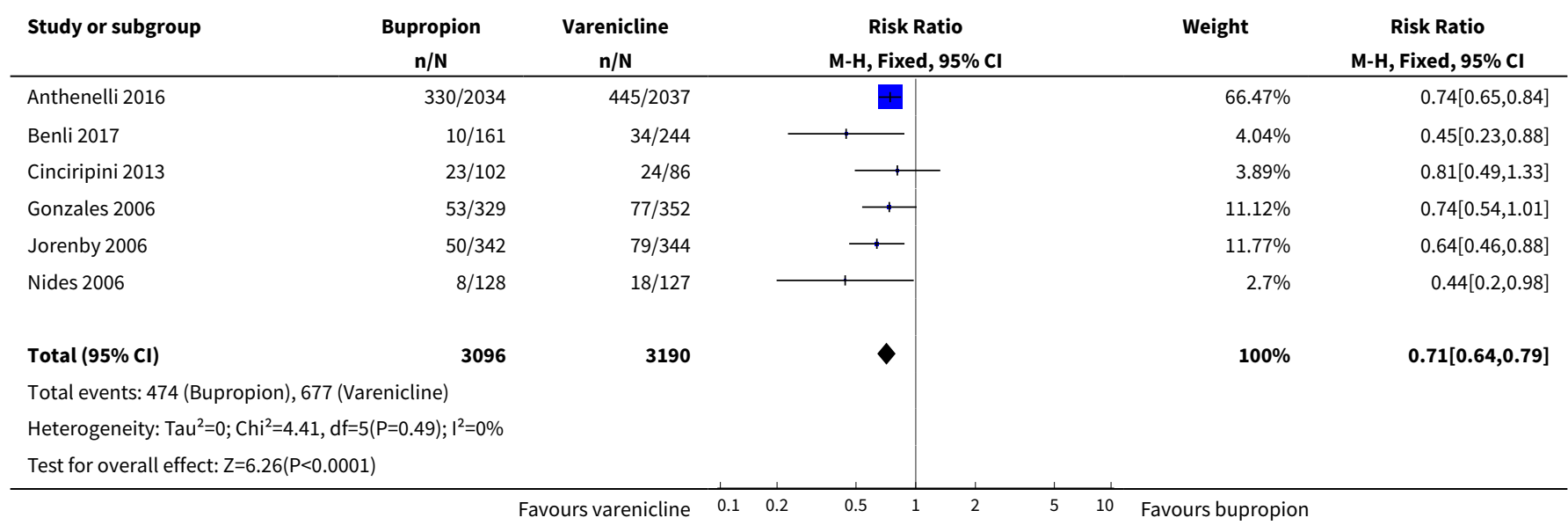

Analysis 5.2. Comparison 5 Bupropion versus varenicline, Outcome 2 Adverse events.

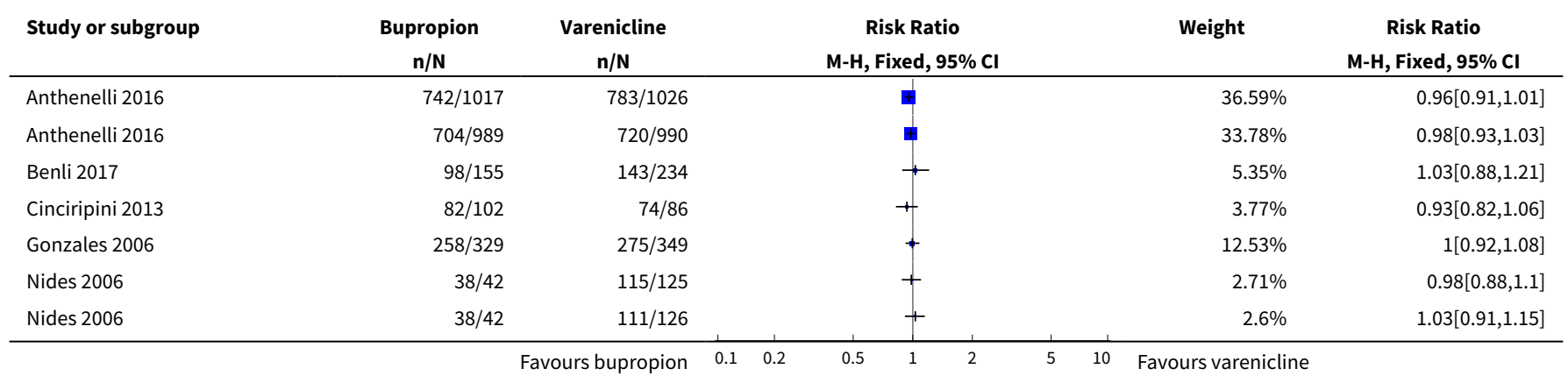




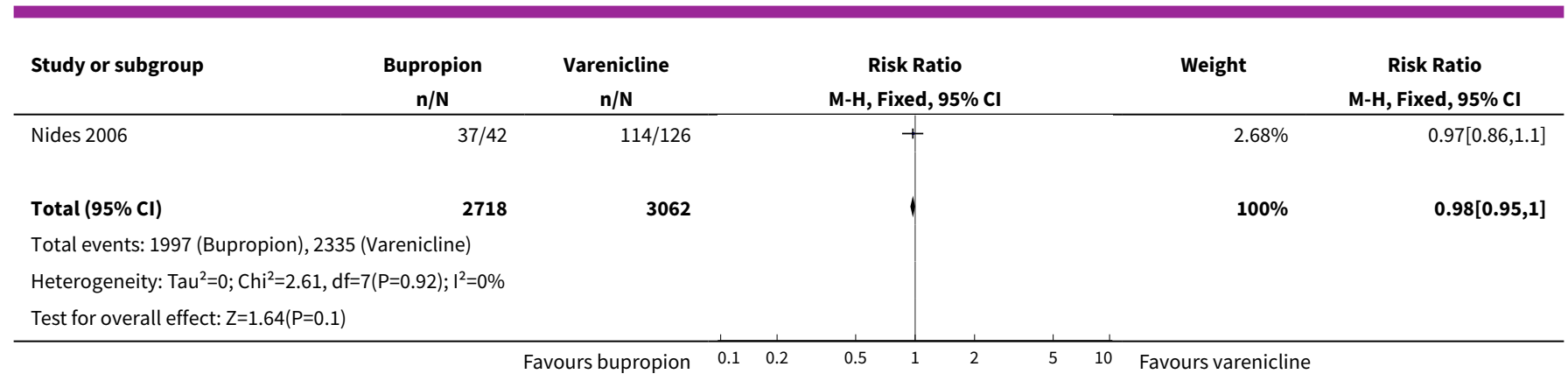

Analysis 5.3. Comparison 5 Bupropion versus varenicline, Outcome 3 Serious adverse events.

\begin{tabular}{|c|c|c|c|c|c|}
\hline Study or subgroup & $\begin{array}{c}\text { Bupropion } \\
\mathrm{n} / \mathrm{N} \\
\end{array}$ & $\begin{array}{c}\text { Varenicline } \\
\mathbf{n} / \mathbf{N} \\
\end{array}$ & $\begin{array}{c}\text { Risk Ratio } \\
\text { M-H, Fixed, 95\% Cl }\end{array}$ & Weight & $\begin{array}{c}\text { Risk Ratio } \\
\text { M-H, Fixed, 95\% Cl }\end{array}$ \\
\hline Anthenelli 2016 & $29 / 1017$ & $23 / 1026$ & 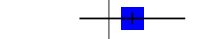 & $54.43 \%$ & $1.27[0.74,2.18]$ \\
\hline Anthenelli 2016 & $19 / 989$ & $16 / 990$ & $\longrightarrow$ & $38.01 \%$ & $1.19[0.61,2.3]$ \\
\hline Cinciripini 2013 & $3 / 102$ & $2 / 86$ & & $5.16 \%$ & $1.26[0.22,7.4]$ \\
\hline Gray 2012 & $0 / 14$ & $0 / 15$ & & & Not estimable \\
\hline Nides 2006 & $1 / 42$ & $0 / 126$ & & $0.6 \%$ & $8.86[0.37,213.46]$ \\
\hline Nides 2006 & $2 / 42$ & $1 / 125$ & & $1.2 \%$ & $5.95[0.55,63.99]$ \\
\hline Nides 2006 & $1 / 42$ & $0 / 126$ & & $0.6 \%$ & $8.86[0.37,213.46]$ \\
\hline Total $(95 \% \mathrm{Cl})$ & 2248 & 2494 & & $100 \%$ & $1.39[0.94,2.04]$ \\
\hline \multicolumn{6}{|c|}{ Total events: 55 (Bupropion), 42 (Varenicline) } \\
\hline \multicolumn{6}{|c|}{ Heterogeneity: Tau $^{2}=0 ; \mathrm{Chi}^{2}=4.37, \mathrm{df}=5(\mathrm{P}=0.5) ; \mathrm{I}^{2}=0 \%$} \\
\hline Test for overall effect & & & & & \\
\hline
\end{tabular}

Analysis 5.4. Comparison 5 Bupropion versus varenicline, Outcome 4 Psychiatric adverse events.

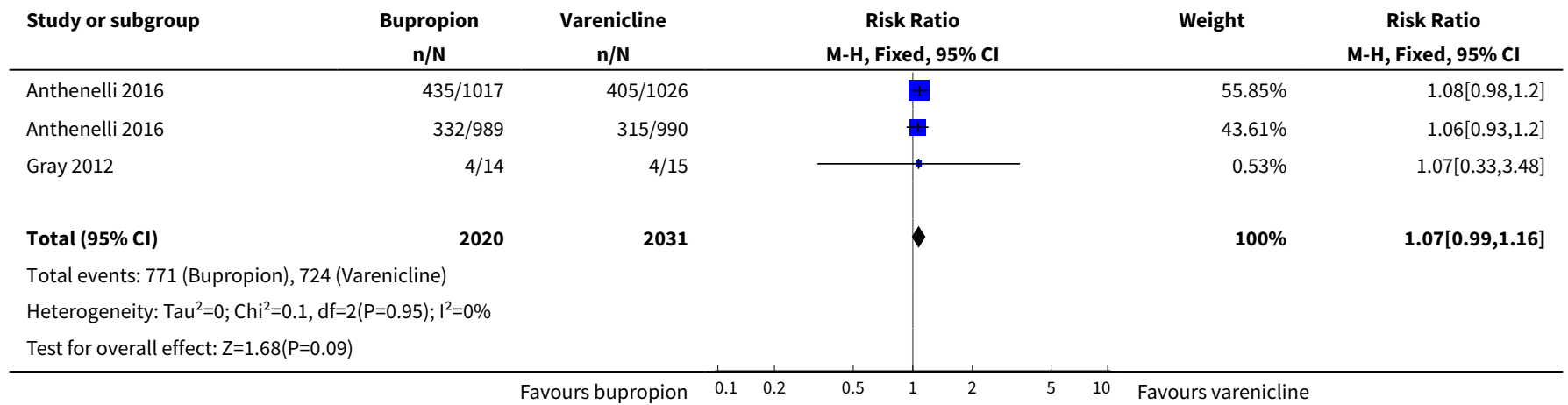


Analysis 5.5. Comparison 5 Bupropion versus varenicline, Outcome 5 Seizures.

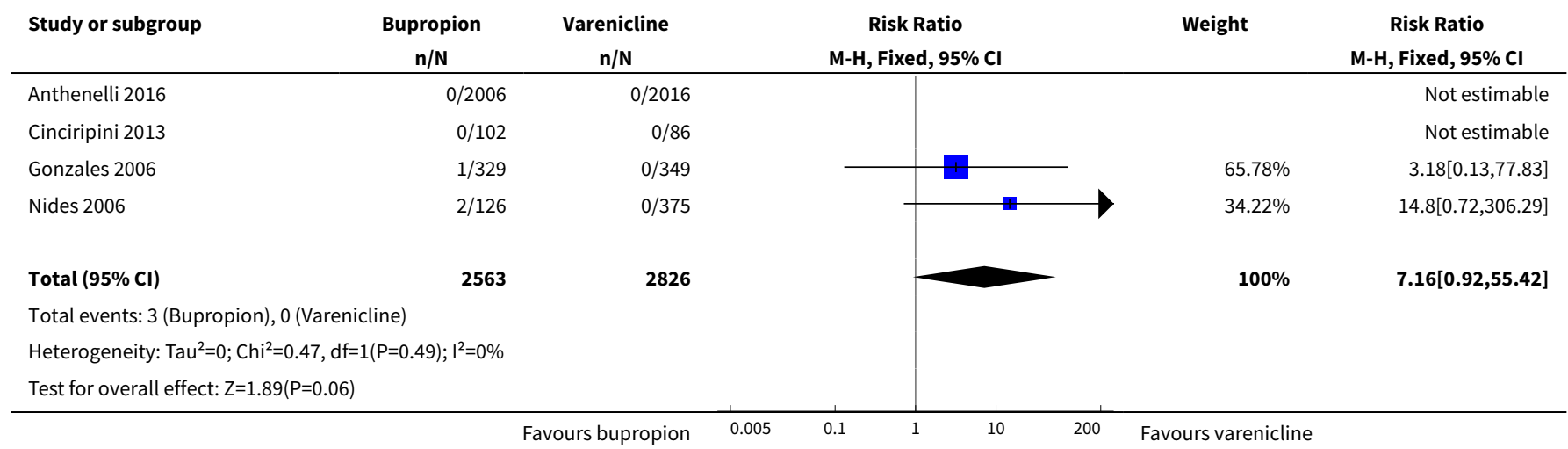

Analysis 5.6. Comparison 5 Bupropion versus varenicline, Outcome 6 Overdoses.

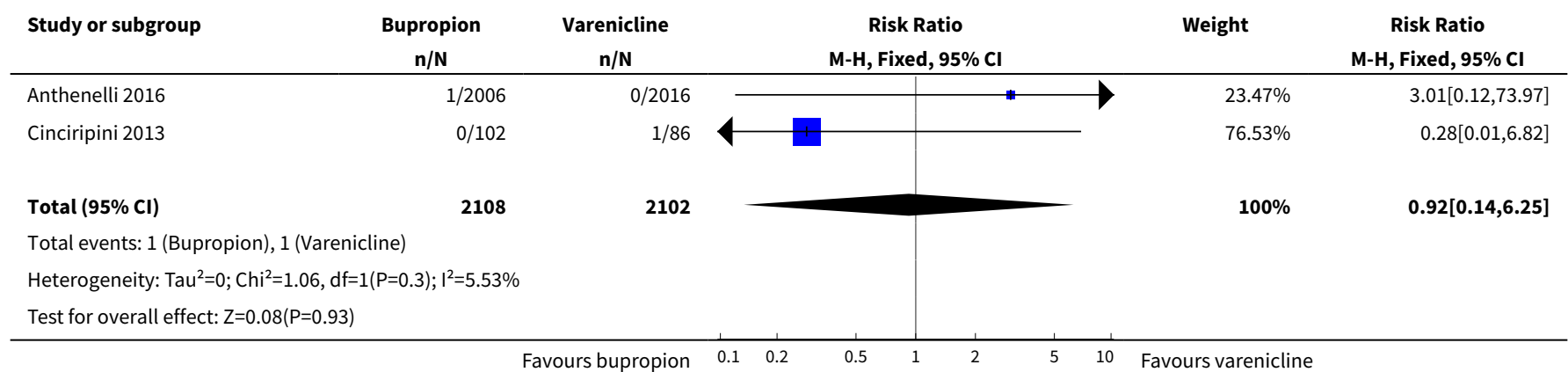

Analysis 5.7. Comparison 5 Bupropion versus varenicline, Outcome 7 Suicide attempts.

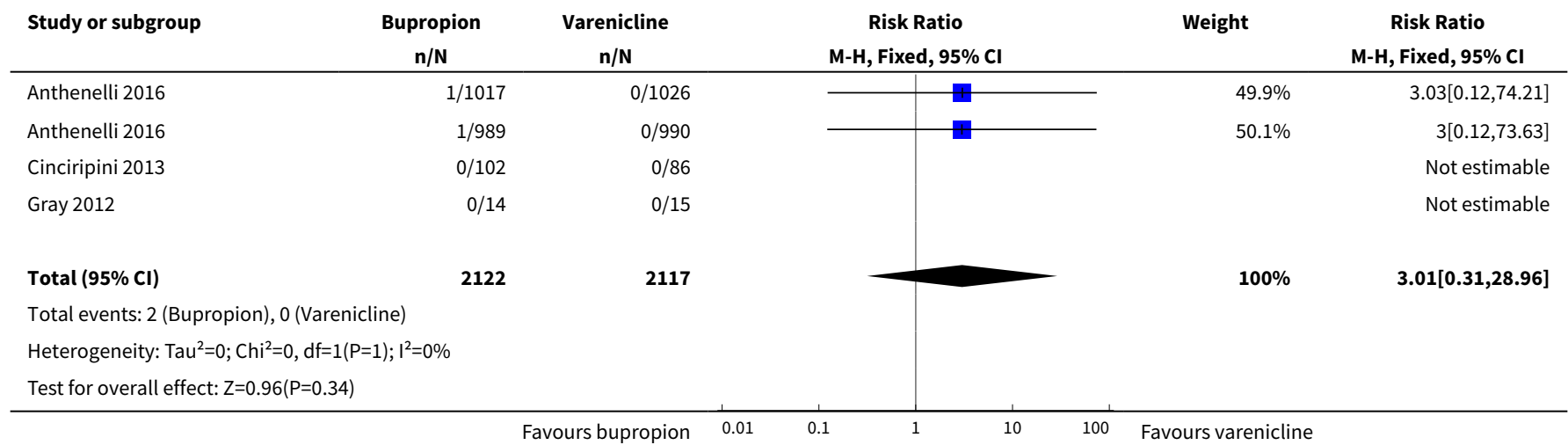


Analysis 5.8. Comparison 5 Bupropion versus varenicline, Outcome 8 Death by suicide.

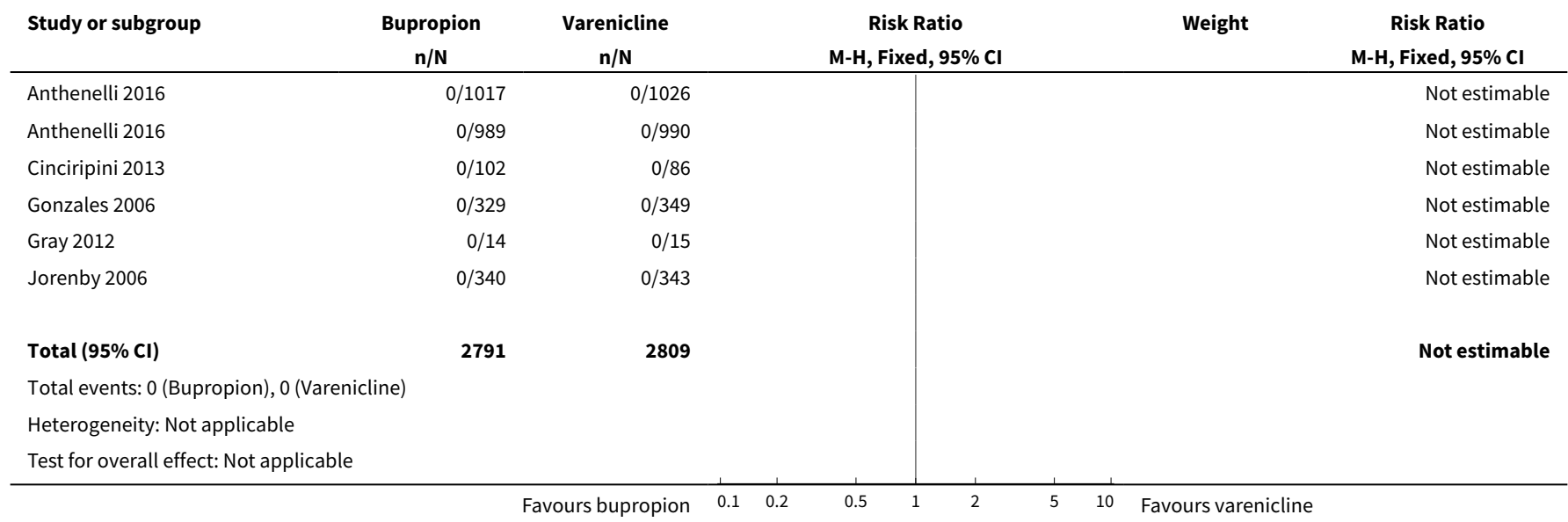

Analysis 5.9. Comparison 5 Bupropion versus varenicline, Outcome 9 All-cause mortality.

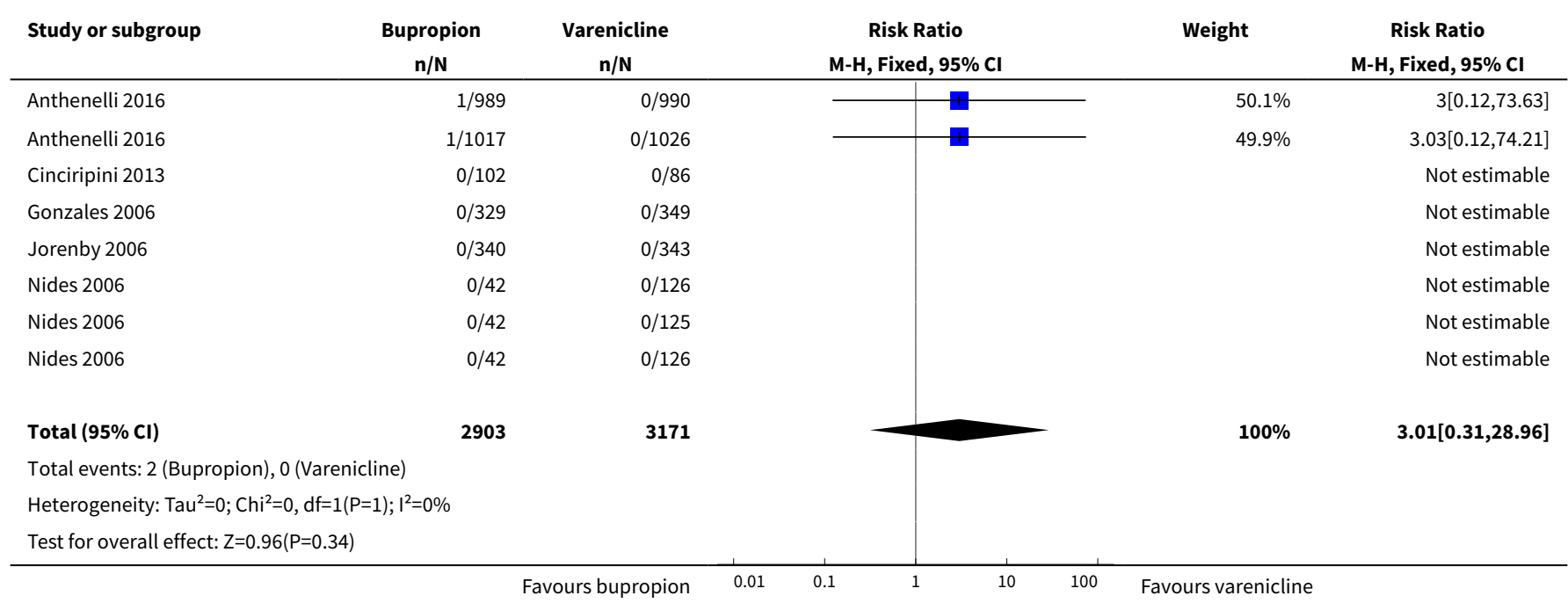

Analysis 5.10. Comparison 5 Bupropion versus varenicline, Outcome 10 Insomnia.

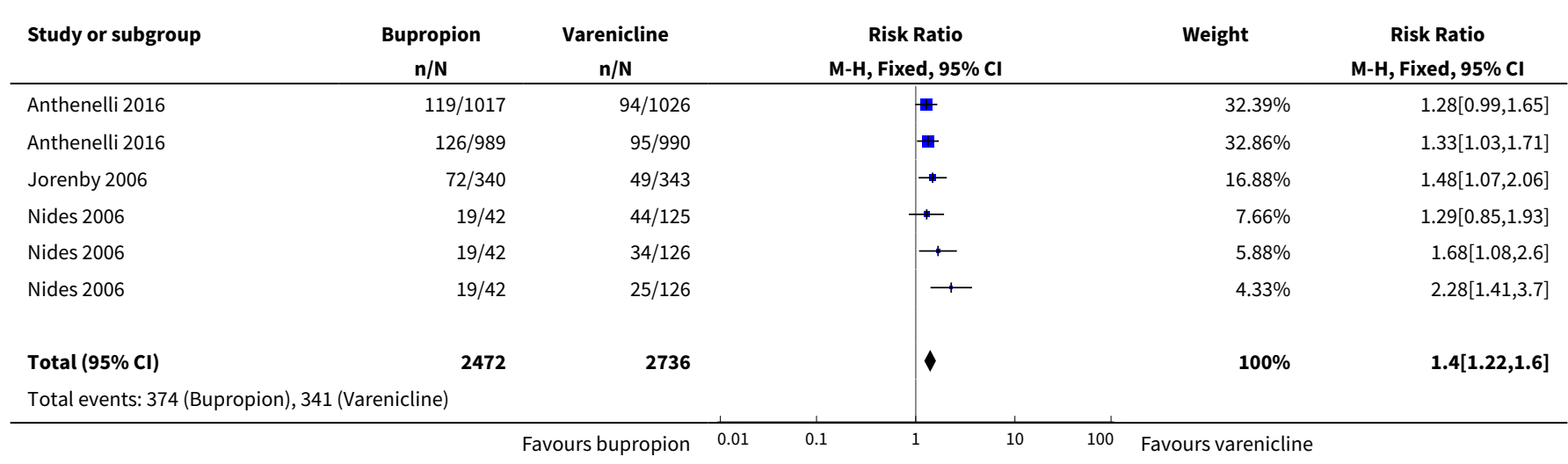




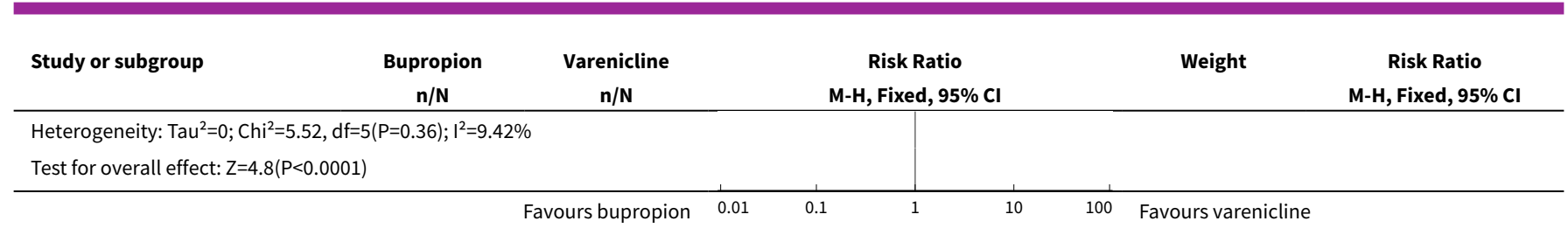

Analysis 5.11. Comparison 5 Bupropion versus varenicline, Outcome 11 Anxiety.

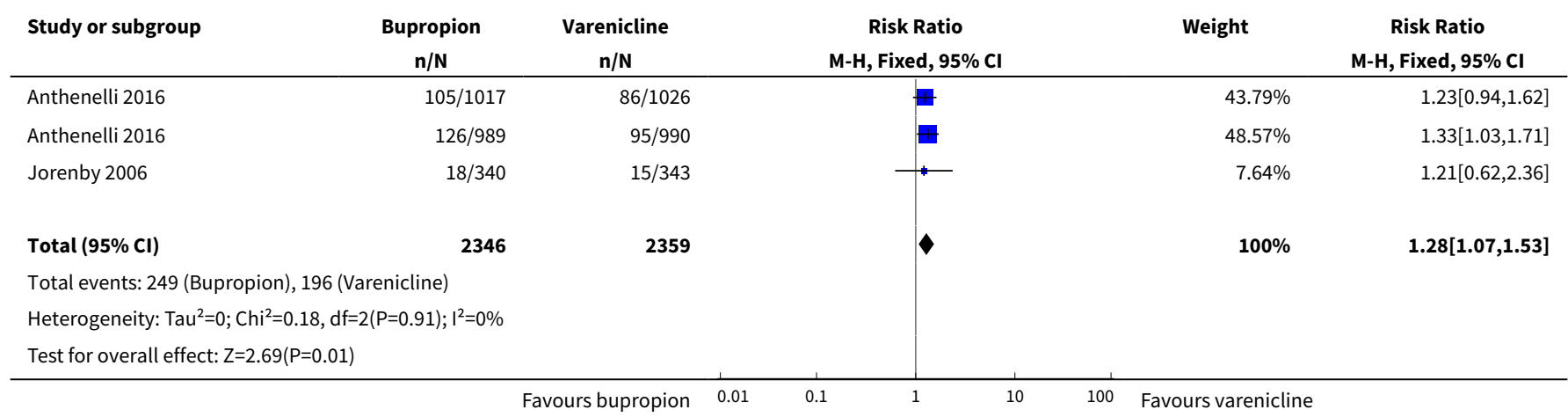

Analysis 5.12. Comparison 5 Bupropion versus varenicline, Outcome 12 Dropouts due to drug.

\begin{tabular}{|c|c|c|c|c|c|}
\hline Study or subgroup & $\begin{array}{c}\text { Bupropion } \\
\mathrm{n} / \mathrm{N}\end{array}$ & $\begin{array}{c}\text { Varenicline } \\
\mathrm{n} / \mathrm{N}\end{array}$ & $\begin{array}{c}\text { Risk Ratio } \\
\text { M-H, Fixed, } 95 \% \mathrm{Cl}\end{array}$ & Weight & $\begin{array}{c}\text { Risk Ratio } \\
\text { M-H, Fixed, } 95 \% \mathrm{Cl}\end{array}$ \\
\hline Anthenelli 2016 & $101 / 1017$ & $109 / 1026$ & $\rightarrow-$ & $40.29 \%$ & $0.93[0.72,1.21]$ \\
\hline Anthenelli 2016 & $75 / 989$ & $57 / 990$ & $\longrightarrow$ & $21.15 \%$ & $1.32[0.94,1.84]$ \\
\hline Cinciripini 2013 & $1 / 102$ & $2 / 86$ & & $0.81 \%$ & $0.42[0.04,4.57]$ \\
\hline Gonzales 2006 & $50 / 329$ & $30 / 349$ & 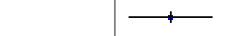 & $10.81 \%$ & $1.77[1.15,2.71]$ \\
\hline Gray 2012 & $2 / 14$ & $0 / 15$ & & $0.18 \%$ & $5.33[0.28,102.26]$ \\
\hline Jorenby 2006 & $16 / 340$ & $14 / 343$ & & $5.18 \%$ & $1.15[0.57,2.33]$ \\
\hline Nides 2006 & $12 / 42$ & $40 / 126$ & - & $7.43 \%$ & $0.9[0.52,1.55]$ \\
\hline Nides 2006 & $12 / 42$ & $39 / 125$ & & $7.28 \%$ & $0.92[0.53,1.58]$ \\
\hline Nides 2006 & $12 / 42$ & $37 / 126$ & $\longrightarrow$ & $6.87 \%$ & $0.97[0.56,1.69]$ \\
\hline Total $(95 \% \mathrm{Cl})$ & 2917 & 3186 & 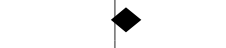 & $100 \%$ & $1.12[0.96,1.31]$ \\
\hline \multicolumn{6}{|c|}{ Total events: 281 (Bupropion), 328 (Varenicline) } \\
\hline \multicolumn{6}{|c|}{ Heterogeneity: $\mathrm{Tau}^{2}=0 ; \mathrm{Chi}^{2}=10.34, \mathrm{df}=8(\mathrm{P}=0.24) ; \mathrm{I}^{2}=22.61 \%$} \\
\hline Test for overall effec & & & & & \\
\hline
\end{tabular}

Comparison 6. Bupropion versus nicotine replacement therapy (NRT)

\begin{tabular}{lllll}
\hline Outcome or subgroup title & $\begin{array}{l}\text { No. of } \\
\text { studies }\end{array}$ & $\begin{array}{l}\text { No. of } \\
\text { partici- } \\
\text { pants }\end{array}$ & Statistical method & Effect size \\
\hline 1 Smoking cessation & 10 & 8230 & Risk Ratio (M-H, Fixed, 95\% Cl) & $0.99[0.91,1.09]$ \\
\hline
\end{tabular}




\begin{tabular}{|c|c|c|c|c|}
\hline Outcome or subgroup title & $\begin{array}{l}\text { No. of } \\
\text { studies }\end{array}$ & $\begin{array}{l}\text { No. of } \\
\text { partici- } \\
\text { pants }\end{array}$ & Statistical method & Effect size \\
\hline 1.1 Patch & 8 & 5778 & Risk Ratio (M-H, Fixed, 95\% Cl) & $1.04[0.92,1.16]$ \\
\hline 1.2 Lozenge & 2 & 694 & Risk Ratio (M-H, Fixed, 95\% Cl) & $0.91[0.67,1.22]$ \\
\hline 1.3 Patch + lozenge & 2 & 720 & Risk Ratio (M-H, Fixed, 95\% Cl) & $0.74[0.55,0.98]$ \\
\hline 1.4 Choice of NRT & 2 & 1038 & Risk Ratio (M-H, Fixed, 95\% Cl) & $1.08[0.87,1.33]$ \\
\hline 2 Adverse events & 2 & 4097 & Risk Ratio (M-H, Fixed, 95\% Cl) & $1.02[0.98,1.06]$ \\
\hline 3 Serious adverse events & 5 & 5624 & Risk Ratio (M-H, Fixed, 95\% Cl) & $1.22[0.83,1.80]$ \\
\hline 4 Psychiatric adverse events & 2 & & Risk Ratio (M-H, Fixed, 95\% Cl) & Totals not selected \\
\hline 5 Seizures & 1 & 4028 & Risk Ratio (M-H, Fixed, 95\% Cl) & $0.34[0.01,8.24]$ \\
\hline 6 Overdoses & 1 & 4028 & Risk Ratio (M-H, Fixed, 95\% Cl) & $3.02[0.12,74.19]$ \\
\hline 7 Suicide attempts & 2 & 4514 & Risk Ratio (M-H, Fixed, 95\% Cl) & $1.68[0.22,12.75]$ \\
\hline 8 Death by suicide & 2 & 4514 & Risk Ratio (M-H, Fixed, 95\% Cl) & $0.0[0.0,0.0]$ \\
\hline 9 All-cause mortality & 3 & 5313 & Risk Ratio (M-H, Fixed, 95\% Cl) & $1.36[0.38,4.84]$ \\
\hline 10 Insomnia & 2 & 4128 & Risk Ratio (M-H, Fixed, 95\% Cl) & $1.31[1.10,1.55]$ \\
\hline 11 Anxiety & 2 & 4855 & Risk Ratio (M-H, Fixed, 95\% Cl) & $1.31[1.06,1.62]$ \\
\hline 12 Dropouts due to drug & 4 & 4825 & Risk Ratio (M-H, Fixed, 95\% CI) & $1.14[0.95,1.38]$ \\
\hline
\end{tabular}

\section{Analysis 6.1. Comparison 6 Bupropion versus nicotine replacement therapy (NRT), Outcome 1 Smoking cessation.}

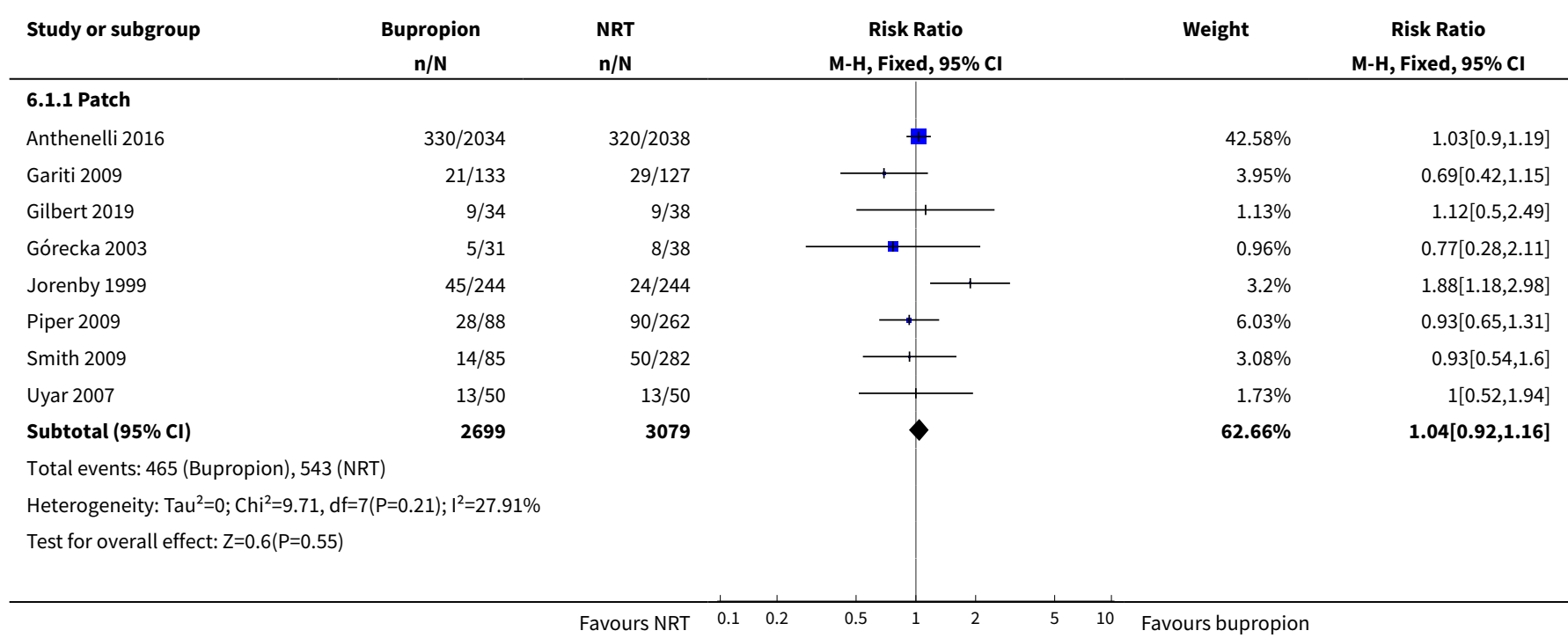




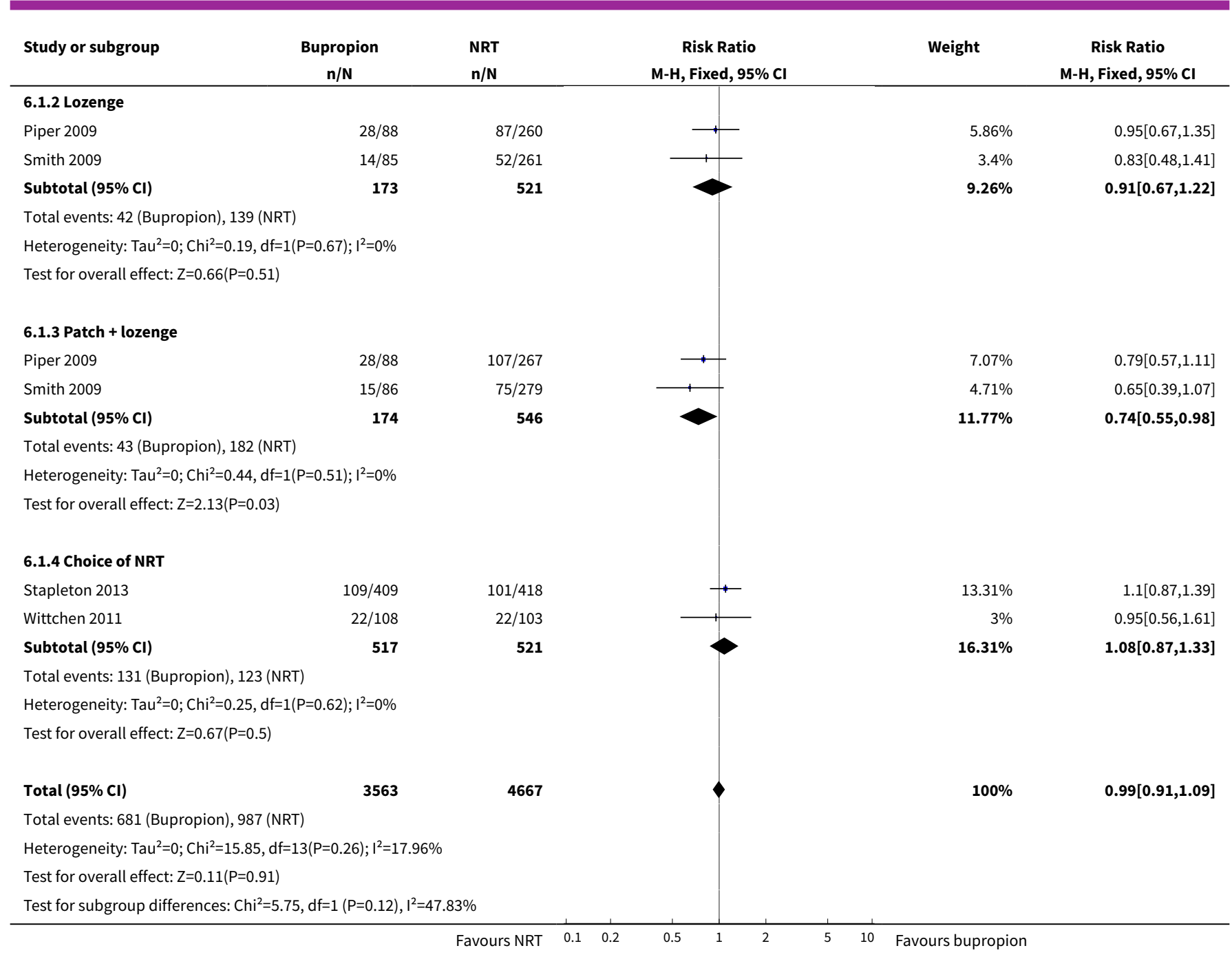

Analysis 6.2. Comparison 6 Bupropion versus nicotine replacement therapy (NRT), Outcome 2 Adverse events.

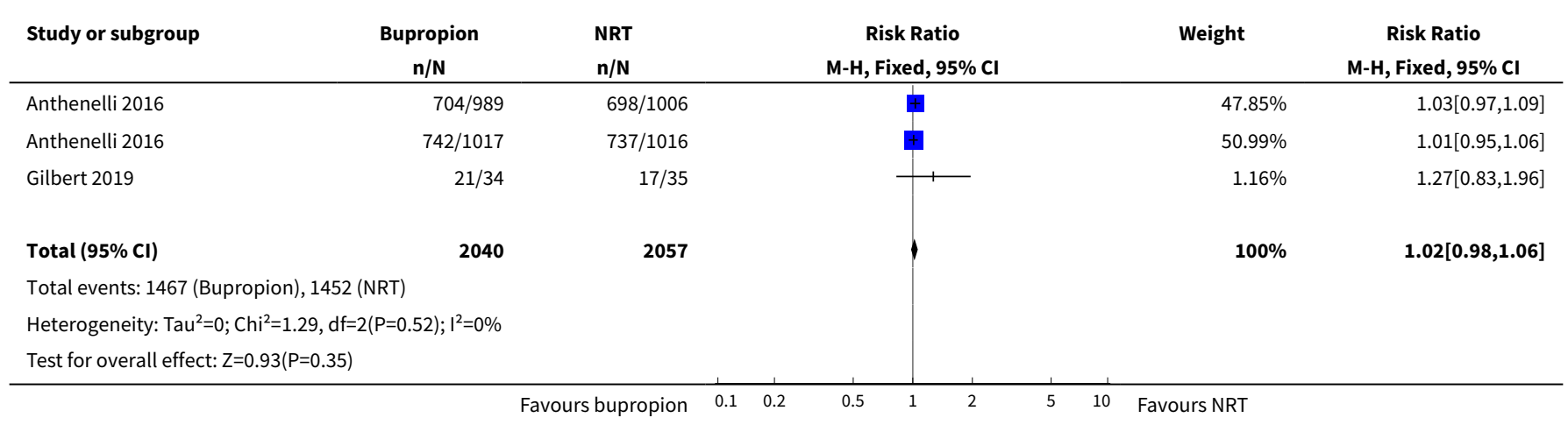


Analysis 6.3. Comparison 6 Bupropion versus nicotine replacement therapy (NRT), Outcome 3 Serious adverse events.

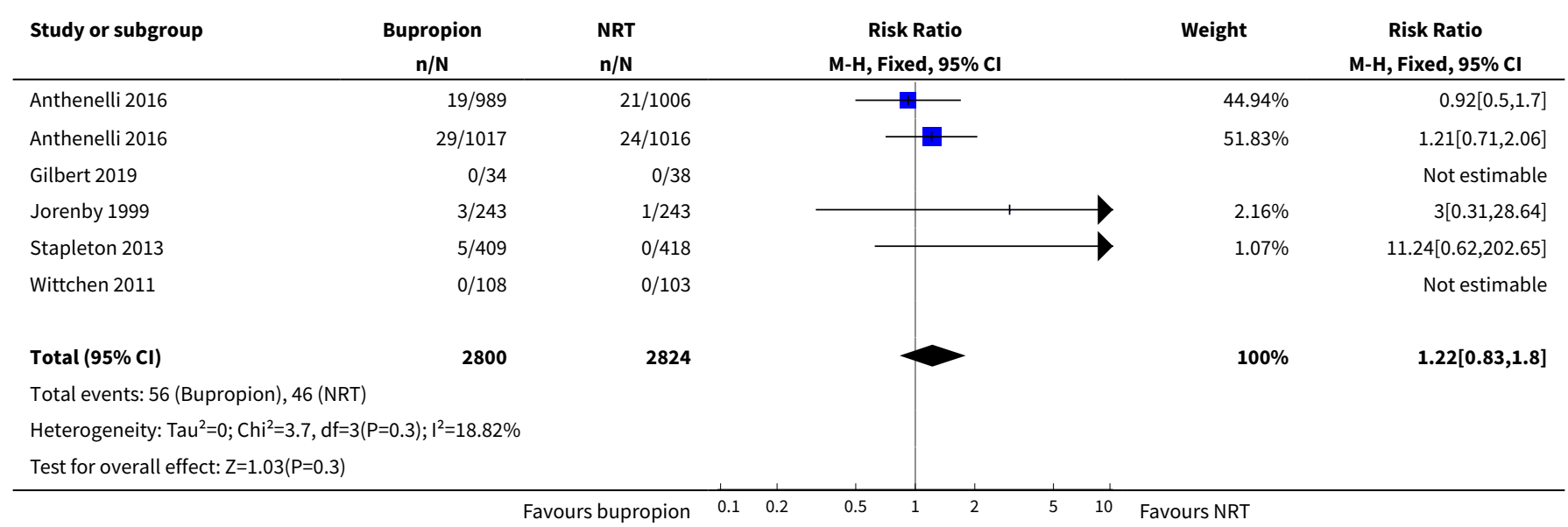

Analysis 6.4. Comparison 6 Bupropion versus nicotine replacement therapy (NRT), Outcome 4 Psychiatric adverse events.

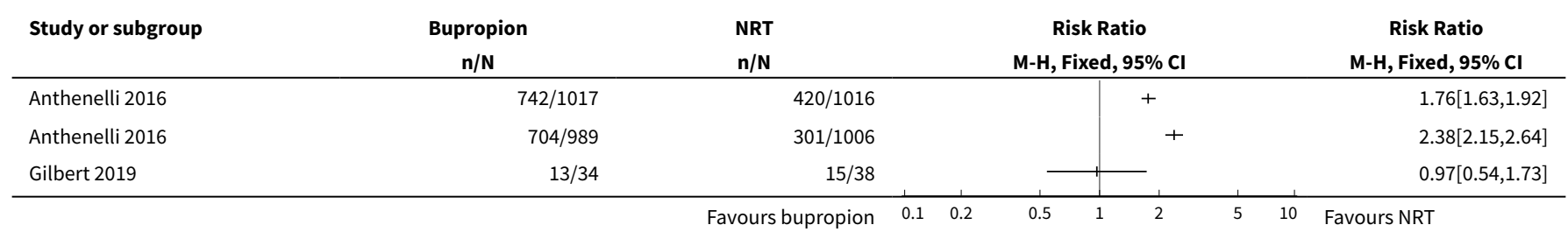

Analysis 6.5. Comparison 6 Bupropion versus nicotine replacement therapy (NRT), Outcome 5 Seizures.

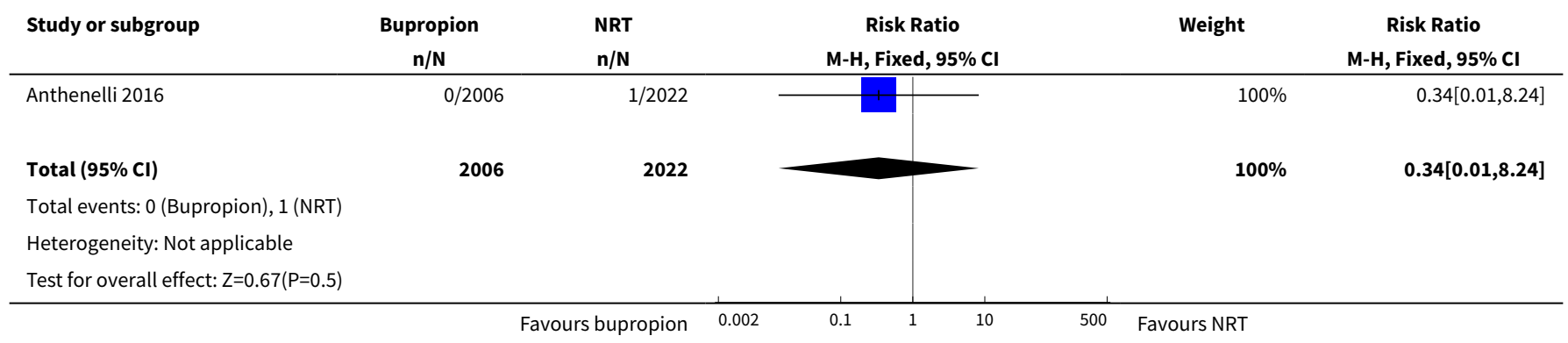

Analysis 6.6. Comparison 6 Bupropion versus nicotine replacement therapy (NRT), Outcome 6 Overdoses.

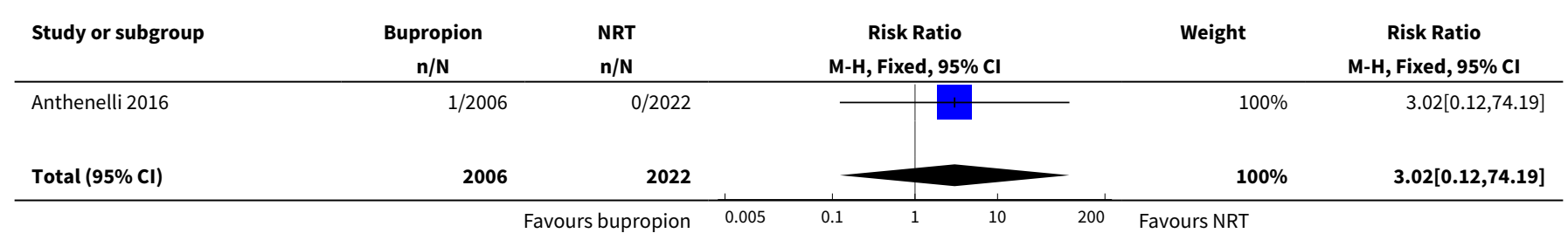




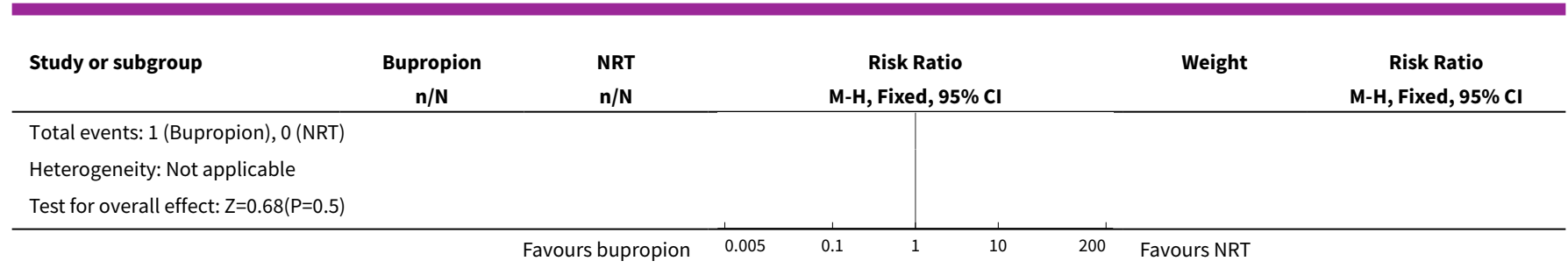

\section{Analysis 6.7. Comparison 6 Bupropion versus nicotine replacement therapy (NRT), Outcome 7 Suicide attempts.}

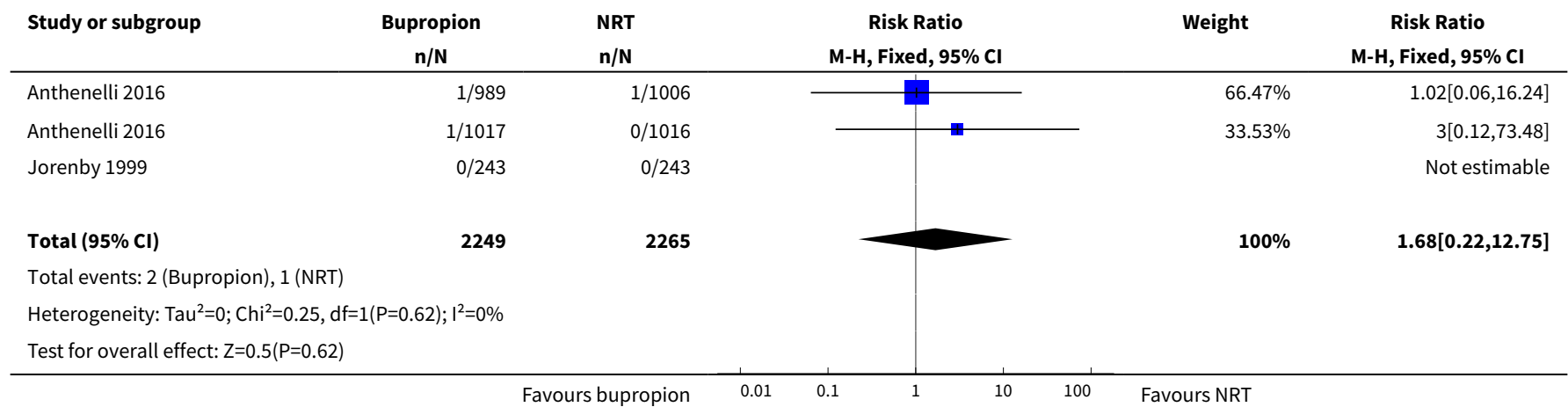

\section{Analysis 6.8. Comparison 6 Bupropion versus nicotine replacement therapy (NRT), Outcome 8 Death by suicide.}

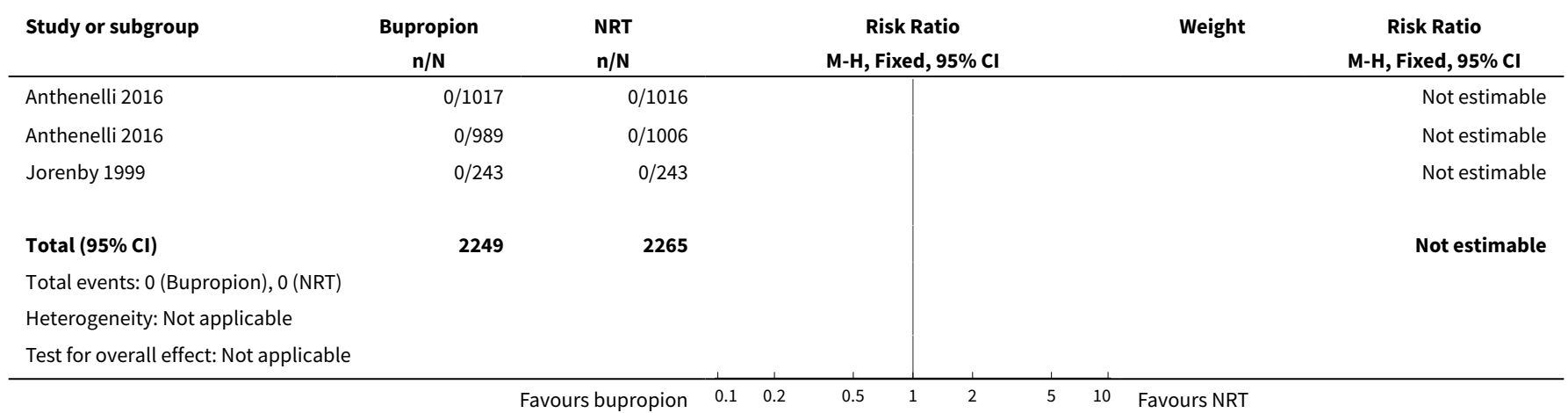

Analysis 6.9. Comparison 6 Bupropion versus nicotine replacement therapy (NRT), Outcome 9 All-cause mortality.

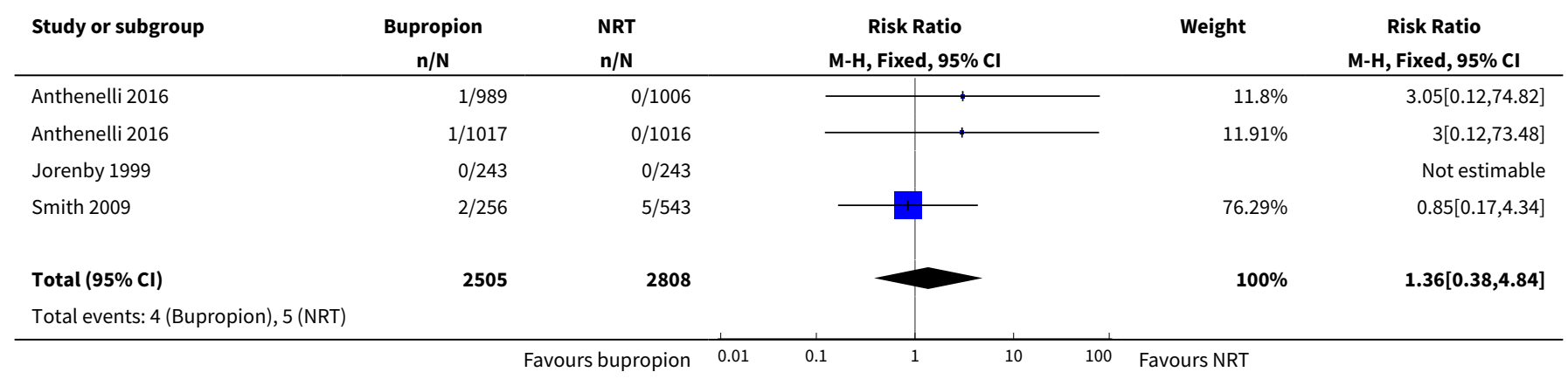




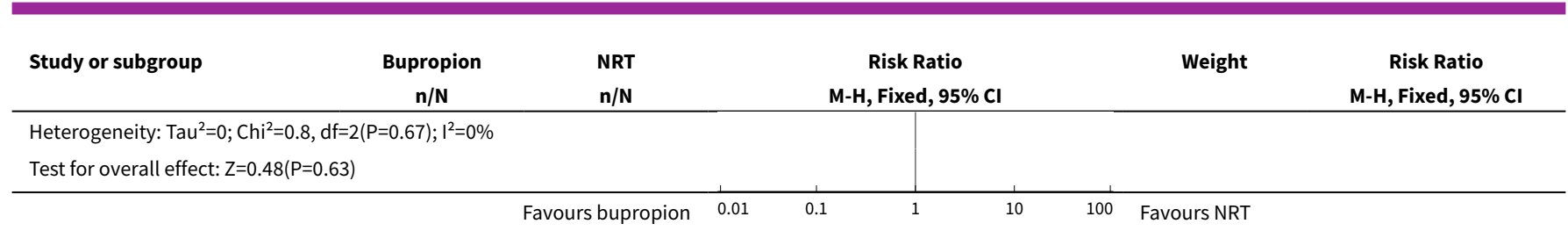

Analysis 6.10. Comparison 6 Bupropion versus nicotine replacement therapy (NRT), Outcome 10 Insomnia.

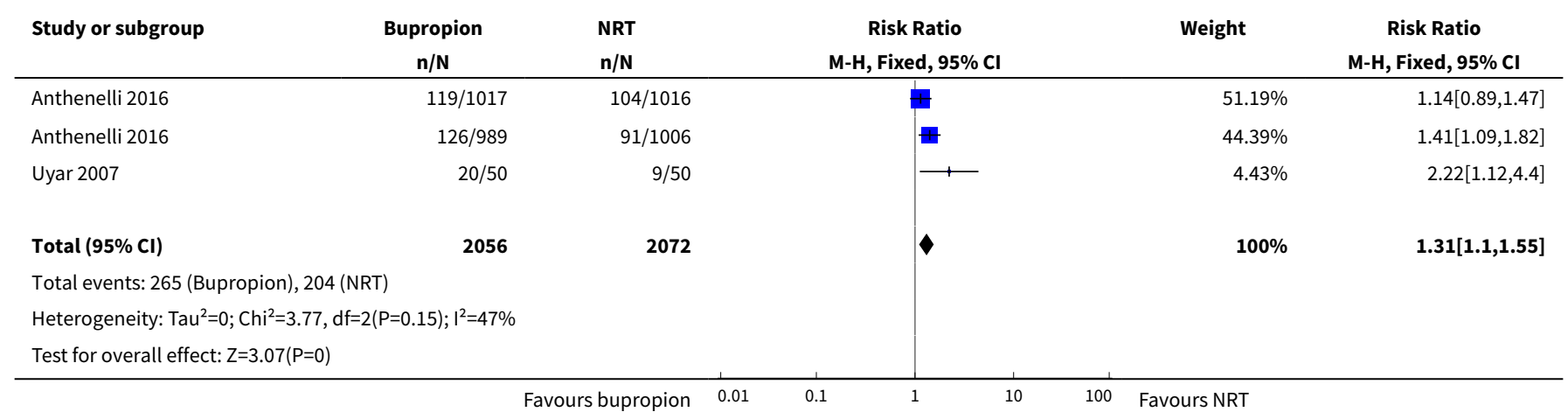

Analysis 6.11. Comparison 6 Bupropion versus nicotine replacement therapy (NRT), Outcome 11 Anxiety.

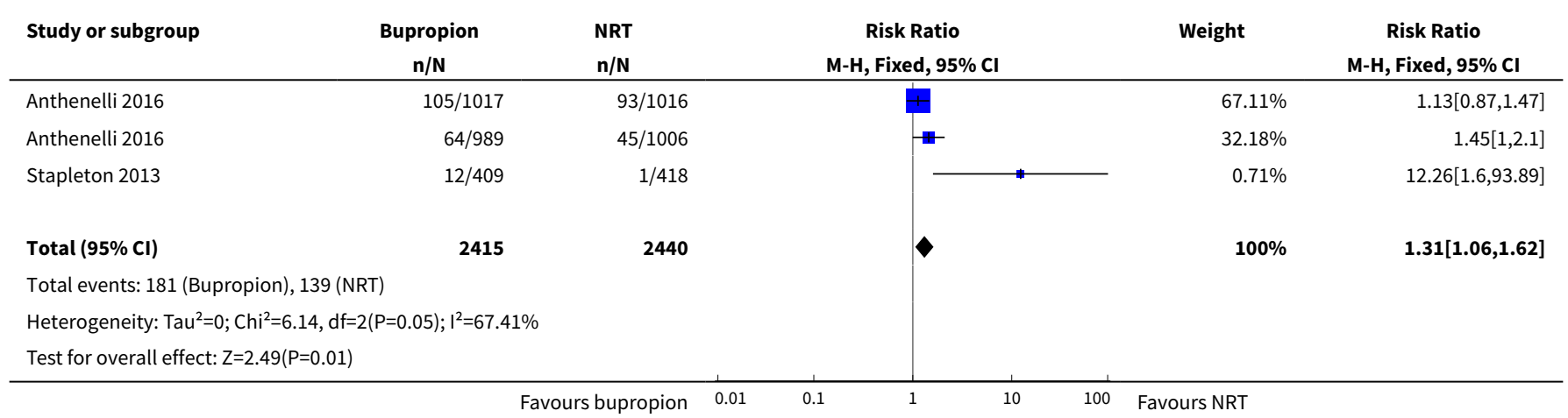

Analysis 6.12. Comparison 6 Bupropion versus nicotine replacement therapy (NRT), Outcome 12 Dropouts due to drug.

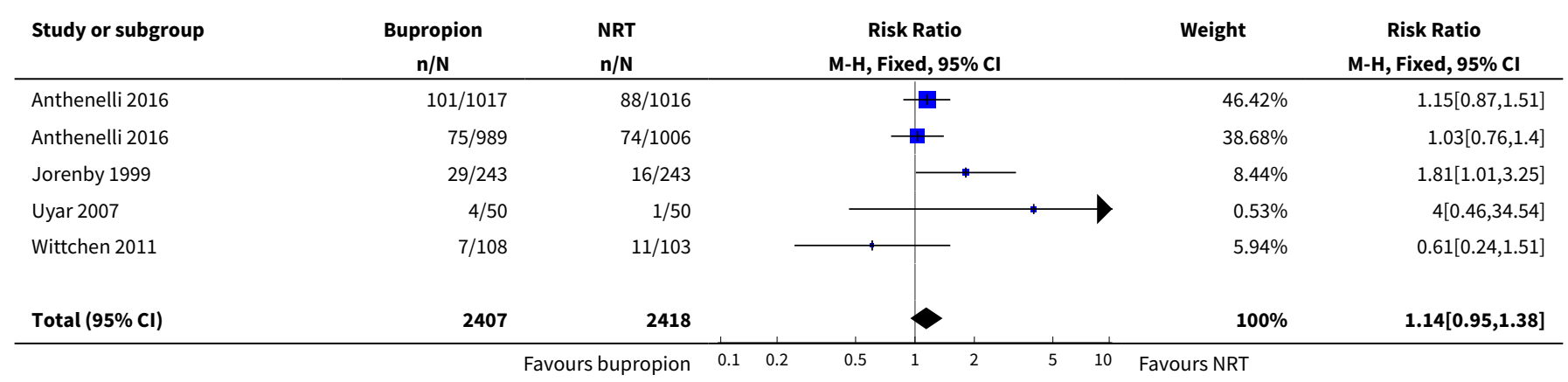




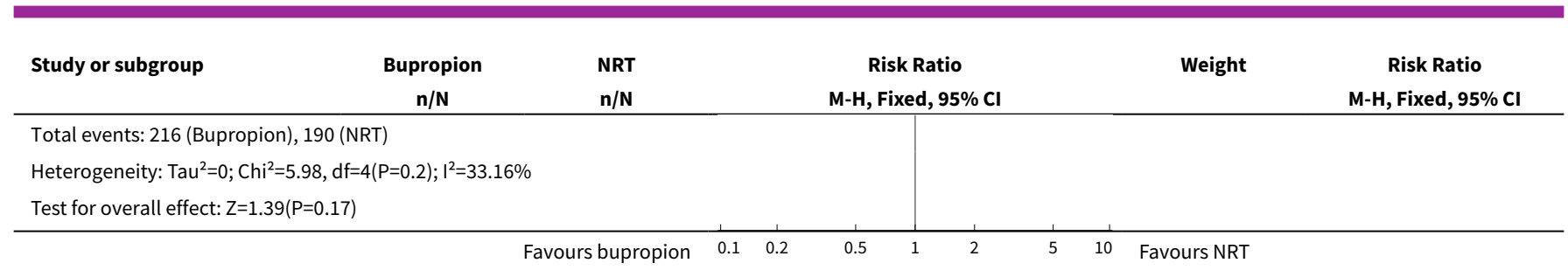

\section{Comparison 7. Bupropion versus nortriptyline}

\begin{tabular}{lllll}
\hline Outcome or subgroup title & $\begin{array}{l}\text { No. of } \\
\text { studies }\end{array}$ & $\begin{array}{l}\text { No. of } \\
\text { partici- } \\
\text { pants }\end{array}$ & Statistical method & Effect size \\
\hline 1 Smoking cessation & 3 & 417 & Risk Ratio (M-H, Fixed, 95\% Cl) & $1.30[0.93,1.82]$ \\
\hline 2 Serious adverse events & 1 & 105 & Risk Ratio (M-H, Fixed, 95\% Cl) & $0.0[0.0,0.0]$ \\
\hline 3 Insomnia & 2 & & Risk Ratio (M-H, Fixed, 95\% Cl) & Totals not selected \\
\hline 4 Dropouts due to drug & 2 & 240 & Risk Ratio (M-H, Fixed, 95\% Cl) & $0.83[0.47,1.44]$
\end{tabular}

Analysis 7.1. Comparison 7 Bupropion versus nortriptyline, Outcome 1 Smoking cessation.

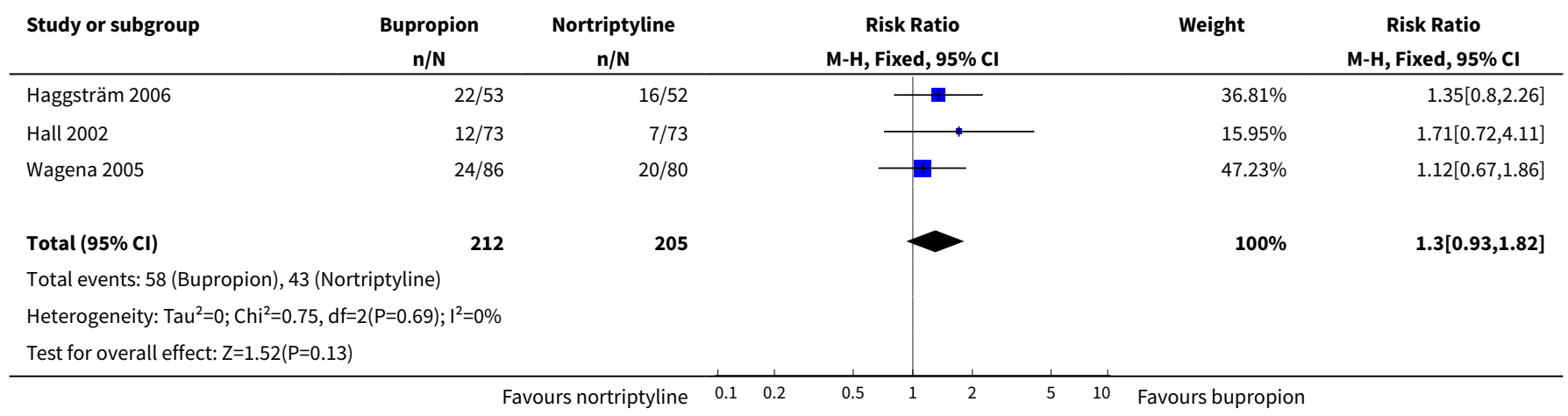

\section{Analysis 7.2. Comparison 7 Bupropion versus nortriptyline, Outcome 2 Serious adverse events.}

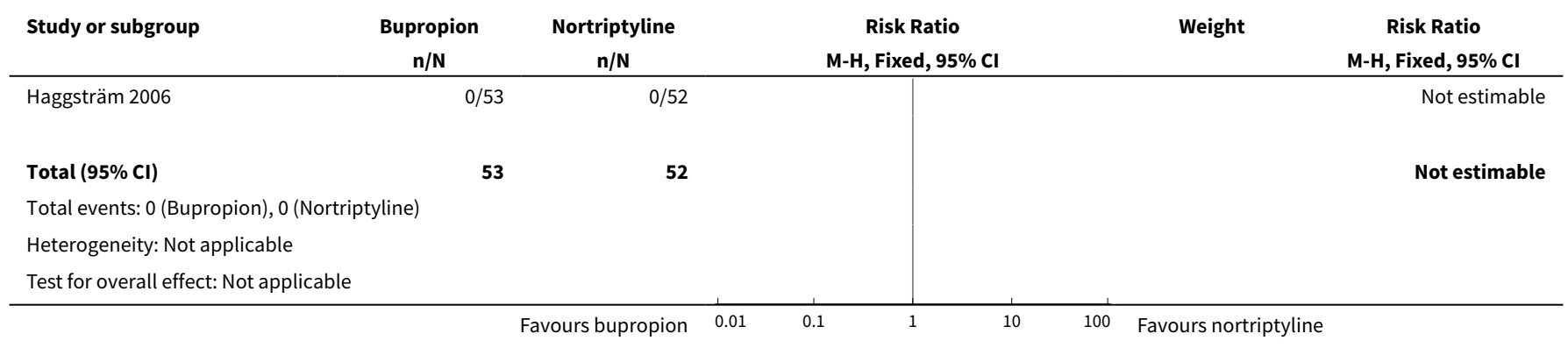


Analysis 7.3. Comparison 7 Bupropion versus nortriptyline, Outcome 3 Insomnia.

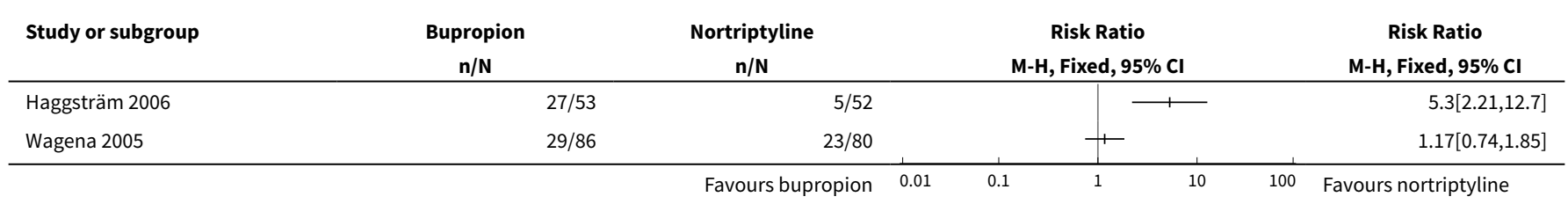

Analysis 7.4. Comparison 7 Bupropion versus nortriptyline, Outcome 4 Dropouts due to drug.

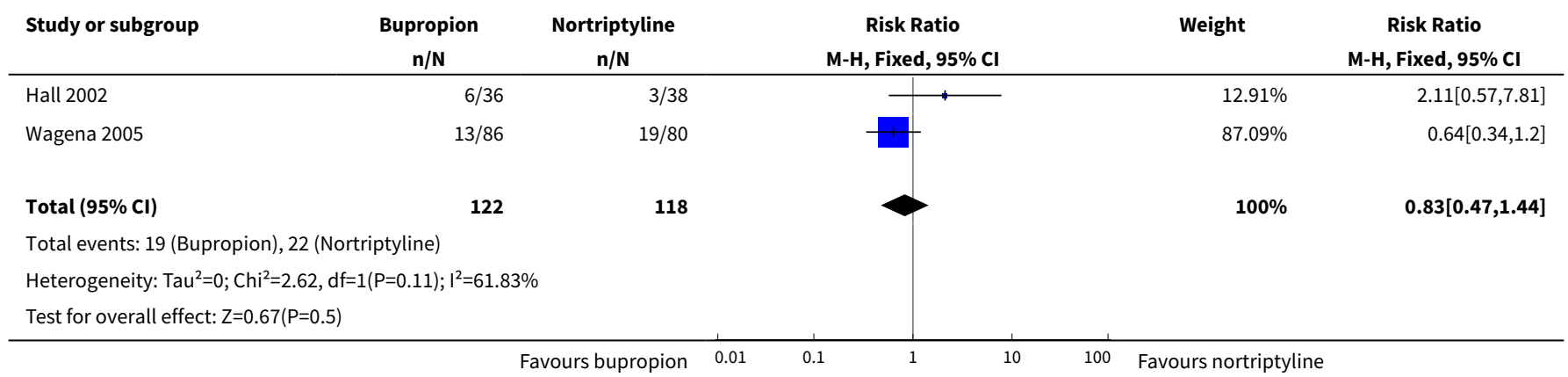

Comparison 8. Bupropion versus gabapentin

\begin{tabular}{llllll}
\hline Outcome or subgroup title & $\begin{array}{l}\text { No. of } \\
\text { studies }\end{array}$ & $\begin{array}{l}\text { No. of } \\
\text { partici- } \\
\text { pants }\end{array}$ & Statistical method & Effect size \\
\hline 1 Serious adverse events & 1 & 36 & Risk Ratio (M-H, Fixed, 95\% Cl) & $0.0[0.0,0.0]$ \\
\hline 2 Dropouts due to drug & 1 & 36 & Risk Ratio (M-H, Fixed, 95\% Cl) & $2.24[0.50,10.06]$ \\
\hline
\end{tabular}

Analysis 8.1. Comparison 8 Bupropion versus gabapentin, Outcome 1 Serious adverse events.

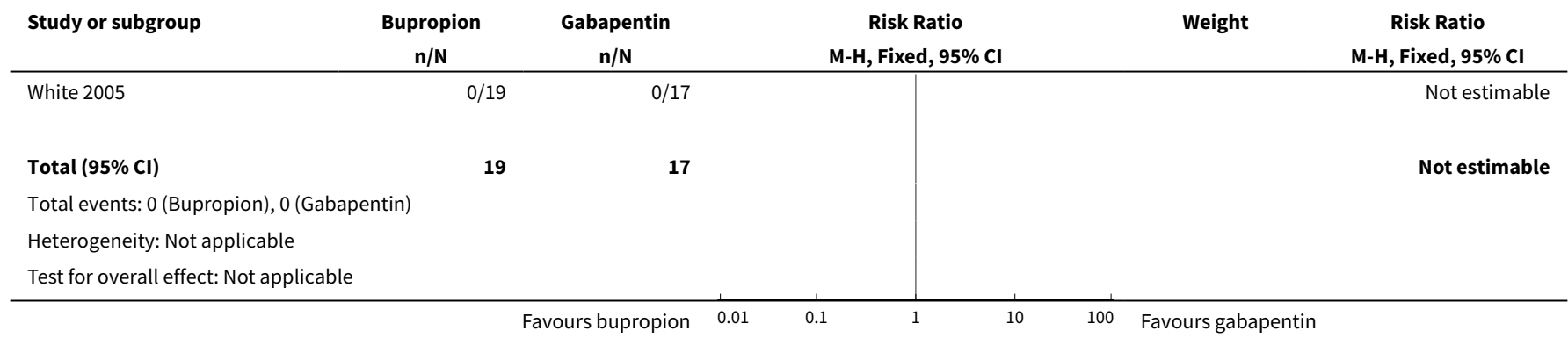


Analysis 8.2. Comparison 8 Bupropion versus gabapentin, Outcome 2 Dropouts due to drug.

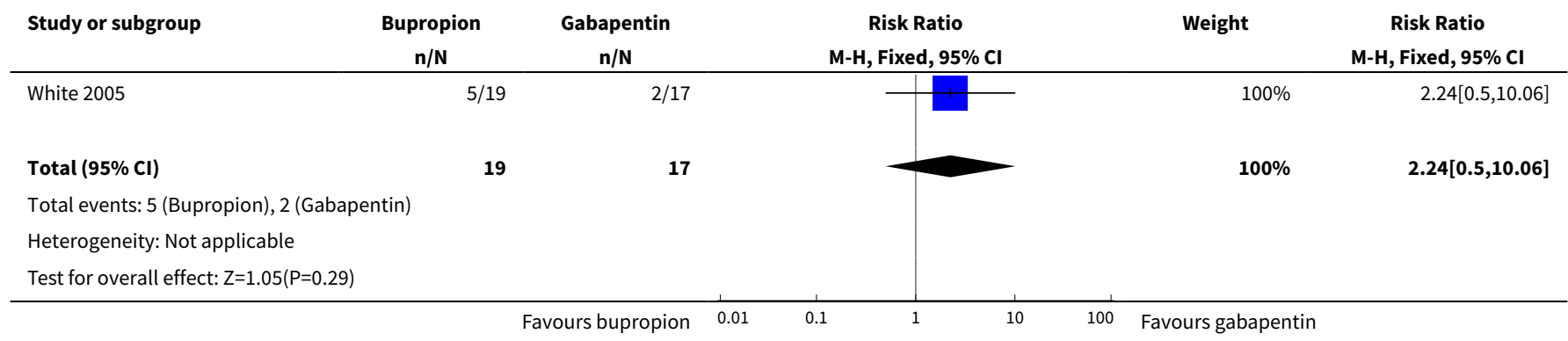

\section{Comparison 9. Bupropion (different doses)}

\begin{tabular}{lllll}
\hline Outcome or subgroup title & $\begin{array}{l}\text { No. of } \\
\text { studies }\end{array}$ & $\begin{array}{l}\text { No. of } \\
\text { partici- } \\
\text { pants }\end{array}$ & Statistical method & Effect size \\
\hline 1 Smoking cessation & 3 & 2042 & Risk Ratio (M-H, Fixed, 95\% Cl) & $1.08[0.93,1.26]$ \\
\hline 2 Serious adverse events & 2 & 518 & Risk Ratio (M-H, Fixed, 95\% Cl) & $1.33[0.30,5.94]$ \\
\hline 3 Overdoses & 1 & 209 & Risk Ratio (M-H, Fixed, 95\% Cl) & $0.34[0.01,8.17]$ \\
\hline 4 Suicide attempts & 2 & 518 & Risk Ratio (M-H, Fixed, 95\% Cl) & $0.34[0.01,8.17]$ \\
\hline 5 Death by suicide & 2 & 518 & Risk Ratio (M-H, Fixed, 95\% Cl) & $0.0[0.0,0.0]$ \\
\hline 6 All-cause mortality & 2 & 518 & Risk Ratio (M-H, Fixed, 95\% Cl) & $2.94[0.12,71.68]$ \\
\hline 7 Insomnia & 1 & 309 & Risk Ratio (M-H, Fixed, 95\% Cl) & $1.18[0.85,1.63]$ \\
\hline 8 Anxiety & 1 & 309 & Risk Ratio (M-H, Fixed, 95\% Cl) & $0.87[0.35,2.20]$ \\
\hline 9 Dropouts due to drug & 1 & 309 & Risk Ratio (M-H, Fixed, 95\% Cl) & $1.82[0.75,4.44]$ \\
\hline
\end{tabular}

Analysis 9.1. Comparison 9 Bupropion (different doses), Outcome 1 Smoking cessation.

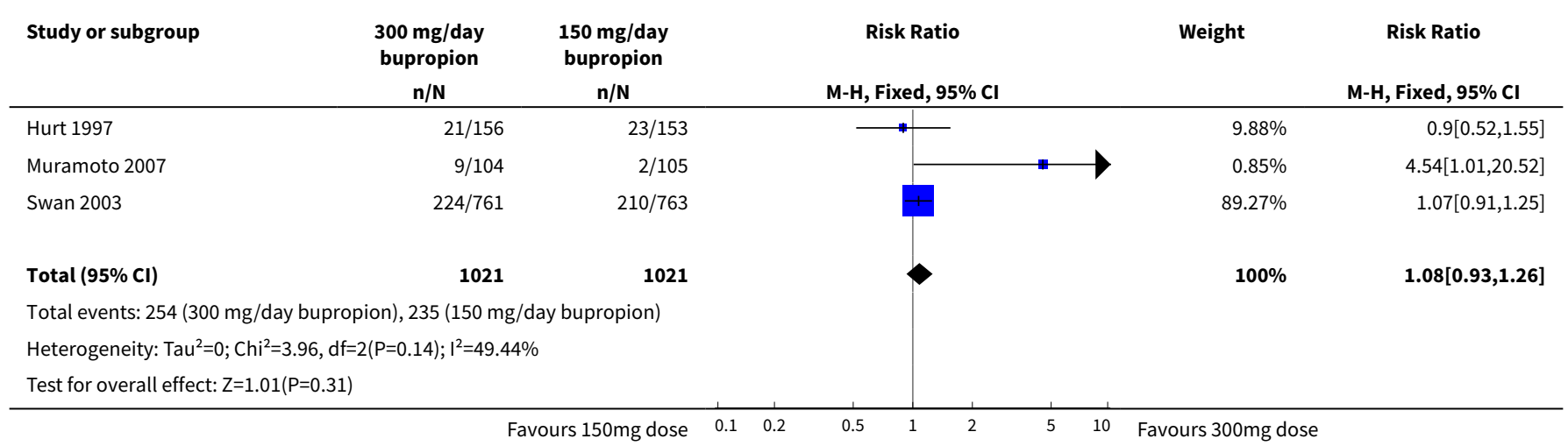


Analysis 9.2. Comparison 9 Bupropion (different doses), Outcome 2 Serious adverse events.

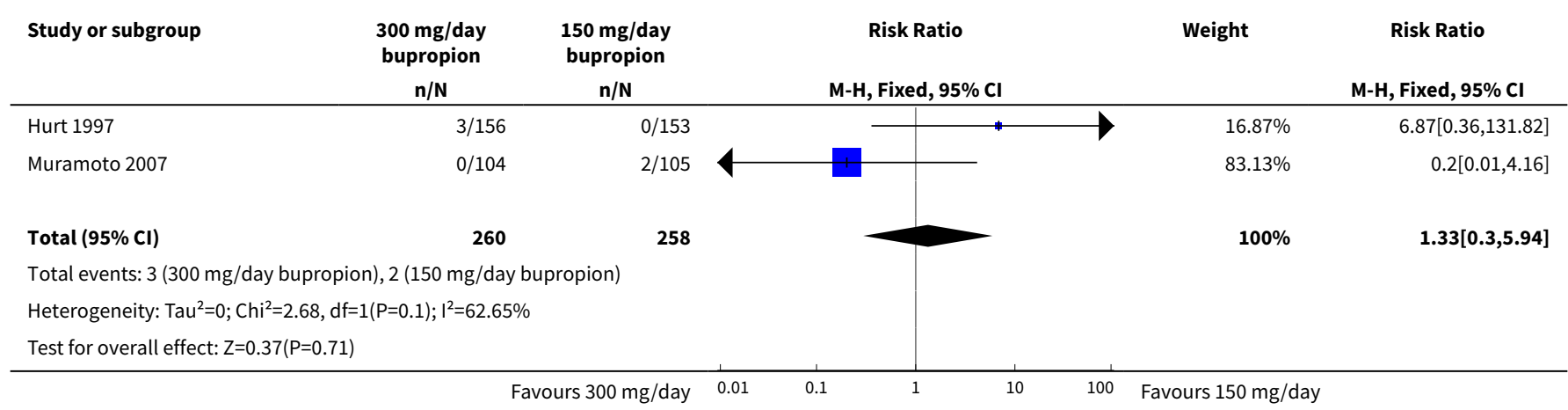

Analysis 9.3. Comparison 9 Bupropion (different doses), Outcome 3 Overdoses.

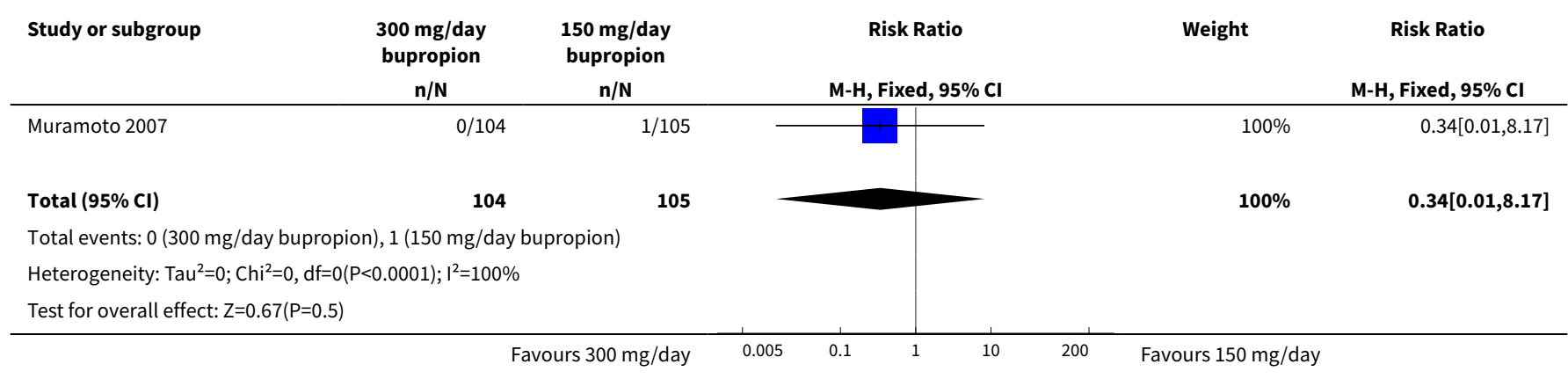

Analysis 9.4. Comparison 9 Bupropion (different doses), Outcome 4 Suicide attempts.

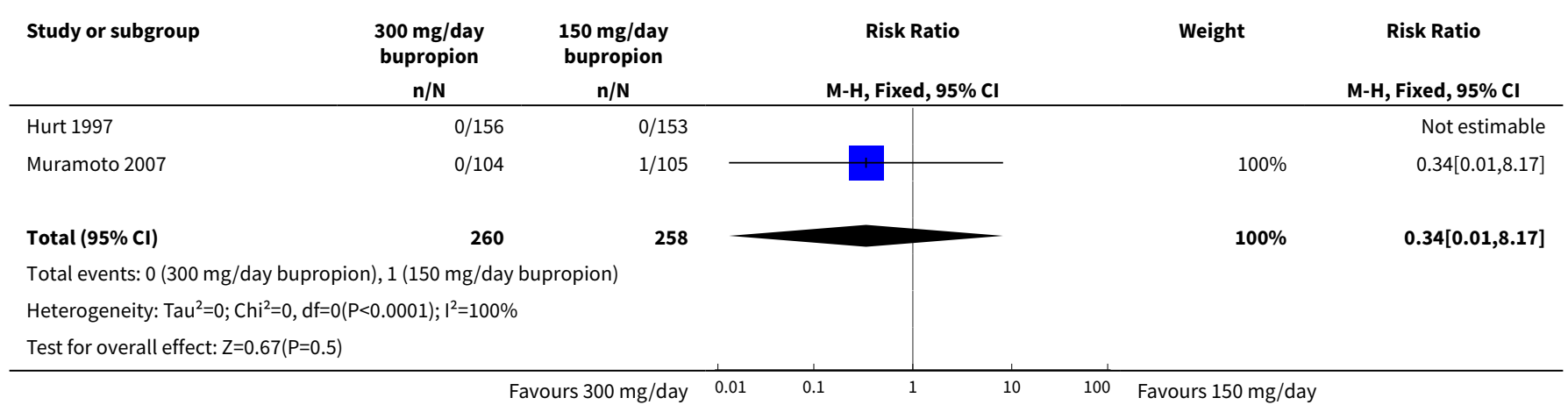


Analysis 9.5. Comparison 9 Bupropion (different doses), Outcome 5 Death by suicide.

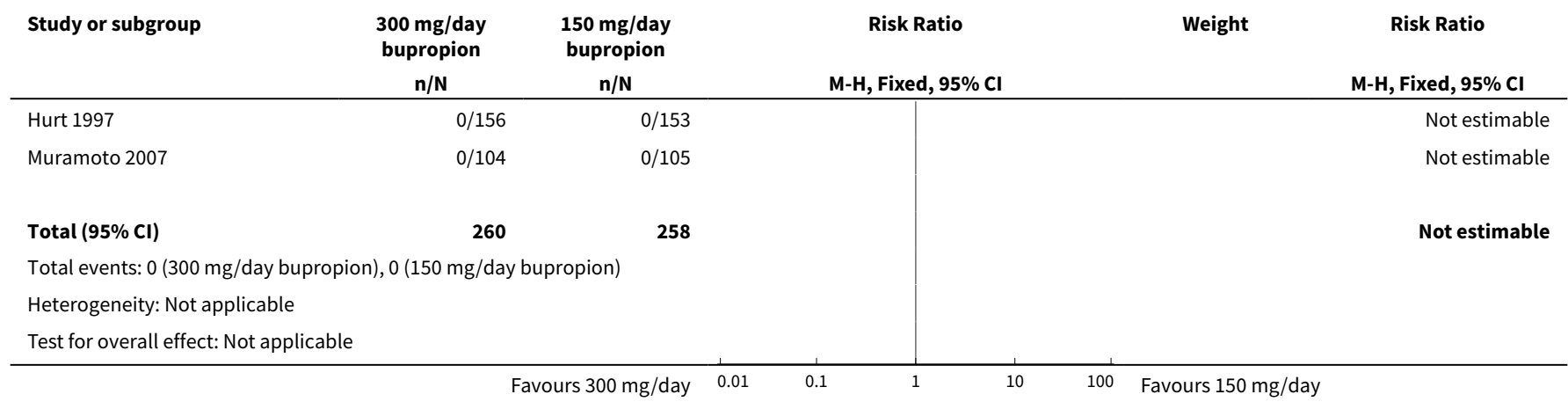

Analysis 9.6. Comparison 9 Bupropion (different doses), Outcome 6 All-cause mortality.

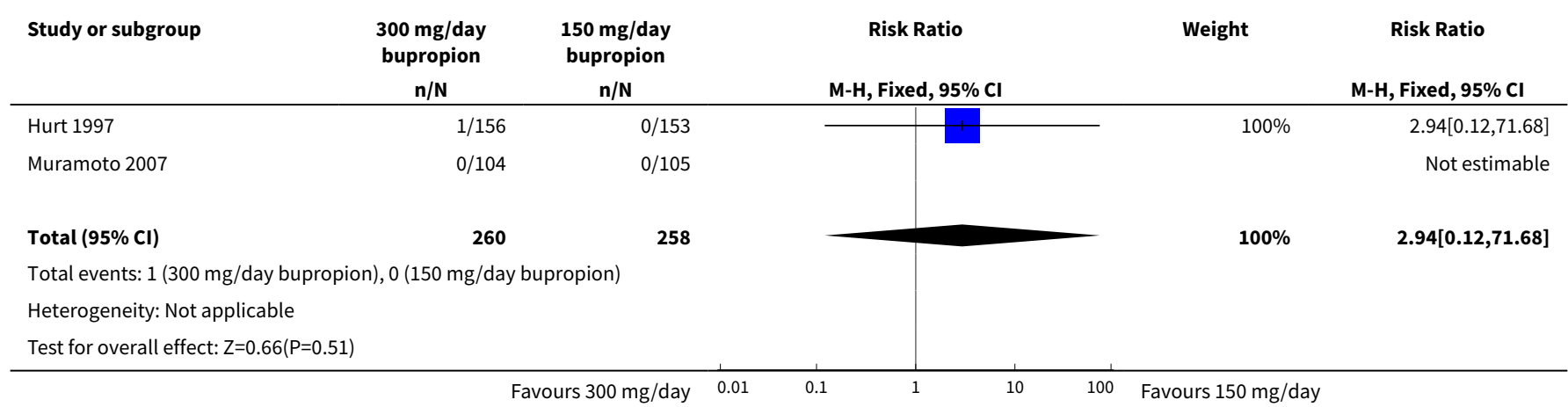

Analysis 9.7. Comparison 9 Bupropion (different doses), Outcome 7 Insomnia.

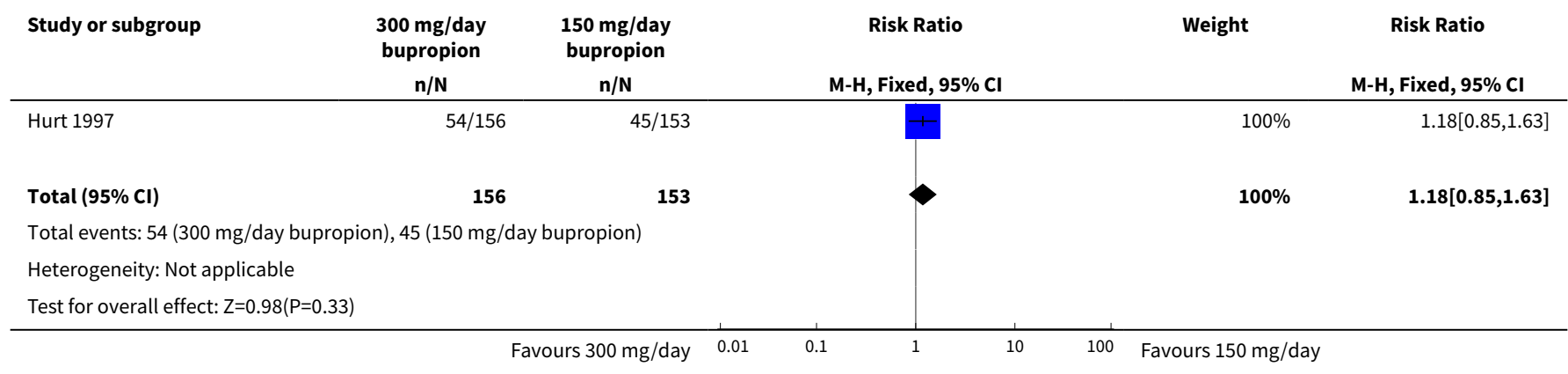

Analysis 9.8. Comparison 9 Bupropion (different doses), Outcome 8 Anxiety.

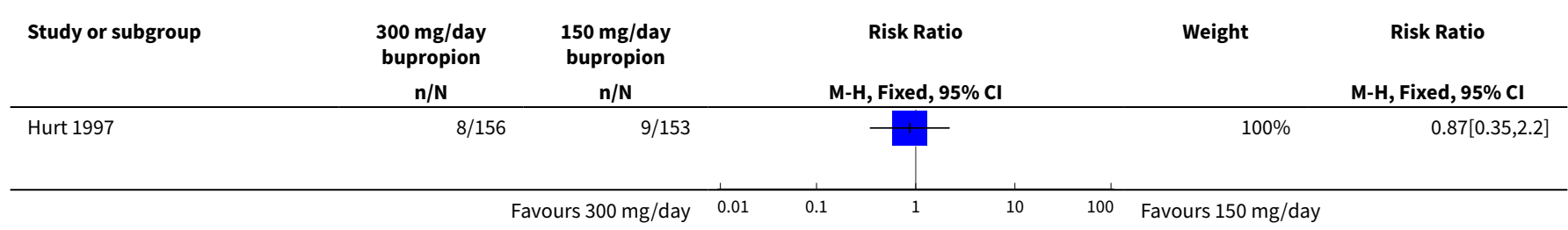




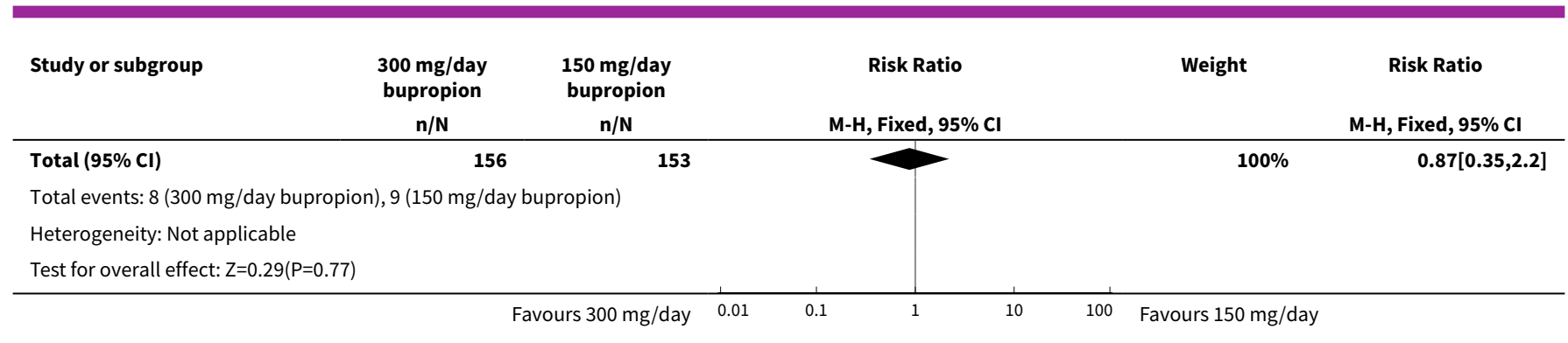

Analysis 9.9. Comparison 9 Bupropion (different doses), Outcome 9 Dropouts due to drug.

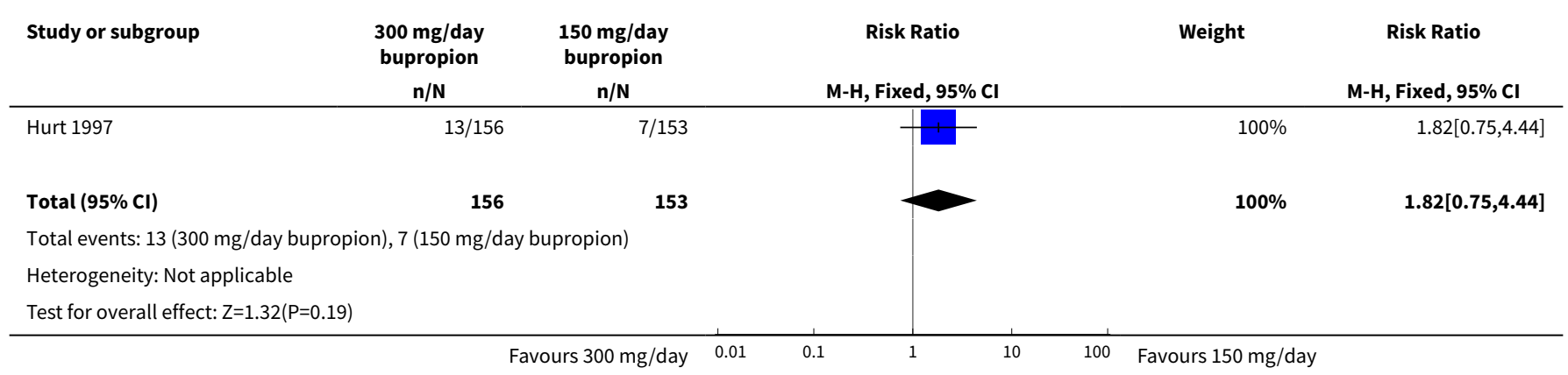

\section{Comparison 10. Nortriptyline versus placebo}

\begin{tabular}{lllll}
\hline Outcome or subgroup title & $\begin{array}{l}\text { No. of } \\
\text { studies }\end{array}$ & $\begin{array}{l}\text { No. of } \\
\text { partici- } \\
\text { pants }\end{array}$ & Statistical method & Effect size \\
\hline 1 Smoking cessation & 6 & 975 & Risk Ratio $(\mathrm{M}-\mathrm{H}$, Fixed, $95 \% \mathrm{Cl})$ & $2.03[1.48,2.78]$ \\
\hline 2 Serious adverse events & 1 & 103 & Risk Ratio (M-H, Fixed, 95\% Cl) & $0.0[0.0,0.0]$ \\
\hline 3 Insomnia & 2 & 247 & Risk Ratio $(\mathrm{M}-\mathrm{H}$, Fixed, $95 \% \mathrm{Cl})$ & $0.58[0.28,1.21]$ \\
\hline 4 Anxiety & 1 & 144 & Risk Ratio (M-H, Fixed, 95\% Cl) & $0.64[0.34,1.20]$ \\
\hline 5 Dropouts due to drug & 4 & 537 & Risk Ratio $(\mathrm{M}-\mathrm{H}$, Fixed, $95 \% \mathrm{Cl})$ & $1.99[1.18,3.36]$
\end{tabular}

Analysis 10.1. Comparison 10 Nortriptyline versus placebo, Outcome 1 Smoking cessation.

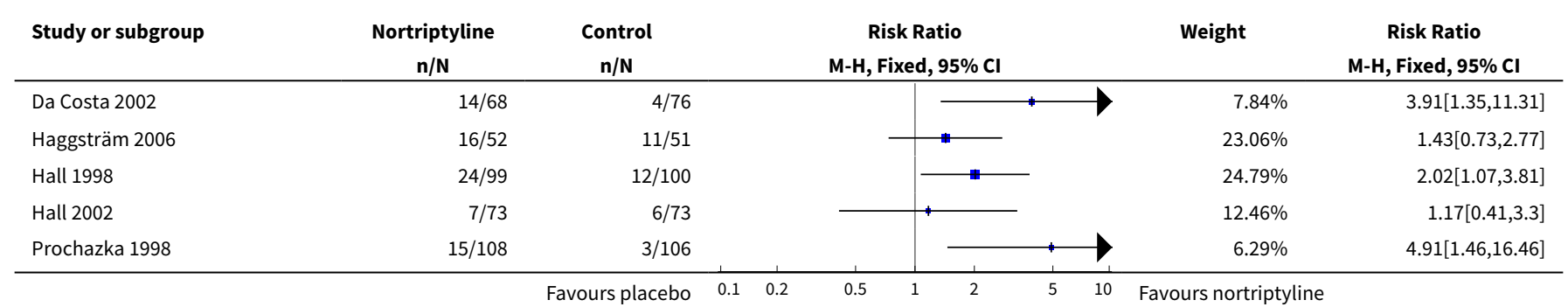




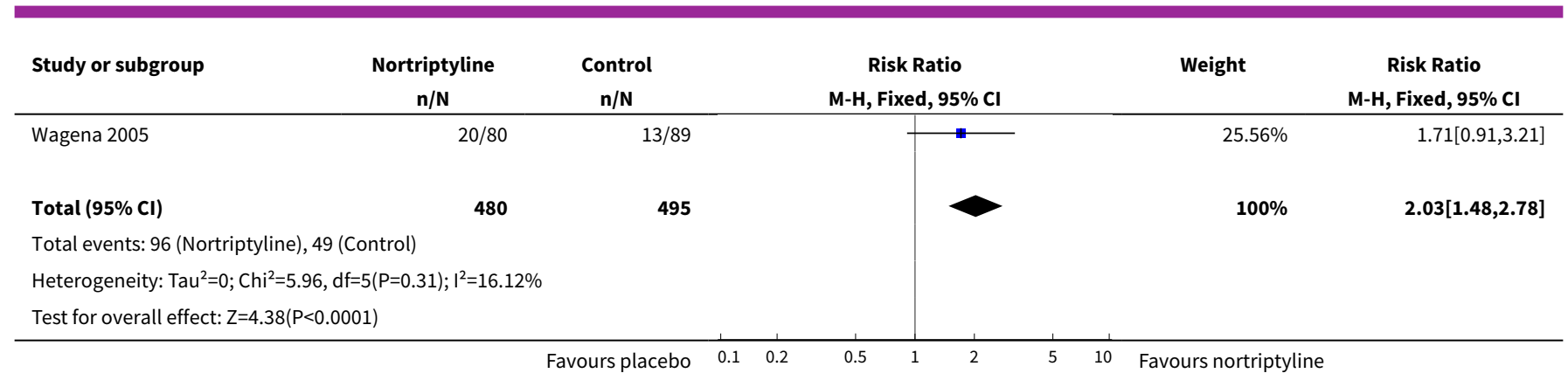

Analysis 10.2. Comparison 10 Nortriptyline versus placebo, Outcome 2 Serious adverse events.

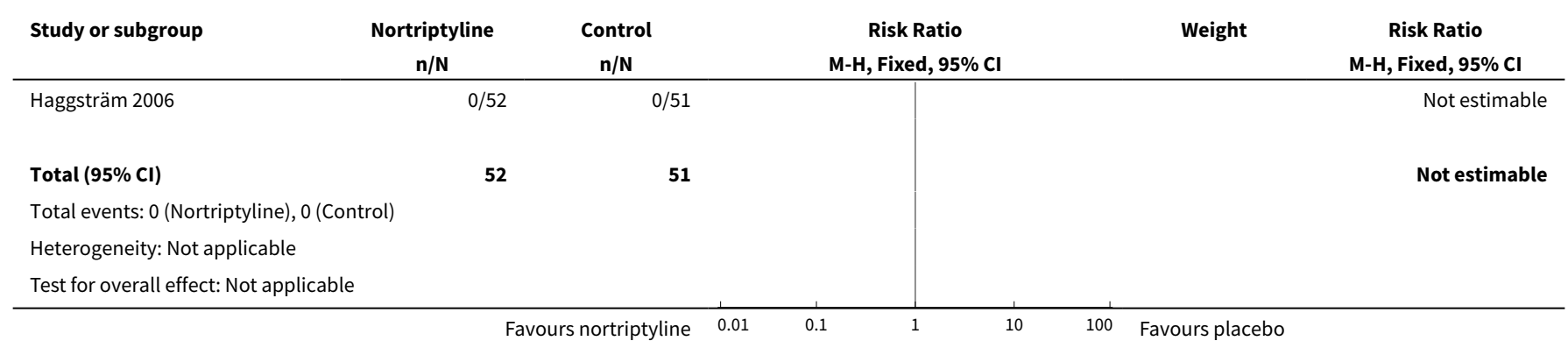

Analysis 10.3. Comparison 10 Nortriptyline versus placebo, Outcome 3 Insomnia.

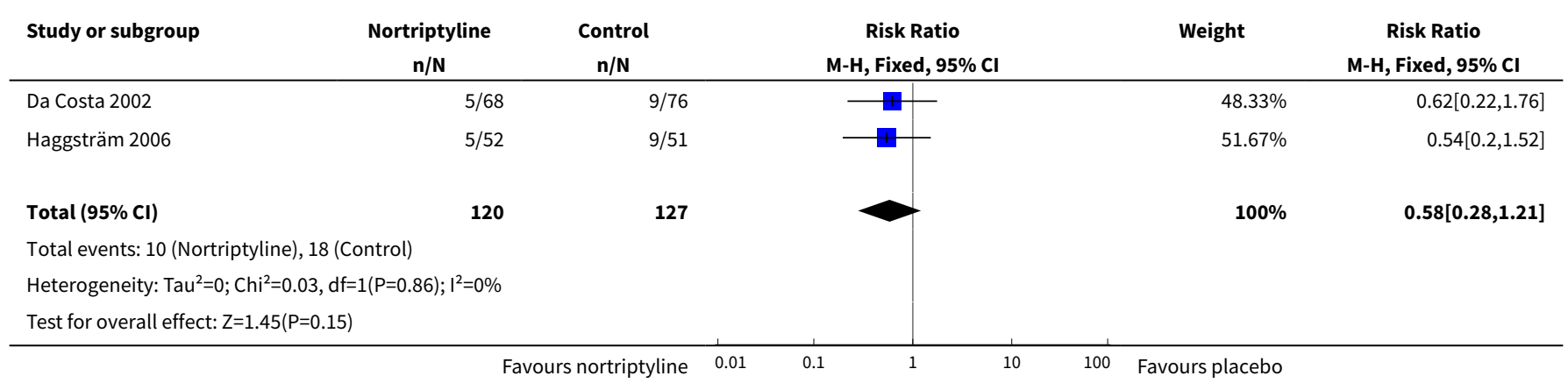

Analysis 10.4. Comparison 10 Nortriptyline versus placebo, Outcome 4 Anxiety.

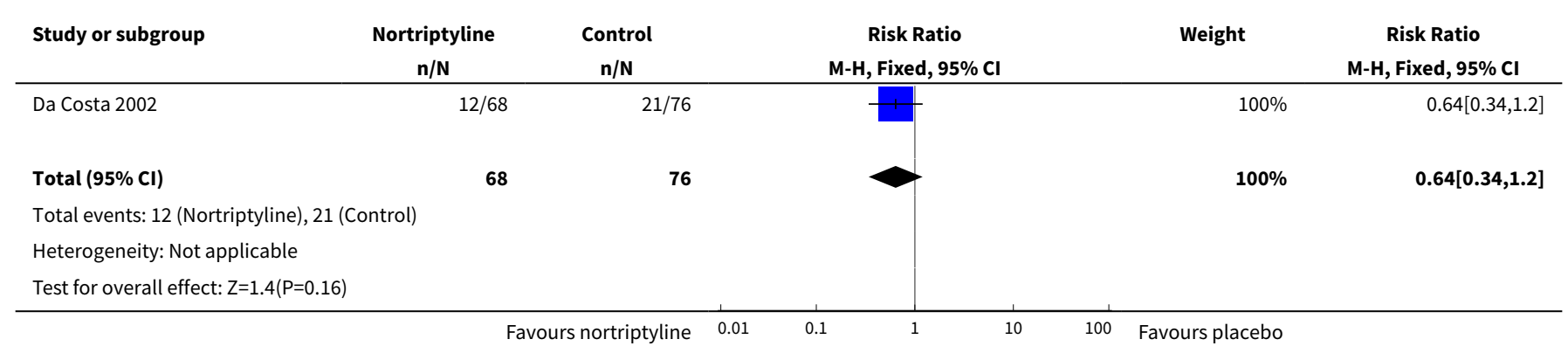


Analysis 10.5. Comparison 10 Nortriptyline versus placebo, Outcome 5 Dropouts due to drug.

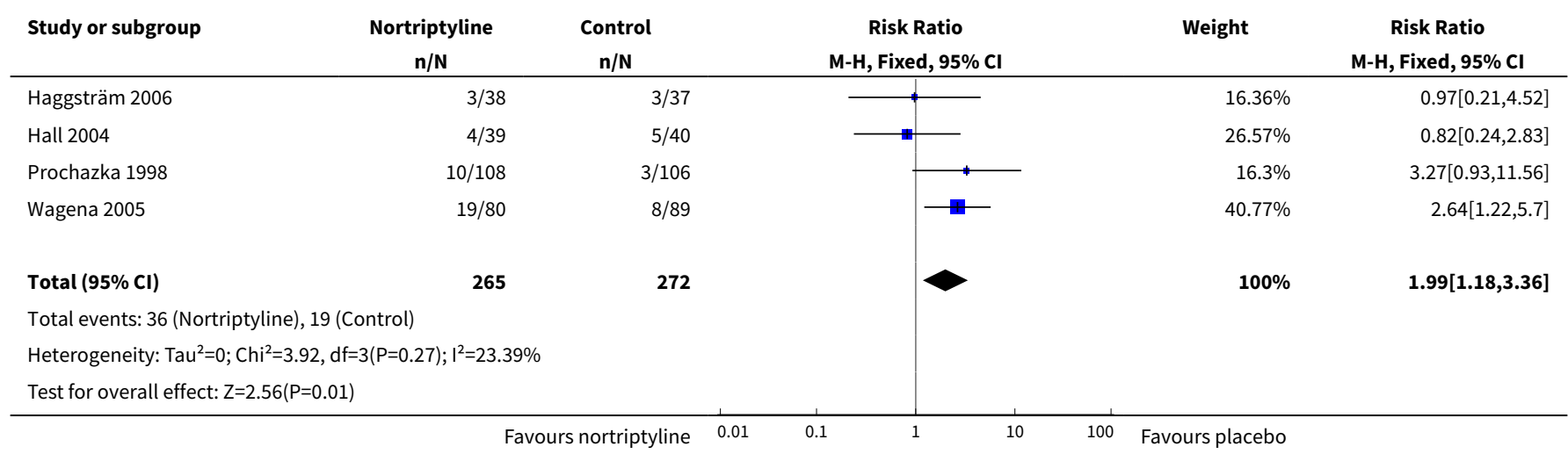

\section{Comparison 11. Selective serotonin reuptake inhibitors (SSRIs) versus placebo}

\begin{tabular}{lllll}
\hline Outcome or subgroup title & $\begin{array}{l}\text { No. of } \\
\text { studies }\end{array}$ & $\begin{array}{l}\text { No. of } \\
\text { partici- } \\
\text { pants }\end{array}$ & Statistical method & Effect size \\
\hline 1 Smoking cessation & 4 & 1594 & Risk Ratio (M-H, Fixed, 95\% Cl) & $0.93[0.71,1.22]$ \\
\hline 1.1 Fluoxetine & 2 & 1236 & Risk Ratio (M-H, Fixed, 95\% Cl) & $0.92[0.65,1.30]$ \\
\hline 1.2 Paroxetine & 1 & 224 & Risk Ratio (M-H, Fixed, 95\% Cl) & $1.08[0.64,1.82]$ \\
\hline 1.3 Sertraline & 1 & 134 & Risk Ratio (M-H, Fixed, 95\% Cl) & $0.71[0.30,1.64]$ \\
\hline 2 Adverse events & 1 & 206 & Risk Ratio (M-H, Fixed, 95\% Cl) & $2.78[0.11,67.40]$ \\
\hline 2.1 Fluoxetine & 1 & 206 & Risk Ratio (M-H, Fixed, 95\% Cl) & $2.78[0.11,67.40]$ \\
\hline 3 Dropouts due to drug & 3 & 1270 & Risk Ratio (M-H, Fixed, 95\% Cl) & $2.59[1.70,3.94]$ \\
\hline 3.1 Fluoxetine & 2 & 1136 & Risk Ratio (M-H, Fixed, 95\% Cl) & $2.72[1.75,4.23]$ \\
\hline 3.2 Sertraline & 1 & 134 & Risk Ratio (M-H, Fixed, 95\% Cl) & $1.29[0.30,5.56]$ \\
\hline
\end{tabular}

Analysis 11.1. Comparison 11 Selective serotonin reuptake inhibitors (SSRIs) versus placebo, Outcome 1 Smoking cessation.

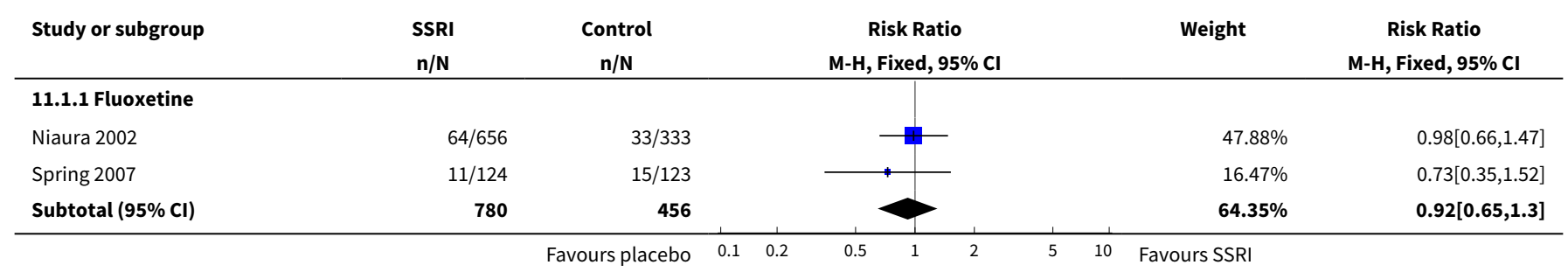




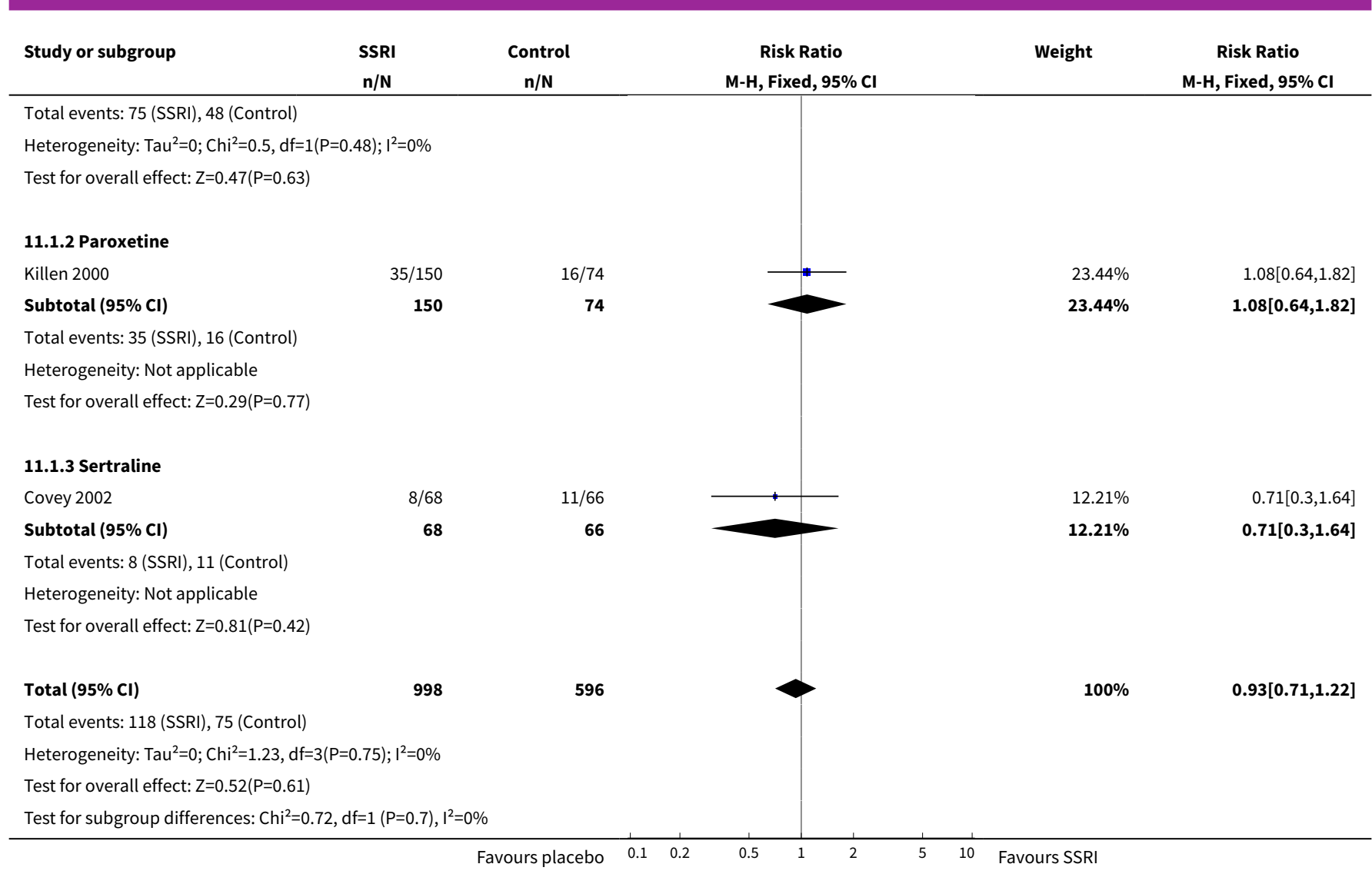

Analysis 11.2. Comparison 11 Selective serotonin reuptake inhibitors (SSRIs) versus placebo, Outcome 2 Adverse events.

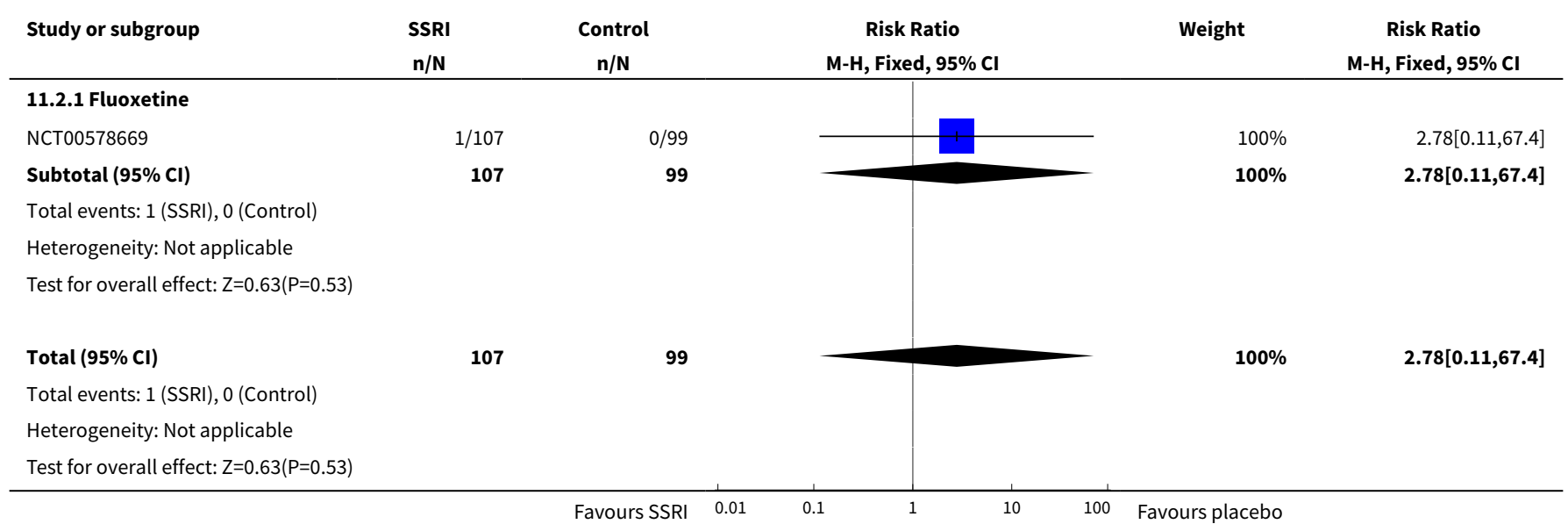


Analysis 11.3. Comparison 11 Selective serotonin reuptake inhibitors (SSRIs) versus placebo, Outcome 3 Dropouts due to drug.

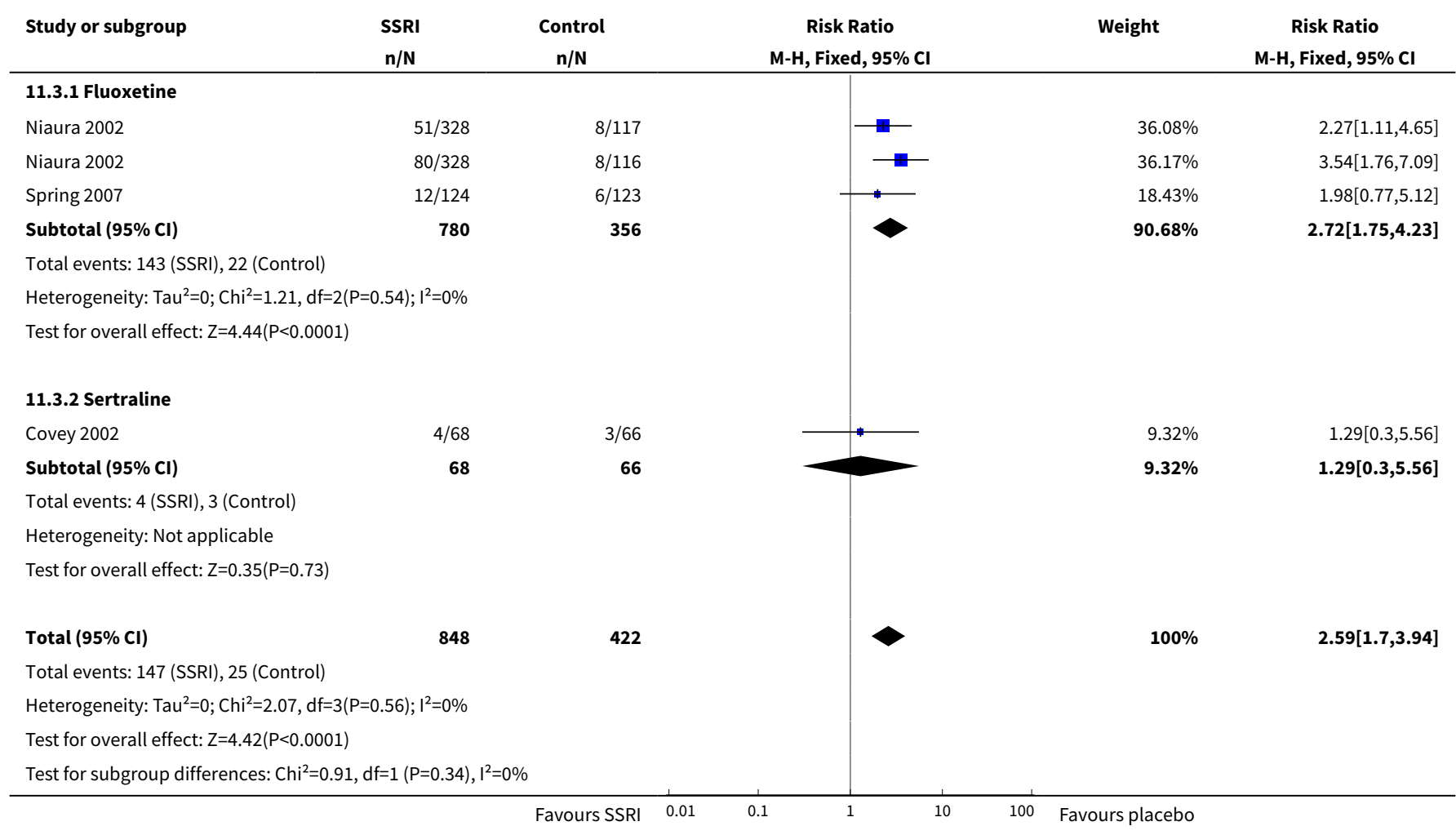

\section{Comparison 12. Monoamine oxidase inhibitor (MAOI) versus placebo}

\begin{tabular}{lllll}
\hline Outcome or subgroup title & $\begin{array}{l}\text { No. of } \\
\text { studies }\end{array}$ & $\begin{array}{l}\text { No. of } \\
\text { partici- } \\
\text { pants }\end{array}$ & Statistical method & Effect size \\
\hline 1 Smoking cessation & 6 & 827 & Risk Ratio (M-H, Fixed, 95\% Cl) & $1.29[0.93,1.79]$ \\
\hline 1.1 Moclobemide & 1 & 88 & Risk Ratio (M-H, Fixed, 95\% Cl) & $1.57[0.67,3.68]$ \\
\hline 1.2 Selegiline & 5 & 739 & Risk Ratio (M-H, Fixed, 95\% Cl) & $1.25[0.88,1.78]$ \\
\hline 2 Adverse events & 2 & 391 & Risk Ratio (M-H, Fixed, 95\% Cl) & $1.02[0.93,1.12]$ \\
\hline 2.1 Selegeline & 1 & 101 & Risk Ratio (M-H, Fixed, 95\% Cl) & $1.02[0.91,1.16]$ \\
\hline 2.2 EVT302 & 1 & 290 & Risk Ratio (M-H, Fixed, 95\% Cl) & $1.02[0.90,1.15]$ \\
\hline 3 Psychiatric adverse events & 1 & & Risk Ratio (M-H, Fixed, 95\% Cl) & Subtotals only \\
\hline 3.1 Selegeline & 1 & 5 & Risk Ratio (M-H, Fixed, 95\% Cl) & $0.27[0.02,3.74]$ \\
\hline 4 Serious adverse events & 4 & 804 & Risk Ratio (M-H, Fixed, 95\% Cl) & $1.17[0.37,3.68]$ \\
\hline 4.1 Moclobemide & 1 & 87 & Risk Ratio (M-H, Fixed, 95\% Cl) & $0.0[0.0,0.0]$ \\
\hline
\end{tabular}




\begin{tabular}{|c|c|c|c|c|}
\hline Outcome or subgroup title & $\begin{array}{l}\text { No. of } \\
\text { studies }\end{array}$ & $\begin{array}{l}\text { No. of } \\
\text { partici- } \\
\text { pants }\end{array}$ & Statistical method & Effect size \\
\hline 4.2 Selegeline & 1 & 101 & Risk Ratio (M-H, Fixed, 95\% Cl) & $0.0[0.0,0.0]$ \\
\hline 4.3 Lazabemide & 1 & 326 & Risk Ratio (M-H, Fixed, 95\% Cl) & $0.53[0.12,2.32]$ \\
\hline 4.4 EVT302 & 1 & 290 & Risk Ratio (M-H, Fixed, 95\% Cl) & $7.0[0.36,134.32]$ \\
\hline 5 Insomnia & 5 & 752 & Risk Ratio (M-H, Fixed, 95\% Cl) & $1.50[1.15,1.97]$ \\
\hline 5.1 Moclobemide & 1 & 87 & Risk Ratio (M-H, Fixed, 95\% Cl) & $5.21[1.64,16.61]$ \\
\hline 5.2 Selegeline & 3 & 339 & Risk Ratio (M-H, Fixed, 95\% Cl) & $1.20[0.91,1.60]$ \\
\hline 5.3 Lazabemide & 1 & 326 & Risk Ratio (M-H, Fixed, 95\% Cl) & $2.66[0.78,9.00]$ \\
\hline 6 Anxiety & 2 & 427 & Risk Ratio (M-H, Fixed, 95\% Cl) & $1.03[0.48,2.22]$ \\
\hline 6.1 Selegeline & 1 & 101 & Risk Ratio (M-H, Fixed, 95\% Cl) & $0.98[0.42,2.27]$ \\
\hline 6.2 Lazabemide & 1 & 326 & Risk Ratio (M-H, Fixed, 95\% Cl) & $1.25[0.19,8.32]$ \\
\hline 7 Dropouts due to drug & 5 & 910 & Risk Ratio (M-H, Fixed, 95\% Cl) & $1.75[1.07,2.86]$ \\
\hline 7.1 Moclobemide & 1 & 87 & Risk Ratio (M-H, Fixed, 95\% Cl) & $1.95[0.38,10.12]$ \\
\hline 7.2 Selegeline & 2 & 203 & Risk Ratio (M-H, Fixed, 95\% Cl) & $1.90[0.94,3.85]$ \\
\hline 7.3 Lazabemide & 1 & 330 & Risk Ratio (M-H, Fixed, 95\% Cl) & $1.58[0.69,3.62]$ \\
\hline 7.4 EVT302 & 1 & 290 & Risk Ratio (M-H, Fixed, 95\% Cl) & $1.5[0.25,8.84]$ \\
\hline
\end{tabular}

Analysis 12.1. Comparison 12 Monoamine oxidase inhibitor (MAOI) versus placebo, Outcome 1 Smoking cessation.

\begin{tabular}{|c|c|c|c|c|c|}
\hline Study or subgroup & $\begin{array}{l}\text { MAOI } \\
\mathrm{n} / \mathrm{N} \\
\end{array}$ & $\begin{array}{c}\text { Control } \\
\mathrm{n} / \mathrm{N}\end{array}$ & $\begin{array}{c}\text { Risk Ratio } \\
\text { M-H, Fixed, 95\% CI }\end{array}$ & Weight & $\begin{array}{c}\text { Risk Ratio } \\
\text { M-H, Fixed, 95\% Cl }\end{array}$ \\
\hline \multicolumn{6}{|l|}{ 12.1.1 Moclobemide } \\
\hline Subtotal $(95 \% \mathrm{Cl})$ & 44 & 44 & & $12.96 \%$ & $1.57[0.67,3.68]$ \\
\hline \multicolumn{6}{|c|}{ Total events: 11 (MAOI), 7 (Control) } \\
\hline \multicolumn{6}{|c|}{ Heterogeneity: Not applicable } \\
\hline \multicolumn{6}{|c|}{ Test for overall effect: $Z=1.04(P=0.3)$} \\
\hline \multicolumn{6}{|l|}{ 12.1.2 Selegiline } \\
\hline George 2003 & $4 / 20$ & $1 / 20$ & & $1.85 \%$ & $4[0.49,32.72]$ \\
\hline Biberman 2003 & $14 / 56$ & $6 / 53$ & $\longrightarrow$ & $11.41 \%$ & $2.21[0.92,5.32]$ \\
\hline Kahn 2012 & $11 / 121$ & $7 / 125$ & $\longrightarrow$ & $12.75 \%$ & $1.62[0.65,4.05]$ \\
\hline Weinberger 2010 & $6 / 51$ & $8 / 50$ & $\longrightarrow$ & $14.95 \%$ & $0.74[0.27,1.97]$ \\
\hline Subtotal $(95 \% \mathrm{CI})$ & 369 & 370 & & $87.04 \%$ & $1.25[0.88,1.78]$ \\
\hline
\end{tabular}




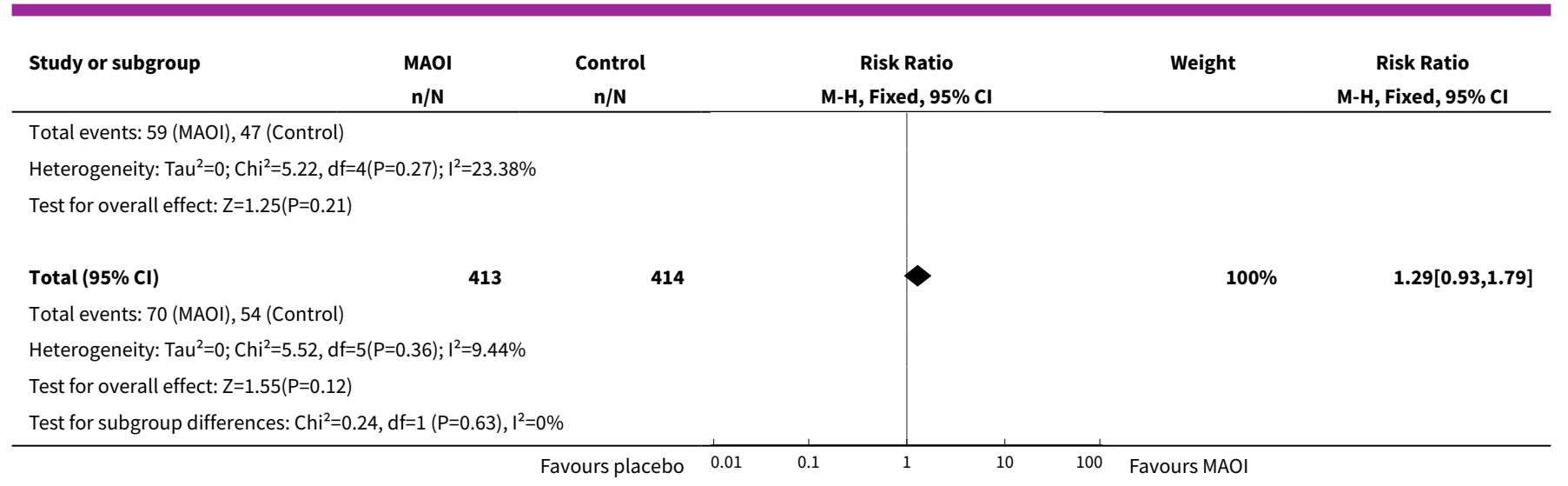

\section{Analysis 12.2. Comparison 12 Monoamine oxidase inhibitor (MAOI) versus placebo, Outcome 2 Adverse events.}

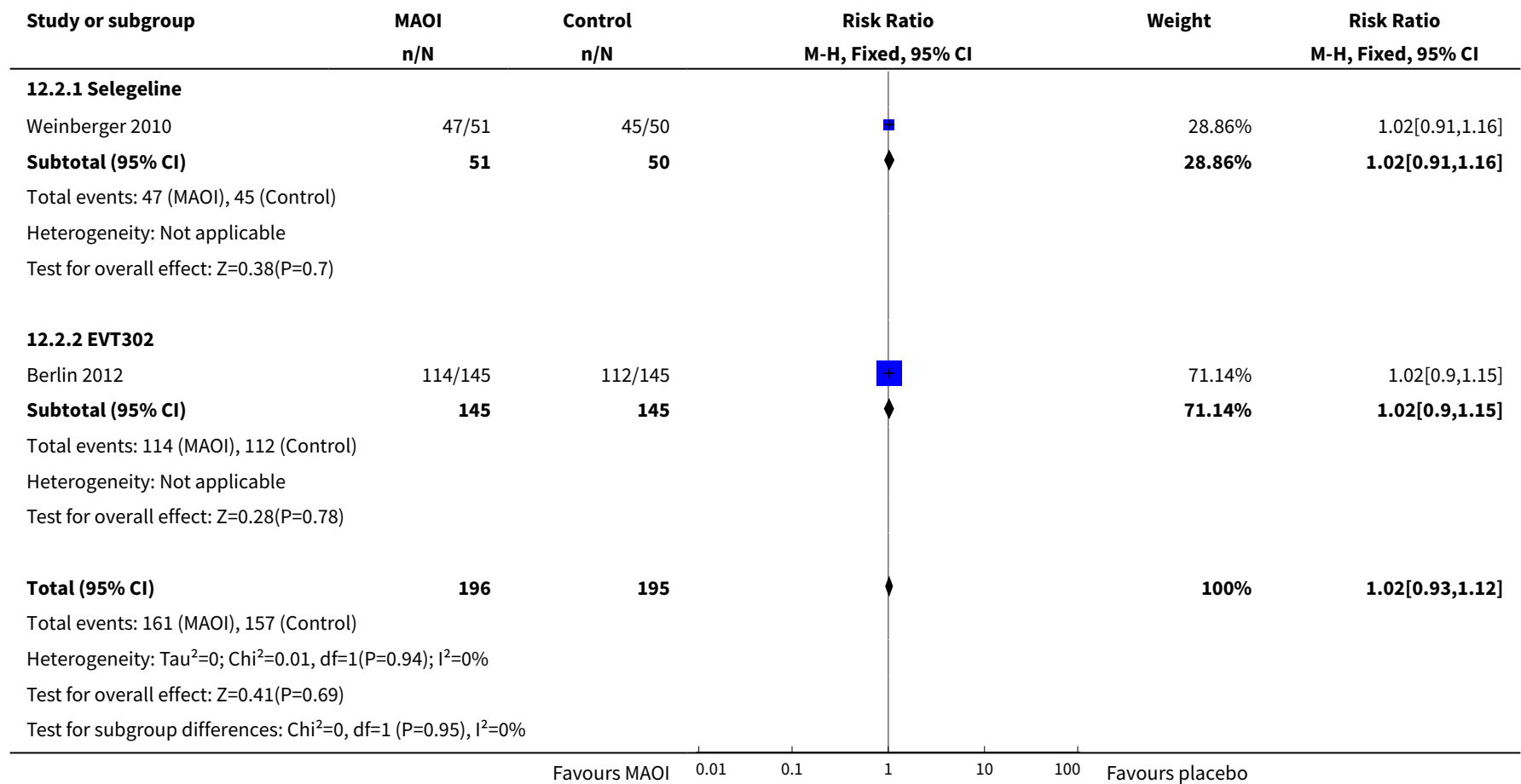

Analysis 12.3. Comparison 12 Monoamine oxidase inhibitor

(MAOI) versus placebo, Outcome 3 Psychiatric adverse events.

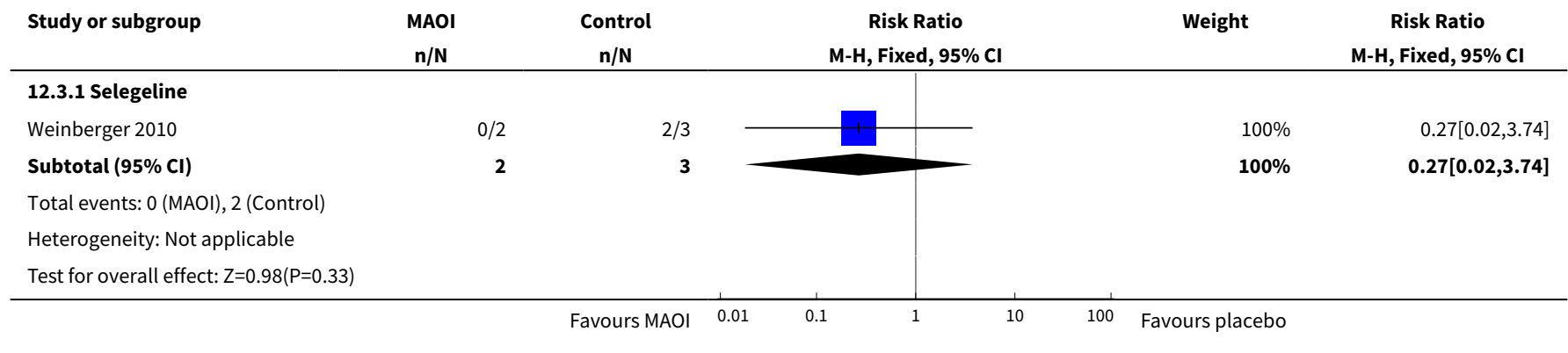


Analysis 12.4. Comparison 12 Monoamine oxidase inhibitor

(MAOI) versus placebo, Outcome 4 Serious adverse events.

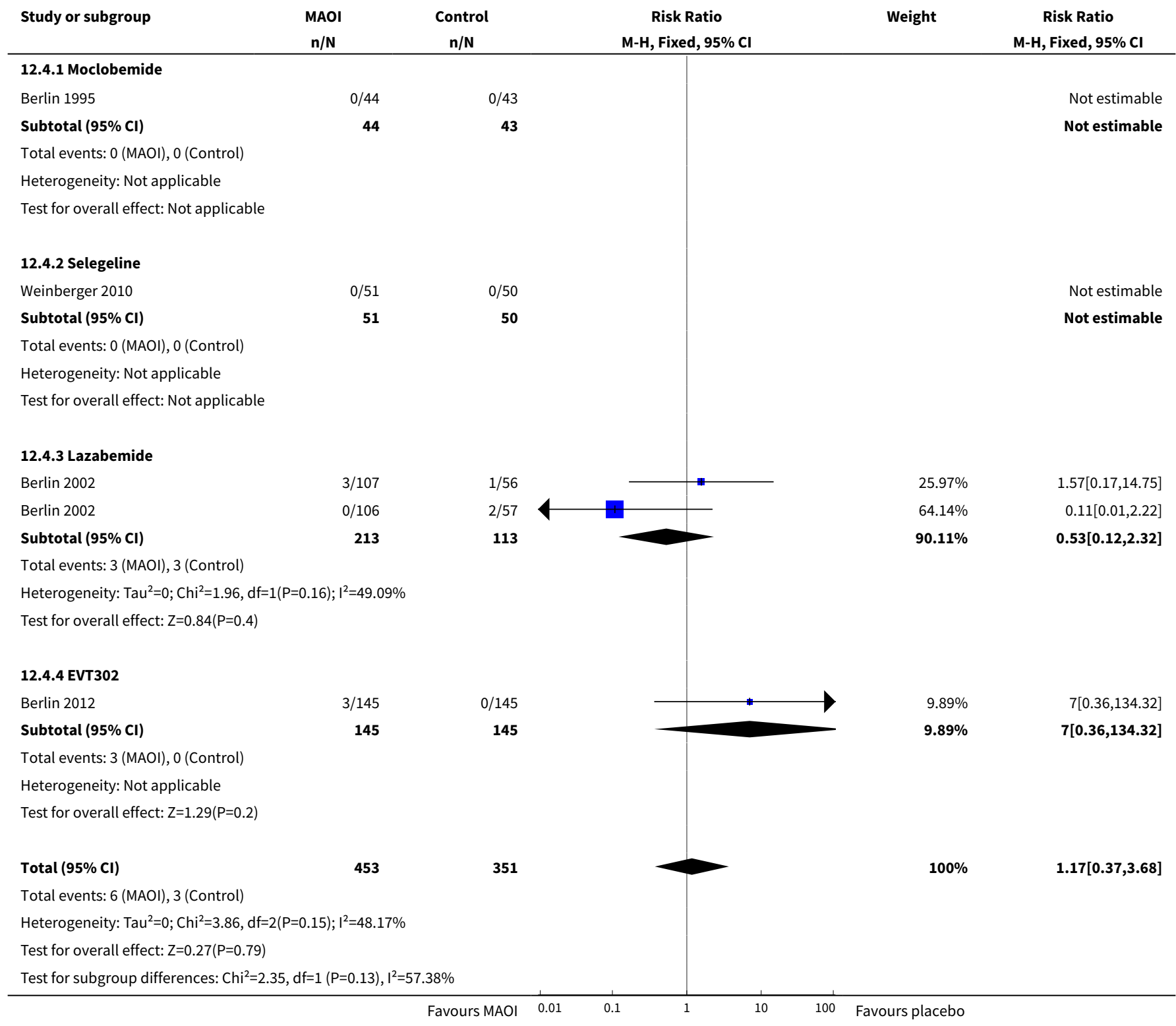

Analysis 12.5. Comparison 12 Monoamine oxidase inhibitor (MAOI) versus placebo, Outcome 5 Insomnia.

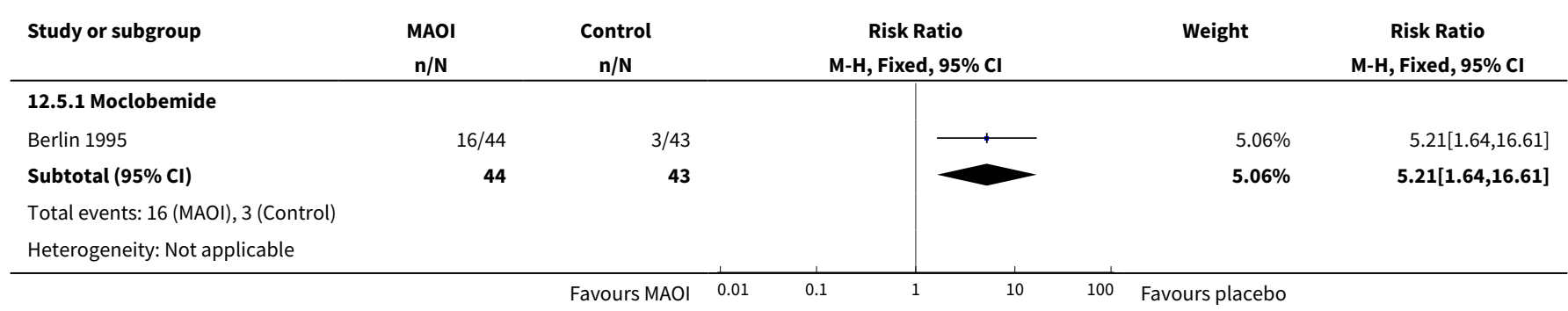




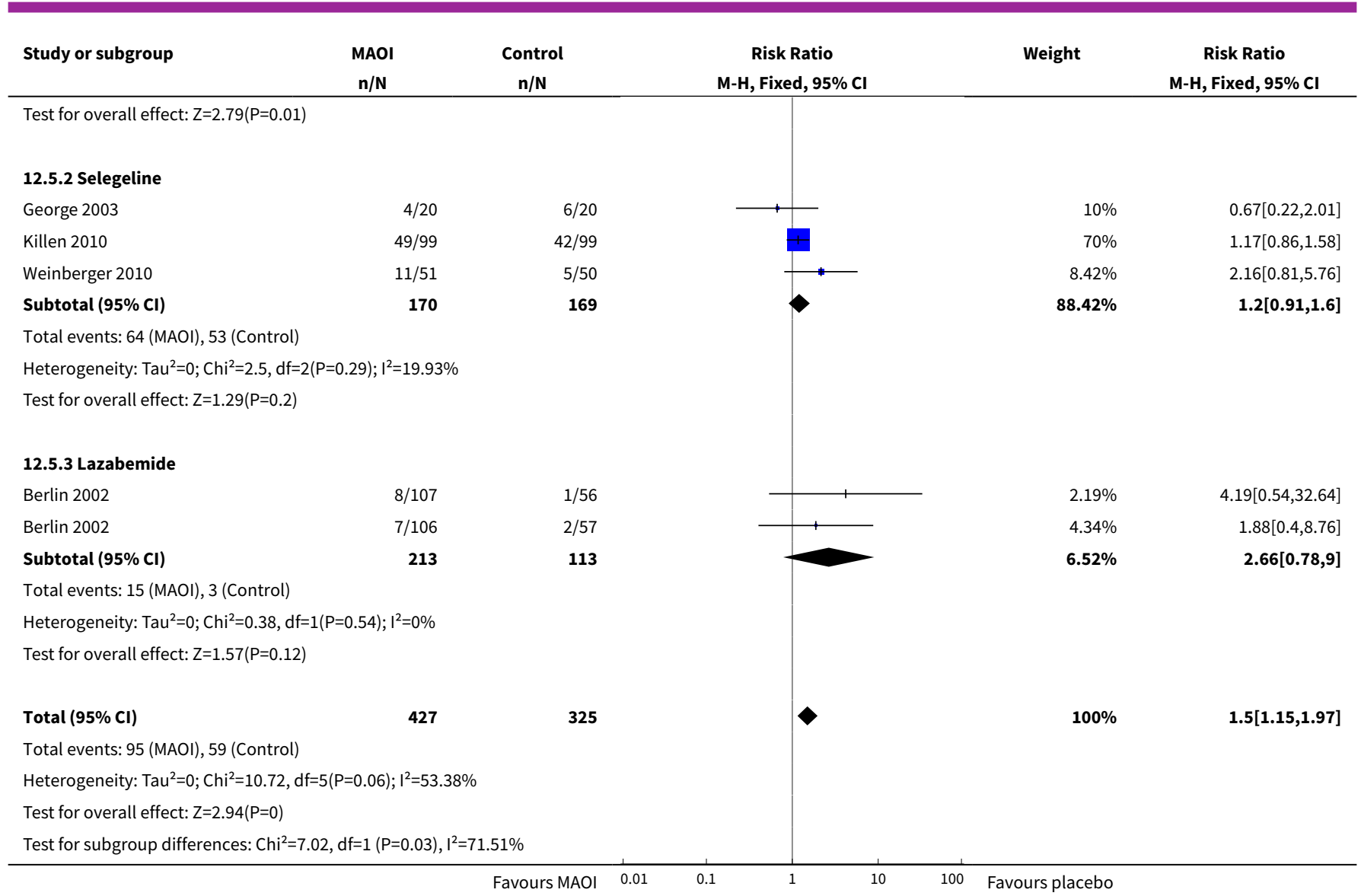

\section{Analysis 12.6. Comparison 12 Monoamine oxidase inhibitor (MAOI) versus placebo, Outcome 6 Anxiety.}

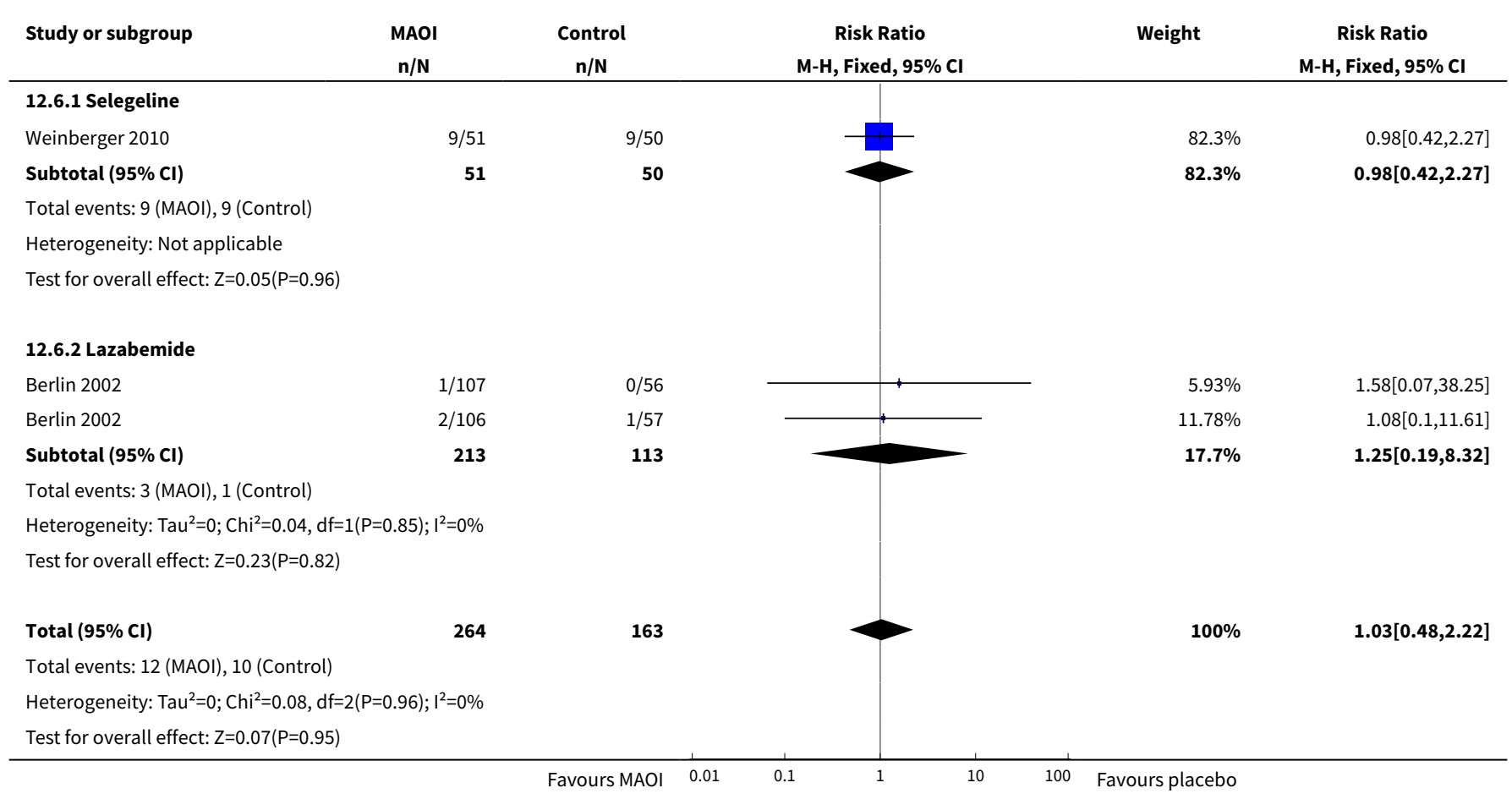




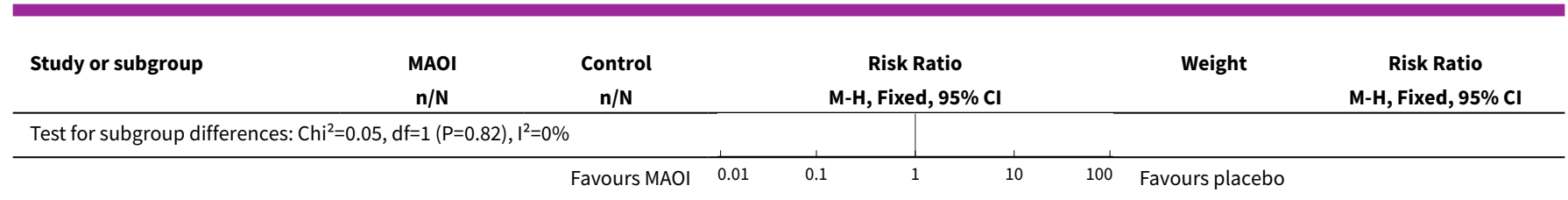

\section{Analysis 12.7. Comparison 12 Monoamine oxidase inhibitor (MAOI) versus placebo, Outcome 7 Dropouts due to drug.}

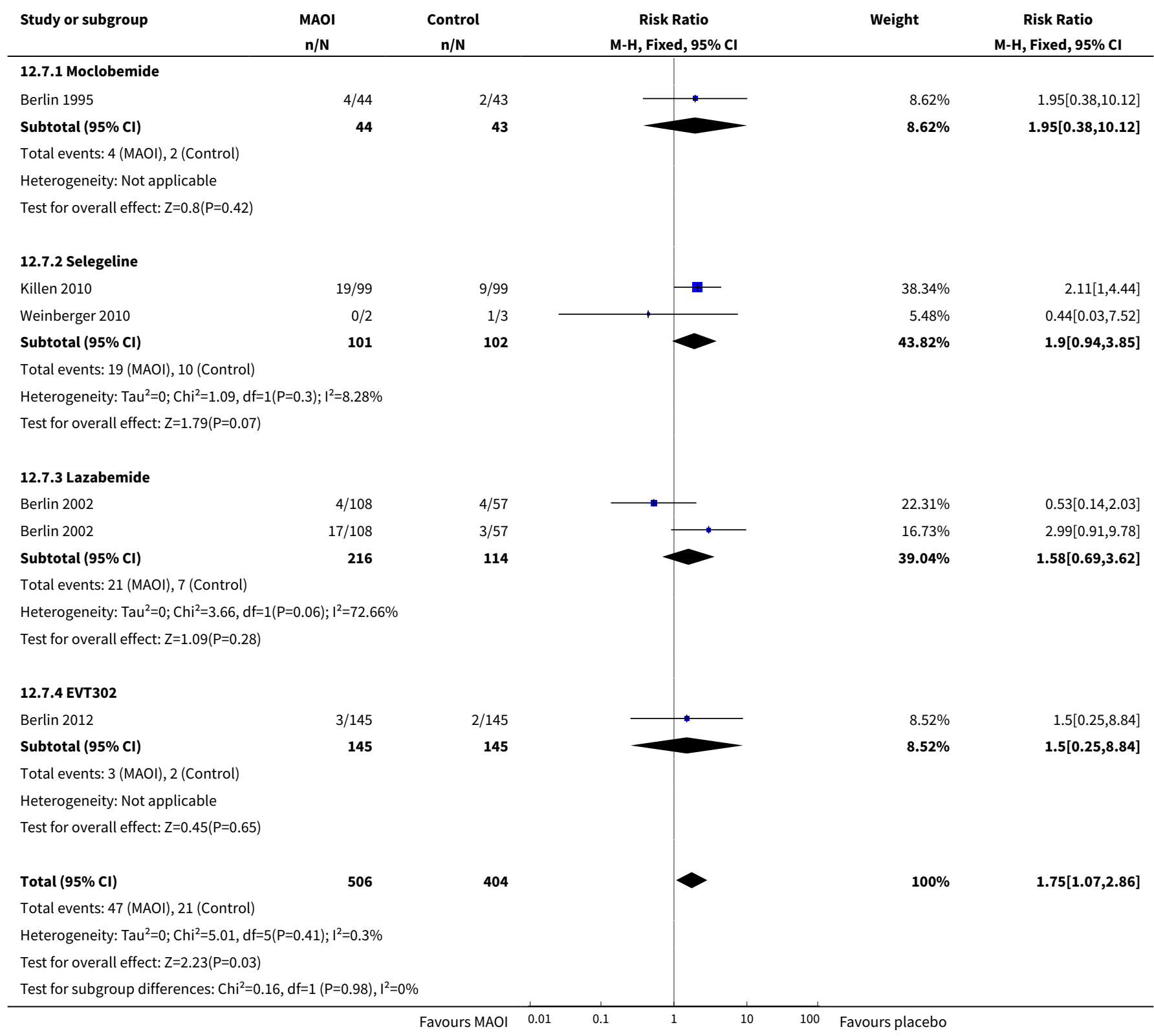


Comparison 13. Venlafaxine versus placebo

\begin{tabular}{lllll}
\hline Outcome or subgroup title & $\begin{array}{l}\text { No. of } \\
\text { studies }\end{array}$ & $\begin{array}{l}\text { No. of } \\
\text { partici- } \\
\text { pants }\end{array}$ & Statistical method & Effect size \\
\hline 1 Smoking cessation & 1 & & Risk Ratio (M-H, Fixed, 95\% Cl) & Subtotals only \\
\hline 2 Dropouts due to drug & 1 & 152 & Risk Ratio (M-H, Fixed, 95\% Cl) & $3.08[0.33,28.95]$ \\
\hline
\end{tabular}

Analysis 13.1. Comparison 13 Venlafaxine versus placebo, Outcome 1 Smoking cessation.

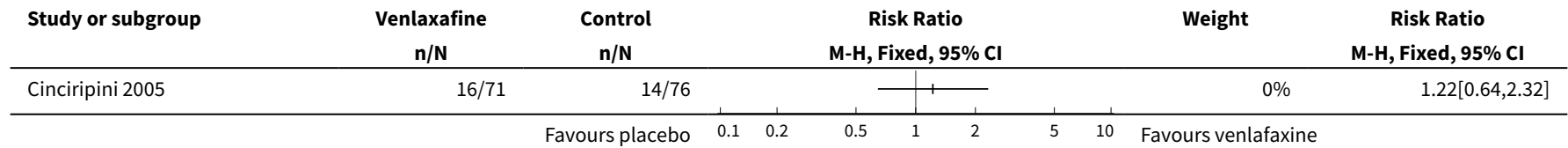

Analysis 13.2. Comparison 13 Venlafaxine versus placebo, Outcome 2 Dropouts due to drug.

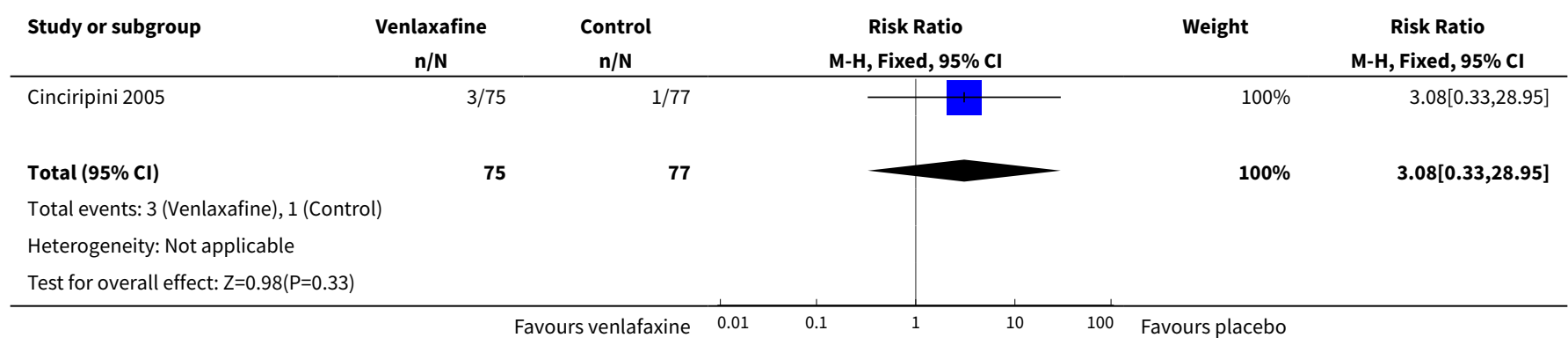

\section{Comparison 14. Hypericum (St John's wort) versus placebo}

\begin{tabular}{lllll}
\hline Outcome or subgroup title & $\begin{array}{l}\text { No. of } \\
\text { studies }\end{array}$ & $\begin{array}{l}\text { No. of } \\
\text { partici- } \\
\text { pants }\end{array}$ & Statistical method & Effect size \\
\hline 1 Smoking cessation & 2 & 261 & Risk Ratio (M-H, Fixed, 95\% Cl) & $0.81[0.26,2.53]$ \\
\hline 2 Serious adverse events & 1 & 143 & Risk Ratio (M-H, Fixed, 95\% Cl) & $2.37[0.36,15.57]$ \\
\hline 3 All-cause mortality & 1 & 143 & Risk Ratio (M-H, Fixed, 95\% Cl) & $3.08[0.13,73.24]$ \\
\hline 4 Dropouts due to drug & 1 & 141 & Risk Ratio (M-H, Fixed, 95\% Cl) & $1.20[0.36,3.96]$ \\
\hline
\end{tabular}


Analysis 14.1. Comparison 14 Hypericum (St John's wort) versus placebo, Outcome 1 Smoking cessation.

\begin{tabular}{|c|c|c|c|c|c|}
\hline Study or subgroup & $\begin{array}{c}\text { St John's Wort } \\
n / N\end{array}$ & $\begin{array}{c}\text { Placebo } \\
n / N\end{array}$ & $\begin{array}{c}\text { Risk Ratio } \\
\text { M-H, Fixed, 95\% Cl }\end{array}$ & Weight & $\begin{array}{c}\text { Risk Ratio } \\
\text { M-H, Fixed, 95\% CI }\end{array}$ \\
\hline Parsons 2009 & $3 / 71$ & $6 / 72$ & - & $89.94 \%$ & $0.51[0.13,1.95]$ \\
\hline Sood 2010 & $3 / 79$ & $0 / 39$ & 1 & $10.06 \%$ & $3.5[0.19,66.12]$ \\
\hline Total $(95 \% \mathrm{Cl})$ & 150 & 111 & & $100 \%$ & $0.81[0.26,2.53]$ \\
\hline \multicolumn{6}{|c|}{ Total events: 6 (St John's Wort), 6 (Placebo) } \\
\hline \multicolumn{6}{|c|}{ Test for overall effect: $\mathrm{Z}=0.37(\mathrm{P}=0.71)$} \\
\hline
\end{tabular}

Analysis 14.2. Comparison 14 Hypericum (St John's wort) versus placebo, Outcome 2 Serious adverse events.

\begin{tabular}{|c|c|c|c|c|c|}
\hline Study or subgroup & $\begin{array}{c}\text { St John's Wort } \\
n / N\end{array}$ & $\begin{array}{l}\text { Placebo } \\
\mathrm{n} / \mathrm{N}\end{array}$ & $\begin{array}{c}\text { Risk Ratio } \\
\text { M-H, Fixed, } 95 \% \mathrm{Cl} \\
\end{array}$ & Weight & $\begin{array}{c}\text { Risk Ratio } \\
\text { M-H, Fixed, } 95 \% \mathrm{Cl} \\
\end{array}$ \\
\hline Parsons 2009 & $2 / 36$ & $0 / 37$ & \begin{tabular}{l|l} 
& $=-1$
\end{tabular} & $33.04 \%$ & $5.14[0.26,103.39]$ \\
\hline Parsons 2009 & $1 / 35$ & $1 / 35$ & & $66.96 \%$ & $1[0.07,15.36]$ \\
\hline Total $(95 \% \mathrm{Cl})$ & 71 & 72 & & $100 \%$ & $2.37[0.36,15.57]$ \\
\hline \multicolumn{6}{|c|}{ Total events: 3 (St John's Wort), 1 (Placebo) } \\
\hline \multicolumn{6}{|c|}{ Heterogeneity: $\operatorname{Tau}^{2}=0 ; \mathrm{Chi}^{2}=0.64, \mathrm{df}=1(\mathrm{P}=0.42) ; 1^{2}=0 \%$} \\
\hline Test for overall effect & & & & & \\
\hline
\end{tabular}

Analysis 14.3. Comparison 14 Hypericum (St John's wort) versus placebo, Outcome 3 All-cause mortality.

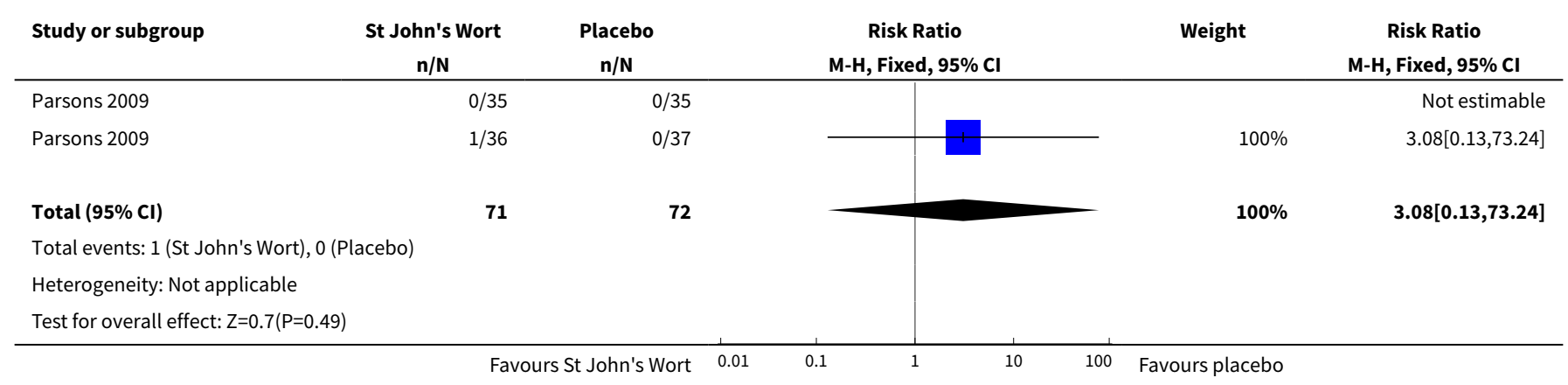

Analysis 14.4. Comparison 14 Hypericum (St John's wort) versus placebo, Outcome 4 Dropouts due to drug.

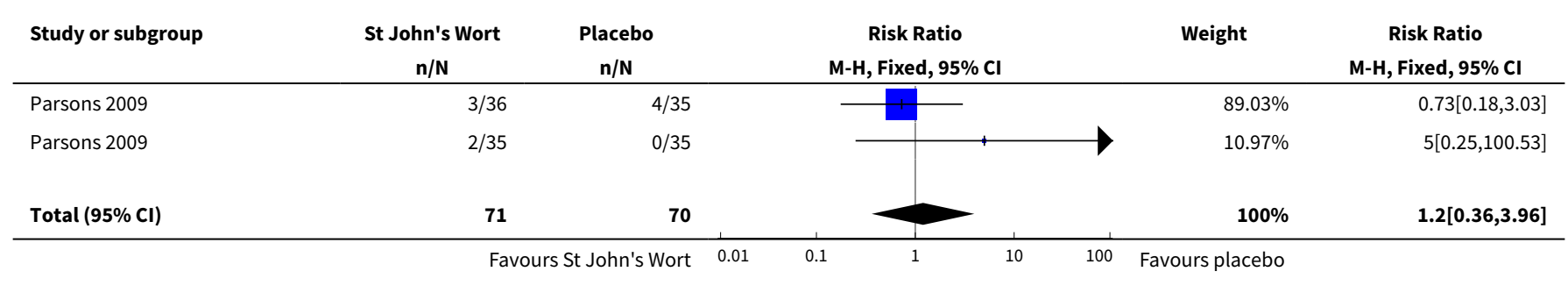




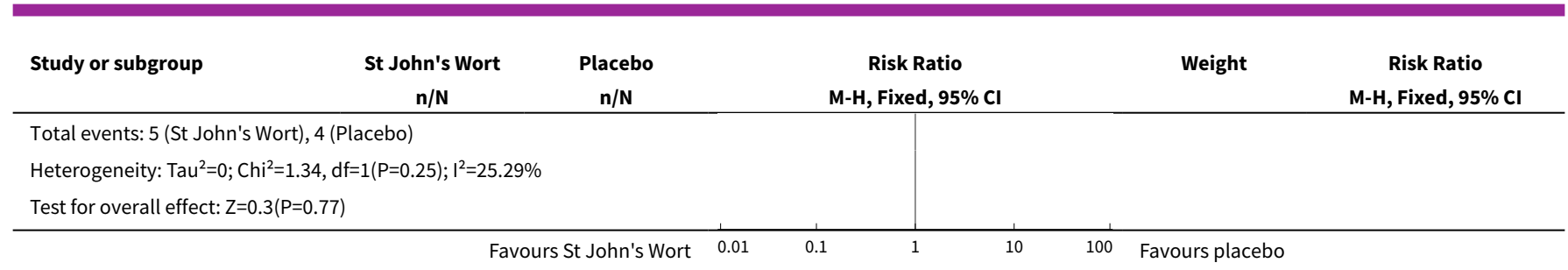

Comparison 15. S-Adenosyl-L-Methionine (SAMe) versus placebo

\begin{tabular}{lllll}
\hline Outcome or subgroup title & $\begin{array}{l}\text { No. of } \\
\text { studies }\end{array}$ & $\begin{array}{l}\text { No. of } \\
\text { partici- } \\
\text { pants }\end{array}$ & Statistical method & Effect size \\
\hline 1 Smoking cessation & 1 & & Risk Ratio (M-H, Fixed, 95\% Cl) & Totals not selected \\
\hline 2 Adverse events & 1 & 120 & Risk Ratio (M-H, Fixed, 95\% Cl) & $1.58[0.69,3.65]$ \\
\hline 3 Insomnia & 1 & 120 & Risk Ratio (M-H, Fixed, 95\% Cl) & $1.54[0.07,36.11]$ \\
\hline 4 Dropouts due to drug & 1 & 120 & Risk Ratio (M-H, Fixed, 95\% Cl) & $2.05[0.24,17.76]$ \\
\hline
\end{tabular}

Analysis 15.1. Comparison 15 S-Adenosyl-L-Methionine (SAMe) versus placebo, Outcome 1 Smoking cessation.

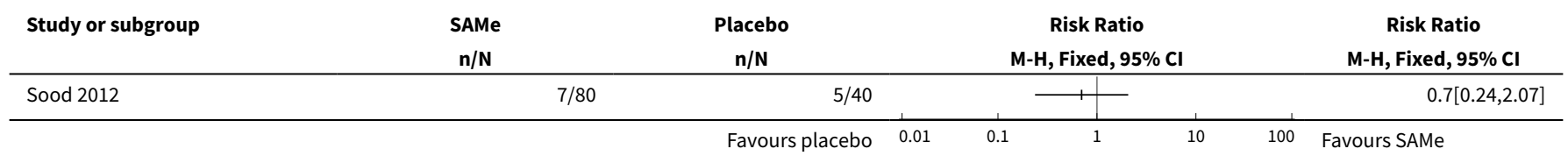

Analysis 15.2. Comparison 15 S-Adenosyl-L-Methionine (SAMe) versus placebo, Outcome 2 Adverse events.

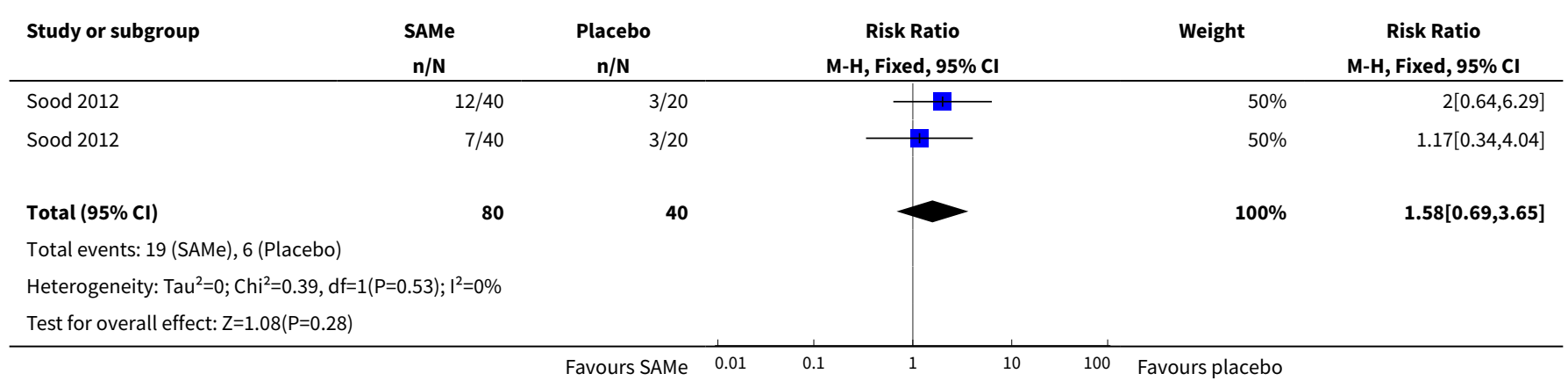


Analysis 15.3. Comparison 15 S-Adenosyl-L-Methionine (SAMe) versus placebo, Outcome 3 Insomnia.

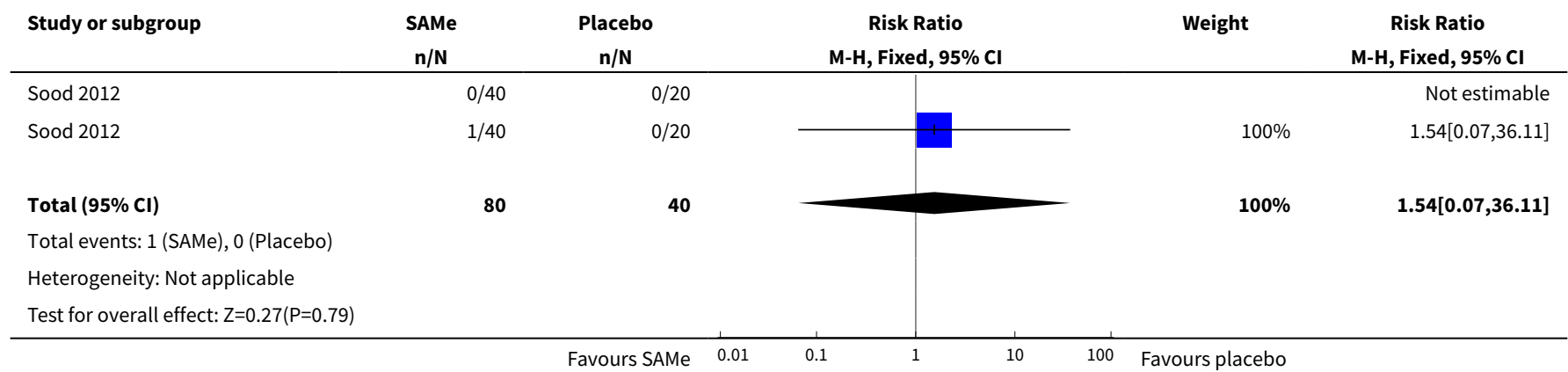

Analysis 15.4. Comparison 15 S-Adenosyl-L-Methionine (SAMe) versus placebo, Outcome 4 Dropouts due to drug.

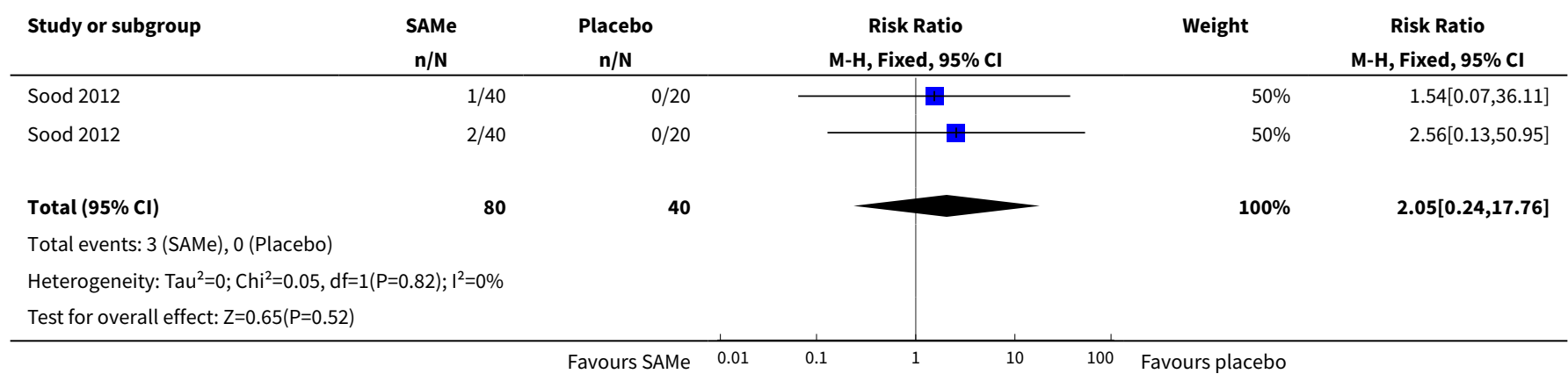

Comparison 16. Nortriptyline plus nicotine replacement therapy (NRT) versus NRT alone

\begin{tabular}{lllll}
\hline Outcome or subgroup title & $\begin{array}{l}\text { No. of } \\
\text { studies }\end{array}$ & $\begin{array}{l}\text { No. of } \\
\text { partici- } \\
\text { pants }\end{array}$ & Statistical method & Effect size \\
\hline 1 Smoking cessation & 4 & 1644 & Risk Ratio (M-H, Fixed, 95\% Cl) & $1.21[0.94,1.55]$ \\
\hline 2 Insomnia & 1 & 158 & Risk Ratio (M-H, Fixed, 95\% Cl) & $1.0[0.30,3.32]$ \\
\hline 3 Dropouts due to drug & 1 & 158 & Risk Ratio (M-H, Fixed, 95\% Cl) & $10.0[1.31,76.28]$ \\
\hline
\end{tabular}

Analysis 16.1. Comparison 16 Nortriptyline plus nicotine replacement therapy (NRT) versus NRT alone, Outcome 1 Smoking cessation.

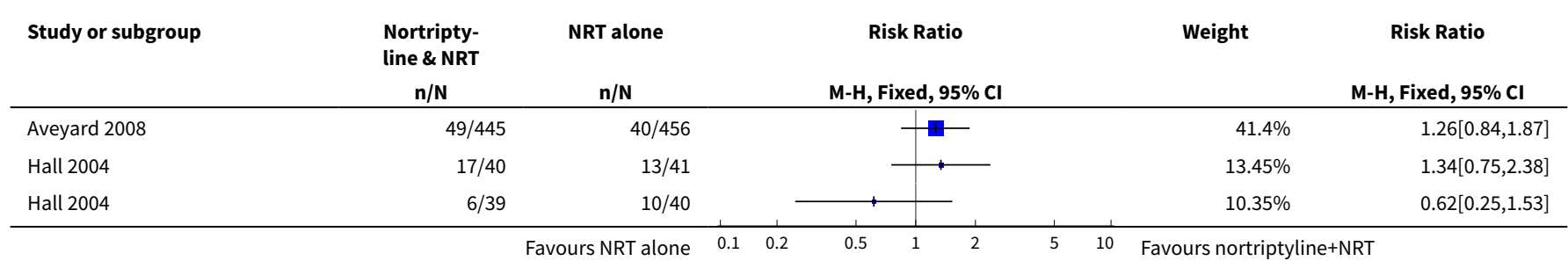




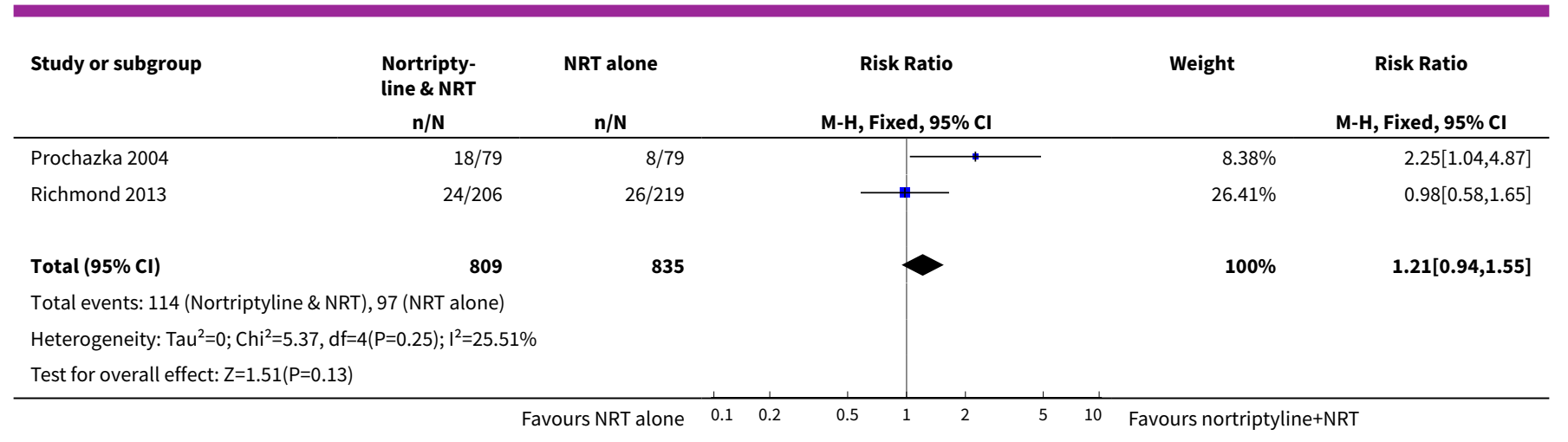

Analysis 16.2. Comparison 16 Nortriptyline plus nicotine replacement therapy (NRT) versus NRT alone, Outcome 2 Insomnia.

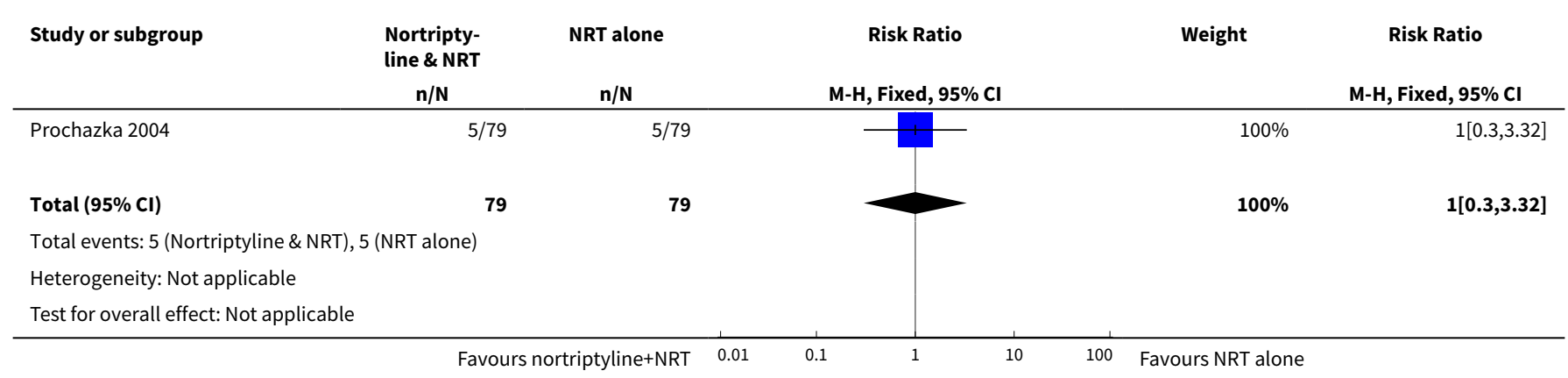

Analysis 16.3. Comparison 16 Nortriptyline plus nicotine replacement therapy (NRT) versus NRT alone, Outcome 3 Dropouts due to drug.

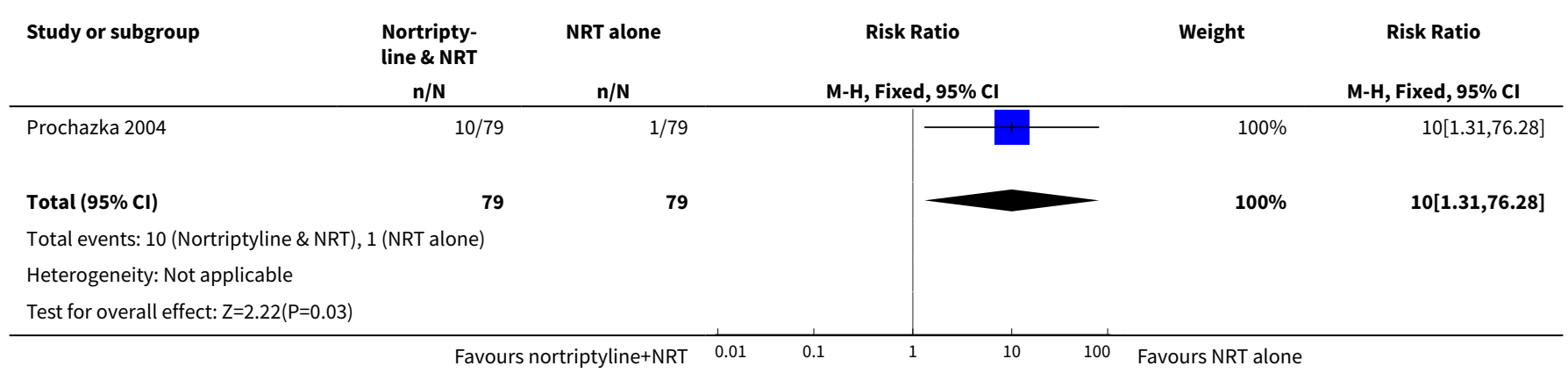

\section{Comparison 17. Selective serotonin reuptake inhibitor (SSRI) plus NRT versus NRT alone}

\begin{tabular}{lllll}
\hline Outcome or subgroup title & $\begin{array}{l}\text { No. of } \\
\text { studies }\end{array}$ & $\begin{array}{l}\text { No. of par- } \\
\text { ticipants }\end{array}$ & Statistical method & Effect size \\
\hline 1 Smoking cessation & 3 & 466 & Risk Ratio (M-H, Fixed, 95\% Cl) & $0.70[0.48,1.03]$ \\
\hline 1.1 Fluoxetine & 3 & 466 & Risk Ratio (M-H, Fixed, 95\% Cl) & $0.70[0.48,1.03]$ \\
\hline
\end{tabular}


Analysis 17.1. Comparison 17 Selective serotonin reuptake inhibitor (SSRI) plus NRT versus NRT alone, Outcome 1 Smoking cessation.

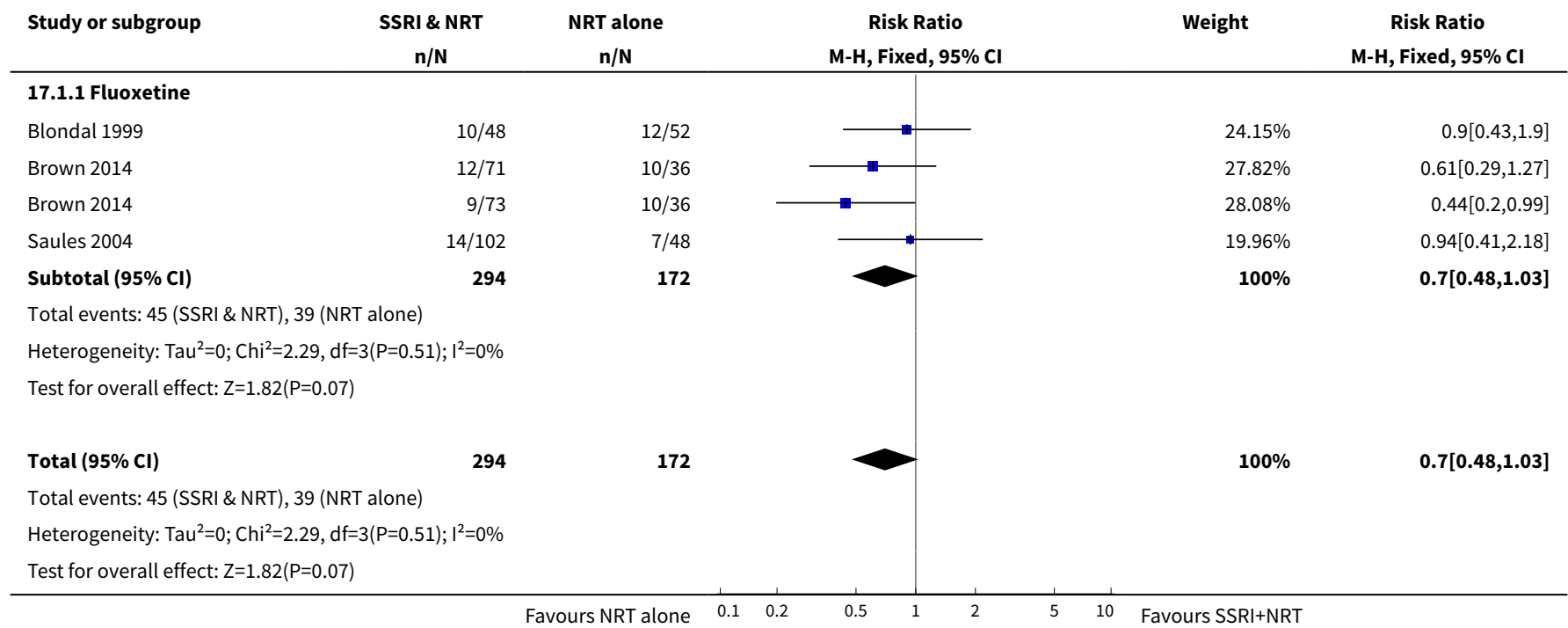

\section{Comparison 18. Selegeline plus nicotine replacement therapy (NRT) versus NRT alone}

\begin{tabular}{lllll}
\hline Outcome or subgroup title & $\begin{array}{l}\text { No. of } \\
\text { studies }\end{array}$ & $\begin{array}{l}\text { No. of par- } \\
\text { ticipants }\end{array}$ & Statistical method & Effect size \\
\hline 1 Serious adverse events & 1 & 109 & Risk Ratio (M-H, Fixed, 95\% Cl) & $0.0[0.0,0.0]$ \\
\hline 2 Dropouts due to drug & 1 & 109 & Risk Ratio (M-H, Fixed, 95\% Cl) & $1.42[0.42,4.75]$ \\
\hline
\end{tabular}

Analysis 18.1. Comparison 18 Selegeline plus nicotine replacement therapy (NRT) versus NRT alone, Outcome 1 Serious adverse events.

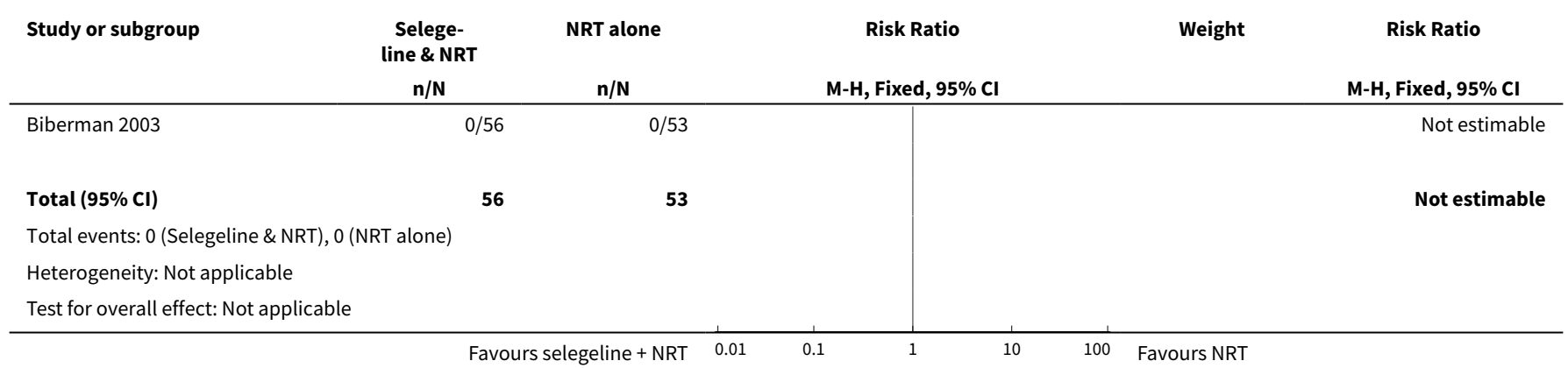


Analysis 18.2. Comparison 18 Selegeline plus nicotine replacement therapy (NRT) versus NRT alone, Outcome 2 Dropouts due to drug.

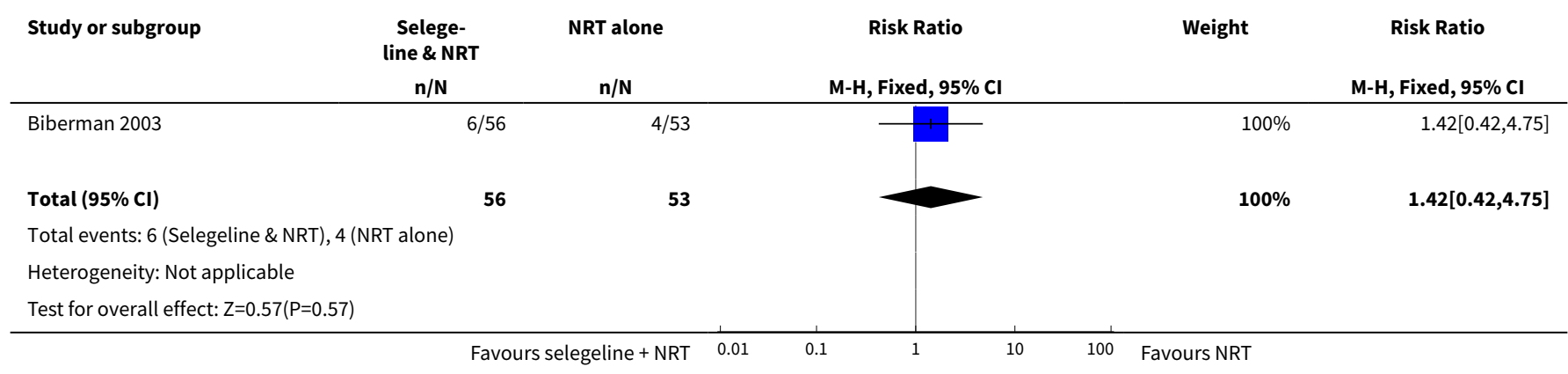

Comparison 19. EVT302 plus nicotine replacement therapy (NRT) versus NRT alone

\begin{tabular}{lllll}
\hline Outcome or subgroup title & $\begin{array}{l}\text { No. of } \\
\text { studies }\end{array}$ & $\begin{array}{l}\text { No. of } \\
\text { partici- } \\
\text { pants }\end{array}$ & Statistical method & Effect size \\
\hline 1 Adverse events & 1 & 122 & Risk Ratio (M-H, Fixed, 95\% Cl) & $1.06[0.90,1.25]$ \\
\hline 2 Serious adverse events & 1 & 122 & Risk Ratio (M-H, Fixed, 95\% Cl) & $3.0[0.12,72.23]$ \\
\hline 3 Dropouts due to drug & 1 & 122 & Risk Ratio (M-H, Fixed, 95\% Cl) & $3.0[0.12,72.23]$ \\
\hline
\end{tabular}

Analysis 19.1. Comparison 19 EVT302 plus nicotine replacement therapy (NRT) versus NRT alone, Outcome 1 Adverse events.

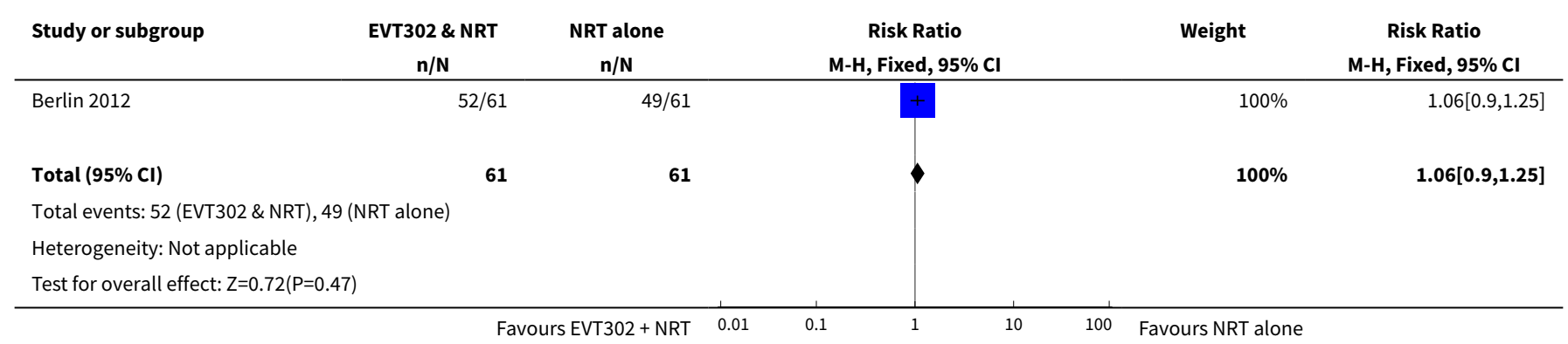

Analysis 19.2. Comparison 19 EVT302 plus nicotine replacement therapy (NRT) versus NRT alone, Outcome 2 Serious adverse events.

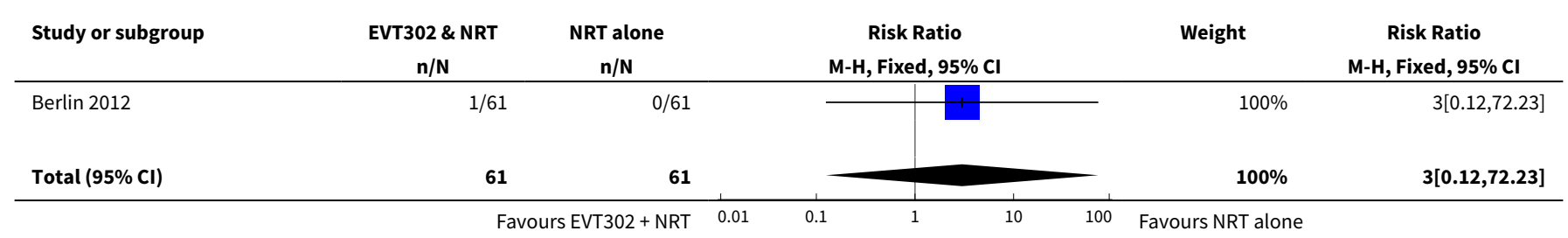




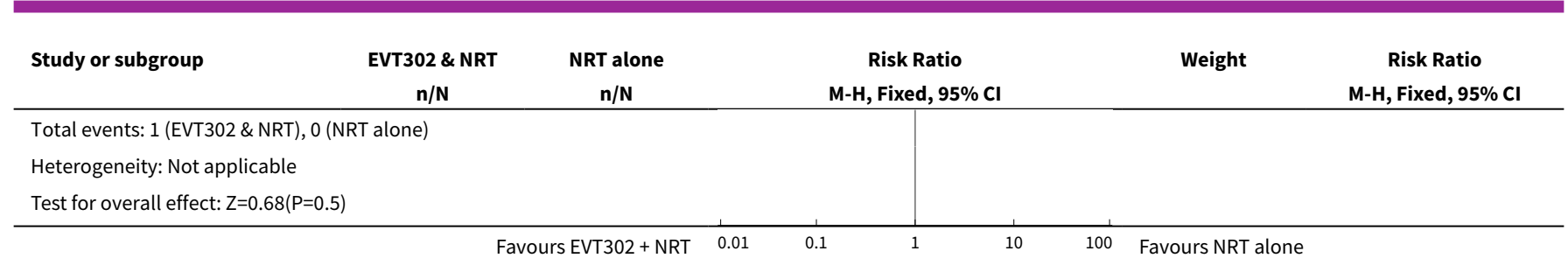

Analysis 19.3. Comparison 19 EVT302 plus nicotine replacement therapy (NRT) versus NRT alone, Outcome 3 Dropouts due to drug.

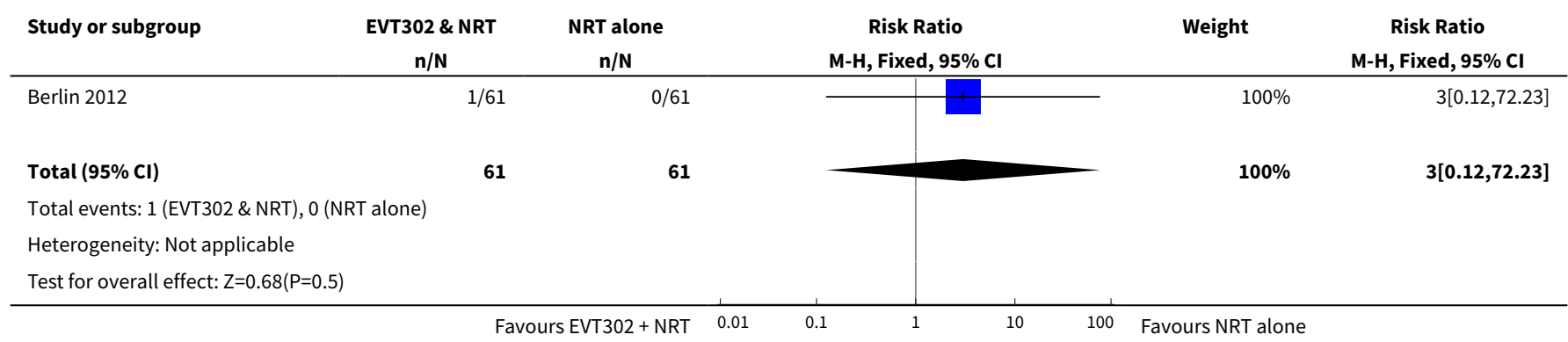

\section{Comparison 20. Fluoxetine (30 mg versus $60 \mathrm{mg}$ )}

\begin{tabular}{lllll}
\hline Outcome or subgroup title & $\begin{array}{l}\text { No. of } \\
\text { studies }\end{array}$ & $\begin{array}{l}\text { No. of } \\
\text { partici- } \\
\text { pants }\end{array}$ & Statistical method & Effect size \\
\hline 1 Smoking cessation & 1 & & Risk Ratio (M-H, Fixed, 95\% Cl) & Subtotals only \\
\hline 2 Dropouts due to drug & 1 & 656 & Risk Ratio (M-H, Fixed, 95\% Cl) & $0.64[0.46,0.87]$ \\
\hline
\end{tabular}

Analysis 20.1. Comparison 20 Fluoxetine (30 mg versus $60 \mathrm{mg}$ ), Outcome 1 Smoking cessation.

\begin{tabular}{|c|c|c|c|c|c|}
\hline Study or subgroup & $\begin{array}{c}30 \mathrm{mg} \\
\mathrm{n} / \mathrm{N}\end{array}$ & $\begin{array}{c}60 \mathrm{mg} \\
\mathrm{n} / \mathrm{N}\end{array}$ & $\begin{array}{c}\text { Risk Ratio } \\
\text { M-H, Fixed, 95\% Cl }\end{array}$ & Weight & $\begin{array}{c}\text { Risk Ratio } \\
\text { M-H, Fixed, } 95 \% \text { CI }\end{array}$ \\
\hline Niaura 2002 & $32 / 328$ & $32 / 328$ & + & $0 \%$ & $1[0.63,1.59]$ \\
\hline
\end{tabular}

Analysis 20.2. Comparison 20 Fluoxetine (30 mg versus $60 \mathrm{mg}$ ), Outcome 2 Dropouts due to drug.

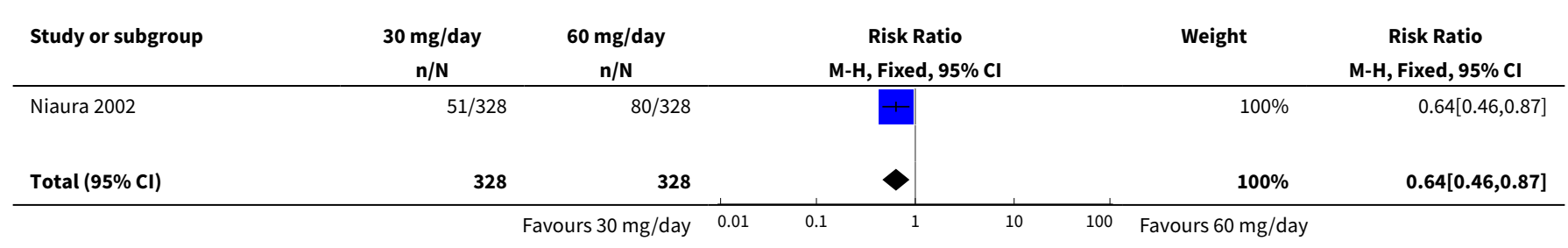




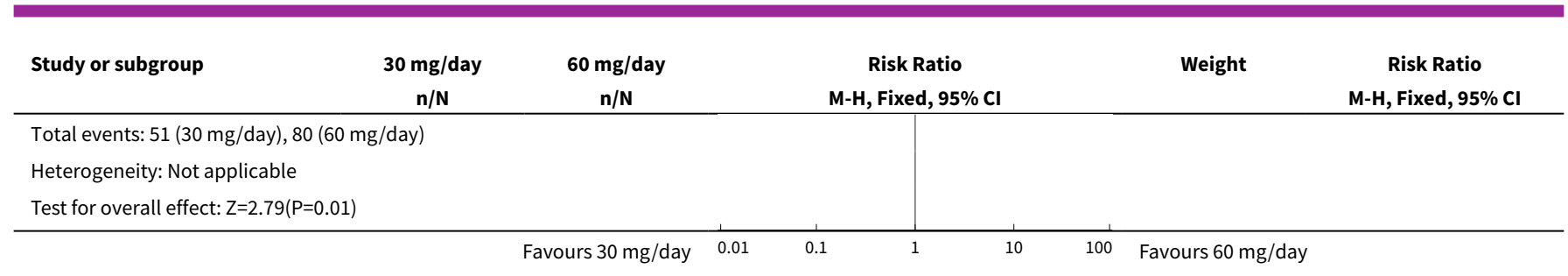

\section{Comparison 21. Lazabemide (100 $\mathrm{mg}$ versus $200 \mathrm{mg}$ )}

\begin{tabular}{lllll}
\hline Outcome or subgroup title & $\begin{array}{l}\text { No. of } \\
\text { studies }\end{array}$ & $\begin{array}{l}\text { No. of } \\
\text { partici- } \\
\text { pants }\end{array}$ & Statistical method & Effect size \\
\hline 1 Serious adverse events & 1 & 213 & Risk Ratio (M-H, Fixed, 95\% Cl) & $0.0[0.0,0.0]$ \\
\hline 2 Insomnia & 1 & 213 & Risk Ratio (M-H, Fixed, 95\% Cl) & $1.13[0.43,3.01]$ \\
\hline 3 Anxiety & 1 & 213 & Risk Ratio (M-H, Fixed, 95\% Cl) & $0.50[0.05,5.38]$ \\
\hline 4 Dropouts due to drug & 1 & 216 & Risk Ratio (M-H, Fixed, 95\% Cl) & $4.25[1.48,12.22]$
\end{tabular}

Analysis 21.1. Comparison 21 Lazabemide (100 mg versus $200 \mathrm{mg}$ ), Outcome 1 Serious adverse events.

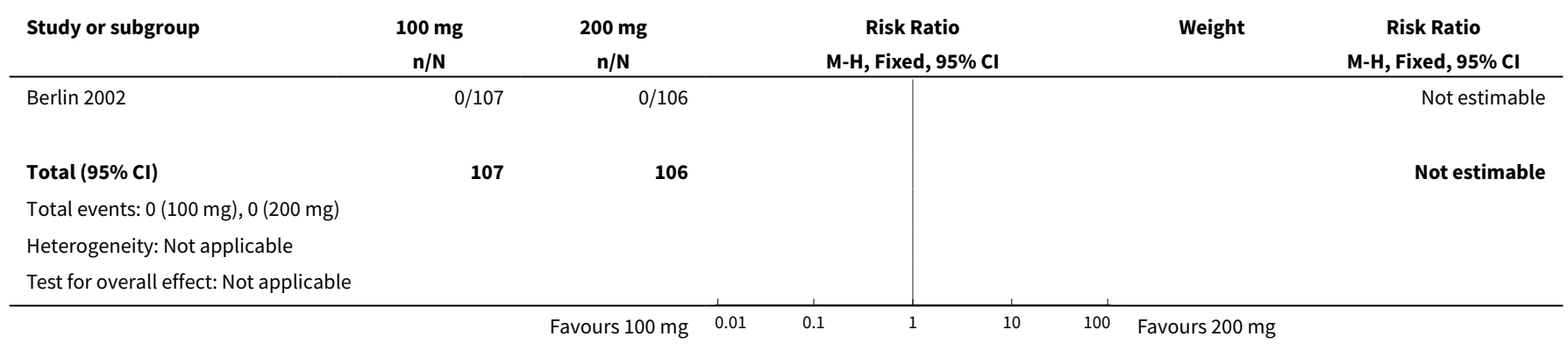

Analysis 21.2. Comparison 21 Lazabemide (100 mg versus $200 \mathrm{mg}$ ), Outcome 2 Insomnia.

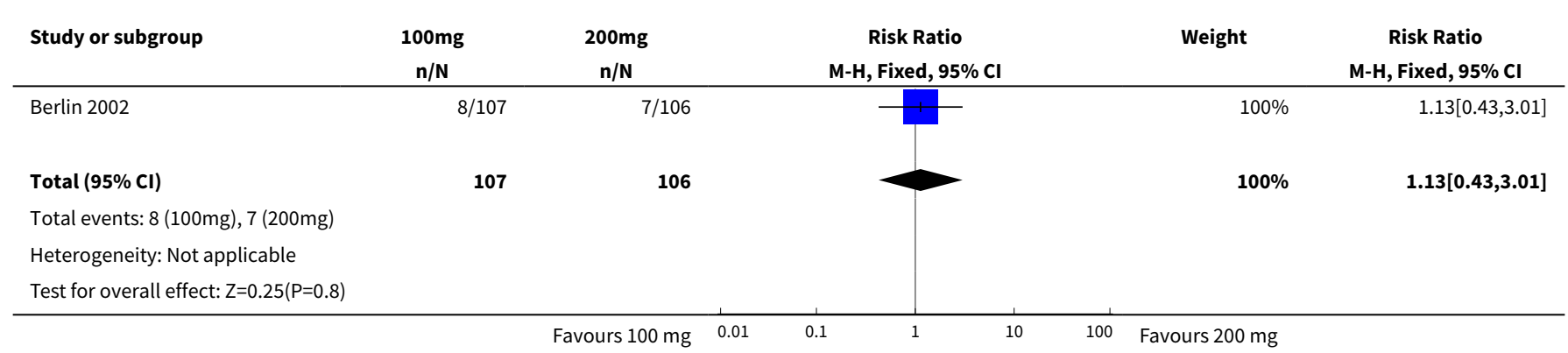


Analysis 21.3. Comparison 21 Lazabemide ( $100 \mathrm{mg}$ versus $200 \mathrm{mg}$ ), Outcome 3 Anxiety.

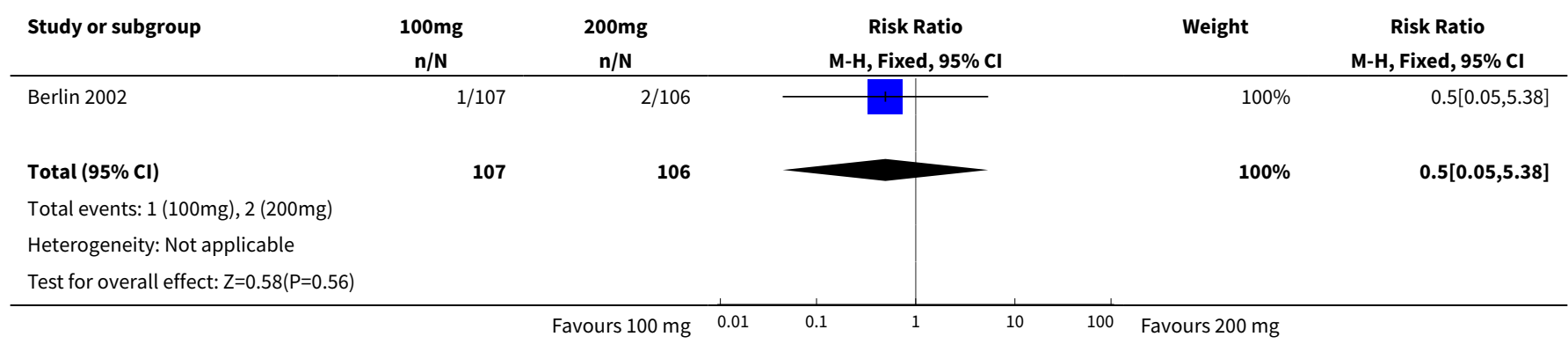

Analysis 21.4. Comparison 21 Lazabemide ( $100 \mathrm{mg}$ versus $200 \mathrm{mg}$ ), Outcome 4 Dropouts due to drug.

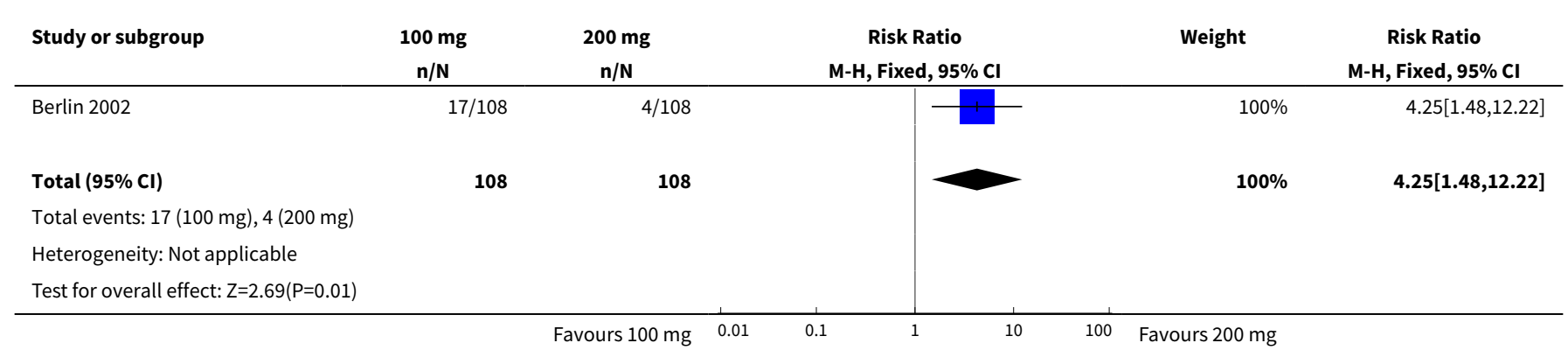

Comparison 22. Hypericum (St John's wort) (300 mg versus $600 \mathrm{mg}$ )

\begin{tabular}{lllll}
\hline Outcome or subgroup title & $\begin{array}{l}\text { No. of } \\
\text { studies }\end{array}$ & $\begin{array}{l}\text { No. of } \\
\text { partici- } \\
\text { pants }\end{array}$ & Statistical method & Effect size \\
\hline 1 Smoking cessation & 1 & & Risk Ratio (M-H, Fixed, 95\% Cl) & Subtotals only \\
\hline 2 Adverse events & 1 & 28 & Risk Ratio (M-H, Fixed, 95\% Cl) & $1.3[0.63,2.67]$ \\
\hline
\end{tabular}

Analysis 22.1. Comparison 22 Hypericum (St John's wort) (300 mg versus $600 \mathrm{mg}$ ), Outcome 1 Smoking cessation.

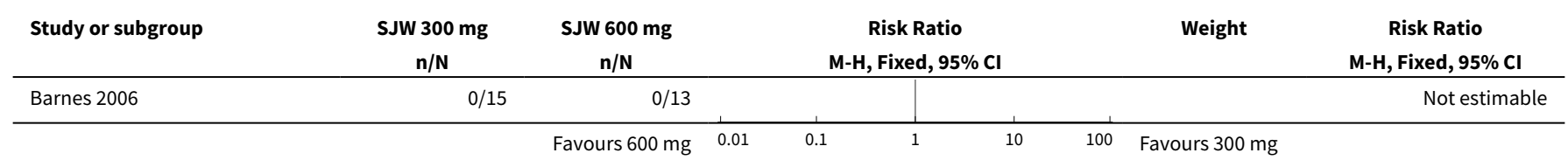


Analysis 22.2. Comparison 22 Hypericum (St John's wort) (300 mg versus $600 \mathrm{mg}$ ), Outcome 2 Adverse events.

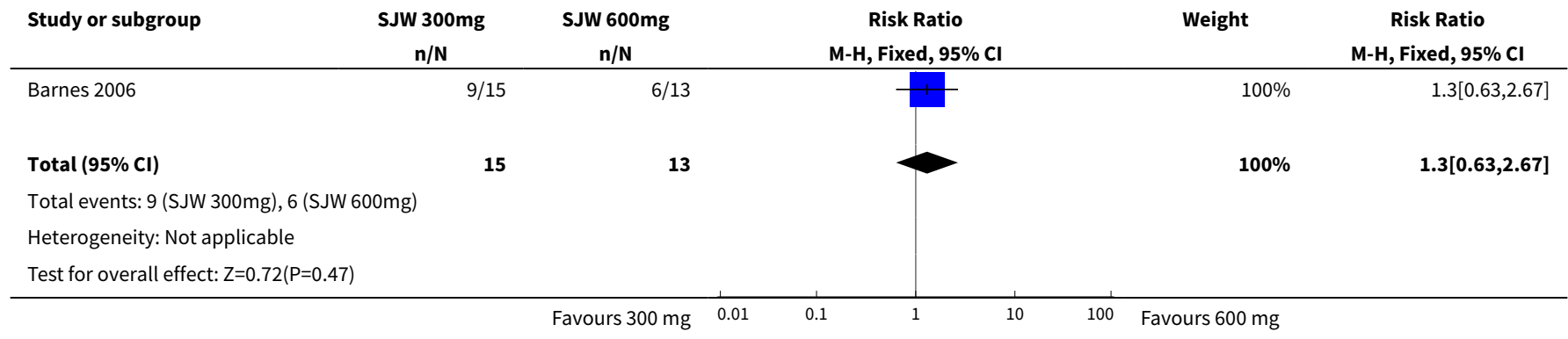

Comparison 23. S-Adenosyl-L-Methionine (SAMe) (800 mg versus $1600 \mathrm{mg}$ )

\begin{tabular}{lllll}
\hline Outcome or subgroup title & $\begin{array}{l}\text { No. of } \\
\text { studies }\end{array}$ & $\begin{array}{l}\text { No. of } \\
\text { partici- } \\
\text { pants }\end{array}$ & Statistical method & Effect size \\
\hline 1 Adverse events & 1 & 80 & Risk Ratio (M-H, Fixed, 95\% Cl) & $0.58[0.26,1.33]$ \\
\hline 2 Dropouts due to drug & 1 & 80 & Risk Ratio (M-H, Fixed, 95\% Cl) & $2.0[0.19,21.18]$ \\
\hline
\end{tabular}

Analysis 23.1. Comparison 23 S-Adenosyl-L-Methionine (SAMe) (800 mg versus $1600 \mathrm{mg}$ ), Outcome 1 Adverse events.

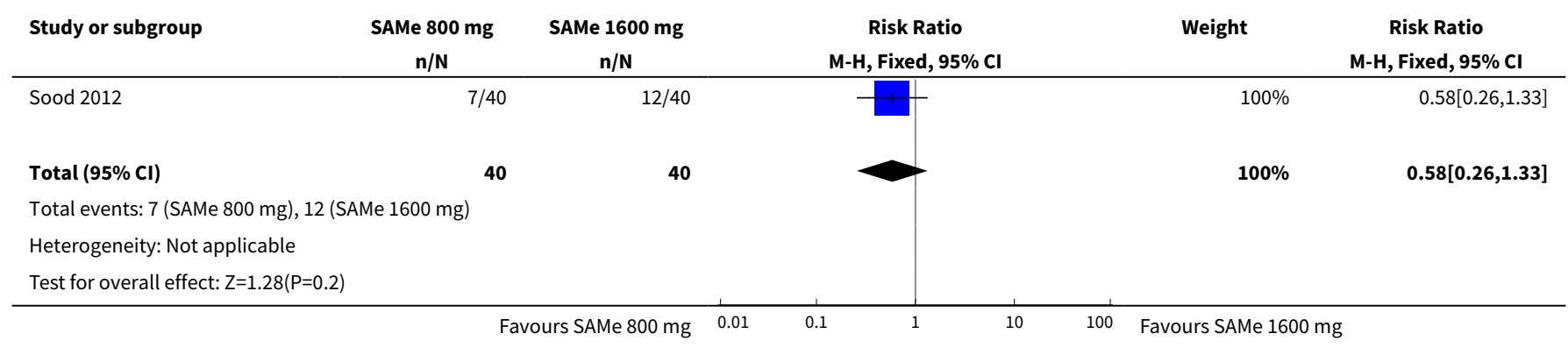

Analysis 23.2. Comparison 23 S-Adenosyl-L-Methionine (SAMe)

(800 mg versus $1600 \mathrm{mg}$ ), Outcome 2 Dropouts due to drug.

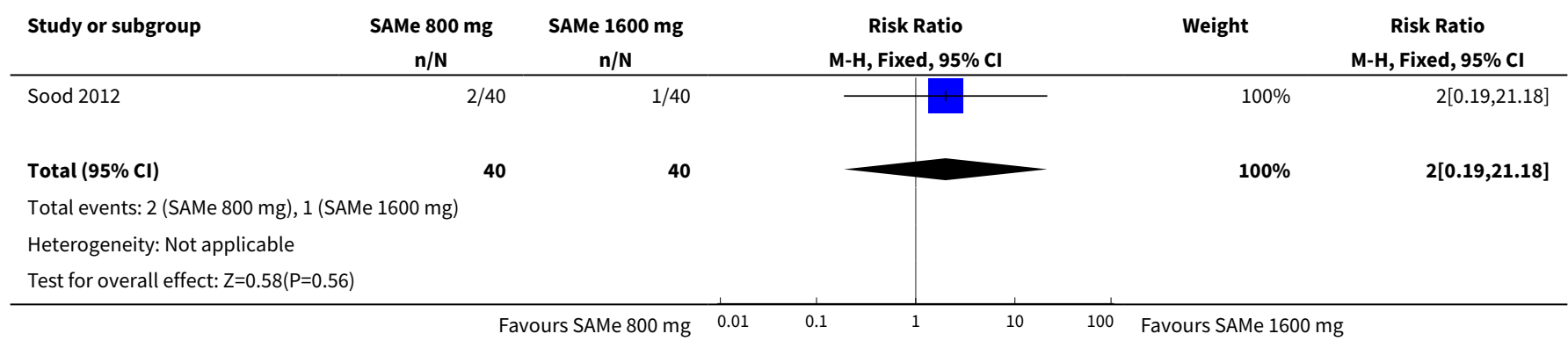


ADDITIONAL TABLES

Table 1. Sensitivity analyses excluding industry-supported studies

\begin{tabular}{|c|c|c|}
\hline $\begin{array}{l}\text { Comparison and out- } \\
\text { come }\end{array}$ & RR and $\mathrm{Cl}$ excluding industry funded studies & $\begin{array}{l}\text { RR and } \mathrm{Cl} \text { excluding studies with funding or } \\
\text { medication provided by industry }\end{array}$ \\
\hline Analysis 1.1 & 1.49 (1.33 to 1.66$) ;$ studies $=26$ & 1.48 (1.26 to 1.74$) ;$ studies $=14$ \\
\hline Analysis 1.4 & 1.24 (1.14 to 1.35$) ;$ studies $=9$ & 1.24 (1.09 to 1.41$) ;$ studies $=7$ \\
\hline Analysis 1.5 & $0.85(0.60$ to 1.21$) ;$ studies $=11$ & $0.88(0.61$ to 1.26$) ;$ studies $=10$ \\
\hline Analysis 1.6 & 1.19 (0.72 to 1.94$) ;$ studies $=4$ & 1.19 (0.72 to 1.94$) ;$ studies $=4$ \\
\hline Analysis 1.7 & 2.04 (0.23 to 17.84$) ;$ studies $=7$ & 2.61 (0.11 to 60.51$) ;$ studies $=6$ \\
\hline Analysis 1.8 & Not estimable & Not estimable \\
\hline Analysis 1.9 & Not estimable & Not estimable \\
\hline Analysis 1.10 & Not estimable & Not estimable \\
\hline Analysis 1.11 & $1.51(0.44$ to 5.27$) ;$ studies $=6$ & 1.51 ( 0.44 to 5.27$) ;$ studies $=6$ \\
\hline Analysis 1.12 & 2.08 ( 0.93 to 4.64$) ;$ studies $=4$ & 2.27 (0.46 to 11.17$) ;$ studies $=2$ \\
\hline Analysis 1.13 & 1.85 (1.55 to 2.20$)$; studies $=11$ & 1.85 ( 1.55 to 2.20$) ;$ studies $=7$ \\
\hline Analysis 1.14 & $1.32(0.98$ to 1.77$) ;$ studies $=11$ & 1.11 ( 0.77 to 1.58$) ;$ studies $=8$ \\
\hline Analysis 2.1 & 1.09 (0.91 to 1.32$) ;$ studies $=11$ & $0.78(0.46$ to 1.32$) ;$ studies $=4$ \\
\hline Analysis 2.2 & 1.21 (1.02 to 1.43 ); studies $=2$ & 1.24 (0.98 to 1.56$) ;$ studies $=1$ \\
\hline Analysis 2.3 & 2.06 (0.20 to 21.67$) ;$ studies $=2$ & Not estimable \\
\hline Analysis 2.4 & $2.93(0.12$ to 72.31$) ;$ studies $=1$ & $2.93(0.12$ to 72.31$) ;$ studies $=1$ \\
\hline Analysis 2.5 & Not estimable & Not estimable \\
\hline Analysis 2.6 & Not estimable & Not estimable \\
\hline Analysis 2.7 & 0.68 (0.12 to 3.98$) ;$ studies $=1$ & 0.68 (0.12 to 3.98$) ;$ studies $=1$ \\
\hline Analysis 2.10 & 1.04 (0.16 to 6.83$) ;$ studies $=1$ & Not estimable \\
\hline Analysis 2.8 & $1.26(0.60$ to 2.65$) ;$ studies $=1$ & Not estimable \\
\hline Analysis 2.9 & $1.62(0.72$ to 3.65$) ;$ studies $=2$ & Not estimable \\
\hline Analysis 3.1 & $1.14(0.85$ to 1.51$) ;$ studies $=2$ & Not estimable \\
\hline Analysis 3.2 & 1.05 (0.98 to 1.12 ); studies $=3$ & 1.80 (0.53 to 6.16$) ;$ studies $=1$ \\
\hline
\end{tabular}


Table 1. Sensitivity analyses excluding industry-supported studies

\begin{tabular}{lll} 
Analysis 3.3 & 1.31 (0.60 to 2.84$)$; studies $=3$ & Not estimable \\
\hline Analysis 3.4 & $1.15(1.03$ to 1.30$)$; studies $=2$ & Not estimable \\
\hline Analysis 3.5 & Not estimable & Not estimable \\
\hline Analysis 3.6 & $0.34(0.01$ to 8.27$)$; studies $=2$ & Not estimable \\
\hline Analysis 3.7 & $0.34(0.04$ to 3.27$)$; studies $=2$ & Not estimable \\
\hline Analysis 3.8 & Not estimable & Not estimable \\
\hline Analysis 3.9 & $0.34(0.01$ to 8.40$) ;$ studies $=1$ & Not estimable \\
\hline Analysis 3.12 & $0.72(0.37$ to 1.40$) ;$ studies $=4$ & Not estimable \\
\hline Analysis 3.10 & $1.49(0.95$ to 2.33$) ;$ studies $=1$ & Not estimable \\
\hline Analysis 3.11 & $1.48(1.15$ to 1.89$)$ & Not estimable
\end{tabular}

$\mathrm{Cl}$ : confidence interval; RR: risk ratio

Table 2. Depression as a moderator of the relationship between antidepressants and smoking cessation

\begin{tabular}{llll}
\hline Study ID & $\begin{array}{l}\text { Antidepres- } \\
\text { sant }\end{array}$ & $\begin{array}{l}\text { Direction of } \\
\text { relationship }\end{array}$ & Evidence for interaction \\
\hline $\begin{array}{lll}\text { Anthenelli } \\
2016\end{array}$ & Bupropion & None & $\begin{array}{l}\text { "Varenicline, bupropion and NRT were all effective in smokers with mental health } \\
\text { problems (assessed with a number of variables, e.g. diagnostic history, HADS, use of } \\
\text { psychotropic medication), and their relative efficacy was similar to that in smokers } \\
\text { without a psychiatric history." }\end{array}$ \\
\hline
\end{tabular}

Aubin $2004 \quad$ Bupropion $\quad$ None $\quad \begin{aligned} & \text { "A similar subgroup analysis performed according to previous history of depres- } \\ & \text { sion (evaluated by the MINI questionnaire) also failed to reveal an interaction with } \\ & \text { bupropion treatment." }\end{aligned}$

$\begin{array}{ll}\begin{array}{l}\text { Aveyard Nortriptyline None } \\ 2008\end{array} & \text { "Participants randomised to nortriptyline plus nicotine replacement therapy for } \\ & \text { smoking cessation experienced less depression (OR 0.15) and anxiety early in the } \\ & \text { quit attempt when the risk of return to smoking is at its highest than those ran- } \\ & \text { domised to placebo plus nicotine replacement therapy. Contrary to expectations, } \\ \text { no evidence was found that this led to greater abstinence." }\end{array}$

Cinciripini Bupropion None "Several measures failed to demonstrate significant effects as a function of time,
2018 treatment, or the interaction of treatment and time. For example, CES-D scales including Depressive Affect, Interpersonal Relations, Positive Affect, and Somatic Symptoms, failed to demonstrate any effects of treatment or any treatment by time interactions."

\begin{tabular}{llll}
\hline $\begin{array}{l}\text { Da Costa } \\
2002\end{array}$ & Nortriptyline & Negative & $\begin{array}{l}\text { "The best results were obtained with educational intervention, in those patients } \\
\text { having no personal history of depression, who received the active drug. A negative } \\
\text { history of depression was, however, the most important factor for the success of the } \\
\text { treatment." }\end{array}$ \\
\hline George 2003 & Selegiline & $\begin{array}{l}\text { None (histo- } \\
\text { ry), negative } \\
\text { (current) }\end{array}$ & $\begin{array}{l}\text { "There was no significant influence of a past history of major depression on smok- } \\
\text { ing cessation outcomes }(B=-0.49, S E=0.90, \text { Wald Statistic }=0.29, d f=1, p=.59), \text { and } \\
\text { when past history of major depression was entered into the logistic regression mod- } \\
\text { el as a covariate, it did not predict treatment failure with selegiline study medica- }\end{array}$ \\
\hline
\end{tabular}


Table 2. Depression as a moderator of the relationship between antidepressants and smoking cessation (Continued) tion (medication past history of depression status interaction: $\mathrm{B}=-0.02, \mathrm{SE}=1.03$, Wald statistic $=0.00, \mathrm{df}=1, \mathrm{p}=.98) . "$ and "Furthermore, bivariate logistic regression analysis confirmed that having depressive symptoms at baseline negatively predicted smoking cessation outcomes with SEL on this continuous abstinence measure (B $=18.9, \mathrm{SE}=0.58$, Wald statistic $=1048.9, \mathrm{df}=1, \mathrm{P}<.01) . "$

\begin{tabular}{|c|c|c|c|}
\hline Hall 2002 & $\begin{array}{l}\text { Bupropion, } \\
\text { nortripyline }\end{array}$ & $\begin{array}{l}\text { Positive (for } \\
\text { bupropion) }\end{array}$ & $\begin{array}{l}\text { "There were higher abstinence rates for bupropion than nortriptyline for partici- } \\
\text { pants with a history of depressive disorder" }\end{array}$ \\
\hline Kahn 2012 & Selegiline & None & $\begin{array}{l}\text { "At the final HAM-D assessment, the selegiline group }(n=90) \text { reported a mean in- } \\
\text { crease of } 0.41 \text { points and the placebo group }(n=85) \text { reported a mean increase of } \\
0.21 \text { points. The difference between treatment groups was not statistically signifi- } \\
\text { cant ( } t \text { test, } p=.65) . "\end{array}$ \\
\hline Kalman 2011 & Bupropion & None & $\begin{array}{l}\text { "Interaction effects between medication and tobacco dependence and medication } \\
\text { and depressive symptoms were also nonsignificant." }\end{array}$ \\
\hline Killen 2000 & Paroxetine & None & $\begin{array}{l}\text { "A stepwise logistic regression analysis was used to examine the association of ab- } \\
\text { stinence at Week } 26 \text { with the variables [including depression scores] listed in Table } \\
1 . \text { None of these variables were prospectively associated with abstinence." }\end{array}$ \\
\hline Saules 2004 & Fluoxetine & None & $\begin{array}{l}\text { "Examination of pre-specified subgroups (i.e., gender, race, and history of major } \\
\text { depressive disorder) did not reveal significant differences in smoking cessation by } \\
\text { group" }\end{array}$ \\
\hline Spring 2007 & Fluoxetine & None & $\begin{array}{l}\text { Fluoxetine initially enhanced cessation for smokers with a history of major depres- } \\
\text { sion }(P=.02) \text { but subsequently impaired cessation regardless of depressive history. }\end{array}$ \\
\hline $\begin{array}{l}\text { Stapleton } \\
2013\end{array}$ & Bupropion & Positive & $\begin{array}{l}\text { "There was some evidence that the relative effectiveness of bupropion and NRT dif- } \\
\text { fered according to depression ( } \mathrm{X} 2=2.86, \mathrm{P}=0.091 \text { ), with bupropion appearing more } \\
\text { beneficial than NRT in those with a history of depression ( } 29.8 \text { versus } 18.5 \%) . "\end{array}$ \\
\hline Wagena 2005 & $\begin{array}{l}\text { Bupropion, } \\
\text { nortriptyline }\end{array}$ & $\begin{array}{l}\text { Positive (for } \\
\text { bupropion) }\end{array}$ & $\begin{array}{l}\text { "Results indicated that bupropion SR [sustained release] treatment was efficacious } \\
\text { in helping smokers who were classified as depressed in achieving prolonged absti- } \\
\text { nence from smoking throughout the } 26 \text {-week period. The number of depressed par- } \\
\text { ticipants from the nortriptyline-treated group was considered too low to study this } \\
\text { relationship." }\end{array}$ \\
\hline
\end{tabular}

CES-D: Center for Epidemiologic Studies Depression; df: degrees of freedom; HADS: Hospital Anxiety and Depression scale; HAM-D: Hamilton Depression Rating Scale; MINI: Mini-International Neuropsychiatric Interview; NRT: nicotine replacement therapy; OR: odds ratio; SE: standard error

\section{AP PEN DICES}

\section{Appendix 1. Specialized Register search strategy}

Searched using CRS web

\#1 (bupropion or zyban):TI,AB,MH,EMT,KY,XKY

\#2 nortriptyline:TI,AB,MH,EMT,KY,XKY

\#3 (monoamine oxidase inhib`):TI,AB,MH,EMT,KY,XKY

\#4 (moclobemide or selegiline or lazabemide):TI,AB,MH,EMT,KY,XKY

\#5 (SSRI ${ }^{\star}$ or (selective serotonin re?uptake inhibitor $\left.\left.{ }^{\star}\right)\right): T I, A B, M H, E M T, K Y, X K Y$

\#6 (fluoxetine or sertraline or paroxetine or zimelidine):TI,AB,MH,EMT,KY,XKY 
\#7 (doxepin or imipramine or tryptophan or venlafaxine):TI,AB,MH,EMT,KY,XKY

\#8 ((john?s wort) or hypericum):TI,AB,MH,EMT,KY,XKY

\#9 \#1 OR \#2 OR \#3 OR \#4 OR \#5 OR \#6 OR \#7 OR \#8

(MH, EMT, KY and XKY are keyword fields)

WHAT'S NEW

\begin{tabular}{lll}
\hline Date & Event & Description \\
\hline 24 January 2020 & $\begin{array}{l}\text { New citation required but conclusions } \\
\text { have not changed }\end{array}$ & $\begin{array}{l}33 \text { new included studies; additional safety analyses added. Main } \\
\text { conclusions remain unchanged }\end{array}$ \\
\hline 24 January 2020 & New search has been performed & $\begin{array}{l}33 \text { new included studies identified and study data added to exist- } \\
\text { ing comparators }\end{array}$ \\
\hline
\end{tabular}

\section{H I S T O R Y}

Protocol first published: Issue 3, 1997

Review first published: Issue 3, 1997

\begin{tabular}{lll}
\hline Date & Event & Description \\
\hline 14 June 2016 & Amended & $\begin{array}{l}\text { Corrected typographical error in Abstract results. Risk ratio } \\
\text { for buproprion + NRT (12 trials) changed from 1.9 to 1.19. Now } \\
\text { matches meta-analysis 1.5 }\end{array}$ \\
& & \\
\hline
\end{tabular}

\begin{tabular}{|c|c|c|}
\hline 8 October 2013 & New search has been performed & $\begin{array}{l}\text { Updated with } 24 \text { new included studies. Studies of S-Adenosyl-L- } \\
\text { Methionine and St John's wort included for the first time. Meta- } \\
\text { analyses of serious adverse events added }\end{array}$ \\
\hline 8 October 2013 & $\begin{array}{l}\text { New citation required but conclusions } \\
\text { have not changed }\end{array}$ & Conclusions largely unchanged. Efficacy findings unchanged \\
\hline 22 June 2011 & Amended & Additional table converted to appendix to correct pdf format \\
\hline 5 October 2009 & Amended & Correction to excluded studies table, detail added to Carrão 2007 \\
\hline 30 July 2009 & New search has been performed & $\begin{array}{l}\text { Updated with } 13 \text { new included trials including } 3 \text { of selegiline, not } \\
\text { previously covered. No substantial change to effects; main con- } \\
\text { clusions not altered }\end{array}$ \\
\hline 17 June 2008 & Amended & Converted to new review format \\
\hline 11 October 2006 & $\begin{array}{l}\text { New citation required but conclusions } \\
\text { have not changed }\end{array}$ & $\begin{array}{l}\text { Seventeen new trials were added to the review for Issue 1, } 2007 . \\
\text { There were no major changes to the reviewers' conclusions. }\end{array}$ \\
\hline 16 July 2004 & $\begin{array}{l}\text { New citation required but conclusions } \\
\text { have not changed }\end{array}$ & $\begin{array}{l}\text { New trials of bupropion, nortriptyline and fluoxetine were added } \\
\text { for Issue } 4,2004 \text {, and additional information on adverse effects } \\
\text { was included. There were no major changes to the reviewers' } \\
\text { conclusions. }\end{array}$ \\
\hline
\end{tabular}




\begin{tabular}{lll}
\hline Date & Event & Description \\
\hline 8 January 2003 & $\begin{array}{l}\text { New citation required but conclusions } \\
\text { have not changed }\end{array}$ & $\begin{array}{l}\text { New trials of bupropion and nortriptyline were added to the re- } \\
\text { view in Issue 2, 2003. There were no major changes to the review- } \\
\text { ers' conclusions. }\end{array}$ \\
\hline 19 September 2001 & $\begin{array}{l}\text { New citation required but conclusions } \\
\text { have not changed }\end{array}$ & $\begin{array}{l}\text { Four new studies on bupropion, and one each on nortriptyline } \\
\text { and paroxetine were added to the review in Issue 1, 2002. In } \\
\text { press data from a trial of fluoxetine are included which differ } \\
\text { from unpublished data previously used. The reviewers' conclu- } \\
\text { sions about the efficacy of bupropion and nortriptyline were not } \\
\text { changed substantively. }\end{array}$ \\
\hline 28 August 2000 & $\begin{array}{l}\text { New citation required and conclusions } \\
\text { have changed }\end{array}$ & $\begin{array}{l}\text { Updates the earlier Cochrane Review 'Anxiolytics and antide- } \\
\text { pressants for smoking cessation'. Anxiolytics are evaluated in a } \\
\text { separate review. }\end{array}$ \\
\hline
\end{tabular}

\section{CONTRIBUTIONS OF AUTHORS}

For the most recent update $\mathrm{NL}, \mathrm{JHB}$ and $\mathrm{SH}$ decided on changes to analyses and the presentation of the review. SH updated the text of the review and all other authors commented. SH, NL, JHB, JLB screened and extracted study data, and BH also extracted study data.

\section{DECLARATIONS OF INTEREST}

$\mathrm{SH}$ : none reported

JHB: none reported

JLB: none reported

$\mathrm{BH}:$ none reported

NL: none reported

\section{SOURCES OF SUPPORT}

\section{Internal sources}

- Nuffiled Department of Primary Care Health Sciences, University of Oxford, UK.

Editorial base for Cochrane Tobacco Addiction

\section{External sources}

- National Institute for Health Research, UK. Infrastructure funding for Cochrane Tobacco Addiction

- Research England's Strategic Priorities Fund (SPF), UK. Funding to carry out this particular Cochrane Tobacco Addiction Review

\section{DIFFERENCES BETWEEN PROTOCOL AND REVIEW}

The changes below were made for the 2020 update.

- We no longer include harm reduction and relapse prevention studies as these are covered in other reviews (Lindson-Hawley 2016; Livingstone-Banks 2019).

- We changed the wording of the primary outcome from smoking abstinence to smoking cessation. These terms measure the same thing however we feel that the latter term makes it clearer that we are measuring the act of quitting smoking.

- We have specified exactly which safety and tolerability outcomes were assessed as follows: 1) adverse events (AEs), 2) serious adverse events (SAEs), and 3) dropouts due to AEs, and also collected information on the following specific SAEs: seizures; overdoses; suicide 
attempts; death by suicide; and all-cause mortality. We went back to all previously included studies to check that these were extracted uniformly across studies.

- We explicitly state that we investigated whether studies had investigated depression status as a modifier of efficacy. This has been extracted uniformly across studies and the information is now summarized in Table 2.

- Any observational studies are now excluded from this review. There were previously included to assess safety outcomes.

- We have explicitly stated that "We excluded trials where an additional, uncontrolled non-antidepressant intervention component was used in only one of the trial arms" and checked that included studies conform to this requirement.

- We no longer assess the outcome: reduction in smoking, as this is not deemed to be a clinically-relevant outcome - there is no evidence that it results in health benefits, and studies that aim specifically to reduce smoking are covered in our harm reduction review (LindsonHawley 2016).

- We restructured our 'Summary of findings' tables to include the most clinically-relevant comparators and to include safety outcomes as well as efficacy.

- We carry out sensitivity analyses, excluding studies from meta-analyses with industry funding, or where the medication was supplied by the pharmaceutical industry. We judged whether this exclusion notably altered the pooled risk ratios (RRs) (95\% confidence interval (CI)) and summarized the results in Table 1.

- We carried out a post hoc, exploratory analysis merging the following safety and tolerability outcome data: AEs, psychiatric AEs, SAEs and dropouts due to drug, across three comparisons, that effectively all compared bupropion to no bupropion treatment (1) bupropion versus placebo/no pharmacotherapy control; 2) bupropion plus nicotine replacement therapy (NRT) versus NRT; 3) bupropion plus varenicline versus varenicline). We carried out a subgroup analysis to test for any interactions between comparisons.

\section{NOTES}

This review was first published as part of the review 'Anxiolytics and antidepressants for smoking cessation.' From Issue 4, 2000 the classes of drugs are reviewed separately.

\section{INDEX TERMS}

\section{Medical Subject Headings (MeSH)}

Anti-Anxiety Agents [adverse effects] [*therapeutic use]; Antidepressive Agents [adverse effects] [ ${ }^{\star}$ therapeutic use]; Bupropion [therapeutic use]; Nortriptyline [therapeutic use]; Randomized Controlled Trials as Topic; Serotonin Uptake Inhibitors [therapeutic use]; Smoking [ ${ }^{\star}$ drug therapy] [psychology]; Smoking Cessation [ ${ }^{\star}$ methods] [psychology]; Tobacco Use Cessation Devices

\section{MeSH check words}

Humans 